\title{
TRACER-LEVEL RADIOACTIVE PILOT-SCALE TEST OF IN SITU VITRIFICATION FOR THE STABILIZATION OF CONTAMINATED SOIL SITES AT ORNL
}

B. P. Spalding, G. K. Jacobs, N. W. Dunbar ${ }^{1}$, M. T. Naney, J. S. Tixier', and T. D. Powell ${ }^{2}$

${ }^{1}$ Currently affiliated with The New Mexico Bureau of Mines and Mineral Resources, Socorro, NM 87801.

2Pacific Northwest Laboratory (operated bv Battelle Memorial Institute for the U. S. Department of Energy under contract DE-AC06-76RLO1830), P.O. Box 999, Richland, Washington 99352.

Environmental Sciences Division Publication No. 3962

Date Published: November 1992

Prepared for the Office of Technology Development (EW 402010 0)

Prepared by the

OAK RIDGE NATIONAL LABORATORY

Oak Ridge, Tennessee 37831-6285

managed by MARTIN MARIETTA ENERGY SYSTEMS, INC. for the U.S. Department of Energy under contract DE-AC05-84OR21400 


\section{CONTENTS}

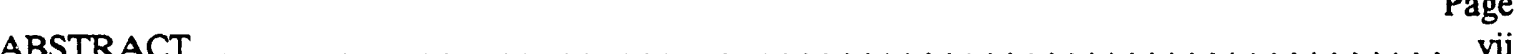

FIGURES $\ldots \ldots \ldots \ldots \ldots \ldots \ldots \ldots \ldots \ldots \ldots \ldots \ldots \ldots \ldots \ldots \ldots \ldots$ viii

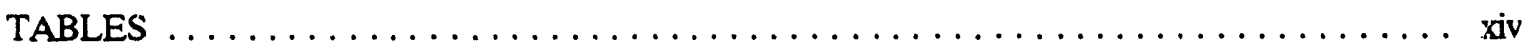

ACKNOWLEDGMENTS $\ldots \ldots \ldots \ldots \ldots \ldots \ldots \ldots \ldots \ldots \ldots \ldots \ldots \ldots \ldots$

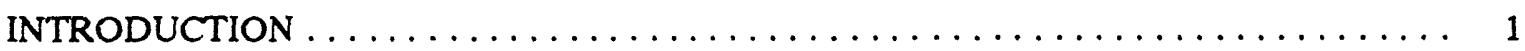

ORNL SEEPAGE PITS AND TRENCHES $\ldots \ldots \ldots \ldots \ldots \ldots \ldots \ldots \ldots$

DESCRIPTION OF THE ISV TECHNOLOGY $\ldots \ldots \ldots \ldots \ldots \ldots \ldots \ldots \ldots$

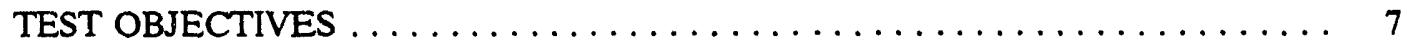

Demonstrate Reduction in ${ }^{137} \mathrm{Cs}$ Accumulation in the Off-Gas Processing Trailer ........................... 7

Assess Radiological and Operational Activities of the ISV System $\ldots \ldots \ldots 10$

Confirm Durability of ISV Waste Form . . . . . . . . . . . . . . . . 10

Evaluate Seismic Imaging and Advanced Thermometry for Monitoring Melt

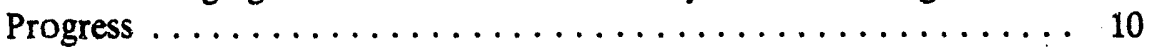

DESCRIPTION OF THE PILOT-SCALE ISV TEST SYSTEM $\ldots \ldots \ldots \ldots \ldots \ldots$

Power System Design $\ldots \ldots \ldots \ldots \ldots \ldots \ldots \ldots \ldots \ldots \ldots \ldots$

Electrodes and Electrode Feed System $\ldots \ldots \ldots \ldots \ldots \ldots \ldots$

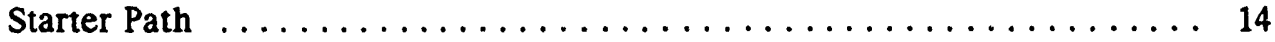

Off-Gas Containment Hood $\ldots \ldots \ldots \ldots \ldots \ldots \ldots \ldots \ldots$

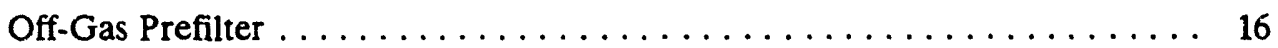

Off-Gas Treatment System $\ldots \ldots \ldots \ldots \ldots \ldots \ldots \ldots \ldots \ldots \ldots$

Data Acquisition Systems . . . . . . . . . . . . . . . . . . 19

SITE SELECTION, CHARACTERIZATION, AND PREPARATION $\ldots \ldots \ldots \ldots$

EQUIPMENT AND TRENCH SET-UP . . . . . . . . . . . . . . . . . . 19

DESCRIPTION AND PLACEMENT OF TEST MONITORING SENSORS . . . . . 22

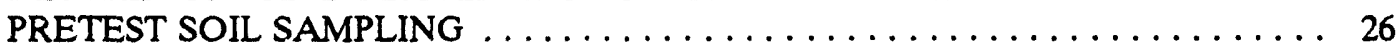

CHARACTERIZATION AND PLACEMENT OF SLUDGE AND TRACERS . . . 30

TEST EQUIPMENT OPERATIONS AND MONITORING . . . . . . . . . . . . . . 33

MELT DEPTH AND ELECTRICAL POWER MONITORING . . . . . . . . . 33

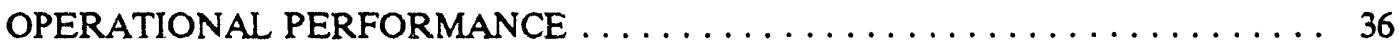

Electrical Power System Performance . . . . . . . . . . . . . . 37

Electrode and Electrode Feed System Performance . . . . . . . . . . . . 39

Off-Gas Treatment System Performance .................. 39

Off-Gas Prefilter Performance . . . . . . . . . . . . . . . . 41

TEST TRENCH SENSORS MONITORING . . . . . . . . . . . . . . . . . 44

TEMPERATURE ..............................44

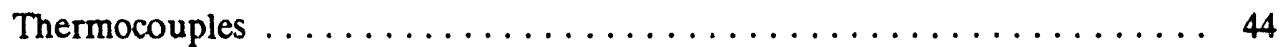

Type-K Thermocouples . . . . . . . . . . . . . . . . . . 45

Type-C and Type-S Thermocouples . . . . . . . . . . . . . . . 46

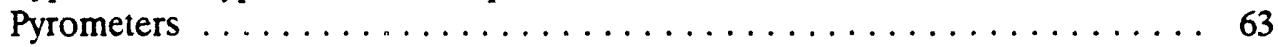

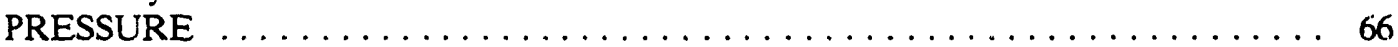

OXYGEN FUGACITY $\ldots \ldots \ldots \ldots \ldots \ldots \ldots \ldots \ldots \ldots \ldots$

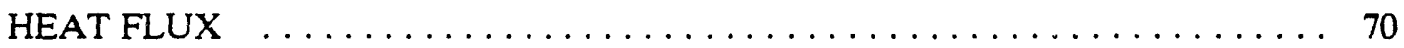


VOLATILE AND PARTICULATE OFF-GAS EMISSIONS $\ldots \ldots \ldots \ldots \ldots \ldots \ldots \ldots$

SAMPLING OF FIXED GASES FROM THE ISV MELT $\ldots \ldots \ldots \ldots \ldots \ldots .74$

MODIFIED METHOD FIVE OFF-GAS SAMPLING $\ldots \ldots \ldots \ldots \ldots \ldots \ldots 75$

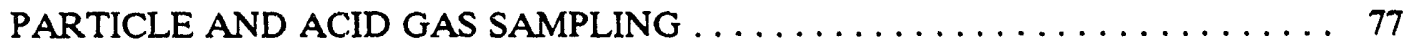

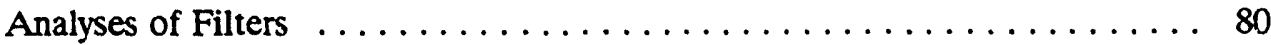

Particle Morphology and Composition $\ldots \ldots \ldots \ldots \ldots \ldots \ldots \ldots \ldots .61$

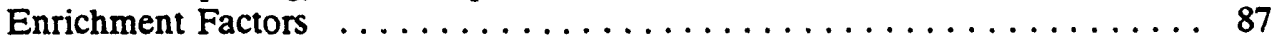

Composition of the Fluid Emitted from the ISV Melt . . . . . . . . . 89

Mechanisms of Volatile Emission .................... 91

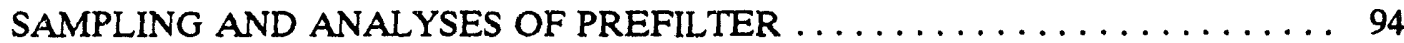

Analytical Procedures for Radioisotopes and Elements in Prefilter Samples ........................... 94

Elements Deposited on the Prefilter ................... 96

Radioisotopes Deposited on the Prefilter ................ 98

Rare Earth Tracers (Ce, La, and Nd) Deposited on the Prefilter ....... 98

OFF-GAS SCRUB SOLUTION MONITORING .................. 100

SAMPLING AND ANALYSES OF OFF-GAS PROCESSING EQUIPMENT $\ldots \ldots 103$

Distribution of ${ }^{137} \mathrm{Cs}$ Within the Off-Gas Hood and Ducting $\ldots \ldots \ldots \ldots 105$

DISTRIBUTION AND BEHAVIOR OF ${ }^{137} \mathrm{CS}$ DURING THE ISV TEST $\ldots \ldots \ldots \ldots \ldots 106$

VOLATILIZATION OF ${ }^{137}$ CS DURING THE ORNL PILOT-SCALE TEST $\ldots \ldots .108$

DIFFERENCES IN CESIUM VOLATILITY BETWEEN 1987 AND 1991 ORNL

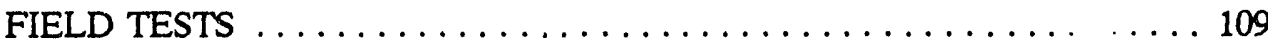

CONCEPTUAL MODEL OF SEMIVOLATILE METAL VOLATILIZATION

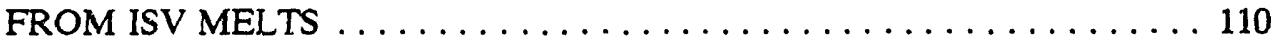

Physicochemical Forms of Semivolatile Constituents $\ldots \ldots \ldots \ldots \ldots \ldots 110$

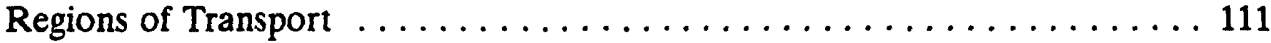

Elucidation of Mechanisms ............................ 112

LABORATORY STUDIES OF FACTORS AFFECTING CESIUM

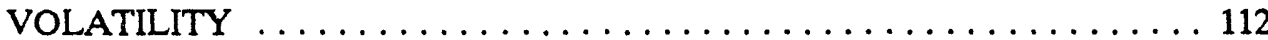

Volatilization of Radiocesium at Varying Soil-Limestone Ratio . . . . . . 112

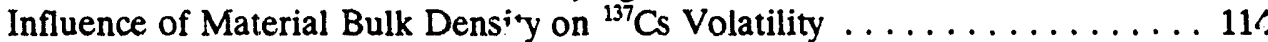

Influence of Burial Depth on Radiocesium Volatility . . . . . . . . . 115

Influence of Melting Rate on Radiocesium Volatility $\ldots \ldots \ldots \ldots \ldots \ldots 118$

DESCRIPTION AND ANALYSES OF FIELD ISV PRODUCT $\ldots \ldots \ldots \ldots \ldots \ldots \ldots \ldots 120$

FIELD DESCRIPTIONS AND SAMPLING METHODS $\ldots \ldots \ldots \ldots \ldots \ldots \ldots 120$

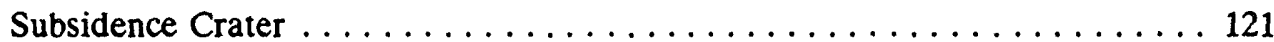

Field Measurement of Depth to Top of ISV Product . . . . . . . . . . 122

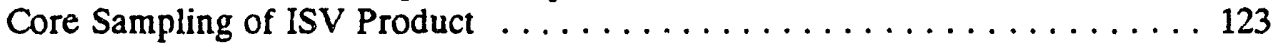

Posttest Soil Sampling Around ISV Product . ............... 124

COMPOSITION OF ISV PRODUCT BY ANALYSES OF SAMPLE DIGESTS $\ldots 126$

ISV PRODUCT WEIGHT ESTIMATION BY TRACER DILUTION $\ldots \ldots \ldots \ldots 128$

CRYSTALLIZATION AND COMPOSITIONAL EVOLUTION WITHIN THE ISV

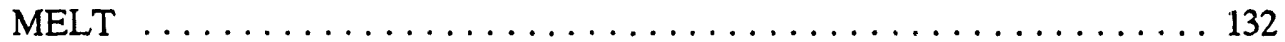

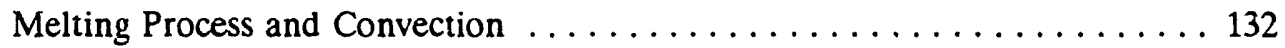

Distribution, Appearance, and Composition of Crystals .......... 135

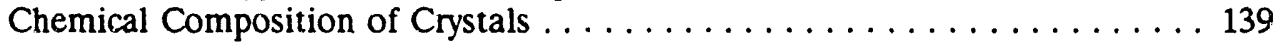

Chemical Composition and Distribution of Residual Glass .......... 143 
CONTENTS (continued)

DENSITY OF VITRIFIED PRODUCT $\ldots \ldots \ldots \ldots \ldots \ldots \ldots \ldots \ldots \ldots$

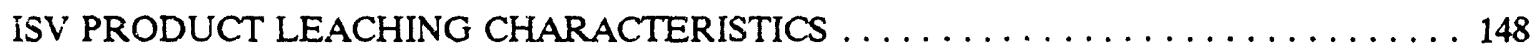

LEACHING OF ${ }^{90}$ SR AND ${ }^{137} \mathrm{CS}$ WITH EXCHANGEABLE CATIONS AND

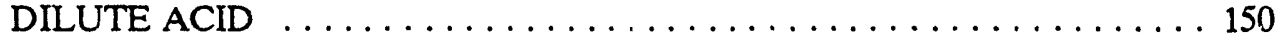

PRODUCT CONSISTENCY TESTING (PCT) $\ldots \ldots \ldots \ldots \ldots \ldots \ldots \ldots \ldots \ldots$

MODELS FOR DEPTH AND SHAPE OF THE 1991 ORNL ISV PRODUCT $\ldots \ldots \ldots \ldots 158$

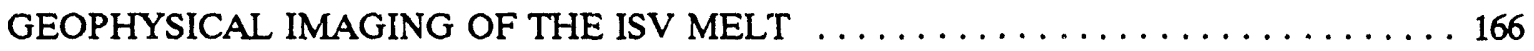

COST ANALYSIS OF ISV FOR PITS AND TRENCHES AT ORNL $\ldots \ldots \ldots \ldots \ldots \ldots 7$

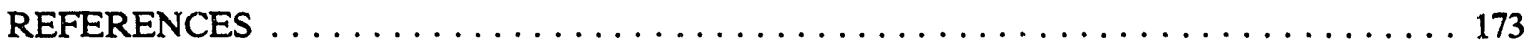




\begin{abstract}
A field demonstration of in situ vitrification (ISV) was completed in May 1991, and produced approximately $12 \mathrm{Mg}$ of melted earthen materials containing $12.7 \mathrm{mCi}$ of radioactivity within $500 \mathrm{~g}$ of sludge in a model of an old seepage trench waste disposal unit. Past waste disposal operations at Oak Ridge National Laboratory have left several contaminated seepage sites where over a million curies of radioactive liquid waste was disposed between 1951 and 1966. In planning for remediation of such sites, ISV technology has been identified as a leading candidate because of the high risks associated with any retrieval option and because of the usual high quality of vitreous waste form. Major isotopes placed in the test trench were ${ }^{137} \mathrm{Cs}$ and ${ }^{90} \mathrm{Sr}$, with lesser amounts of ${ }^{60} \mathrm{Co},{ }^{241} \mathrm{Am}$, and ${ }^{239,240} \mathrm{Pu}$. A total of $29 \mathrm{MWh}$ of electrical power was delivered to the ground over a 5-day period producing a melt depth of $8.5 \mathrm{ft}$. During melting, $2.4 \%$ of the ${ }^{137} \mathrm{Cs}$ volatilized from the melt into an off-gas containment hood and was captured quantitatively on a high efficiency particulate air filter. No volatilization of ${ }^{90} \mathrm{Sr}$, ${ }^{241} \mathrm{Am}$, or ${ }^{239,240} \mathrm{Pu}$ was detected and $>99.993 \%$ retention of these isotopes in the melt was estimated. The use of added rare earth tracers ( $\mathrm{Ce}, \mathrm{La}$, and $\mathrm{Nd}$ ), as surrogates for transuranic isotopes, led to estimated melt retentions of $>99.9995 \%$ during the test. The molten material, composed of the native soil and dolomitic limestone used for filling the test trench, reached a processing temperature of $1500^{\circ} \mathrm{C}$. The spatial and temporal variations in temperature during and after melting were monitored with a suite of 87 thermocouples and 6 optical pyrometers placed at selected depths and distances from the center of the melt so that the size and shape of the molten zone could be inferred and the flux of heat from the melt determined. A delay during cooling of the melt was observed and interpreted to be a release of latent heat during crystallization of minerals from the melt. Core sampling revealed extensive crystallization with only a small amount of vitreous product. Electron microprobe analyses of the crystalline material showed it to be a mixture of diopsidic pyroxene (calcium-magnesium-silicate), plagioclase feldspar (calcium-aluminum-silicate), and potassium feldspar (potassium-aluminum-silicate). The bulk product was $52.10 \% \mathrm{SiO}_{2}, 15.70 \%$ $\mathrm{Al}_{2} \mathrm{O}_{3}, 4.85 \% \mathrm{FeO}, 0.12 \% \mathrm{MnO}, 5.94 \% \mathrm{MgO}, 16.96 \% \mathrm{CaO}, 0.11 \% \mathrm{P}_{2} \mathrm{O}_{5}, 0.75 \% \mathrm{TiO}_{2}, 3.26 \% \mathrm{~K}_{2} \mathrm{O}$, and $0.20 \% \mathrm{Na}_{2} \mathrm{O}$. The large degree of crystallization, rather than vitrification, that was observed in the field product, was probably due to the low sodium and high calcium plus magnesium contents. The field ISV converted the ${ }^{90} \mathrm{Sr}$ in the sludge from near quantitative extractability, by a sequence of dilute $\mathrm{CaCl}_{2}$ and $\mathrm{HCl}$, to a material with less than $1 \%$ extractability. The leachability of ${ }^{137} \mathrm{Cs}$ was also decreased in the ISV product; however, the starting sludge exhibited only about $1 \%$ leachability so that vitrification was not necessary for ${ }^{137} \mathrm{Cs}$ waste form improvement. Standardized leaching procedures using Product Consistency Testing indicated that the ISV product has excellent characteristics relative to other vitreous nuclear waste forms.
\end{abstract}




\section{FIGURES}

1. ORNL Waste Area Grouping 7 which contains the seven seepage pits and trenches used

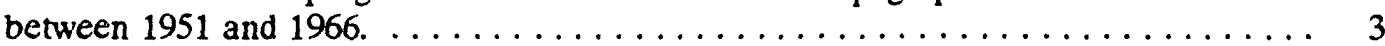

2. Construction design details of ORNL liquid seepage pit $7 . \ldots \ldots \ldots \ldots \ldots \ldots \ldots \ldots$

3. Disposition of materials during in situ vitrification processing. $\ldots \ldots \ldots \ldots \ldots \ldots \ldots$

4. Schematic illustration showing the ISV process applied to a seepage trench. $\ldots \ldots \ldots 6$

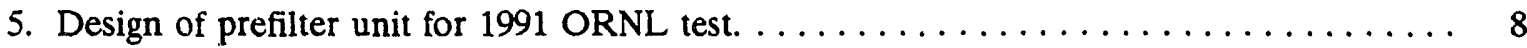

6. Prefilter housing assembly as installed for 1991 ORNL. ISV test. . . . . . . . . . 9

7. Cutaway view of the pilot-scale ISV equipment, including the HEPA prefilter assembly that was specially designed for this test. $\ldots \ldots \ldots \ldots \ldots \ldots \ldots \ldots \ldots \ldots \ldots$

8. Schematic diagram of the Scott-connected transformer used in the pilot-scale ISV

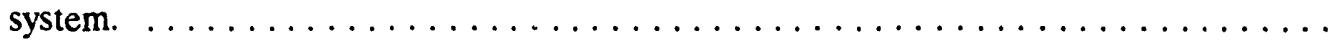

9. Electrode feed system stationary (upper) and moveable (lower) clamps to control

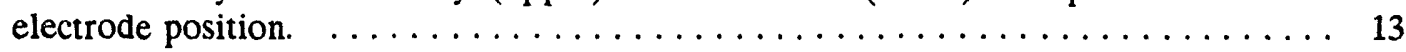

10. Starter path configuration to initiate melting at the beginning of ISV applications. $\ldots \ldots 14$

11. Photograph of the prefilter assembly showing the two parallel filters, air-actuated valves,

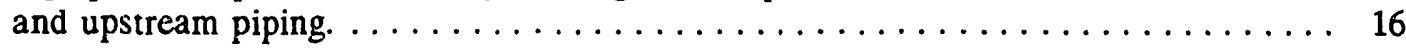

12. Schematic diagram of the off-gas treatment system. $\ldots \ldots \ldots \ldots \ldots \ldots \ldots \ldots \ldots$

13. Schematic diagram of the two-stage Hydro-Sonic ${ }^{\circledR}$ scrubber. $\ldots \ldots \ldots \ldots \ldots \ldots \ldots$

14. Field arrangement of ISV equipment for the 1991 ORNL test showing position of the off-gas prefilter between the off-gas hood and the processing trailer. . . . . . . 20

15. Position of off-gas containment hood and electrode adjustment controls used in the 1991

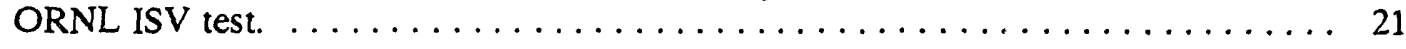

16. Plan view of ISV off-gas hood, electrodes, limestone trench, and thermal sensors used in the 1991 oRNL test. . . . . . . . . . . . . . . . . . . . . 22

17. Cross sectional profile along east-west axis of 1991 ORNL ISV test trench showing

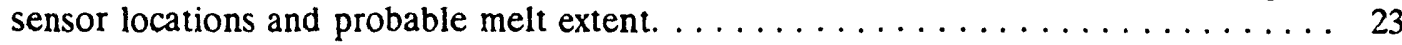

18. Cross sectional profile along north-south axis of 1991 ORNL ISV test trench showing sensor locations and probable final melt extent. . . . . . . . . . . . . 24

19. Dry soil bulk density depth profiles at the 1991 ORNL ISV site before and after test

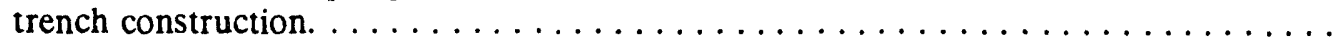


20. The 3-inch diameter polyvinylchloride access pipe during test trench construction at completion of limestone gravel backfilling. . . . . . . . . . . . . . . 31

21. Depth of melting vs run time during 1991 ORNL ISV test as measured by both thermocouple burnouts and electrode penetrations. . . . . . . . . . . . 35

22. Electrical power and cumulative energy applied to the 1991 ORNL ISV test trench. . . . 36

23. Resistance of the $\mathrm{B}$ phase during the ISV test. $\ldots \ldots \ldots \ldots \ldots \ldots \ldots \ldots \ldots \ldots$

24. Hood vacuum as a function of run time. $\ldots \ldots \ldots \ldots \ldots \ldots \ldots \ldots \ldots \ldots \ldots \ldots \ldots \ldots \ldots$

25. Off-gas flow rate as a function of run time. $\ldots \ldots \ldots \ldots \ldots \ldots \ldots \ldots \ldots \ldots$

26. Temperature at the inlet and outlet of the venturi-scrubber. $\ldots \ldots \ldots \ldots \ldots \ldots \ldots 42$

27. Differential pressure across the prefilter during the ISV test. $\ldots \ldots \ldots \ldots \ldots \ldots \ldots$

28. Temperature as a function of run time for the vertical array of type- $\mathrm{K}$ thermocouples placed along the central axis of the melt volume through depth $=5.5 \mathrm{ft} . \quad \ldots \ldots \ldots 48$

29. Temperature as a function of run time for the vertical array of type-K thermocouples placed along the central axis of the melt volume through depth $=8.5 \mathrm{ft} . \ldots \ldots \ldots 49$

30. Temperature history at a depth of $\sim 1 \mathrm{~m}(3.5 \mathrm{ft})$ for type- $\mathrm{K}$ thermocouples placed -1.2

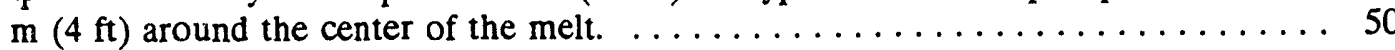

31. Temperature history at a depth of $\sim 1 \mathrm{~m}(3.5 \mathrm{ft})$ for type-K thermocouples placed $\sim 1.8$

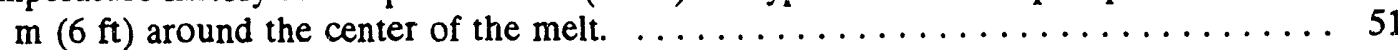

32. Temperature history at a depth of $\sim 1 \mathrm{~m}(3.5 \mathrm{ft})$ for type-K thermocouples placed $\sim 2.1$ $\mathrm{m}(7 \mathrm{ft})$ around the center of the melt. $\ldots \ldots \ldots \ldots \ldots \ldots \ldots \ldots \ldots \ldots \ldots \ldots \ldots \ldots \ldots \ldots$

33. Temperature history at a depth of $\sim 2 \mathrm{~m}(6.5 \mathrm{ft})$ for type- $\mathrm{K}$ thermocouples placed $\sim 1.2$ $\mathrm{m}(4 \mathrm{ft})$ from the center of the melt. $\ldots \ldots \ldots \ldots \ldots \ldots \ldots \ldots \ldots \ldots \ldots$

34. Temperature history at a depth of $\sim 2 \mathrm{~m}(6.5 \mathrm{ft})$ for type- $\mathrm{K}$ thermocouples placed $\sim 1.8$ $\mathrm{m}(6 \mathrm{ft})$ from the center of the melt. ....................... 54

35. Temperature history at a depth of $\sim 2 \mathrm{~m}(6.5 \mathrm{ft})$ for type-K thermocouples placed $\sim 2.1$

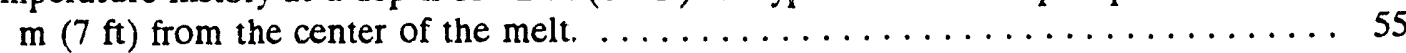

36. Temperature history at a depth of $\sim 2.3 \mathrm{~m}(7.5 \mathrm{ft})$ for type- $\mathrm{K}$ thermocouples placed $\sim 1.2$ $\mathrm{m}(4 \mathrm{ft})$ from the center of the melt. $\ldots \ldots \ldots \ldots \ldots \ldots \ldots \ldots \ldots \ldots \ldots$

37. Temperature history at a depth of $\sim 2.6 \mathrm{~m}(8.5 \mathrm{ft}$ ) for type- $\mathrm{K}$ thermocouples placed $\sim 1.8$ m (6 ft) from the center of the melt. 
38. Temperature history at a depth of $-2.6 \mathrm{~m}(8.5 \mathrm{ft})$ for type-K thermocouples placed $\sim 2.1$ $\mathrm{m}(7 \mathrm{ft})$ from the center of the melt. $\ldots \ldots \ldots \ldots \ldots \ldots \ldots \ldots \ldots \ldots \ldots$

39. Temperature history for three thermocouples at a depth of $-8.5 \mathrm{ft}(2.6 \mathrm{~m}) . \ldots \ldots \ldots 59$

40. Temperature history at a depth of $-2.6 \mathrm{~m}(8.5 \mathrm{ft})$ for type- $\mathrm{K}$ thermocouples placed $60^{\circ}$ apart $-0.6 \mathrm{~m}(2 \mathrm{ft})$ around the center of the melt. ................... 60

41. Temperatures for type- $C$ thermocouples in a vertical array down the central axis of the

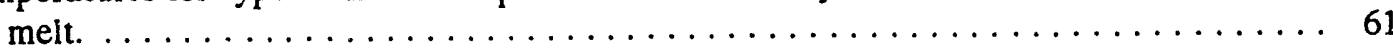

42. Temperature history at a depth of $-1.5 \mathrm{~m}(5 \mathrm{ft})$ for type- $\mathrm{C}$ thermocouples placed $\sim 0.6$ $\mathrm{m}(2 \mathrm{ft})$ around the center. . . . . . . . . . . . . . . . . . 62

43. Temperature history at a depth of $2.1 \mathrm{~m}\left(7 \mathrm{ft}\right.$ ) for type-C thermocouples placed $90^{\circ}$

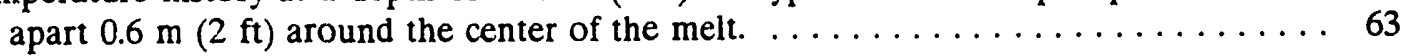

44. Temperature history for type-S thermocouples at a depth of $\sim 2 \mathrm{~m}(6.5 \mathrm{ft}) \ldots \ldots \ldots \ldots 64$

45. Schematic illustration of blackbody well/protection tube for Accufiber HF 4 pyrometer

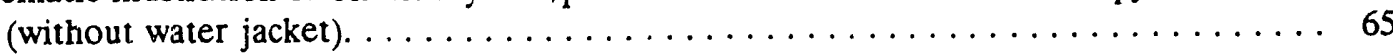

46. Schematic illustration of water jacket assembly for optical pyrometers. . . . . . . 66

47. Temperature as a function of run time for pyrometer TEP3609072. . . . . . . 67

48. Pressure as a function of run time for sensor PTG0000024. $\ldots \ldots \ldots \ldots \ldots \ldots \ldots 68$

49. Schematic illustration of oxygen fugacity sensor assembly. $\ldots \ldots \ldots \ldots \ldots \ldots \ldots$

50. Temperature and heat flux at a depth of $-4.5 \mathrm{ft}$. under the center of the melt. . . . 71

51. Temperature and heat flux at a depth of $\sim 8.5 \mathrm{ft}$. under the center of the melt. $\ldots \ldots \ldots 72$

52. Heat flux as a function of time for four sensors placed around the outside edge of the

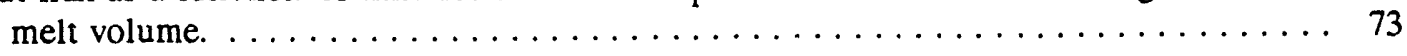

53. Temperatures and heat flux $\sim 7 \mathrm{ft}$. from the center of the melt and at depths of -5.5 and

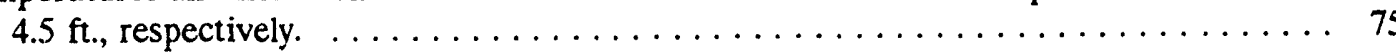

54. Schematic diagram of the Modified Method 5 sampling system used to collect particulates and gases from the main ISV off-gas line. . . . . . . . . . 79

55. Schematic diagram of the ISV site, showing electrode configuration, general melt shape, subsidence zone, hood, and filter sample location. . . . . . . . . . . . 81

56. Scanning electron microscope images of ISV particles $(3000 \times)$ on filters with total width a total view of $44 \mu \mathrm{m}$. 
57. Trapping efficiency of type 1 and type 2 filter sets for $\mathrm{Sb},{ }^{137} \mathrm{Cs}$, and $\mathrm{Br} . \ldots \ldots \ldots$

58. Power input and ${ }^{137} \mathrm{Cs}$ activity in off-gas from the ISV melt as a function of time. $\ldots \ldots 85$

59. Schematic diagram on melt depth, trace burial depth, and first appearance of tracers on

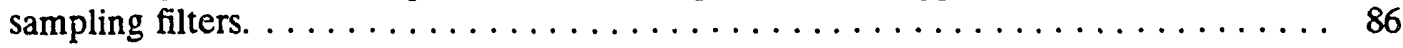

60. Mean enrichment factors calculated for ISV melt compared with enrichment factors reported for natural volcanic systems. $\ldots \ldots \ldots \ldots \ldots \ldots \ldots \ldots \ldots \ldots$

61. Enrichment factors calculated for the ISV melt at times of high and low power, as well as at the time of antimony $(\mathrm{Sb})$ incorporation into the melt. . . . . . . . . 90

62. Power input and antimony $(\mathrm{Sb})$ and Bromine $(\mathrm{Br})$ outputs from the ISV melt as a

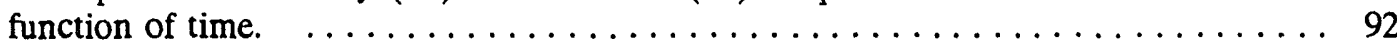

63. The $\mathrm{pH}$ of ISV off-gas venturi-ejector scrub solution during the 1991 ORNL ISV test. $\ldots 102$

64. Dissolved solids in ISV off-gas venturi-ejector scrub solution during ORNL ISV test. $\ldots 103$

65. Distribution of ${ }^{137} \mathrm{Cs}$ activity on surfaces within the ISV off-gas hood following completion of the field demonstration at ORNL in May 1991. . . . . . . . . . 106

66. Distribution of ${ }^{137} \mathrm{Cs}$ after the 1991 ORNL pilot-scale ISV test. $\ldots \ldots \ldots \ldots \ldots \ldots 108$

67. Volatilization of ${ }^{137} \mathrm{Cs}$ from the $1991 \mathrm{ORNL}$ ISV melt as a function of depth of melting and radioactive sludge burial depth interval. . . . . . . . . . . . . . . . 109

68. Volatilization of ${ }^{134} \mathrm{Cs}$ at $1500^{\circ} \mathrm{C}$ from crucibles containing mixtures of soil and limestone materials used in the 1987 and 1991 ORNL ISV field tests. . . . . . . . . . 113

69. Volatilization of ${ }^{137} \mathrm{Cs}$ from 7:3 soil:limestone mixtures packed to various premelt bulk

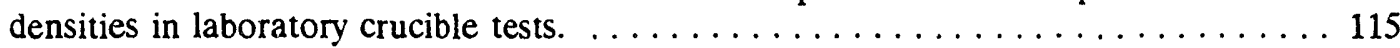

70. Average depth of placement of ${ }^{134} \mathrm{Cs}$ activity in laboratory crucibles on its volatilization

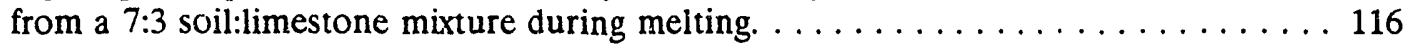

71. Effect of depth of overlying uncontaminated soil:limestone mixture on the degree of volatilization of ${ }^{134} \mathrm{Cs}$ from laboratory crucibles during melting. $\ldots \ldots \ldots \ldots \ldots 117$

72. Heating regimes for two high-temperature furnaces (box and crucible) used for laboratory crucible studies of ${ }^{134} \mathrm{Cs}$ and ${ }^{137} \mathrm{Cs}$ volatilization. . . . . . . . . . . 119

73. Subsidence crater after completion of the 1991 ORNL ISV field test showing cut-off electrodes and at least four relict cold cap layers adhering to walls. . . . . . . . 121

74. Orientation and position of cold caps expoied in the subsidence crater after the 1991

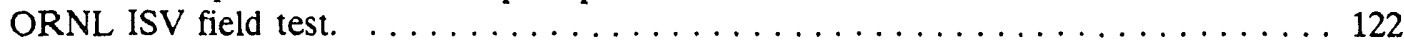




\section{FIGURES (continued)}

75. ORNL grid locations of the upper layer of the limestone-filled trench corners, the electrode placements, the four transects for penetration tests, and core samples.

76. Activity of ${ }^{137} \mathrm{Cs}$ in the population of all soil samples obtained from beneath core holes into the 1991 ORNL ISV test site. . . . . . . . . . . . . . . . . 125

77. Activities of ${ }^{137} \mathrm{Cs}$ and ${ }^{90} \mathrm{Sr}$ in the population of samples from the ISV product arranged

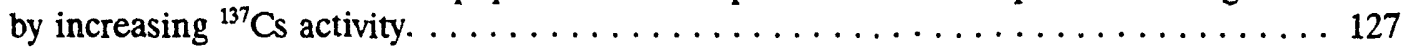

78. Shape of ISV melt as determined by cores drilled through the cooled body showing the

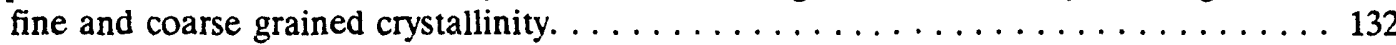

79. Rubidium and thorium content of ISV rock, soil and dolomitic limestone as analyzed by

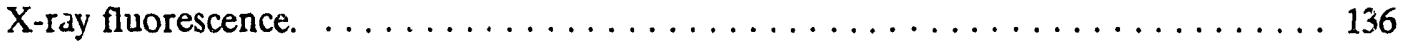

80. Reflected-light photomicrographs of samples of ISV rock taken at various distances from the margin. Field of view of all photos is $1 \mathrm{~mm} . \ldots \ldots \ldots \ldots \ldots \ldots \ldots \ldots \ldots$

81. Pyroxene compositions as analyzed by electron microprobe displayed on a standard

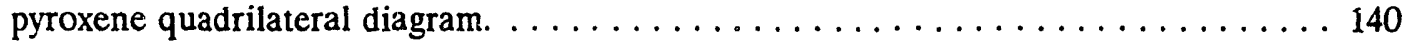

82. Electron microprobe step scan analyses across a single pyroxene lath.

83. Pyroxene compositions as znalyzed by electron microprobe expressed as a ternary of

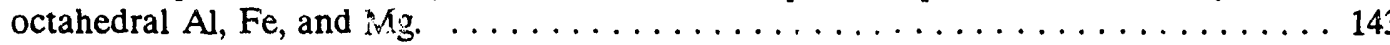

84. Feldspar compositions as analyzed by electron microprobe expressed as orthociase (Or), albite $(\mathrm{Ab})$, and anorthite $(\mathrm{An})$ end members. ..................... 144

85. Histogram of electron microprobe analyses of uncrystallized ISV glass ("primitive"), glass found in partially crystallized area of rock ("intermediate"), and rhyolitic glass from highest crystalline, central area of rock body (evolved).

86. Ion microprobe image of the distribution of potassium (K) and cesium (Cs) on a $100 \times$

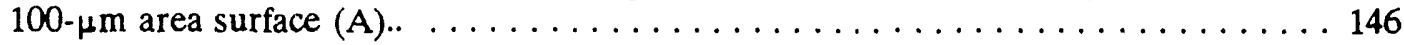

87. Density of core fragments from the population of ISV product samples. $\ldots \ldots \ldots \ldots 148$

88. Sections of 1-in.-diam core, recovered from the 1991 ORNL ISV test product, which shows the pore space and acicular crystals frequently found. . . . . . . . . . . 149

89. Sequential leaching of ${ }^{90} \mathrm{Sr}$ from whole and pulverized ISV product and from ORNL

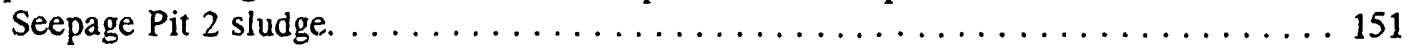

90. Sequential leaching of ${ }^{137} \mathrm{Cs}$ from whole and pulverized ISV product and from ORNL Seepage Pit 2 sludge. ................................. 153 
91. Normalized release rates $\left(\mathrm{g} / \mathrm{m}^{2}\right)$ for $\mathrm{Al}, \mathrm{Ca}, \mathrm{K}, \mathrm{Mg}$, and $\mathrm{Si}$ from ORNL ISV samples. For each element, bars represent most crystalline to least crystalline from left to right. . . 156

92. Percentage of ${ }^{137} \mathrm{Cs}$ and ${ }^{90} \mathrm{Sr}$ removed from ISV products of different crystallinity during Product Consistency Tests. . . . . . . . . . . . . . . . . . . . 157

93. Comparison of normalized releases $\left(\mathrm{g} / \mathrm{m}^{2}\right)$ for $\mathrm{Al}, \mathrm{Ca}, \mathrm{K}, \mathrm{Mg}$, and Si from ORNL ISV material, Hanford 116-B Crib ISV material, and West Valley glass. . . . . . . . 158

94. Depth versus time for the ISV melt front as determined from the central array of type-K thermocouples. A sixth-order polynomial was fit to the data. . . . . . . . . . 159

95. Depth of the ISV melt front as a function of square root of time. $\ldots \ldots \ldots \ldots \ldots$

96. Melt rate $(\mathrm{m} / \mathrm{h})$ vs run time with power input to the melt superposed. The melt rate was determined by differentiating the sixth-order polynomial of depth vs time. $\ldots \ldots \ldots 161$

97. Schematic diagram of the subsidence zone and melt body. $\ldots \ldots \ldots \ldots \ldots \ldots \ldots$

98. Volume of ISV melt as a function of time. $\ldots \ldots \ldots \ldots \ldots \ldots \ldots \ldots \ldots \ldots \ldots \ldots \ldots$

99. (a) Elevation contours for the bottom of the ISV body.. $\ldots \ldots \ldots \ldots \ldots \ldots \ldots \ldots$

100. Three-dimensional interpolation and visualization of the thermocouple data at $t=125$

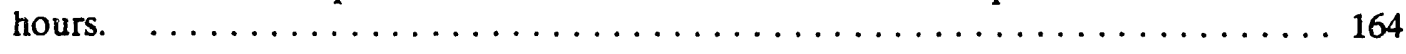

101. Seismic section of soil strata following construction of test trench using migrated data from vertical-component, surface geophones. . . . . . . . . . . . . . 166

102. Seismic section of the partially crystallized melt body before thermal arrest with superimposed cross section of the solidified ISV body (dark pattern) and thermally

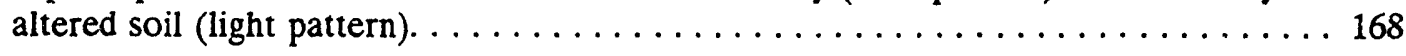

103. Seismic section of the fully solidified ISV body after thermal arrest with superimposed cross section of ISV body (dark pattern) and of thermally altered soil (light pattern). 


\section{TABLES}

1. Summary characteristics of ORNL seepage pits and trenches

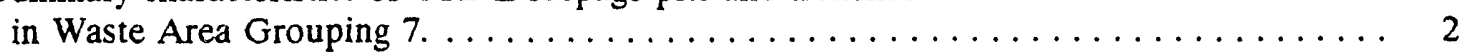

2. Inventory of radionuclides in ORNL Seepage Trench 7 in Waste Area Grouping $7 \ldots \ldots 7$

3. Expected distribution of ${ }^{137} \mathrm{Cs}$ activity in ISV off-gas system after vitrifying $10,000 \mathrm{Ci} \ldots \ldots 7$

4. Surveyed positions of the limestone gravel-filled trench and graphite electrode centers

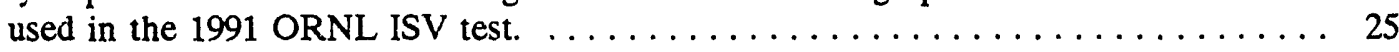

5. Surveyed sensor locations used in the 1971 ORNL ISV test. $\ldots \ldots \ldots \ldots \ldots \ldots \ldots$

6. Types of sensors and positions within the 1991 ORNL ISV test trench. $\ldots \ldots \ldots \ldots \ldots 27$

7. Types of sensors and positions within ORNL ISV test trench. $\ldots \ldots \ldots \ldots \ldots \ldots \ldots 28$

8. Radioisotopic composition of the ORNL Pit 2 sludge material used in ISV test. . . . . . 30

9. Chemical analysis of the ORNL Pit 2 sludge mat $\epsilon_{\text {ial }}$ uscd for ISV test. $\ldots \ldots \ldots \ldots 32$

10. Amounts and burial depths of tracers and sludge in $\mathrm{SV}$ test. . . . . . . . . . 32

11. Results and criteria for the Toxicity Characteristic Leach Procedure (TCLP) for the sludge used in the ORNL ISV test. $\ldots \ldots \ldots \ldots \ldots \ldots \ldots \ldots \ldots \ldots \ldots \ldots \ldots$

12. Description of electrical anomalies during ORNL ISV test. $\ldots \ldots \ldots \ldots \ldots \ldots \ldots$

13. Major gas constituents, in percentages, in samples collected from the ISV off-gas hood

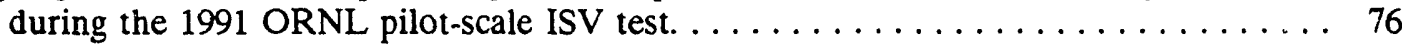

14. Operational data for the Modified Method 5 ISV off-gas samplers. $\ldots \ldots \ldots \ldots \ldots \ldots 77$

15. Activity of ${ }^{137} \mathrm{Cs}$ and solids deposited on filters of U.S. EPA Modified Method 5 samplers

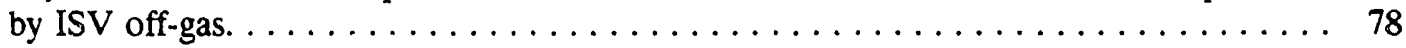

16. Amount of tracers on Modified Method 5 filters during 1991 ORNL ISV test. . . . . . 78

17. Calculated total amount of tracers in off-gas from 1991 ORNL ISV test. . . . . . . . 79

18. Fraction of ${ }^{137} \mathrm{Cs}$ and rare earth tracers volatilized during 1991 ORNL ISV test. . . . . 80

19. ISV off-gas filter samples taken May $13-18,1991 \ldots \ldots \ldots \ldots \ldots \ldots \ldots \ldots \ldots$

20. Trace element composition for ISV product and sublimate-encrusted ISV product. $\ldots \ldots 87$

21. Fluid concentrations and fractionation factors determined for ISV melt off-gas. . . . . 91

22. Inventories and activities of ${ }^{137} \mathrm{Cs}$ and ${ }^{90} \mathrm{Sr}$ and total solids deposited on the prefilter used in 1991 ORNL ISV test. . . . . . . . . . . . . . . . . . . . . 95 
TABLES (continued)

23. Average elemental concentrations, net deposition, and relative deposition factors for the prefilter and unused filter from the ORNL 1991 pilot-scale ISV test. . . . . . . . . 97

24. Deposition of radioisotopes on the prefilter, amounts in the ISV product, and meit retention factors during the 1991 ORNL pilot-scale field test. . . . . . . . . . . 99

25. Deposition of rare earth tracers on the prefilter, amounts in the ISV product, and retention factors during the 1991 ORNL pilot-scale field test. . . . . . . . . . .

26. Chemical composition and acid-extractable concentrations of ISV waste scrub solutions

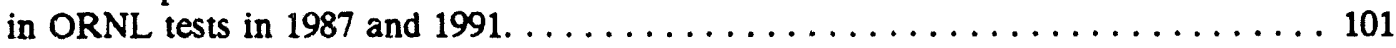

27. Scrub solution anaiyses during the 1991 ORNL pilot-scale ISV test. $\ldots \ldots \ldots \ldots \ldots 104$

28. Anions in the scrub solution at $94 \mathrm{~h}$ during the 1991 ORNL pilot-scale test. . . . . . . 104

29. Activity and inventory of ${ }^{137} \mathrm{Cs}$ on ISV off-gas handling components after completion of 1991 ORNL test. . . . . . . . . . . . . . . . . . . . . . . . . 107

30. Effects of heating and melting rates on the volatilization of ${ }^{237} \mathrm{Cs}$ from laboratory crucibles of $7: 3$ soil:limestone. . . . . . . . . . . . . . . . . . 120

31. Activities of ${ }^{137} \mathrm{Cs}$ and ${ }^{90} \mathrm{Sr}$ and concentrations of tracer elements in the five cold caps of ISV products above the bulk meit zone. . . . . . . . . . . . . . . 128

32. Chemical and radionuclide composition of ISV product and starting materials. . . . . 129

33. Elemental and radionuclide retention factors and percent retention in the ISV melt and calculated soil incorporation fraction during the 1991 ORNL ISV pilot-scale test. . . 130

34. The estimated weight of ISV product formed during the 1991 ORNL pilot-scale test based on the calculated dilution of radionuclides and rare earth tracers. . . . . . 131

35. Major and trace element analyses from the rock body and from premelt soil and limestone as analyzed by X-ray fluorescence and neutron activation. . . . . . . 134

36. Calculation of soil:limestone mixing ratio in producing the ISV product. $\ldots \ldots \ldots \ldots 135$

37. Calculation of final melt mass based on amounts of added tracers and their ambient concentrations in starting materials. $\ldots \ldots \ldots \ldots \ldots \ldots \ldots \ldots \ldots \ldots \ldots \ldots \ldots$

38. Representative electron microprobe elemental percentages of phenocryst and glass materials from the 1991 ORNL ISV product. . . . . . . . . . . . . . . 141

39. Normalized leachate elemental values from Product Consistency Tests of 1991

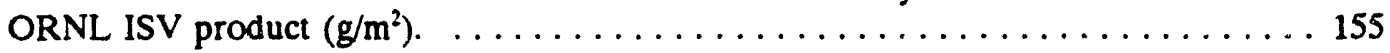

40. Equipment cost for in situ vitrification of the ORNL seepage pits and trenches. $\ldots \ldots 170$ 
TABLES (continued)

41. Hourly costs for personnel to be used for in situ vitrification of ORNL seepage pits and trenches.

42. Hourly rates and related parameters for in situ vitrification operations on the ORNL

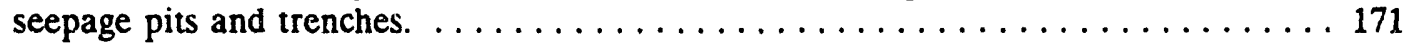

43. Personnel requirements for setup of equipment for in situ vitrification of ORNL seepage

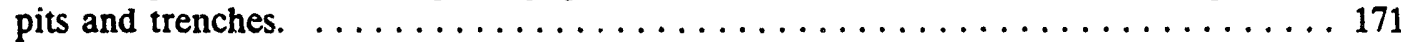

44. Personnel requirement for in situ vitrification operations at the ORNL seepage pits and trenches. 172

45. Cost summary for in situ vitrification of an ORNL seepage trench. 


\section{ACKNOWLEDGMENTS}

Mary Peterson, the Pacific Northwest Laboratory (PNL) project manager during the planning and implementation of the in situ vitrification (ISV) test, was instrumental to the successful completion of the test. The PNL ISV staff, which consisted of Jim Bates, Chuck Bigelow, Roger Fichter, Dave Gibby, Randy Garcia, Ja-Kael Luey, Reed Sharp, and Bill Sliger, successfully operated the ISV egunt under both normal and adverse conditions. Their professional behavior and extraordinat forts are appreciated. Other PNL staff who provided essential help included Kathy Olson for rforming the product consistency tests, Dan Yeager of PNL for the design of the prefilter, and Brie Helgerson, secretary to the PNL staff, who ably organized extensive document preparation and travel arrangements. Mike Campbell and his crew at CamEd, Inc., did an outstanding job on the fabrication of the prefilter.

Special thanks go to Dave Farmer of Oak Ridge National Laboratory (ORNL) who helped with the site preparation and characterization efforts. His common sense was an essential influence during the field work. Tammy McKenzie helped with training documentation, shipping requests, obtaining phone pagers ay portable phone communications, tracked critical purchase requisitions, and acted as a communications contact for ORNL, PNL, and U.S. Department of Energy (DOE) staff before, during, and after the test. Monty Ross did a superb job in arranging for training classes, documentation, and special access badges for the entire ISV crew. Tim McKnight, Cary Long, and Bill Murray successfully designed, constructed, and programmed the ORNL computer data acquisition system. The geophysical crew that imaged the melt included Rick Williams, Marvin Speece, John Hanson, and Keni Conatser of the University of Tennessee, and Alan Witten, John Switek, and Bob Kennard of CRNL. Brian Spies of Schlumberger-Doll Research patiently waited until the power was terminated to obtain DC resistivity measurements on the melt. He then worked from midnight till 4:00 a.m. to collect his data. Jon Nyquist performed ground-penetrating radar of the solidified ISV body after the site had been cleared of equipment. Lee Riciputi performed the ion microprobe analyses at ORNL. Portions of the $\mathrm{X}$-ray fluorescence and neutron activation analyses were performed at the New Mexico Institute of Mining and Technology, Los Alamos National Laboratory, and the University of Missouri.

Jeff Riggs and Roy Freeman helped install speciaı cameras at the last minute to monitor the ISV test and helped repair the PNL data acquisition system during the test so that there was minimal impact to the data collection. Bobby Herrell is commended for his excellent backhoe operation and for enduring our requests for careful excavation during placement of the instrumentation. The speed and efficiency of Larry Reeves and his rigging crew during equipment assembly and disassembly were greatly appreciated. Steve Bridges and Bob Bracher helped arrange for craft support and were always willing to handle our crises.

We are especially grateful to the electrical line crew (J. Fritz, R. Cleveland, G. Jones, H. Jones, D. French, and D. Hickman). Their efforts on Mother's Day to install new power lines in the rain so that the test could continue are commendable. Lynn Degenhardt designed changes in the existing power line arrangement to accommodate the power needed to continue the test.

Ray Flanery and Toby Mitchell used their interpolation and computer visualization skills to help us visualize the 3-d thermal data. Vasili Alexiades and Alan Solomon provided wonderful insight on interpretations of the heat transfer aspects of ISV and the thermal data obtained during this test.

A multitude of other craft support, favors from colleagues, and loans of equipment are gratefully acknowledged.

The ISV test itself was sponsored by DOE's Office of Technology Development. The petrologic and seismic studies were supported by the Geosciences Research Program of DOE's Office of Basic Energy Sciences. Seismic data-processing software used at The University of Tennessee was provided in part by funding from the National Science Foundation to the Incorporated Research Institutions for Seismology. 


\section{INTRODUCTION}

This report summarizes the activities that were performed through fiscal year (FY) 1992 for the tracer-level radioactive pilot-scale in situ vitrification (ISV) test. This test is the second step in evaluating ISV as a remedial action for the pits and trenches at Oak Ridge National Laboratory (ORNL). A previous pilot-scale ISV test, using nonradioactive tracers for $\mathrm{Cs}$ and $\mathrm{Sr}$, was completed in 1987 and reported in 1989 (Spalding and Jacobs 1989; Jacobs et al. 1988; Carter et al. 1988). The present test again used a one-half scale model of trench 7 and Department of Energy (DOE) pilot-scale ISV equipment which was operated by Pacific Northwest Laboratory (PNL). A small and precisely known amount of waste from a liquid waste disposal pit was used, rather than an actual contaminated waste site, because the test required an exactly known inventory of radionuclides so that a precise measurement of the volatilization of various constituents to the off-gas could be determined. The demonstration had four major objectives:

1. demonstrate a reduction in ${ }^{137} \mathrm{Cs}$ accumulation in the off-gas processing equipment from the $0.12 \%$ of inventory that was achieved in the 1987 demonstration,

2. assess the radiological and operational performance factors associated with applying ISV to a radioactive site,

3. confirm the durability of an ISV waste form containing radioactive components, and

4. evaluate seismic imaging and advanced thermometric methods for monitoring the progression of melting.

PNL delivered and operated the DOE pilot-scale ISV equipment in May 1991. ORNL prepared the site and helped ready existing equipment for operation by PNL. ORNL sampled and characterized the waste sludge specimen from archived cores from liquid waste disposal pit 2 and determined the chemical and radionuclide composition. On the basis of this information, an amount of sludge was selected sufficient to track the behavior of key radionuclides through the ISV system during and after vitrification of the test trench. Samples of off-gas scrub solutions were obtained during the test for analyses by ORNL and PNL. After the ISV mass cooled and solidified, core samples were collected and analyzed for their leachability and for their chemical, radioisotopic, and mineralogical composition.

\section{ORNL SEEPAGE PITS AND TRENCHES}

A series of seven seepage pits and trenches (Fig. 1) was used between 1951 and 1966 for the disposal of approximately $4.3 \times 10^{7}$ gal of liquid radioactive wastes at ORNL. Approximately 200,000 $\mathrm{Ci}$ of ${ }^{90} \mathrm{Sr}, 200,000 \mathrm{Ci}$ of ${ }^{106} \mathrm{Ru}$ (which has now decayed to nondetectable levels), and $600,000 \mathrm{Ci}$ of ${ }^{137} \mathrm{Cs}$, along with smaller quantities of other fission products, uranium, and transuranic elements, were disposed in this series of pits and trenches (Table 1). To facilitate the seepage of liquids, the trenches were constructed on the tops of ridges, were oriented perpendicular to the strike of the bedding of the formation, and were filled with crushed limestone or dolomite (Fig. 2). As the liquids seeped out, the $\mathrm{Cs}$ and $\mathrm{Sr}$ remained within or close to the trenches. Cesium is generally irreversibly sorbed by the illite-rich soils at ORNL. Strontium, on the other hand, is poorly sorbed. To reduce the mobility of $\mathrm{Sr}$, the pits and trenches were treated with a highly alkaline solution $(\mathrm{NaOH})$ at the time of disposal. All of the pits and trenches are now covered with asphalt caps to reduce the direct flow of precipitation through the waste. Currently, the pits and trenches do not contribute significantly to surface-water contamination, and most of the $\mathrm{Cs}$ and $\mathrm{Sr}$ remains close to the bottom of the pits and trenches. However, the large inventory of ${ }^{137} \mathrm{Cs}$ and ${ }^{90} \mathrm{Sr}$, the close proximity of the wastes to the surface and White Oak Creek, and the potential for significant releases in the future necessitates either a long-term site maintenance and monitoring program or some form of remedial action to allow 
Table 1. Summary characteristics of ORNL seepage pits and trenches in Waste Area Grousing 7.

\begin{tabular}{|c|c|c|c|c|c|}
\hline Waste Unit & $\begin{array}{l}\text { Size } \\
(1 \times w \times d-f t)\end{array}$ & Dates Used & $\begin{array}{l}\text { Volume Disposed } \\
\text { (gal) }\end{array}$ & $\begin{array}{l}\text { Activity }^{\mathrm{a}} \\
\text { (Ci) }\end{array}$ & Isotopes \\
\hline Pit $1^{b}$ & $100 \times 20 \times 15$ & 1951 (leak) & 120,000 & 389 & $\mathrm{Cs}, \mathrm{Sr}, \mathrm{Ru}$ \\
\hline Pits 2,3 , and 4 & $200 \times 100 \times 15$ & $1952-1962$ & $24,000,000$ & 480,000 & $\mathrm{Cs}, \mathrm{Sr}, \mathrm{Ru}$ \\
\hline $\begin{array}{l}\text { Pit } 4 \text { only, } \\
\text { additional disposal }\end{array}$ & $200 \times 100 \times 15$ & $1956-1976$ & $9,000 /$ week & undetermined & $\begin{array}{l}\text { Sludge from } \\
\text { Process Water } \\
\text { Treatment Plant }\end{array}$ \\
\hline Trench 5 & $300 \times 10 \times 15$ & $1960-1966$ & $9,500,000$ & 308,500 & $\mathrm{Cs}, \mathrm{Sr}, \mathrm{TRU}$ \\
\hline Trench 6 & $450 \times 10 \times 15$ & 1961 (leak) & 130,000 & 1,335 & $\mathrm{Cs}, \mathrm{Sr}, \mathrm{TRU}$ \\
\hline Trench 7 & $200 \times 10 \times 15$ & $1962-1966$ & $9,500,000$ & 283,900 & Cs, Sr, TRU \\
\hline
\end{tabular}

activity at the time of disposal.

${ }^{b}$ Pit 1 also received drain discharges from a decontamination building from 1962-1976 but there was probably no significant change in radionuclide inventory.

Source: Spalding 1987.

the sites to be permanently decommissioneci.

In situ vitrification is one possible technology that could be applied to the pits and trenches (others include grouting and ground densification). ISV, developed and patented for DOE by PNL, involves placing four electrodes in a square array around the contaminated volume of soil, applying power to the electrodes, and melting the entire mass of soil into a chemically homogeneous and durable glassy-to-microcrystalline waste form (U.S. EPA 1992). The melting is initiated at the surface of the soil and progresses downward through the contaminated zone. Gases produced during the high-temperature operation (1300 to $2000^{\circ} \mathrm{C}$, depending on the earthen materials) are collected through an off-gas hood and scrubbed to remove possible contaminants in a process trailer (Fig. 3 ). The ISV technology has been extensively tested by PNL at electrode spacings from approximately 0.3 to $6 \mathrm{~m}$. The pits and trenches at ORNL are good candidates for ISV because of their small area and shallow depth $(<6 \mathrm{~m})$. The potential for reduced personnel exposure from the high concentrations of ${ }^{90} \mathrm{Sr}$ and ${ }^{137} \mathrm{Cs}$ in the pits and trenches makes an in situ technology highly desirable compared with one that would require excavation of the highly contaminated material.

The previous pilot-scale "cold" (nonradioactive) demonstration of ISV technology, performed in 1987 jointly by ORNL and PNL, had four main objectives: (1) complete an application of ISV technology away from the Hanford Site to evaluate the feasibility of technology transfer to ORNL; (2) assess the operational performance of ISV for applications in structurally heterogeneous, highcarbonate soils and rocks; (3) determine the retention factors (mass in melted product divided by mass in off-gas) for Cs and Sr under field conditions; and (4) evaluate the durability of the waste form produced in an ORNL soil. The field-scale vitrification of a cold model of seepage trench 7 was completed on July 20,1987 . An estimated $20 \mathrm{Mg}$ of soil and crushed limestone backfill were melted. The desired melting depth of $2 \mathrm{~m}$ was achieved. The molten mass tended to grow parallel to the long axis of the trench rather than symmetrically around the square array of electrodes. All melt geometry, 


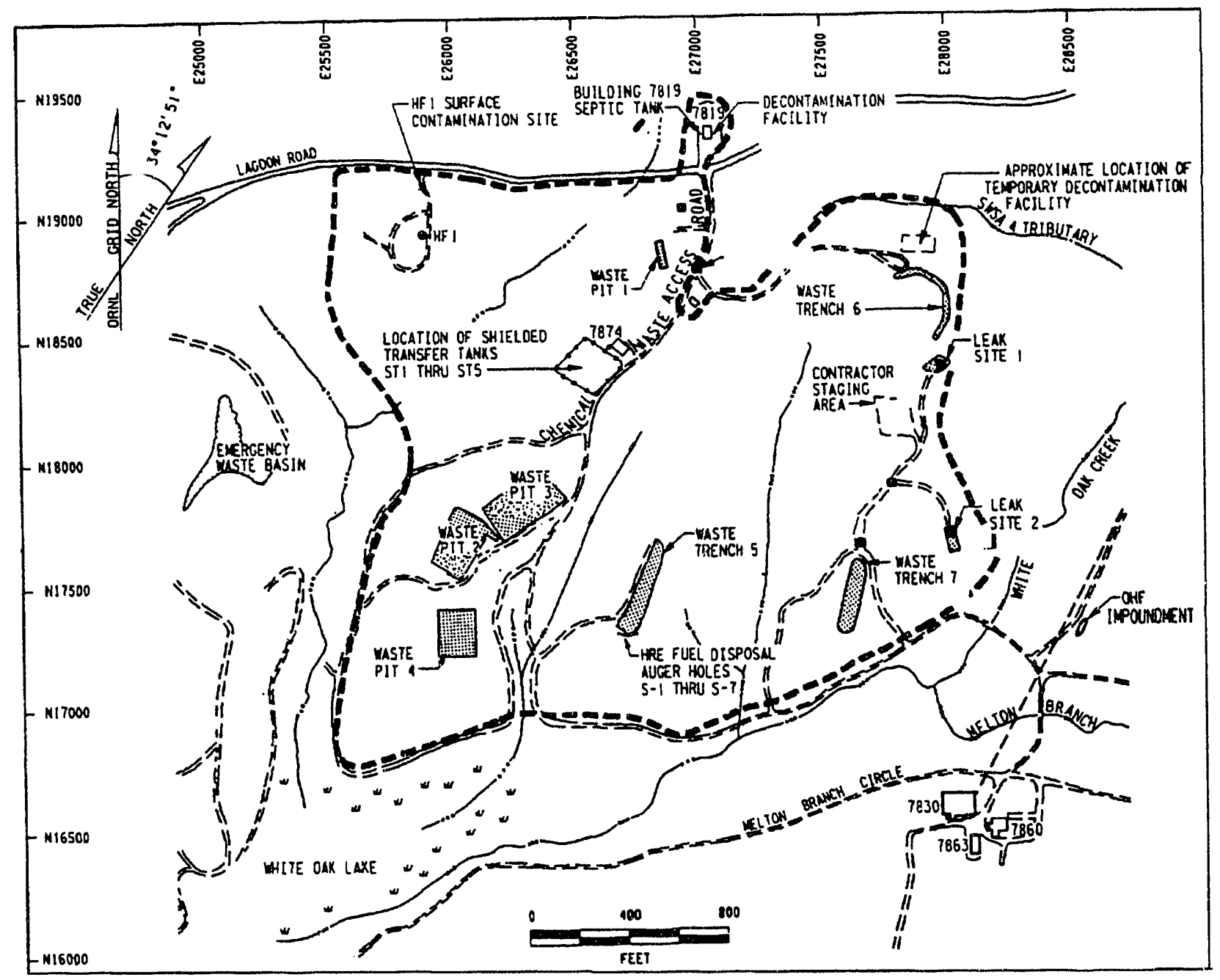

Fig. 1. ORNL Waste Area Grouping 7 which contains the seven seepage pits and trenches used between 1951 and 1966.

safety, and process performance objectives were achieved satisfactorily. A 2-month cooling period was required before core sampling of the vitrified product could be initiated. Analyses of samples of the off-gas scrub solutions indicated that 99.88 and $>99.99 \%$ of the cesium and strontium tracers, respectively, were retained in the vitrified product. Samples of the field-produced material were found to be as good or better than two standard high-level nuclear vitreous waste forms using standard leach tests. Approximately half of the block crystallized to pseudowollastonite and plagioclase feldspar mineral phases during cooling. However, crystallization produced no significant change in the leach properties of the material (Carter et al. 1988; Spalding and Jacobs 1989). 


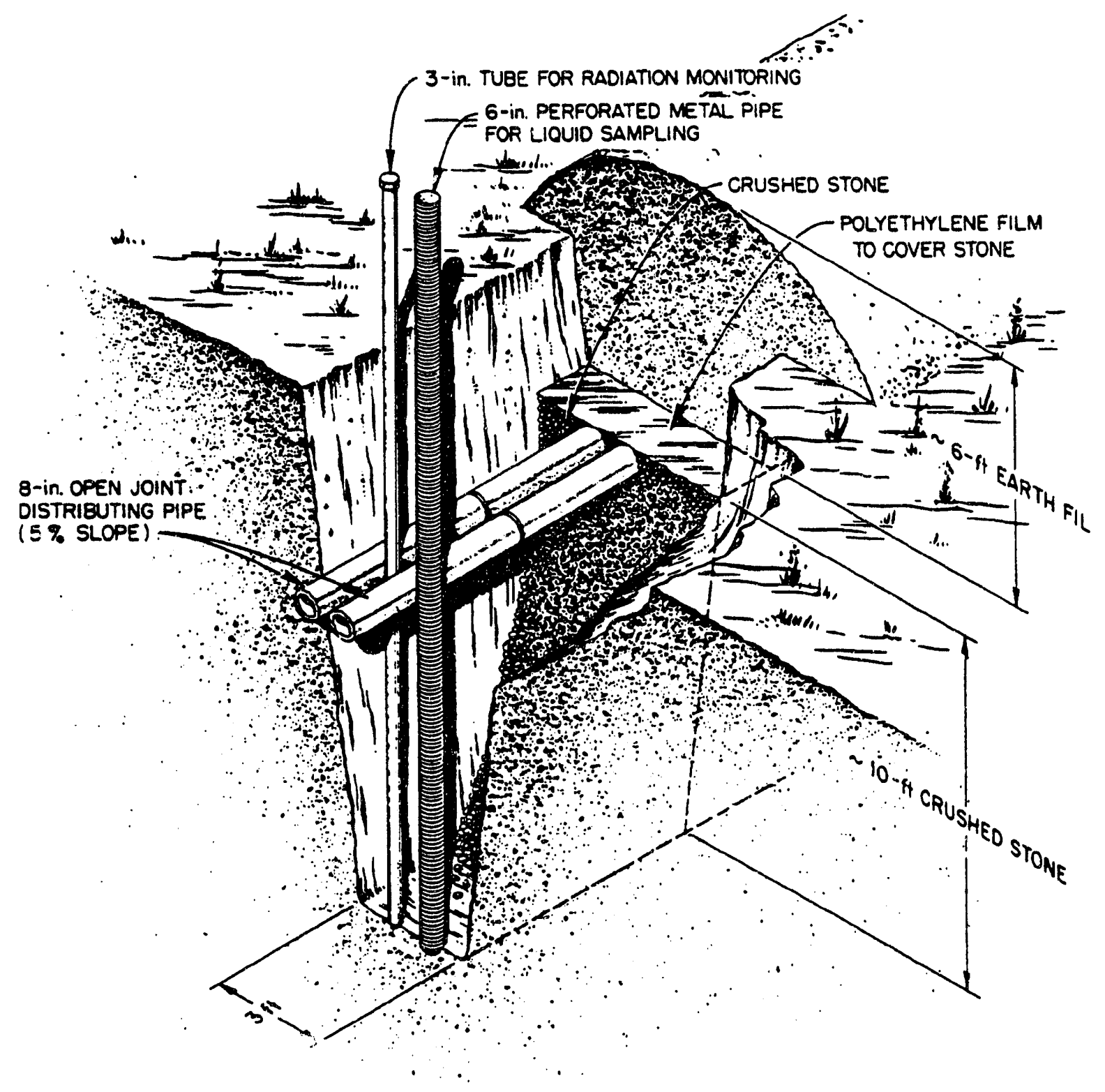

Typical Woste Disposal Trench.

Fig. 2 Construction design details of ORNL liquid seepage pit 7.

\section{DESCRIPTION OF THE ISV TECHNOLOGY}

The ISV process relies on joule-heating and is based on the glass melter technology developed and patented for the DOE by PNL for immobilizing high-level nuclear waste. In situ vitrification was originally tested by PNL researchers in August 1980 (Brouns et al. 1983). Since then, over 150 tests and demonstrations have been conducted, ranging from bench- and engineering-scale tests in the laboratory to pilot- and large-scale tests in the field. The large-scale field tests have produced vitrified soil monoliths as large as 900 tons and $40 \mathrm{ft}$ in diameter. In 1987 the technology was transferred to the Geosafe Corporation for commercial remediation of soils contaminated with hazardous wastes. 


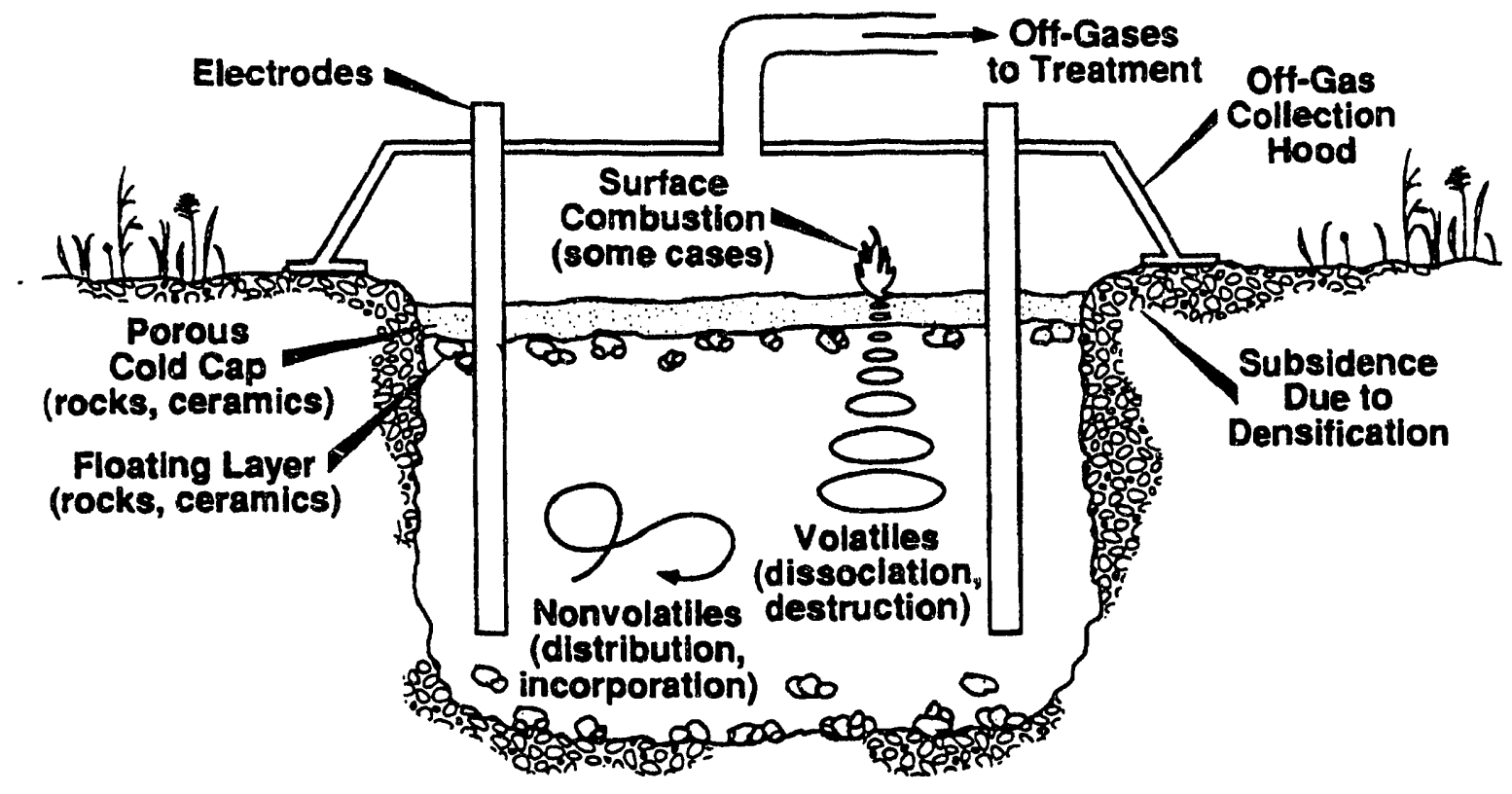

Fig. 3. Disposition of materials during in situ vitrification processing.

Figure 4 depicts the ISV processing sequence as applied to a liquid waste disposal seepage trench. An array of vertical electrodes is inserted into the soil to a nominal depth (about two electrode diameters) above the waste site and, since dry soil is not electrically conductive, a conductive material (typically glass frit and graphite flake) is placed in paths between the electrodes to act as a resistive heating element. The soil-melting process is initiated when an electric potential applied to the electrodes establishes a current in the path, in turn heating the path and the soil surrounding the path to temperatures above the melting point of soil. Once molten, the soil becomes electrically conductive. Power to the melt is controlled as the process continues and the molten soil mass grows downward and outward (typically maintaining temperatures between $1400^{\circ} \mathrm{C}$ and $2000^{\circ} \mathrm{C}$ ). The melt dissolves and/or encapsulates radionuclides and nonvolatile hazardous elements, such as heavy metals, and destroys organic components by pyrolysis. Semivolatile and volatile metals are largely retained in the melt, but the small quantity of material that does escape from the melt is captured and treated. The fate and disposition of various materials during ISV processing is depicted in Fig. 3.

A hood placed over the area being vitrified confines the gases released from the melt and directs them to an off-gas treatment system that uses a combination of wet-scrubbing and dry-filtering. Power to the melt is maintained until the desired depth is obtained and the soil and its contents are melted. Since the conductivity of the melt increases as the melt volume increases, the ISV power supply is equipped with a series of voltage taps to maintain a constant power level to the melt. Upon cooling, the molten soil solidifies into a vitrified mass resembling natural obsidian in appearance and, most importantly, in durability, with a leach resistance approaching that of high-quality laboratory glassware (Buelt et al. 1987; Callow et al. 1991). 


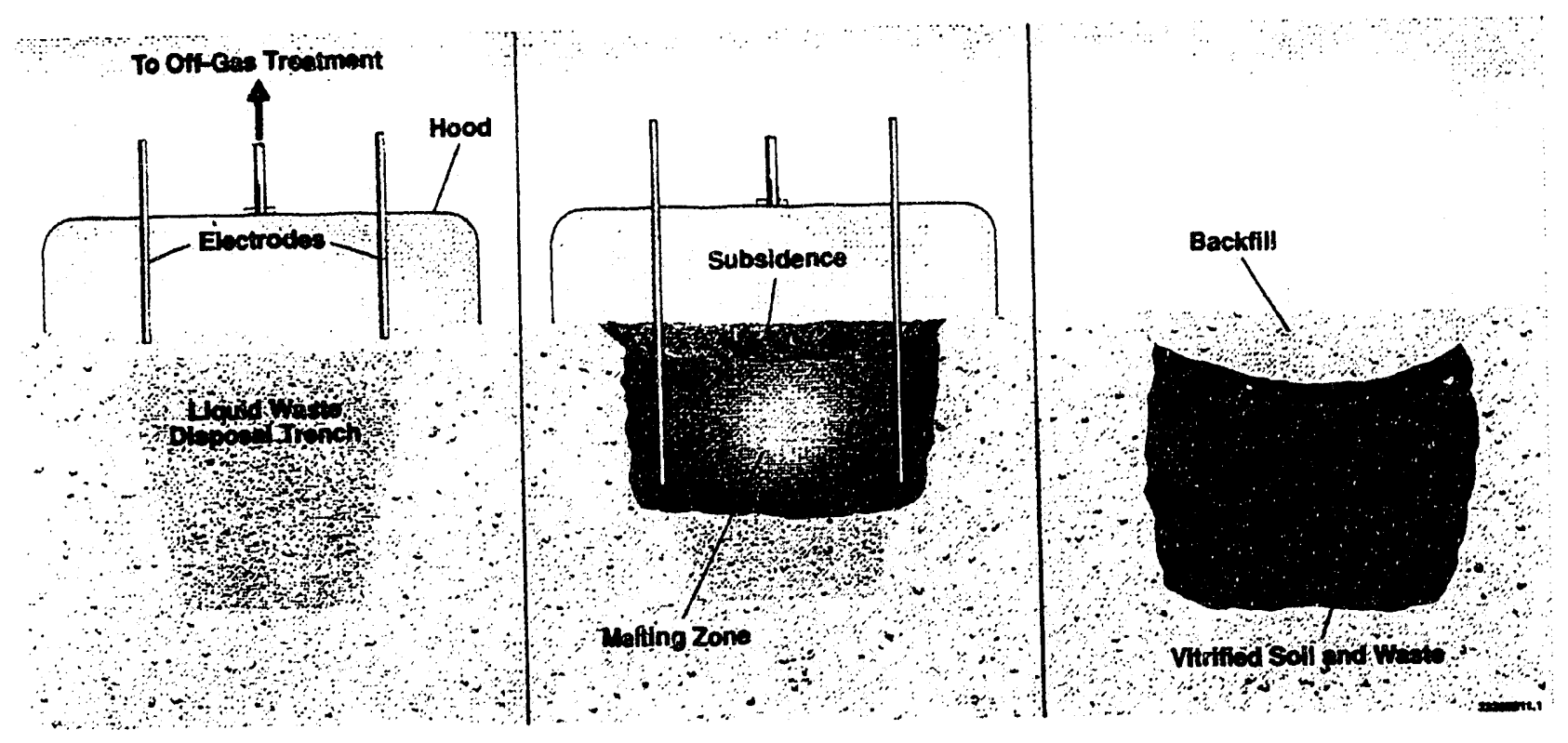

Fig. 4. Schematic illustration showing the ISV process applied to a seepage trench.

During the ISV process, the electrode feed system is used to control the vertical position of the electrodes in the melt. The electrodes can be fed in either a passive or active mode. In the passive mode they are allowed to feed downward by gravity, constantly resting on the bottom of the melt. In the active mode they can be retracted, held, or advanced as necessary, especially to raise the electrodes out of a molten metal pool and thus eliminate the possibility of an electrical short circuit. The baseline ISV technology has used fixed, or preplaced, electrodes at the site to be vitrified; these electrodes are inserted into casings that are pounded or drilled to the target treatment depth. The electrode feed system has grown out of a need to remotely control the vertical position of the electrodes used during ISV. The primary driver for the development and implementation of the electrode feeding technology was to improve the performance of the ISV when processing a site containing buried metal (Farnsworth et al. 1990). Metal inclusions melt when they are contacted by the molten soil region. Molten metal is more dense than molten soil and stratifies at the bottom of the melt, thus creating the possibility of an electrical short circuit between the electrodes. Eventually, it would be impossible to continue melting after an electrical short circuit when using fixed electrodes. The electrode feed system has been successfully implemented on the engineering- and pilot-scale ISV system and was successfully used during the test described in this report. In July 1991 the electrode feed system was successfully demonstrated with the large-scale system and has been recommended to replace the fixed electrode technique as the new baseline electrode placement technology for all future full-scale ISV demonstrations and remediation campaigns at DOE and commercial sites. While the metals content of the ORNL pits and trenches is minimal and would not present a problem for the fixed electrode technique, there are other substantial advantages to implementing the electrode feed system. Compared with the baseline technology, the electrode feed system greatly reduces equipment costs, generation of secondary wastes, risk of electrode failure by oxidation, setup time per setting, and exposure of personnel and equipment to environmental hazards, while at the same time increasing the flexibility of the ISV process. 


\section{TEST OBJECTIVES}

Demonstrate Reduction in ${ }^{137} \mathrm{Cs}$ Accumulation in the Off-Gas Processing Trailer

Table 2. Inventory of radionuclides in ORNL Seepage Trench 7 in Waste Area Grouping 7.

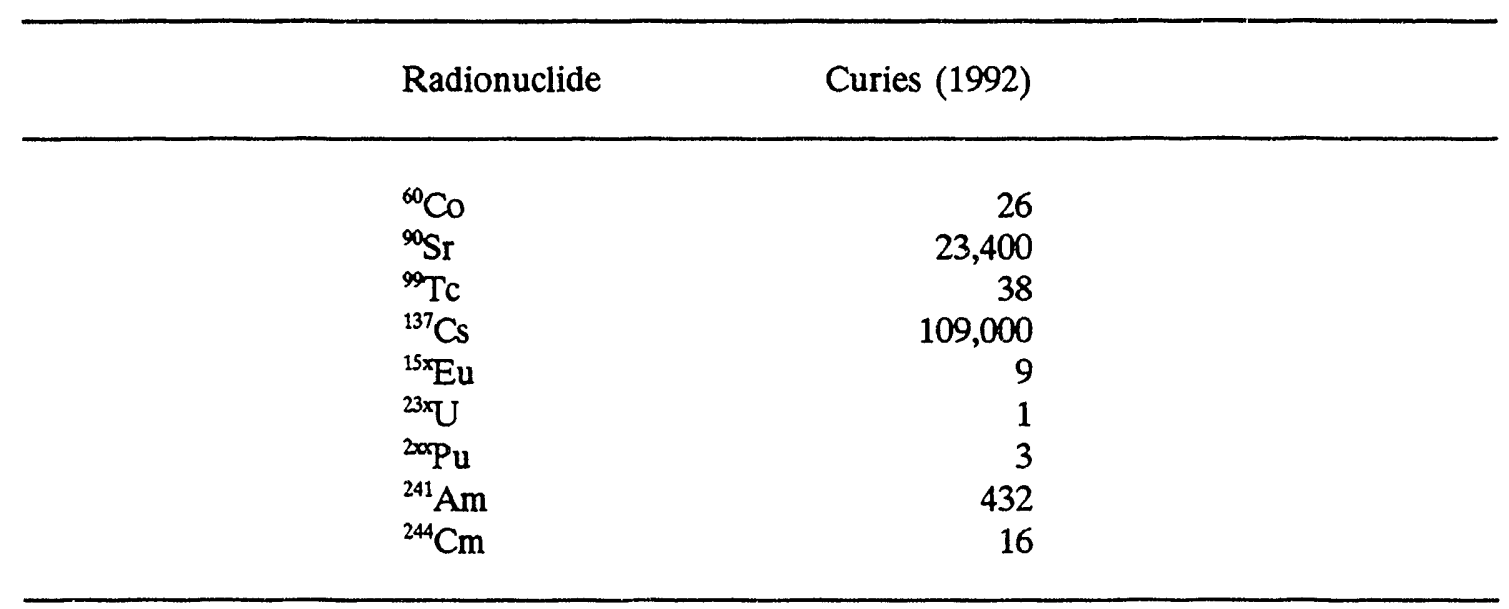

Source: Spalding 1987.

Table 3. Expected distribution of ${ }^{137} \mathrm{Cs}$ activity in ISV off-gas system after vitrifying $10,000 \mathrm{Ci}$.

\begin{tabular}{|c|c|c|c|c|}
\hline \multirow[b]{2}{*}{$\begin{array}{l}\text { Off-Gas System } \\
\text { Component }\end{array}$} & \multicolumn{2}{|c|}{$0.12 \%$ Volatilized } & \multicolumn{2}{|c|}{$2.4 \%$ Volatilized } \\
\hline & $\begin{array}{l}\text { Amount } \\
{ }^{137} \mathrm{Cs} \\
(\mathrm{Ci})\end{array}$ & $\begin{array}{l}\text { Amount per } \\
\text { Unit Area } \\
\left(\mu \mathrm{Ci} / \mathrm{cm}^{2}\right)\end{array}$ & $\begin{array}{l}\text { Amount } \\
{ }^{137} \mathrm{Cs} \\
\text { (Ci) }\end{array}$ & $\begin{array}{l}\text { Amount per } \\
\text { Unit Area } \\
\left(\mu \mathrm{Ci} / \mathrm{cm}^{2}\right)\end{array}$ \\
\hline Hood & 0.079 & 0.24 & 1.44 & 4.37 \\
\hline Ducting & 0.401 & 5.5 & 7.68 & 105.3 \\
\hline Scrub Solutions & 11.74 & $0.5(\mu \mathrm{Ci} / \mathrm{mL})$ & 225.6 & $9.6(\mu \mathrm{Ci} / \mathrm{mL})$ \\
\hline Primary HEPA Filter & 0.293 & 1.46 & 5.52 & 27.5 \\
\hline $\begin{array}{c}\text { Secondary HEPA } \\
\text { Filter }\end{array}$ & 0.008 & 0.04 & 0.16 & 0.8 \\
\hline
\end{tabular}

The reiention of Cs in the ISV product during the 1987 pilot-scale test was encouraging at a value of $99.88 \%$. However, during an actual application to an ORNL pit or trench, the amount of ${ }^{137} \mathrm{Cs}$ volatilization corresponding to this retention factor could result in significant radiological hazard to personnel. To illustrate the magnitude of this potential exposure problem, the vitrification of a 
segment of ORNL trench 7 can be considered. The inventory of radionuclides in trench 7 in 1992 is presented in Table 2. Considering the size of trench 7 and the present melt size capabilities of ISV equipment, approximately ten settings (separate melts) would be required to complete its stabilization by ISV. Thus, each of the ten settings would be expected to process approximately $10,000 \mathrm{Ci}$ of ${ }^{137} \mathrm{Cs}$ (1992 activity) during vitrification. Table 3 indicates the expected fate of any volatilized ${ }^{137} \mathrm{Cs}$ in the off-gas processing system (i.e., as in the 1987 test). If a magnitude of volatilization of $0.12 \%$ of inventory were experienced, as was found in the 1987 demonstration, then approximately $12 \mathrm{Ci}$ of ${ }^{137} \mathrm{Cs}$ would be deposited in the process trailer scrub solutions. Using the dose modeling coefficient of 0.39 $\mathrm{R} / \mathrm{h} / \mathrm{Ci}$ of ${ }^{137} \mathrm{Cs}$ for the radiation field at the tank wall (Oma et al. 1982), operations personnel would be exposed to $4.6 \mathrm{R} / \mathrm{h}$ during ISV of one trench 7 segment. As illustrated in Table 3, if $2.4 \%$ of the ${ }^{137} \mathrm{Cs}$ volatilized, as was experienced in the present test, then radiation fields of $99 \mathrm{R} / \mathrm{h}$ would be encountered. Obviously, such exposures would not be allowed, but this scenario illustrates the mandate to control either or both (1) the degree of ${ }^{137} \mathrm{Cs}$ volatilization and (2) the accumulation of ${ }^{137} \mathrm{Cs}$ in the off-gas processing system. Even if a lower degree of ${ }^{137} \mathrm{Cs}$ volatilization viere attained, experience has shown that removal or decontamination of residual contamination from the present off-gas scrubbers, tanks, and heat exchanger is virtually impossible. Residual contamination would be expected to build during each ISV run resulting in growing radiation fields with continued use.

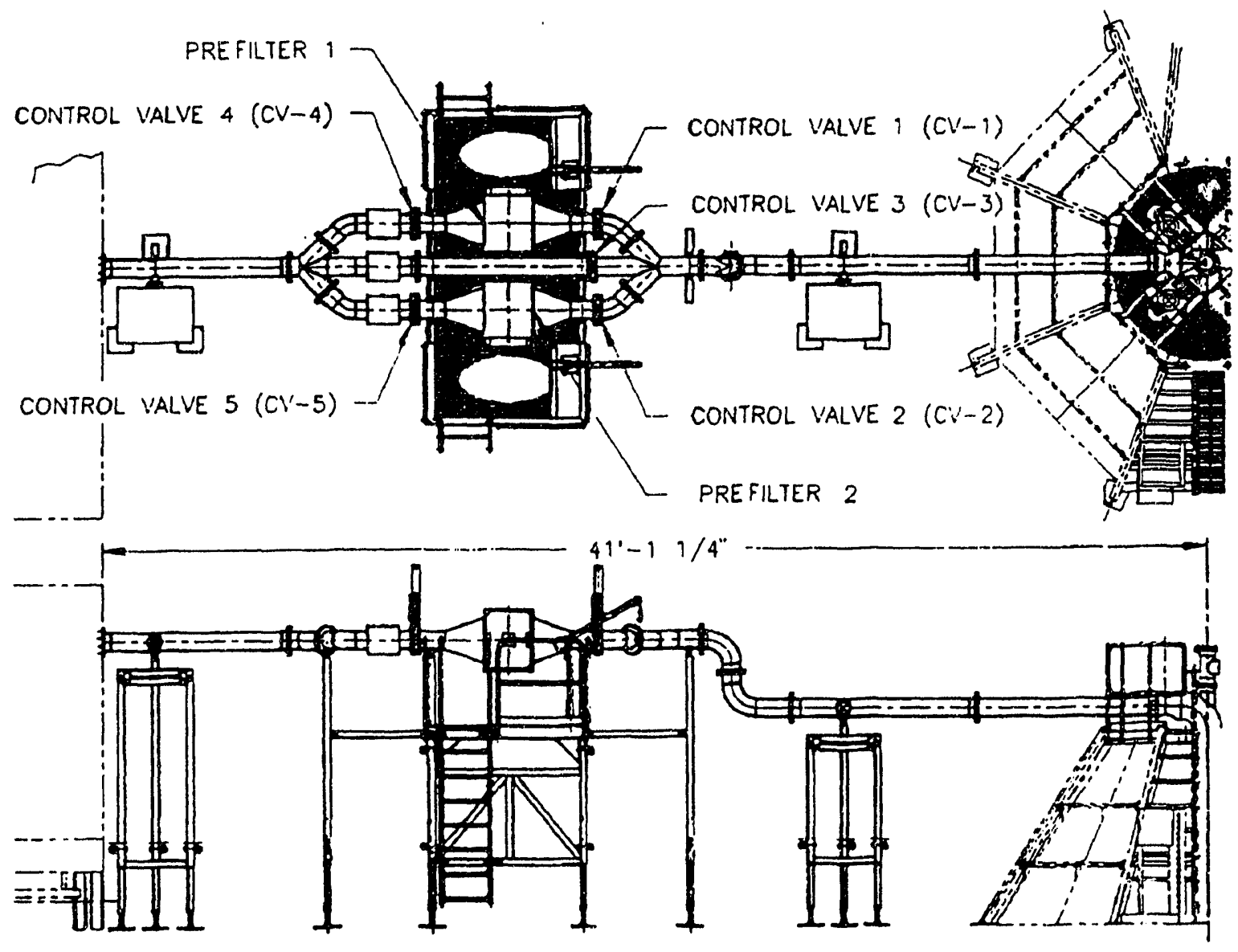

Fig. 5. Design of prefilter unit for 1991 ORNL test. 


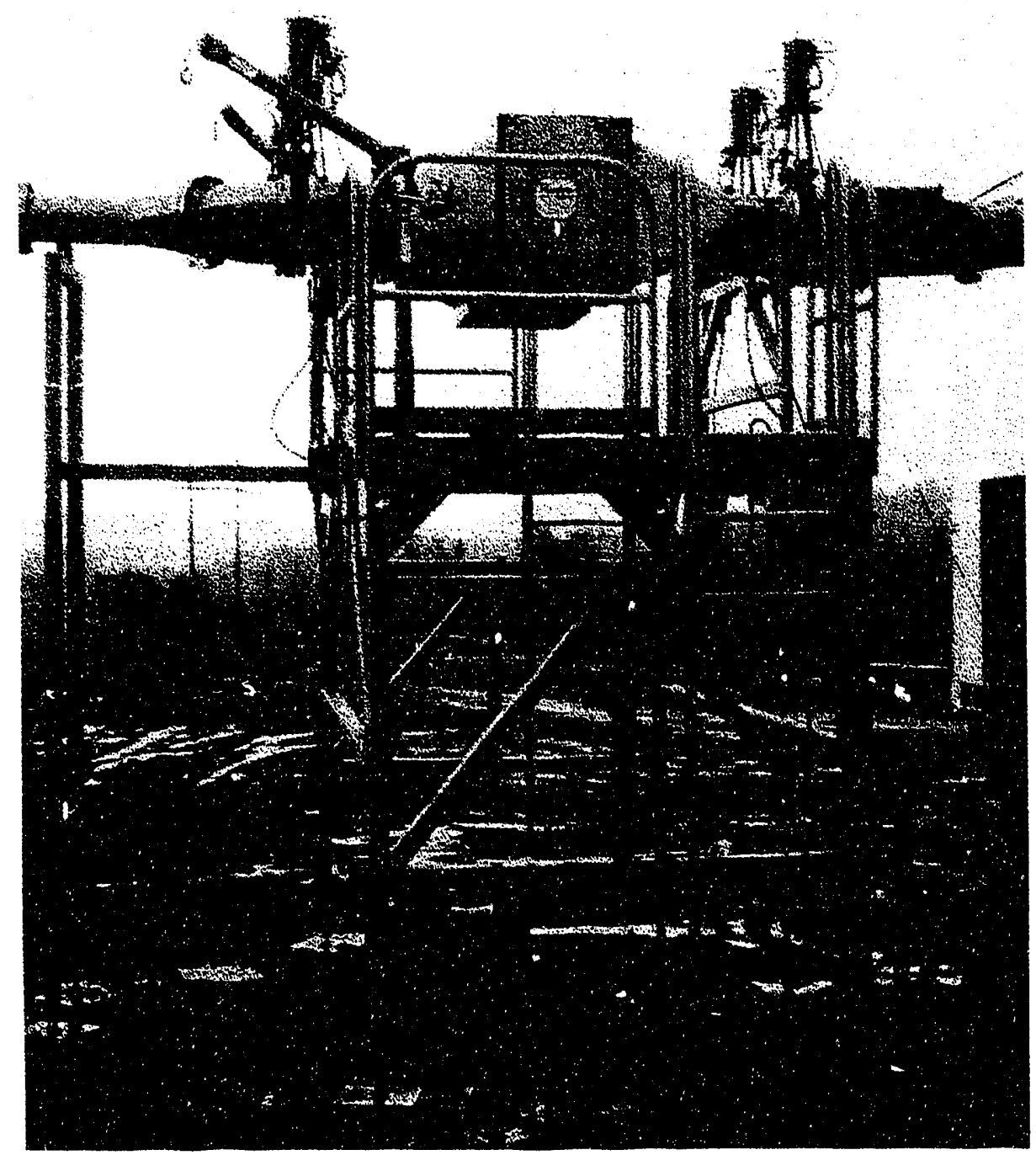

Fig. 6. Prefilter housing assembly as installed for 1991 ORNL ISV test.

Thus, several engineered methods were employed in the present test to evaluate their potential to minimize the accumulation of ${ }^{137} \mathrm{Cs}$ in the off-gas processing trailer during this tracer-level radioactive pilot-scale test. The methods for evaluation included (1) real-time monitoring of the ${ }^{137} \mathrm{Cs}$ release using radiation monitors in the ISV off-gas ducting system prior to flow into the trailer, with potential feedback to limit power input to the melt to induce cold cap formation and to lower melt operating temperature; (2) direct monitoring of melt temperatures with feedback to power input to the melt; and (3) reducing ${ }^{137} \mathrm{Cs}$ accumulation in the off-gas trailer by switching off-gas flow through a prefilter in the ducting (Figs. 5 and 6 ) during the interval of the run when the melting mass 
approaches the depth where the ${ }^{137} \mathrm{Cs}$ was placed.

\section{Assess Radiological and Operational Activities of the ISV System}

The tracer-level, pilot-scale ISV test contained trace levels of actual waste so that most activities required during an application of ISV to a contaminated site were performed and evaluated. Several operational problems occurred during the 1987 test, including breakup of the starter path, spurious radiation alarms, and malfunctions of the power delivery system. These problems, which are not significant for a cold test, are of great concern during the application of ISV to a site containing radioactivity. For the cold test, electrodes were placed in predrilled augerholes. For a contaminated site, it would be advantageous to avoid drilling into contaminated zones. Therefore, during this tracer-level test the electrode feed system, that lowers the electrodes as melting proceeds, was used.

\section{Confirm Durability of ISV Waste Form}

All previous waste forms produced during ISV tests are extremely resistant to leaching with respect to short-lived radionuclides (e.g., half-lives $<100$ years). The presence of radionuclides, and other sludge components likely to be encountered in the pits and trenches at ORNL, is not anticipated to degrade this durability. However, leach tests were performed on the resulting waste form to confirm these assumptions. In addition, a sample of actual waste from one of the pits was analyzed and its leachability determined so that a direct comparison of the improved performance of the waste form can be made.

\section{Evaluate Seismic Imaging and Advanced Thermometry for Monitoring Melt Progress}

Direct monitoring of melt temperatures during field-scale applications of ISV has not previously been accomplished. To provide direct feedback to power input levels so that minimum melt temperatures (thus, minimum volatility of ${ }^{137} \mathrm{Cs}$ ) can be maintained, direct monitoring is highly desirable. At the anticipated temperature of the melt $\left(1300\right.$ to $\left.2000^{\circ} \mathrm{C}\right)$, most thermocouples, except the expensive alumina-sheathed type- $\mathrm{C}$, tend to lose their calibration quickly. Optical thermometric methods are not susceptible to this problem. Therefore, in addition to thermocouples, optical pyrometers were used.

For pilot-scale tests, the depth from the original ground surface to the bottom of the melt (hereafter termed melt depth) can be measured by monitoring thermocouples placed in the test trench in a vertical array during its construction. An extensive array of various types of thermocouples was constructed for the present demonstration. However, during application to an actual waste site, this method of depth monitoring is not feasible because of the contamination present. Estimates of depth usually are based on computer models of energy input and the thermal properties of the system. However, as was shown for ORNL sites during the 1987 pilot-scale test, the heterogeneous nature of the soil makes this model somewhat inaccurate. The electrode feed system also offers a means of monitoring depth via the electrode penetration depth which is presumed to be the melt depth. However, even under optimal conditions, the electrode depth sounding can only provide information at those specific points and cannot provide melt depth information at other points nor any information about melt width. Even occasional electrode breakage, as was experienced on all four electrodes in the present test, introduces significant uncertainty in estimating melt depth. To overcome such limitations, nondestructive geophysical monitoring using seismic and electrical resistivity imaging methods were tested for use in monitoring the progress of melting. Images were obtained before, during, and after melting and should be able to resolve the spatial configuration of the melt relative to the surrounding soil. 


\section{DESCRIPTION OF THE PILOT-SCALE ISV TEST SYSTEM}

The pilot-scale test equipment consists of a power supply and control system, a high-efficiency particulate air (HEPA) prefilter and an off-gas treatment system housed in a portable semitrailer, and an off-gas containment hood over the test site (see Fig. 7).

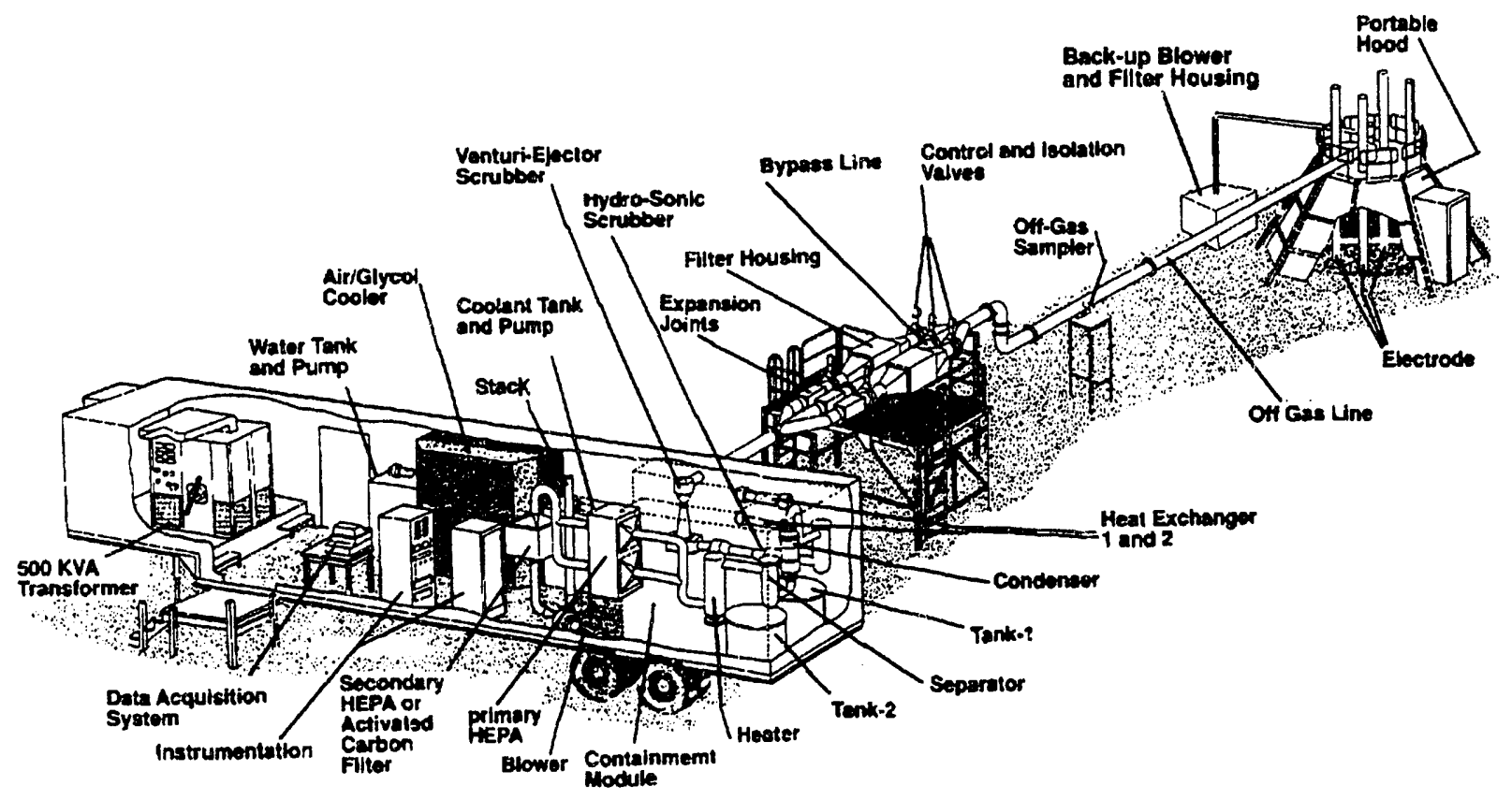

Fig. 7. Cutaway view of the pilot-scale ISV equipment, including the HEPA prefilter assembly that was specially designed for this test.

\section{Power System Design}

The pilot-scale electrode power system uses a $500 \mathrm{kVA}$ Scott-connected transformer that produces variable voltage output through a range of four operator-selectable voltage taps. Power output is controlled at the primary side of the transformer with silicon control rectifier (SCR) technology which uses a single potentiometer selectable for either voltage or current control. The Scott-connected transformer is a system to convert primary 3-phase power (three-wire) to secondary 4-phase (four-wire) power. In order to accomplish this, the tapped winding must resonate between its halves and operate one winding at a leading power factor of $30^{\circ}$ and the other winding at a lagging power factor of $30^{\circ}$. To accomplish these balanced phase shifts, the utility or portable power generator must have three voltages of equal magnitude and separated by phase angles of $120^{\circ}$. The two secondary windings yield quadrature voltages, which, when ungrounded, provide the four phases, which are of equal magnitude and are separated by 90 electrical degrees only if the secondary loads are equal and of unity power factor. This unique balance of voltages and currents is valid for one frequency. The transformer has four separate voltage tap settings: $1000,650,430$, and $250 \mathrm{~V}$. The voltage taps have corresponding current ratings of $250,385,580$, and $1000 \mathrm{~A}$ per phase, respectively. 
A schematic diagram of the Scott-connected transformer is shown in Fig. 8.

The entire pilot-scale system, including both vitrification power and equipment operating power, requires $750 \mathrm{kVA}$ at $480 \mathrm{VAC}, 800 \mathrm{~A}$, 3-phase, and $60 \mathrm{~Hz}$. A backup diesel generator is utilized to provide energy for the operation of all essential equipment for personnel and environmental safety in the event that utility line power is interrupted. These include the off-gas system, data acquisition system, environmental and system monitoring equipment, heating and air-

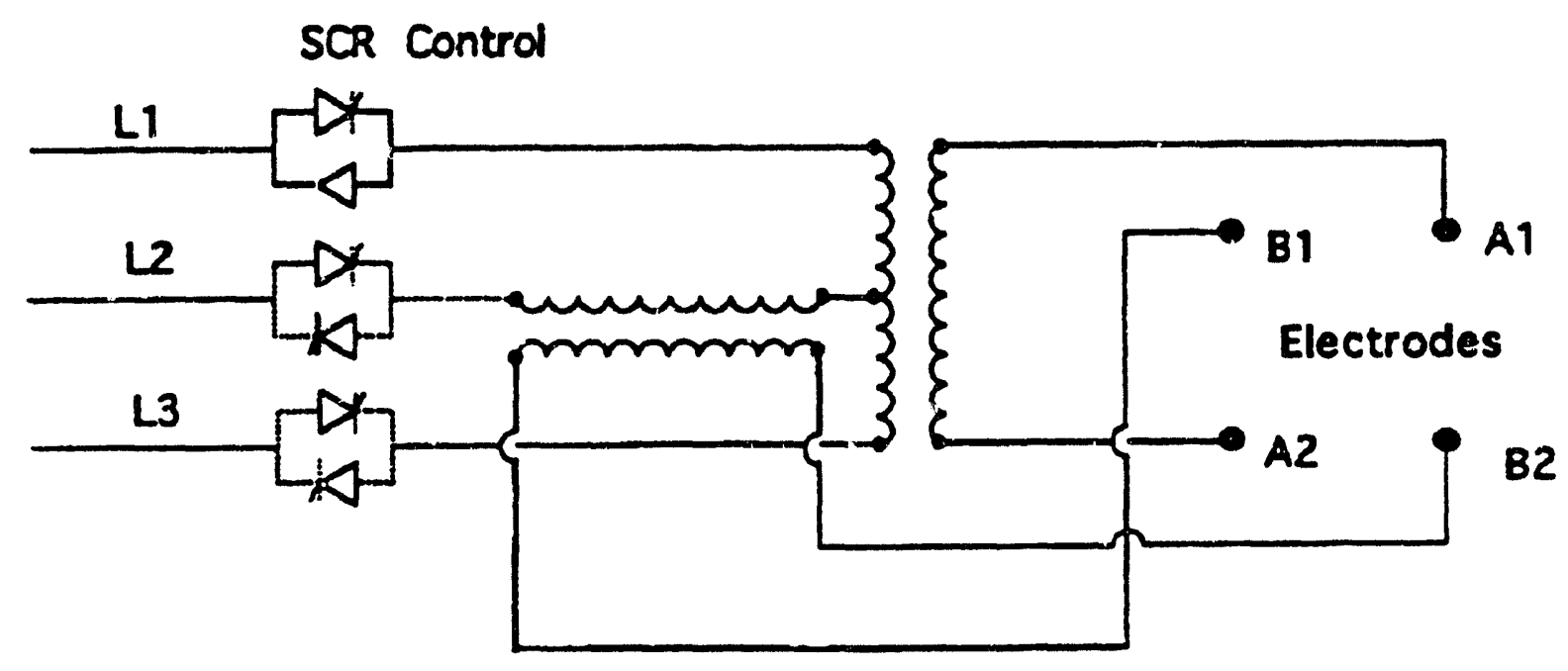

Fig. 8. Schematic diagram of the Scott-connected transformer used in the pilot-scale ISV system.

conditioning, and system lighting. "ihe diesel generator provides $90 \mathrm{kVA}$ at $480 \mathrm{VAC}$, 3-phase, and $60 \mathrm{~Hz}$. Activation of the generator is automatic upon loss of utility line power, thus providing uninterrupted power to essential process equipment.

\section{Electrodes and Electrode Feed System}

The electrodes, used to conduct current to the molten soil, are cylinders of graphite measuring 6 in. $(15 \mathrm{~cm})$ in diameter and approximately $6 \mathrm{ft}(1.8 \mathrm{~m})$ in length. Each electrode section is machined at both ends with female threads to allow connection of successive lengths via double-male threaded graphite connecting pins. The electrodes are initiaiiy buried to depths of about $30 \mathrm{~cm}$, and the starter path consisting of graphite and glass frit is laid around and between the electrodes. For this test the electrodes were arranged in a square array with a center-to-center separation of $3.5 \mathrm{ft}$ $(1.07 \mathrm{~m})$ per side of the square.

The electrode feed system consists of four independently controlled, pneumatically powered units, one feed unit for each electrode, and a control unit with manually operated valves for each feed unit. Compressed air is supplied by an electrical air compressor. Each feed unit has a pneumatic motor that provides vertical movement for an air-actuated clamp allowing for the retraction or 


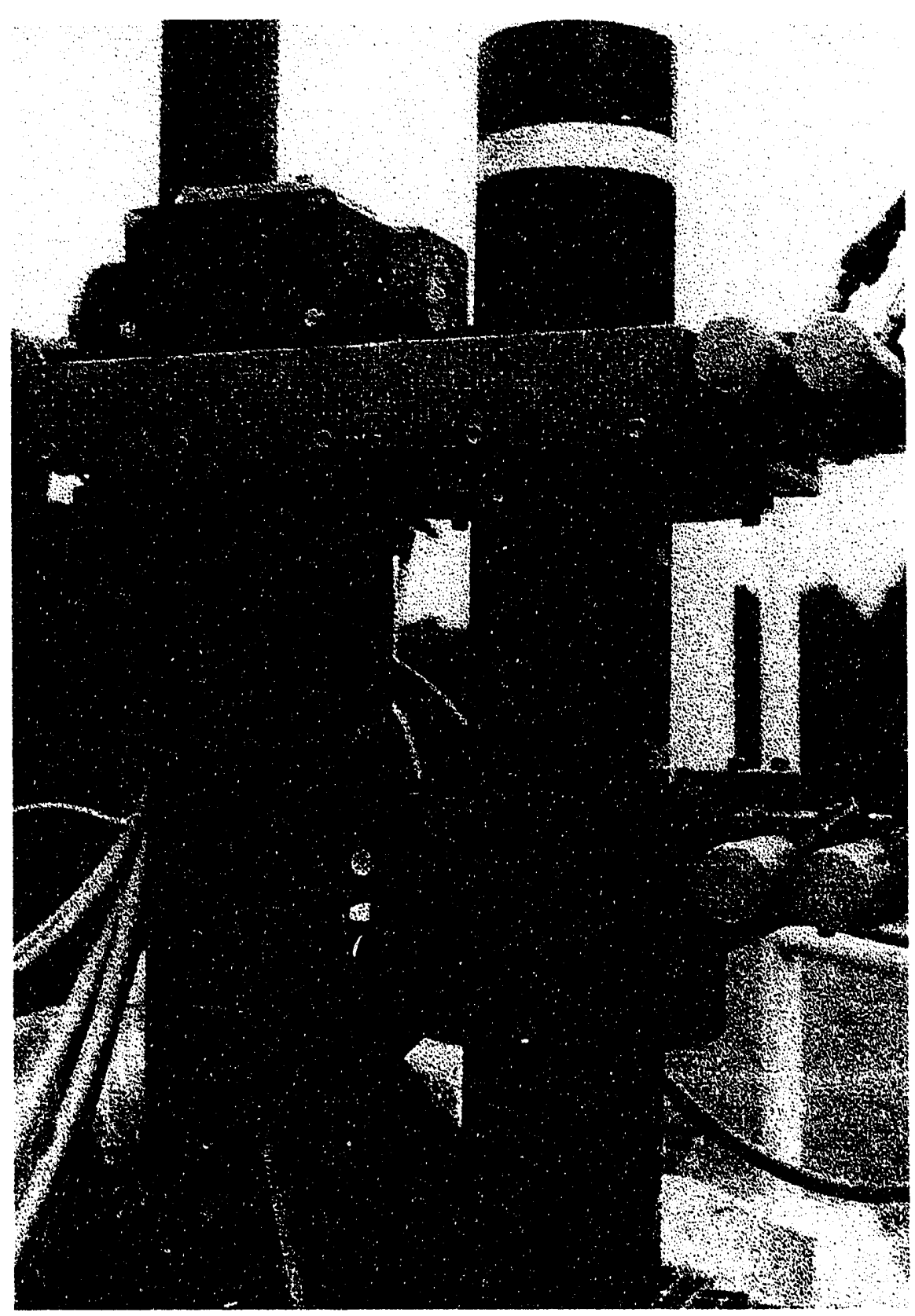

Fig. 9. Electrode feed system stationary (upper) and moveable (lower) clamps to control electrode position.

insertion of a given electrode. A stationary clamp is provided to hold the electrode when the moveable clamp is being repositioned to provide additional electrode movement. Electrical contact from the power cables to each electrode is provided by a copper contact ring (brushes). Contact with the electrode is optimized by using a set of adjustable tension springs on the contact ring. Normally, operations are conducted with the electrodes in a gravity-fed, nongripped mode (electrode feed system clamps not engaged), allowing the electrodes to rest on the bottom of the advancing melt front. As metallic objects, molten metal pools, or other electrically disruptive situations are encountered, the 
feed system is utilized to retract the affected electrode(s) until a stable electrical balance is achieved. Typically, retraction of only 2 to $3 \mathrm{~cm}$ is needed to restore balance. The electrode feed system is shnwn in Fig. 9.

The addition of the electrode feed system has provided some beneficial cost savings to the ISV operations. These savings include the use of less expensive solid graphite electrodes compared with the previous molybdenum core graphite collar design, the elimination of predrilling holes into the ground and the handling of drilling spoils for insertion of stationary electrodes and simplified electrode setup and recovery procedures.

\section{Starter Path}

The starter path consists of a mixture of $35 \%$ glass frit and $65 \%$ graphite flake. The starter path configuration is a rectangle with the four electrodes at each corner and an "X" connecting the diagonally opposed electrodes (Fig. 10). The area to be vitrified is prepared for laying the starter path

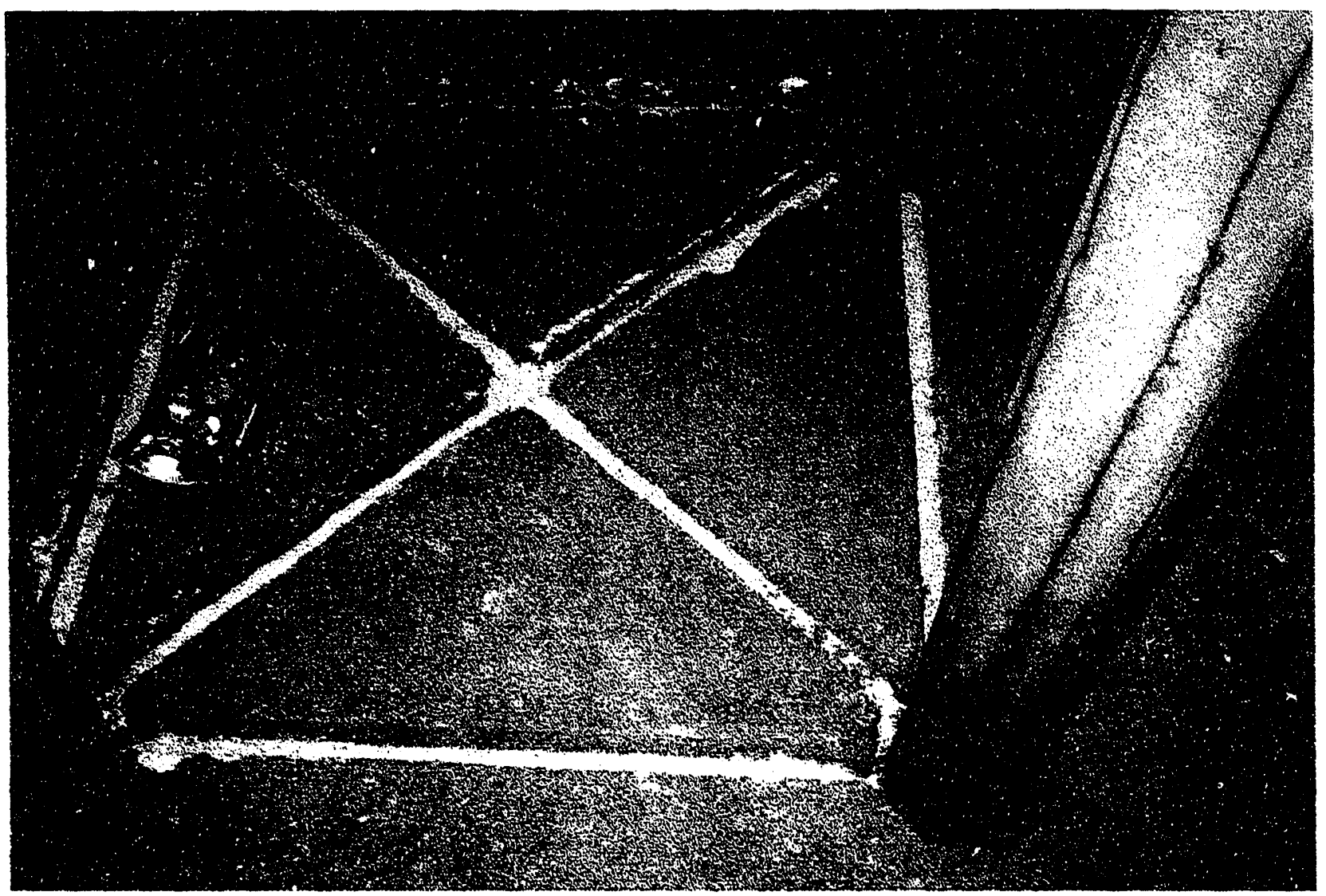

Fig. 10. Starter path configuration used to initiate melting at the beginning of ISV applications.

by ensuring that the top soil covering the area is free of coarse rock and other inclusions. Typically, the area is covered with a 6 -in. $(15-\mathrm{cm})$ layer of sand. Next, a form is constructed from wooden $1.5-$ $\times 3.5$-in. $(4-\times 9-\mathrm{cm})$ boards. The forms are cut to lengths corresponding to th $\mathrm{celectrode}$ separation 
distances and buried horizontally in sand to grade level. A small amount of water is added to the sand in the starter path area to set the soil around the forms. Once the water has permeated the sand to at least the bottom of the boards, the boards are carefully removed leaving a molded trench with the approximate dimensions of $1.5 \mathrm{in} .(4 \mathrm{~cm})$ wide by $3.5 \mathrm{in} .(9 \mathrm{~cm})$ deep. Trenches of the same dimensions are formed by hand around each of the four electrodes. At this point, a 1 in. $(2.5 \mathrm{~cm})$ deep layer of pure graphite flake is placed around the circumference of each electrode. Next, a 1-in. $(2.5-\mathrm{cm})$ layer of the graphite/frit mixture is placed above the layer of pure graphite. Finally, a 1.5to 2 -in. (4- to $5-\mathrm{cm}$ ) layer of the graphite/frit mixture is placed in the rectangular trench and in the trenches of the diagonally opposing electrode pairs.

Once the starter path is complete, it is covered with a 1- to 2-in. (2.5- to 5.0-cm) layer of fine soil or sand that is carefully compacted into place. This layer of soil has been demonstrated to help reduce graphite particulate generation and carryover to the off-gas treatment system once powered operations are initiated.

Finally, two layers of a 1-in. $(2.5-\mathrm{cm})$ thick, alumina-silica fiber insulation is placed over the area to be vitrified. This insulating blanket is used to minimize heat losses from the molten soil during startup and to promote subsidence. During the later stages of operations, after the melt has achieved greater depths, heat losses are limited by the formation of the naturally occurring cold cap, which is a frozen layer of glass on top of the molten zone.

\section{Off-Gas Containment Hood}

The off-gas containment hood consists of a steel shell (plenum) and a superstructure for supporting the shell as well as the electrode feed units. The off-gas containment hood is designed to collect off-gases emanating from the melt and direct them to an off-gas treatment system. The hood is operated at a slight vacuum that is created by an induced draft blower. Typical conditions in the hood range between 1- and 3-in. water column (W.C.) vacuum below ambient atmospheric pressure and between 200 and $400^{\circ} \mathrm{C}$ plenum temperature. The hood, with a volume of approximately $975 \mathrm{ft}^{3}$ $\left(27.6 \mathrm{~m}^{3}\right)$, provides a surge capacity that minimizes vacuum loss during periods of sudden gas release. The surge capacity is equal to the off-gas outlet flowrate as dictated by the off-gas treatment system. The surge of off-gas from the vitrification process simply replaces an equal amount of passive combustion air entering the hood at the combustion air inlet. With a flow of between 10 and 15 $\mathrm{m}^{3} / \mathrm{min}$, gases in the hood were designed to have a residence time of approximately $2 \mathrm{~min}$.

The containment hood is constructed from $304 \mathrm{~L}$ stainless steel sheet. The side panels are constructed from 18-gage sheet and the top is constructed of 14-gage sheet. The containment hood is fitted with a removable door for entry prior to and following the test. A viewing window to observe the melt during processing is included as an integral part of the door design. The electrodes penetrate through the roof of the hood down to the zone to be vitrified. The seals around each electrode are composed of three independent layers of a tight-weave, high-silica fabric suitable for use in high temperature applications. The electrode seals are created by a press fit of the 6-in. $(15.25-\mathrm{cm})$-diam electrodes through 5.5-in. (14-cm)-diam holes in each of the fabric layers providing a wiping action around each electrode. The base of the containment shell is sealed to the ground by piling soil around the base.

Attached to the hood via a 6-in. stainless steel pipe is a seal pot assembly with a HEPA filter assembly and a blower. The seal pot assembly allows combustion air into the hood via a regulating valve. The regulating valve is used to maintain a specific vacuum in the hood as conditions change during operation. The seal pot also acts as a passive pressure-relief system if the hood pressurizes from sudden gas releases. Overpressures of approximately 1 in. W.C. cause a water seal to be relieved, thus allowing off-gases to exit through the seal pot and the HEPA filter. Gases exiting the filter are then released to the environment. A backup blower provides assistance to the main blower to keep the hood under a slight vacuum. Under normal operating conditions, the backup blower is not energized. Control of the backup blower is linked to a pressure transducer mounted on the hood and is activated automatically when the hood vacuum falls below a predetermined setpoint. 


\section{Off-Gas Prefilter}

During actual ISV remediation on an ORNL seepage trench with high ${ }^{137} \mathrm{Cs}$ content, the capture of radioactive particulate in the off-gas system would create high dose rates for operators working inside the process off-gas trailer. In order to accomplish the first test objective, the off-gas prefilter assembly was developed to remove radioactive particulate entrained in the off-gas before the off-gas enters the main off-gas treatment equipment in the process trailer. This allows remote handling and reduced worker exposure by limiting the collection area of the ${ }^{137} \mathrm{Cs}$ to the prefilter, upstream piping, and off-gas hood. The prefilter system is composed of parallel Flanders ${ }^{\circledR}$ E-6 HEPA

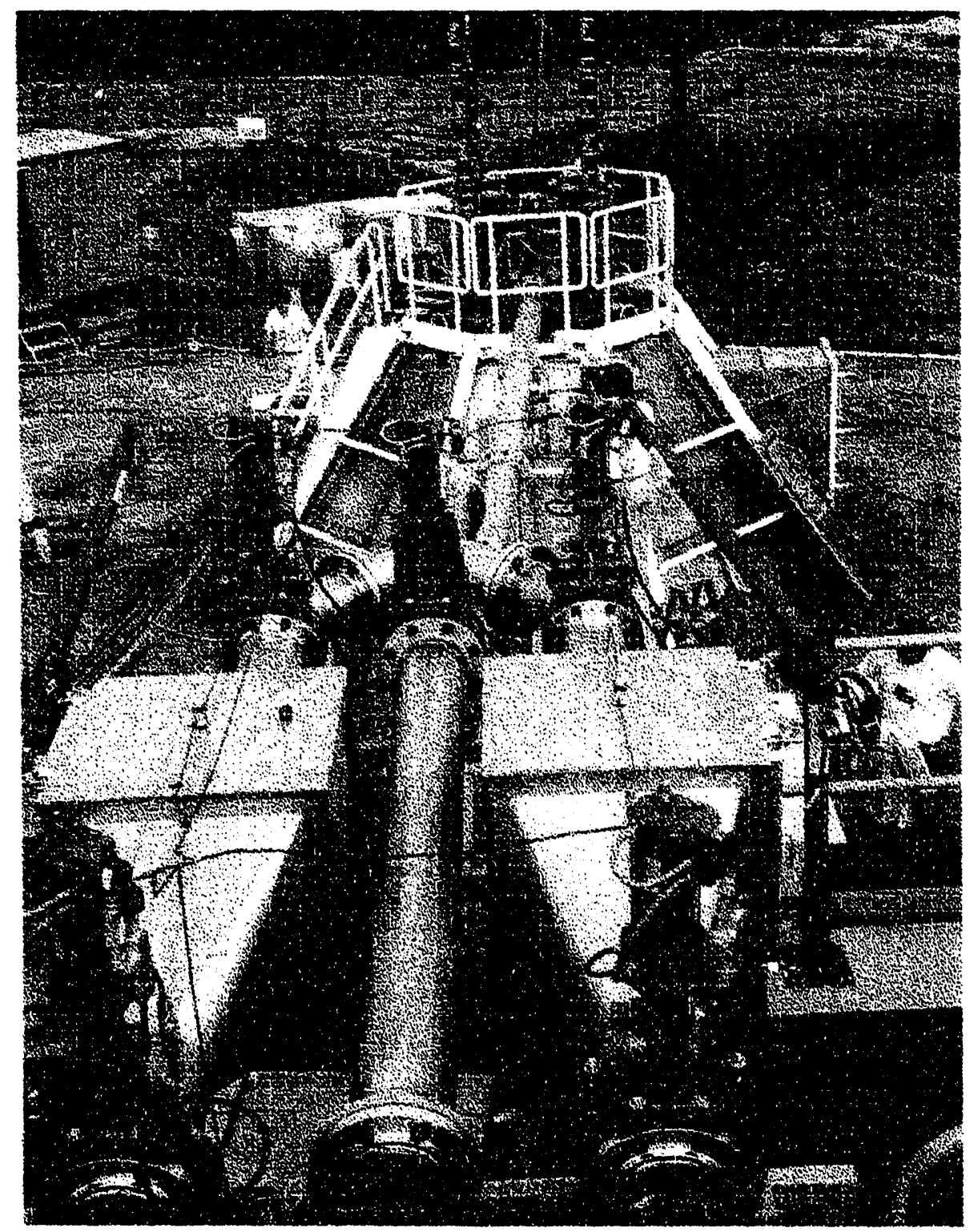

Fig. 11. Photograph of the prefilter assembly showing the two parallel filters, air-actuated valves, and upstream piping. 
bag-out housings with a $24-\times 24-\times 11.5$-in. high-temperature $\left(1000^{\circ} \mathrm{F}\right)$ HEPA filters with metal frames. Flow through the prefilter system can be directed through either filter, both filters simultaneously, or through the bypass line by the operation of remote-controlled air-actuated valves. The prefilter assembly is shown in Fig. 11. Parallel filters allow changing one filter while flow is directed through the other. Differential pressure is measured across each filter housing and is used to determine particulate loading for change-out. Full-scale application would utilize radiation monitoring devices for radiological safety and change-out. During full-scale operation, it would be more likely that the prefilter would require change-out because of radioactive contaminant loading before particulate loading resulted in high differential pressure.

\section{Off-Gas Treatment System}

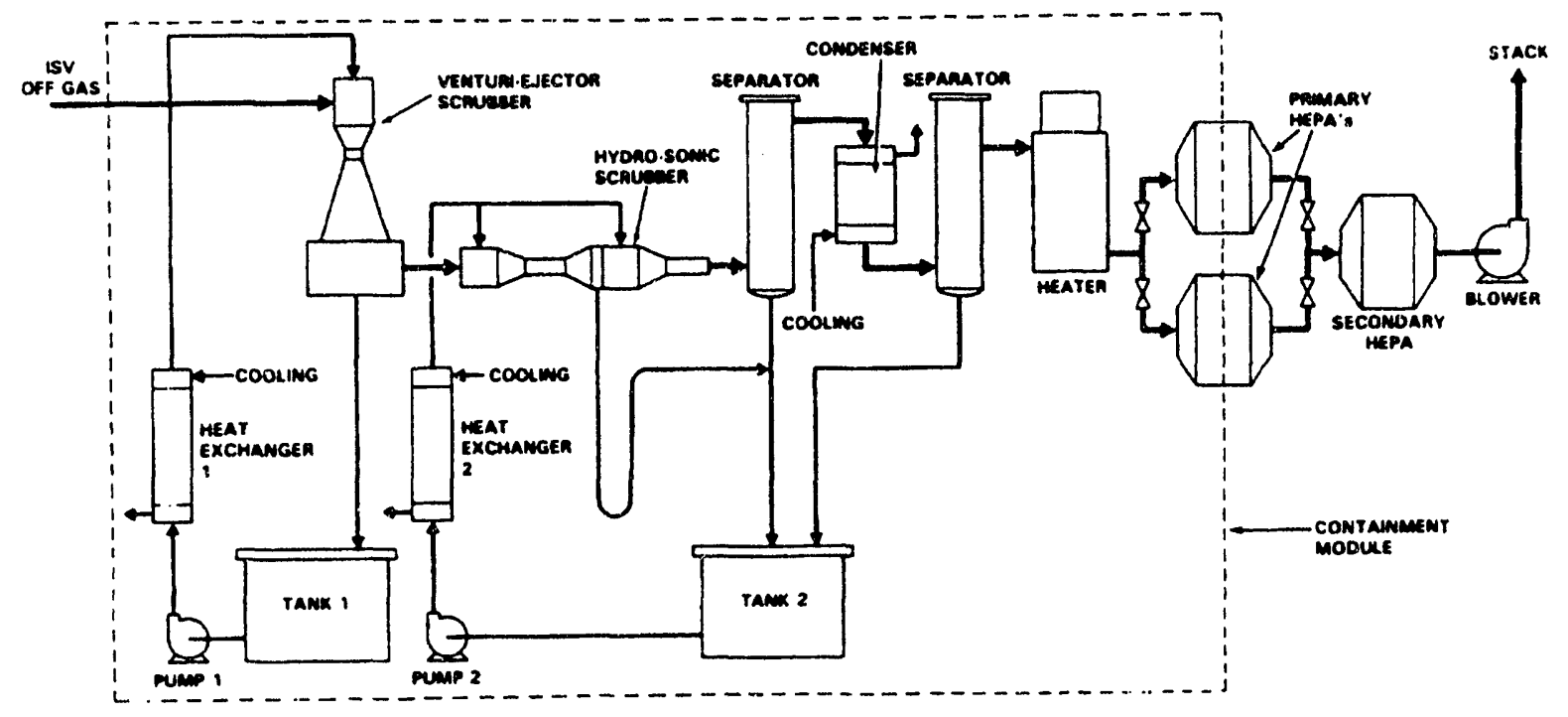

Fig. 12. Schematic diagram of the off-gas treatment system.

The off-gas treatment system is shown schematically in Fig. 12. The off-gas passes through a venturi-ejector scrubber and a separator, a Hydro-Sonic ${ }^{\circledR}$ scrubber, a separator, a condenser, another separator, a heater, two stages of HEPA filtration, and a blower. Liquid to the two wetscrubbers is supplied by two independent liquid recirculation tanks, each equipped with a pump and heat exchanger. The entire off-gas treatment system, along with the ISV power supply, has been installed in a $45 \mathrm{ft}-(13.7-\mathrm{m})$-long semitrailer to facilitate transport to sites. All off-gas components, except the final-stage HEPA filter and blower, are housed within a secondary containment module. The containment module, designed for radioactive processing applications, has gloved access ports for remote operations and is maintained under a slight vacuum. This system was originally designed by PNL for testing ISV at the Hanford Site on radioactive-contaminated soil.

Heat is removed from the off-gas primarily in the venturi-ejector scrubber where aqueous 
scrubbing solution is sprayed into the off-gas stream. A closed loop removes heat from the scrub solution. The closed loop consists of an air/liquid heat exchanger, a coolant storage tank, and a pump. A 50\% water/ethylene glycol mix is pumped from the storage tank through the shell side of the condenser and the two scrub solution heat exchangers and then through the air/liquid exchanger, where heat is removed from the coolant and discharged to the environment. In addition to its role as a quencher, the venturi-ejector scrubber serves as a high-energy gas scrubber.

The second scrubber is a two-stage Hydro-Sonic ${ }^{\circledR}$ scrubber (tandem nozzle scrubber) which

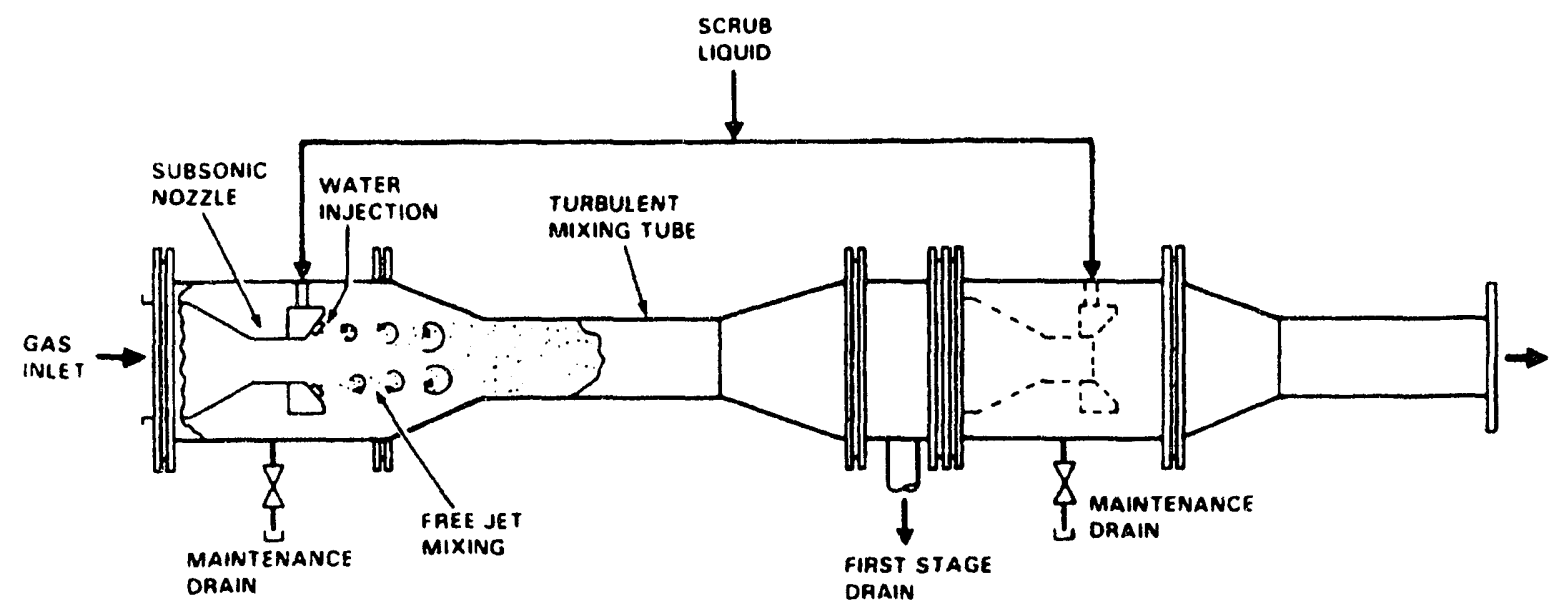

Fig. 13. Schematic diagram of the two-stage Hydro-Sonic scrubber.

is illustrated in Fig. 13. The first stage condenses vapors, removes larger particles, and initiates growth of the finer particles so that they are more easily captured in the second stage. Particulate is captured when the gas is mixed with fine water droplets produced by spraying water into the exhaust of the subsonic nozzle. Mixing and droplet growth continue down the length of the mixing tube. Large droplets containing the particulate are then removed by a vane separator and drained back into the scrub tank. The Hydro-Sonic scrubber is designed to remove over $90 \%$ of all particulate greater than $0.5 \mu \mathrm{m}$ in diameter when operated at a differential pressure of $50 \mathrm{in} .(127 \mathrm{~cm})$ water. Removal efficiency increases with an increase in pressure differential.

Additional water is removed from the off-gas by a tube and shell condenser that has a heat exchange area of $96 \mathrm{ft}^{2}\left(8.9 \mathrm{~m}^{2)}\right.$ and a final separator. The gases are then reheated to $-25^{\circ} \mathrm{C}$ above the dew point with a $30-\mathrm{kW}$ heater to prevent condensation in the HEPA filters.

The first stage of filtration consists of two $24-\times 24-\times 11.5$-in. $(61-\times 61-\times 29-\mathrm{cm})$ nuclear grade HEPA filters in parallel. During operation, one filter is used, and the other remains as a backup in case the primary filter becomes loaded. The primary filter can be changed during operation 
without process shutdown. The second-stage filter acts as a backup particulate filter in case a firststage filter fails. This second-stage filter is identical to the initial stage filters in construction and filtering efficiency. If required, the second-stage filter housing can be fitted with an activated carbon filter for the removal of organics.

The final component in the off-gas treatment system is an induced draft blower that creates a vacuum of approximately $100 \mathrm{in}$. W.C., relative to ambient atmospheric pressure, at $10 \mathrm{~m}^{3} / \mathrm{min}$. The blower can typically provide total off-gas flow of between 10 and $15 \mathrm{~m}^{3} / \mathrm{min}$.

\section{Data Acquisition Systems}

The data acquisition system (DAS) and associated instrumentation provide extensive processmonitoring capabilities for ISV testing. For process monitoring, inputs from process instruments are routed through a Hewlett Packard model 3497A data acquisition and control unit linked to a MacIntosh IIcx computer operating LabView 2.0 software. The DAS scans, records, displays, and files riocess-control data at the predetermined rate of two samples per minute for each channel. Process control c'ata include numerous off-gas temperature and flow measurements, differential pressures of scrubbing components, vitrification electrical power volts/amps, soil temperatures, etc.

A second independent system named the priority data system scans, records, displays, and files critical process data at the rate of one sample per second for each channel. The priority data system also features a visual alarm function to notify operators that operational limits (design parameters) have been reached. This system utilizes a second MacIntosh IIcx computer operating LabView 2.0 software to rnonitor the following eight data points associated with the off-gas containment hood.

- Two hood vacuums

- One off-gas plenum temperature

- One off-gas exit temperature

- Two external off-gas hood-wall temperatures

- Two off-gas connecting-pipe temperatures

The pressure transducers, which measure off-gas hood vacuum, are variable reluctance-type transducers with a response time significantly better than $1 \mathrm{~s}$. The ranges for the transducers are set from 5 in. W.C. vacuum to 5 in. W.C. pressure. The hood temperatures monitored by the priority data system are acquired via $1 / 8$-in. ungrounded, stainless steel sheathed, type-K thermocouples. The response time for these type- $\mathrm{K}$ thermocouples in air is approximately $10 \mathrm{~s}$ to reach $62 \%$ of the instantaneous maximum temperature.

\section{SITE SELECTION, CHARACTERIZATION, AND PREPARATION}

\section{EQUTPMENT AND TRENCH SET-UP}

The PNL pilot-scale ISV equipment (Figs. 14 and 15) was positioned near a trench that was constructed at a scale of approximately one-half the actual scale of low-level liquid waste disposal trench 7 (Figs. 16, 17, and 18). The trench was located within Waste Area Grouping (WAG) 6 at a site chosen for its similarity in topographical, geological, and hydrological features to trench 7 . The location of the test trench was near Solid Waste Storage Area (SWSA) 6 survey benchmark C-12 [ORNL Grid North $17480 \mathrm{ft}$, East $24810 \mathrm{ft}$, and $838.4 \mathrm{ft}$ above National Geodetic Vertical Datum (NGVD)]. The center of the trench was positioned at North $17442 \mathrm{ft}$, East $24,849 \mathrm{ft}$, and $837.8 \mathrm{ft}$ above NGVD. WAG 6 was also selected because it is an approved disposal site for radioactive solid 


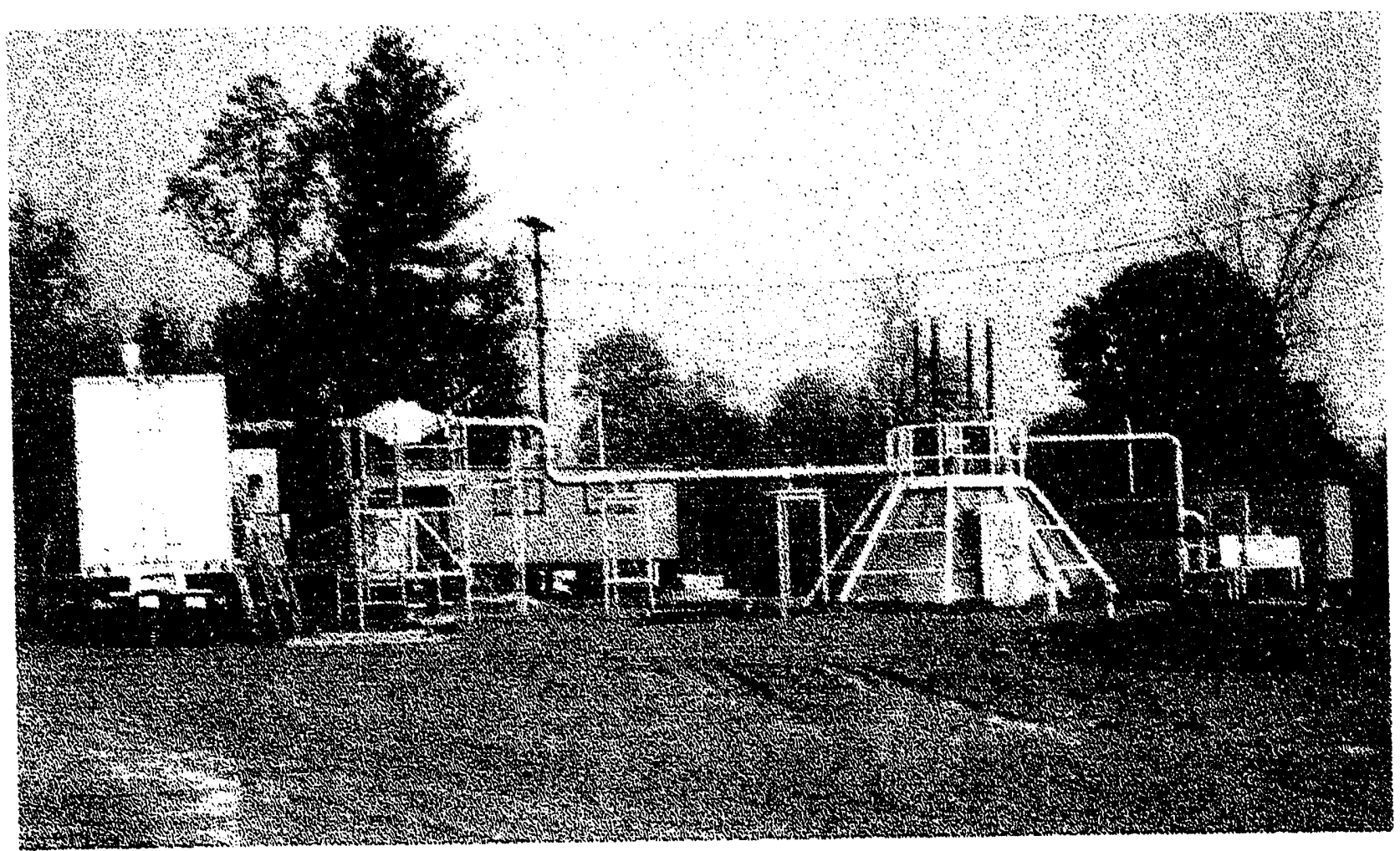

Fig. 14. Field arrangement of ISV equipment for the 1991 ORNL test showing position of the off-gas prefilter between the off-gas hood and the processing trailer.

waste at ORNL. The core and sludge samples, taken by Lomenick et al. (1967) and used in this test, had been stored in the 8711 Area, west of WAG 4. These samples would ultimately have been dis ssed in a silo or tumulus in WAG 6, regardless of their present use. Therefore, the radioactively contaminated ISV product resulting from this test can be considered disposed in place.

The placement of thermocouples and other sensors at selected depths and distances from the central axis of the melt necessitated an initial excavation considerably wider and deeper than an excavation required only to construct the scale model of trench 7 . A pit $18 \mathrm{ft}$ square at a depth of $14 \mathrm{ft}$ and $44 \mathrm{ft}$ square at the surface was excavated to begin placement of sensors and construction of the scale model of trench 7. A pit this size was required to have sloping walls that were stable enough for staff to work inside without the threat of wall collapse. The scale model trench itself was $4 \mathrm{ft}$ high, $6 \mathrm{ft}$ long, with a width of $3 \mathrm{ft}$ at the top and $1 \mathrm{ft}$ at the bottom. The bottom of the trench was started at a depth of $6 \mathrm{ft}$ from the surface. The trench was constructed using wooden forms to hold the crushed limestone/dolostone. The forms were removed once the trench was stabilized by soil backfilled around it. The limestone/dolostone and soil backfill were compacted only by mild tamping with shovels to avoid damage to or movement of the various buried sensors. The center of the trench and all eight corners were surveyed for their positions with a laser-based theodolite. Once the trench 


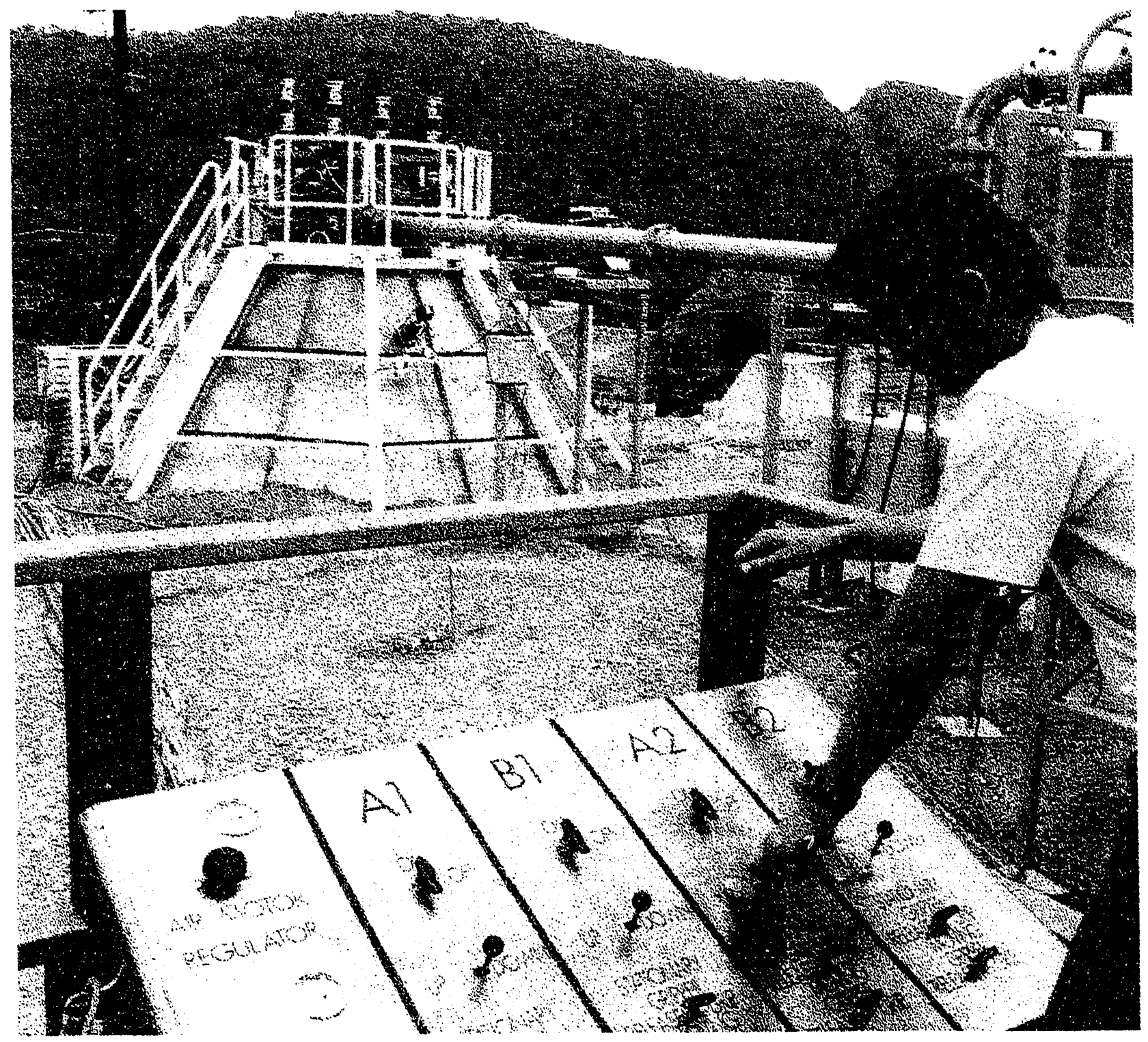

Fig. 15. Position of off-gas containment hood and electrode adjustment controls used in the 1991 ORNL ISV test.

and excavation were complete, positions for the final placement of the electrodes were also surveyed. Table 4 contains the positions as ORNL-grid coordinates.

Tht. irench was filled with crushed limestone similar to that used for the nonradioactive test in 1987. However, a dolomitic limestone $(17 \% \mathrm{MgO}$ and $29 \% \mathrm{CaO}$ ) was selected rather than the limestone $(2 \% \mathrm{MgO}$ and $30 \% \mathrm{CaO})$ used in 1987 . Whether the ORNL seepage pits and trenches contain limestone, magnesian limestone, or dolostone is not presently known and probably varies from trench to trench. The local "limestone" quarry randomly produces all types depending on which specific formation is being excavated. Previously, an engineering-scale test, using ORNL-supplied 


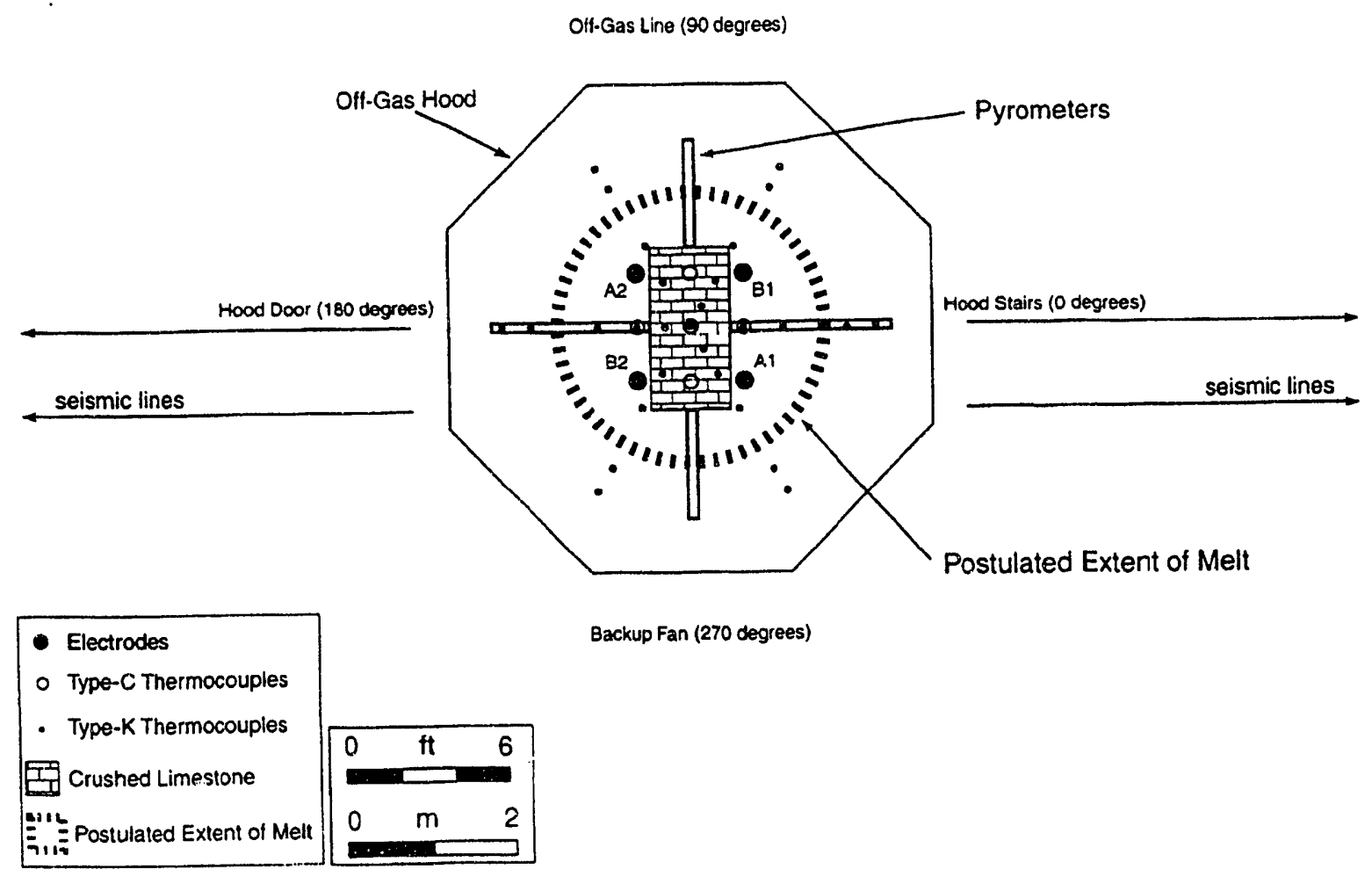

Fig. 16. Plan view of ISV off-gas hood, electrodes, limestone trench, and thermal sensors used in the 1991 ORNL test.

"lirnestone," actually used a dolomite and produced greater crystallization (Carter et al. 1987) than was observed when the more calcitic limestone was used in the 1987 field pilot-scale test. The dolomitic limestone, used in the present study, was selected to produce a field-scale waste form that might be expected to form from such $\mathrm{MgO}$-rich materials. Considerable field-scale waste form analyses and leaching properties have already been determined for the higher calcium types in the 1987 test.

\section{DESCRIPTION AND PLACEMENT OF TEST MONITORING SENSORS}

Table 5 lists the position for each sensor which is expressed in cylindrical coordinates as a radius from the central axis of the melt (i.e., the 3-in PVC access pipe), depth below ground surface, and angle of rotation (counterclockwise from the stairs of the off-gas hood). The length of the sensor and its physical orientation are also included in Tables 6 and 7; sensor orientation and length were designed to maximize sensor survival during melt progression. Although the codes used to label each sensor in Tables 5, 6, and 7 reflect the desired locations for placement within the test trench, actual positions vary as a result of the accuracy of placement. Positions of each sensor were surveyed as described above for the trench. Significant settling of the soil backfill occurred during the 3-week 


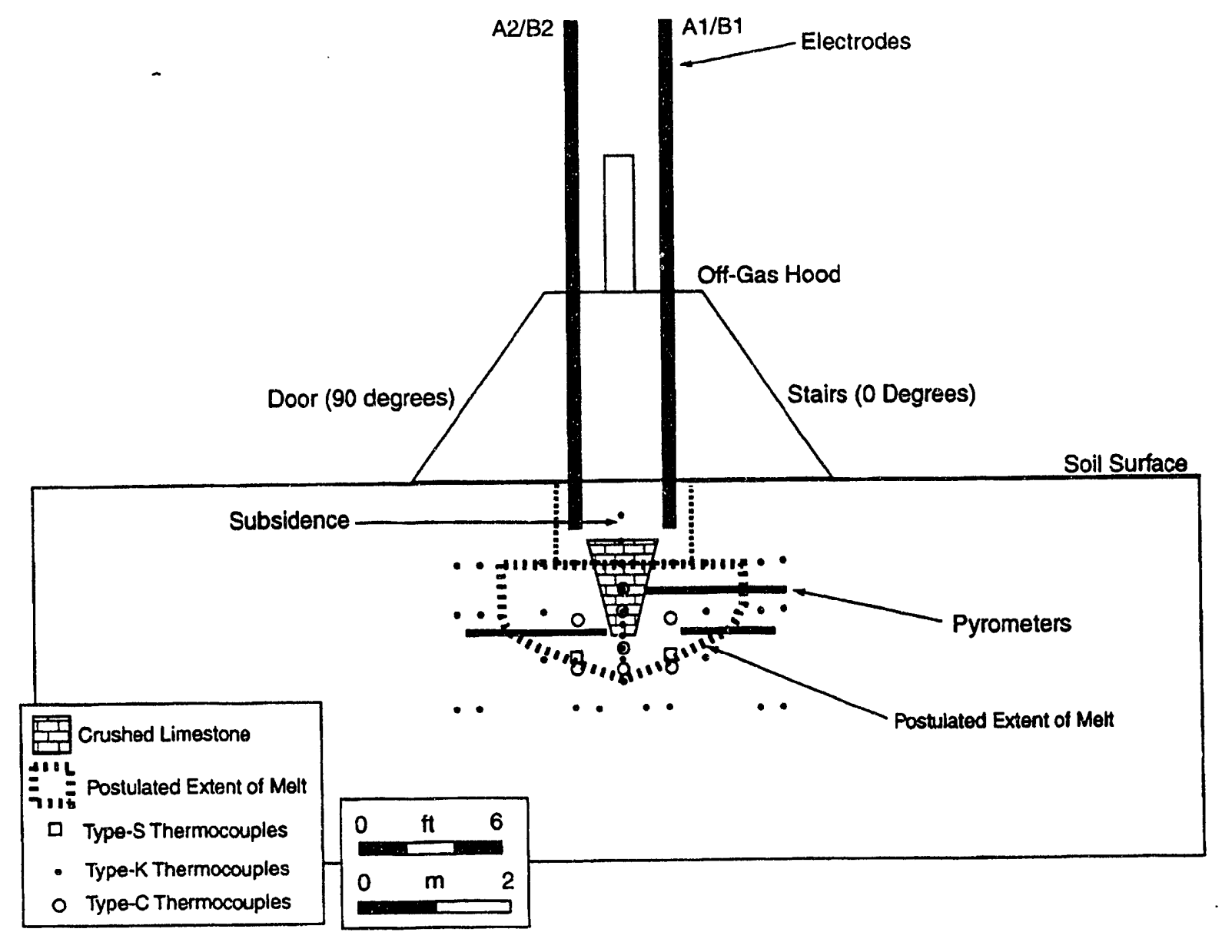

Fig. 17. Cross sectional profile along east-west axis of 1991 ORNL ISV test trench showing sensor locations and probable melt extent.

interval required to complete trench construction. Therefore, some depth values were adjusted on the basis of observed settling rates and were recorded in Table 5. The uncertainty in sensor depth is likely to be at least $\pm 0.75 \mathrm{ft}$.

A total of 87 thermocouples, including 73 type-K (chromel vs alumel), 12 type-C (W-5\%Re vs W-26\%Re) assemblies protected by closed-end alumina tubes, and 2 type-S (Pt vs Pt-10\%Rh) contained in oxygen fugacity probes, were installed at desired locations within the constructed trench during backfilling (Table 7). Six optical thermometry devices were placed in and around the trench to monitor the temperatures during and after the test (Figs. 17 and 18). Two oxygen fugacity probes were included to determine the oxidation status of the melt during processing. Five pressure transducers were also included in the test trench to measure any transient pressurization that might occur during melting of soil in such configurations. Eight heat-flux sensors were positioned in the soil to provide information on heat flow outside the melt. The heat-flux sensors were placed within approximately $1 \mathrm{ft}(0.3 \mathrm{~m})$ of type- $\mathrm{K}$ thermocouples so that coupled measurements of heat flux and temperature could be obtained. The sensors were not placed any closer to avoid possible influence on heat flux by the conductive metal sheaths of the thermocouples.

Commercially available sensors and data acquisition equipment were integrated at ORNL to 


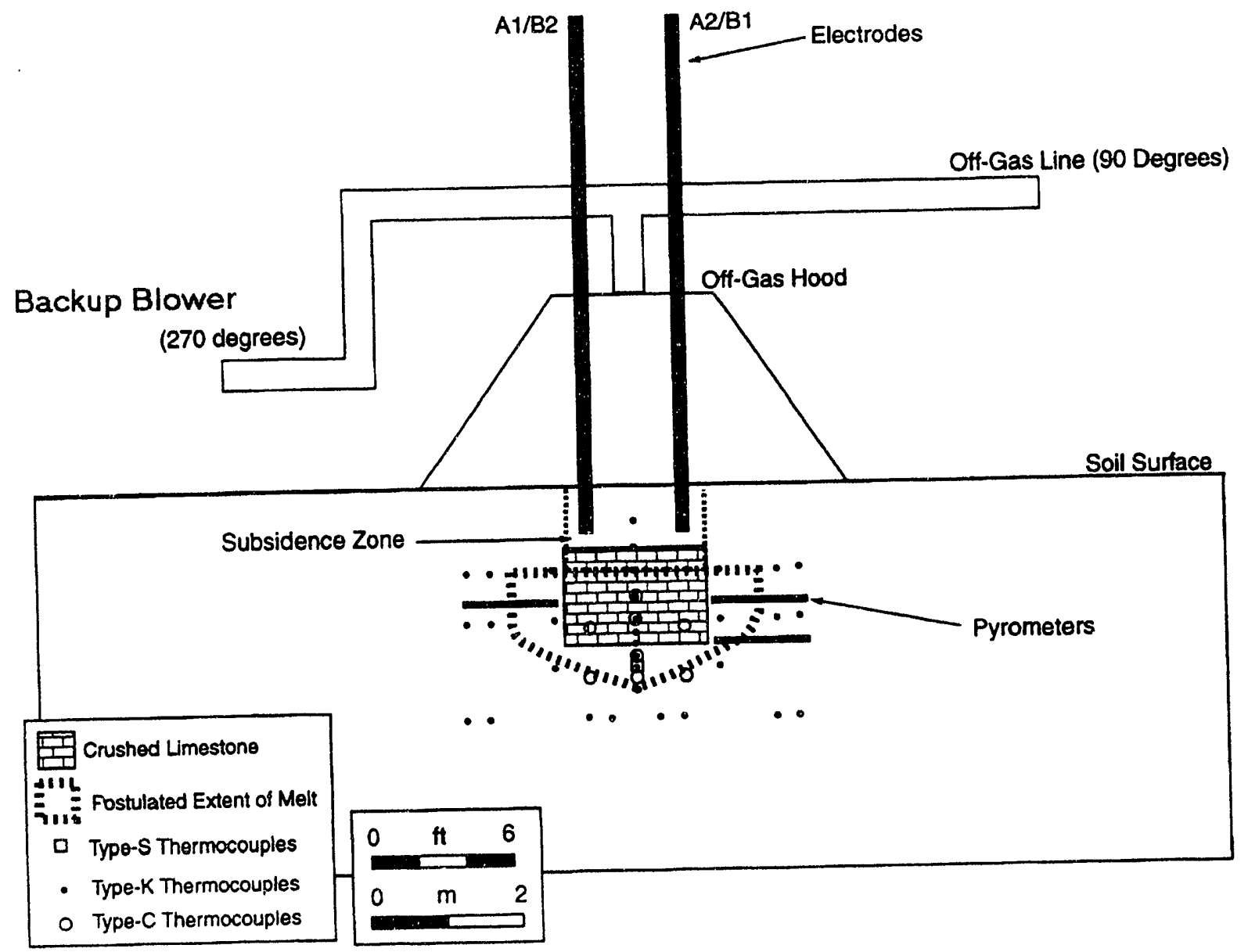

Fig. 18. Cross sectional profile along north-south axis of 1991 ORNL ISV test trench showing sensor locations and probable final melt extent.

configure an automated data acquisition system. The principal data acquisition components included an Apple Macintosh IIcx computer with 8-Mbyte RAM; an 80-Mbyte internal hard disk drive; one 1.44-Mbyte internal floppy disk drive; a dual 44-Mbyte I-Omega Bernoulli cartridge drive; National Instruments IEEE-488 NUBUS interface card; four Hewlett Packard 3421A data acquisition units (each capable of 30 channels of low-level data input); an Accufiber Model 100C, 8-channel optical fiber temperature measuring system; and a $1.5-\mathrm{kW}$ Best Technology uninterruptible power supply system. LabView 2.0 software (National Instruments, Austin, Texas) was used to develop a custom data acquisition program for this application. Sensors were obtained from the following sources: type-K thermocouple assemblies (MgO-insulated, inconel 600-sheathed, with moisture-resistant transition potting compounds and teflon-insulated extension wire), GMI, Knoxville, Tennessee; type-C thermocouple assemblies $\left(\mathrm{Hf}_{2} \mathrm{O}_{3}\right.$-insulated, molybdenum-sheathed, with moisture-resistant transition potting compounds and teflon-insulated extension wire), Delta-M Corp., Oak Ridge, Tennessee; yttriastabilized zirconia oxide closed-on-one-end tubes for fabrication of oxygen fugacity sensors, Zircoa Corp., Solon, Ohio; optical pyrometers and fiber optic cables (small focal spot, 4- and 6-ft focal length) Accufiber, Inc., Beaverton, Oregon; Model A, thermal flux meters, International Thermal Instrument Co., Del Mar, California; 0-25 psig pressure transducers, Omega Engineering, Inc., 
Table 4. Surveyed positions of the limestone gravel-filled trench and graphite electrode centers used in the 1991 ORNL ISV test.

\begin{tabular}{|c|c|c|c|}
\hline \multirow[b]{2}{*}{ Location } & \multicolumn{2}{|c|}{ ORNL Grid Coordinates: } & \multirow{2}{*}{$\begin{array}{l}\text { NGVD } \\
\text { Elevation } \\
\text { (ft) }\end{array}$} \\
\hline & $\begin{array}{l}\text { North } \\
\text { (ft) }\end{array}$ & $\begin{array}{l}\text { East } \\
(\mathrm{ft})\end{array}$ & \\
\hline Trench Center & 17442.969 & 24848.846 & 837.775 \\
\hline Trench Bottom, NE & 17441.350 & 24850.720 & 831.493 \\
\hline Trench Bottom, NW & 17446.158 & 24816.961 & 831.641 \\
\hline Trench Bottom, SW & 17445.558 & 24846.213 & 831.620 \\
\hline Trench Bottom, SE & 17440.657 & 24849.879 & 831.462 \\
\hline Trench Top, NE & 17441.853 & 24851.564 & 835.534 \\
\hline Trench Top, NW & 17446.441 & 24847.939 & 835.720 \\
\hline Trench Top, SW & 17439.975 & 24849.246 & 835.521 \\
\hline Trench Top, SE & 17444.470 & 24845.840 & 835.666 \\
\hline Electrode A1 & 17443.169 & 24851.157 & 838.475 \\
\hline Electrode B1 & 17445.613 & 24848.818 & 838.645 \\
\hline Electrode A2 & 17443.317 & 24846.126 & 838.470 \\
\hline Electrode B2 & 17440.798 & 24848.436 & 838.330 \\
\hline
\end{tabular}

Stamford, Connecticut; isolated thermocouple transmitters, [linearized 0-10 VDC output, for $0-2300^{\circ} \mathrm{C}$ type-C thermocouple 9IPTS-90 calibration)], M-System Technology, Inc., Dallas, Texas; porous stainless steel tubes (for use with pressure sensors and uptical pyrometer assemblies), Newmet Krebsoge, Inc., Terryville, Connecticut.

Every type-C thermocouple that was anticipated to be immersed in the melt during the test was fitted with two nesting; closed-one-end, dense alumina tubes. These tubes provided both chemical and electrical isolation from the melt and also afforded mechanical support. Two nesting tubes were used to provide sufficient material for sacrificial corrosion protection and to maximize mechanical support of the thermocouple assemblies. Electrochemical cells were assembled to measure oxygen fugacity of gases in equilibrium with the melt. Yttria-stabilized, zirconia closed-one-end tubes forming the sensing element were isolated from the melt by a modified, heavy-wall, closed-on-one-end, alumina tube. The closed end of the alumina tube was penetrated by four $0.125 \mathrm{in}$. diam holes to provide a gas pathway to the zirconia sensor, while restricting melt access to the zirconia sensor. The annular space between the alumina tube and the zirconia tube was filled with hollow zirconia-alumina insulating spheres. Electrical isolating amplifiers were used with each sensor that was anticipated to be immersed in the melt. This signal-conditioning circuitry was used to protect personnel and data acquisition equipment from electrical current away from the melt. All input signals to the data acquisition equipment were also equipped with lightning protection circuitry.

High temperature measurements of the melt were obtained using type-C and type-S thermocouples and optical pyrometry equipment. Accufiber optical pyrometer heads collected light from custom fabricated targets positioned in the anticipated melt zone and transmitted light via fiberoptic cables to photodetectors and signal conditioning electronics provided by an Accufiber Model $100 \mathrm{C}$ optical fiber temperature control system. The pyrometer heads were contained in air-purged housings provided by Accufiber. These housings served to (1) isolate the pyrometer heads from cooling water when they were placed inside custom-designed water cooling jackets, (2) direct argon purge gas around the body of the pyrometer heads and sweep contaminants away from the front lens, and (3) provide an inert atmosphere inside the graphite site tubes that were connected to the purge housings. Site tubes and targets for the pyrometers were fabricated from graphite "fluxing" tubes (3-in. O.D. $\times 1$-in. I.D.) approximately 4 or $6 \mathrm{ft}$ in length. The ends of these tubes to be immersed in the melt were fitted with a threaded graphite plug that also served as a target for the pyrometers. These plugs incorporated a conical cavity on the interior face of the plug that served as a "blackbody 
Table 5. Surveyed sensor locations used in the 1991 ORNL ISV test.

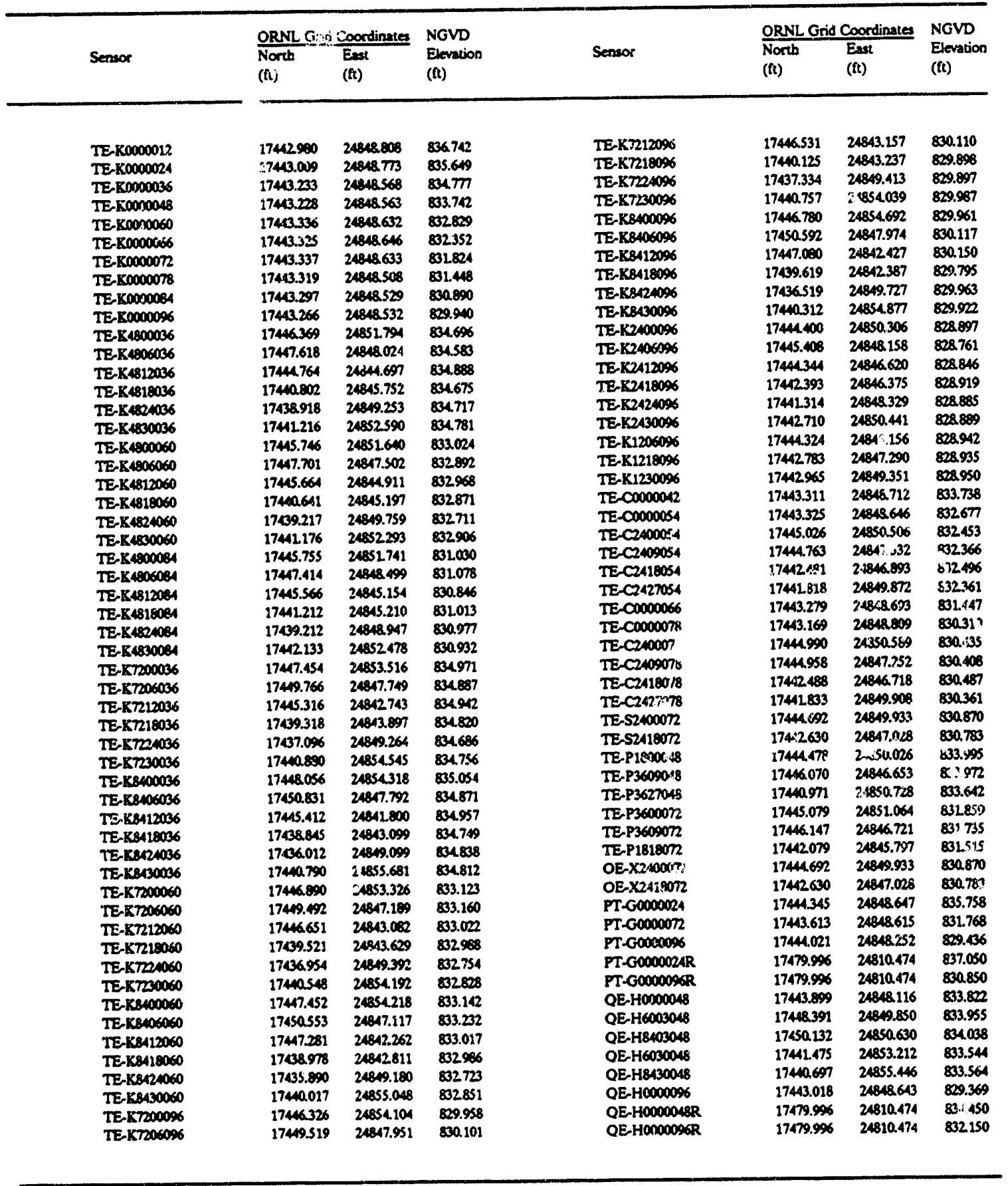

radiator".

PRETEST SOIL SAMPLING

Pretest characterizatior of the site included measurements of soil moisture, soil bulk density, and a survey for unexpected contamination at the site. The soil formation at the ISV test site was sampled at two locations on April 23, 1990. The samples were collected with a split-spoon sampler (ASTM 1984); undisturbed soil core was collected every $18 \mathrm{in.}$ to a total depth of $15 \mathrm{ft}$. Standard 
Table 6. Types of sensors and positions within the 1991 ORNL ISV test trench.

\begin{tabular}{|c|c|c|c|c|c|c|}
\hline Sensor & $\begin{array}{l}\text { Sensor } \\
\text { Code }\end{array}$ & $\begin{array}{r}\text { Depth }{ }^{\mathrm{a}} \\
(\mathrm{ft})\end{array}$ & $\begin{array}{r}\text { Angle } \\
\text { (degrees) }\end{array}$ & $\begin{array}{r}\text { Radius } \\
\text { (ft) }\end{array}$ & $\begin{array}{r}\text { Length } \\
(\mathrm{ft})\end{array}$ & Orientation \\
\hline Thermo-Type-K & TE-K0000012 & 1.60 & 0.00 & 0.00 & 7.50 & Vertical \\
\hline Thermo-Type-K & TE-K0000024 & 2.70 & 0.00 & 0.00 & 6.50 & Vertical \\
\hline Thermo-Type-K & TE-K0000036 & 3.60 & 0.00 & 0.00 & 5.50 & Vertical \\
\hline Thermo-Type-K & TE-K0000048 & 4.60 & 0.00 & 0.00 & 4.50 & Vertical \\
\hline Thermo-Type-K & TE-K0000060 & 5.50 & 0.00 & 0.00 & 3.50 & Vertical \\
\hline Thermo-Type-K & TE-K0000066 & 6.00 & 0.00 & 0.00 & 3.00 & Vertical \\
\hline Thermo-Type-K & TE-K0000072 & 6.50 & 0.00 & 0.00 & 250 & Vertical \\
\hline Thermo-Type-K & TE-K0000078 & 6.90 & 0.00 & 0.00 & 2.00 & Vertical \\
\hline Thermo-Type-K & TE-K0000084 & 7.50 & 0.00 & 0.00 & 1.50 & Vertical \\
\hline Thermo-Type-K & TE-K0000096 & 8.40 & 0.00 & 0.00 & 0.50 & Vertical \\
\hline Thermo-Type-K & TE-K4800036 & 3.70 & 0.00 & 4.00 & 4.00 & Horizontal \\
\hline Thermo-Type-K & TE-K4806036 & 3.80 & 60.00 & 4.00 & 4.00 & Horizontal \\
\hline Thermo-Type-K & TE-K4812036 & 3.50 & 120.00 & 4.00 & 4.00 & Horizontal \\
\hline Thermo-Type-K & TE-K4818036 & 3.70 & 180.00 & 4.00 & 4.00 & Horizontal \\
\hline Thermo-Type-I & TE-K4824036 & 3.60 & 240.00 & 4.00 & 4.00 & Horizontal \\
\hline Thermo-Type-K & TE-K4830036 & 3.60 & 300.00 & 4.00 & 4.00 & Horizontal \\
\hline Thermo-Type-K & TE-K4800060 & 5.30 & 0.00 & 4.00 & 4.00 & Horizontal \\
\hline Thermo-Type-K & TE-K4806060 & 5.50 & 60.00 & 4.00 & 4.00 & Horizontal \\
\hline Thermo-Type-K & TE-K4812060 & 5.40 & 120.00 & 4.00 & 4.00 & Horizontal \\
\hline Thermo-Type-K & TE-K4818060 & 5.50 & 180.00 & 4.00 & 4.00 & Horizontal \\
\hline Thermo-Type-K & TE-K4824060 & 5.60 & 240.00 & 4.00 & 4.00 & Horizontal \\
\hline Thermo-Type-K & TE-K4830060 & 5.40 & 300.00 & 4.00 & 4.00 & Horizontal \\
\hline Thermo-Type-K & TE-K4800084 & 7.30 & 0.00 & 4.00 & 4.00 & Horizontal \\
\hline Thermo-Type-K & TE-K4806084 & 7.30 & 60.00 & 4.00 & 4.00 & Horizontal \\
\hline Thermo-Type-K & TE-K4812084 & 7.50 & 120.00 & 4.00 & 4.00 & Horizontal \\
\hline 1 hermo-Type-K & TE-K4818084 & 7.30 & 180.00 & 4.00 & 4.00 & Horizontal \\
\hline Thermo-Type-K & TE-K4824084 & 7.40 & 240.00 & 4.00 & 4.00 & Horizontal \\
\hline Thermo-Type-K & TE-K4830084 & 7.40 & 300.00 & 4.00 & 4.00 & Horizontal \\
\hline Thermo-Type-K & TE-K7200036 & 3.40 & 0.00 & 6.00 & 200 & Horizontal \\
\hline Thermo-Type-K & TE-K7206036 & 3.50 & 60.00 & 6.00 & 200 & Horizontal \\
\hline 1 hermo-Type-K & TE-K7212036 & 3.40 & 120.00 & 6.00 & 200 & Horizontal \\
\hline Thermo-Type-K & TE-K7218036 & 3.50 & 180.00 & 6.00 & 200 & Horizontal \\
\hline Thermo-Type-K & TE-K7224036 & 3.70 & 240.00 & 6.00 & 2.00 & Horizontal \\
\hline Thermo-Type-K & TE-K7230036 & 3.60 & 300.00 & 6.00 & 200 & Horizontal \\
\hline TI rmo-Type-K & TE-K8400036 & 3.30 & 0.00 & 7.00 & 1.00 & Horizontal \\
\hline Thermo-1 ype-K & TE-K8406036 & 3.50 & 60.00 & 7.00 & 1.00 & Horizontal \\
\hline Thermo-Type-K & $1 \% \cdot \times 8412036$ & 3.40 & 120.00 & 7.00 & 1.00 & Horizontal \\
\hline Thermo-Ty, & TE-K8418036 & 3.60 & 180.00 & 7.00 & 1.00 & Horizontal \\
\hline Thermo-Type-K & TE-K\$424036 & 3.50 & 240.00 & 7.00 & 1.00 & Horizontal \\
\hline Thermo-Type-K & TE-K8430036 & 3.50 & 300.00 & 7.00 & 1.00 & Horizontal \\
\hline Thermo-Type-\$ & TE-K7200060 & 5.20 & 0.00 & 6.00 & 200 & Horizontal \\
\hline Thermo-T, pe-K & TE-K7206060 & 5.20 & 60.00 & 6.00 & 200 & Horizontal \\
\hline Thermo-Type-K & TE-K7212060 & 5.30 & 120.00 & 6.00 & 200 & Horizontal \\
\hline Thermo-Type-K & TE-K7218060 & 5.40 & 180.00 & 6.00 & 200 & Horizontal \\
\hline Thermo-Type-K & TE-K7224060 & 5.60 & 240.00 & 6.00 & 200 & Horizontal \\
\hline Thermo-Type-K & TE-K7230060 & 5.50 & 300.00 & 6.00 & 200 & Horizontal \\
\hline Thermo-Type-K & TE-K8400060 & 5.20 & 0.00 & 7.00 & 1.00 & Horizontal \\
\hline Thermo-Type-K & TE-K8406060 & 5.10 & 60.00 & 7.00 & 1.00 & Horizontal \\
\hline Thermo-Type-K & TE-K8412060 & 5.30 & 120.00 & 7.00 & 1.00 & Horizontal \\
\hline Thermo-Type-K & TE-K8418060 & 5.40 & 180.00 & 7.00 & 1.00 & Horizontal \\
\hline Thermo-Type-K & TE-K8424060 & 5.60 & 240.00 & 7.00 & 1.00 & Horizontal \\
\hline Thermo-Type-K & TE-K8430060 & 5.50 & 300.00 & 7.00 & 1.00 & Horizontal \\
\hline Thermo-Type-K & TE-K7200096 & 8.40 & 0.00 & 6.00 & 200 & Horizontal \\
\hline
\end{tabular}

penetration resistance measurements were also collected. From the length of core recovered and the known diameter of the sampler, a sample volume was computed. Samples were stored in moisture- 
Table 7. Types of sensors and positions within ORNL ISV test trench.

\begin{tabular}{|c|c|c|c|c|c|c|}
\hline Sensor & $\begin{array}{l}\text { Sensor } \\
\text { Code }\end{array}$ & $\begin{array}{l}\text { Depth } \\
\text { (ft) }\end{array}$ & $\begin{array}{r}\text { Angle } \\
\text { (degrees) }\end{array}$ & $\begin{array}{l}\text { Radius } \\
\text { (ft) }\end{array}$ & $\begin{array}{l}\text { Length } \\
\text { (ft) }\end{array}$ & Orientation \\
\hline Thermo-Type-K & TE-K7206096 & 8.30 & 60.00 & 6.00 & 200 & Horizontal \\
\hline Thermo-Type-K & TE-K7212096 & 8.20 & 120.00 & 6.00 & 200 & Horizontal \\
\hline Thermo-Type-K & TE-K7218096 & 8.50 & 180.00 & 6.00 & 200 & Horizontal \\
\hline Thermo-Type-K & TE-K7224096 & 8.50 & 240.00 & 6.00 & 2.00 & Horizontal \\
\hline Thermo-Type-K & TE-K7230096 & 8.40 & 300.00 & 6.00 & 200 & Horizontal \\
\hline Thermo-Type-K & TE-K8400096 & 8.40 & 0.00 & 7.00 & 1.00 & Horizontal \\
\hline Thermo-Type-K & TE-K8406096 & 8.20 & 60.00 & 7.00 & 1.00 & Horizontal \\
\hline Thermo-Type-K & TE-K8412096 & 8.20 & 120.00 & 7.00 & 1.00 & Horizontal \\
\hline Thermo-Type-K & TE-K8418096 & 8.60 & 180.00 & 7.00 & 1.00 & Horizontal \\
\hline Thermo-Type-K & TE-K8424096 & 8.40 & 240.00 & 7.00 & 1.00 & Horizontal \\
\hline Thermo-Type-K & TE-K8430096 & 8.40 & 300.00 & 7.00 & 1.00 & Horizontal \\
\hline Thermo-Type-K & TE-K2400096 & 9.50 & 0.00 & 200 & 4.00 & Horizontal \\
\hline Thermo-Type-K & TE-K2406096 & 9.60 & 60.00 & 200 & 4.00 & Horizontal \\
\hline Thermo-Type-K & TE-K2412096 & 9.50 & 120.00 & 200 & 4.00 & Horizontal \\
\hline Thermo-Type-K & TE-K2418096 & 9.40 & 180.00 & 2.00 & 4.00 & Horizontal \\
\hline Thermo-Type-K & TE-K2424096 & 9.50 & 240.00 & 200 & 4.00 & Horizontal \\
\hline Thermo-Type-K & TE-K2430096 & 9.50 & 300.00 & 2.00 & 4.00 & Horizontal \\
\hline Thermo-Type-K & TE-K1206096 & 9.40 & 60.00 & 1.00 & 5.00 & Hor/Vert \\
\hline Thermo-Type-K & TE-K1218096 & 9.40 & 180.00 & 1.00 & 5.00 & Hor/Vert \\
\hline Thermo-Type-K & TE-K1230096 & 9.40 & 300.00 & 1.00 & 5.00 & Hor/Nert \\
\hline Thermo-Type-C & TE-C0000042 & 4.60 & 0.00 & 0.00 & 5.00 & Vertical \\
\hline Thermo-Type-C & TE-C0000054 & 5.70 & 0.00 & 0.00 & 4.00 & Vertical \\
\hline Thermo-Type-C & TE-C2400054 & 5.90 & 0.00 & 200 & 4.00 & Vertical \\
\hline Thermo-Type-C & TE-C2409054 & 6.00 & 90.00 & 200 & 4.00 & Vertical \\
\hline Thermo-Type-C & TE-C2418054 & 5.90 & 180.00 & 200 & 4.00 & Vertical \\
\hline Thermo-Type-C & TE-C2427054 & 6.00 & 270.00 & 200 & 4.00 & Vertical \\
\hline Thermo-Type-C & TE-C0000066 & 6.90 & 0.00 & 0.00 & 3.00 & Vertical \\
\hline Thermo-Type-C & TE-C0000078 & 8.00 & 0.00 & 0.00 & 2.00 & Vertical \\
\hline Thermo-Type-C & TE-C2400078 & 7.90 & 0.00 & 200 & 200 & Vertical \\
\hline Thermo-Type-C & TE-C2409078 & 7.90 & 90.00 & 200 & 200 & Vertical \\
\hline Thermo-Type-C & TE-C2418078 & 7.90 & 180.00 & 200 & 200 & Vertical \\
\hline Thermo-Type-C & TE-C2427078 & 8.00 & 270.00 & 2.00 & 200 & Vertical \\
\hline Thermo-Type-S & TE-S2400072 & 7.50 & 0.00 & 200 & 3.00 & Vertical \\
\hline Thermo-Type-S & TE-S2418072 & 7.60 & 180.00 & 2.00 & 3.00 & Vertical \\
\hline Pyrometer & TE-P1800048 & 4.40 & 0.00 & 1.50 & 6.00 & Horizontal \\
\hline Pyrometer & TE-P3609048 & 4.40 & 90.00 & 3.00 & 4.00 & Horizontal \\
\hline Pyrometer & TE-P3627048 & 4.70 & 270.00 & 3.00 & 4.00 & Horizontal \\
\hline Pyrometer & TE-P3600072 & 6.50 & 0.00 & 3.00 & 4.00 & Horizontal \\
\hline Pyrometer & TE-P3609072 & 6.60 & 90.00 & 3.00 & 4.00 & Horizontal \\
\hline Pyrometer & TE-P1818072 & 6.80 & 180.00 & 1.50 & 6.00 & Horizontal \\
\hline Oxygen & OE-X2400072 & 7.50 & 0.00 & 200 & 3.00 & Vertical \\
\hline Oxygen & OE-X2418072 & 7.60 & 180.00 & 200 & 3.00 & Vertical \\
\hline Pressure & PT-G0000024 & 2.60 & 0.00 & 0.00 & $\mathbf{n a}^{\mathbf{a}}$ & na \\
\hline Pressure & PT-G0000072 & 6.60 & 0.00 & 0.00 & na & na \\
\hline Pressure & PT-G0000096 & 9.30 & 0.00 & 0.00 & na & na \\
\hline Pressure & PT-G0000024R & 1.30 & Reference & & & \\
\hline Pressure & PT-G0000096R & 7.50 & Reference & & & \\
\hline Heat Flux & QE-HOOOOO48 & 4.50 & 0.00 & 0.00 & na & Horizontal \\
\hline Heat Flux & QE-H6003048 & 4.40 & 30.00 & 5.00 & na & Vertical \\
\hline Heat Flux & QE-H8403048 & 4.30 & 30.00 & 7.00 & na & Vertical \\
\hline Heat Flux & QE-H6030048 & 4.80 & 300.00 & 5.00 & na & Vertical \\
\hline Heat Flux & QE-H8430048 & 4.80 & 300.00 & 7.00 & na & Vertical \\
\hline Heat Flux & QE-H0000096 & 9.30 & 0.00 & 0.00 & na & Horizontal \\
\hline Heat Flux & QE-H0000048R & 3.90 & Reference & na & na & Vertical \\
\hline Heat Flux & QE-H0000096R & 6.20 & Reference & na & na & Horizontal \\
\hline
\end{tabular}

anot applicable. Reference indicates a sensor placed in soil far from the melt to monitor background values.

proof polyethylene bags for transport to the laboratory and subsequent storage. Samples were weighed, dried to constant weight at $80^{\circ} \mathrm{C}$ in a forced-air oven, and weighed again to determine their 


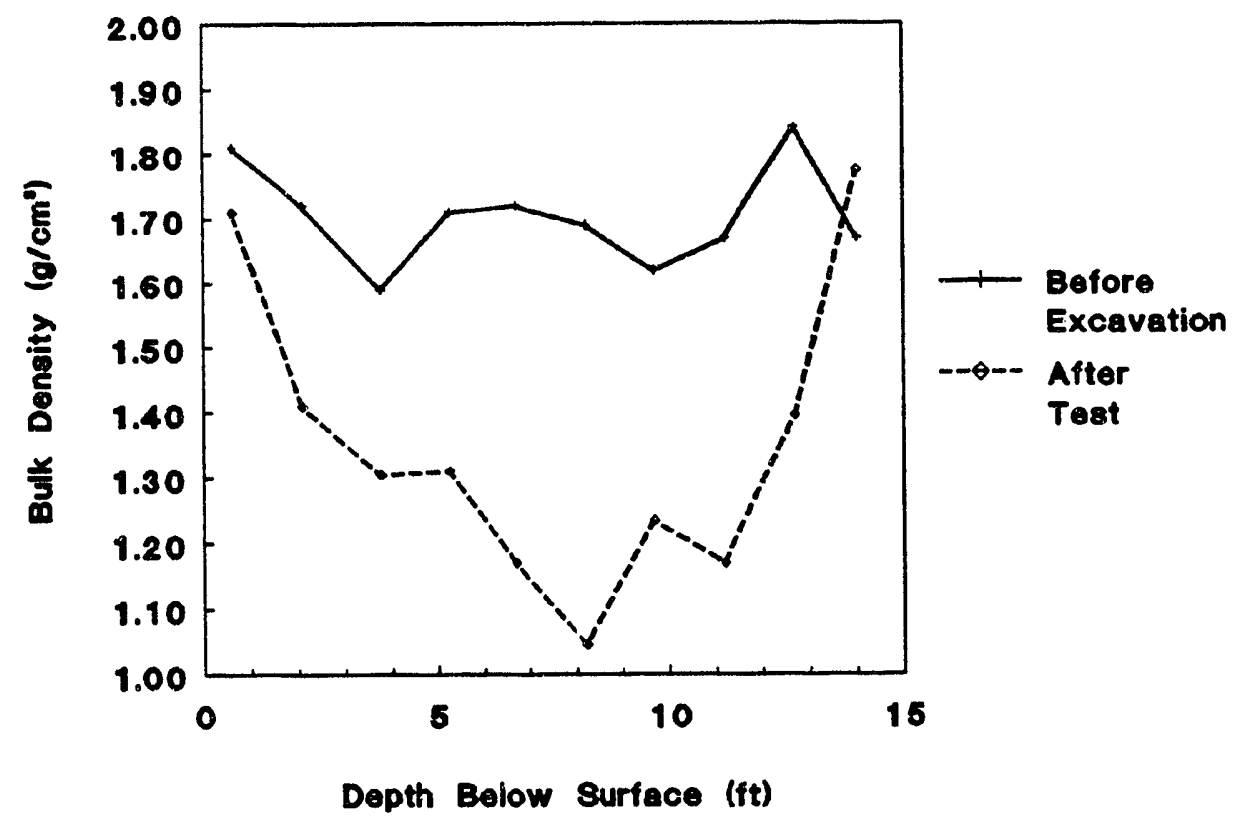

Fig. 19. Dry soil bulk density depth profiles at the 1991 ORNL ISV site before and after test trench construction.

field moisture content. The weight of oven-dried soil was divided by the sample volume to calculate the dry soil bulk density. Samples were then sieved to $<2 \mathrm{~mm}$ and the weights of both the soil $(<2$ $\mathrm{mm}$ ) and coarse fragments ( $>2 \mathrm{~mm}$ ) were determined. The profile of preexcavation soil bulk density is depicted in Fig. 19. The average dry soil bulk density was $1.69 \mathrm{~g} / \mathrm{cm}^{3}$ with an average soil moisture of $17.4 \%$ (dry weight basis). On September 27,1991 , two soil profiles were again sampled at locations approximately $2 \mathrm{ft}$ east and west of the edge of the melt. The average pre- and postconstruction soil bulk density profile is also depicted in Fig. 19. The average profile bulk density was $1.35 \mathrm{~g} / \mathrm{cm}^{3}$ indicative of the lower density of the reconstituted soil backfill in the test trench. Obviously, the soil surface had undergone some coinpaction resulting from the traffic and equipment loads at the site. The average moisture content at this sampling date was $19.2 \%$, although, during the ISV melt in May 1991 , the soil moisture content was probably considerably higher because of the wet conditions at that time.

Ten gram aliquots of the sieved soil were weighed into $25-\mathrm{mL}$ plastic scintillation vials and assayed for ${ }^{137} \mathrm{Cs},{ }^{60} \mathrm{Co}$, and ${ }^{90} \mathrm{Sr}$. These samples were counted for 10 min each using a NaI detector for gamma-ray spectroscopy (Cerling and Spalding 1981). The activity of ${ }^{90} \mathrm{Sr}$ was estimated from bremsstrahlung radiation detection in the lower energy region of the gamma-ray spectrum below the ${ }^{137} \mathrm{Cs}$ photopeak region. Cross talk into this bremsstrahlung window was subtracted using factors determined from ${ }^{137} \mathrm{Cs}$ and ${ }^{60} \mathrm{Co}$ standards in $10 \mathrm{~g}$ soil samples and the measured samples activities of ${ }^{137} \mathrm{Cs}$ and ${ }^{60} \mathrm{Co}$. Other background counts in the bremsstrahlung window were subtracted using soil blanks without added isotopes. Standards of ${ }^{90} \mathrm{Sr}$ in soil were prepared to measure the bremsstrahlung 
counting efficiency, which generally averaged about $4.4 \%$. The bremsstrahlung method for ${ }^{90} \mathrm{Sr}$ assay is known to be highly dependent on counting geometry and sample material characteristics, but these were held constant for all samples and standards. The reported ${ }^{90} \mathrm{Sr}$ activities would also include other hard-beta emitters, other than ${ }^{137} \mathrm{Cs}$ and ${ }^{60} \mathrm{Co}$, which might also produce bremsstrahlung emission. Unambiguous methods for the determination of ${ }^{80} \mathrm{Sr}$ in soil involve complete sample dissolution and radiochemical fractionation with final beta counting. The savings in cost and time were judged adequate compensation for the small uncertainty resulting from this sample assay method. It is reassuring that the technique does not produce false negatives; if ${ }^{90} \mathrm{Sr}$ is present in a soil sample above the detection limit of $1.9 \mathrm{dpm} / \mathrm{g}$, it can be detected. No ${ }^{137} \mathrm{Cs},{ }^{60} \mathrm{Co}$, or ${ }^{90} \mathrm{Sr}$ was detected in any of these soil profile samples either before or after the ISV test; detection limits were $0.5,0.5$, and 1.9 $\mathrm{dpm} / \mathrm{g}$, respectively (or $0.2,0.2$, and $0.9 \mathrm{pCi} / \mathrm{g}$, respectively).

Table 8. Radioisotopic composition of the ORNL Pit 2 sludge material used in ISV test.

\begin{tabular}{lcc}
\hline Isotope & $\mu \mathrm{Ci} / \mathrm{g}$ \\
\hline${ }^{60} \mathrm{Co}$ & 0.014 & \\
${ }^{137} \mathrm{Cs}$ & 20.62 & \\
${ }^{137} \mathrm{Cs}$ & 20.70 & $( \pm 7.4 \%$, ESD Analyses $)$ \\
& $<0.022$ & \\
${ }^{152} \mathrm{Eu}$ & $<0.012$ & \\
${ }^{154} \mathrm{Eu}$ & $<0.009$ & \\
${ }^{155} \mathrm{Eu}$ & 0.065 & \\
$\mathrm{Gross} \alpha$ & 28.92 & \\
$\mathrm{Gross} \mathrm{B}$ & 0.024 & \\
${ }^{241} \mathrm{Am}$ & 0.042 & \\
${ }^{239.240} \mathrm{Pu}$ & 5.297 & \\
${ }^{90} \mathrm{Sr}$ & 5.119 & $( \pm 2.2 \%$, ESD Analyses $)$ \\
${ }^{90} \mathrm{Sr}$ & $<0.054$ & \\
${ }^{228,232} \mathrm{Th}$ & $<0.459$ & \\
${ }^{229} \mathrm{Th}$ & $<0.405$ & \\
${ }^{23 \times} \mathrm{U}$ & $<0.078$ & \\
${ }^{131} \mathrm{I}$ & &
\end{tabular}

All analyses by ORNL Analytical Chemistry Division except as indicated.

\section{CHARACTERIZATION AND PLACEMENT OF SLUDGE AND TRACERS}

During construction of the test trench, a small amount of actual waste, sealed in plastic bottles, was placed near the bottom of the crushed limestone layer. The amount that was added was determined on the basis of several factors. First, the maximum amount of ${ }^{137} \mathrm{Cs}$ that could be accommodated within the off-gas processing trailer was calculated; several $\mu \mathrm{Ci}$ of ${ }^{137} \mathrm{Cs}$ could be contained without measurable $(<0.025 \mathrm{mR} / \mathrm{h})$ increase in radiation dose rate within the off-gas processing trailer, assuming the dose conversion of $<1 \mu \mathrm{R} / \mathrm{h}$ per $\mu \mathrm{Ci}$ at the wall of the process trailer scrub solution tank (Oma et al. 1982). A sample of the waste was collected and analyzed at ORNL to determine both its radionuclide and chemical composition (Tables 8 and 9). Residual core material from the pits 2 and 3 characterization study of Lomenick et al. (1967) was used as the source of waste. The maximum activities of ${ }^{137} \mathrm{Cs}$ and ${ }^{90} \mathrm{Sr}$ in the sludge samples, analyzed by Lomenick et al. (1967), 


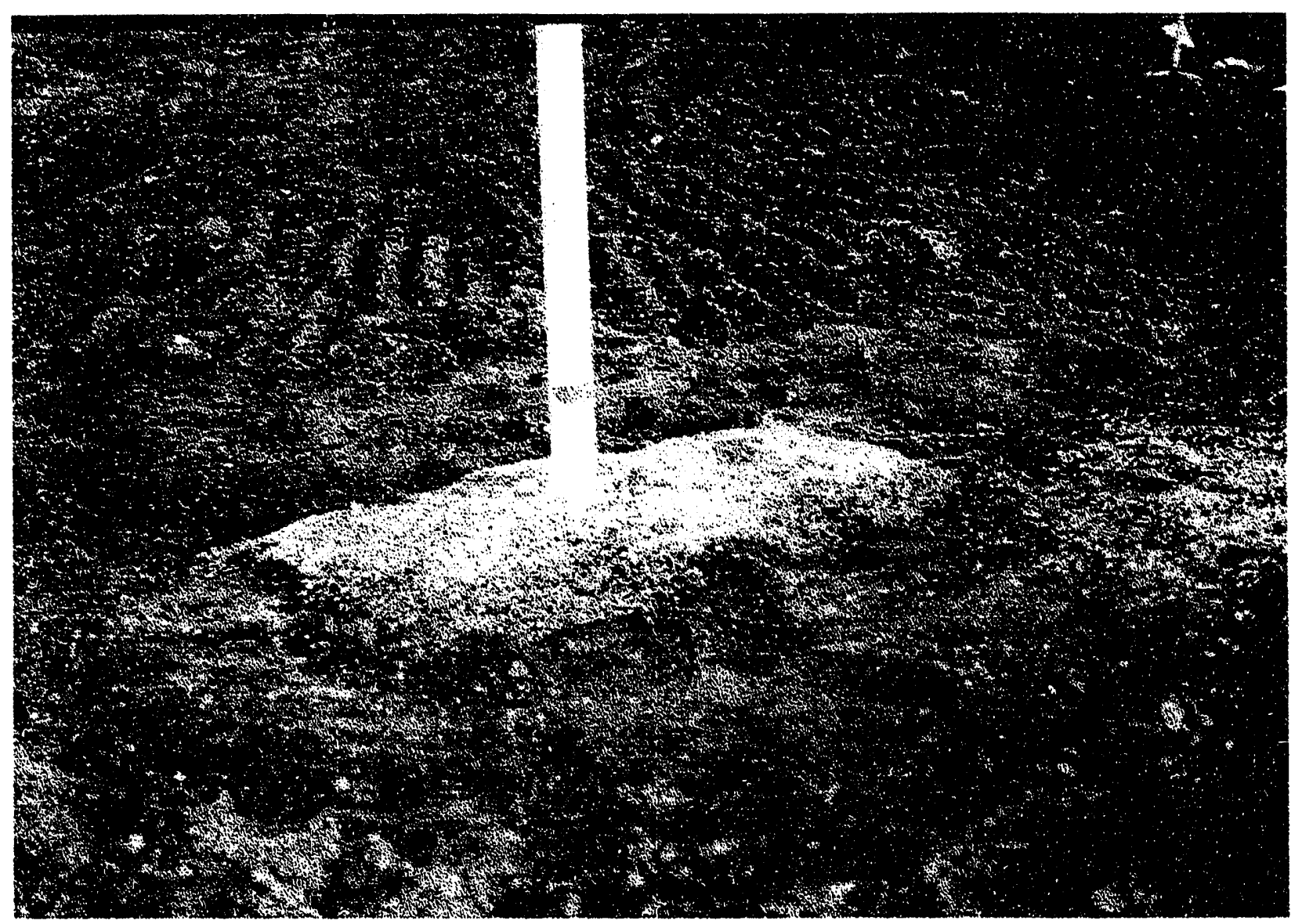

Fig. 20. The 3-inch diameter polyvinylchloride access pipe during test trench construction at completion of limestone gravel backfilling.

were 415 and $32 \mu \mathrm{Ci} / \mathrm{g}$, respectively. However, the specific sample used for the present test was found to contain only 20.6 and $5.3 \mu \mathrm{Ci} / \mathrm{g}$, respectively. Analyses performed by the ORNL Analytical Chemistry Division and those performed in triplicate by the ISV project personnel, using the $\mathrm{HF} / \mathrm{HNO}_{3}$ digestion procedure described in the section on HEPA filter and ORNL ISV product analyses, agreed quite well for both ${ }^{90} \mathrm{Sr}$ and ${ }^{137} \mathrm{Cs}$ (Table 8). A total of $489.9 \mathrm{~g}$ of this sludge was placed into the test trench on May 8, 1991, just prior to the initiation of melting. The sludge was contained in four polyethylene screw-cap bottles, which were placed inside a 3-in. diam PVC pipe that had been positioned vertically to the bottom of the limestone gravel in the center of the trench (Fig. 20). The amounts and depth positions of various tracer additions to the trench through the PVC pipe are listed in Table 10. The $\mathrm{Nd}, \mathrm{Ce}$, and $\mathrm{La}$ tracers were considered nonvolatile at the anticipated maximum meit temperatures $\left(1500-2000^{\circ} \mathrm{C}\right)$ and were used to simulate transuranic isotopes during the ISV process. In addition, from known additions of these tracers to the melt and their measured concentrations in the ISV product, the amount or weight of ISV product can be calculated. Analyses were also performed on the off-gas scrub solutions and prefilter to determine the amounts of these tracers that were removed from the melt. The Sb and Ir tracers were considered volatile at normal ISV operating temperatures. 
Table 9. Chemical analysis of the ORNL Pit 2 sludge material used for ISV test.

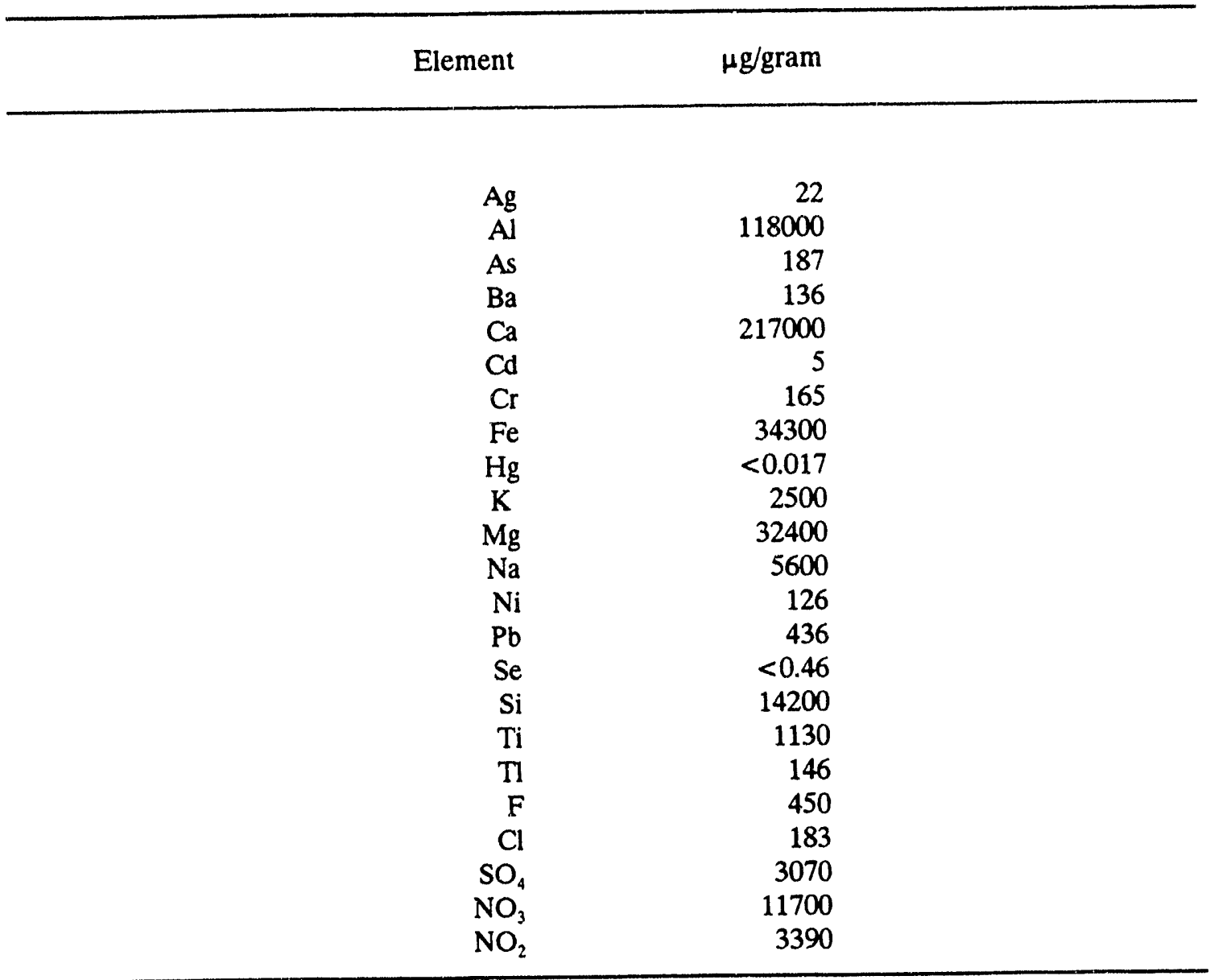

Table 10. Amounts and burial depths of tracers and sludge in ISV test.

\begin{tabular}{lll}
\hline Chemical & $\begin{array}{c}\text { Amount } \\
(\mathrm{g})\end{array}$ & $\begin{array}{c}\text { Burial Depth } \\
(\mathrm{m})\end{array}$ \\
\hline & 20 & $1.63-1.64$ \\
$\mathrm{IrCl}_{3}$ & 1008 & $1.52-1.63$ \\
$\mathrm{Nd}_{2} \mathrm{O}_{3}$ & 1509 & $1.40-1.52$ \\
$\mathrm{CeO}_{2}$ & 1510 & $1.24-1.40$ \\
$\mathrm{La}_{2} \mathrm{O}_{3}$ & 999 & $1.14-1.24$ \\
$\mathrm{Sb}_{2} \mathrm{O}_{3}$ & 490 & $1.91-2.16$ \\
\hline & & \\
\hline
\end{tabular}

It was initially intended that the PVC pipe be withdrawn incrementally as tracer containers were added. However, the pipe, after several months in the ground, proved impossible to remove without massive disturbance to the test trench configuration. Thus it was decided to pack sludge containers within the pipe with approximately $1 \mathrm{ft}$ of overlying soil before the addition of the inorganic tracer containers. It was concluded that the PVC would melt and pyrolyze long before the arrival of temperatures required to melt the soil and limestone. 
The sludge sample was subjected to the Toxicity Characteristic Leach Procedure (TCLP) to determine if it contained hazardous elements above the test criteria concentrations. Only the

Table 11. Results and criteria for the Toxicity Characteristic Leach Procedure (TCLP) for the sludge used in the ORNL ISV test.

\begin{tabular}{lrr}
\hline & & \\
Element & $\begin{array}{r}\text { Concentration } \\
\text { Found } \\
(\mathrm{mg} / \mathrm{L})\end{array}$ & $\begin{array}{r}\text { Concentration } \\
\text { Allowed } \\
(\mathrm{mg} / \mathrm{L})\end{array}$ \\
\hline & & 5 \\
$\mathrm{As}$ & 1.9 & 100 \\
$\mathrm{Ba}$ & 2.45 & 1 \\
$\mathrm{Cd}$ & 0.021 & 5 \\
$\mathrm{Cr}$ & 0.038 & 5 \\
$\mathrm{~Pb}$ & 1.35 & 0.2 \\
$\mathrm{Hg}$ & $<0.001$ & 1 \\
$\mathrm{Se}$ & $<0.005$ & 5 \\
$\mathrm{Ag}$ & 0.008 & $\mathrm{NA}$ \\
$\mathrm{Ni}$ & 0.235 & $\mathrm{NA}$ \\
$\mathrm{Tl}$ & 1.1 & \\
& & \\
\hline
\end{tabular}

inorganic elements in the TCLP were analyzed because no semivolatile organic compounds were detected in the sludge analysis. The specimen was determined to be nonhazardous (Table 11). Considering that $500 \mathrm{~g}$ of sludge was incorporated homogeneously into approximately $12 \mathrm{Mg}$ of ISV product, the concentration of any hazardous component would have been diluted by a factor of 30,000 . Although such dilution of potential hazardous elements in the ISV product is incidental to and not the goal of ISV technology, this observation is made only to illustrate that a nonhazardous waste cannot be converted to a hazardous one by ISV.

\section{TEST EQUIPMENT OPERATIONS AND MONITORING}

\section{MELT DEPTH AND ELECTRICAL POWER MONITORING}

During the ISV test, thermal data was collected on the spatial and temporal progress of the melt and its effects on the surrounding soil. As the primary measure of melt depth, the time of burnout of each type- $\mathrm{K}$ thermocouple in the central array was recorded. Type- $\mathrm{K}$ thermocouples ceased to function when temperatures between 1100 and $1300^{\circ} \mathrm{C}$ were encountered although these thermocouples occasionally survived for short intervals up to $1500^{\circ} \mathrm{C}$. From this thermal monitoring, the melt depth vs run time function can be determined (Fig. 21). Additional real-time estimates of melt depth were made using visual monitoring of depth of penetration of the four graphite electrodes (Fig. 21). The agreement between these two independent methods of melt depth estimation was excellent. However, without an independent depth estimate from either thermocouple data or geophysical methods, electrode breakage and occasional freezing of electrodes may cause less confidence to be placed in these estimates in general applications. The melt depth vs time relationship should not be interpreted as a continuous function. In addition to planned power shutdowns during seismic activities, other electrical power delivery problems were encountered during 
Table 12. Description of electrical anomalies during ORNL ISV test.

\begin{tabular}{|c|c|c|}
\hline riute & Time & Problem \\
\hline $5-10-91$ & $15: 54$ & Power on; start of test. \\
\hline$n$ & $16: 41$ & $\begin{array}{l}\text { Power off, fuses at ORNL substation blown, too much } \\
\text { load on line. Backup generator on. }\end{array}$ \\
\hline$n$ & $17: 55$ & Process trailer shutdown. \\
\hline $5-11-91$ & & Consult ORNL electrical utilities engineers. \\
\hline $5-12-91$ & $08: 30$ & $\begin{array}{l}\text { Reconfigure substation in parallel with another } \\
\text { to provide enough power for all line users. }\end{array}$ \\
\hline$n$ & $16: 18$ & $\begin{array}{l}\text { Power on for start } 2 \text {. Limited to } 100 \mathrm{~kW} \text { until starter path } \\
\text { consumed. }\end{array}$ \\
\hline n & $21: 44$ & Starter path consumed, power to $200 \mathrm{~kW}$. \\
\hline $5-13-91$ & $01: 30$ & $\begin{array}{l}\text { Power surges, bubbling around B2 electrode; pushed } \\
\text { in to alleviate surging. }\end{array}$ \\
\hline n & $09: 15$ & Data acquisition system fails; spare installed. \\
\hline$n$ & $11: 30$ & Power spikes, repeated at 12:15. \\
\hline$n$ & $19: 50$ & $\begin{array}{l}\text { Power off. Line fuse at pole blown. Must limit primary } \\
\text { power to } 550 \text { amps per phase. Fuse replaced. }\end{array}$ \\
\hline$n$ & $21: 17$ & Power on. \\
\hline $5-14-91$ & $10: 45$ & Power off $45 \mathrm{~min}$ for seismic survey tests. \\
\hline & $12: 50$ & Power off $1 \mathrm{~h}$ for seismic survey tesis. \\
\hline$n$ & $15: 48$ & Power off $45 \mathrm{~min}$ for seismic survey tests. \\
\hline $5-15-91$ & $08: 30$ & Power off to add $6 \mathrm{ft}$ extensions to all electrodes. \\
\hline$n$ & $09: 35$ & Power on $(300 \mathrm{~kW})$. \\
\hline 5-16-91 & $12: 25$ & Power off intermittently for $7 \mathrm{~h}$ for seismic surveys. \\
\hline $\begin{array}{l}5-16-91 \\
n\end{array}$ & $\begin{array}{l}01: 2.5 \\
05: 00\end{array}$ & $\begin{array}{l}\text { Hood ground cable sparking. Limit personnel access. } \\
\text { Process transformer making unusual noises; blower } \\
\text { amperage surging. }\end{array}$ \\
\hline$"$ & $06: 24$ & $\begin{array}{l}30 \text { amps in hood grounding cable; move excess line } \\
\text { coils; drops to } 5 \text { amps. }\end{array}$ \\
\hline$n$ & $11: 00$ & $\begin{array}{l}\text { Power fluctuations severe, transformer thumping, lights } \\
\text { flickering. Line voltages measured at } 470(\mathrm{~A}), 487 \text { (B) } \\
\text { and } 482(\mathrm{C}) \text { which are concluded to be too unbalanced } \\
\text { for the Scott-connected transformer. All process equipment } \\
\text { run on backup generator and any power to the melt from line. }\end{array}$ \\
\hline$n$ & $15: 30$ & Power back on at roughly $230 \mathrm{~kW}$. \\
\hline$n$ & $16: 45$ & Thyristor failed on process trailer transformer. \\
\hline$" 7-17-91$ & $18: 15$ & Power on after replacing thyristor. \\
\hline $5-17-91$ & $\begin{array}{l}05: 57 \\
14: 45\end{array}$ & A2 electrode drops about $3 \mathrm{ft}$. \\
\hline$n$ & $\begin{array}{l}14: 45 \\
18: 20\end{array}$ & $\begin{array}{l}\text { Added extensions to } \mathrm{A} 1 \text { and } \mathrm{A} 2 \text { electrodes. } \\
\mathrm{B} 2 \text { electrode dropped about } 5 \mathrm{ft} \text { and was gripped. }\end{array}$ \\
\hline n & $19: 50$ & Large power fluctuation noted. \\
\hline n & $21: 26$ & $\begin{array}{l}\text { Severe arcing noted in hood; broken electrode floating } \\
\text { and shorting; } 100 \mathrm{amp} / \text { phase surges. }\end{array}$ \\
\hline$n$ & $23: 50$ & End of test; melt at $8 \mathrm{ft} 8$ in. estimated from electrode depth. \\
\hline
\end{tabular}

the test resulting in many discontinuities in applied power and durations (Fig. 22). A cumulative energy of $29 \mathrm{MWh}$ was consumed over the 5-d test period. The calculated average applied power was 


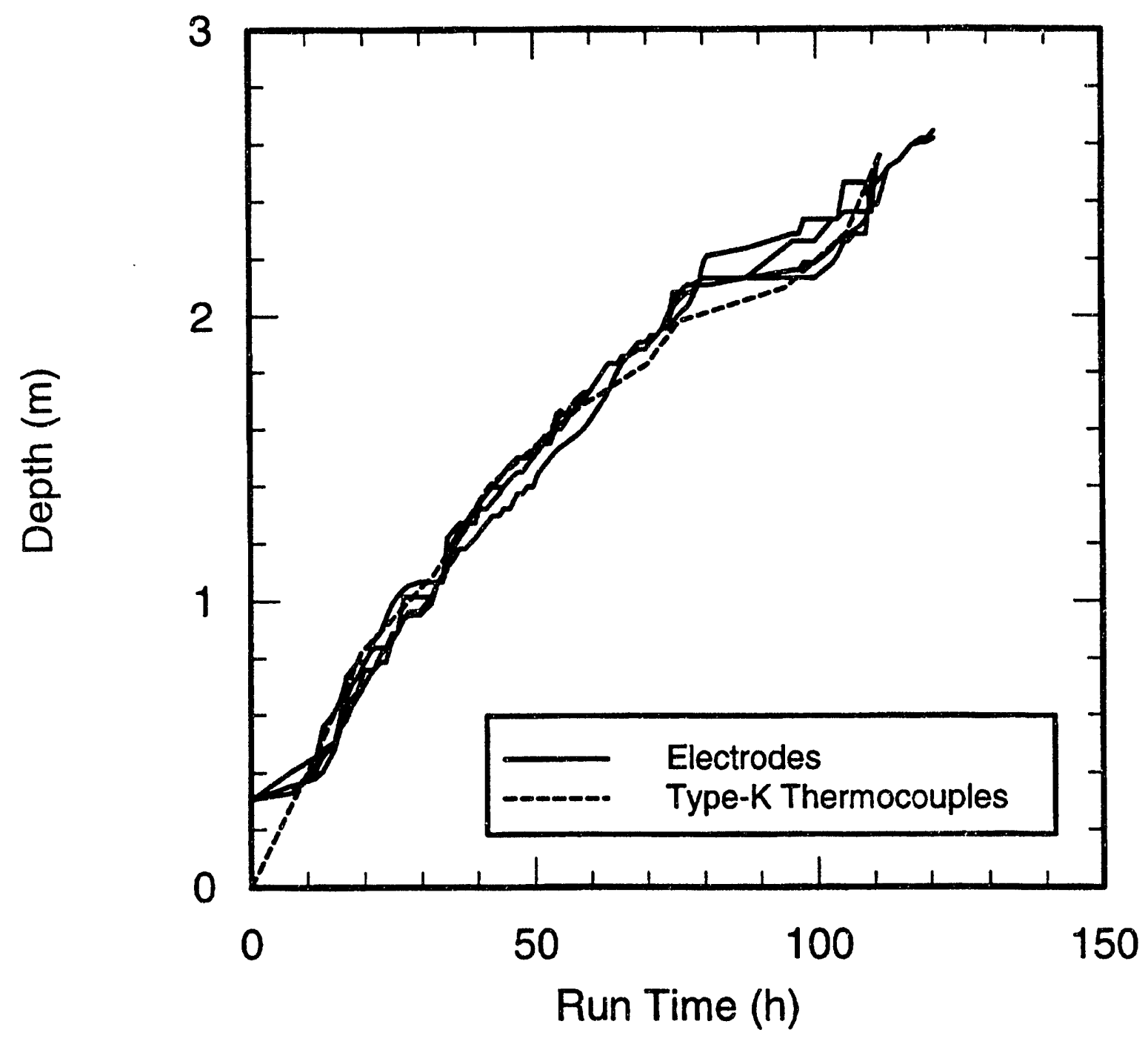

Fig. 21. Depth of melting vs run time during 1991 ORNL ISV test as measured by both thermocouple burnouts and electrode penetrations.

$220 \mathrm{~kW}$ with maximum applied power of about $350 \mathrm{~kW}$ during the intervals of minimal power equipment control problems. A complete chronology of these electrical anomalies is presented in Table 12 along with probable causes and remedies for the problems encountered. The most serious unresolved problem occurred on May 16 when power fluctuations, presumably caused by the inability of the Scott-Tee transformer to handle significant voltage variations among the three-phase power of the ORNL electrical utility line, resulted in a decision to operate all off-gas trailer equipment on "clean" power from the emergency generator. Subsequently, only power to the melt was taken from the ORNL utility line. Similar problems were encountered in 1987 during the nonradioactive ISV demonstration at ORNL when interruption of service to other line users resulted. In future ISV operations at ORNL, consideration should be given to obtaining electrical power from portable generators to avoid the possibility of interrupting other ORNL users. Using generators as the source 

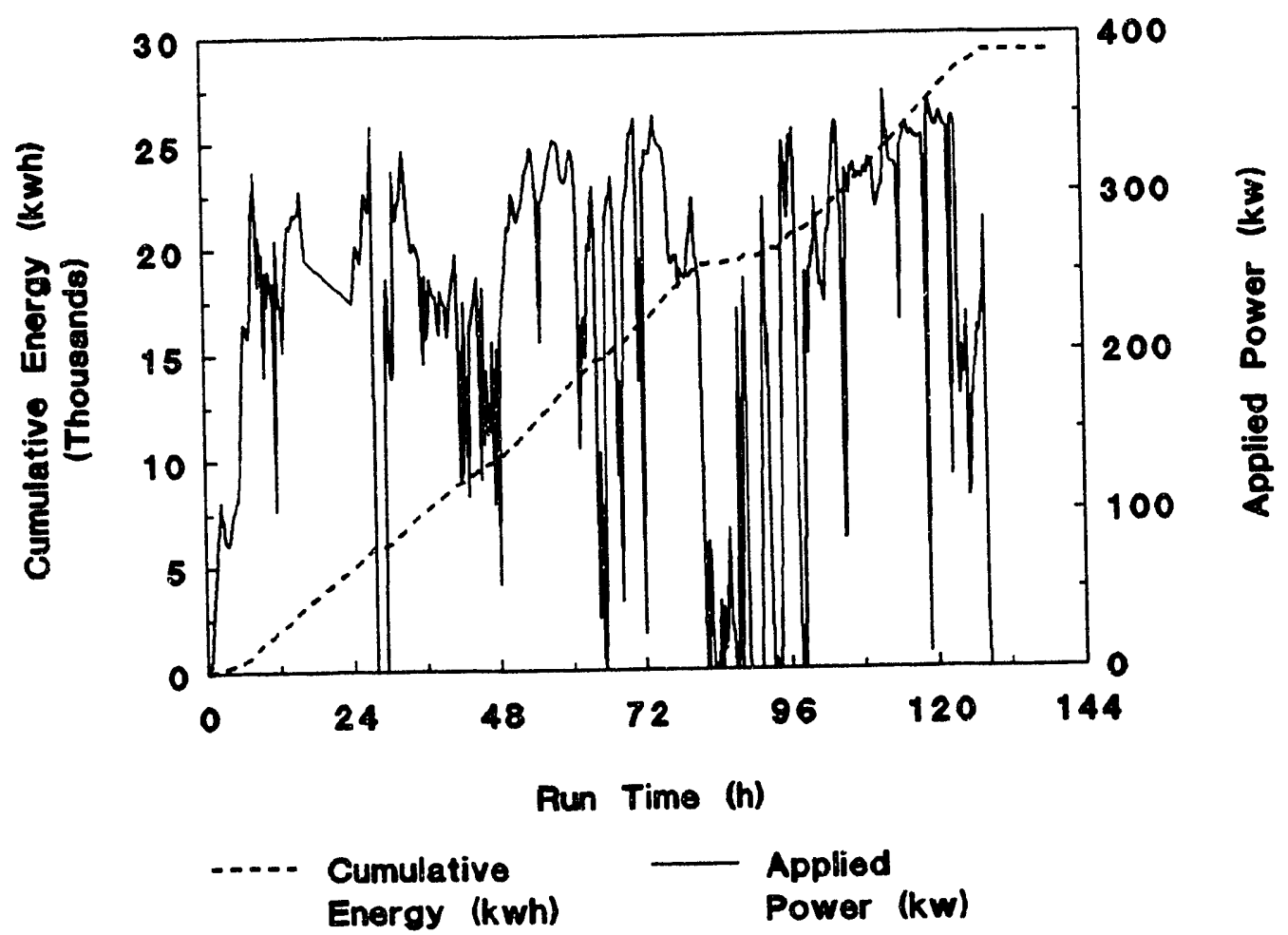

Fig. 22. Electrical power and cumulative energy applied to the 1991 ORNL ISV test trench.

of power should also relieve the ORNL electrical utility department from the difficulty of delivering balanced voltage among the three phases at significant distance from substation control points. However, the possible effects of load imbalances among electrical phases on generator performance must be evaluated prior to selecting generators for ISV applications.

\section{OPERATIONAL PERFORMANCE}

The primary test objectives for the tracer-level radioactive test relative to equipment and process operations were to:

1. demonstrate reduction in ${ }^{137} \mathrm{Cs}$ accumulation in the off-gas processing trailer and

2. assess radiological and operational activities of the ISV system.

The test successfully met each of these objectives and the data generated will provide important information for the application of a full-scale system capable of remediating ORNL seepage pits and trenches. Specific test accomplishments include: 
- The target melt depth of $8.5 \mathrm{ft}$ was achieved.

- All of the waste placed into the simulated trench was successfully immobilized or treated by the ISV process.

- The prefilter successfully stopped radioactivity from reaching the off-gas processing trailer. The counting of periodic off-gas samples provided a means of deciding when to direct the offgas through the prefilter, thus avoiding premature loading of the prefilter.

- Although power delivery problems were encountered during the test, they were overcome, thus demonstrating the ability of ISV to be successful despite significant power interruptions. For a portion of the test, the off-gas equipment was powered by a diesel generator which allowed more utility power to be available for melting soil.

- Several operational problems, encountered during the 1987 pilot-scale test at ORNL, including breakup of the starter path, spurious radiation alarms and malfunctions of the power delivery system, were not encountered during the radioactive tracer test. This is primarily due to refinements in the process and equipment. These refinements will be detailed further later in this section.

- Electrode breakage experienced during the test were successfully handled with the electrode feed system. The feed system was able to hold the broken electrode in place in the molten soil, allowing ISV processing to continue prior to adding new electrode sections.

\section{Electrical Power System Performance}

A total of $29 \mathrm{MWh}$ of electrical power was delivered to the ground over a 128 -h period producing a melt depth of 8.5 feet. With downtime included, the average applied power over the 128$\mathrm{h}$ period was $220 \mathrm{~kW}$. Power to the molten soil was discontinued while seismic measurements were in progress so that quality seismic data could be obtained. This created numero'ss power drops as evident in Fig. 22. A plot of electrical resistance for B phase is provided in Fig. " $j$. The electrical resistance for A phase was nearly identical. Electrical resistance in the soil peaked at approximately $20 \mathrm{ohms}$ during the startup phase of the test and leveled off at $0.2 \mathrm{ohms}$ for the majority of the remainder of the test. During periods of downtime (power to the melt discontinued), cooling of the molten soil caused electrical resistance to increase. These changes in electrical resistance are revealed as spikes in Fig. 23.

Occasional periods of electrical imbalance between phases were encountered during the test. It should be noted that no significant changes to the molten soil resistance were measured subsequent to vitrifying the dolomite limestone trench region which was encountered by the melt between approximately $16 \mathrm{~h}$ through $66 \mathrm{~h}$. The calcium oxide content of the dolomite (29\%) may not have been significant enough to affect the electrical resistance of the molten soil.

The test was initiated at 4:00 p.m. on May 10, 1991. Approximately 40 min into the test, power to the test site was disrupted because a fuse blew on the utility line feeding the site. Investigation of this situation revealed that inadequate power was available for the test site from the single feeder substation; to correct the situation, another feeder line substation was connected in parallel to the original line to provide sufficient power for the pilot-scale ISV process. Upon completion of the utility power upgrade, an inspection of the starter path determined a restart could be accomplished without relaying the starter path. The visual inspection of the starter path revealed that the small amount of power applied $(20 \mathrm{kWh})$ only removed the moisture in the immediate area of the starter path. The test was restarted at 4:18 p.m. on May 12, 1991 and corresponds to runtime $=0$ throughout this report.

The ISV power supply system was operated throughout the test with only one minor 


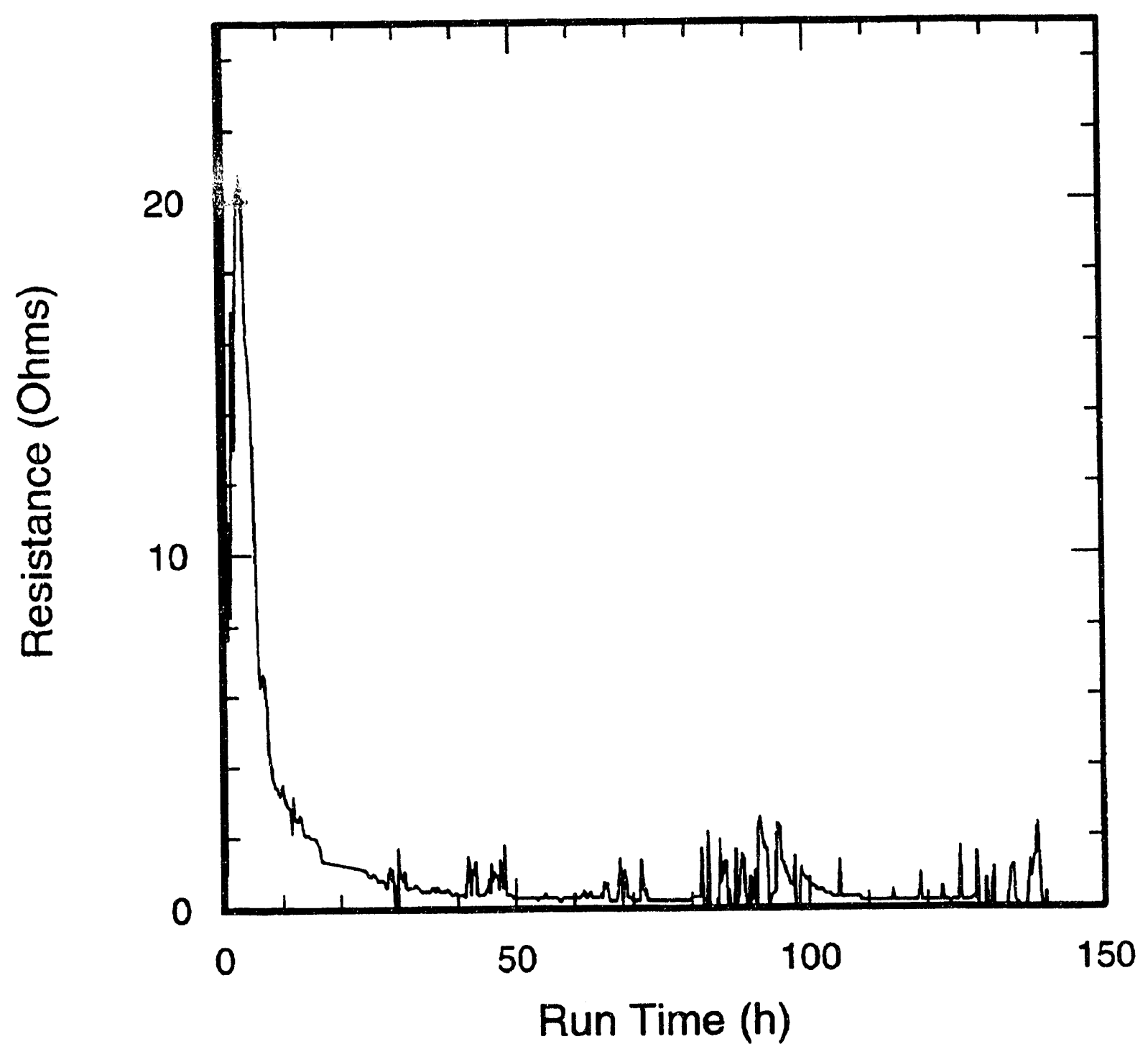

Fig. 23. Resistance of the B phase during the ISV test.

transformer component failure which was quickly repaired by the PNL operators. Late in the test, more probleins were encountered caused by unbalanced utility line voltage to the ISV pilot-scale process. The Scott-connected transformer will not operate correctly when fed with unbalanced threephase line voltage and further undesirable complications would be created as a result of line imbalance. In this situation, harmful effects to other users on the utility line can result and the problem would be magnified with power level. During the test, the off-gas blower operation became erratic when power levels to the melt were high. Since the off-gas blower is a critical component of the ISV process, power for all the off-gas and auxiliary equipment was switched over to dieselgenerated power leaving only the Scoti-connected transformer operating off the utility line. This modification completely eliminated the problem with the off-gas blower; however, other users on the utility line could still have been effected. The final power shutdown occurred at 11:50 p.m. on May 17,1991 , for a total test duration of $127.5 \mathrm{~h}$. 
Effects of severe line voltage imbalance would be unacceptable for a large-scale system using a Scott-connected transformer. An alternative would be to provide power to the operation with a diesel generator or to use an ISV power system more compatible with three-phase utilities. PNL is presently researching the applicability of other power transformers which would be more compatible with three-phase utilities and has completed some laboratory tests with three-phase designs (Luey et al. 1992).

\section{Electrode and Electrode Feed System Performance}

The electrode feed system operated as designed throughout the test with no riajor problems. The electrodes progressed downward with the advancing melt front (gravity fed) for the majority of the test. Electrode breakage occurred on each of the four graphite electrode sets as a result of oxidation at the molten soil and plenum atmosphere interface. Breakage of the electrode due to oxidation is accelerated if the electrode becomes stationary in the melt for an extended period of time as occurred several times during this test. However, none of the electrode breakage occurrences resulted in any operational problems beyond control of the electrode feed system or the power delivery system. Some electrical arcing was experienced as a broken piece of electrode would come into contact with the remaining intact electrode column. All of the breakage and electrical arcing occurred inside the hood and down in the subsidence zone and posed no danger to operating personnel, equipment, or the environment. Two of the electrode breakage occurrences took place near the end of the test and involved large pieces $(\sim 5 \mathrm{ft}$.) of electrode. When the large piece of electrode broke away from the electrode column, the electrode column was gravity-fed into the melt, replacing the 5-ft section. This required operators to use the electrode feed system to hold the remaining electrode in place until a crane could be used to add additional electrode sections. While electrode breakage should be avoided, no downtime was experienced due to broken electrodes with the exception that the power was suspended for $1 \mathrm{~h}$ while electrode sections were added. However, during a large-scale application in an actual contaminated site, electrode breakage could be a more serious problem, especially if operator intervention within the off-gas hood were required. Thus, methods to reduce the probability of electrode breakage should be pursued.

\section{Off-Gas Treatment System Performance}

The off-gas treatment system operated effectively during the test without release of any untreated off-gas to the environment. The off-gas flowrate for the test averaged $9.26 \mathrm{~m}^{3} / \mathrm{min}$ providing an average vacuum of 2 in. W.C. (498.2 Pa) in the hood as shown in Fig. 24.

The off-gas flowrate data shown in Fig. 25 is a corrected flowrate derived from the off-gas velocity profile established with the calibrated off-gas sampling systems (see section on Modified Method 5 off-gas sampling). ISV processing of ORNL soil with an assumed average soil moisture content of $18 \%$ resulted in a volume of water $(-2500 \mathrm{~L})$ being removed from the soil and entering the off-gas system. The 1987 ISV pilot-scale test conducted at ORNL resulted in excessive secondary scrub solution waste $(1974 \mathrm{~L})$ as a result of water being removed from the soil during processing and being collected in the scrub tanks and eventually removed into drums. By increasing the scrub solution temperature from a previous limit of $35^{\circ} \mathrm{C}$ to $55^{\circ} \mathrm{C}$ through control of the scrub solution heat exchangers, the rate of scrub solution evaporation equaled or exceeded the rate of water vapor generation rrom processing the ORNL soil and resulted in a volume of only $183 \mathrm{~L}$ of scrub solution waste for disposal compared with the $1974 \mathrm{~L}$ in 1987 . The moisture content of the off-gas averaged $11.8 \%$ for the test.

The venturi-ejector scrubber removes the majority of the thermal energy in the off-gas stream as illustrated in Fig. 26. In addition to providing this function, the venturi-ejector also typically removes 81 to $92 \%$ of the nonvolatile particulate from the off-gas. The use of the prefilter greatly reduced the burden on the venturi-ejector to remove particulate from the off-gas. Without the use of a prefilter, the solids removed by the venturi-ejector accumulate in the scrub solution eventually 


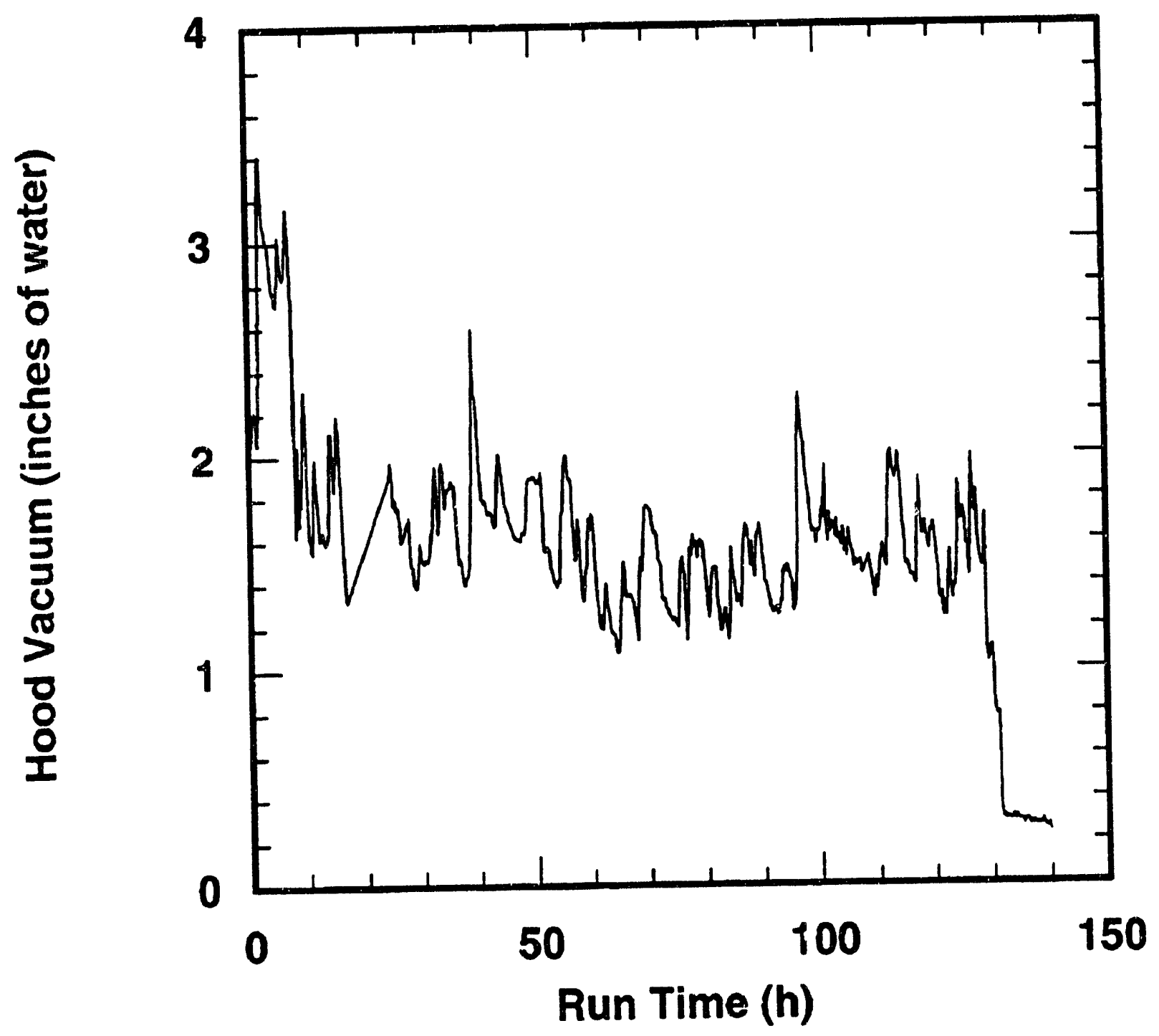

Fig. 24. Hood vacuum as a function of run time.

requiring that the solids be removed to avoid potential clogging of the throat of the venturi-ejector and other off-gas treatment components. Furthermore, a large quantity of solids in the scrub solution will reduce the life of the scrub pump and increase the amount and cost of maintenance required on an ISV off-gas system. In the present test, scrub solution samples were taken from the scrub tanks at times corresponding to every 6 in. of melt depth advancement. These samples were analyzed for anions, cations, ${ }^{137} \mathrm{Cs}, \mathrm{Ph}$, and solids. Levels of ${ }^{137} \mathrm{Cs}$ remained virtually unchanged in the scrub solution throughout the test (trace amounts of ${ }^{137} \mathrm{Cs}$ were already present in the off-gas scrubbing equipment as the result of a test performed in 1984), providing solid evidence that all the ${ }^{137} \mathrm{Cs}$ was removed from the off-gas by the off-gas prefilter.

The Hydro-Sonic ${ }^{\circ}$ scrubber, when operated at a differential pressure greater than $50 \mathrm{in.} \mathrm{W.C.,}$ provides a removal efficiency of greater than $90 \%$ for particulate size $0.5 \mathrm{\mu m}$ or larger. The combination of the venturi-ejector and the Hydro-Sonic ${ }^{\bullet}$ scrubber provides an efficient means for 


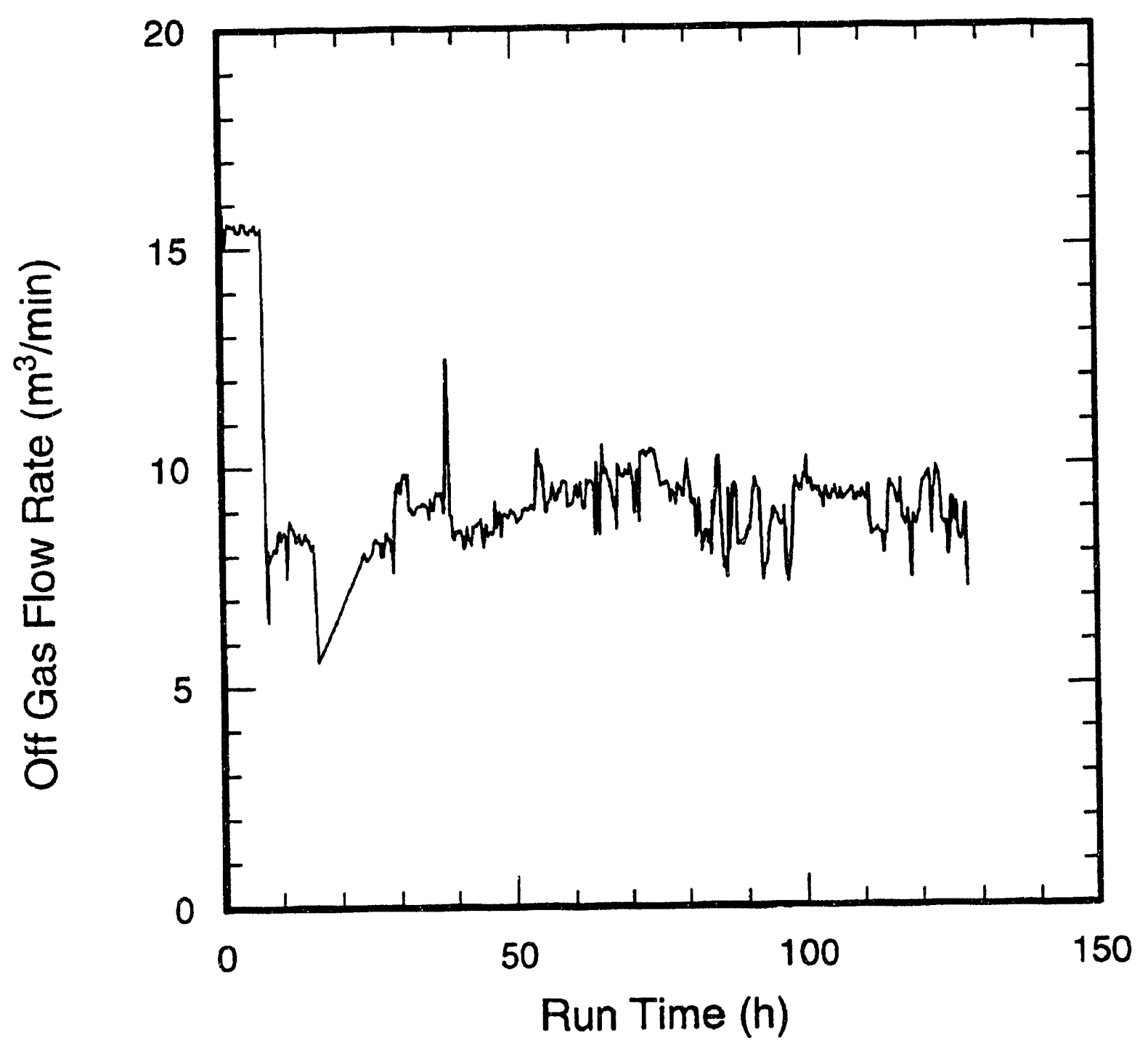

Fig. 25. Off-gas flow rate as a function of run time.

removing heat and particulate from the off-gas. This efficiency is further demonstrated by the lack of particulate loading on the primary HEPA filters. Only one of the two primary HEPA filters was needed throughout the test.

\section{Off-Gas Prefilter Performance}

The prefilter was valved into the off-gas flow as thermocouple data indicated the melt front was approaching the radioactive sludge sample (run time $48 \mathrm{~h}$ ). As expected, the prefilter was very efficient at collecting the volatilized radioactive cesium in the off-gas. No radioactivity was detected downstream from the prefilter during the test or in posttest sampling. Off-gas temperatures remained high enough throughout the use of the prefilter to allow water vapor in the off-gas to pass through the filter without condensing. At the time the prefilter was valved in, a substantial amount of molten 


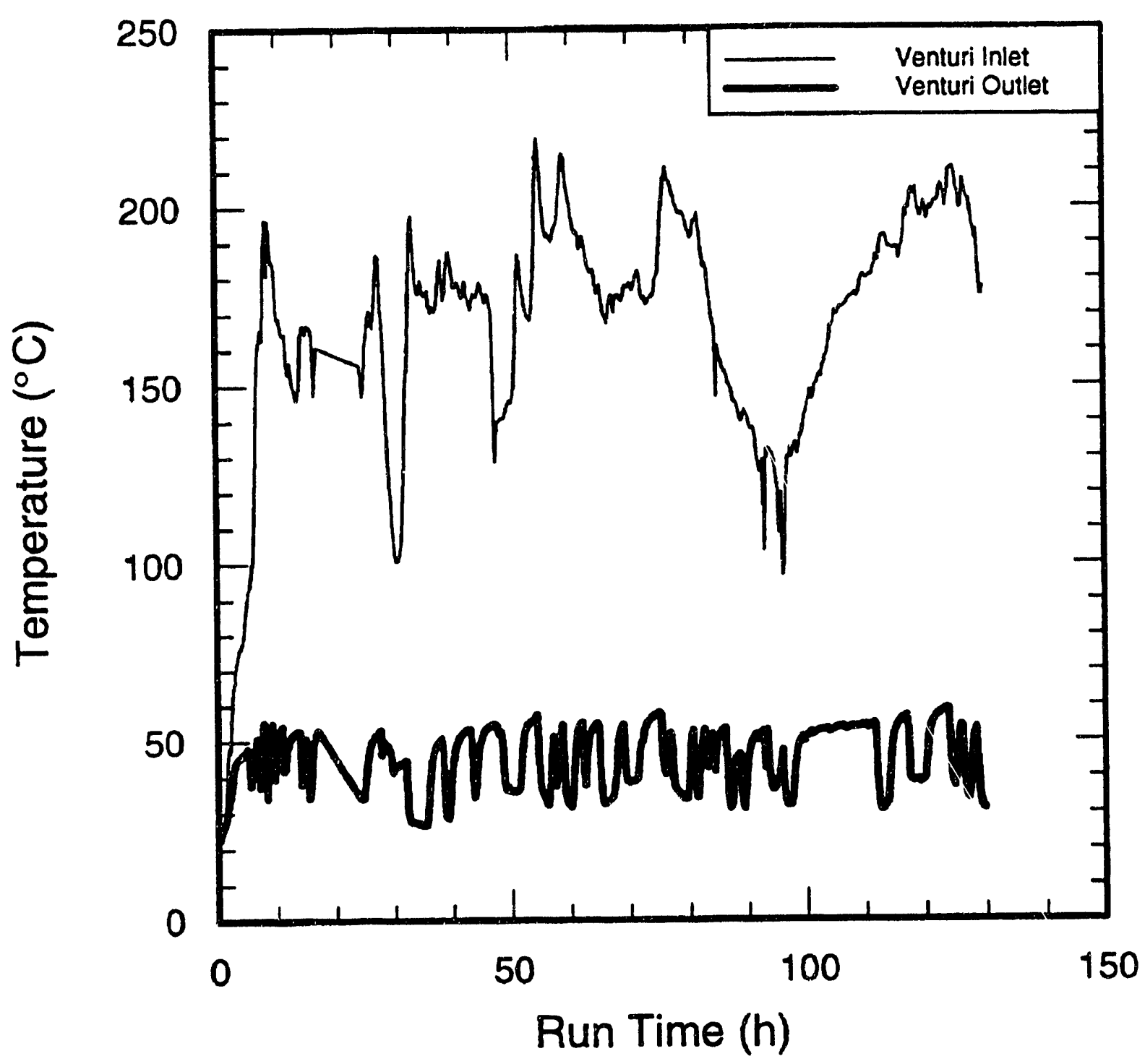

Fig. 26. Temperature at the inlet and outlet of the venturi-scrubber.

soil was present, which reduced the amount of particulate in the off-gas, and thus reduced the loading of solids on the filter. Only one filter was needed for the test. The differential pressure across the filter is shown in Fig. 27. A steady increase in the differential pressure across the prefilter was observed up to about $85 \mathrm{~h}$. At that point, difficulties with power delivery to the melt resulted in downtime which allowed a cold cap to form at the melt surface. This interruption of power delivery and cold cap formation greatly reduced the generation of particulate as well as the temperature and volume of off-gas. The reduction in off-gas volume was indicated by the drop in the differential pressure across the prefilter from 85 to $95 \mathrm{~h}$ (Fig. 27).

The sharp increase in differential pressure near the end of the test was due to the entrainment of graphite in the off-gas as a result of the electrode arcing discussed previously.

As mentioned earlier, the use of the prefilter greatly reduces the burden on the wet-scrubbing devices for particulate removal. However, the use of standard size (24 in. $\times 24$ in. $\times 11.5$ in.) HEPA 


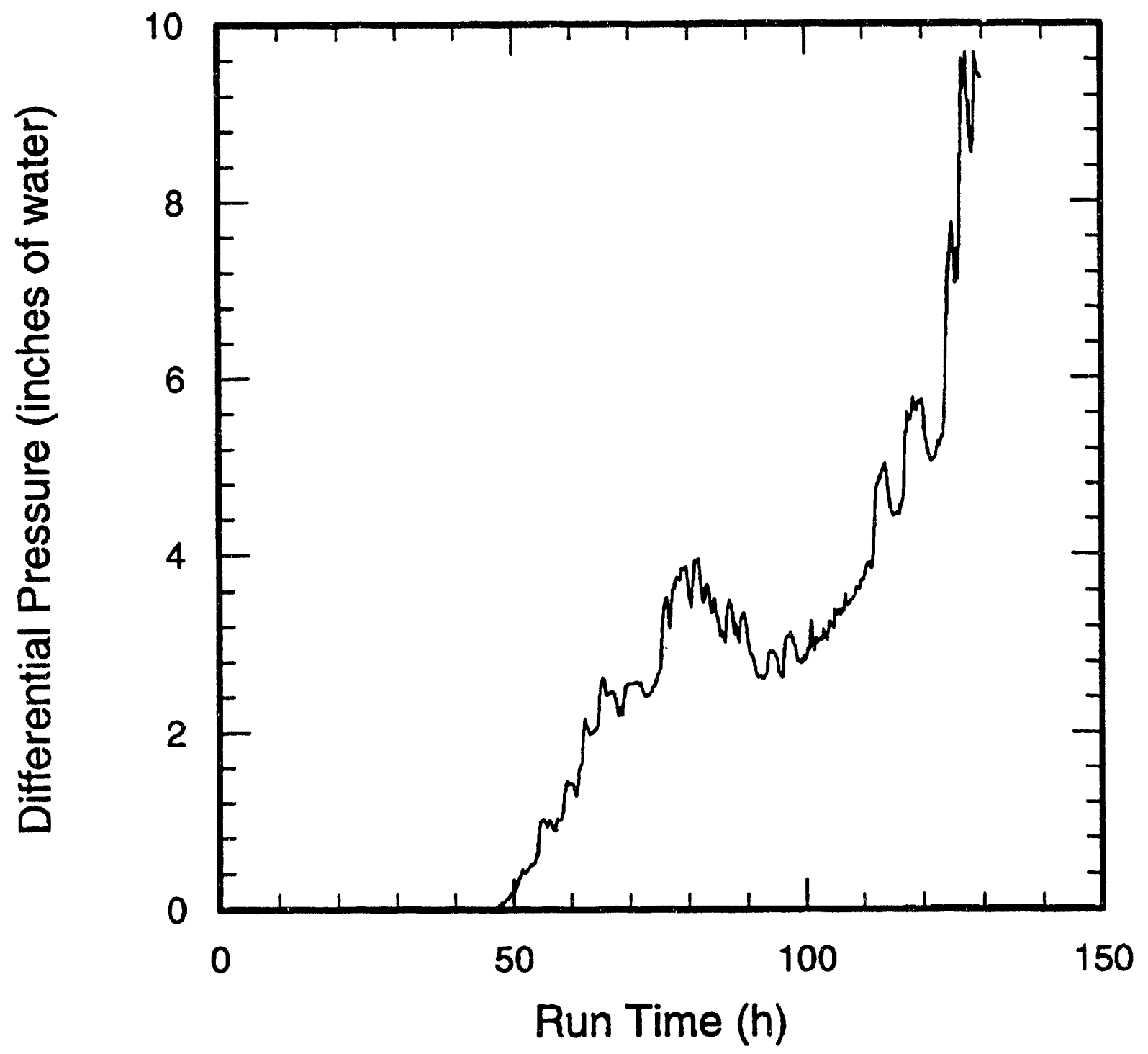

Fig. 27. Differential pressure across the prefilter during the ISV test. Use of the filter was started at $\sim \mathbf{4 8} \mathrm{h}$.

filters during actual trench remediation may result in a large volume of HEPA filters for disposal. A possible alternative to the present HEPA filter would be a reusable metal filter. This metal filter uses a pulsed blowback cleaning system to remove solids captured on the filter and deposit them in a collection vessel. In this way, a substantial volume reduction in secondary waste could be achieved. 


\section{TEST TRENCH SENSORS MONITORING}

\section{TEMPERATURE}

Type-K thermocouples, whether sheathed by stainless steel or iconel, typically burn out between 1200 and $1400^{\circ} \mathrm{C}$, so they provide temperatures only until contacted by the melt. It was assumed that, when a type- $\mathrm{K}$ thermocouple reached $1100^{\circ} \mathrm{C}$, it had been engulfed by the melt. Thus their burnout times would indicate the extent of the melt at those times. The type-S thermocouples were part of the oxygen fugacity probes; they survived contact with the melt and provided a total history of temperature. However, because of the large thermal mass and flow of cool air through them, they may have recorded temperatures that were lower than the actual temperatures of the melt. The type- $\mathrm{C}$ thermocouples were designed and placed to provide a complete record of temperatures from ambient through melting and cooling. For all thermocouples, there is some uncertainty with the actual position. Settling of the soil after emplacement is known to have occurred. Thermocouples within the melt may also have moved as a result of convection within the melt. There is no way to determine the extent of such movement. Thus it was assumed that the positions are as determined and reported in Tables 6 and 7.

Typical behavior for a thermocouple was to rapidly approach $100^{\circ} \mathrm{C}$ when a zone of boiling water, which is established ahead of the melt front, encompasses the thermocouples. These soil thermocouples then remained at $-100^{\circ} \mathrm{C}$ until the water was boiled away as the melt front approached. Then the temperature of the soil increased rapidly until the melt encompassed the position. For type-K thermocouples, the thermocouples burned out and recorded the position of the melt at that time. Type-C and type-S thermocouples continued to operate even after they are engulfed by the melt.

\section{Thermocouples}

Type-C thermocouples (W-5Re/W-26Re) were supplied by Delta-M Corp., Oak Ridge, Tennessee, according to specifications which included the following requirements: molybdenumsheathed assemblies 20.125 in. diameter; 0.020 -in. diameter element wires (accuracy $\pm 1 \%$ of reading for temperatures $>425^{\circ} \mathrm{C}$ ); hafnia insulation; insulated thermocouple junction; high-temperature, moisture-resistant transition to thermocouple extension wire rated for operation to $600^{\circ} \mathrm{F} ; 20 \mathrm{~m}$ of 24 American Wire Gage (AWG) teflon-insulated extension wire; and assemblies backfilled with inert gas (He or Ar) to minimize thermocouple wire oxidation and corrosion. Assemblies of the following lengths were used: 5 each. - 24 in., 1 each - 36 in., 5 each - 48 in., and 1 each - 60 in.. Type-K thermocouples (chromel-alumel) were supplied by GMI, Knoxville, Tennessee, according to specifications which included the following requirements: inconel 600 -sheathed assemblies 0.125 in. diam; 0.020 in. diam element wires; $\mathrm{MgO}$ insulation; insulated thermocouple junction; high-temperature, moisture-resistant transition to thermocouple extension wire rated for operation to $600^{\circ} \mathrm{F} ; 20 \mathrm{~m}$ of $24 \mathrm{AWG}$ teflon-insulated extension wire. Assemblies of the following lengths were used: 1 each - 6 in., 18 each - 12 in., 1 each - 18 in., 19 each - 24 in., 1 each - 30 in., 1 each - 36 in., 1 each - 42 in., 24 each - 48 in., 1 each - 54 in., 3 each - 60 in., 1 each - 66 in., 1 each - 78 in., and 1 each - 90 in.. Type-S thermocouples were fabricated at ORNL from 0.020 -in. diam matched platinum and platinum-10\% rhodium thermocouple wire pairs obtained from the ORNL stores system. This wire is obtained from commercial sources in accordance with specifications developed by the ORNL Instrumentation and Controls Division. The junction was welded using a gas-torch welder. The thermocouple wires were cleaned with hexane and acetone and annealed by resistance heating using the facilities and procedure developed by the Metrology Laboratory of the ORNL Instrumentation and Controls Division. The output signals of the type-C and type-S thermocouples were transmitted to the data acquisition system by electrically isolating thermocouple signal conditioner/transmitters supplied by M-System Technology, Inc., Dallas, Texas. The output of the modules used with type-C thermocouples (model 11JT-04-K) provided a linearized 0-10 VDC output signal for the range 0 to 
$2300^{\circ} \mathrm{C}$ with an overall accuracy of $\pm 2^{\circ} \mathrm{C}$. The output of the modules used with type-S thermocouples (model 11JT-04-K) provided a linearized 1-6 VDC output signal for the range -50 to $1760^{\circ} \mathrm{C}$ with an overall accuracy of $\pm 2^{\circ} \mathrm{C}$. Both types of modules provide cold-junction compensation. The output of type- $\mathrm{K}$ thermocouples was processed by one of two methods depending on the position of the thermocouple in the test area. First, the output of thermocouples used for monitoring melt depth progression was transmitted to the data acquisition system by electrically isolating thermocouple signal conditioners/transmitters incorporated in the pilot-scale test equipment. The output of the modules, used with the pilot-scale test equipment's type-K thermocouples, provided a linearized 0-5 VDC output signal for the range 0 to $1300^{\circ} \mathrm{C}$. Second, the output of other thermocouples used for monitoring areas outside the melt zone were linearized using National Institutes of Standards and Technology polynomials and corrected for room temperature.

\section{Type-K Thermocouples}

Figures 28 and 29 show the record of the type-K thermocouples placed in a vertical array along the central axis of the melt volume. The time to $1100^{\circ} \mathrm{C}$ was used to determine the depth of melting during the test. The time that each thermocouple spends at $100^{\circ} \mathrm{C}$ increases with increasing depth. This result may suggest that the extent of the boiling water zone increases as the melt grows deeper and wider (A. Solomon, ORNL, personal communication) or that more water accumulates around the melt as the venting of the vapor is inhibited by the greater depth (longer path to the surface) so it takes longer to dry.

Figures 30,31 , and 32 show the temperature history at a depth of $\sim 1 \mathrm{~m}(3.5 \mathrm{ft})$ for type-K thermocouples placed on radial arcs of $\sim 1.2 \mathrm{~m}(4 \mathrm{ft}), 1.8 \mathrm{~m}(6 \mathrm{ft})$, and $2.1 \mathrm{~m}(7 \mathrm{ft})$ around the center of the melt. Six thermocouples were placed $60^{\circ}$ apart on each arc. At $55-65 \mathrm{~h}$ into the test, the melt reached the sensors at a radius of $4 \mathrm{ft}$. The sensors that were placed 6 and $7 \mathrm{ft}$ from the center of the melt reached roughly $100^{\circ} \mathrm{C}$ near the end of the test. One thermocouple, TEK7230036 (Fig. 31), recorded fluctuations in temperature around $90 \mathrm{~h}$. It is possible that the soil in this area was close to being completely dried out, thus allowing temperatures to increase rapidly. But then saturation occurred and the temperature fell back to $100^{\circ} \mathrm{C}$. The slight decrease in temperature around $90 \mathrm{~h}$ (Figs. 30 and 31) is a result of the low power period between 80 and $90 \mathrm{~h}$. Note that at $\sim 180 \mathrm{~h}$, after the soil had begun to cool off, there was an increase that reached a maximum temperature depending on the position of the thermocouple relative to the melt. This behavior is interpreted to be caused by heat being released from crystallization processes and reaching these zones after several hours. The thermocouples at radius $=6 \mathrm{ft}$ were at $100^{\circ} \mathrm{C}$ for a long time, whereas the thermocouples at radius $=7 \mathrm{ft}$ barely reached $100^{\circ} \mathrm{C}$. This behavior suggests that the horizontal extent of the boiling zone was near the 7 - $\mathrm{ft}$ radius limit at this depth of $3.5 \mathrm{ft}$ and that the melt radius was between 4 and $5 \mathrm{ft}$.

Figures 33, 34, and 35 show the temperature history at a depth of $\sim 2 \mathrm{~m}(6.5 \mathrm{ft})$ for type-K thermocouples placed $\sim 1.2 \mathrm{~m}(4 \mathrm{ft}), 1.8 \mathrm{~m}(6 \mathrm{ft})$, and $2.1 \mathrm{~m}(7 \mathrm{ft})$ around the center of the melt. Six thermocouples were placed $60^{\circ}$ apart on each arc. All the sensors at a radius of $4 \mathrm{ft}$ burned out -100 $h$ into the test. The sensors that were placed $6 \mathrm{ft}$ from the center of the melt reached $\sim 100^{\circ} \mathrm{C}$ at $\sim 60$ $\mathrm{h}$. The slight decrease in temperatures around 90 to $100 \mathrm{~h}$ (Fig. 34 and 35) is a result of the low power period between 80 and $90 \mathrm{~h}$. Note that at $\sim 180 \mathrm{~h}$, five of the thermocouples at the 6 - $\mathrm{ft}$ radius began to record temperature increases (Fig. 34). Figure 35 shows that some of the thermocouples at the 7-ft radius began to record temperature decreases but then increased for a short while. This behavior is again interpreted to be a result of heat from crystallization processes being released and reaching these zones after several hours. All but one of the thermocouples at a radius of $6 \mathrm{ft}$ reached temperatures of $>100^{\circ} \mathrm{C}$. The thermocouples at a radius of $7 \mathrm{ft}$ remained at $100^{\circ} \mathrm{C}$ for an extended time. Thus, the extent of the boiling zone was somewhere beyond the $7-\mathrm{ft}$ radius.

Figure 36 shows the temperature history at a septh of $-2.3 \mathrm{~m}(7.5 \mathrm{ft}$ ) for type-K thermocouples placed $\sim 1.2 \mathrm{~m}(4 \mathrm{ft})$ around the center of the melt. Figures 37 and 38 show the temperature history at depths of $\sim 2.6 \mathrm{~m}(8.5 \mathrm{ft})$ for type- $\mathrm{K}$ thermocouples placed on arcs of $\sim 1.8 \mathrm{~m}$ $(6 \mathrm{ft})$ and $2.1 \mathrm{~m} \mathrm{(7ft)}$ around the center of the melt, respectively. Six thermocouples were placed $60^{\circ}$ 
apart on each arc at each depth. All the sensors at a radius of $4 \mathrm{ft}$ reached temperatures $>350^{\circ} \mathrm{C}$ approximately 160 to $180 \mathrm{~h}$ into the test. Such high temperatures imply that the melt almost reached these positions. The sensors that were placed $6 \mathrm{ft}$ from the center of the melt reached $\sim 100^{\circ} \mathrm{C}$ near the end of the test. Some of the thermocouples $7 \mathrm{ft}$ from the center of the melt reached $100^{\circ} \mathrm{C}$ near the end of the test. These data imply that the boiling zone at this depth may have been less extensive than at $6.5 \mathrm{ft}$ depth. This behavior is consistent with the hemispherical shape of the melt. Thus temperatures near the bottom of the melt would not extend out as far as those at depths corresponding to the widest part of the melt body. The sharp decrease in temperature at $380 \mathrm{~h}$ in Fig. 36 could be related to either (1) a heavy rainfall at the site or (2) some transient electrical surge.

Figure 39 shows temperature histories for three thermocouples at depths of $-8.5 \mathrm{ft}(2.6 \mathrm{~m})$. These thermocouples were placed $120^{\circ}$ apart $\sim 1 \mathrm{ft}(0.3 \mathrm{~m})$ from the center of the melt. Thus these sensors would be nearly directly below the maximum depth of the melt. All three sensors recorded temperatures $>350^{\circ} \mathrm{C}$ well after termination of power. Figure 40 shows the temperature histories at a depth of $-2.6 \mathrm{~m}(8.5 \mathrm{ft})$ for type-K thermocouples placed $60^{\circ}$ apart $\sim 0.6 \mathrm{~m}(2 \mathrm{ft})$ around the center of the melt. These thermocouples recorded maximum temperatures of $-200^{\circ} \mathrm{C}$ after the test ended. These increases in temperature might be a result of the heat of crystallization because the rise above $100^{\circ} \mathrm{C}$ occurs at roughly 180 to $200 \mathrm{~h}$, consistent with temperature increases for other sensors many hours after power was terminated. This behavior might also be caused by the sensible heat released from the melt during cooling, as these thermocouples were close to the maximum depth and extent of the melt. For these thermocouples located directly under the melt, the data are insufficient to distinguish between the effects of latent heat and thermal inertia in creating the related temperature rise.

During the cooling period $(200-500 \mathrm{~h})$, several type-K thermocouples exhibit a "waveform" behavior (e.g., Fig. 37) that may be a result of diurnal temperature changes at the reference junction. It is not known why this behavior is found only in some thermocouples. The magnitude of the waveform variation is small and does not affect interpretations based on temperature history.

\section{Type-C and Type-S Thermocouples}

Figure 41 shows the temperatures for type- $\mathrm{C}$ thermocouples in a vertical array down the central axis of the melt. Sensors TEC0000042, TEC0000054, and TEC0000066 appear to record reasonable temperatures until $-120 \mathrm{~h}$. Then they all decrease in temperature rapidly. Values past $120 \mathrm{~h}$ are not considered accurate. Sensor TEC0000078 appeared to cease functioning properly at 145 h. The times of contact with the melt for these thermocouples, as indicated by the sharp increase in temperature from 100 to $1500^{\circ} \mathrm{C}$, are consistent with the times observed from the central array of type-K thermocouples (Figs. 28 and 29).

Figure 42 illustrates temperatures at a depth of $-5 \mathrm{ft}(1.5 \mathrm{~m})$. The four type-C sensors are $90^{\circ}$ apart $2 \mathrm{ft}(0.6 \mathrm{~m})$ from the center of the melt. The melt reaches sensor TEC2400054 after the other three are already engulfed. Maximum melt temperature is $-1500^{\circ} \mathrm{C}$ at high power. During 80 to $90 \mathrm{~h}$, when power was low, the melt temperature decreases rapidly to $-1200^{\circ} \mathrm{C}$. No significant thermal gradients are recorded among these thermocouples. After termination of power, the temperature drops rapidly to $-1170^{\circ} \mathrm{C}$. It remains near that temperature for $-24 \mathrm{~h}$. This therma! arrest is interpreted to be a result of heat released during crystallization processes. After crystallization is complete, the temperature decreases rather fast as the solid cools conductively. It is the heat released during the 140 to $160 \mathrm{~h}$ period that is thought to be the reason that thermocouples outside the melt zone record increases in temperature after temperatures had begun to decrease in the soil (e.g., Fig 39).

Figure 43 illustrates temperatures at a depth of $\sim 7 \mathrm{ft}(2.1 \mathrm{~m})$. The four type-C sensors are $90^{\circ}$ apart $2 \mathrm{ft}(0.6 \mathrm{~m})$ from the center of the melt. None of these type- $\mathrm{C}$ thermocouples were engulfed by the melt. However, the melt must have been close to these coordinates because each thermocouple recorded a temperature of at least $\sim 700^{\circ} \mathrm{C}$.

Figure 44 illustrates temperatures at a depth of $-6.5 \mathrm{ft}(2 \mathrm{~m})$. The two type-S sensors are 
$180^{\circ}$ apart $2 \mathrm{ft}(0.6 \mathrm{~m})$ from the center of the melt. These sensors were in the melt only briefly and help to define the extent of melting in this region. The maximum recorded temperatures are 70 to $100^{\circ} \mathrm{C}$ less than those of the type-C thermocouples (Fig. 42). This difference may be attributable to thermal gradients, as these sensors were much closer to the edge of the melt. However, the design of the sensor assembly may also result in low temperature readings. The thermal arrest is also apparent in these thermocouples. The timing is similar to that of the type- $\mathrm{C}$ thermocouples, but occurs at a temperature of $\sim 1070$ to $1100^{\circ} \mathrm{C}$, approximately $70^{\circ} \mathrm{C}$ lower than the arrest measured by the type-C sensors. This observation would be consistent with the fact that the thermocouple nearest the edge of the melt body recorded shorter, and somewhat cooler, thermal arrests as a result of crystallization and conductive cooling.

The operating temperature of $-1500^{\circ} \mathrm{C}$ is similar to the value of the temperature of 100 -poise viscosity (T100P) measured by Shade and Piepel (1990) for a similar mixture of soil and limestone. Viscosities of the Shade and Piepel (1990) mixtures and of the 1991 ISV product composition were calculated using the model of Shaw (1972). The model was in excellent agreement with the data of Shade and Piepel (1990). Using this model, the viscosity of the $1991 \mathrm{ISV}$ melt at $1500^{\circ} \mathrm{C}$ calculated to 43 poise. Upon cooling to $1250^{\circ} \mathrm{C}$, the temperature recorded during the low-power period between 80 and $90 \mathrm{~h}$, the viscosity would have increased to 412 poise. Thus, even at the lower operating temperatures, this melt would have maintained a low viscosity and probably would have convected well, unless crystallization had started and had begun to freeze the melt.

The type- $C$ thermocouples provide the most valuable information throughout the entire time of the test. It is clearly important to know the position of each sensor as precisely as possible and to find a way to correct for settling of soil after the sensors are placed.

The temperature data were used in a three-dimensional interpolation program (Toby Mitchell, ORNL Engineering, Physics, and Mathematics Division, personal communication). The interpolated output was used to produce a three-dimensional visualization using the Application Visualization System program on a Stardent work station. This tool provided a three-dimensional image of the shape of the melt at any time during the test. It was apparent that even this relatively dense sampling of temperatures during the test was not adequate for accurate interpolations by this program. It is suggested that a future test melt be instrumented in at least one zone of the melt with a very dense array of thermocouples. Such a sampling scheme would allow better resolution of small but important features. 

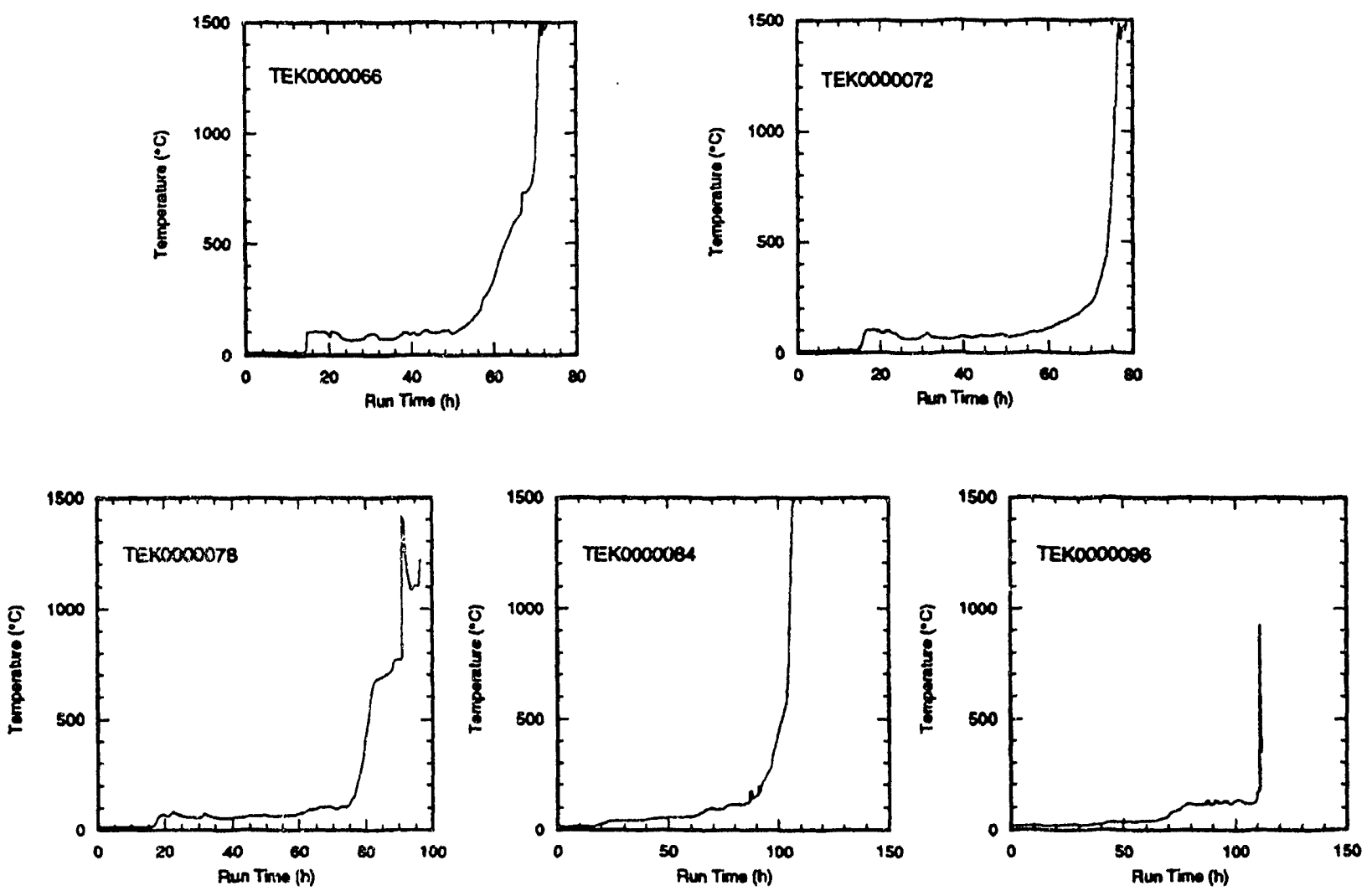

Fig. 28. Temperature as a function of run time for the vertical array of type-K thermocouples placed along the central axis of the melt volume through depth $=5.5 \mathrm{ft}$. 

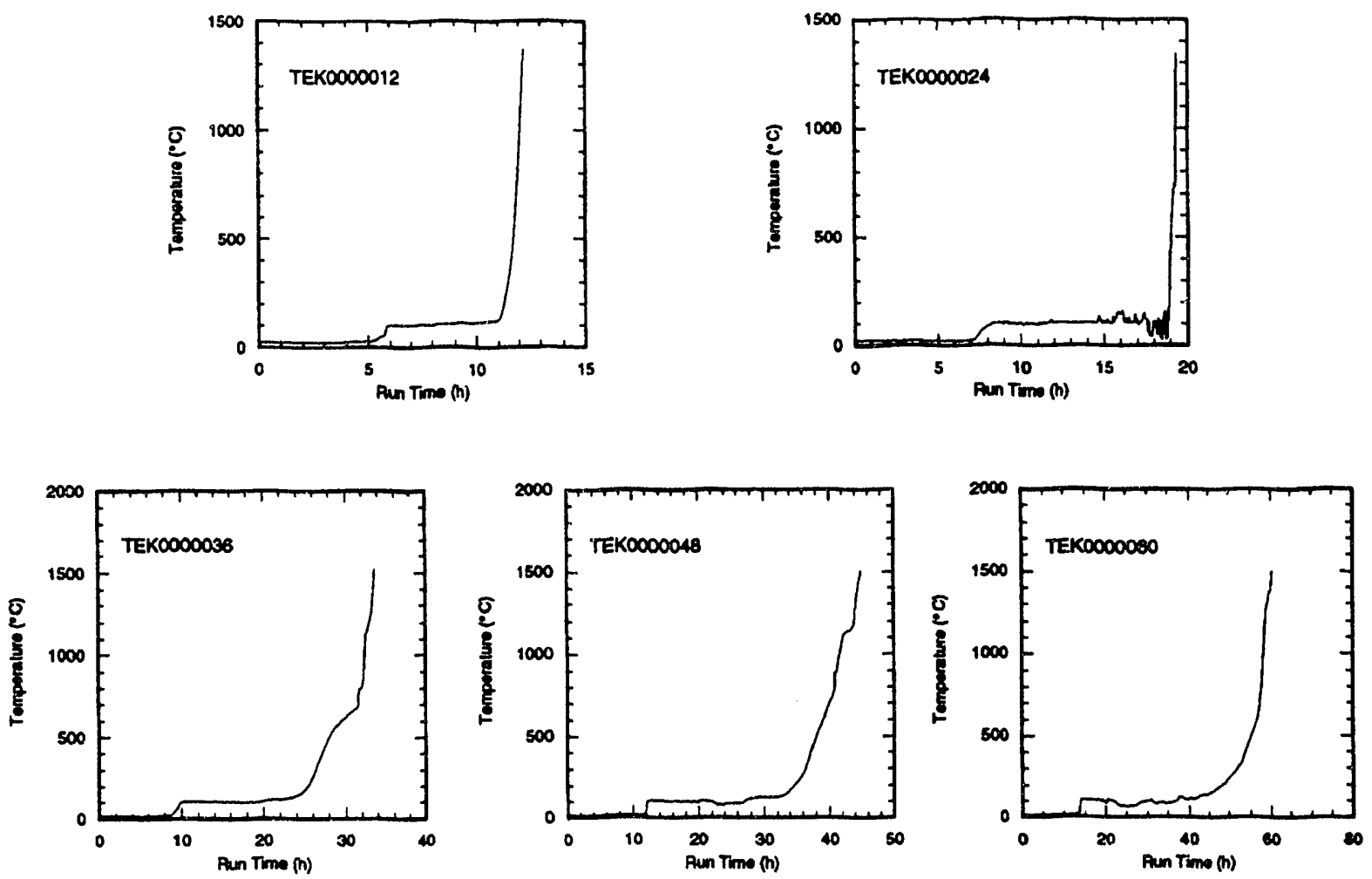

Fig. 29. Temperature as a function of run time for the vertical array of type-K thermocouples placed along the central axis of the melt volume through depth $=8.5 \mathrm{ft}$. 

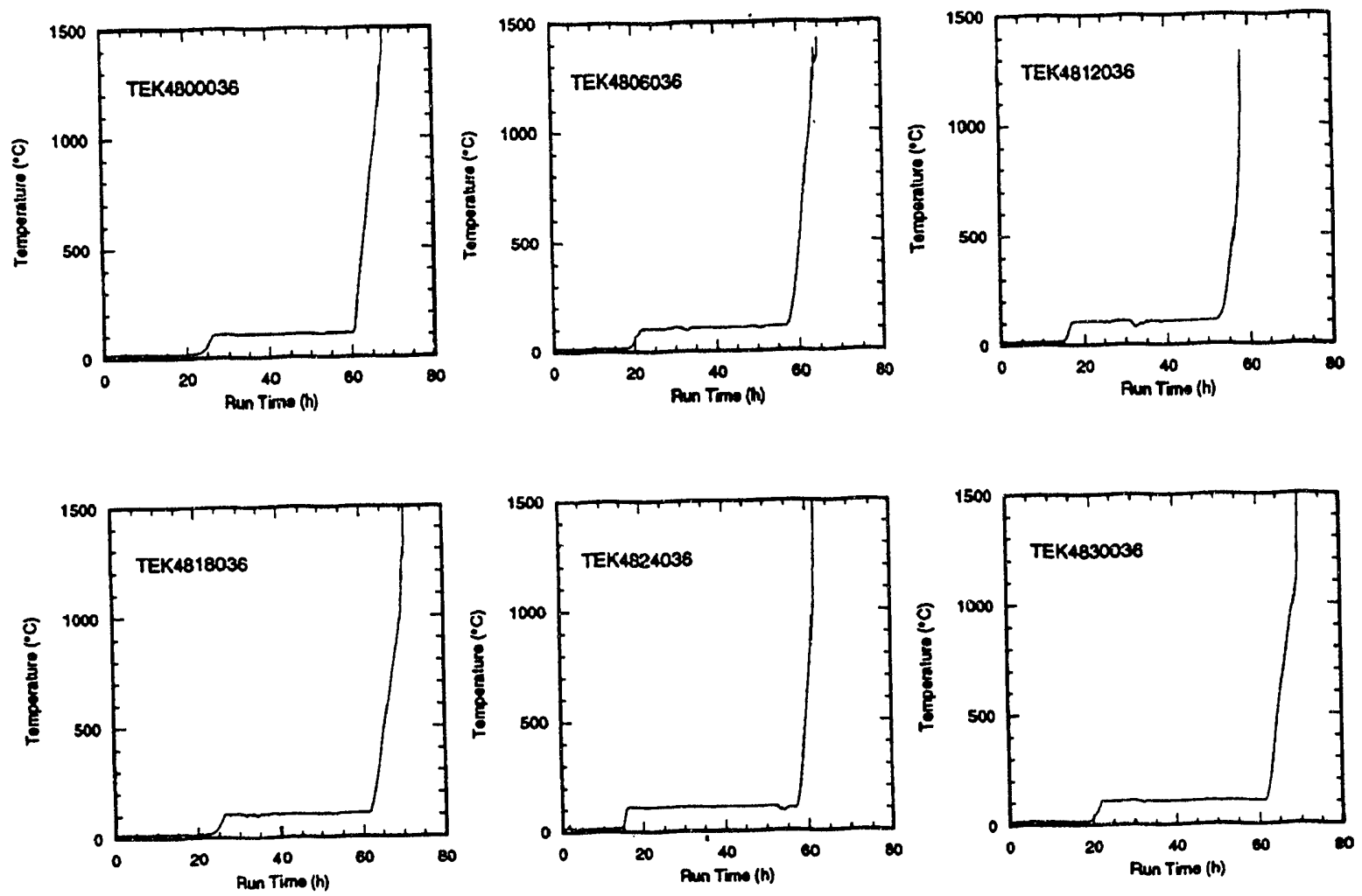

Fig. 30. Temperature history at a depth of $\sim 1 \mathrm{~m}$ (3.5 ft) for type-K thermocouples placed $\sim 1.2 \mathrm{~m}(4 \mathrm{ft})$ around the center of the melt. Six thermocouples were placed $60^{\circ}$ apart. 

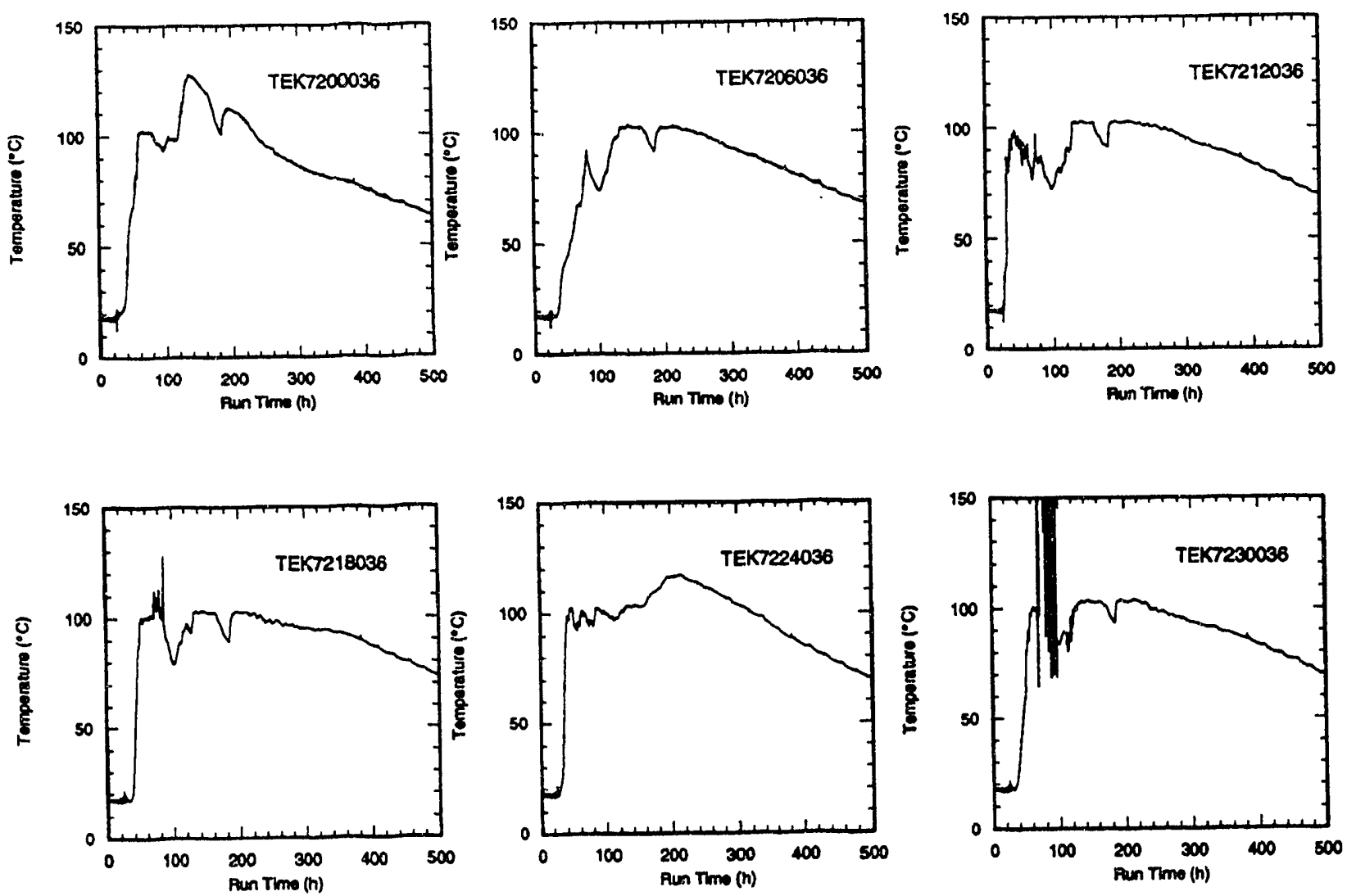

Fig. 31. Temperature history at a depth of $-1 \mathrm{~m}(3.5 \mathrm{ft})$ for type-K thermocouples placed

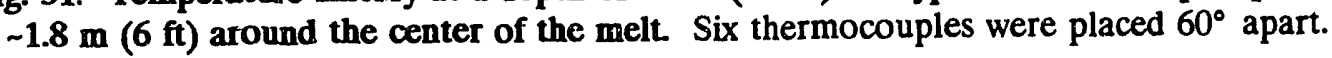



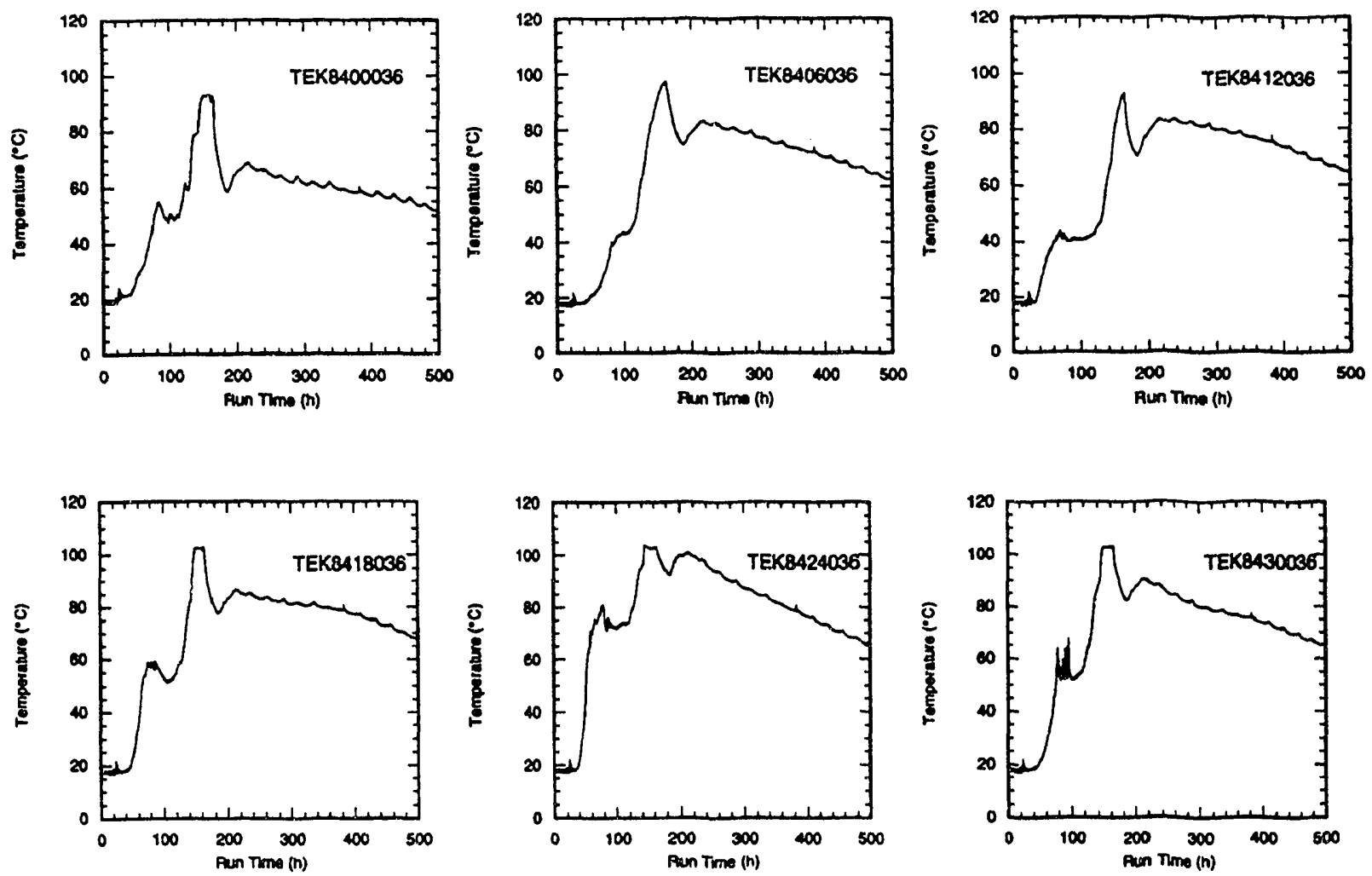

Fig. 32. Temperature history at a depth of $\sim 1 \mathrm{~m}(3.5 \mathrm{ft})$ for type-K thermocouples placed

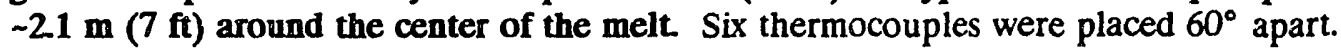



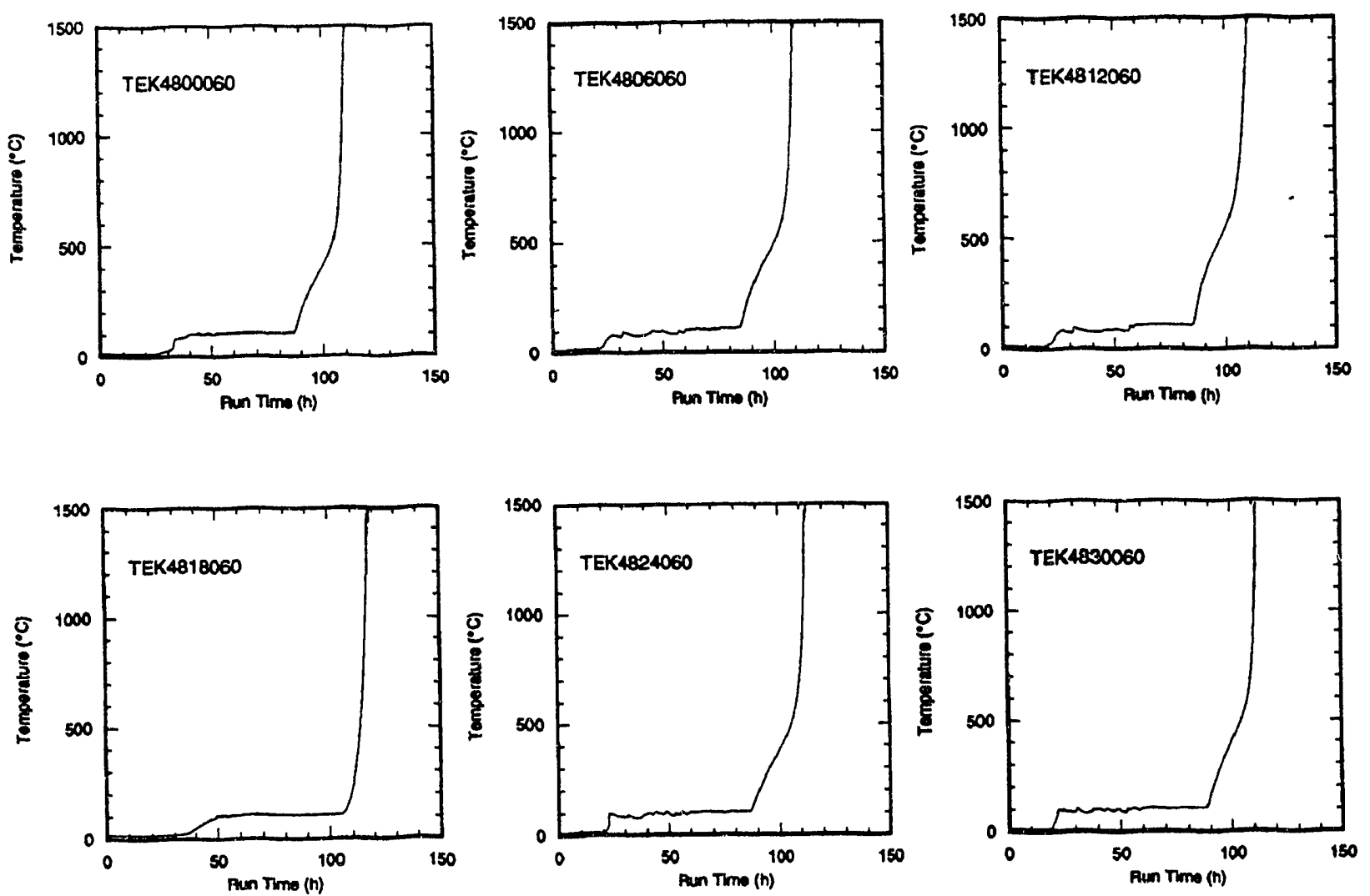

Fig. 33. Temperature history at a depth of $-2 \mathrm{~m}(6.5 \mathrm{ft})$ for type-K thermocouples placed

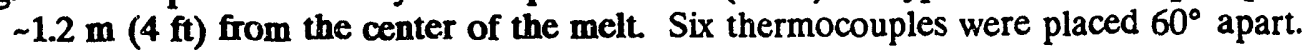



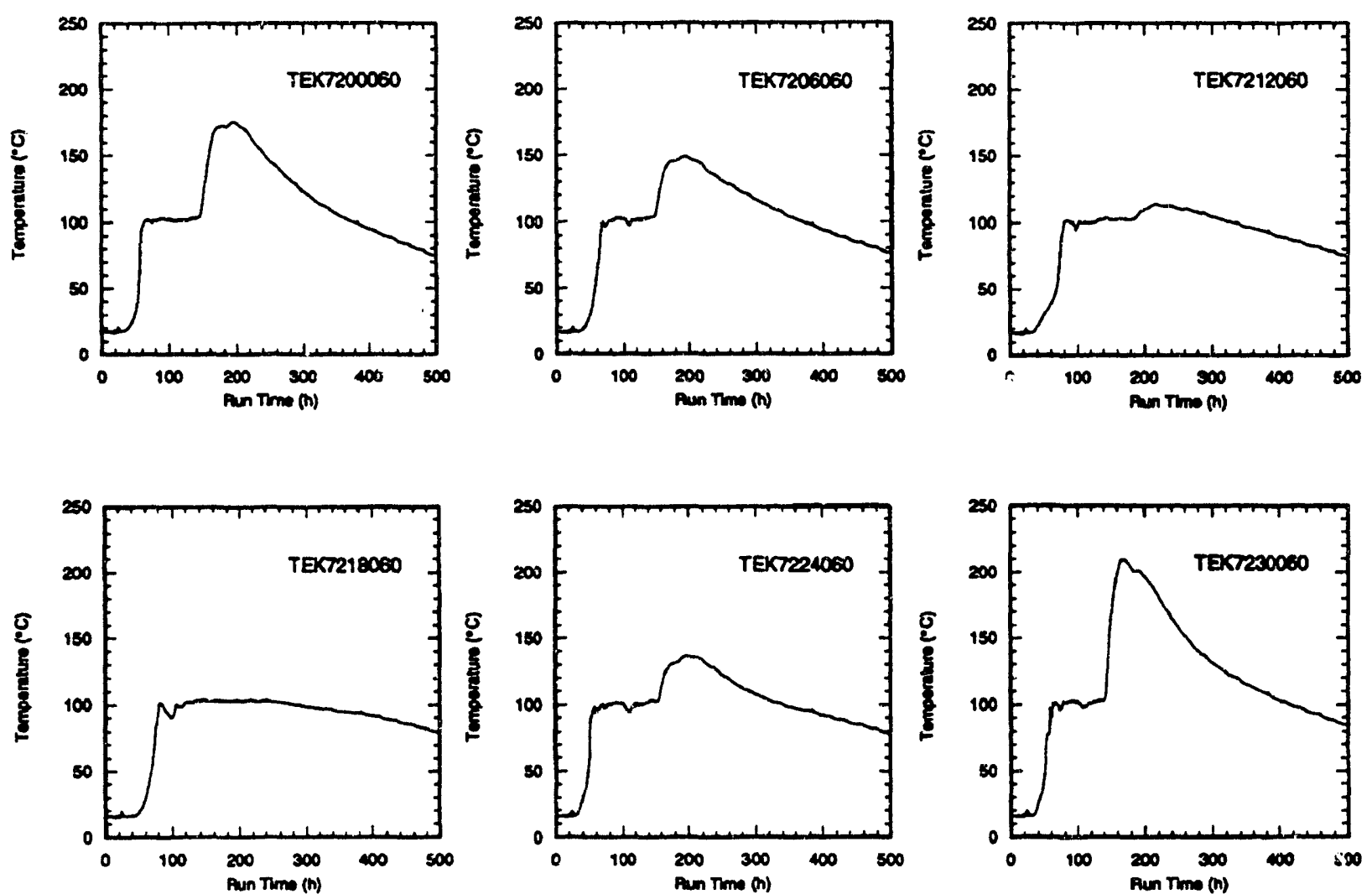

Fig. 34. Temperature history at a depth of $-2 \mathrm{~m}(6.5 \mathrm{ft})$ for type-K thermocouples placed $-1.8 \mathrm{~m}$ (6 ft) from the center of the melt. Six thermocouples were placed $60^{\circ}$ apart. 

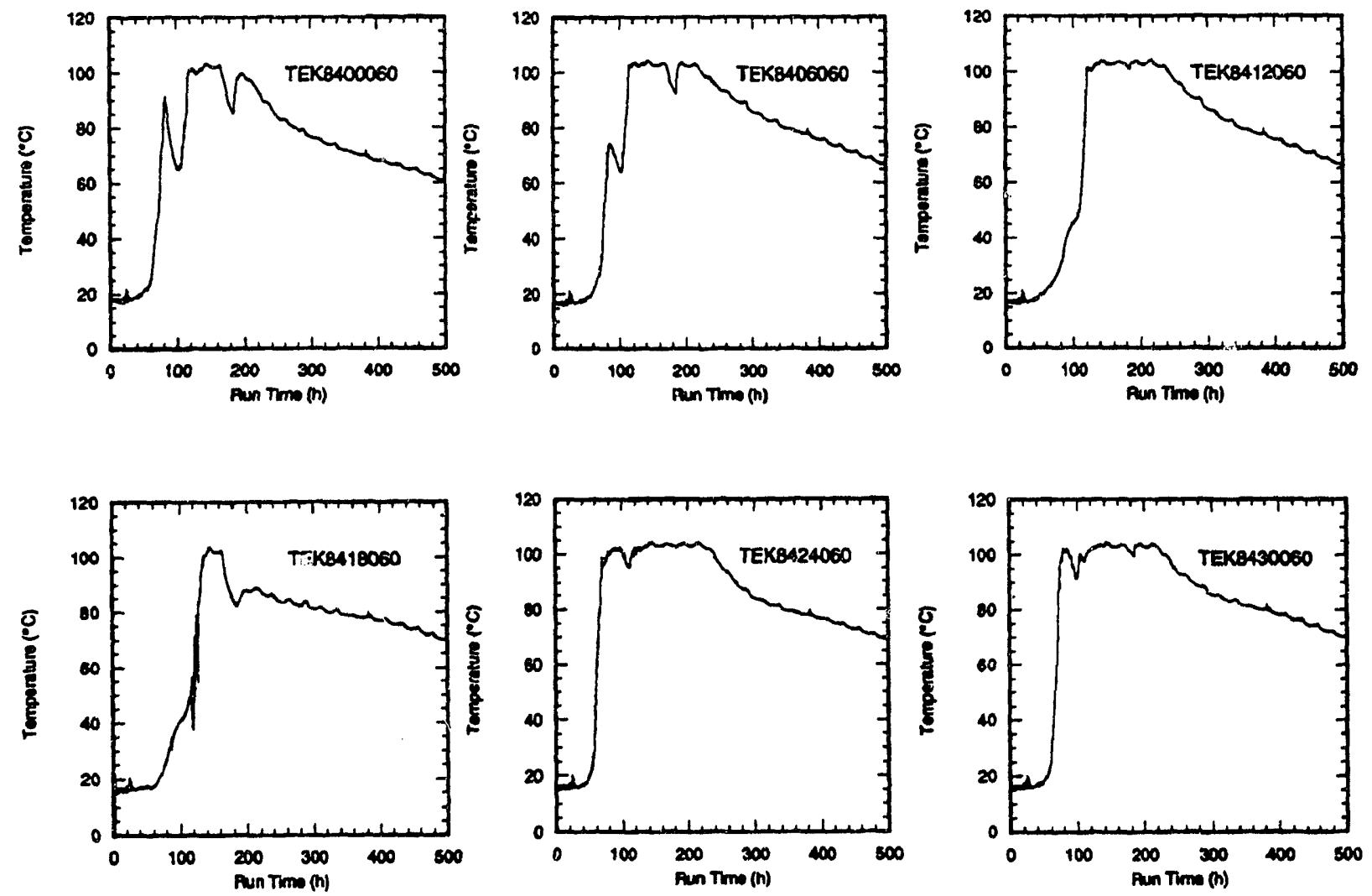

Fig. 35. Temperature history at a depth of $-2 \mathrm{~m}$ ( $6.5 \mathrm{ft}$ ) for type-K thermocouples placed $-2.1 \mathrm{~m}$ (7 ft) from the center of the melt. Six thermocouples were placed $60^{\circ}$ apart. 

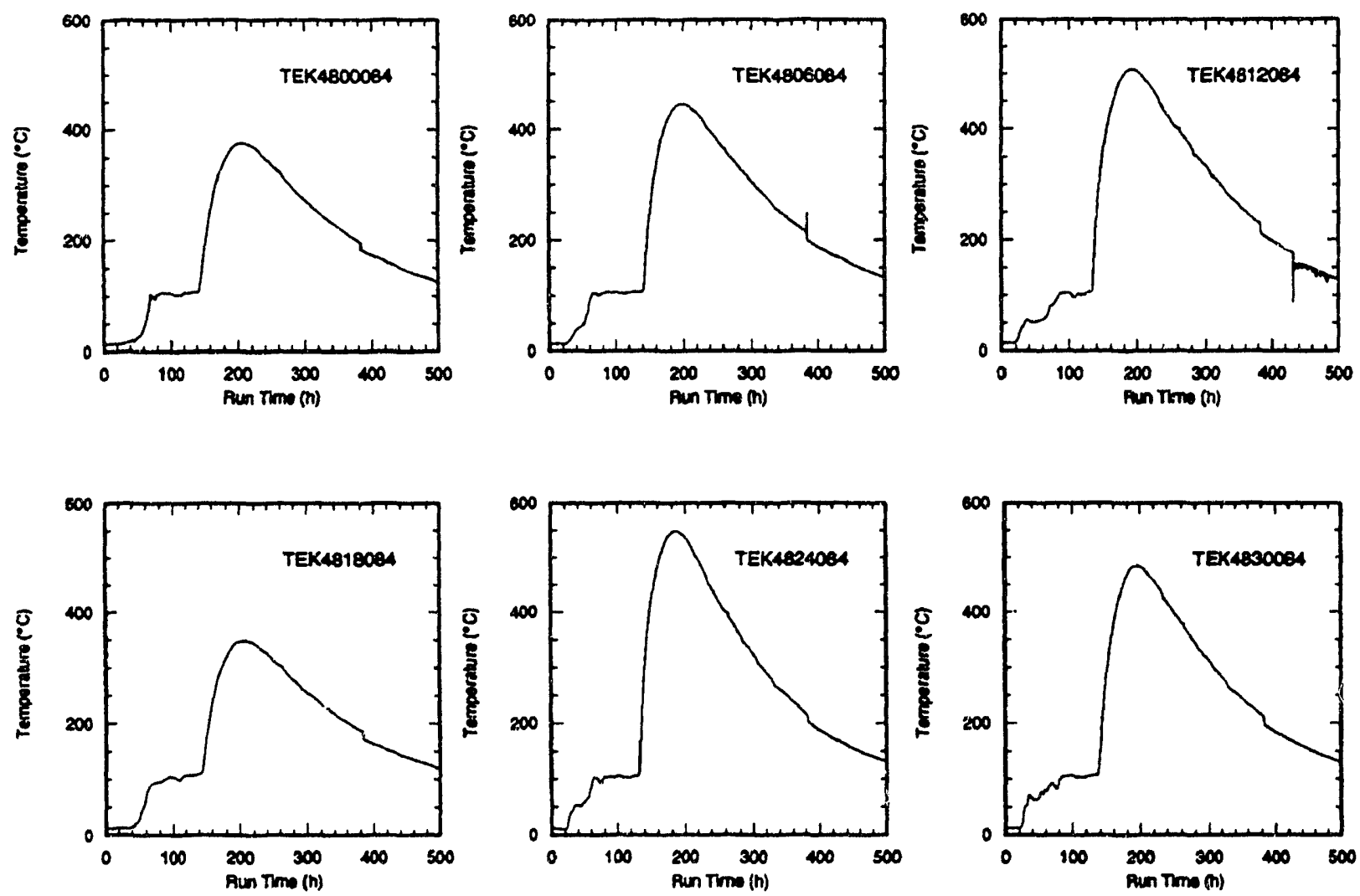

Fig. 36. Temperature history at a depth of $-2.3 \mathrm{~m}(7.5 \mathrm{ft})$ for type-K thermocouples placed $-1.2 \mathrm{~m}$ ( $4 \mathrm{ft}$ ) from the center of the melt. Six thermocouples were placed $60^{\circ}$ apart. 

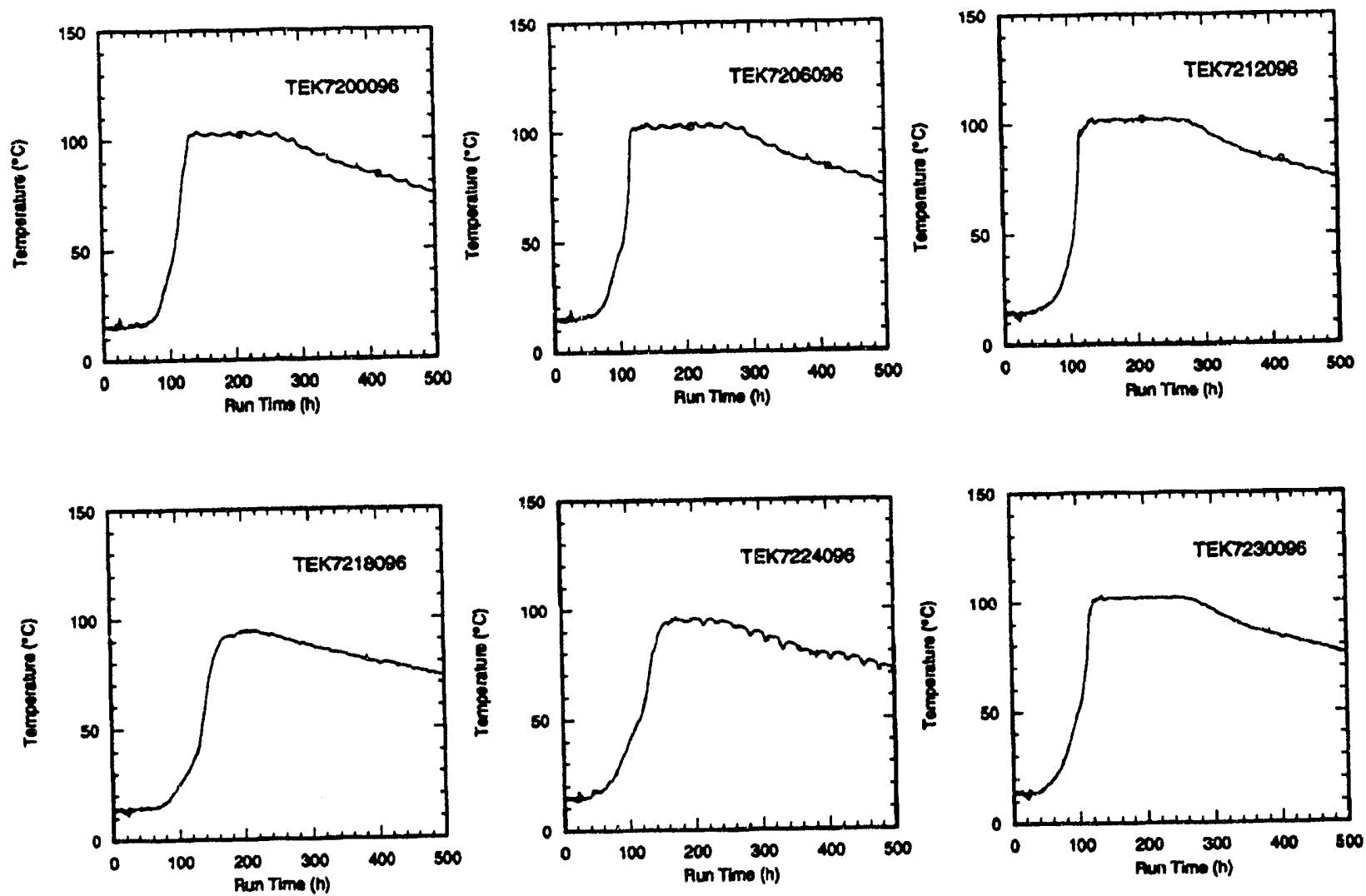

Fig. 37. Temperature history at a depth of $-2.6 \mathrm{~m}(8.5 \mathrm{ft})$ for type-K thermocouples placed $-1.8 \mathrm{~m}$ (6 ft) from the center of the melt. Six thermocouples were placed $60^{\circ}$ apart. 

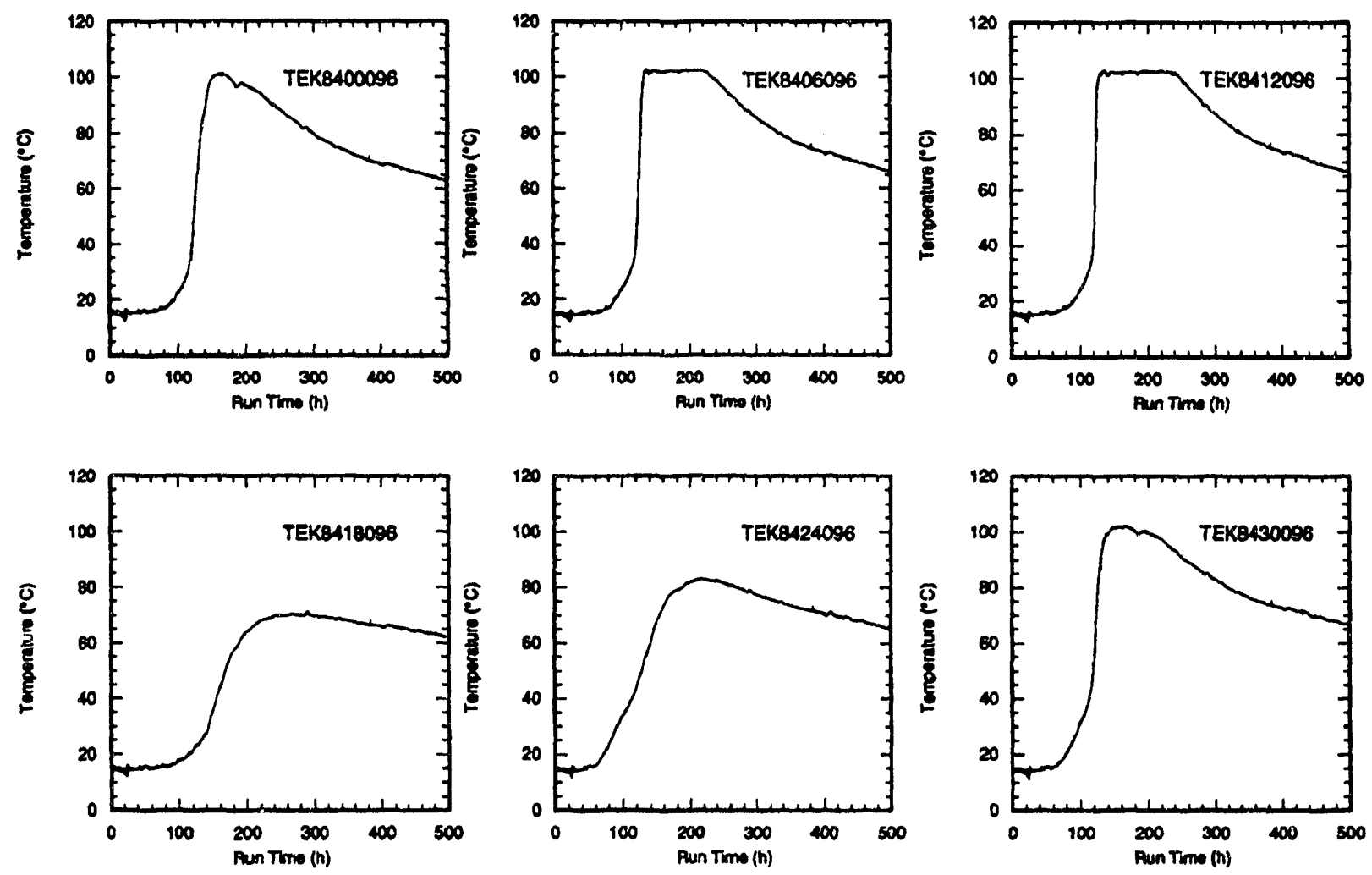

Fig. 38. Temperature history at a de th of $\sim 26 \mathrm{~m}(8.5 \mathrm{ft})$ for type-K thermocouples placed $\sim 2.1 \mathrm{~m}$ (7 ft) from the center of the melt. Six thermocouples were placed $60^{\circ}$ apart. 

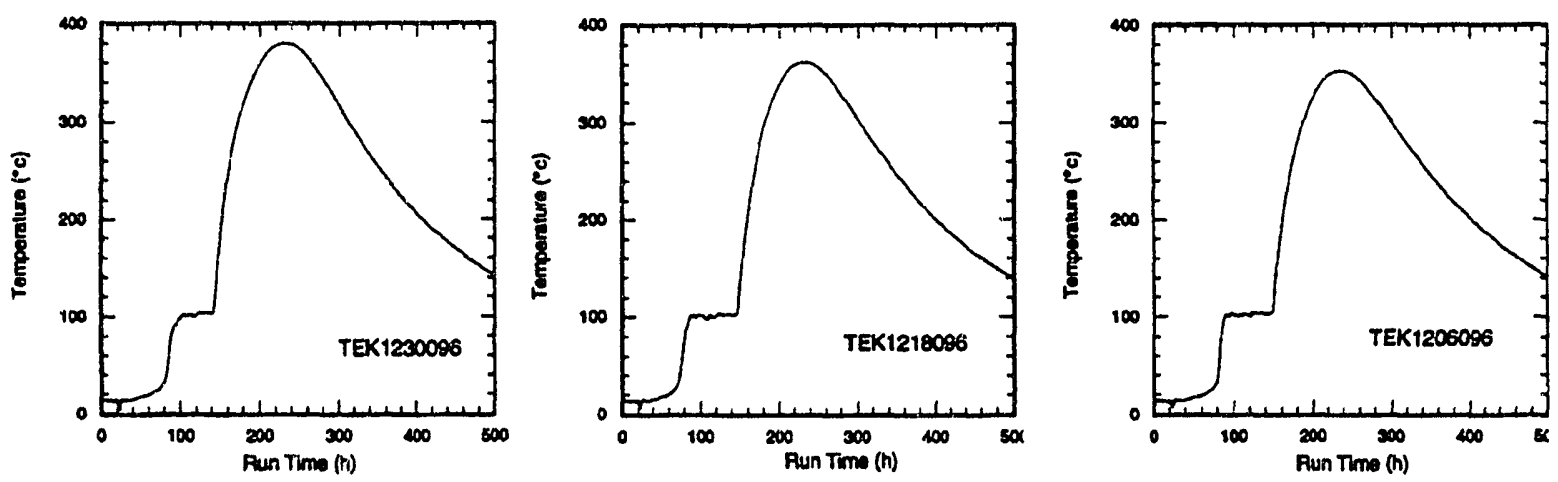

Fig. 39. Temperature history for three thermocouples at a depth of $-8.5 \mathrm{ft}(2.6 \mathrm{~m})$. Thermocouples were placed $60^{\circ}-1 \mathrm{ft}(0.3 \mathrm{~m})$ from the center of the melt. 

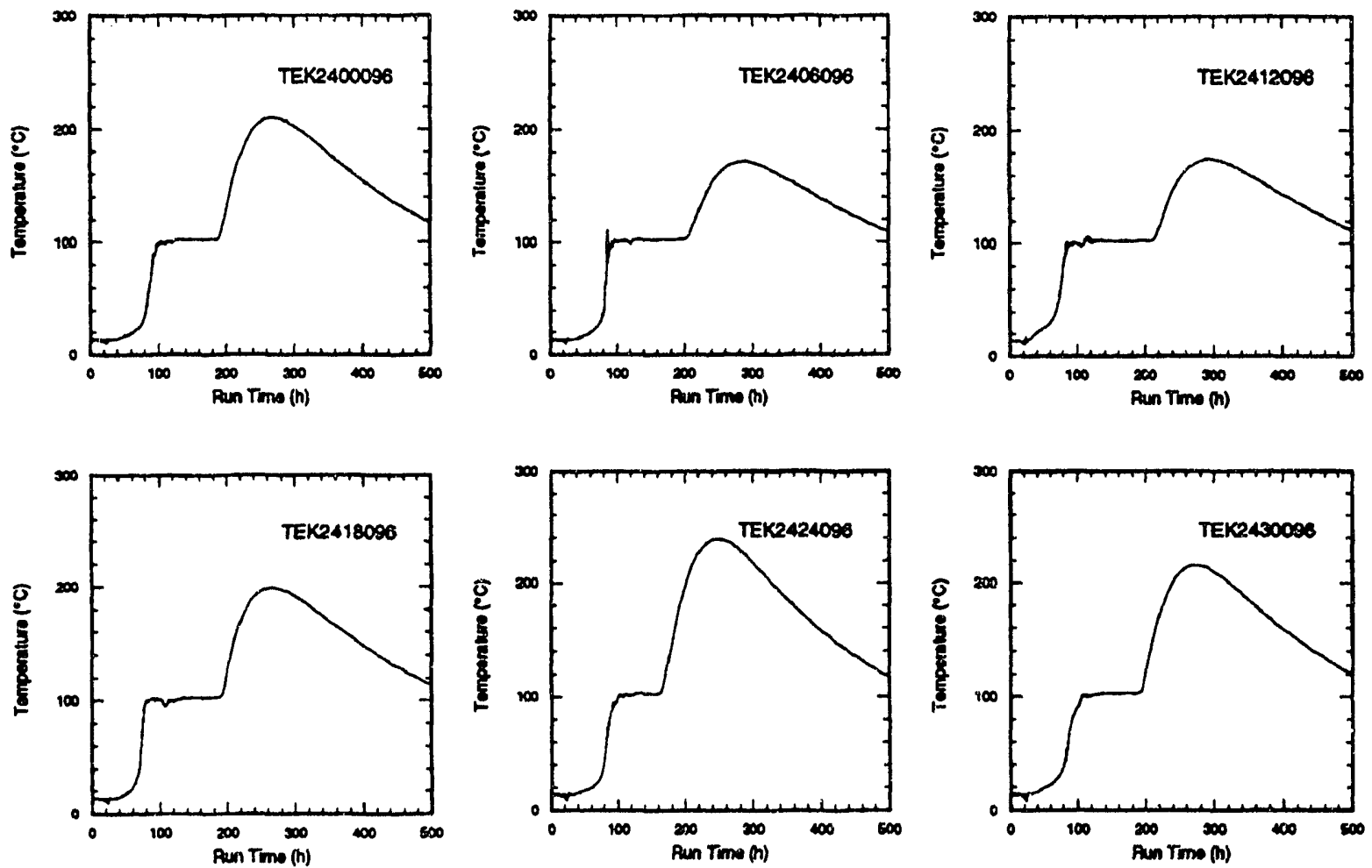

Fig. 40. Temperature history at a depth of $-2.6 \mathrm{~m}$ (8.5 ft) for type-K thermocouples placed $60^{\circ}$ apart $\sim 0.6 \mathrm{~m}(2 \mathrm{ft})$ around the center of the melt. 

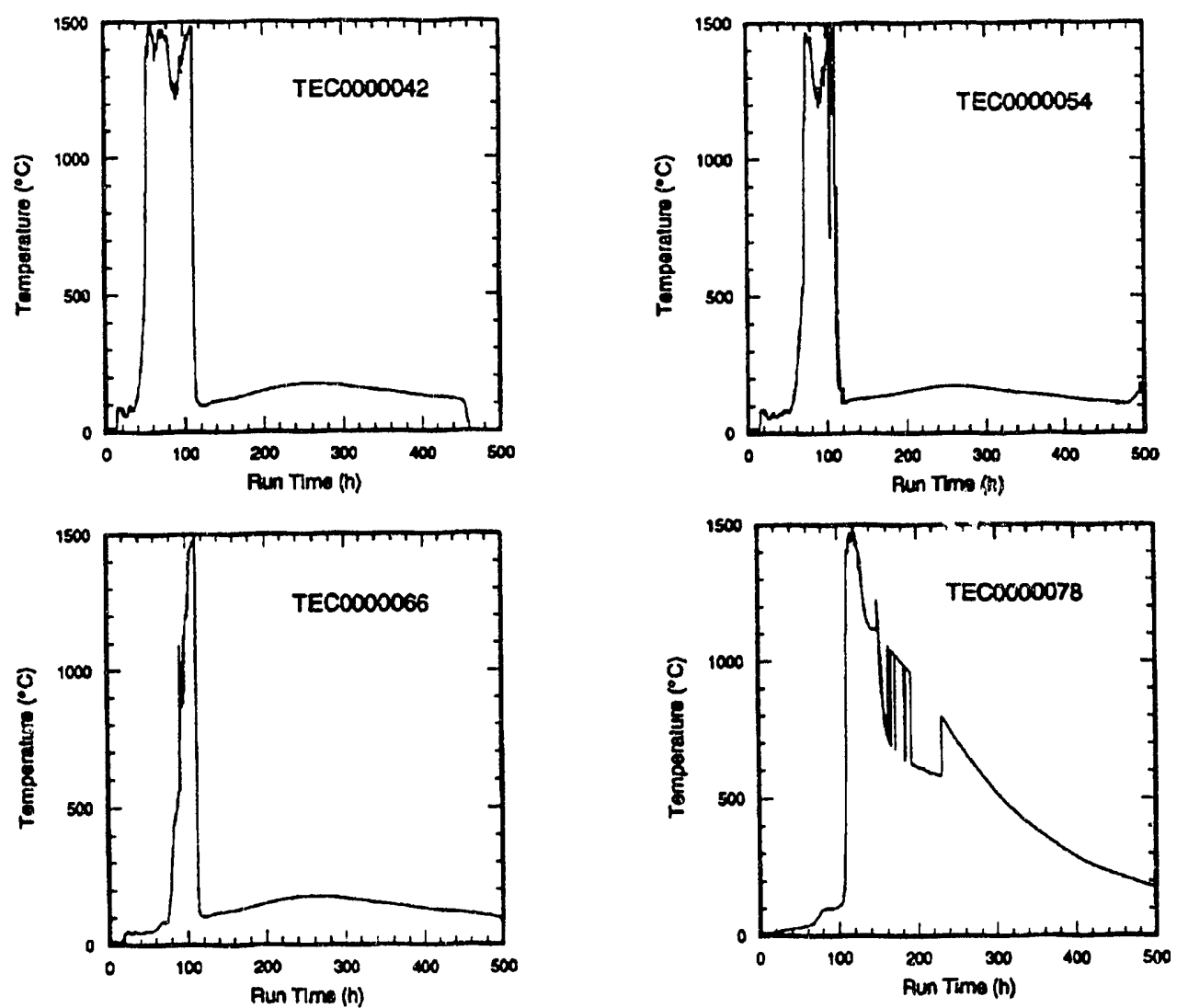

Fig. 41. Temperatures for type-C thermocouples in a vertical array down the central axis of the melt. 

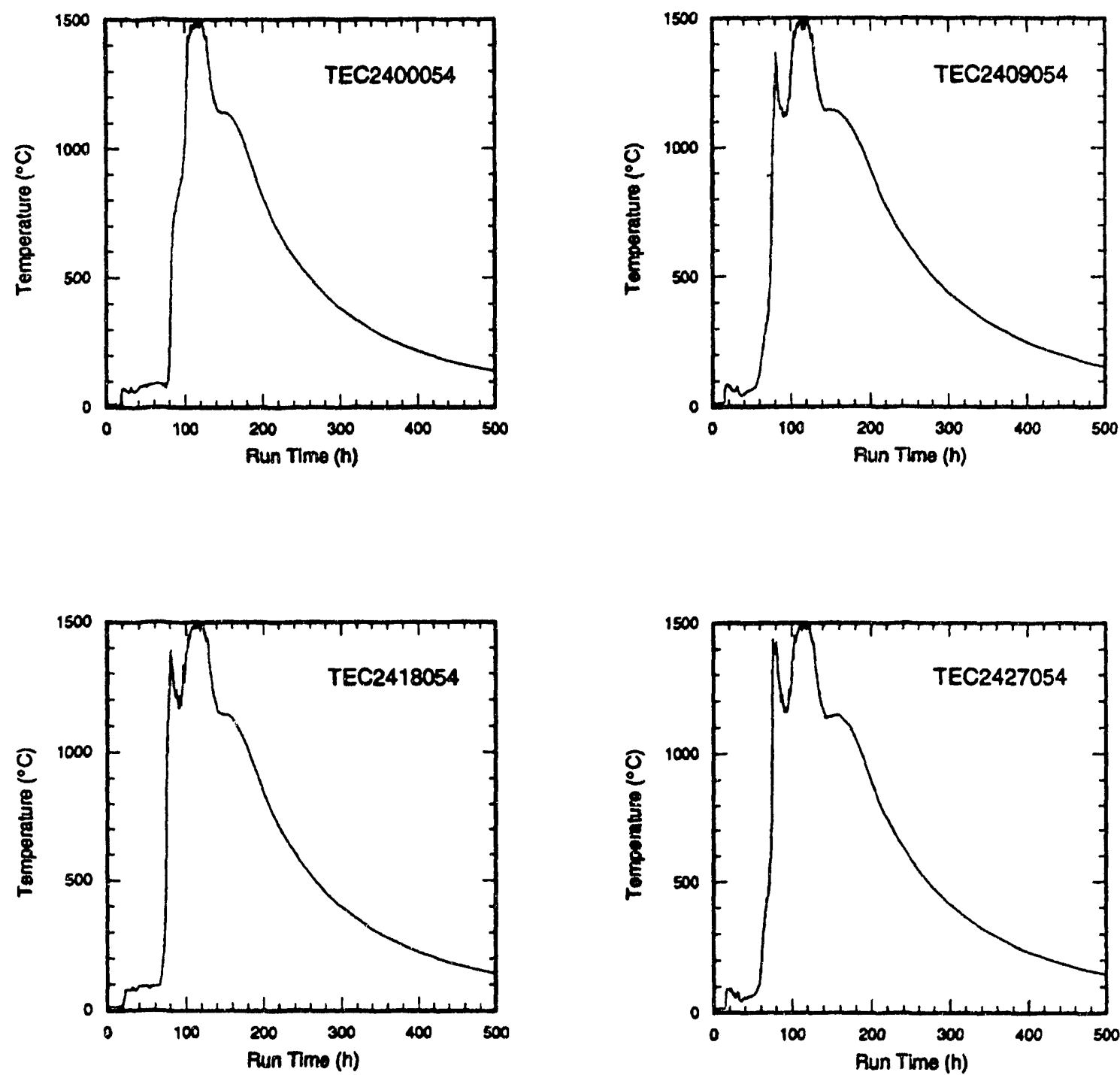

Fig. 42. Temperature history at a depth of $\sim 1.5 \mathrm{~m}(5 \mathrm{ft})$ for type-C thermocouples placed $-0.6 \mathrm{~m}(2 \mathrm{ft})$ around the center. The four sensors are $90^{\circ}$ apart $-0.6 \mathrm{~m}(2 \mathrm{ft})$ from the center. 

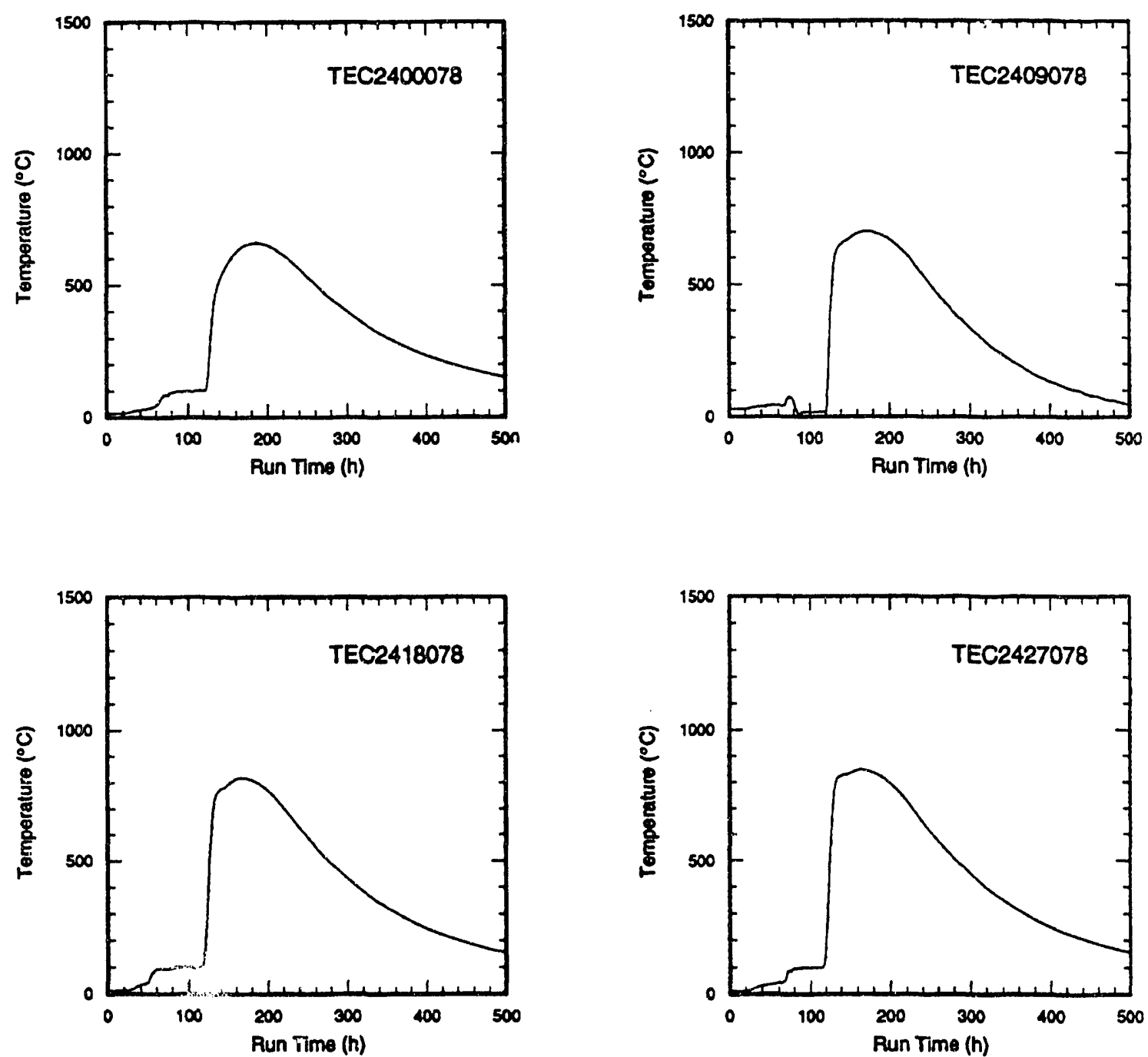

Fig. 43. Temperature history at a depth of $-2.1 \mathrm{~m}(7 \mathrm{ft})$ for type-C thermocouples placed $90^{\circ}$ apart $0.6 \mathrm{~m}(2 \mathrm{ft})$ around the center of the melt.

\section{Pyrometers}

Six small-spot optical pyrometer heads (model HF-4, focal length $=4 \mathrm{ft}$; model HF-4.5, focal length $=6 \mathrm{ft}$ ); air purge housings for the pyrometer heads (model 940-3825C); photodetector/signal conditioning (model $100 \mathrm{C}$, two channels of two color input - 800 and $950 \mathrm{~nm}$; four channels of single color input - $950 \mathrm{~nm}$ ); and optical fiber interconnecting cables supplied by Accufiber, Inc., Beaverton, Oregon, were used in conjunction with water-cooling jackets and sight tubes/targets custom designed by ORNL to measure temperature within the projected zone of melting. These measurements were in addition to those obtained from type-C and type-S thermocouples. The measuring range of the system is 500 to $3000^{\circ} \mathrm{C}$. Temperature measuring instruments based on fiber optics were used because 

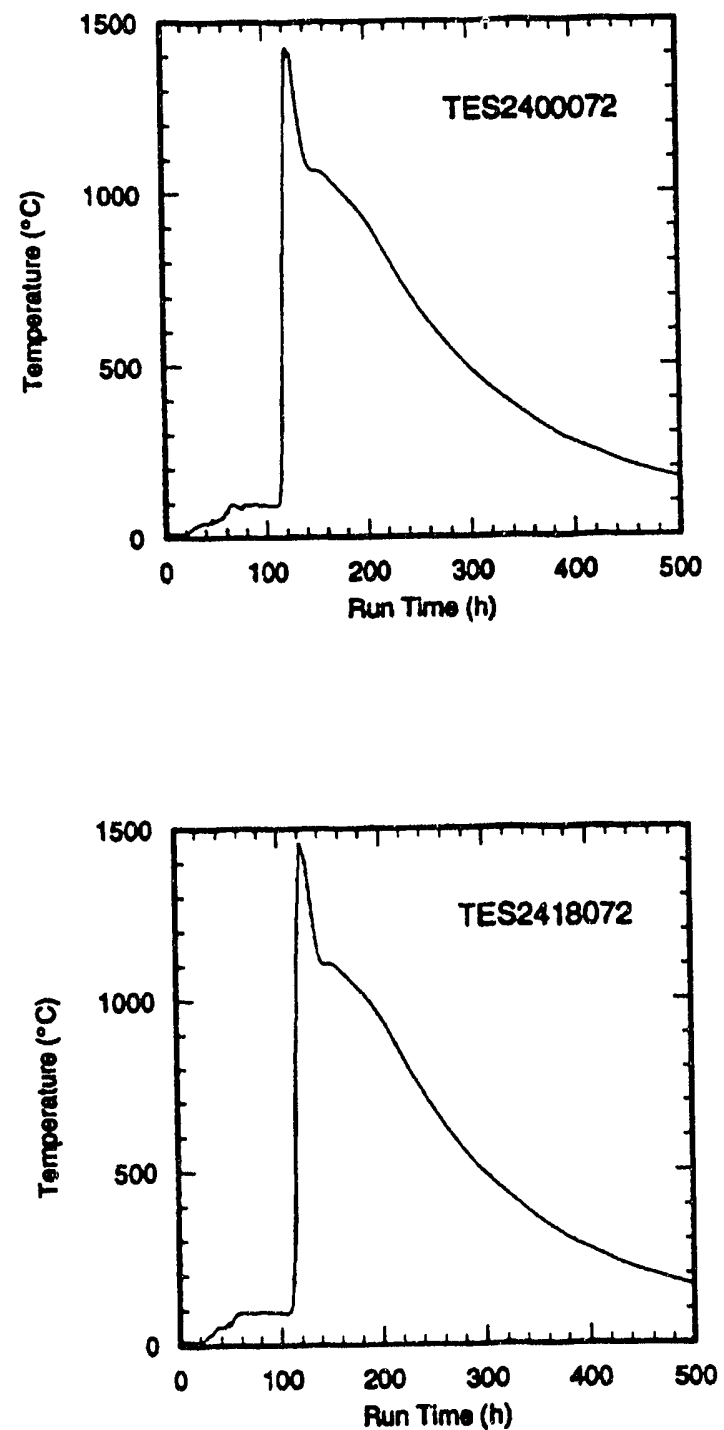

Fig. 44. Temperature history for type-S thermocouples at a depth of $\sim 2 \mathrm{~m}(6.5 \mathrm{ft})$. The two sensors are $180^{\circ}$ apart $0.6 \mathrm{~m}(2 \mathrm{ft})$ from the center of the melt.

(1) the pretest uncertainty of the survivability of thermocouples, (2) anticipated resolution $\left(0.1^{\circ} \mathrm{C}\right)$ and accuracy $\left(0.2 \% @ 1000^{\circ} \mathrm{C}\right)$ of temperature measurements made using the fiber-optic instruments, and (3) inherent immunity of fiber-optic instruments to radio frequency and/or electromagnetic noise produced by industrial power sources. The Accufiber pyrometer heads were placed inside air-purged housings and these assemblies were placed inside a stainless steel water jacket housing coupled to a graphite sight tube and target via a thermal and electrical insulating coupling (Fig. 45). The water jackets were used to insure the integrity of the optical pyrometer heads and optical cable connection which have an operating temperature limit of $65^{\circ} \mathrm{C}$ when in continuous use (Fig. 46). Water jackets were assembled from custom-fabricated components and, when possible, standard stainless steel pipe fittings. All connecting threads were standard pipe threads. Pipe thread fasteners were selected for reasons of economy and the inherent sealing capability of tapered thread designs. Commercially 


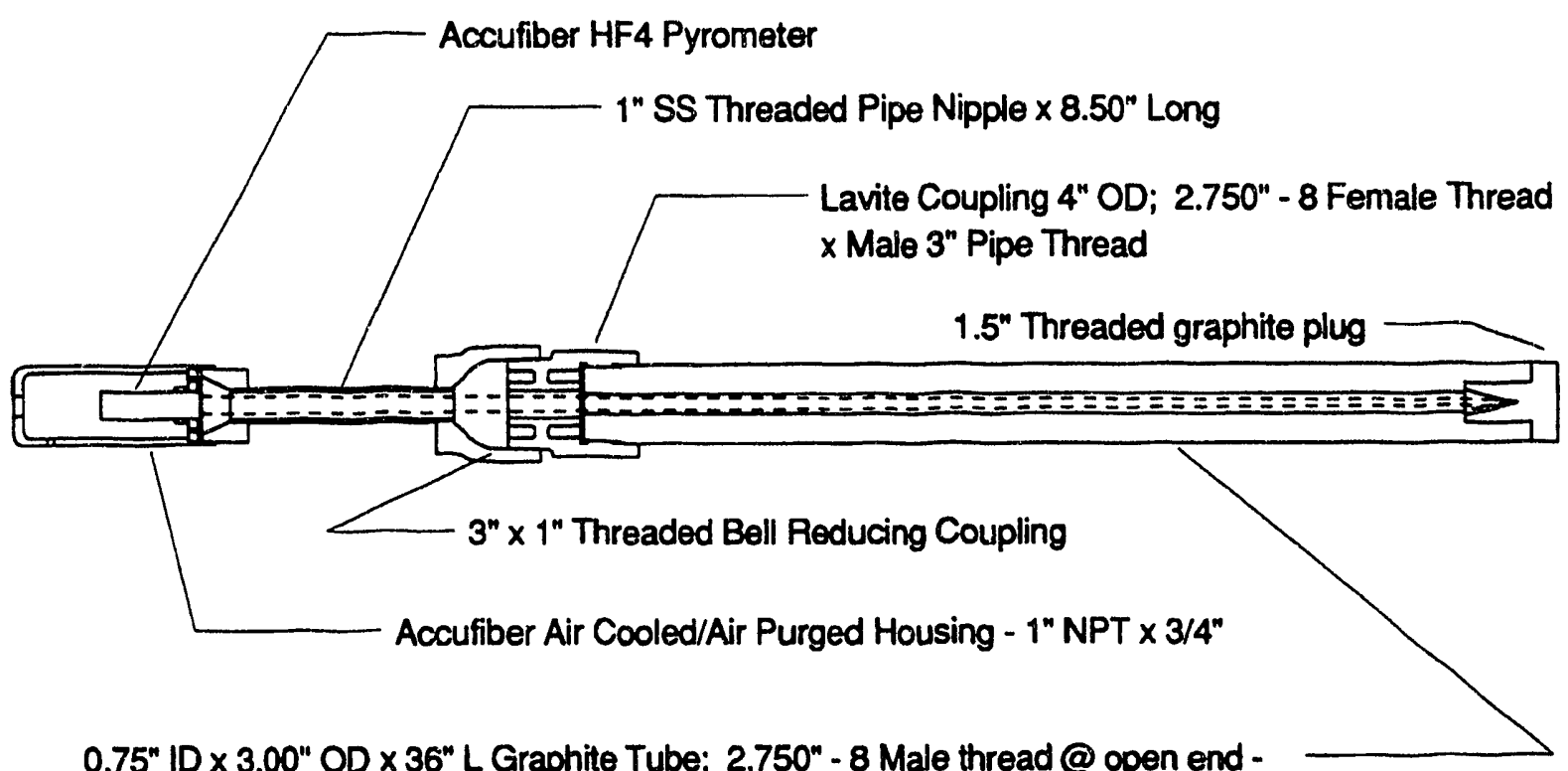

$1.5^{n}$ - 8 NC machine threaded plug @ closed end

Fig. 45. Schematic illustration of blackbody well/protection tube for Accufiber HF 4 pyrometer (without water jacket).

available pyrophyllite (trade name - Lavite) was used to fabricate a coupling to join the water jackets to the sight tubes which provided both thermal and electrical insulation. Lavite was chosen because it provided adequate thermal stability $\left(1200^{\circ} \mathrm{C}\right)$ and, as supplied by the vendor, is machinatsle with standard tooling. When fired, the material irreversibly expands by approximately $2 \%$ to a hard ceramic. Sight tubes of appropriate length were fabricated from commercially available "fluxing tubes" having nominal dimensions of 3 in. O. D. $\times 0.75$ in. I.D. which were supplied by the Carbon/Graphite Group, Inc., St. Marys, Pennsylvania. A target for the pyrometers was fabricated from block graphite obtained at ORNL as a plug that was threaded into the open end of the sight tube. The plug design incorporated a conical cavity to serve as a blackbody radiator. Grafoil washer rings were used in conjunction with the threaded plugs to seal the high-temperature end of the sight tubes.

The Accufiber instrument parameters were stored in LabView files and downloaded to the model $100 \mathrm{C}$ during application startup. Temperatures measured by the Accufiber system were transmitted to the data acquisition system via an RS-232C interface. Temperatures measured by the Accufiber instruments were generally lower than those measured by type-C and type-S thermocouples. The observed offsets can be explained if the sight tubes/targets moved either subsequent to installation, because of soil compaction and settling, or in response to hydrodynamic forces exerted by the motion of the silicate melt. In either case, movement of the sight tube relative to the optical pyrometer heads would result in misalignment. If the sight tube were misaligned, the focal spot of a pyrometer head would be displaced to an elliptical area on the side wall of the sight tube at a position toward the pyrometer head. It is anticipated that the temperature of these sections of the sight tube would be lower than the plugged end of the tube. Misalignment in the present test was the result of nonconcentricity of one or more of the tapered pipe thread joints. The nonconcentricity required that some graphite-to-lavite joints be loosened during installation to achieve optical 


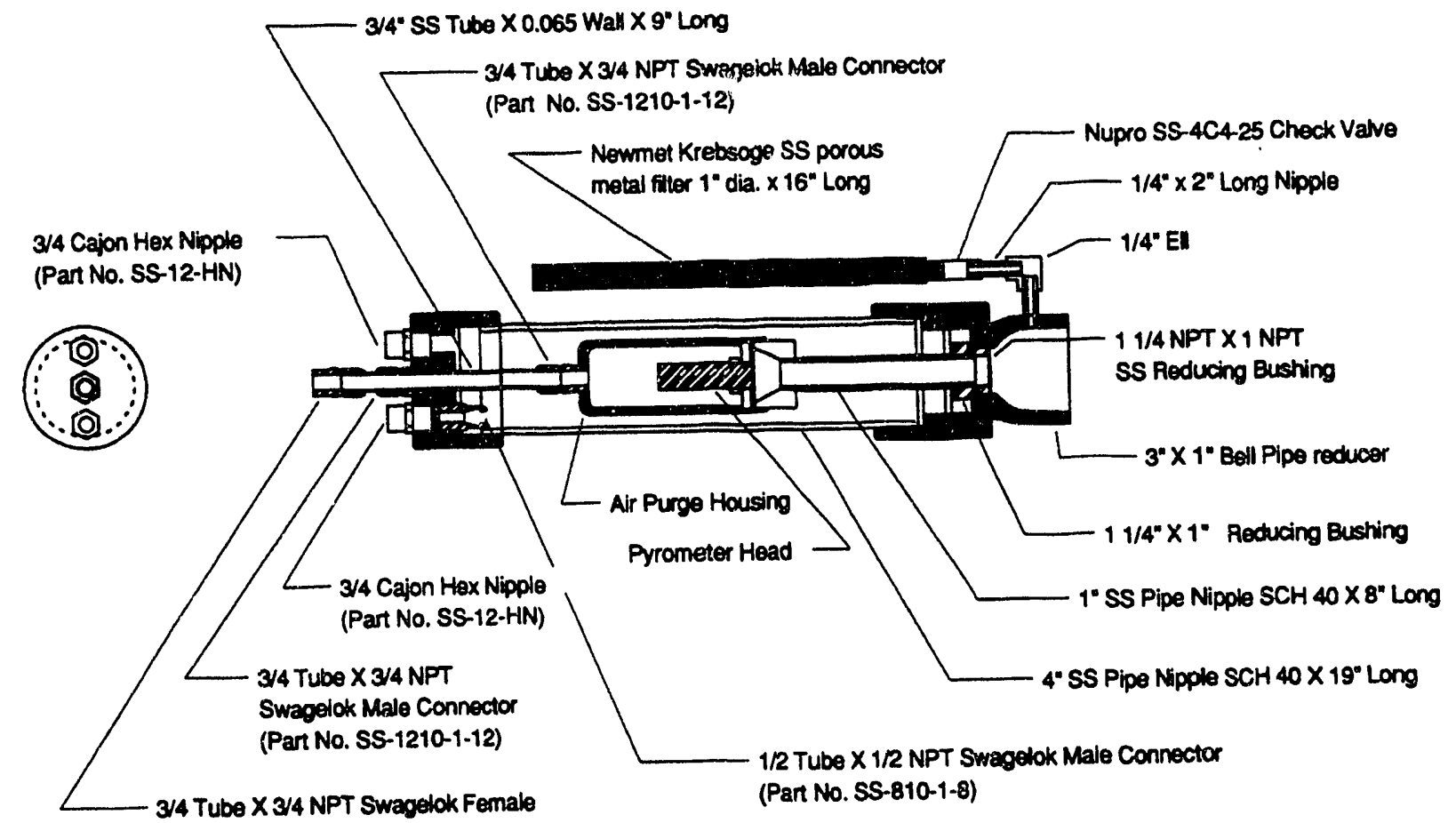

3/4 Tube X 3/4 NPT Swagelok Femalo

Note-Drawing shows male connector

Fig. 46. Schematic illustration of water jacket assembly for optical pyrometers.

alignment. A plot of the data set for pyrometer TEP3609072 is presented in Fig. 47. The temperature profile of this sensor is similar in shape to those recorded by thermocouples and is the only pyrometer data set to clearly record the thermal arrest during cooling. Future application of this type of optical pyrometer would require either redesign of the water jacket/sight tubes to incorporate machine threads and additional seals or care in fabrication or modification of tapered thread components to assure optical alignment of the sealed assemblies.

\section{PRESSURE}

Pressure transducers were placed at three depths $(24,72$, and 96 in.) along the central thermocouple array in the zone targeted for melting to provide measurements of soil gas pressure during heating. Two additional pressure transducers were placed at depths of 24 and 96 in. in soil at a distance of approximately $55 \mathrm{ft}$ from the targeted melting zone to provide reference measurements of "ambient" soil gas pressure. Transducers with a measuring range of $0-25$ psia were supplied by Omega Engineering, Inc., Stamford, Connecticut (model PX176-025A5V). The excitation voltage for ihese transducers is $9-20 \mathrm{VDC}$ at $15 \mathrm{~mA}$, and the output is $1-6 \mathrm{VDC}$. The manufacturers performance specifications are accuracy $\pm 1.0 \%$ full scale; linearity $\pm 0.5 \%$ full scale; hysteresis $\pm 0.25 \%$ full scale; zero balance $\pm 1.0 \%$ full scale; operable temperature range -55 to $105^{\circ} \mathrm{C}$; compensated temperature range 0 to $85^{\circ} \mathrm{C}$; thermal zero effect $\pm 0.02 \%$ reading $/{ }^{\circ} \mathrm{C}$, and thermal sensitivity effect $\pm 0.02 \%$ reading $/{ }^{\circ} \mathrm{C}$ within compensated temperature range (thermal zero and thermal sensitivity effects at $100^{\circ} \mathrm{C}$ are estimated to be two times these manufacturer's specifications). The output signal of each 


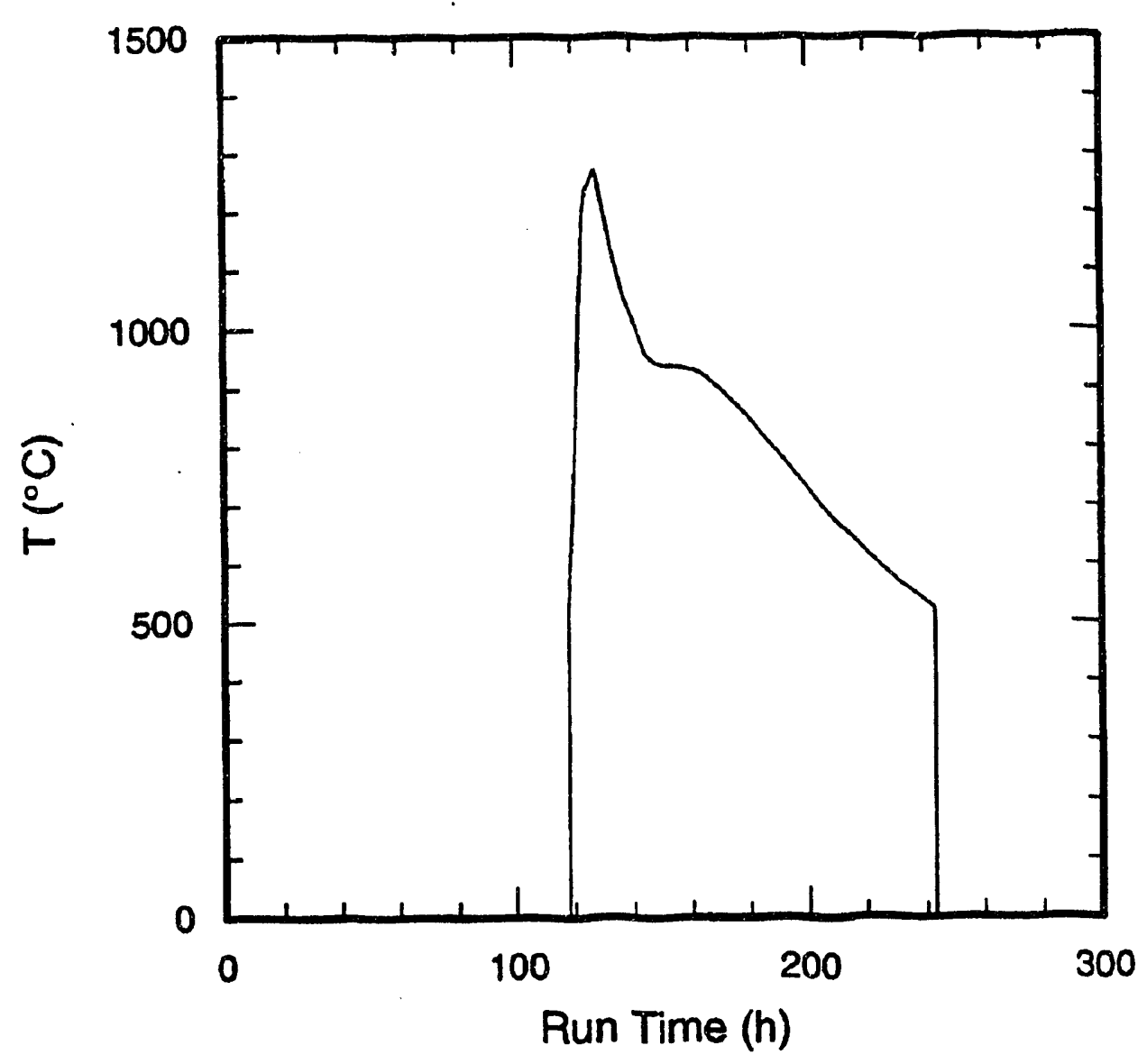

Fig. 47. Temperature as a function of run time for pyrometer TEP3609072. The optical pyrometer functions only at temperatures greater than $500^{\circ} \mathrm{C}$.

transducer was electrically isolated from the data acquisition system by transmitters (model 11JT-04-K; 1-6 VDC output, for 1-6 VDC input) supplied by M-System Technology, Inc., Dallas, Texas.

The input orifice of each pressure transducer was fitted with a group of porous 316 stainless steel tubes that were connected by fittings in the shape of a trident. The porous tubes served to increase the volume of soil monitored by each transducer and decrease the possibility of transducer plugging by wet soil. These arrays of porous tubes connected to pressure transducers were buried during construction of the simulated trench in an orientation that placed the plane formed by porous tubes of the trident, parallel to the ground surface. The porous stainless steel tubes, supplied by Newmet Krebsoge, Terryville, Connecticut, were 0.5 in. O.D. and 3, 6, or 12 in. long with a pore size of $3 \mu \mathrm{m}$.

The output of each pressure transducer was recorded sequentially at approximately 4-min intervals during the test. Data are considered to be valid for run times up to $20 \mathrm{~h}$ into the test. At approximately that point electrical problems developed that required rewiring of several transducers and shutdown of the reference transducers. The response of the pressure transducer placed at a depth of $24 \mathrm{in.}$ in the target zone (PTG0000024) provides the only record that is intuitively interpretable (Fig. 48). Pressure remained constant at a value of approximately 0.98 bars during the first $8 \mathrm{~h}$ of the test. Beginning at that point, the pressure rose to a maximum value of 1.05 bars in a period of $1 \mathrm{~h}$ 


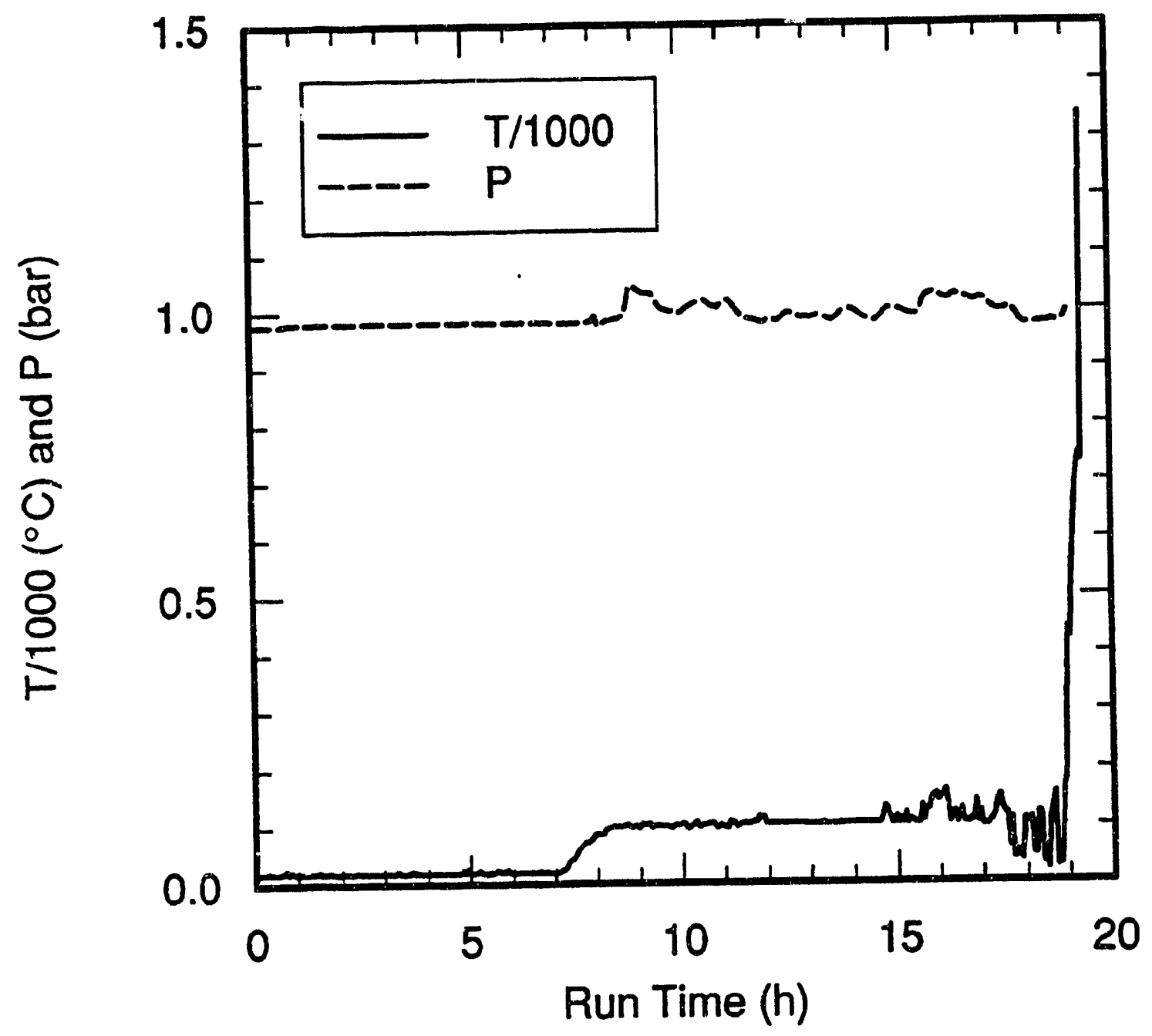

Fig. 48. Pressure as a function of run time for sensor PTG0000024.

and subsequently oscillated between 1.03 and 0.98 bars up to a run time of $19 \mathrm{~h}$, when the sensor became engulfed by the melt. The initial pressure rise can be correlated with the arrival of the $100^{\circ} \mathrm{C}$ isotherm as recorded by thermocouple TEK0000024 (Fig. 28). The recorded pressure oscillations are accompanied by temperature oscillations ranging from a few degrees up to $100^{\circ} \mathrm{C}$. These pressure and temperature oscillations are consistent with the placement of both the pressure transducer and thermocouple at the horizon marking the interface between the top of the crushed limestone (simulated trench) and overlying soil. This zone should have retained porosity during heating because of the coarse size of the limestone fragments $(1-2 \mathrm{~cm}$ diam). Steam generated by heating the soil may have migrated through the porous crushed limestone in pulses that gave rise to both the recorded pressure and temperature oscillations. The maximum pressure variation, 0.07 bars, represents a change in pressure equivalent to that produced by a 28.6 -in.-high column of water. 


\section{OXYGEN FUGACITY}

Two eiectrochemical cells were assembled to measure oxygen fugacity of gases in equilibrium with the melt (Fig. 49). Sensor configuration was based on the design described by Williams and

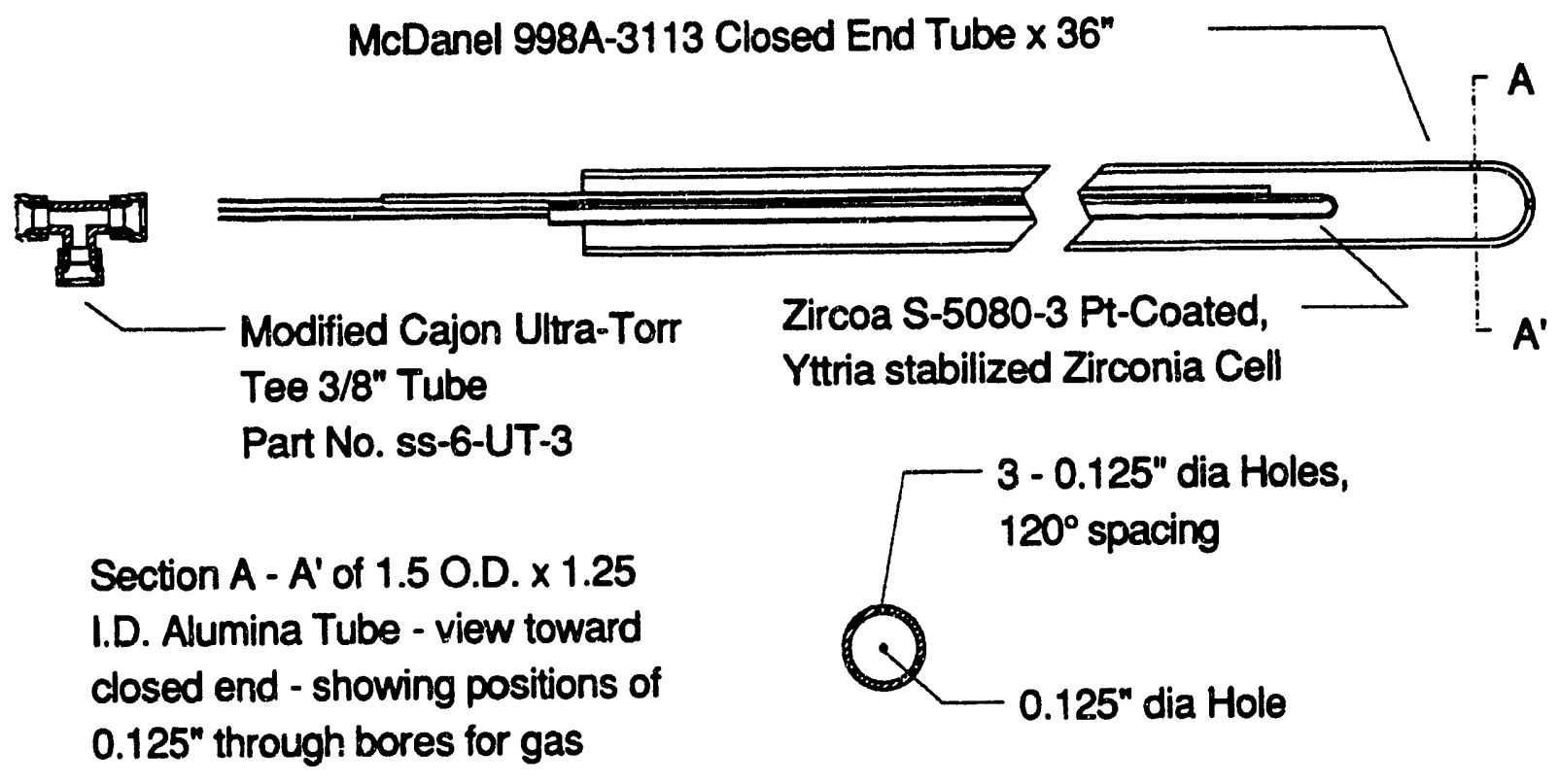

Fig. 49. Schematic illustration of oxygen fugacity sensor assembly.

Mullins (1981) that was developed to measure oxygen fugacity of mixed gas atmospheres in laboratory vertical tube furnaces. Yttria (Yttrium oxide)-stabilized (8\%), zirconia closed-on-one-end tubes forming the sensing element were obtained from Zircoa Corp., Solon, Ohio (S-5080-3 coated cell). Nominal tube dimensions were 0.375 in. O.D. $\times 0.312$ in. I.D. $\times 33.5$ in. long. The outside and inside of the closed end of the tube were supplied with platinized surfaces to facilitate good electrical contact of 0.017-in.-diam platinum-wire electrodes. The cell was equipped with a three-bore aluminum oxide insulator inserted into the bore of the closed-on-one-end zirconia tube to support and electrically insulate the internal platinum electrode and a type-S bare-wire thermocouple fabricated at ORNL from 0.020 -in.-diam matched platinum and platinum-10\% rhodium thermocouple wire pairs. The external platini'm electrode was insulated and supported by a 0.125 -in.-diam single-hore aluminum oxide insulator. The open end of the cell was fitted with Cajon stainless steel tube fittings modified after the design of Williams and Mullins (1981).

These fittings permitted introduction of dry air as a reference atmosphere to the interior of the cell during operation. An apparent critical flaw in adapting the design of Williams and Mullins (1981), which was developed for laboratory use, was the omission of a tube to carry the reference gas back to ground surface. Without this return tube it is believed that the air reference gas back pressure was sufficient to force air into the cavity of the modified design that was provided to sample gases in equilibrium with the silicate melt. Therefore, in operation the cell may have operated with an air atmosphere at both the anode and cathode of the electrochemical cell. 
The electrochemical cells were isolated from the melt by a modified, heavy-wall, closed-onone-end alumina tube. The closed end of the alumina tube was penetrated by four 0.125 -in.-diam holes to provide a gas pathway, while at the same time restricting melt access to the zirconia sensor. Tubes (1.500 in. OD $\times 1.250$ in. ID $\times 36$ in. long) were supplied by McDanel Refractory Company (998A CF 90 044501R0) with three holes bored through the wall of the tube adjacent to the closed end and one hole parallel to the tube axis through the closed end of the tube. The annular space between the alumina protection tube and the zirconia sensor tube was filled with aerospheres (hollow, 40 vol\% zirconia- 60 vol\% alumina insulating spheres) supplied for experimental purposes by Professor J. K. Cochran, Jr., School of Materials Engineering, Georgia Institute of Technology. The aerospheres were used to (1) support and minimize movement of the zirconia sensor tube within the protection tube, (2) minimize access of silicate melt to the zirconia sensor tube, and (3) provide a refractory material chemically compatible with both alumina and zirconia. Stabilized zirconia has been used to measure oxygen fugacity in silicate melts. However, sensors are only expected to survive for periods on the order of seconds when immersed in silicate melts, and therefore sensors intended for in situ melt measurements are designed as expendable devices. Because all sensors were placed in the target zone prior to melting and could not be physically manipulated during the test, oxygen fugacity sensors used for this test were designed to measure the fugacity of gases evolved from the melt. Under equilibrium conditions, these gases would reflect melt redox conditions. By measuring the oxygen fugacity of the gases and not the melt directly, the sensors could be expected to have extended operational life. This was accomplished by using alumina protection tubes having small-diameter penetrations. The intended operation of this sensor design allowed the zirconia sensing tubes to be protected from direct melt contact, but allowed access to gases that evolved from the melt.

Two sensor assemblies were placed at a depth of $72 \mathrm{in}$., $24 \mathrm{in.}$ from the center of the melt zone and $180^{\circ}$ apart (OE-X2400072 and OE-X2418072). Because the sensors are electrochemical concentration cells that operate only at temperatures sufficient for migration of oxygen anions, the lower temperature limit of operation is approximately $600^{\circ} \mathrm{C}$. The output of the sensors was electrically isolated from the data acquisition system and amplified by transmitters (model 11JT-04-K; linearized 1-10 VDC output, for 0-1000 mVDC input) supplied by M-System Technology, Inc., Dallas, Texas. The amplified voltage was measured and stored by the data acquisition system. Engineering units [log of oxygen fugacity $\left(\mathrm{f}_{22}\right)$ ] was computed after calculating the sensor output voltage knowing the amplification factor of the transmitter according to the following relationship:

$$
\log \mathrm{f}_{\mathrm{O} 2}=\left[(((\text { Output }-1) \mathrm{VDC} \times 2.50) \times 1000 \mathrm{mv} / \mathrm{VDC} \times 20.159) /\left(\mathrm{T}+273.15^{\circ} \mathrm{K}\right)\right]-0.68 \text {, }
$$

where $\mathrm{T}$ is the temperature measured by the type-S thermocouple incorporated into the oxygen fugacity sensor assembly. The constant, -0.68 , corrects the calculated log oxygen fugacity for the case when air is used as a reference gas in place of pure oxygen.

For the period during the test when these sensors were exposed to temperatures $>600^{\circ} \mathrm{C}$, the output signal was generally erratic and uninterpretable. However, during the interval $150-156 \mathrm{~h}$, both oxygen fugacity sensors produced consistent, stable output signals. This time interval corresponds with the period during which the melt underwent a thermal arrest, accompanying crystallization. The log $\mathrm{f}_{\mathrm{O} 2}$ value during this time was approximately -0.5 , which approximates the output of sensors used in laboratory gas-mixing furnace applications $(-0.67)$ when the fugacity of air is measured with a pure oxygen reference gas. However, the constant -0.5 value more probably represents a calibration offset from a value of zero produced if the cell operated with an air atmosphere at both the anode and cathode.

\section{HEAT FLUX}

Heat-flux sensors were used to collect data for (1) analyzing heat inventories and fluxes during the test and (2) validating ISV models being developed at PNL and Idaho National Engineering Laboratory (INEL). The sensors were rated to function at temperatures up to $-300^{\circ} \mathrm{C}$. To obtain 
accurate values of heat flux, the sensors would have to be calibrated in soils under conditions anticipated during the test. It was desided that for this test, the sensors would be used uncalibrated just to evaluate their potential for use in isture tests. Thus the values $\left(\mathrm{kJ} / \mathrm{m}^{2} \circ \mathrm{s}\right)$ obtained should be used only in comparisons within a single sensor over the period of the test. However, as will be discussed, the data suggest that fluxes measured by all the sensors are of similar magnitude and behavior, and perhaps more weight could be placed on the values after looking for internal consistency among thermocouples and heat flux sensors.

Figures 50 and 51 show the heat-flux values obtained during the test from two sensors,

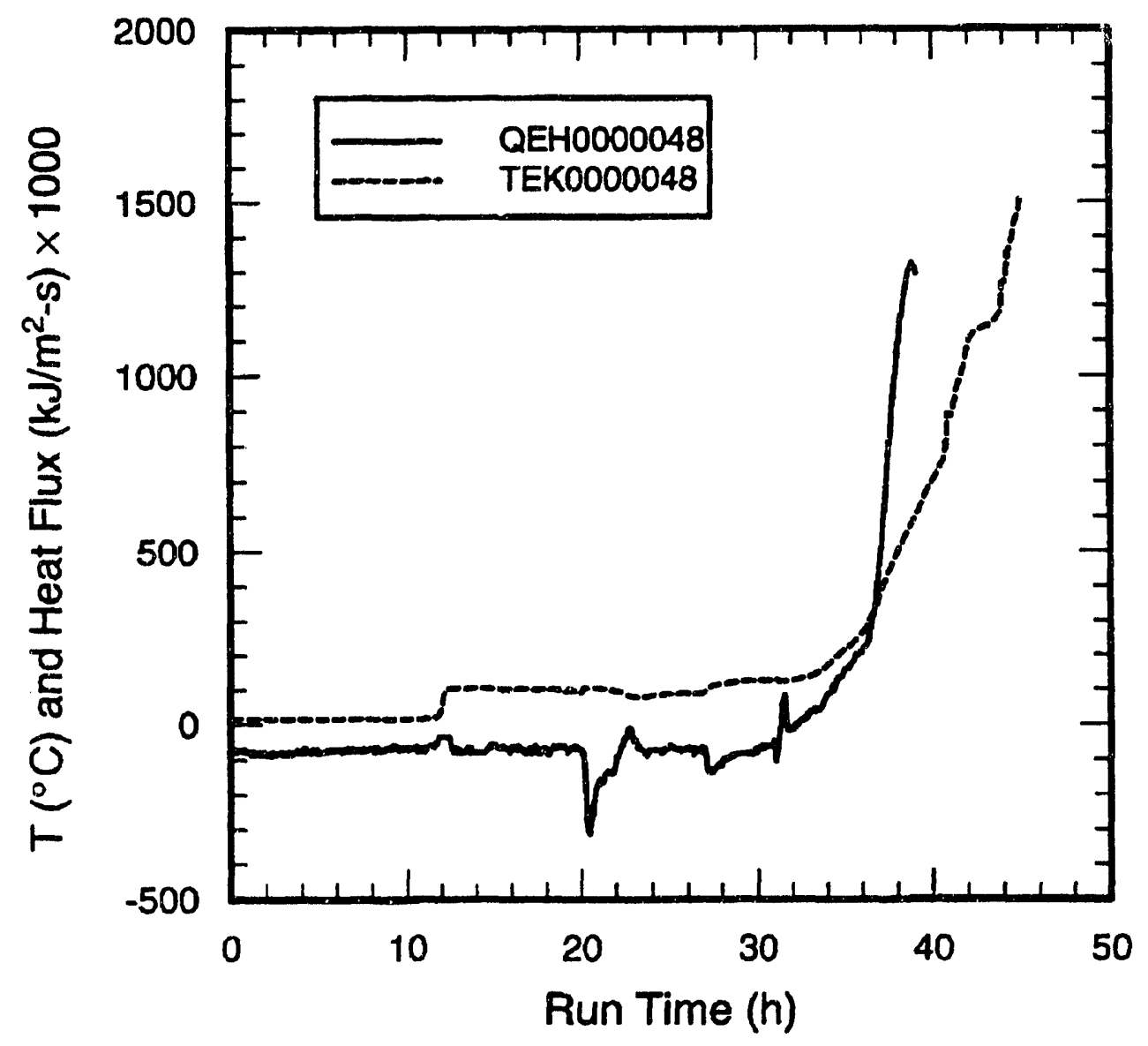

Fig. 50. Temperature and heat flux at a depth of $\sim 4.5 \mathrm{ft}$ under the center of the melt. Note that heat flux is multiplied by 1000 on the figure.

QEH0000048 (4.5-ft depth) and QEH0000096 (8.5- $\mathrm{ft}$ depth), placed in a vertical array under the center of the melt. The sensors, flat metal plates, were placed in horizontal positions so that the flux perpendicular to the bottom of the melt would be measured. Figure 50 illustrates that at $12 \mathrm{~h}$, when the soil began to heat up toward $100^{\circ} \mathrm{C}$, the heat flux increases slightly to a value $\sim 0.05 \mathrm{~kJ} / \mathrm{m}^{2} \circ \mathrm{s}$ above the baseline value. As the temperature reaches $100^{\circ} \mathrm{C}$ and water boils, the heat flux drops to baseline values because heat is consumed by the vaporization of water and not transmitted as a net flux of heat. The oscillations from 14 to $26 \mathrm{~h}$ are unexplained. At $28 \mathrm{~h}$, the soil begins to heat beyond $100^{\circ} \mathrm{C}$ as the melt approaches this depth. The heat flux also shows an increase at this time. As the 
melt advances rapidly, the soil temperature reaches the maximum operating temperature of the heatflux sensor $\left(300^{\circ} \mathrm{C}\right)$ at $-36 \mathrm{~h}$, where a heat flux of $\sim 0.4 \mathrm{~kJ} / \mathrm{m}^{2} \circ \mathrm{s}$ above the baseline value is recorded. After this time the heat flux sensor ceases to record a gradual increase in heat flux and is assumed to be nonfunctional.

Figure 51 shows relationships between the heat-flux and temperature sensors that are similar

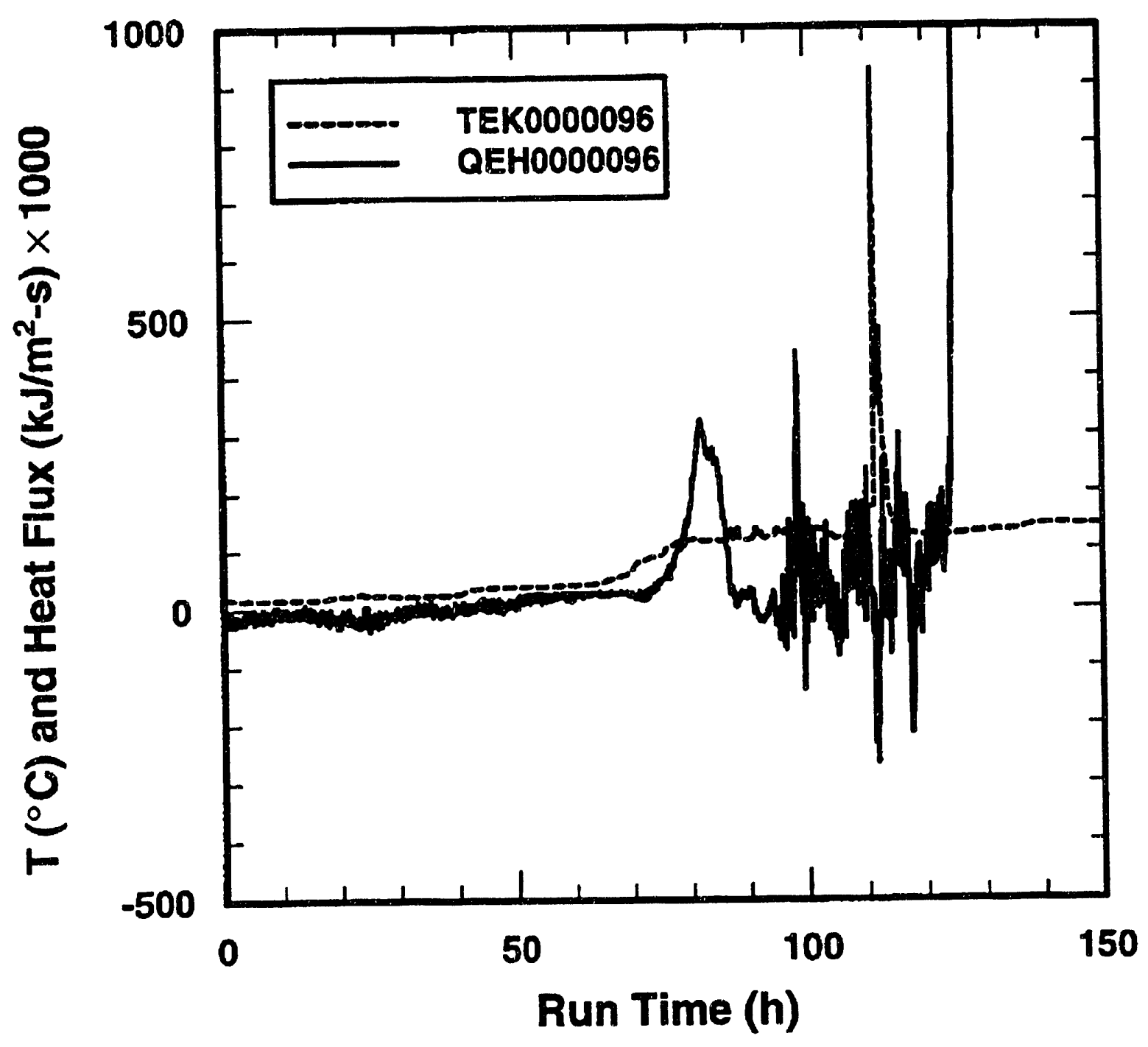

Fig. 51. Temperature and heat flux at a depth of $\sim 8.5 \mathrm{ft}$. under the center of the melt. Note that heat flux is multiplied by 1000 on the figure.

to those in Fig. 50.. As the temperature begins to approach $100^{\circ} \mathrm{C}$, the heat flux increases above zero and peaks at a value of $-0.35 \mathrm{~kJ} / \mathrm{m}^{2} \circ \mathrm{s}$. As the temperature reaches $100^{\circ} \mathrm{C}$, the heat flux drops back to near zero values. The fluctuations in temperature and heat flux from 90 to $110 \mathrm{~h}$ suggest that the soil may be in a region of drying and wetting from $90 \mathrm{~h}$. As the temperature climbs past $100^{\circ} \mathrm{C}$ rapidly at $110 \mathrm{~h}$, the neat flux sensor appears to cease to function. 
Figure 52 shows the heat flux values for four sensors placed to record fluxes perpendicular
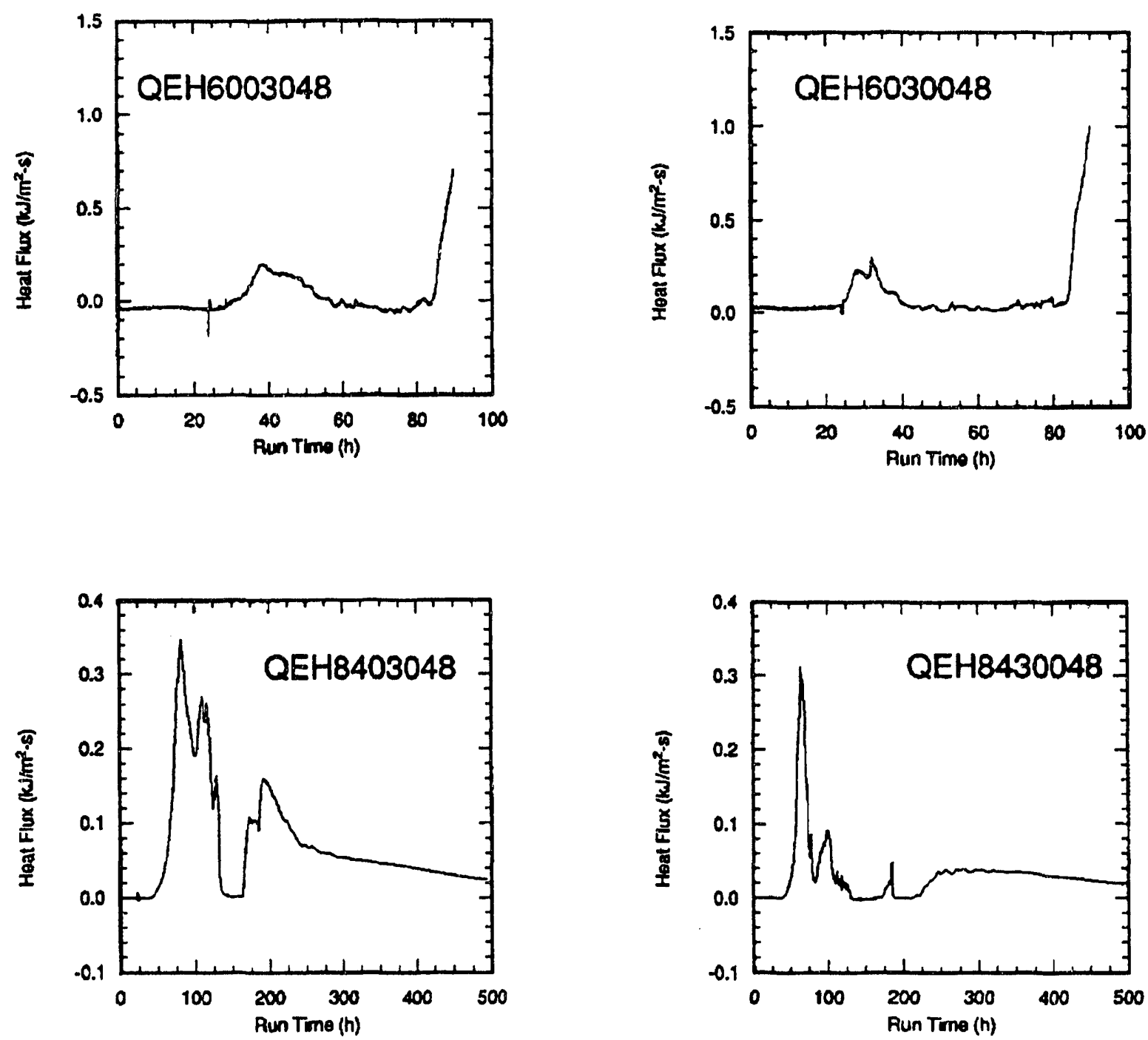

Fig. 52. Heat flux as a function of time for four sensors placed around the outside edge of the melt volume. Sensor labels define their location (see Tables 6 and 7).

to the sides of the melt. The sensors were placed approximately $4.5 \mathrm{ft}(1.4 \mathrm{~m})$ deep at angles of 30 and $300^{\circ}$ counterclockwise from the hood stairs on arcs $5 \mathrm{ft}(1.5 \mathrm{~m})$ and $7 \mathrm{ft}(2.1 \mathrm{~m})$ from the center of the melt. See Tables 6 and 7 for actual positions of the sensors. The sensors at the radius of 5 $\mathrm{ft}$ (upper two plots of Fig. 52) record an increase of heat flux to $-0.25 \mathrm{~kJ} / \mathrm{m}^{2} \bullet \mathrm{s}$ above the baseline value as the soil heats from ambient to $100^{\circ} \mathrm{C}$ approximately $30 \mathrm{~h}$ into the test. The flux then decreases to essentially zero as the water in the soil boils and consumes heat. The flux rises rapidly as the boiling water front is established beyond the position of the sensor $(80$ to $90 \mathrm{~h})$. The sensor then ceases to function as the temperature reaches $300^{\circ} \mathrm{C}$ at roughly $90 \mathrm{~h}$ into the test. The last heat flux estimated to be reliable is $-0.4-0.5 \mathrm{~kJ} / \mathrm{m}^{2} \circ \mathrm{s}$ above the baseline value. The sensors at a radius 
of $7 \mathrm{ft}$ (lower two plots of Fig. 52) do not burn out, but rather provide a complete flux history. Figure 53 shows superposed data from sensor QEH8403048 and thermocouple TEK8400060. The thermocouple is at the same radius, but $1 \mathrm{ft}$ deeper and offset by $30^{\circ}$. The thermal history at these two positions should be fairly similar. As the soil heated up from ambient to near $100^{\circ} \mathrm{C}$, the heat flux increased to a value of $-0.35 \mathrm{~kJ} / \mathrm{m}^{2}$ os during $\mathrm{t}=40$ to $80 \mathrm{~h}$. At $80 \mathrm{~h}$, the power to the melt decreased significantly. The effect of low power was seen on both the temperatures and heat flux. The temperature dropped to $70^{\circ} \mathrm{C}$ and the heat flux decreased to $0.2 \mathrm{~kJ} / \mathrm{m}^{2} \circ$. Power to the melt was restored at $\sim 100 \mathrm{~h}$ and both the temperature and heat flux increased to previous levels. As the soil temperature reached $100^{\circ} \mathrm{C}$ at $110 \mathrm{~h}$ and water vaporization began, the heat flux dropped to zero while the heat was consumed instead of transported through the soil. The power was terminated at $127 \mathrm{~h}$, but the temperature remained at $100^{\circ} \mathrm{C}$ and the heat flux remained at zero. At $\mathrm{t}=170 \mathrm{~h}$, the temperature in the soil began to drop and water ceased to boil. This allowed positive heat fluxes to be measured (e.g., the increase from 0 to $0.1 \mathrm{~kJ} / \mathrm{m}^{2} \odot \mathrm{s}$ ). As significant cooling occurred and the temperature dropped further, the heat flux also began to drop as expected. However, at $t=180 \mathrm{~h}$, the temperature began to increase as well as the heat flux. These increases are consistent with the hypothesis that heats of crystallization processes were released during the thermal arrest from $t=140$ to $160 \mathrm{~h}$. The heat took approximately $20 \mathrm{~h}$ to reach just a few $\mathrm{ft}$ beyond the edge of the melt. The pulse of elevated heat-flux values lasted approximately $30 \mathrm{~h}$, corresponding to the time period in which heat was released during crystallization. The slope of the heat-flux curve decreased around $250 \mathrm{~h}$, which, presumably, was when the pulse of crystallization heat had passed that location in the soil.

The heat-flux data obtained in this ISV test suggest that with calibrations performed in the soil of interest under relevant conditions, precise values may be obtained. It would be beneficial to use heat-flux sensors that can withstand higher temperatures so that a measure of heat flux just before the soil undergoes partial melting could be measured. Also, with sensors that function to higher temperatures, it might be possible to detect the consumption of heat (i.e., heat flux going to zero) associated with devolatilization reactions within the soil (release of $\mathrm{H}_{2} \mathrm{O}$ and $\mathrm{CO}_{2}$ ). It would be best to have thermocouples in close proximity to each heat-flux sensor so that consistency can be checked. Also, a method should be developed to ensure that the sensor remains perpendicular to the direction of interest for flux measurements. If the sensors shift so that they are not at right angles to the flux heat, the calibration would be negated.

\section{VOLATILE AND PARTICULATE OFF-GAS EMISSIONS}

The volatile and particulate emissions from the pilot-scale ISV melt were monitored ting a number of different techniques. Fixed gases from the ISV melt were sampled using evaciastis SUMMA ${ }^{\circ}$ canisters. Patterns of particulate and halogen emissions throughout the test use 1,0 independent techniques: 1) Modified Method 5 (MM5) (U.S.EPA 1991) isokinetic samplers in ihe system off-gas handling pipe and 2) pore-sized and base-treated series of filters using fixed-flow dr?ivn by a vacuum pump. Finally, total emissions of most elements and radioisotopes of interest vere analyzed using the off-gas prefilter and off-gas scrub solutions to determine the inventory of all material in the melt off-gas.

\section{SAMPLING OF FIXED GASES FROM THE ISV MELT}

Bulk samples of the gas phase emitted from the melt were taken in staintes canisters at two times during active melting. Integrated gas samples were collecied over $24 \mathrm{~h}$ using an inlet valve with low flow rate. The first sample was taken early in the melt periof coetween 12:30 a.m., April 14, and 8:10 a.m., April 15, 1991), before significant amounts of limestone were being actively incorporated into the melt. The second was taken later (between 9:47 a.m., April 16 and 9:45 a.m., April 17, 1991), while larger quantities of limestone were being melted. These samples were analyzed by Coast-to-Coast Analytical Services, using gas chromatography. Results of the analyses are shown in Table 13. The elevated $\mathrm{CO}_{2}$ content relative to normal atmospheric abundance $(0.03 \%)$ 


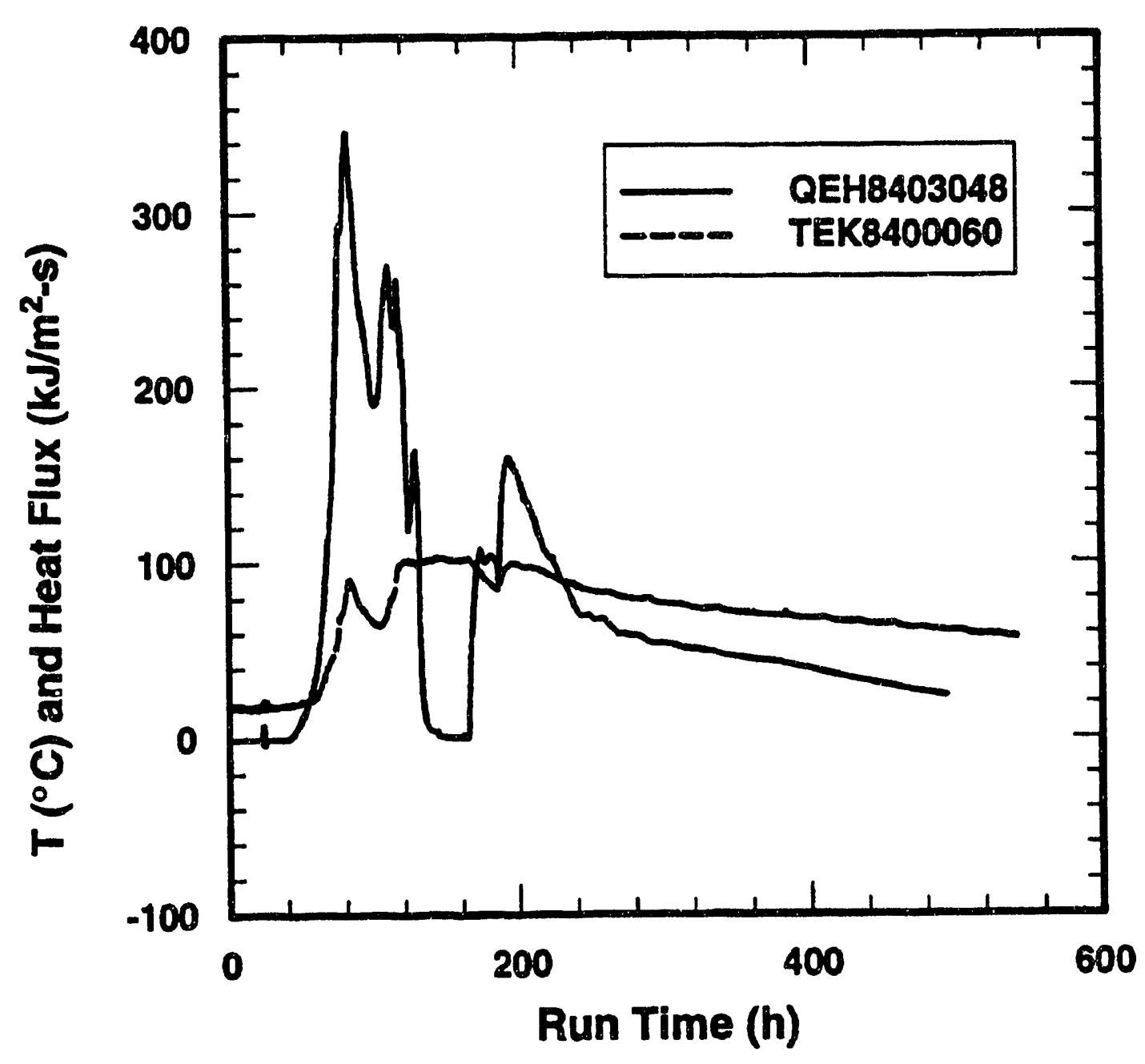

Fig. 53. Temperatures and heat flux $\sim 7 \mathrm{ft}$ from the center of the melt and at depths of -5.5 and $4.5 \mathrm{ft}$, respectively.

is a result of limestone decarbonation and oxidation of the graphite electrodes, and the variation in $\mathrm{CO}_{2}$ between the two samples is a result of melting different proportions of limestone to soil. As with the MM5 samples, these fixed-gas samples are integrated over their sampling interval and thus do not permit resolution of temporal effects at less than daily intervals.

\section{MODIFIED METHOD FTVE OFF-GAS SAMPLING}

Off-gases generated during the test were sampled from the off-gas line at two locations upstream from the prefilter and one location at the stack exiting the off-gas treatment system. These off-gas samples were used to determine the effectiveness of the off-gas prefilter as well as to provide data on stack emissions and offer a determination of elemental mass balance. Samples were collected using a commercial stack sampler, which has been built in accordance with Environmental Protection Agency (EPA) specifications (U.S.EPA 1991). Off-gas samples were isokinetically extracted from the off-gas line through a nozzle and a heated probe into a heated filter where the particulate was 
Table 13. Major gas constituents, in percentages, in samples collected from the ISV off-gas hood during the 1991 ORNL pilot-scale ISV test.

\begin{tabular}{llllll}
\hline & $\mathrm{CO}_{2}$ & $\mathrm{O}_{2}$ & $\mathrm{~N}_{2}$ & $\mathrm{CH}_{4}$ & $\mathrm{CO}$ \\
\hline Sample 1 & 1 & 20 & 79 & none none \\
Sample 2 & 4.8 & 19 & 76 & none none
\end{tabular}

Analyses accurate to $\pm 10 \%$ and precise to $\pm 2 \%$.

removed. The hot gases are then passed through a series of cold water impingers (contained in an ice bath), where the condensibles were removed and the gases cooled before going to the pump, dry gas meter, and flow orifice. This sampling method is described in Title 40, Code of Federal Regulations, Part 60, Appendix A as Modified Method 5, Determination of Particulate Emissions From Stationary Sources. A schematic of the sampling system used on the off-gas line is shown in Fig. 54. The filter media used to capture particulate is composed of borosilicate glass fibers and has a collection efficiency of $99.97 \%$ on $>0.3-\mu \mathrm{m}$ particles (standard filter penetration test). Deionized water was used as an impinger solution to capture any ${ }^{137} \mathrm{Cs}$ passing through the filter. The first and second impingers used deionized water for scrubbing. The third impinger began the sampling period empty and was used to collect moisture that is condensed from the off-gas stream. The fourth and last impinger in the sampling train contained $300 \mathrm{~g}$ of color indicating silica gel to capture any remaining moisture in the sample stream. The samplers were operated continuously during the test with the exception of filter and solution change-out. The data collected from the samplers were used to help determine tracer emissions and the amount of ${ }^{137} \mathrm{Cs}$ present in the off-gas. In addition to composition, off-gas velocity, flow rate, percent moisture, and sample flow rate were determined.

MM5 off-gas line sampling was initiated as soon as the starter path was consumed (15 h run time). Sampling upstream of the off-gas treatment system was not initiated until the starter path was consumed to eliminate excessive loading of starter path particulate on the filters. The stack sampler was initiated with the application of electrical power to the soil. The samplers were operated for the remainder of the test with minimal downtime to change filters and scrub solutions and, on several occasions, to perform maintenance on the vacuum pumps. MM5 sampler 1 was used as the primary data source because of the larger sample volume pulled through it and less downtime experienced. Filter media in all the MM5 samplers were replaced as the advancing melt front approached the level of the radioactive sludge waste (1.4-m depth). This gave researchers the ability to detect any ${ }^{137} \mathrm{Cs}$ captured on the filter media that may have prematurely volatilized from the soil. Table 14 shows data collected for MM5 off-gas line sampler 1 during the initial data collection period (prefilter by-passed, 0 - to $1.4-\mathrm{m}$ depth), and for the remainder of the test with the prefilter in use (1.4- to $2.5-\mathrm{m}$ depth). A total of six filters were used for the sampler. The calculated values for off-gas flow rate, sample flow rate and percentage of total flow are average values for each particulate filter used (Tables 15 through 18).

Two of the MM5 samplers were used to take isokinetic samples from the off-gas between the hood and the prefilter unit, while the third was used to sample the treated off-gas at the process trailer stack. Calculations of isokinetic sampling rates were $0.43,0.15$, and $0.15 \%$ for MM5 samplers 1,2 , and 3, respectively. The glass fiber filters from MM5 sampling trains were changed, at most, three times after melting within the depth interval of sludge placement. Thus these filters offer only integrated sampling and provide little temporal resolution of any trapped contaminants, e.g., ${ }^{137} \mathrm{Cs}$. The ${ }^{137} \mathrm{Cs}$ activity and the mass of total solids that was deposited on these filters are listed in Table 15. Activities of ${ }^{137} \mathrm{Cs}$ were determined using Nal gamma spectroscopy, similar to the counting procedures described above, except that the filters were contained in plastic 15 -cm-diam Petri dishes; a standard for ${ }^{137} \mathrm{Cs}$ was prepared on an unused filter to determine counting efficiencies, and unused 
Table 14. Operational data for the Modified Method 5 ISV off-gas samplers.

\begin{tabular}{lcccccc}
\hline $\begin{array}{l}\text { Filter } \\
\text { sample }\end{array}$ & $\begin{array}{c}\text { Start } \\
\text { run time } \\
\text { (h) }\end{array}$ & $\begin{array}{c}\text { Stop } \\
\text { run time } \\
\text { (h) }\end{array}$ & $\begin{array}{c}\text { Time } \\
\text { used } \\
\text { (h) }\end{array}$ & $\begin{array}{c}\text { Sample } \\
\text { flowrate } \\
\text { (SCFM) }\end{array}$ & $\begin{array}{c}\text { Off-gas } \\
\text { flowrate } \\
\text { (SCFM) }\end{array}$ & $\begin{array}{c}\text { Sample\% } \\
\text { of total } \\
\text { flow }\end{array}$ \\
\hline MM5 (1)-1 & 15.32 & 31.57 & 16.25 & 0.807 & 184.53 & 0.43 \\
MM5 (1)-4 & 31.90 & 46.20 & 14.30 & 0.761 & 175.25 & 0.43 \\
MN.15 (1)-6 & 46.62 & 66.70 & 20.05 & 0.741 & 170.87 & 0.43 \\
& & & HEPA prefilter valved in & & \\
MM5 (1)-8 & 66.70 & 100.58 & 33.8 & 0.766 & 173.37 & 0.43 \\
MM5 (1)-8a & 100.70 & 115.55 & 14.8 & 0.751 & 173.00 & 0.43 \\
MM5 (1)-2 & 115.72 & 130.55 & 14.8 & 0.751 & 169.86 & 0.43 \\
\hline
\end{tabular}

filters were used to check for background levels of ${ }^{137} \mathrm{Cs}$. The minimum detectable activity was determined to be $9 \mathrm{pCi}$ per sample. Deposition of solids on each filter was determined by weighing the dried filter prior to and after use. It is important to note that no detectable activity was released from the test through the off-gas processing trailer stack to the atmosphere. Using the isokinetic sampling percentages of the two MM5 samplers, which were sampling off-gas just prior to the prefilter, and the observed ${ }^{137} \mathrm{Cs}$ activities on the MM5 filters, total ${ }^{137} \mathrm{Cs}$ volatilized from the melt amounted to 221 and $307 \mu \mathrm{Ci}$ for the two samplers. These estimates are 93 to $129 \%$ of that determined from analysis of the prefilter.

The analytical results for each filter from MM5 off-gas line sampler 1 are presented in Table 16. Table 17 shows the calculated quantities of the ${ }^{137} \mathrm{Cs}$ and chemical tracers in the off-gas for the entire test. Table 18 shows the calculated percentages of these materials volatilized from the ISV melt into the off-gas. The filter samples were analyzed using gamma energy analysis to account for the ${ }^{137} \mathrm{Cs}$ content, and inductively coupled plasma / mass spectrometry (ICP/MS) was used to measure the quantity of the chemical tracers on the filters.

Data indicate that none of the ${ }^{137} \mathrm{Cs}$ was volatilized from the vitrified zone before the off-gas flow was valved through the prefilter. Approximately $0.20 \mathrm{mCi}$ or $2.0 \%$ of the ${ }^{137} \mathrm{Cs}$ placed into the soil was volatilized and captured on the prefilter.

\section{PARTICLE AND ACID GAS SAMPLING}

Samples of the off-gas emitted from the melt were collected on filters every $2 \mathrm{~h}$ throughout most of the 127-h melting period and for $12 \mathrm{~h}$ after melting was complete and power to the melt was terminated. Samples were, taken with 47-mm Swin-Lok filter holders loaded with a series of particle and/or base-treated filters. The base-treated filters were Whatman-100 cellulose filters treated with a LiOH and glycerol basic solution (Finnegan et al. 1989), and are designed to react with, and trap, any acidic gas component (e.g., $\mathrm{HCl}, \mathrm{HF}, \mathrm{SO}_{x}$ or $\mathrm{NO}_{x}$ ) of the plume.

Two types of filter arrangements were used because of the particle-rich nature of the off-gas. The first (type 1) was designed for determination of particle size distribution and consisted of a Nucleopore $8-\mu \mathrm{m}$ filter, followed by a Nucleopore $0.4-\mu \mathrm{m}$ filter, followed by a base-treated filter. The 
Table 15. Activity of ${ }^{137} \mathrm{Cs}$ and solids deposited on filters of U.S. EPA Modified Method 5 samplers by ISV off-gas.

\begin{tabular}{|c|c|c|c|c|c|}
\hline Sampler & Sequence & Stop date & Stop time & $\begin{array}{l}{ }^{137} \mathrm{Cs} \\
(\mu \mathrm{Ci})\end{array}$ & $\begin{array}{c}\text { Solids } \\
\text { (g) }\end{array}$ \\
\hline \multicolumn{6}{|l|}{ First sampler: } \\
\hline Off-gas MM5 & First & 16-May-91 & $21: 00$ & 0.808 & 1.204 \\
\hline Off-gas MM5 & Second & 17-May-91 & $11: 51$ & 0.103 & 1.817 \\
\hline Off-gas MM5 & $\frac{\text { Third }}{\text { Total }}$ & 18-May-91 & $12: 00$ & $\frac{0.043}{0.954}$ & $\frac{1.946}{4.967}$ \\
\hline \multicolumn{6}{|c|}{ Second sampler: } \\
\hline Off-gas MM5 & First & 16-May-91 & $21: 00$ & 0.370 & 1.638 \\
\hline Off-gas MM5 & $\frac{\text { Second }}{\text { Total }}$ & 18-May-91 & $12: 00$ & $\frac{0.091}{0.461}$ & $\frac{1.994}{3.632}$ \\
\hline \multicolumn{6}{|l|}{ Third sampler: } \\
\hline Stack MM5 & First & 16-May-91 & $21: 00$ & 0.000 & 0.008 \\
\hline Stack MM5 & Second & 18-May-91 & $12: 00$ & $\underline{0.000}$ & $\frac{0.005}{0.012}$ \\
\hline
\end{tabular}

Table 16. Amount of tracers on Modified Method 5 filters during 1991 ORNL ISV test.

\begin{tabular}{|c|c|c|c|c|c|}
\hline $\begin{array}{c}\text { Filter } \\
\text { sample }\end{array}$ & $\begin{array}{l}{ }^{137} \mathrm{Cs} \\
(\mu \mathrm{Ci})\end{array}$ & $\begin{array}{l}\mathrm{Sb} \\
(\mu \mathrm{g})\end{array}$ & $\begin{array}{c}\mathrm{La} \\
(\mu \mathrm{g})\end{array}$ & $\underset{(\mu \mathrm{g})}{\mathrm{Ce}}$ & $\begin{array}{c}\mathrm{Nd} \\
(\mu \mathrm{g})\end{array}$ \\
\hline MM5 (1)-1 & ND & 110 & 7.6 & 16.1 & 6.96 \\
\hline MM5 (1)-4 & ND & 37200 & 4.28 & 1.57 & 0.66 \\
\hline MM5 (1)-6 & ND & 76400 & 8.79 & 4.71 & 3.28 \\
\hline \multicolumn{6}{|c|}{ Prefilter valved in } \\
\hline MM5 (1)-8 & 0.75 & 50200 & 3.0 & 2.0 & $<4.0$ \\
\hline MM5 (1)-8a & 0.08 & 35300 & 2.6 & 2.0 & $<4.4$ \\
\hline MM5 (1)-2 & 0.034 & 17500 & 4.0 & 4.8 & $<4.0$ \\
\hline
\end{tabular}

second filter set (type 2), was designed to trap completely all emitted particulate and acid gas species and consisted of a Whatman-100 non-size-specific cellulose filter, followed by two base-treated filters. These two filter sets were used alternately throughout the melting period. The filters will be referred to as $A, B$, and $C$, where $A$ is the first filter through which the off-gas flowed and $C$ is the last. Off- 
Table 17. Calculated total amount of tracers in off-gas from 1991 ORNL ISV test.

\begin{tabular}{|c|c|c|c|c|c|}
\hline $\begin{array}{c}\text { Filter } \\
\text { sample }\end{array}$ & $\begin{array}{l}{ }^{137} \mathrm{Cs} \\
(\mathrm{mCi})\end{array}$ & $\begin{array}{l}\mathrm{Sb} \\
(\mathrm{g})\end{array}$ & $\underset{(\mu \mathrm{g})}{\mathrm{La}}$ & $\begin{array}{c}\mathrm{Ce} \\
(\mu \mathrm{g})\end{array}$ & $\begin{array}{c}\mathrm{Nd} \\
(\mu \mathrm{g})\end{array}$ \\
\hline MM5 (1)-1 & 0 & 0.4 & 2814.81 & 5962.96 & 2577.78 \\
\hline MM5 (1)-4 & 0 & 15.5 & 1783.33 & 654.17 & 275.00 \\
\hline MM5 (1)-6 & 0 & 34.73 & 3995.45 & 2140.91 & 1490.91 \\
\hline \multicolumn{6}{|c|}{ Prefilter valved in } \\
\hline MM5 (1)-8 & 0.17 & 21.83 & 1304.35 & 869.57 & 4.00 \\
\hline MM5 (1)-8a & 0.02 & 15.35 & 1130.43 & 869.57 & 4.00 \\
\hline MM5 (1)-2 & 0.01 & 7.95 & 1818.18 & 2181.82 & 4.0 \\
\hline Totals & 0.20 & 95.76 & 12846.55 & 12679.00 & 4355.69 \\
\hline
\end{tabular}

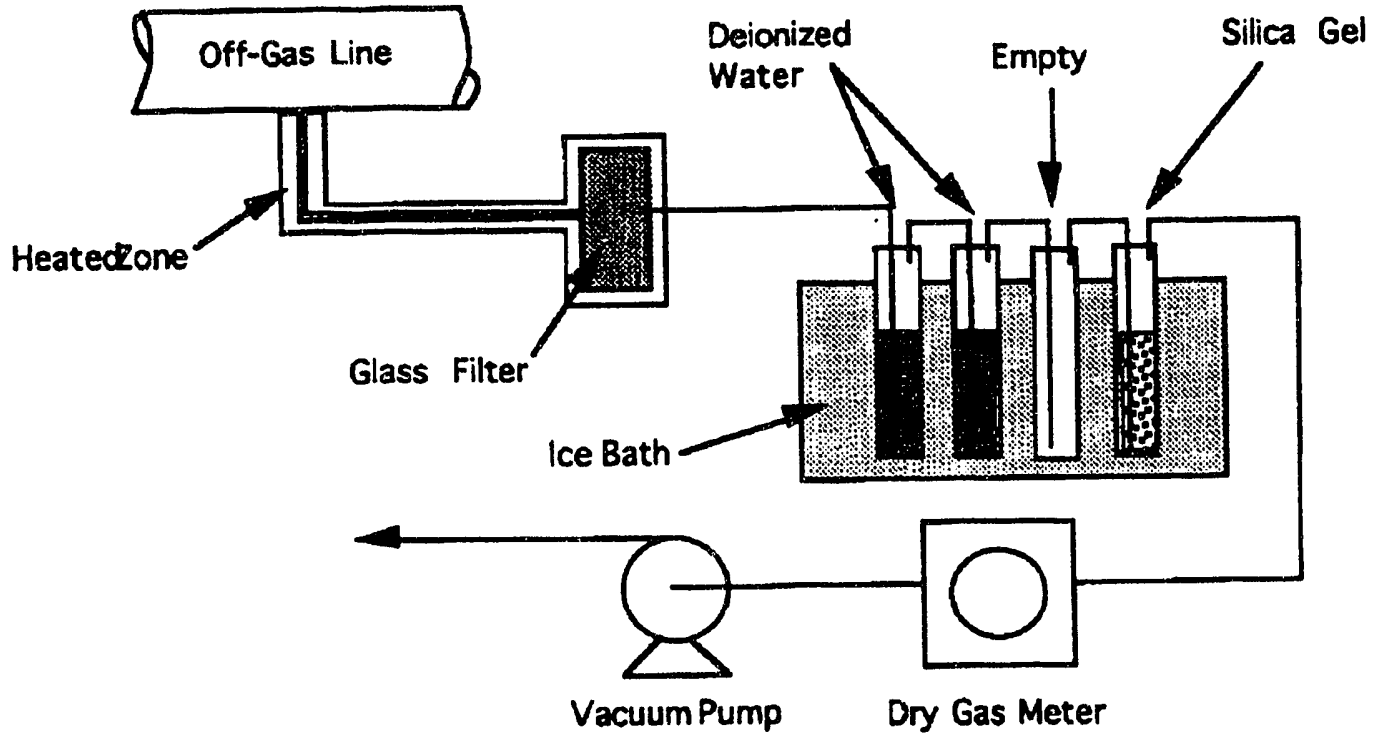

Fig. 54. Schematic diagram of the Modified Method 5 sampling system used to collect particulates and gases from the main ISV off-gas line.

gas from the ISV melt was sampled through a stainless steel tube and a short section of Tygon tube before passing through the filters (Fig. 55). The sampling point within the hood was approximately $1.2 \mathrm{~m}$ from the initial melt surface. Temperature of the gas at the intake point was $-300^{\circ} \mathrm{C}$, and the tube outside the hood was heated so that the gas temperature could not drop below $100^{\circ} \mathrm{C}$. A 
Table 18. Fraction of ${ }^{137} \mathrm{Cs}$ and rare earth tracers volatilized during 1991 ORNL ISV test.

\begin{tabular}{|c|c|c|c|}
\hline & $\begin{array}{l}\text { Mass of tracers } \\
\text { within ISV melt } \\
\text { (g) }\end{array}$ & $\begin{array}{c}\text { Mass of tracers found } \\
\text { in the off-gas } \\
(\mu \mathrm{g})\end{array}$ & $\begin{array}{l}\text { Volatilized into } \\
\text { the off-gas } \\
(\%)\end{array}$ \\
\hline $\mathrm{Sb}$ & 835.7 & $50.4(\mathrm{~g})$ & 6.03 \\
\hline $\mathrm{La}$ & 2114 & 7039.5 & 0.00033 \\
\hline $\mathrm{Ce}$ & 2676 & 7051.2 & 0.00026 \\
\hline \multirow[t]{3}{*}{$\mathrm{Nd}$} & 1886 & 2546.88 & 0.00014 \\
\hline & $\begin{array}{l}{ }^{137} \mathrm{Cs} \text { added to soil } \\
(\mathrm{mCi})\end{array}$ & $\begin{array}{c}{ }^{137} \mathrm{Cs} \text { in off-gas } \\
(\mathrm{mCi})\end{array}$ & $\begin{array}{l}\text { Volatilized into off-gas } \\
\qquad(\%)\end{array}$ \\
\hline & 10 & 0.20 & 2.0 \\
\hline
\end{tabular}

thermocouple, which was placed in the gas stream directly before the filterpack, indicated that the gas introduced into the filters was typically between 110 and $130^{\circ} \mathrm{C}$. Gas was pulled through the filters using a small diaphragm pump, and flow rates were recorded during collection of each sample, so that. total flow through the filters could be estimated. Following collection, filters were removed from filterpacks with plastic tweezers, folded in quarters with the working surface inward, and placed in individual sterilized Whirlpak bags and kept frozen to prevent decomposition of the cellulose by $\mathrm{LiOH}$ (Finnegan et al. 1989). A list of all collected filters and relevant information is given in Table 19.

\section{Analyses of Filters}

Particle sizes, morphologies, and major chemical constituents were determined by scanning electron microscope (SEM) and energy-dispersive X-ray analysis (EDAX). EDAX analysis is not quantitative, but allows elements present above $\sim 5 \mathrm{wt} \% \circ$ be identified. An International Scientific Instrument ISI-40 SEM with a Tracor Northern EDAX system was used. The SEM was operated at $30 \mathrm{kV}$ with a beam current of $50 \mu \mathrm{A}$. SEM imaging of material trapped on particle filters indicates that the particles trapped on the filters are spherical to subcrystalline. The bulk of the particles were trapped on the $0.4-\mu \mathrm{m}$ filter, and the average particle size appears to be $\sim 1 \mu \mathrm{m}$ (Fig. 56A). The size of individual particles was surprisingly uniform, and material trapped on the 8- $\mu \mathrm{m}$ filter appears to be mainly aggregates of smaller particles (Fig. 56B). Material trapped on $\mathrm{LiOH}$ or plain cellulose filters also contains spherical particles. However, the cellulose fibers that make up the filter appear to be coated also with material from the off-gas (Fig. 56C). EDAX analysis identified the presence of $\mathrm{F}, \mathrm{Cl}, \mathrm{K}, \mathrm{Ca}, \mathrm{Sb}$ (not in order of abundance), and possibly $\mathrm{S}$. There does not appear to be any significant difference in composition between the material trapped on the particle filters and that trapped on the treated filters.

The ${ }^{137} \mathrm{Cs}$ concentration on all filters was determined by gamma counting. A Packard AutoGamma Scintillation spectrometer with a $\mathrm{NaI}$ detector was used, and the counted area included the $0.662-\mathrm{Mev}$ gamma peak. The entire filter sample was loaded into the scintillation vial still inside the Whirlpak bag, avoiding any possibility of contamination. A number of prepared standards with various concentrations of ${ }^{137} \mathrm{Cs}$ were also counted. Because of the ease and nondestructive nature of 


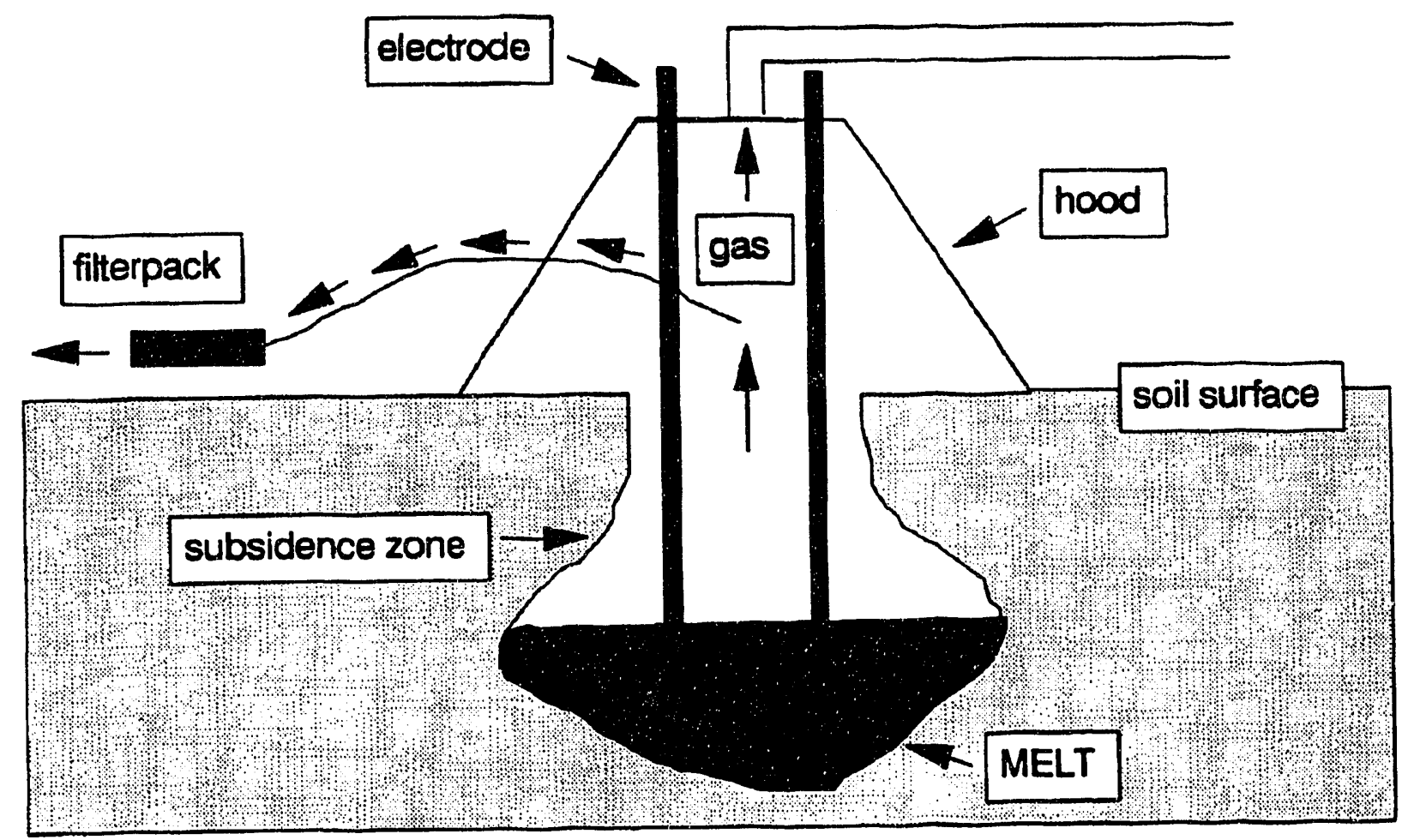

Fig. 55. Schematic diagram of the ISV site, showing electrode configuration, general melt shape, subsidence zone, hood, and filter sample location.

these analyses, all individual collected filters were analyzed using this method.

Detailed chemical analyses of filters were made using instrumental neutron activation analysis (INAA). Analyses were made at Los Alamos National Laboratory (LANL) using the Omega West reactor in a thermal neutron flux of 0.5 to $1 \times 10^{12}$ neutrons $/ \mathrm{cm}^{2} \mathrm{~s}$. The filters were cut in half in a laminar-flow clean hood before being placed in polyethylene containers for analysis. Each sample was irradiated three times in order to efficiently determine short- and long-half-lived elements. Blanks of all filter types were also collected and analyzed. The irradiation and counting procedures are discussed in Finnegan (1984). Not all filters were analyzed by this technique because of the timeconsuming nature of INAA. Filters for analysis were selected based on high concentrations of ${ }^{137} \mathrm{Cs}$ as determined by previously discussed gamma counting, and attempts were also made to analyze complete filter sets wherever possible.

\section{Particle Morphology and Composition}

The material trapped on filters from the ISV off-gas consists mainly of elements that would be expected to be volatilized in a magmatic setting (Symonds et al. 1987, 1992; Crowe et al. 1987; Toutain et al. 1990). Notably lacking on the filters are typical lithophile elements, such as $\mathrm{Si}, \mathrm{Al}, \mathrm{Ca}$, $\mathrm{Sr}, \mathrm{Th}$, and $\mathrm{Zr}$, which would be transported from the melt only as ash fragments. Virtually no ash fragments were detected on the filters by SEM observations, suggesting that although the melt underwent constant small-scale bubbling, virtually no ash was produced. More vigorous fragmentation of a magmatic surface than that observed in the ISV melt must be necessary to produce significant ash.

A number of characteristics of the particles trapped on the off-gas sampline filters suggest 
Table 19. ISV off-gas filter samples taken May 13-18, 1991.

\begin{tabular}{|c|c|c|c|c|c|}
\hline $\begin{array}{l}\text { Sample } \\
\text { number }\end{array}$ & $\begin{array}{l}\text { Date } \\
\text { run }\end{array}$ & $\begin{array}{l}\text { Sta:t } \\
\text { sime } \\
\text { (b) }\end{array}$ & $\begin{array}{l}\text { Sampling } \\
\text { durntion } \\
\text { (b) }\end{array}$ & $\begin{array}{l}\text { Average gas } \\
\text { temperature } \\
\left({ }^{\circ} \mathrm{C}\right)\end{array}$ & $\begin{array}{l}\text { Total gas } \\
\text { flow } \\
\left(\mathrm{ft}^{3}\right)\end{array}$ \\
\hline ISVF.91.2 & $5 / 13 / 91$ & 11.3 & 1.0 & 112 & 28 \\
\hline ISVF-91-3 & $5 / 13 / 91$ & 13.3 & 0.4 & 110 & 4 \\
\hline ISVF.91-4 & $5.13 / 91$ & 15.5 & 1.8 & 115 & 77 \\
\hline ISVF-91-5 & $5 / 13 / 91$ & 17.4 & 0.4 & 128 & 4 \\
\hline ISVF-91 6 & $5 / 13: 91$ & 19.4 & 22 & 118 & 94 \\
\hline ISVF-91-7 & $5 / 1301$ & 21.7 & 0.5 & 110 & 5 \\
\hline ISVF-91-8 & $5 / 13 / 91$ & 23.5 & 0.8 & 120 & 28 \\
\hline [SVF-91.9 & $5 / 14 / 91$ & 2.3 & 0.3 & 40 & 3 \\
\hline ISVF-91-10 & $5 / 14 / 91$ & 3.4 & 0.9 & 122 & 37 \\
\hline ISVF-91-11 & $5 / 14 / 91$ & $\$ .5$ & 0.3 & 56 & 3 \\
\hline ISVF-91-12 & $s / 14,91$ & 7.3 & 1.8 & 107 & 47 \\
\hline ISVF.91.13 & $S / 14 / 91$ & 9.5 & 0.5 & 107 & 5 \\
\hline ISVF.91.14 & $5 / 14 / 91$ & 11.6 & 20 & 118 & 59 \\
\hline ISVF-91-15 & $5 / 14 / 91$ & 13.6 & 0.4 & 120 & 4 \\
\hline ISVF-91-16 & $5 / 14 / 91$ & 15.7 & 28 & 320 & 9 \\
\hline ISVF-91-17 & $5 / 14 / 91$ & 17.5 & 1.2 & 114 & 12 \\
\hline ISVF-91-18 & $5 / 2491$ & 19.9 & 16 & 116 & 42 \\
\hline ISVF-91-19 & $5 / 1491$ & 21.8 & 0.5 & 100 & 5 \\
\hline ISVF-91-20 & $s / 1491$ & 23.4 & 1.0 & 116 & 26 \\
\hline ISVF-91-21 & $5 / 15 / 91$ & 1.3 & 0.3 & 60 & 3 \\
\hline [SVF-91-22 & $5 / 15 / 91$ & 3.5 & 1.0 & 115 & 45 \\
\hline ISVF-91-23 & $5 / 15 / 91$ & 5.4 & 0.2 & 69 & 2 \\
\hline ISVF-91-24 & $5 / 15 / 91$ & 7.9 & 1.7 & 110 & 67 \\
\hline ISVF-91-2S & $S / 15 / 91$ & 9.7 & 0.3 & 118 & 3 \\
\hline ISVF-91-26 & $S / 15 / 91$ & 11.6 & 1.8 & 110 & 75 \\
\hline [SVF-91-27 & $5 / 15 / 91$ & 13.5 & 0.3 & 105 & 3 \\
\hline ISVF-91-28 & $5 / 15 / 91$ & 15.6 & 21 & 110 & $\$ 4$ \\
\hline ISVF.91-29 & $S / 1 S / 91$ & 17.8 & 0.4 & 110 & 4 \\
\hline ISVF-91-30 & $5 / 15 / 91$ & 19.5 & 20 & 110 & 66 \\
\hline ISVF-91-31 & $S / 1 S / 91$ & 21.6 & 0.3 & 105 & 4 \\
\hline ISVF.91-32 & $S / 1 S / 91$ & 23.5 & 1.0 & 115 & 40 \\
\hline ISVF-91-33 & $5 / 16 / 91$ & 1.3 & 0.3 & 70 & 3 \\
\hline ISVF-91-34 & $5 / 16 / 91$ & 3.4 & 0.9 & 115 & 51 \\
\hline ISVF-91-35 & $S / 16 / 91$ & 5.5 & 0.2 & 115 & 8 \\
\hline ISVF.91.36 & $5 / 16 / 91$ & 8.8 & 16 & 117 & 123 \\
\hline ISVF-91-37 & $5 / 16991$ & 10.4 & 1.2 & 110 & 92 \\
\hline ISVF-91-38 & $5 / 16 / 91$ & 12.8 & 2.8 & 117 & 118 \\
\hline LSVF-91-39 & $5 / 16 / 91$ & 13.7 & 1.8 & 114 & 114 \\
\hline ISVF-91-40 & $s / 16 / 91$ & 15.5 & 1.9 & 115 & 113 \\
\hline ISVF-91-41 & $5 / 16 / 91$ & 17.5 & 1.3 & 110 & 19 \\
\hline ISVF-91-42 & $5 / 16 / 91$ & 19.4 & 20 & 110 & 102 \\
\hline ISVF-91-43 & $5 / 16 / 91$ & 21.5 & 0.5 & 113 & 5 \\
\hline ISVF-91-44 & $5 / 16 / 91$ & 23.4 & 1.9 & 80 & 115 \\
\hline ISVF-91-AS & $5 / 17 / 91$ & 1.4 & 0.5 & 120 & 5 \\
\hline ISVF.91.46 & $5 / 17 / 91$ & 3.3 & 20 & 110 & 89 \\
\hline [SVF, $91-47$ & $5 / 17 / 91$ & 5.3 & 0.7 & 172 & 7 \\
\hline ISVF-91-48 & $5 / 17 / 91$ & 7.9 & 1.7 & 110 & 24 \\
\hline ISVF-91-49 & $5 / 17 / 91$ & 9.8 & 1.7 & 110 & 57 \\
\hline ISVF-91-50 & $5 / 17 / 91$ & 11.5 & 2.2 & 115 & 78 \\
\hline ISVF-91-S1 & $5 / 17 / 91$ & 13.7 & 0.3 & 98 & 3 \\
\hline ISVF.91.52 & $5 / 17 / 91$ & 15.5 & 1.9 & 110 & 69 \\
\hline ISVF.91-53 & $5 / 17 / 91$ & 27.7 & 0.7 & 107 & 7 \\
\hline ISVF.91.54 & $5 / 17 / 91$ & 19.6 & 1.8 & 107 & 48 \\
\hline ISVF-91-55 & $5 / 17 / 91$ & 21.5 & 1.2 & 110 & 23 \\
\hline ISVF-91.56 & $S / 17 / 91$ & 23.4 & 20 & 122 & 89 \\
\hline ISVF-91-57 & $5 / 18 / 91$ & 1.5 & 0.5 & 134 & 18 \\
\hline ISVF.91-58 & $S / 18,91$ & 7.9 & 1.6 & 115 & 123 \\
\hline ISVF.91.59 & $5 / 18 / 91$ & 9.5 & 22 & 113 & 162 \\
\hline 15VF-91-60 & $5 / 18 / 91$ & 11.7 & i. 7 & 110 & 150 \\
\hline ISVF-91-61 & $5 / 18 / 91$ & 13.5 & 1.9 & 107 & 142 \\
\hline [SVF.91-62 & $S / 18 / 91$ & 15.4 & 1.4 & 109 & 99 \\
\hline
\end{tabular}

that volatile components sublimated directly from a vapor phase in the gas stream. Most individual particles analyzed by SEM-EDAX analysis contain a wide range of elements, suggesting a multiphase makeup. Analyses indicated that each spherical sublimate particle contained a wide range of elements, mainly $\mathrm{K}, \mathrm{Na}, \mathrm{Sb}, \mathrm{Cl}$, and $\mathrm{F}$, so the particles were likely to consist of mixed halide phases. No significant compositional variation was observed between different particles. Virtually all of the 

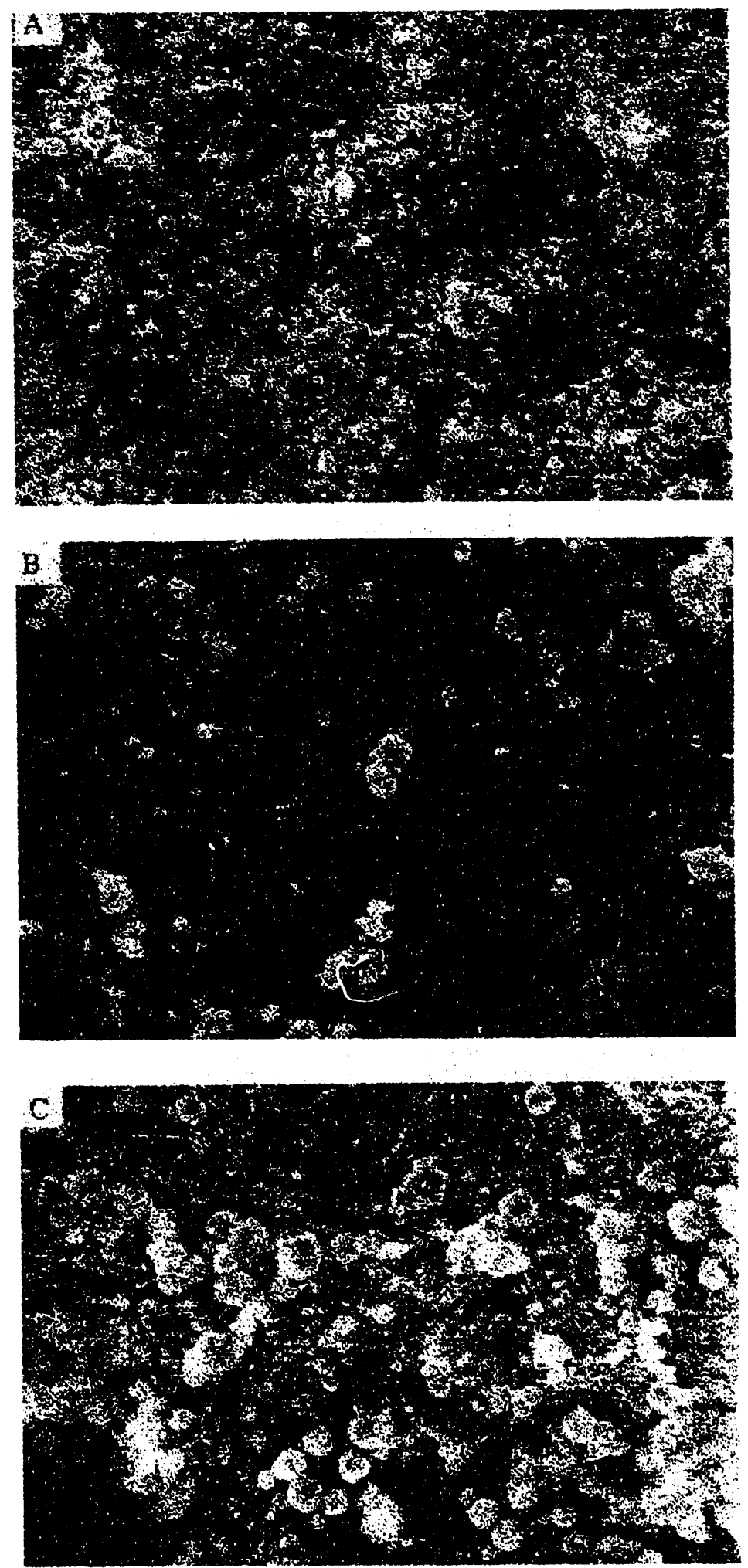

Fig. 56. Scanning electron microscope images of ISV particles $(3000 x)$ on filters with total width of view of $44 \mu \mathrm{m}$. (A) $0.4-\mu \mathrm{m}$ sized (B) $8-\mu \mathrm{m}$ sized (C) non-sized cellulose. 
particles observed have a spherical to subcrystalline morphology, consistent with sublimation from a gas phase (Toutain et al. 1990; Bernard and LeGuern 1986). These authors observed mainly subcrystalline phases, but the spherical morphologies observed to be emitted from the ISV melt are likely to be aggregates of small, finely crystalline components that formed and coalesced in the traceelement-rich gas stream. The strikingly uniform particulate grain size of $\sim 1 \mu \mathrm{m}$ has also been observed in other ISV melts (L.E. Thompson, personal communication, 1992), but has not been reported in volcanic systems. The uniform sublimate grain size observed may be related to the uniform nature of the ISV system with respect to vapor evolution. All vapor is emitted from the melt surface and travels upwards into the hood, undergoing similar cooling patterns. The temperature profile and gas travel paths within the ISV hood are likely to remain relatively constant throughout the entire test duration. All particles are likely to nucleate at similar temperatures, probably between 600 and $800^{\circ} \mathrm{C}$ (Toutain et al. 1990), and continue growing and accreting until trapped by the filters. Deposition of sublimates continues at $-100^{\circ} \mathrm{C}$ as evidenced by the "coated" appearance of some filters (Fig. 56C). Because grain size was very fine, analyses of individual crystalline phases were not obtained. The coatings on the cellulose filter fibers (Fig. 56C) appear to be roughly the same composition as the individual sublimate particles, which is consistent with deposition of halides over a wide temperature range, down to as low as $100^{\circ} \mathrm{C}$ (Toutain et al. 1990; Hampton and Bailey 1985).

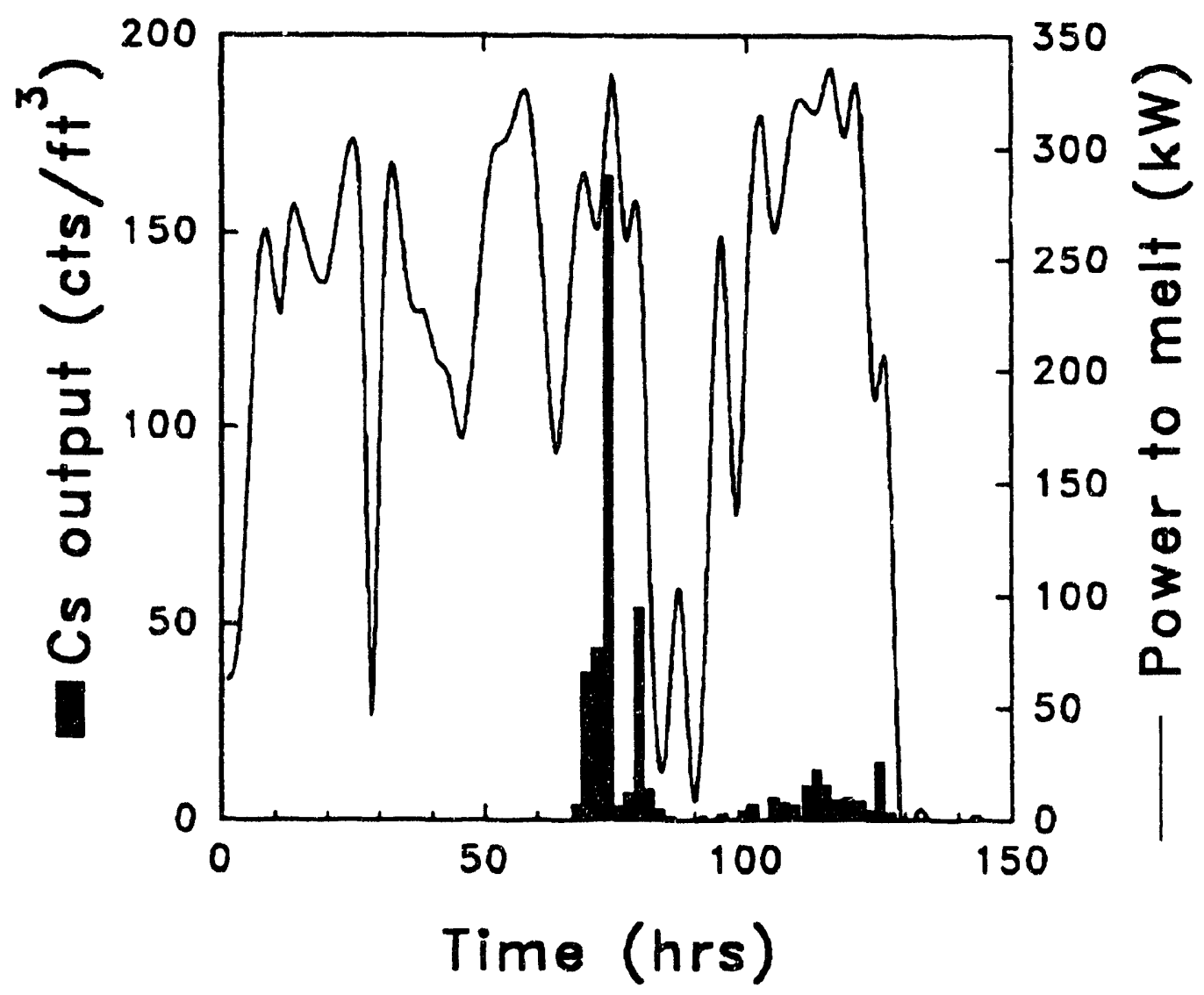

Fig. 58. Power input and ${ }^{137} \mathrm{Cs}$ activity in off-gas from the ISV melt as a function of time. 

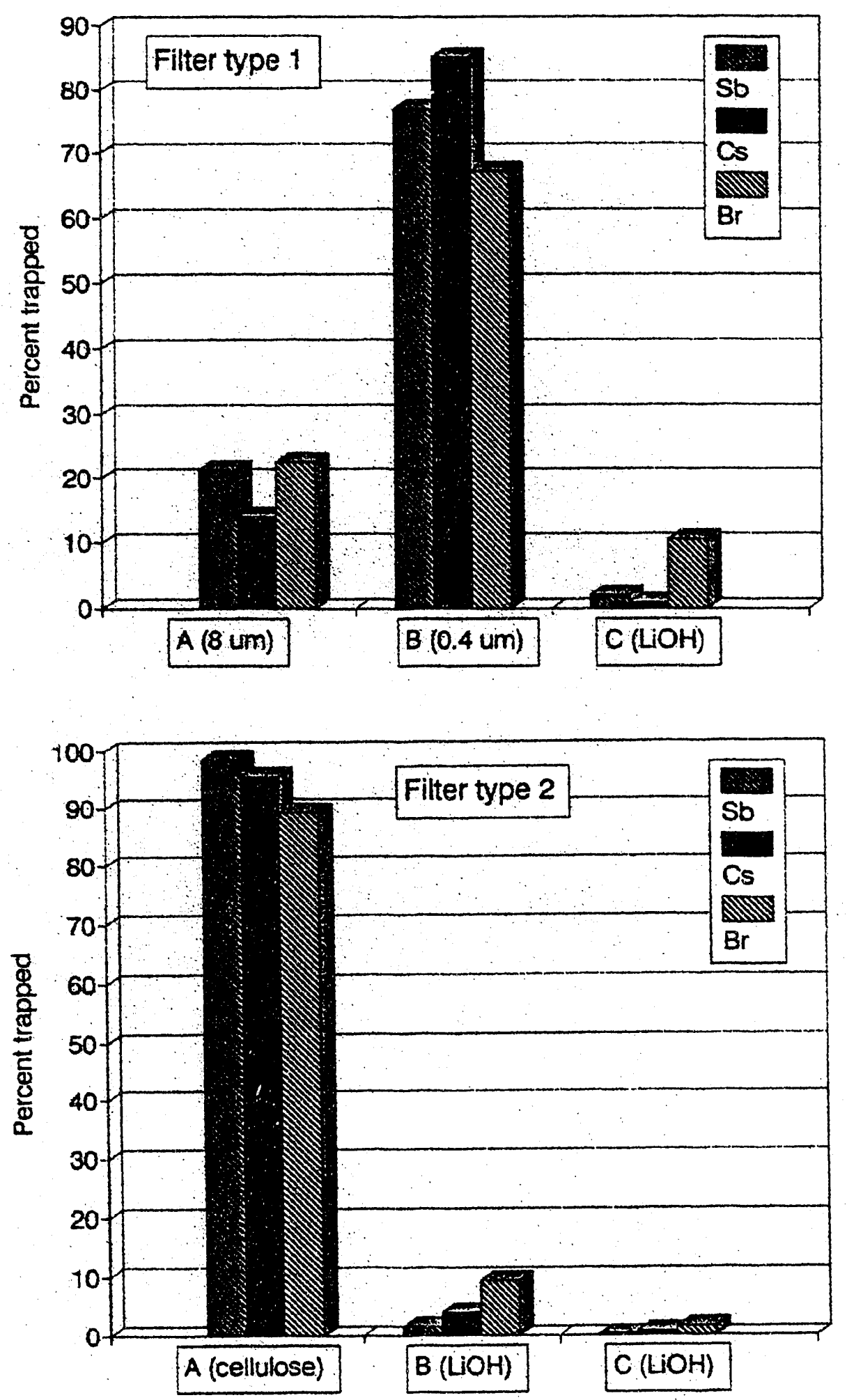

Fig. 57. Trapping efficiency of type 1 and type 2 filter sets for $\mathrm{Sb},{ }^{137} \mathrm{Cs}$, and $\mathrm{Br}$. 
Typical distributions of ${ }^{137} \mathrm{Cs}$ on the A, B and C filters for both types of filterpacks are shown in Fig. 57. The ${ }^{137} \mathrm{Cs}$ is most concentrated on the A filter of the base-treated filter set (type 2), but more ${ }^{137} \mathrm{Cs}$ is present on the $0.4-\mu \mathrm{m}$ than on the $8-\mu \mathrm{m}$ particle filters, consistent with SEM observations of particle grain size (Fig. 57). Virtually all of the ${ }^{137} \mathrm{Cs}$ is present on the $\mathrm{A}$ and $\mathrm{B}$ filters of both types of filterpacks, indicating that the filters efficiently remove ${ }^{137} \mathrm{Cs}$ from the off-gas. There is no apparent difference in ${ }^{137} \mathrm{Cs}$ content between the particle and treated filterpack sets when the ${ }^{137} \mathrm{Cs}$ content is normalized to the total air flow through the filter. Based on the total ${ }^{137} \mathrm{Cs}$ content of individual filterpacks $(A+B+C$ filters) and the total air flow through the filter, relative levels of emissions from the melt as a function of time can be determined (Fig. 58). Cesium-137 was first detected on the filters at approximately the time when the melt had reached the depth at which the tracer was buried (Fig. 59). A large amount of ${ }^{137} \mathrm{Cs}$ was released when the tracer is first incorporated into the melt. Following the initial release, the ${ }^{137} \mathrm{Cs}$ release varied as a function of the power input to the melt, but never again attains the initial release level.

The dominant trace elements emitted from the ISV melt, based on filter analysis, are $\mathrm{F}, \mathrm{Cl}$,

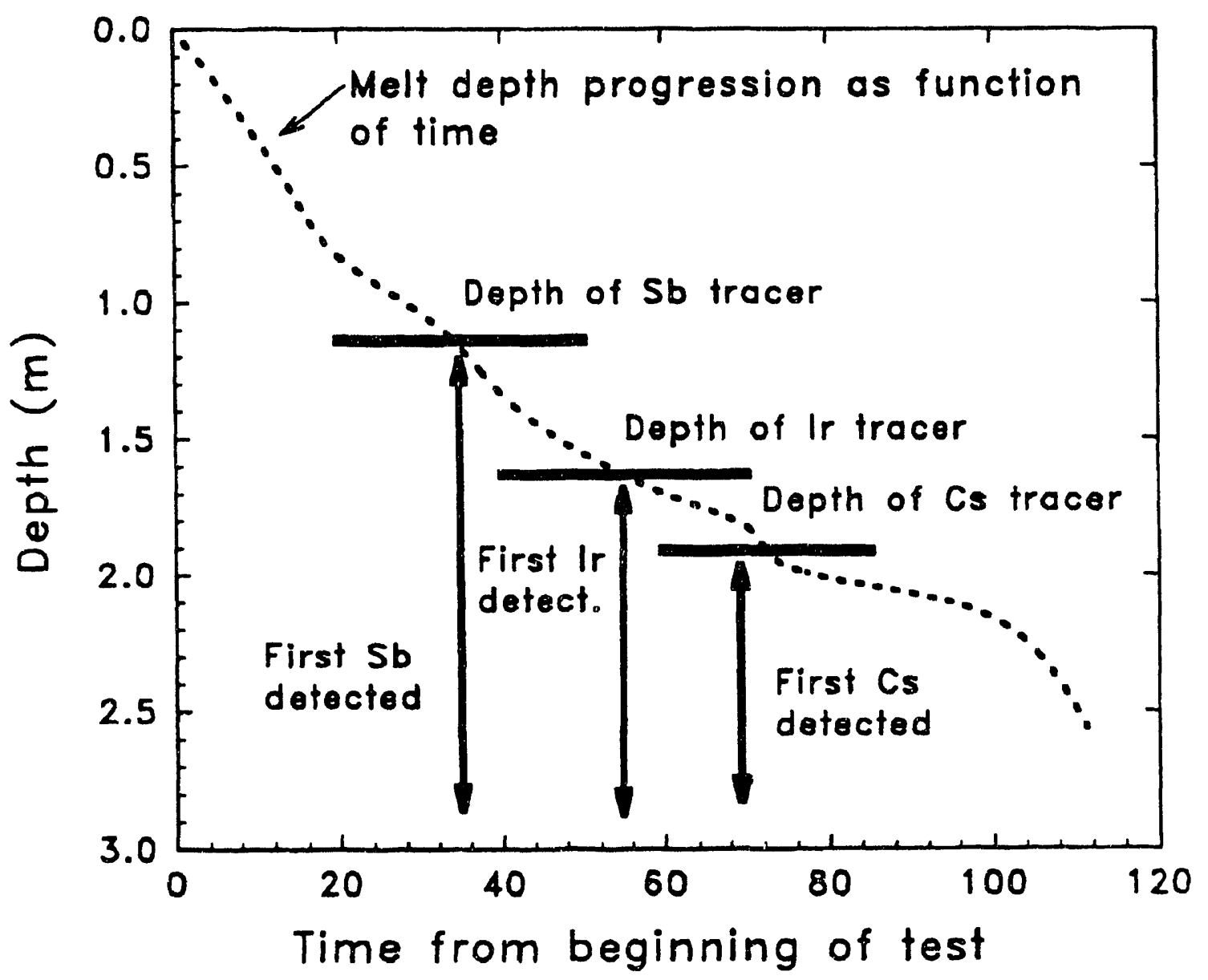

Fig. 59. Schematic diagram on melt depth, trace burial depth, and first appearance of tracers on sampling filters.

$\mathrm{K}, \mathrm{Na}, \mathrm{Sb}$ (tracer), $\mathrm{As}, \mathrm{Br}$, and I. Other elements present in small amounts include $\mathrm{Cs}, \mathrm{Sc}, \mathrm{V}, \mathrm{Rb}, \mathrm{Au}$, $\mathrm{Ag}, \mathrm{W}, \mathrm{Ir}$ (tracer), and In. The quantity of Ir added to the melt was small $(\sim 12.6 \mathrm{~g})$, and although the 
Ir can be detected on the filters (Fig. 59), further analyses would be necessary to quantify the results. As was the case for ${ }^{137} \mathrm{Cs}$, most analyzed elements were concentrated on the B filter in type 1 filter sets and on the A filter in the type 2 sets (Fig. 58). The $C$ filter of both types of filter sets had low concentrations of all elements (Fig. 58). The elements $\mathrm{Cl}$ and $\mathrm{F}$, however, and to a certain extent, $\mathrm{Br}$, are relatively more concentrated on the $\mathrm{LiOH}$ filters with respect to untreated cellulose filters, suggesting that some portion of these elements was present as an acid gas species in the plume.

The trace elements that are listed above are those that are efficiently detected by neutron

Table 20. Trace element composition for ISV product and sublimate-encrusted ISV product.

\begin{tabular}{lccccccccc}
\hline & $\begin{array}{l}\mathrm{Pb}^{\mathrm{a}} \\
\mathrm{ppm}\end{array}$ & $\begin{array}{l}\mathrm{Rb}^{\mathrm{a}} \\
\mathrm{ppm}\end{array}$ & $\begin{array}{l}\mathrm{Na}^{\mathrm{b}} \\
\mathrm{ppm}\end{array}$ & $\begin{array}{l}\mathrm{As}^{\mathrm{b}} \\
\mathrm{ppm}\end{array}$ & $\begin{array}{l}\mathrm{Fe}^{\mathrm{b}} \\
\mathrm{ppm}\end{array}$ & $\begin{array}{l}\mathrm{Co}^{\mathrm{b}} \\
\mathrm{ppm}\end{array}$ & $\begin{array}{l}\mathrm{Zn}^{\mathrm{b}} \\
\mathrm{ppm}\end{array}$ & $\begin{array}{l}\mathrm{Sb}^{\mathrm{b}} \\
\mathrm{ppm}\end{array}$ & $\begin{array}{l}\mathrm{Cs}^{\mathrm{b}} \\
\mathrm{ppm}\end{array}$ \\
\hline $\begin{array}{l}\text { ISV product } \\
\begin{array}{l}\text { Sublimate-encrusted } \\
\text { ISV product }\end{array}\end{array}$ & 16 & 109 & 0.22 & 1.3 & 4.75 & 13.97 & 172 & 27 & 3.72 \\
& 258 & 132 & 3.70 & 25.0 & 4.91 & 19.93 & 32.63 & 761 & 5.24
\end{tabular}

${ }^{2}$ Analysis by $\mathrm{X}$-ray fluorescence. Analytical error (all $\left.\pm 1 \mathrm{ppm}\right): \mathrm{Pb} 3 ; \mathrm{Rb} 4$.

${ }^{b}$ Analysis by INAA. Analytical error (all in $\pm 1 \mathrm{ppm}$ ): $\mathrm{Na} 0.02$; As 0.5 ; Fe 0.05; Co $0.16 ; \mathrm{Zn} \mathrm{4}$; Sb 0.4; Cs 0.06 .

activation analysis. However, other elements, such as $\mathrm{Pb}$, are certainly emitted from the melt and may be present on the filters, but are simply not detectable by neutron activation analysis. Furthermore, elements $\mathrm{Fe}, \mathrm{Mg}, \mathrm{Cr}, \mathrm{Co}$, and $\mathrm{Zn}$ were present in high abundances on the filters, but may be a result of contamination from the stainless steel sampling pipe (Shevenell 1990). However, sublimateencrusted glass samples were taken from within the subsidence zone (Fig. 55) of the ISV melt and were analyzed by INAA and X-ray fluorescence (Table 20). Analyses of the sublimate-encrusted glass samples allow some estimates of elements that cannot be determined on the filters, either because of analytical limitations or contamination by the stainless steel pipe. Elements were detected during these analyses that could not be quantitatively determined, including $\mathrm{Pb}, \mathrm{Fe}, \mathrm{Co}$, and $\mathrm{Zn}$, and, of these, $\mathrm{Pb}$ and $\mathrm{Zn}$ were the most volatile.

\section{Enrichment Factors}

A general comparison of the mechanisms of volatile emissions from the ISV melt natural magmatic systems can be assessed by comparing the respective degree of volatility of elements. The degree of volatility of particular elements from a melt can be estimated by calculating an enrichment factor $(E F)$ between the melt and a vapor phase:

$$
E F=\frac{\left(X_{\text {gas }} / Y_{\text {gas }}\right)}{\left(X_{\text {mel }} / Y_{\text {melt }}\right)}
$$

where $X$ is the concentration of an element of interest and $Y$ is the concentration of a reference 


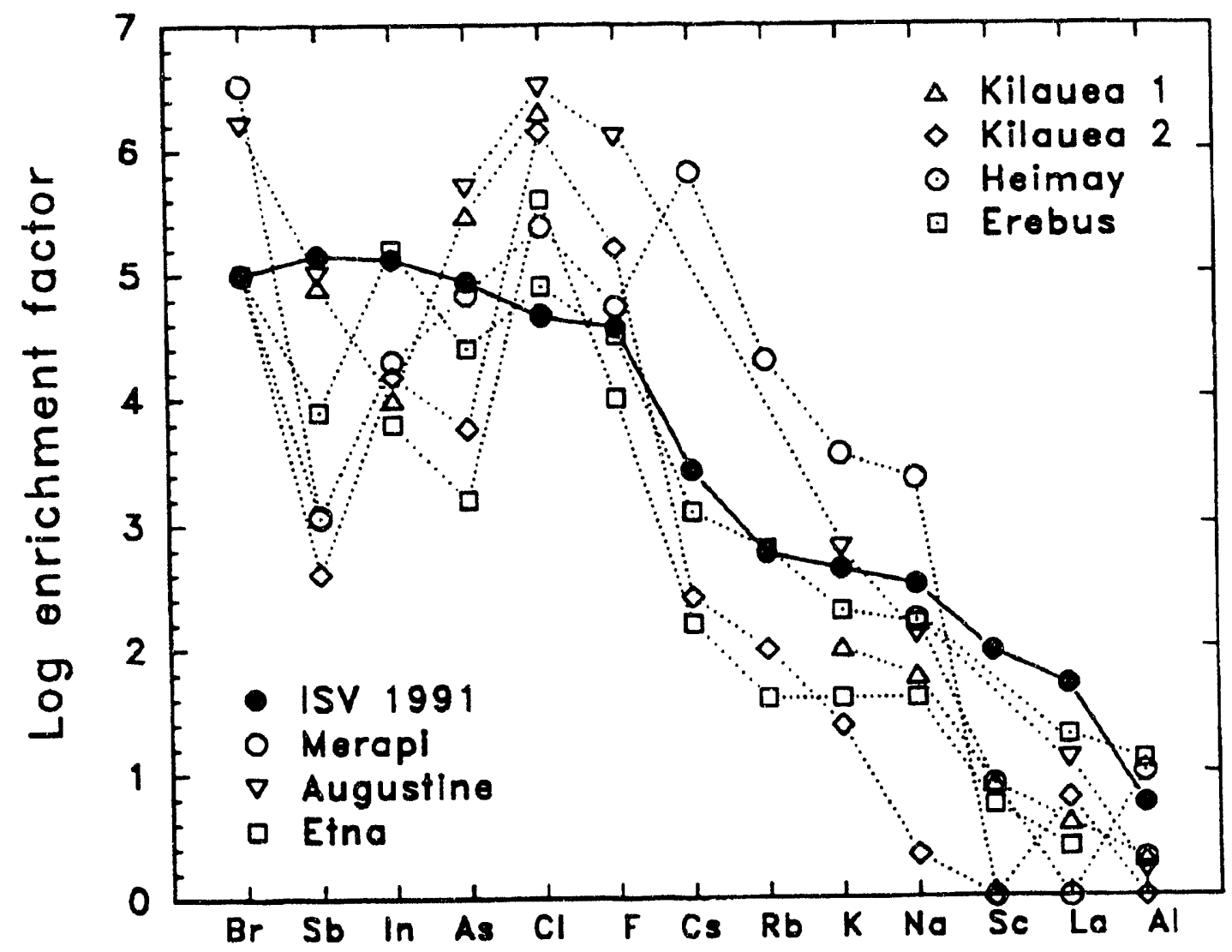

Fig. 60. Mean enrichment factors calculated for ISV melt compared with enrichment factors reported for natural volcanic systems.

element chosen for normalization. In natural systems, the ratios of species must be used because it is difficult to determine the degree of atmospheric dilution that the plume has undergone after emission from the melt surface, and therefore it is impossible, based on filter samples alone, to determine absolute trace element fluxes from the melt. As will be discussed later, it is possible to determine a dilution factor for the ISV melt, but EFs were calculated in order to compare them with those in natural systems. Analyses of the ISV product have been made for a number of trace elements (see product composition section), and these values were used as "melt" values in calculation of enrichment factors. Fluorine and chlorine were not analyzed in this melt, but were estimated at concentrations of $-250 \mathrm{ppm}$, based on typical concentrations in soil and limestone. EFs for the ISV emissions were calculated using $\mathrm{Br}$ as the reference element and are compared with EFs calculated for a number of natural magmas (Fig. 60). The choice of reference elements other than $\mathrm{Br}$ in some natural systems (other reference elements include $\mathrm{Al}$ and $\mathrm{Na}$ ) cause the magnitude of EFs to vary. The EF from some of the volcanic systems were increased by a multiple of $10\left(10,10^{2}\right.$, etc.) so that the logarithm of the lowest EF would be around 0 . The factors used are noted in the subsequent discussion. Multiplying by a factor will cause all of the EFs to be proportionately higher or lower, but will not affect the overall pattern of relative volatilities.

The relative patterns of ISV EF values are strikingly similar to those for natural volcanic 
systems (Fig. 60), despite the very different major element composition of the ISV melt compared with natural magmatic systems. As in most volcanic systems, the most highly volatile elements include $\mathrm{Br}, \mathrm{Sb}$, In, $\mathrm{As}, \mathrm{Cl}$, and $\mathrm{F}$. ISV sublimate data, normalized to $\mathrm{Br}$, were multiplied by $10^{5}$. Merapi sublimate data from Symonds et al. (1987), normalized to $\mathrm{Ti}$, were multiplied by 100 . Augustine dome sublimate data from Symonds et al. (1990), were normalized to Mg. Etna data from B. Andres (personal communication 1992), normalized to $\mathrm{Br}$, were multiplied by $10^{5}$. Kilauea 1 data from Crowe et al. (1987), normalized to $\mathrm{Br}$, were multiplied by $10^{5}$. Kilauea 2 data from Olmez et al. (1986), were normalized to Sc. Heimaey data from $\mathrm{Mroz}$ and Zoller (1975) were normalized to Na. Erebus data from Meeker (1988), normalized to $\mathrm{Br}$, were multiplied by $10^{5}$. The volatility of $\mathrm{Sb}$ is higher in the ISV system than in the natural magma, probably because of the large amount of Sb added to the ISV melt as a tracer, whereas most natural magmas have low concentrations of $\mathrm{Sb}$. Based on analyses of sublimate-encrusted glass samples (Table 20), the volatilities of $\mathrm{Pb}$ and $\mathrm{Zn}$ appear to be on the same order as As, whereas volatility of Fe appears to be considerably lower. Although no exact EF can be calculated for these elements, the apparent volatility is consistent with values observed in natural systems. The similarity of EFs between the ISV melt and natural magmas suggests that the mechanisms for partitioning elements into an existing fluid phase in the two types of systems are similar and that volatilization of trace elements in the ISV system could be used as a model for volatilization in natural systems.

The ISV melt underwent a number of power fluctuations during the test, causing several periods of different melt conditions. When power to the melt was low, temperature dropped (from $1500^{\circ} \mathrm{C}$ to as low as $1200^{\circ} \mathrm{C}$ ), convection appeared to be less vigorous, and rate of downward melting and incorporation of $\mathrm{H}_{2} \mathrm{O}$ and $\mathrm{CO}_{2}$ in the partial melt zone decreased. The EF for trace elements from the ISV melt at differen'! melting conditions were calculated (Fig. 61). The high Sb release occurred at $35 \mathrm{~h}$. High power $1 \mathrm{EFs}$ occurred at $73 \mathrm{~h}$, high power 2 EFs occurred at $113 \mathrm{~h}$, and low power EFs at $95 \mathrm{~h}$. No systematic variation of $E F$ as a function of power to the melt was observed, suggesting that there is no change in the relative volatility among different elements as a function of temperature variations in the 1200 to $1500^{\circ}$ range which resulted from power input differences. Furthermore, the relative volatility of different elements does not appear to be affected by the greater volatile flux that results from high power input to the melt.

\section{Composition of the Fluid Emitted from the ISV Melt}

The concentration of halogens and trace metals in the water-dominated fluid phase emitted from a natural magmatic system is difficult to estimate because of atmospheric dilution of the plume. However, the total emission of water from the melt was measured for the duration of the test using the off-gas processing system, which trapped all components emitted from the melt in a series of particle filters and liquid scrub solutions. Some atmospheric $\mathrm{H}_{2} \mathrm{O}$ was contained in the captured water, but this contribution was calculated and subtracted from the total water emission. The total water emission from the ISV melt was determined to be $1700 \mathrm{~L}$.

The total mass of trace elements emitted by the melt can be determined on the basis of emission of the $\mathrm{Sb}$ tracer. A total of $835 \mathrm{~g}$ of $\mathrm{Sb}$ was added to the melt from the tracer, the soil, and the limestone, and if fully retained and dispersed in the final melt mass of $12 \times 10^{6} \mathrm{~g}$, would produce an expected concentration of $67 \mathrm{ppm} \mathrm{Sb}$. The actual whole-rock Sb concentration was $27 \mathrm{ppm}$, indicating that $60 \%$ of $\mathrm{Sb}$, or $522 \mathrm{~g}$, was volatilized during the melting process. The total amount of $\mathrm{Sb}$ detected on the analyzed filters can be normalized to the total mass of Sb emitted from the melt, and this ratio can be used to determine emitted masses of other trace elements (Table 21). The total $\mathrm{Sb}$ released was only normalized to those filters that were analyzed, so barring anomalous releases of individual trace elements onto unanalyzed filters, estimates of emissions of other elements should be valid. The total emission masses calculated from the $\mathrm{LiOH}$-treated and particle filters agree favorably with total trace element inventories determined from analysis of the prefilter and off-gas scrub solutions. The fluid concentration can be based on the total masses of emitted $\mathrm{H}_{2} \mathrm{O}$ and trace elements (Table 21). This calculation does not include the abundances of $\mathrm{CO}_{2}$ in the fluid phase, but 


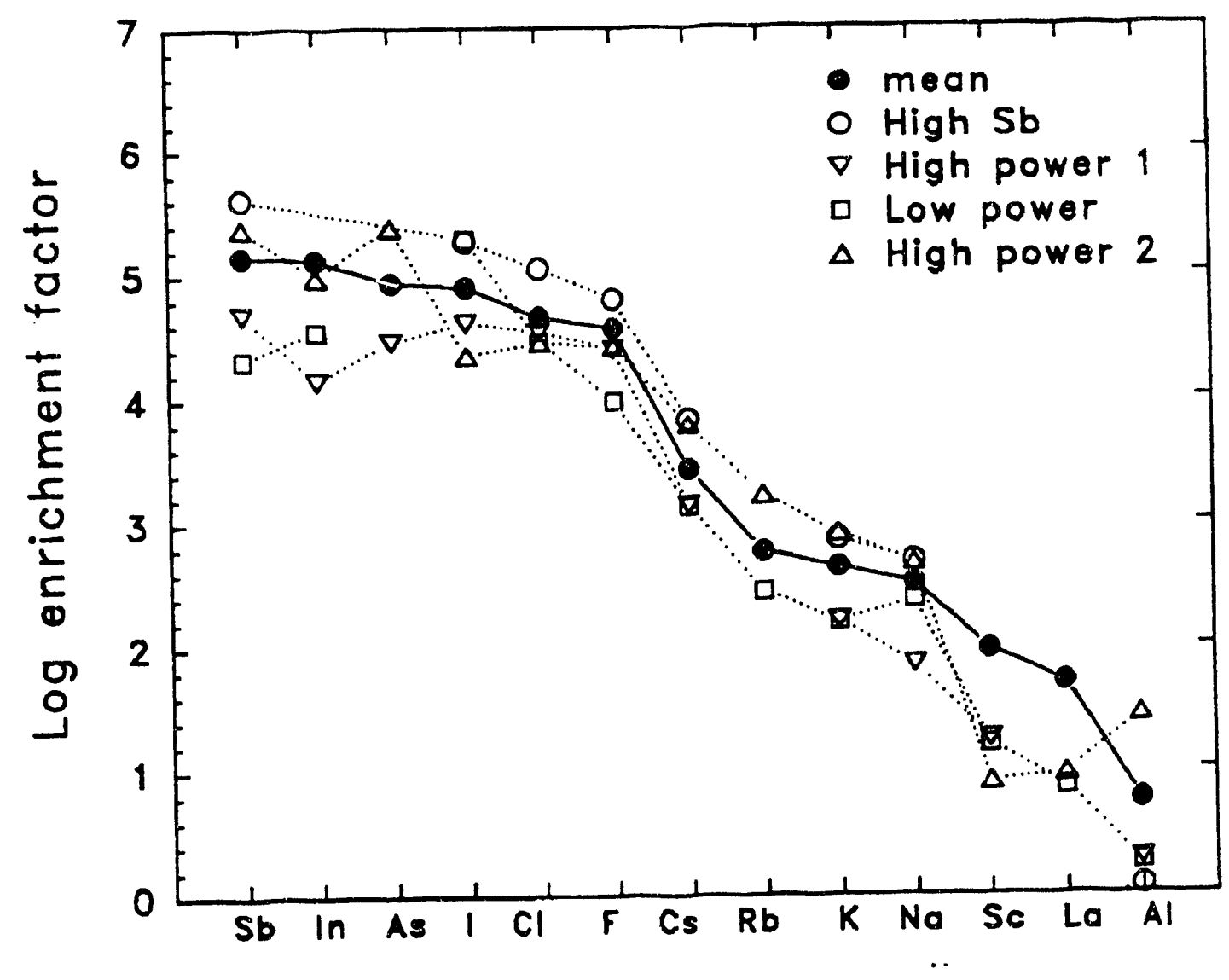

Fig. 61. Enrichment factors calculated for the ISV melt at times of high and low power, as well as at the time of antimony (Sb) incorporation into the melt.

based on analyses of whole gas samples, $\mathrm{CO}_{2}$ is not likely to be a major gas constituent (Table 13). Sulfur species were almost certainly present also, but were not analyzed on the filters or in the whole rock. Analyses of $\mathrm{S}$ from the off-gas processing scrub solutions indicate that these species were subequal to $\mathrm{F}$.

The fluid phase emitted from the ISV melt appears to be very dilute, with $\mathrm{Cl}, \mathrm{F}$, and $\mathrm{K}$ as the main non- $\mathrm{H}_{2} \mathrm{O}$ constituents. The maximum concentration of any analyzed trace element in the fluid is approximately $1200 \mathrm{ppm}$, but many trace metals are in the ppm to sub-ppm range. This degree of dilution may be typical of fluids emitted from magmatic systems that have not undergone any alteration process, such as boiling or interaction with wall rock. Alternatively, the dilute nature of the fluid may be a result of the short contact time between the melt and vapor phases and consequent incomplete partitioning of elements between the two phases. One method to evaluate the completeness of partitioning of halogens and metals between the vapor and melt is to calculate fractionation factors between the melt and vapor. These calculations do not determine true partition coefficients because a demonstrable equilibrium between the two phases is lacking, but they can give some indication of the efficiency of halogen and trace metal fractionation processes (Table 21). The fractionation factors of $\mathrm{Cl}$ and $\mathrm{F}$ between the melt and vapor are both between 3 and 5 . The $\mathrm{Cl}$ fractionation is considerably lower than values that have been reported in the literature for 
Table 21. Fluid concentrations and fractionation factors determined for ISV melt off-gas.

\begin{tabular}{|c|c|c|c|c|}
\hline Element & $\begin{array}{l}\text { Total } \\
\text { emission } \\
(\mathrm{g})\end{array}$ & $\begin{array}{l}\text { Concentration } \\
\text { in fluid } \\
\text { (ppm) }\end{array}$ & $\begin{array}{l}\text { Concentration } \\
\text { in rock } \\
(\mathrm{ppm})\end{array}$ & $\begin{array}{l}\text { Fractionation } \\
\text { factor }^{\mathrm{b}}\end{array}$ \\
\hline $\mathrm{F}$ & 1400 & 820 & 250 & 3.20 \\
\hline $\mathrm{Na}$ & 84 & 50 & 2600 & 0.02 \\
\hline $\mathrm{Cl}$ & 2067 & 1220 & 250 & 4.9 \\
\hline $\mathrm{K}$ & 1416 & 830 & 27000 & 0.03 \\
\hline $\mathrm{Mn}$ & 45 & 25 & 900 & 0.03 \\
\hline $\mathrm{Br}$ & 12 & 8 & 1 & 8 \\
\hline As & 10 & 5 & 1.55 & 3.2 \\
\hline $\mathrm{Rb}$ & 2 & 1 & 120 & 0.01 \\
\hline $\mathrm{Sb}$ & 522 & 310 & 27 & 11.5 \\
\hline
\end{tabular}

equilibrium, high-pressure granitic experiments (Kilinc and Burnham 1972, Keppler and Wyllie 1991, Webster 1992) but is on the same order as $\mathrm{Cl}$ fractionation between a melt and vapor phase in an eruptive rhyolitic system (Dunbar and Kyle 1992). In contrast, the $\mathrm{F}$ fractionation factor between the ISV vapor and melt is similar to, or higher than experimentally determined partition coefficients for high-pressure granites (Webster 1990, Keppler and Wyllie 1991). This discrepancy may be due to the higher solubility of I in a silicic as compared with a mafic melt (Burnham 1979), and does not necessarily imply equitibrium between the vapor and melt. Several metal fractionation factors were also calculated (Table 21), but are difficult to evaluate because detailed information on partition coefficients of metals between a vapor phase and a melt is lacking. The fractionation factors in the ISV melt range from very low ( 0.02 for $\mathrm{Na}$ ) to high (11.5 for Sb). However, values for metal:melt partition coefficients reported in the literature range over six orders of magnitude depending on conditions (e.g., Keppler and Wyllie 1990, 1991; Lowenstern et al. 1991), so it is difficult to estimate how closely trace metal fractionation in the ISV system approached equilibrium.

Based on the time available for partitioning of trace elements between the melt and a vapor phase in the ISV melt, it is unlikely that equilibrium partitioning occurred. However, the halogen fractionation factors are at least in the same order of magnitude as some experimental determinations and are quite similar to fractionation observed in an actively degassing natural system, suggesting that fluids emitted from some magmatic systems may be comparably dilute to those observed during this ISV melt.

\section{Mechanisms of Volatile Emission}

Particle composition and morphology, and enrichment factors, of volatile elements emitted from the ISV melt are similar to those in natural volcanic systems. The well-monitored nature and detailed volatile sampling of the ISV melt allow investigation of the variation of volatile emissions from the ISV melt as a function of time and melt conditions and can be used to help elucidate the mechanisms of volatile release and transport from a melt. Release of volatile components as a function of time can be determined by determining the total amount of a volatile species trapped by an individual filter pack and dividing the total by the air flow through the filter. This approach is not normally possible for a natural system because the dilution of the plume varies continuously, but the ISV melt provides a stable system where dilution is likely to be constant. Most volatile components exhibit similar release patterns from the melt, which are characterized by high release rates when the 

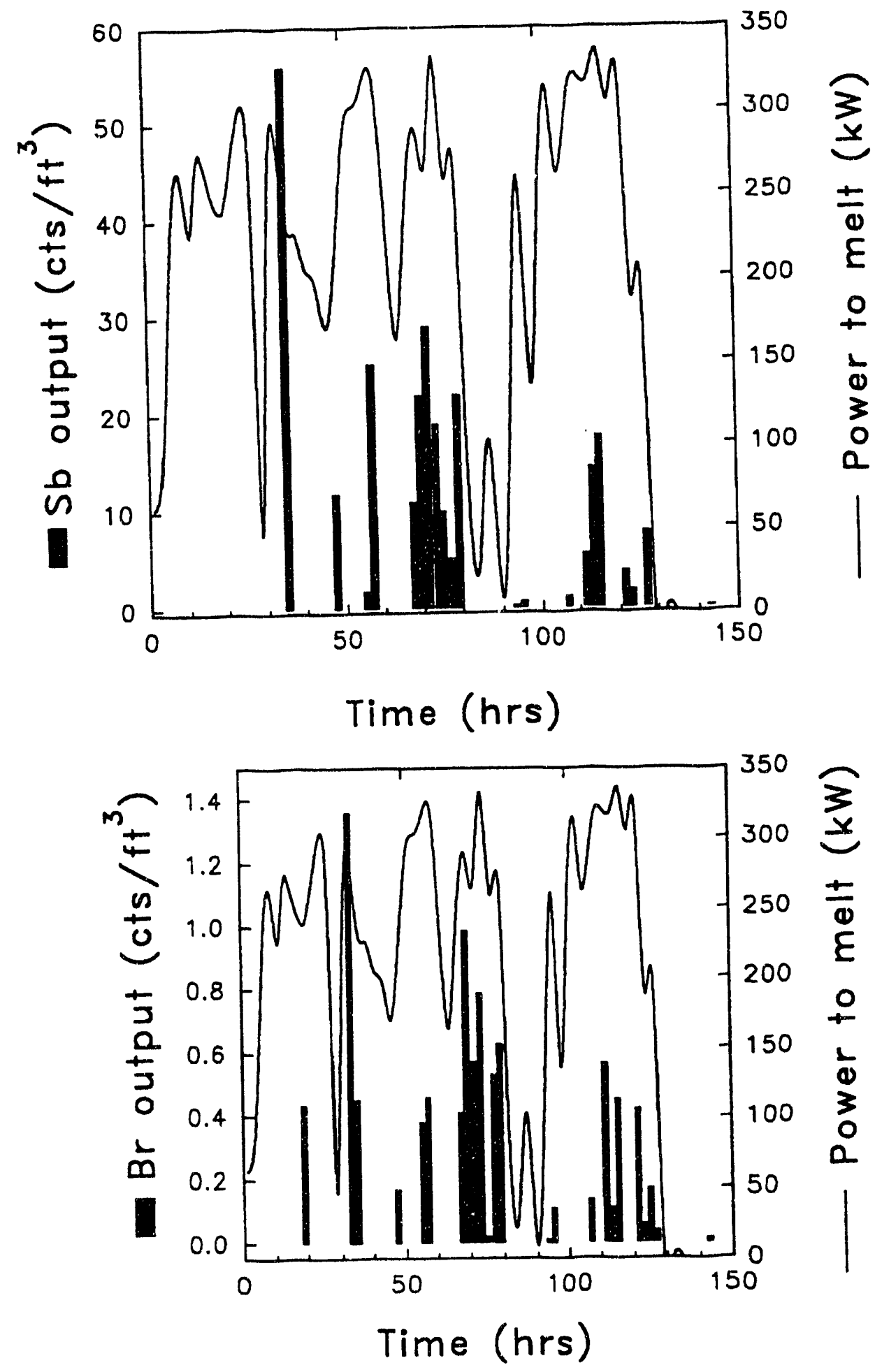

Fig. 62. Power input and antimony (Sb) and bromine (Br) outputs from the ISV melt as a function of time. 
power delivered to the melt is highest (Figs. 61 and Fig. 62). Volatiles that are present only in the soil and limestone and that were not introduced as tracers ( $\mathrm{Br}$ in Fig. 62b) undergo variations in emission rates as a function of power into the melt, but also show some variations between times of high power. This behavior may be a result of natural variations in the composition of the melting material, particularly different mixing ratios between soil and limestone. Halogens $\mathrm{Cl}, \mathrm{F}$, and $\mathrm{Br}$ were all emitted in greater abundance early in the melting process when a greater amount of the limestone was being melted.

However, this problem can be overcome by investigating the release patterns of ${ }^{137} \mathrm{Cs}$ and $\mathrm{Sb}$ tracers, which are present in low abundance in natural soil. These tracers are first detected on filters at close to the time when the melt arrived at the depth where the tracer was buried (Fig. 59). Following an initial pulse when the tracer was first incorporated into the melt, both $\mathrm{Sb}$ and $\mathrm{Cs}$ emissions vary strongly as a function of power input into the melt. The pattern is most striking for ${ }^{137} \mathrm{Cs}$ because all filters were analyzed, whereas analyses for $\mathrm{Sb}$ are not as complete. To understand what the emission patterns men $n$, we must consider the effect of increased power on melt processes. Increased power causes the melt temperature to increase, causing decreased melt viscosity and increased convection rate. However, a more dramatic effect of increased power is a higher rate of melting at the edges of the melt. A higher melting rate increases the amount of volatiles $\left(\mathrm{H}_{2} \mathrm{O}_{ \pm}\right.$ $\mathrm{CO}_{2}$ ) that are incorporated at the melt front and rise upwards through the melt. The bubble dynamics in an ISV melt are different that those in a natural system because the bubbles are incorporated at the melt front, rather than exsolving from an oversaturated melt. Some volatiles are undoubtedly driven away from the melt front by the strong thermal gradient (Kuhn 1992), but physical observations from the partial melt zone of an excavis $\mathrm{d}$ IS $v$ melt plus experimental work done on a heated borehole (McTigue 1990) suggest that $\mathrm{SC}_{\mathrm{A}}$ u bound volatile species will migrate towards a heat source. The soil that produced the 1991 ISV nult also contains $\sim 10 \%$ bound volatiles (predominantly $\mathrm{H}_{2} \mathrm{O}$ in clays), and the limestone, which represented $20 \%$ of melted material, contains $\sim 40 \mathrm{wt} \% \mathrm{CO}_{2}$. Both of these sources provided volatiles that will certainly form bubbles that could rise through the melt or travel to the surface through the dry zone surrounding the ISV melt.

The amount of volatile trace elements emitted from the ISV melt may be a function of the flux of the major fluid phase $\left(\mathrm{H}_{2} \mathrm{O} \pm \mathrm{CO}_{2}\right)$ through the melt. Other factors, such as the halogen content of the gas phase, certainly influence trace element emissions from melts because of their role as complexing agents (Symonds et al. 1992, Candela and Holiand 1986; Keppler and Wyllie 1991), but the total gas flux may play a more important role in influencing total emission. For instance, the pilot-scale ISV melt done at ORNL in 1987 released $0.12 \%$ of the total Cs added to the melt as a tracer, whereas the 1991 ISV melt released approximately $2.4 \%$. Both of these experiments melted approximately the same soil and limestone composition, but the site of the 1987 melt, located on a ridge crest with good drainage, was drier than the 1991 site and included a higher proportion of shaley bedrock and less water-rich clay. The lower Cs release in the 1987 melt may be a function of a lower $\mathrm{H}_{2} \mathrm{O}$ flux through the melt.

The initial pulse of emissions when each tracer was incorporated into the melt may also be related to the presence and abundance of a volatile phase. The locally higher melt concentration of the tracer at the time when incorporation first occurred should not necessarily affect total emission, if Henry's law is obeyed. But a tracer-rich melt in the presence of a locally higher volatile flux through the melt could lead to higher instantaneous emission rates. A high volatile flux at the time that the tracer was incorporated into the melt could be provided by combustion of tracer containers, moist air mixed with the tracers, and/or volatiles incorporated into the melt at the partial melt zone. The locally high concentration of tracers at the time these elements are incorporated into the melt may also affect the volatilization behavior. Local boiling of the tracer may occur and may generate bubbles that are composed dominantly of the tracer, rather than of $\mathrm{H}_{2} \mathrm{O}$ and $\mathrm{CO}_{2}$. This would lead to higher emissions at the time of tracer incorporation. However, this problem requires further investigation, and experimental work is in progress to investigate this as well as the overall effect of volatile flux and composition on trace element emissions from a melt. 


\section{SAMPLING AND ANALYSES OF PREFLTER}

On June 26, 1991, sampling of the prefilter housing [Flanders model E-61X1GG-F(304L)L type 1] and nuclear-grade high-temperature HEP . ilter (Flanders Filter No. 0-007-C-03-03-NG-4323-GGF-U5) was initiated. This filter consisted of pleated fiberglass material bound into a stainless steel frame with a nominal total surface area of $19.97 \mathrm{~m}^{2}$ (by manufacturer's specification and cois ( ned by actual dimensional measurements;. The prefilter housing assembly contained two filters that could be switched in-line if one became loaded, as measured by pressure drop across the unit, or if radioactivity became too high, as measured by periodic monitoring at the housing. Only the first filter was needed during the test because it never became sufficiently loaded to require a change to the second filter line. Although the operator action level for such a change was set at 7.5 in. of differential pressure across the housing, no adverse conditions in the off-gas system were observed even when the differential pressure exceeded this value during the last $5 \mathrm{~h}$ of the test (see Fig. 27). On the prefilter sampling date, the hood had been removed from the melt and placed over the filter housing unit, which had also been removed from the off-gas line and placed on the ground, to function as secondary containment for opening the filter housing. Personnel in full personal protective apparel and fill-face respirators opened the unit, removed the filter frame, and cut the welds on the stainless steel screen which contained the filter material. Using scissors, sections of the filter material of about $20 \times 20 \mathrm{~cm}$ were removed and placed into seal-lock plastic bags. Each plastic bag was subsequently placed inside another seal-lock plastic bag for double containment during transport to the laboratory. Numbering the pleated filter sections from the top, pleats $3 / 4,13,23,33$, 43,53 , and 63 were sampled, giving a representative sample population of the 72 pleats. Except for the initial sample near the top of the unit, all the sections appeared quite uniform in color and density of deposited solids. Care was required to avoid disturbing the flaky material on the filters. The residual filter material was placed in double-plastic bags for disposal as solid low-level radioactive waste following the required ORNL procedures. Uncontaminated samples of HEPA prefilter material were obtained from the unused filter unit, which was sampled prior to the contaminated unit. This material was needed for blank characterization for ${ }^{137} \mathrm{Cs}$ assay and determination of weight per unit area without deposition of solids. The techniques for cutting and handling the samples were also tested on the unused prefilter unit so that exposure and spread of contamination during the sampling of the contaminated filter could be minimized.

\section{Analytical Procedures for Radioisotopes and Elements in Prefilter Samples}

The samples of prefilter were subsampled by cutting $4.0-5.0-\mathrm{cm}$ rectangles and weighing them before placing them into $25-\mathrm{mL}$ plastic scintillation vials. Five blanks of identical size were also cut and weighed for background activity checks. These samples were then assayed preliminarily for activity of ${ }^{137} \mathrm{Cs}$ as described previously for the off-gas filter samples. The 12 samples of the prefilter ( 7 used for off-gas filtration and 5 blanks) were weighed to the nearest $0.0001 \mathrm{~g}$. The samples, ranging in weight from 0.159 to $0.425 \mathrm{~g}$, were transferred to $50-\mathrm{mL}$ tared teflon beakers. The group of teflon beakers was placed in the still-air oven at 100 to $-110^{\circ} \mathrm{C}$ for $1 \mathrm{~h}$, removed, and reweighed to correct for any adsorbed moisture. To each beaker was added $5 \mathrm{~mL}$ of hydrofluoric acid (48\%, EM Science) and $5 \mathrm{~mL}$ of nitric acid (Suprapur, 65\%, EM Science). The hot plate was then turned on to about $200^{\circ} \mathrm{C}$, and the samples were observed while the hydrofluoric and nitric acids were evaporated to dryness. The beaker contents were swirled occasionally to make sure all powder was wetted and subjected to heating. For samples that did not appear to dissolve completely during this initial $\mathrm{HF} / \mathrm{HNO}_{3}$ dissolution, the addition of acids and evaporation was repeated a second time. When the final dried residue in the beaker was obtained, $5 \mathrm{~mL}$ of nitric acid and $5 \mathrm{~mL}$ of distilled water were added. The beaker was returned to the hot plate, the solution warmed to boiling, and the contents swirled to redissolve the residue. The beaker contents were transferred quantitatively to a $50-\mathrm{mL}$ volumetric flask with repeated rinses using $10-\mathrm{mL}$ aliquots of distilled water. After allowing the solutions to cool to room temperature overnight, the flasks were made up to volume with distilled 
Table 22. inventories and activities of ${ }^{137} \mathrm{Cs}$ and $\mathrm{Sr}$ and total solids deposited on the prefilter used in 1991 ORNL ISV test.

\begin{tabular}{|c|c|c|c|}
\hline $\begin{array}{l}\text { HEPA prefilter } \\
\text { (pleat number) }\end{array}$ & $\begin{array}{l}{ }^{137} \mathrm{Cs} \\
\left(\mu \mathrm{Ci} / \mathrm{m}^{2}\right)\end{array}$ & $\begin{array}{l}{ }^{90} \mathrm{Sr} \\
\left(\mu \mathrm{Ci} / \mathrm{m}^{2}\right)\end{array}$ & $\begin{array}{l}\text { Solids } \\
\left(\mathrm{g} / \mathrm{m}^{2}\right)\end{array}$ \\
\hline $\begin{array}{l}3 / 4 \\
13 \\
23 \\
33 \\
43 \\
53 \\
63\end{array}$ & $\begin{array}{r}0.05 \\
8.43 \\
11.20 \\
13.02 \\
12.03 \\
13.48 \\
12.98\end{array}$ & $\begin{array}{l}<0.00013 \\
<0.00013 \\
<0.00013 \\
<0.00013 \\
<0.00013 \\
<0.00013 \\
<0.00013\end{array}$ & $\begin{array}{c}1.4 \\
86.6 \\
1331 \\
120 \\
123.9 \\
131.8 \\
119.2\end{array}$ \\
\hline Average (without layer $3 / 4$ ) & 11.85 & $<0.00013$ & 120.2 \\
\hline Inventory & $\begin{array}{l}{ }_{(\mu \mathrm{CS}}{ }^{137} \mathrm{Cs} \\
(\mu-1)\end{array}$ & $\begin{array}{l}{ }^{90} \mathrm{Sr} \\
(\mu \mathrm{Ci})\end{array}$ & $\begin{array}{l}\text { Solids } \\
(\mathrm{kg})\end{array}$ \\
\hline $\begin{array}{l}\text { Prefilter HEPA } \\
\text { Total off-gas filter } \\
\text { (including MM5 filters) } \\
\text { Total volatilized } \\
\text { (including hood and pipes) }\end{array}$ & $\begin{array}{l}236.7 \\
238.2 \\
244.6\end{array}$ & $\begin{array}{l}<0.0023 \\
<0.0023 \\
<0.0023\end{array}$ & $\begin{array}{l}2.40 \\
2.41\end{array}$ \\
\hline
\end{tabular}

water and mixed. The solution was transferred to a labeled, precleaned plastic bottle and stored at $2^{\circ} \mathrm{C}$ until analyzed.

An aliquot of $20.00 \mathrm{~mL}$ was transferred to a $25-\mathrm{mL}$ polyethylene scintillation vial with a plastic-lined screw cap. The emission of Cerenkov radiation was determined on these scintillation vials after allowing 3 weeks for complete ingrowth of the ${ }^{90} \mathrm{Y}$ daughter of ${ }^{90} \mathrm{Sr}$ using procedures described by Haberer (1965). A Packard model 2000CA TRI-CARB liquid scintillation counter was employed for all Cerenkov radiation measurements. Three regions of interest were set $(0-40.0,2.5$ 40.0 , and $5.0-400 \mathrm{keV})$ to measure Cerenkov radiation. Standards of ${ }^{90} \mathrm{Sr}(0.00395 \mu \mathrm{Ci})$ and ${ }^{137} \mathrm{Cs}$ $(0.345 \mu \mathrm{Ci})$ were prepared in $6.5 \% \mathrm{HNO}_{3}$ to determine counting efficiency for the Cerenkov radiation detection. Typicialy, " $\mathrm{Sr}$ was counted with efficiencies of 62,55 , and $40 \%$ in the three regions of interest, respectively, while ${ }^{137} \mathrm{Cs}$ was counted with efficiencies of $5.5,2.5$, and $0.4 \%$ in these same regions or windows. The narrower region of interest $(5.5-40.0 \mathrm{keV})$ was used for the ${ }^{90} \mathrm{Sr}$ determination in these prefilter digests because of the 100 -fold sensitivity for ${ }^{90} \mathrm{Sr}$ over ${ }^{137} \mathrm{Cs}$. The much lower energy beta emission from ${ }^{137} \mathrm{Cs}$, compared with both ${ }^{90} \mathrm{Sr}$ and its ${ }^{90} \mathrm{Y}$ daughter, is the cause of its poor counting efficiency using Cerenkov radiation (Haberer 1965). However, this was an advantage in the present case because it allowed accurate assays of ${ }^{90} \mathrm{Sr}$ even in the presence of significant amounts of ${ }^{137} \mathrm{Cs}$. The same samples and standards were also assayed for ${ }^{137} \mathrm{Cs}$ activity via gamma spectroscopy; these ${ }^{137} \mathrm{Cs}$ determinations were used for the calculation of prefilter activities and inveniory. In addition, the independently measured activities of ${ }^{137} \mathrm{Cs}$ were used to calculate their contribution to the apparent ${ }^{90} \mathrm{Sr}$ Cerenkov radiation. Using the ${ }^{137} \mathrm{Cs}$ counting efficiency, counts due 
to the ${ }^{137} \mathrm{Cs}$ were subtracted from the total counts in this narrower region of interest. This led to a detection limit of $0.2 \mathrm{dpm}$ of ${ }^{90} \mathrm{Sr}$ in a sample even in the presence of the greatest observed activity of ${ }^{137} \mathrm{Cs}$. However, no ${ }^{90} \mathrm{Sr}$ activity was detected in any of the prefilter digests, and this detection limit led to the calculated minimum inventory of ${ }^{90} \mathrm{Sr}$ on the prefilter (Table 22). Because no ${ }^{90} \mathrm{Sr}$ was detected on the prefilter, where $98 \%$ of the volatilized inventory of ${ }^{137} \mathrm{Cs}$ was found, none of the hood wall or off-gas pipe smear samples were prepared or assayed for ${ }^{90} \mathrm{Sr}$ determination via this Cerenkov radiation technique. The pulverized ISV product, starting soil, and dolomite samples were assayed for ${ }^{90} \mathrm{Sr}$ via this same technique.

Resalts tr all seven samples of the contaminated prefilter are presented in Table 22. The average depositis of both ${ }^{137} \mathrm{Cs}$ and solids can be seen to be quite uniform except for the one sample near the top the prefilter. Thus, the inventory calculated on the basis of the total surface of the prefilter is probably quite precise. The fact that total emissions of ${ }^{137} \mathrm{Cs}$, based on the MM5 samples, amounted to between 93 and $129 \%$ of the prefilter inventory was actually quite reassuring because the magnitude of volatilization measured by both methods was consistent. It is interesting to note that, if the activity of ${ }^{137} \mathrm{Cs}$ on the prefilter is expressed on a per unit weight of deposited solids, i.e., $0.099 \mu \mathrm{Ci} / \mathrm{g}$, then the average activity was over a hundred times the average activity of the cored material, i.e., $0.00085 \mu \mathrm{Ci} / \mathrm{g}$. This result clearly demonstrates that the emission of ${ }^{137} \mathrm{Cs}$ is a true volatilization rather than an attachment of the radionuclide to particles of glass that were then suspended in the off-gas. As indicated in Table 22, the complete inventory of ${ }^{137} \mathrm{Cs}$ should include the activity on the two MM5 sampler filter sets because these were also particulates that would have been deposited on the prefilter if the samplers were not used to remove an isokinetic gas sample.

Other aliquots of the $\mathrm{HF} / \mathrm{HNO}_{3}$ digests were submitted to ORNL Analytical Chemistry Division (ACD) for analyses of elements. All routine elements, determined during inductively coupled plasma (ICP) atomic emission, were analyzed. In addition, flame atomic absorption methods were used to measure concentrations of $\mathrm{La}, \mathrm{Ce}, \mathrm{Nd}$, and Ir (the tracers placed in the test melt, Table 10). Inventories of each element were then calculated from the difference in element concentration in the used and blank prefilter digests. In addition, a combined solid sample of remaining prefilter remnants was pulverized in the ball mill as described in the ISV product sample preparation section. This sample was submitted to the ORNL $\mathrm{ACD}$ for assay of ${ }^{137} \mathrm{Cs},{ }^{60} \mathrm{Co},{ }^{40} \mathrm{~K},{ }^{90} \mathrm{Sr},{ }^{241} \mathrm{Am}$, and ${ }^{239.240} \mathrm{Pu}$. A summary 0 , elemental inventories on the prefilter is presented in Table 23.

\section{Elements Deposited on the Prefilter}

The net deposition of an element on the prefilter is not the simple product of the total weight of filter material times the difference in concentration between the used and unused (blank) filter samples. The used filter samples had a considerable deposition of solids and thus averaged about twoand-a-half times the weight per unit area $\left(20.1 \mathrm{mg} / \mathrm{cm}^{2}\right)$ more than the unused (blank) samples $(8.1$ $\mathrm{mg} / \mathrm{cm}^{2}$ ). Thus, net deposition is calculated for each used sample using the average concentration for an equivalent area (total prefilter area $=199,738 \mathrm{~cm}^{2}$ ) of unused prefilter sample. Net deposition was then calculated:

[(used prefilter concentration $\times$ used prefilter weight $/ \mathrm{cm}^{2}$ )

- (blank prefilter concentration $\times$ blank prefilter weight $\left.\left./ \mathrm{cm}^{2}\right)\right] \times$ total prefilter area

Thus it is theoretically not possible to have a net negative deposition although such negative depositions were calculated for a few elements for other reasons. For example, significant negative depositions were calculated for the elements $\mathrm{Ba}, \mathrm{Na}$, and $\mathrm{Sr}$; other small negative depositions, such as $\mathrm{Al}$ and $\mathrm{Be}$, resulted from small differences in large and variable average concentrations. The "disappearance" of $\mathrm{Ba}$ and $\mathrm{Sr}$ could be ascribed to the singularly low solubility of $\mathrm{BaSO}_{4}$ even to $\mathrm{HF} / \mathrm{HNO}_{3}$ dissolution and thus to $\mathrm{Sr}$ as a coprecipitate, due to in situ deposition of sulfate on the prefilter; sulfate dominates the anion composition of the scrub solution due to the volatilization of $\mathrm{SO}_{x}$ during vitrification. The deposition of sulfate on the postscrubber HEPA filter was observed in 
Table 23. Average elemental concentrations, net deposition, and relative deposition factors for the prefilter and unused filter from the ORNL 1991 pilot-scale ISV test.

\begin{tabular}{|c|c|c|c|c|}
\hline Element & $\begin{array}{l}\text { Prefilter c } \\
\begin{array}{l}\text { Used } \\
(\mathrm{mg} / \mathrm{g})\end{array}\end{array}$ & $\begin{array}{l}\text { entration } \\
\text { Blank } \\
(\mathrm{mg} / \mathrm{g})\end{array}$ & $\begin{array}{l}\text { Net prefilter } \\
\text { deposition } \\
\text { (mg) }\end{array}$ & $\begin{array}{l}\text { Relative } \\
\text { deposition } \\
\text { factor }\end{array}$ \\
\hline $\mathrm{Ag}$ & 0.025385 & 0.001547 & 99.53342 & 34.84314 \\
\hline $\mathrm{Al}$ & 11.72114 & 29.38644 & -657.596 & 0.949101 \\
\hline As & 0.486379 & 0.015476 & 1932.128 & 66.83029 \\
\hline B & 9.268898 & 19.59073 & 5300.964 & 1.139748 \\
\hline $\mathrm{Ba}$ & 0.390460 & 38.35686 & -60659.4 & 0.061755 \\
\hline $\mathrm{Be}$ & 0.001381 & 0.003465 & -0.10004 & 0.982199 \\
\hline $\mathrm{Ca}$ & 15.62441 & 14.23424 & 39643.93 & 2.617723 \\
\hline $\mathrm{Cd}$ & 0.402546 & 0.005874 & 1613.133 & 149.5787 \\
\hline $\mathrm{Ce}$ & 0.006181 & 0.006869 & 13.61508 & 2.316208 \\
\hline Co & 0.032294 & 0.027178 & 86.39895 & 2.613501 \\
\hline $\mathrm{Cr}$ & 0.457172 & 0.956178 & 289.2179 & 1.132551 \\
\hline $\mathrm{Cu}$ & 0.402300 & 0.008441 & 1603.950 & 102.6223 \\
\hline $\mathrm{Fe}$ & 25.15914 & 5.403940 & 93278.54 & 10.12606 \\
\hline Ir & 0.000251 & 0.000309 & 0.501652 & 1.856397 \\
\hline $\mathrm{La}$ & 0.004006 & 0.003714 & 10.03466 & 2.713195 \\
\hline $\mathrm{Li}$ & 170 & 15 & 659670.7 & 25.74446 \\
\hline $\mathrm{Mg}$ & 6.910001 & 1.547006 & 25260.03 & 10.42873 \\
\hline $\mathrm{Mn}$ & 0.316707 & 0.036277 & 1220.886 & 18.81217 \\
\hline Mo & 0.066723 & 0.043960 & 196.3515 & 3.659876 \\
\hline $\mathrm{Na}$ & 6.907836 & 21.59866 & -7430.90 & 0.879978 \\
\hline Nd & 0.003569 & 0.003588 & 8.481561 & 2.561674 \\
\hline $\mathrm{Ni}$ & 0.173069 & 0.066295 & 592.5557 & 5.660488 \\
\hline $\mathrm{P}$ & 2.371715 & 0.245773 & 9136.587 & 20.50218 \\
\hline $\mathrm{Pb}$ & 7.924347 & 0.056337 & 31776.36 & 303.2377 \\
\hline $\mathrm{Sb}$ & 18.74614 & 0.121230 & 75081.50 & 333.2468 \\
\hline $\mathrm{Se}$ & 0.282640 & 0.115211 & 942.3005 & 5.463191 \\
\hline $\mathrm{Si}$ & 34.16069 & 28.53918 & 92555.98 & 2.772311 \\
\hline $\mathrm{Sn}$ & 0.193670 & 0.056343 & 686.4858 & 7.727258 \\
\hline $\mathrm{Sr}$ & 0.078369 & 0.569290 & -609.726 & 0.336966 \\
\hline $\mathrm{Ti}$ & 0.155715 & 0.199907 & 303.0697 & 1.806443 \\
\hline V & 0.073405 & 0.005951 & 286.4405 & 26.60996 \\
\hline $\mathrm{Zn}$ & 82.61244 & 80.91203 & 201655.2 & 2.215155 \\
\hline $\mathrm{Zr}$ & 0.127627 & 0.056955 & 418.6738 & 5.502283 \\
\hline
\end{tabular}

the 1987 demonstration (Spalding and Jacobs 1989); therefore it was probably deposited on the prefilter in this demonstration, although the prefilter was not analyzed for extractable anions. The negative deposition of sodium can be ascribed to a small difference in two relatively large numbers.

Perhaps a more useful way to look at net deposition that will minimize the effects of negative deposition is to calculate a relative deposition factor. This is defined as the ratio of the net amount of an element on the used filter to that on an unused filter: 
(used prefilter concentration $\times$ used prefilter weight $/ \mathrm{cm}^{2}$ ) /

(blank prefilter concentration $\times$ blank prefilter weight $/ \mathrm{cm}^{2}$ )

Thus a ratio of 1.00 would be expected for the case of no net deposition while net positive deposition would lead to values greater than one. Thus, net negative deposition for elements like $\mathrm{Al}, \mathrm{Be}$, and $\mathrm{Na}$ have values of $0.95,0.98$, and 0.88 , respectively, indicating that the net deposition is close to the case of no net deposition. The only other elements with relative deposition factors less than one were $\mathrm{Ba}$ and $\mathrm{Sr}$ ( 0.06 and 0.34 , respectively); this is probably due to the insolubility problem discussed above.

The elemental relative deposition factors worked well to identify those elements with a major release from the melt and would include those with factors greater than 100 , i.e., $\mathrm{Cd}, \mathrm{Cu}, \mathrm{Pb}$, and $\mathrm{Sb}$. Elements with relative deposition factors greater than 10 , but less than 100 , might be classified as less volatile and would include $\mathrm{Ag}, \mathrm{As}, \mathrm{Fe}, \mathrm{Li}, \mathrm{Mg}, \mathrm{Mn}, \mathrm{P}$, and $\mathrm{V}$. The positive relative deposition factor for the added tracer elements $\mathrm{Ce}, \mathrm{La}$, and $\mathrm{Nd}$ were all roughly equivalent at about 2.6 , which is similar to relative deposition factors for such nonvolatile elements as $\mathrm{Si}$ and $\mathrm{Ca}$. Relative deposition factors of this magnitude probably do not arise from any volatility of the element but rather are caused by entrainment of particulates from the melt's turbulence and surrounding soil by the velocity of gases within the off-gas collection system. The enrichment of the filter for $\mathrm{Ce}, \mathrm{La}$, and $\mathrm{Nd}$ indicates that an average of about $10 \mathrm{mg}$ of each element was deposited on the filter from the off-gas due to entrainment of particulates. Thus, the tracers for trivalent actinides and transuranic elements indicate that accurately measured quantities were released from the melt and, when compared with the known amounts added to the melt, can be used to calculate elemental retention factors as discussed later.

\section{Radioisotopes Deposited on the Prefilter}

The prefilter sample was also analyzed for the radioisotopes added to the melt (Table 24). Except for the environmental levels of ${ }^{40} \mathrm{~K}$, the blank filter material was presumed to contain none of the reported radioisotopes. Thus, ret depositions and relative deposition factors cannot be calculated. However, the more impor a melt retention factors have been calculated. These are based on the ratio of the amount in the product, for radioisotopes not analyzed in the starting materials (soil and dolomite), which included ${ }^{40} \mathrm{~K},{ }^{60} \mathrm{Co},{ }^{241} \mathrm{Am}$, and ${ }^{239,240} \mathrm{Pu}$, or the amount added in the sludge sample, which included ${ }^{137} \mathrm{Cs}$ and ${ }^{90} \mathrm{Sr}$. It is obvious that ${ }^{137} \mathrm{Cs}$ is the most volatile of the radioisotopes contained in the sludge sample. Most importantly, the transuranic isotopes, Am and $\mathrm{Pu}$, were strongly retained in the melt as was the hazardous fission product ${ }^{90} \mathrm{Sr}$. Actually, the reported activity of ${ }^{241} \mathrm{Am}$ on the prefilter sample was $5 \pm 11 \mathrm{~Bq} / \mathrm{kg}$, which indicates that the measured value could well be zero within the uncertainty of the count rate observed. But, to be conservative in the estimate of what fraction of the ${ }^{241} \mathrm{Am}$ might leave an ISV melt, the low positive calculated activity was carried through in the retention factor calculation. In essence, the detection limits for the counting of the ${ }^{214} \mathrm{Am}$ and ${ }^{239.240} \mathrm{Pu}$, coupled with the limited activities in the sludge sample, have allowed an estimate that the maximum amount retained in the ISV melt was greater than $99.993 \%$ of the starting activity.

\section{Rare Earth Tracers (Ce, La, and Nd) Deposited on the Prefilter}

To obtain a better estimate for the retention of transuranic and actinide radioisotopes than those estimated conservatively from the detection limits of the actual radioisotopes in the sludge sample, the retention factors of the three rare earth tracer elements were examined (Table 25). For all three elements, the calculated percent retention in the ISV melt was equal to or greater than 99.9995\%. These estimates are considered quite accurate because the amounts on the prefilter were well above background compositions on the unused filter samples and because of the kilogram quantities buried in the ISV trench (Table 10). Thus it would appear that there is little concern for any volatilization or particulate release via entrainment in the off-gas for any of the transuranic 
Table 24. Deposition of radioisotopes on the prefilter, amounts in the ISV product, and melt retention factors during the 1991 ORNL pilot-scale field test.

\begin{tabular}{crrrr}
\hline & $\begin{array}{r}\text { Activity } \\
\text { Found } \\
\text { On Prefilter } \\
(\mathrm{Bq})\end{array}$ & $\begin{array}{r}\text { Activity } \\
\text { Added or } \\
\text { In ISV } \\
\text { Product } \\
(\mathrm{kBq})\end{array}$ & $\begin{array}{r}\text { Retention } \\
\text { Factor }\end{array}$ & $\begin{array}{r}\text { Percent } \\
\text { Retained } \\
(\%)\end{array}$ \\
\hline${ }^{241} \mathrm{Am}$ & 21 & 309 & $>15100$ & $>99.993$ \\
${ }^{60} \mathrm{Co}$ & 262 & 156 & 595 & 99.832 \\
${ }^{137} \mathrm{Cs}$ & 8766500 & 374000 & 42 & 97.66 \\
${ }^{40} \mathrm{~K}$ & 21750 & 12030 & 553 & 99.819 \\
${ }^{239,240} \mathrm{Pu}$ & $<4$ & 63 & $>15700$ & $>99.994$ \\
${ }^{90} \mathrm{Sr}$ & $<85$ & 96040 & $>11.3 \times 10^{6}$ & $>99.9999$ \\
& & & & \\
\hline
\end{tabular}

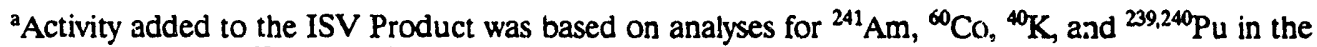
product whereas ${ }^{137} \mathrm{Cs}$ and ${ }^{90} \mathrm{Sr}$ were based on the amounts added in the sludge sample.

Table 25. Deposition of rare earth tracers on the prefilter, amounts in the ISV product, and retention factors during the 1991 ORNL pilot-scale field test.

\begin{tabular}{lcccc}
\hline Tracer & $\begin{array}{r}\text { Amount } \\
\text { Found on } \\
\text { prefilter } \\
(\mathrm{mg})\end{array}$ & $\begin{array}{c}\text { Amount } \\
\text { In ISV } \\
\text { product } \\
(\mathrm{kg})\end{array}$ & $\begin{array}{c}\text { Retention } \\
\text { factor }\end{array}$ & $\begin{array}{c}\text { Percent } \\
\text { retained } \\
(\%)\end{array}$ \\
\hline $\mathrm{Ce}$ & 13.63 & 2.676 & 196500 & 99.9995 \\
$\mathrm{La}$ & 10.03 & 2.114 & 210600 & 99.9995 \\
$\mathrm{Nd}$ & 8.48 & 1.886 & 222300 & 99.9996 \\
\hline
\end{tabular}

isotopes. Although only ${ }^{241} \mathrm{Am}$ and ${ }^{239,240} \mathrm{Pu}$ were detected in this demonstration, this conclusion would hold for other transuranics including $\mathrm{Cm}, \mathrm{Np}$, and probably U. Thus ISV for the ORNL seepage pits and trenches should not be limited by any off-gas radiological hazards imposed by their transuranic isotope contents. 


\section{OFF-GAS SCRUB SOLUTION MONTTORING}

Samples of off-gas scrub solutions were initially collected every $2 \mathrm{~h}$ during the operation of the ISV pilot-scale system but sampling frequency was changed to one sample per 6 in. of melt progress. Samples were divided so that selected analyses could be conducted at PNL to provide a check on the results at ORNL. One of the secondary objectives of the present test was to minimize the volume of liquid waste produced by the off-gas treatment system by limiting condensation of water distilled from the melt. The objective was achieved in that only $183 \mathrm{~L}$ of liquid waste was produced from the off-gas system and most of this was actually rinsing solutions required to purge the scrub solution holding tanks following the test. In the 1987 demonstration, without any attempt at liquid waste minimization, a total of $1974 \mathrm{~L}$ was produced, which was contaminated with radioactivity from residuals in the PNL off-gas trailer. In 1987 a total of $17.1 \mathrm{~kg}$ of solids (dissolved and suspended) was removed by the off-gas scrub solution system, whereas the present demonstration acquired only 3.8 $\mathrm{kg}$ in the scrub solution (as measured in the waste solutions disposal drums). However, the prefilter was valved into the off-gas line at $48 \mathrm{~h}$ into the run, and the solids deposited on it $(2.4 \mathrm{~kg})$ need to be added to the scrub solution total. Thus the total of $6.2 \mathrm{~kg}$ of total solids collected from the melt was considerably less than the $17.1 \mathrm{~kg}$ collected in 1987 for a $70 \%$ larger pilot-scale ISV melt. The reasons for the difference in total solids collected in the present and previous ORNL demonstrations are not apparent. However, the present octagonal hood has a significantly larger volume than the rectangular hood used in the 1987 demonstration. The present hood probably has quite difierent aerodynamics for off-gas transport, which may result in less entrainment of solids from the soil surface. In addition, a better hermetic seal between off-gas hood and ground surface would result in lower off-gas flow rates and, hence, lower suspension of soil particles to maintain the required vacuum on the off-gas hood.

The temporal effect of gaseous emissions from the melt is depicted in the acidity of the offgas treatment scrub solution (Fig. 63). The initial scrub solution was made of near-neutral ORNL process water. As melting progressed, acidic gases, i.e., $\mathrm{HF}, \mathrm{HCl}, \mathrm{CO}_{2}$ and $\mathrm{SO}_{x}$ from the soil and limestone caused the $\mathrm{pH}$ of the solution to drop well below 2. Concomitantly, there was a continuous increase in the dissolved solids content of the scrub solution with i un time (Fig. 64); the last data point in Fig. 64 represents the effect of rinsing operations after the melt was completed. Although an analysis of specific radionuclides in the scrub solution samples was not attempted, measured gross $\alpha$ and $\beta$ activities of the combined unfiltered waste solutions indicated no detectable activity (i.e., $<200 \mathrm{dpm} / \mathrm{L}$ or $<90 \mathrm{pCi} / \mathrm{L}$ ). Thus the waste solution produced was not a mixed (radioactive and hazardous) waste and could be disposed as hazardous liquid waste. The dissolved chemical composition of the combined scrub solution waste is presented in Table 26; total dissolved solids averaged $20,200 \mathrm{mg}^{\prime} \mathcal{L}$, whereas suspended solids averaged only $987 \mathrm{mg} /$, i.e., $<5 \%$ of the total solids. Unlike the 1987 IS der onstration, where sulfate dominated the anions in the scrub solution, the present scrub solution was dominated by fluoride and chloride. The source of the sulfate (i.e., the soil or limestone) was not determined in 1987, and sources of the halides need to be determined in the present test materials. The apparent abundance of halides in the off-gas could be important in understanding the volatilization of cesium as halides are the most likely candidates to form ion pairs with cesium and other alkali metal elements thereby facilitating their emission from the melt. The significant amounts of heavy metals are not indicative of a typical scrub solution composition anticipated from ISV at an ORNL contaminated soil site. The PNL pilot-scale unit had previously been used in a test of ISV on a simulated underground storage tank that contained a simulated sludge with the following constituents: $\mathrm{Cr}_{2} \mathrm{O}_{3}(2315 \mathrm{~g}), \mathrm{Co}\left(\mathrm{NO}_{3}\right)_{2} 6 \mathrm{H}_{2} \mathrm{O}(1630 \mathrm{~g}), \mathrm{CsNO}_{3}(270 \mathrm{~g}), \mathrm{Sr}\left(\mathrm{NO}_{3}\right)_{2}$ $(675 \mathrm{~g}), \mathrm{HrO}(135 \mathrm{~g}), \mathrm{Pb}(4620 \mathrm{~g}), \mathrm{Ni}(1000 \mathrm{~g}), \mathrm{Ba}\left(\mathrm{NO}_{3}\right)_{2}(5138 \mathrm{~g})$, tributyl phosphate $(990 \mathrm{~g})$, and $\mathrm{CdO}(31 \mathrm{~g})$. Thus the significant portions of the inventories of $\mathrm{Cr}, \mathrm{Ni}$, and $\mathrm{Cd}$ (Table 26) could have resulted from residuals in the off-gas scrubbing system in addition to emissions during the present test.

The anionic composition of the scrub solution was significantly different than that attained in 1987. Although the total amounts of $\mathrm{Cl}$ and $\mathrm{F}$ removed from the off-gas into the scrub solution were similar, the amount of $\mathrm{SO}_{4}=$ found in 1987 was about 2.0 times more than in the present test. 
Table 26. Chemical composition and acid-extractable concentrations of ISV waste scrub solutions in ORNL tests in 1987 and 1991.

\begin{tabular}{|c|c|c|c|c|}
\hline Species & $\begin{array}{r}1991 \\
\text { Concentration } \\
(\mathrm{mg} / \mathrm{L})\end{array}$ & $\begin{array}{l}1991 \\
\text { Total } \\
(\mathrm{mg})\end{array}$ & $\begin{array}{r}1987 \\
\text { Total } \\
(\mathrm{mg})\end{array}$ & $\begin{array}{r}1987 \\
\text { Concentration } \\
(\mathrm{mg} / \mathrm{L})\end{array}$ \\
\hline $\mathrm{Ag}$ & $<0.26$ & $<4760$ & $<2170$ & $<1.1$ \\
\hline $\overrightarrow{A l}$ & 179.6 & 328851 & 17317 & 8.2 \\
\hline As & 3.8 & 696 & 3277 & 1.7 \\
\hline B & 88 & 6113 & 281721 & 134 \\
\hline $\mathrm{Ba}$ & 0.44 & 81 & 114 & 0.06 \\
\hline $\mathrm{Be}$ & 0.016 & 3 & $<79$ & $<0.04$ \\
\hline $\mathrm{Ca}$ & 192.1 & 35174 & 35431 & 18.2 \\
\hline $\mathrm{Cd}$ & 3.9 & 714 & 186 & 0.09 \\
\hline Co & 1.9 & 348 & 489 & 0.23 \\
\hline $\mathrm{Cr}$ & 134.2 & 24572 & 15870 & 8.0 \\
\hline $\mathrm{Cu}$ & $<0.36$ & $<66$ & 709 & 0.4 \\
\hline $\mathrm{Fe}$ & 1852.4 & 339174 & 487080 & 231 \\
\hline $\mathrm{Hg}$ & 0.04 & 7 & nd & nd \\
\hline$\hat{\mathrm{Li}}$ & $<770$ & $<141000$ & 78969 & 37.6 \\
\hline $\mathrm{Mg}$ & 59.9 & 10968 & 22127 & 11.1 \\
\hline $\mathrm{Mn}$ & 19.4 & 3552 & 4675 & 2.4 \\
\hline Mo & $<2.0$ & $<366$ & 8045 & 4.1 \\
\hline $\mathrm{Na}$ & $<260$ & $<47600$ & 1628045 & 786 \\
\hline $\mathrm{Ni}$ & 75.1 & 13751 & 6560 & 3.3 \\
\hline$P$ & 42.9 & 7855 & 22975 & 10.8 \\
\hline $\mathrm{Pb}$ & 4.8 & 879 & 14890 & 7.5 \\
\hline $\mathrm{Sb}$ & 16.7 & 3058 & 602 & 0.31 \\
\hline $\mathrm{Se}$ & $<2.6$ & $<476$ & $<8290$ & $<4.2$ \\
\hline $\mathrm{Si}$ & 444 & 81296 & 160816 & 79.4 \\
\hline $\mathrm{Sn}$ & $<2.6$ & $<476$ & 418 & 0.21 \\
\hline $\mathrm{Sr}$ & 0.7 & 128 & 676 & 0.33 \\
\hline $\mathrm{Ti}$ & 7 & 1282 & 862 & 0.44 \\
\hline V & 1.2 & 220 & $<829$ & $<0.42$ \\
\hline $\mathrm{Zn}$ & 214.4 & 39257 & 45803 & 21.5 \\
\hline $\mathrm{Zr}$ & $<1.0$ & $<183$ & 3415 & 1.63 \\
\hline $\mathrm{Br}$ - & $<100$ & $<18300$ & $<98700$ & $<50$ \\
\hline $\mathrm{Cl}-$ & 2513.1 & 460149 & 795000 & 379 \\
\hline F- & 1895.5 & 347066 & 360000 & 173 \\
\hline $\mathrm{NO}_{3}-$ & $<100$ & $<18300$ & $<98700$ & $<50$ \\
\hline $\mathrm{H}_{2} \mathrm{PO}_{4-}^{-}$ & $<100$ & $<18300$ & $<98700$ & $<50$ \\
\hline $\mathrm{SO}_{4}=$ & 1393.4 & 255132 & 4545000 & 2159 \\
\hline
\end{tabular}

This may reflect a limited solubility of $\mathrm{SO}_{\mathrm{x}}$ in water with excess going up the off-gas processing stack rather than a difference in amount of $\mathrm{SO}_{\mathrm{x}}$ evolved during the two tests. The actual concentrations 


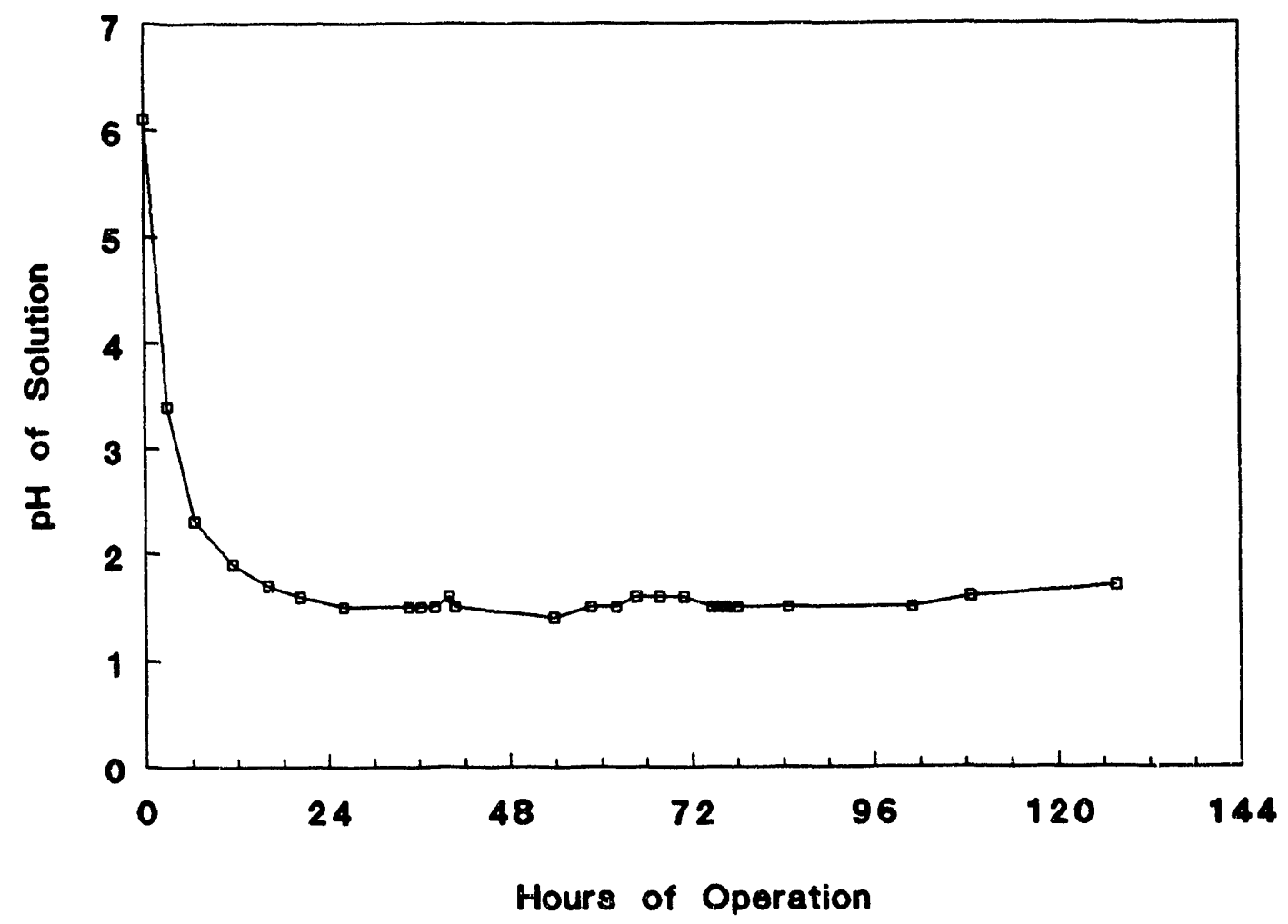

Fig. 63. The pH of ISV off-gas venturi-ejector scrub solution during the 1991 ORNL ISV test.

of sulfate in the scrub solutions in 1987 and 1991 were similar, but in 1991 only $183 \mathrm{~L}$ were generated as opposed to $1974 \mathrm{~L}$ generated in 1987.

The $\mathrm{pH}$, conductivity, total solids, and total dissolved solids for the scrub samples are shown in Table 27. The analysis of the off-gas system scrub samples revealed a large fluctuation or reduction in total solids content for the last $30 \mathrm{~h}$ of the test. The reduction of solids in solution was possibly due to a decrease in the flow through the venturi-ejector scrubber causing a reduction of turbulence in tank 1 (the action of the pump suction and return flow are the only means of agitation for the scrub tanks). It should be assumed that the settling of solids in the scrub solution has produced a considerable amount of bias with regards to sample homogeneity and therefore to analytical results. Also, the use of the prefilter prevented any further accumulation of solids in the scrub tanks when valved into the off-gas line at $48 \mathrm{~h}$. Therefore, the primary means for determining retention values for ${ }^{137} \mathrm{Cs}$ and the rare earth tracers was the analysis of the off-gas prefilter samples, hood and ducting swipes, and the vitrified product. The anionic composition of the scrub solution is displayed in Table 28. The data presented in Table 28 reflect the highest concentration of anions found in the scrub samples analyzed. The sample corresponds to a run time of $94.47 \mathrm{~h}$. 


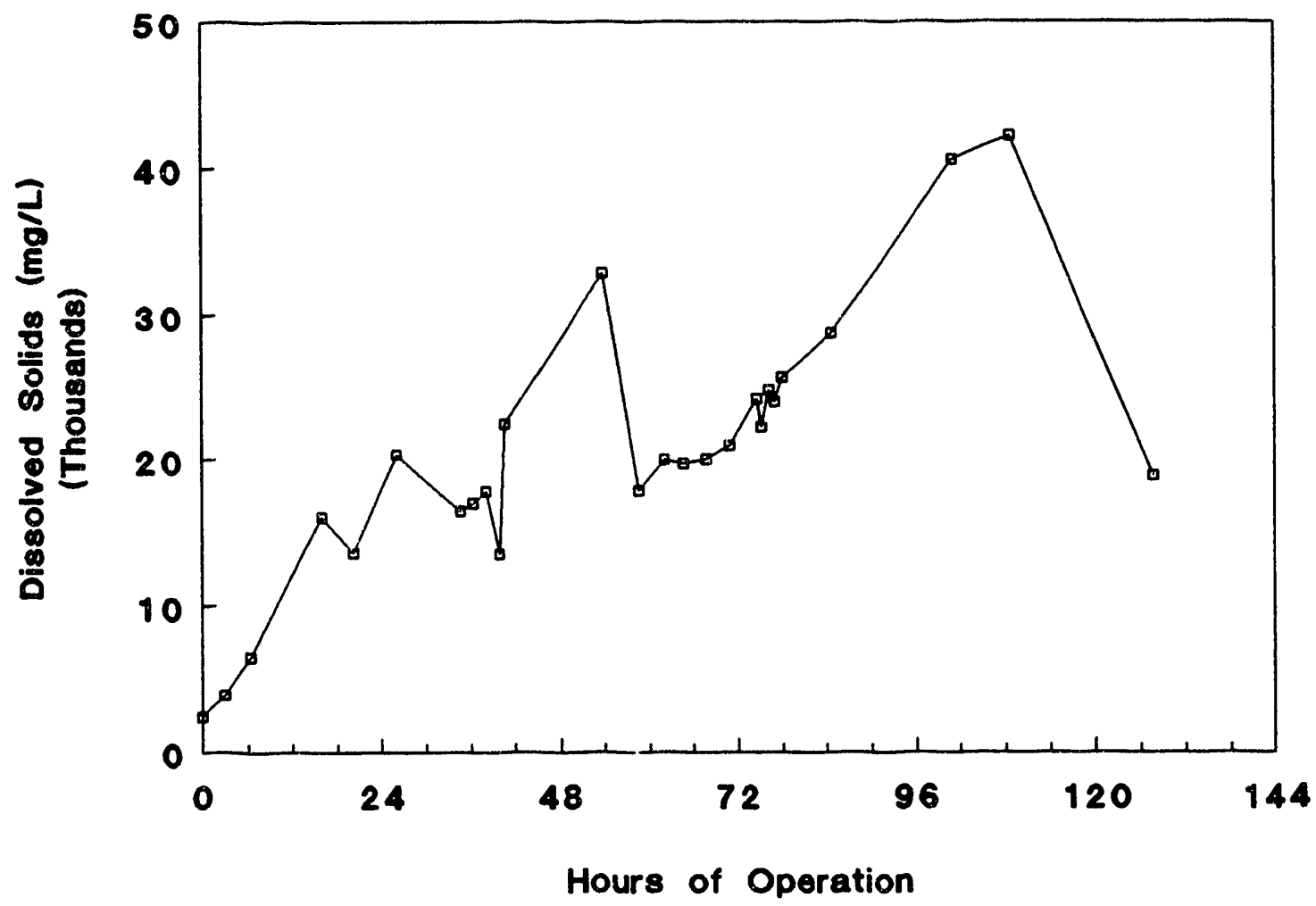

Fig. 64. Dissolved solids in ISV off-gas venturi-ejector scrub solution during ORNL ISV test.

\section{SAMPLING AND ANALYSES OF OFF-GAS PROCESSING EQUIPMENT}

At the end of the ISV melting, the equipment was shut down per PNL procedures, dismantled over the subsequent months, decontaminated where required, and prepared for shipment back to PNL. By mid-June, thermal monitoring of the melt, via the surviving type-C and type-S thermocouples, revealed that the melt had cooled to near ambient temperatures. A major effort was then initiated to determine the fate and extent of ${ }^{137} \mathrm{Cs}$ contamination in the off-gas handling components. The significant amounts of ${ }^{137} \mathrm{Cs}$ on the MM5 filters coupled with the absence of detectable activity in the scrub solution waste indicated that the survey could be focused on the hood and off-gas line upstream from the prefilter. The hood, still in position over the melt, was entered by personnel in full protective clothing and full-face respirators. Areal surveys with alpha and beta/gamma meters revealed that radiation fields were quite low $(<1 \mathrm{mR} / \mathrm{h})$ but that surfaces contained smearable beta/gamma activity (i.e., ${ }^{137} \mathrm{Cs}$ ). Thus the major route of potential exposure to personnel was determined to be through inhalation or ingestion of contaminated particulates. On June 13,1991, four randomly selected 10- $\times 10-\mathrm{cm}$ areas of the off-gas hood walls were marked for subsequent quantitative smear sampling to determine the amount of deposited ${ }^{137} \mathrm{Cs}$; these were outlined and labelled with an indelible marker. A moistened paper towel was then used to smear the discolored area to transfer 
Table 27. Scrub solution analyses during the 1991 ORNL pilot-scale ISV test.

\begin{tabular}{lllllr}
\hline Sample & $\begin{array}{l}\text { Run time } \\
\text { (h) }\end{array}$ & pH & $\begin{array}{l}\text { Electrical } \\
\text { conductivity } \\
(\mathrm{mS} / \mathrm{cm})\end{array}$ & $\begin{array}{l}\text { Total } \\
\text { solids } \\
(\mathrm{mg} / \mathrm{L})\end{array}$ & $\begin{array}{l}\text { Dissolved } \\
\text { solids } \\
(\mathrm{mg} / \mathrm{L})\end{array}$ \\
\hline Scrub 1 & 0 & & & & \\
Scrub 7 & 11.2 & 6.09 & 1.0 & 4140 & 455 \\
Scrub 8 & 15.87 & 1.98 & 7.5 & 7200 & 4400 \\
Scrub 9 & 20.27 & 1.25 & 29.6 & 9950 & 7235 \\
Scrub 12 & 34.32 & 1.14 & 36.7 & 8930 & 7265 \\
Scrub 13 & 37.12 & 1.05 & 44.6 & 12130 & 10115 \\
Scrub 17 & 50.70 & 1.00 & 50.0 & 13930 & 11805 \\
Scrub 21 & 64.95 & 1.09 & 42.4 & 13180 & 11400 \\
Scrub 27 & 77.02 & 1.10 & 41.7 & 13760 & 11940 \\
Scrub 30 & 94.47 & 1.01 & 49.9 & 16800 & 14620 \\
Scrub 31 & 110.05 & 1.05 & 48.1 & 24940 & 19940 \\
Scrub 33 & Posttest & 1.41 & 35.8 & 19830 & 15995 \\
\hline
\end{tabular}

Table 28. Anions in the scrub solution at $94 \mathrm{~h}$ during the 1991 ORNL pilot-scale test.

\begin{tabular}{ccc}
\hline Species & $\begin{array}{c}\text { Sample } \\
\text { concentration } \\
(\mathrm{mg} / \mathrm{L})\end{array}$ & $\begin{array}{c}\text { Quantity in } \\
\text { scrub solution } \\
(\mathrm{g})\end{array}$ \\
\hline Fluoride & 6000 & 1146 \\
Chloride & 6000 & 1146 \\
Nitrate & 80 & 15.28 \\
Phosphate & 25 & 4.584 \\
Sulfate & 4500 & 859.5 \\
\hline
\end{tabular}

the deposited solids to the paper. The initial smearing with the paper towel was designed to remove the majority of coloration from the circumscribed area. A second moistened paper towel was then used to remove any residual deposition by continually rubbing the area until a shiny metallic surface was apparent. Both towels were then placed into a polystyrene $15-\mathrm{cm}$-diam Petri dish, which was sealed with vinyl tape. Hood wall panels $1,3,5$, and 7 were sampled by this procedure at distances of $234,183,117$, and $51 \mathrm{~cm}$ above the ground, respectively; hood panels are numbered clockwise starting with the door panel. The off-gas line was also sampled by this technique at four locations: (1) in the straight pipe section which was attached to the flange on the hood; (2) in the pipe section immediately unflow of the flange which was attached to the prefilter housing assembly; (3) in the pipe section at the intake of the prefilter housing which was valved in during the test; and (4) in the pipe section at the outflow of the prefilter housing (Fig. 5). The circumscribed sampling areas were marked using a flexible $10-\times 10-\mathrm{cm}$ cardboard template. Each moistened towel was placed into a tared $25-\mathrm{mL}$ glass scintillation vial and was subsequently dried at $110^{\circ} \mathrm{C}$ in a still-air oven and reweighed. The samples were then assayed for ${ }^{137} \mathrm{Cs}$ activity, using the standards that had been prepared for the off-gas filter samples described above, to determint counting efficiencies. Several blanks of moistened paper towels were carried through the counting procedures to check for background activities and paper towel characteristics. After completion of these initial counts, the 
glass vials were ashed at $600^{\circ} \mathrm{C}$ for $24 \mathrm{~h}$ and reweighed. By determining the ash content of blank paper towels, the net solids removed from the hood and pipe walls could be calculated. The samples were assayed again for ${ }^{137} \mathrm{Cs}$ activity as before, which verified that no activity had been volatilized by this ashing treatment.

\section{Distribution of ${ }^{137} \mathrm{Cs}$ Within the Off-Gas Hood and Ducting}

On June 21, 1991, the hood was reentered to initiate decontamination efforts, and an integrating beta/gamma detector (Geiger-Mueller pancake probe) was used to collect information on the distribution of activity on the hood walls and covered ground surface. The window-containing face of the probe was pressed against the desired surface and a 1-min integrated count was collected by a r...ter operated outside the hood. Counting rates were collected at four positions within $10 \mathrm{~cm}$ surrounding the four smear sample locations. Because the amount of activity per unit area for these four locations was known accurately from the smedr counts, these areas were used as in situ standards for calibration of the meter readings. Counting rates were also determined within the smeared areas and were found to be near background levels, which confirmed that all activity had been removed by smearing. Counting rates were determined at random locations at the top, middle, and bottom sections of each of the eight hood side panels; at four positions on the hood ceiling; at eight positions on the covered ground surface; at three positions (at the top, middle, and ground surface) on each of the four graphite electrodes, which were still penetrating the off-gas hood into the ISV product; and on the inner and outer surfaces of the off-gas pipes where they protruded into the hood. In addition, the floor positions were counted a second time after rolling back the high-temperature fabric that covered the ground surface inside the hood; this procedure was designed to determine how much activity was contained on the cloth vs the soil surface beneath.

Using the measured activities of ${ }^{137} \mathrm{Cs}$ on the hood and off-gas line smears as in situ standards for the beta/gamma detector, counting efficiencies for the beta/gamma detector were calculated after subtraction of the background counting rate just outside the hood or on thc cleaned surfaces where the smear samples had been removed. Counting efficiency was found to average $0.067 \mathrm{pCi} / \mathrm{cm}^{2} /$ count per min (i.e., 14.8\%) with the Geiger-Mueller probe. Observed counting rates ranged up to sixteen times the background counting rate, which averaged 64 counts per min. The distribution of these activities is depicted in Fig. 65.

Zones of highest activity were observed on the hood ceiling and on the surfaces of both the air inlet pipe and the off-gas outlet pipe. The electrodes near the ground surface exhibited about half as much contamination as the hood ceiling, while the walls of the hood and the fabric floor of the enclosed chamber were only mildly contaminated. One notable exception was the fabric floor immediately in front of the access door, which, because of the air-flow constraints caused by its geometry, seemed to function as a settling area for particles emanating from the ISV melt. Such contaminant distribution information will be helpful in designing off-gas flow handling equipment in the future and in the planning of future posttest decontamination efforts. These in situ activity determinations also provide assurance that significant fractions of the volatilized ${ }^{137} \mathrm{Cs}$ inventory were not sequestered in niches within the off-gas handling system prior to the prefilter.

The results of the hood and pipe smear sampling are presented in Table 29. It was encouraging that the off-gas line smear at the outflow of the prefilter housing assembly showed no detectable activity. This result is consistent with the absence of detectable activity in the waste off-gas scrub solution described previously. Thus no ${ }^{137} \mathrm{Cs}$ passed through the prefilter. This result confirms the approach that emissions of ${ }^{137} \mathrm{Cs}$ can be controlled by use of particulate filtration technology. Obviously, given the extent of contamination of the hood and off-gas pipe between the source and the location of the prefilter, designing a position for the filter closer to the source could have minimized the extent of contaminated components. However, for the present test, the geometric constraints imposed for proper isokinetic off-gas sampling immediately before the prefilter required it to be located after several meters of straight pipe section. Configuration of a filter at the input to the offgas line or, preferably, at the exit of off-gas from the ground should be effective in preventing 


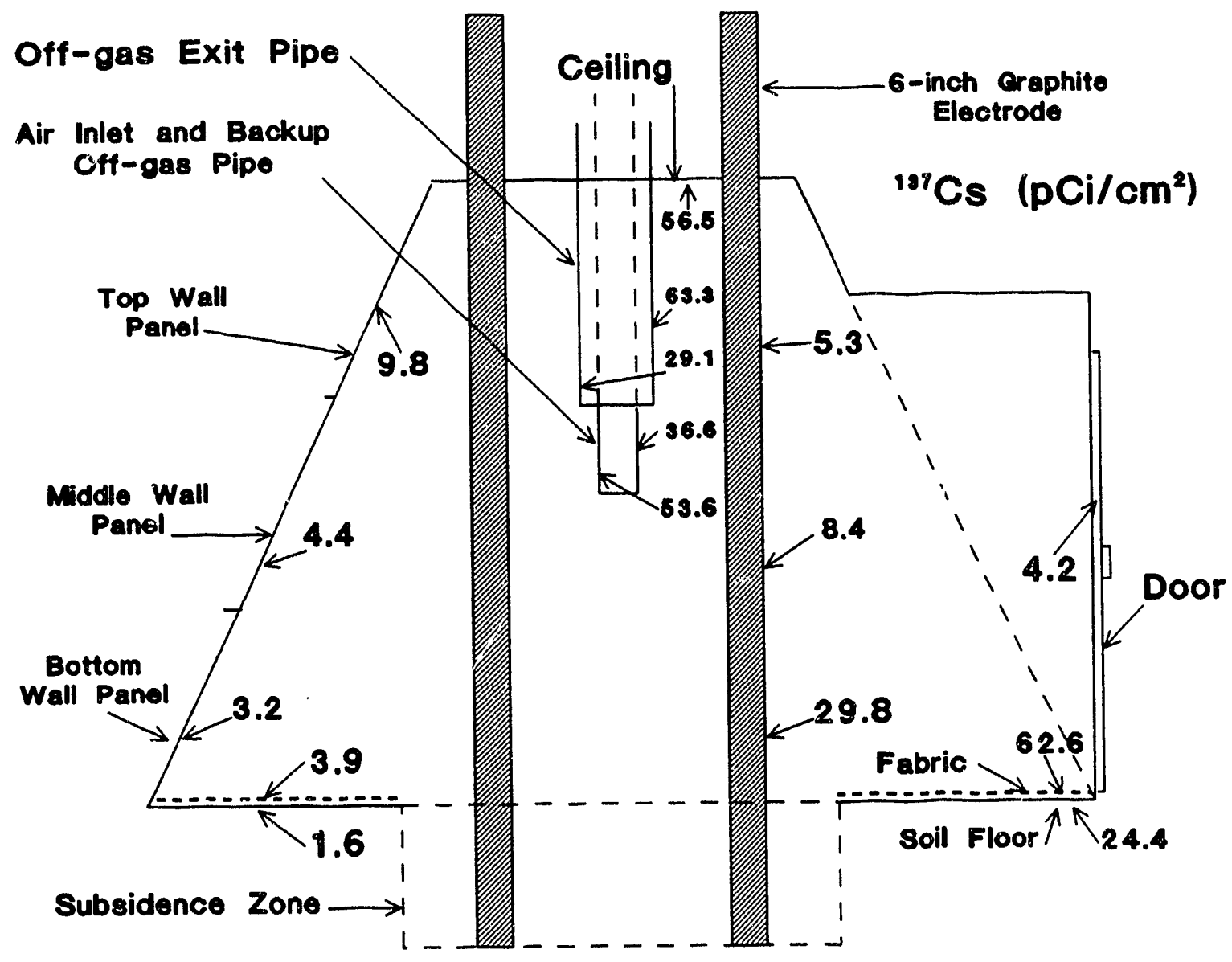

Fig. 65. Distribution of ${ }^{137} \mathrm{Cs}$ activity on surfaces within the ISV off-gas hood following completion of the field demonstration at ORNL in May 1991.

contamination from reaching the process trailer where, in an actual application, radiation doses could be significant (Table 3). Techniques to perform prefiltering in the off-gas hood temperature regime and a filtration renewal or replacement technique need to be developed. It should be pointed out that the level of sophistication of filtration required to remove ${ }^{137} \mathrm{Cs}$ from the ISV off-gas may not require HEPA filter technology; however, such requirements need to be determined so that alternative filtration technologies can be evaluated. Additionally, techniques to return filtered ${ }^{137} \mathrm{Cs}$ to the melt, either in continuous or batch mode, need to be developed.

\section{DISTRIBUTION AND BEHAVIOR OF ${ }^{137}$ CS DURING THE ISV TEST}

Understanding the volatile behavior of ${ }^{137} \mathrm{Cs}$ in an ISV melt is an important objective of the 1991 pilot-scale ISV test. This behavior was observed by analysis of off-gas characteristics and temporal patterns of release plus a comparison with the behavior of cesium in the 1987 pilot-scale ISV test. In addition, laboratory studies of cesium volatility were undertaken to address issues and concerns not capable of being resolved from the test monitoring.

The complete picture of the magnitude and fate of ${ }^{137} \mathrm{Cs}$ volatilized from the melt is depicted 
Table 29. Activity and inventory of ${ }^{137} \mathrm{Cs}$ on ISV off-gas handling components after completion of 1991 ORNL test.

\begin{tabular}{llc}
\hline Sample position & $\begin{array}{l}137 \mathrm{Cs} \\
\left(\mu \mathrm{Ci} / \mathrm{m}^{2}\right)\end{array}$ & $\begin{array}{l}\text { Solids } \\
\left(\mathrm{mg} / \mathrm{m}^{2}\right)\end{array}$ \\
\hline Hood wall panel 1 & 0.168 & 1118 \\
Hood wall panel 3 & 0.055 & 962 \\
Hood wall panel 5 & 0.036 & 1000 \\
Hood wall panel 7 & 0.020 & 390 \\
Off-gas pipe at hood flange & 1.132 & 4226 \\
Off-gas pipe at in-line filter assembly & 0.238 & 3090 \\
Off-gas pipe at inflow of in-line filter & 0.315 & 2858 \\
Off-gas pipe at outflow of in-line filter & 0.000 & 4260 \\
& & \\
Average hood wall & 0.0697 & \\
Average off-gas pipe & 0.5616 & \\
\hline & & \\
Inventory on & ${ }^{137} \mathrm{Cs}$ & \\
Off-gas handling component & $(\mu \mathrm{Ci})$ & \\
& & \\
& Hood wall and ceiling & 2.55 \\
Hood floor & 0.36 & \\
Off-gas pipe & 3.50 & \\
\hline
\end{tabular}

${ }^{a}$ Hood wall area $=36.51 \mathrm{~m}^{2}$, off-gas pipe area $=6.23 \mathrm{~m}^{2}$, hood floor area $=5.27 \mathrm{~m}^{2}$

in Fig. 66. The total starting amount of ${ }^{137} \mathrm{Cs}$ was $10,103 \mu \mathrm{Ci}$, which was calculated from the weight of sludge added (Table 10) and the analyzed activity of the sludge (Table 8). The total amount volatilized was $2.4 \%$ of the activity added to the test trench. Just about all $(97 \%)$ of the volatilized ${ }^{137} \mathrm{Cs}$ was trapped by the prefilter. The observed high percentage of volatilization of ${ }^{137} \mathrm{Cs}$ in this test emphasizes the potential exposure problems that could develop if the existing ISV off-gas processing equipment were used to remediate any of the ORNL seepage trenches. In the 1987 demonstration, only $0.12 \%$ of the Cs inventory was volatilized during a pilot-scale test on an equivalent scale. The volatilization observed in the present demonstration was not anticipated, but has been extremely useful in focusing future ISV development needs on understanding the volatilization mechanisms and controlling volatilization of ${ }^{137} \mathrm{Cs}$ during ISV. The filtration technology has now been demonstrated to control significant volatilization should it occur. But differences between the 1987 and 1991 tests must be explored to determine how volatilization might be controlled. It would obviously be preferred and safer to keep ${ }^{137} \mathrm{Cs}$ in the melt than to have to deal with it above ground, however sophisticated an engineering design might evolve. 


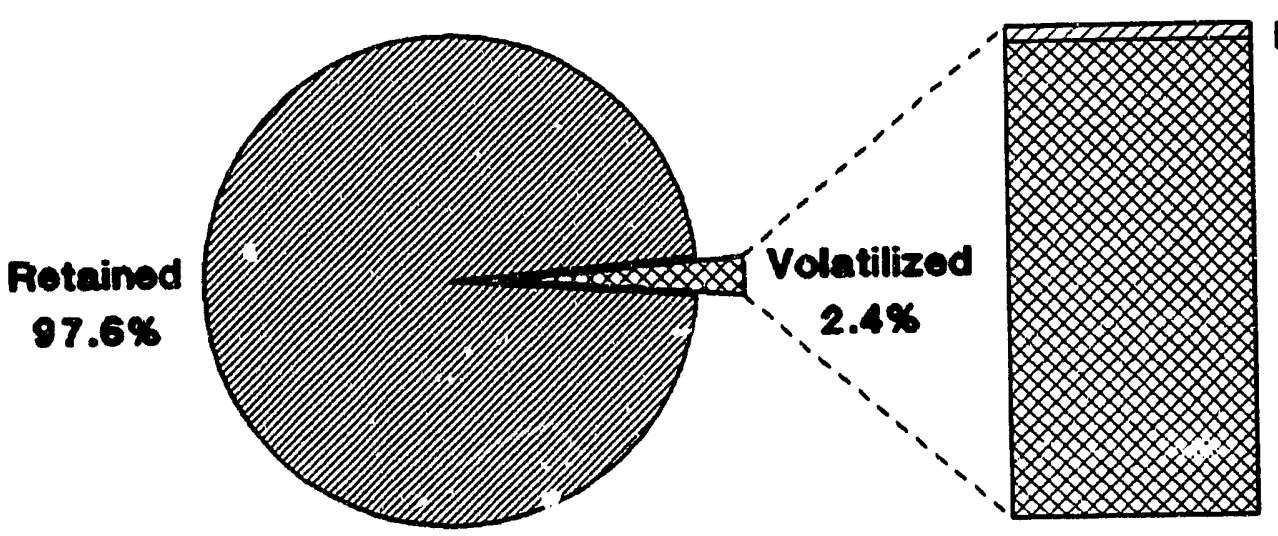

Cesium Fate in ISV Melt Volatilizod Cesium
Hood and Pipes

2.5\%

Prefilter

$97.4 \%$

Ground Surface

$0.2 \%$

Fig. 66. Distribution of ${ }^{137} \mathrm{Cs}$ after the 1991 ORNL pilot-scale ISV test.

\section{VOLATILIZATION OF ${ }^{137}$ CS DURING THE ORNL PILOT-SCALE TEST}

Results of the time series of ${ }^{137} \mathrm{Cs}$ emissions during the test are presented in Fig. 67. There were no detectable ${ }^{137} \mathrm{Cs}$ emissions prior to the meit front reaching the burial depth of $1.5 \mathrm{~m}$ when the prefilter was valved into the off-gas pipe. It does appear in Fig. 67 that the first ${ }^{137} \mathrm{Cs}$ emissions preceded the arrival of the melt front by several hours. However, the uncertainty in the melt depth was about $\pm 0.3 \mathrm{~m}$; thus these apparent early emissions may be ascribed to that uncertainty in the actual melt depth. Nonetheless, the effect was quite small. In addition, it should be noted that the sludge was placed in plastic bc itles inside a PVC pipe with approximately $0.3 \mathrm{~m}$ of soil packed above it to isolate the sludge from the other tracer containers positioned above in the pipe (Table 10). After the melt had incorporated this layer of soil, the melt might have descended rapidly into the cavity that would result from the pyrolysis of the organic materials that compose the PVC and sample bottles. Thus it is possible that the sludge was incorporated into the melt in a relatively short time interval.

Assuming that the sludge was consumed by the melt in a short interval, the majority of the ${ }^{137} \mathrm{Cs}$ release appeared to have occurred during the interval ( 66 to $84 \mathrm{~h}$ ) when the melt reached the depth interval where sludge was buried. Emissions of ${ }^{137} \mathrm{Cs}$ were much reduced after $84 \mathrm{~h}$ presumably because the ${ }^{137} \mathrm{Cs}$ had been incorporated and well mixed within the melt. This observation is consistent with the observations from laboratory crucible melts, which indicate that remelting of ${ }^{137} \mathrm{Cs}$ labelled soil and limestone mixtures results in only minor additional emissions compared to the initial melt (Spalding et al. 1989). Thus it appears that the majority of ${ }^{137} \mathrm{Cs}$ volatilization would be expected during the time when contaminated strata are melted initially. This volatilization during melting would occur when the magnitude of outgassing from the material being melted would be maximal; outgassing would result from decarbonation of any carbonates in the limestone or sludge and 


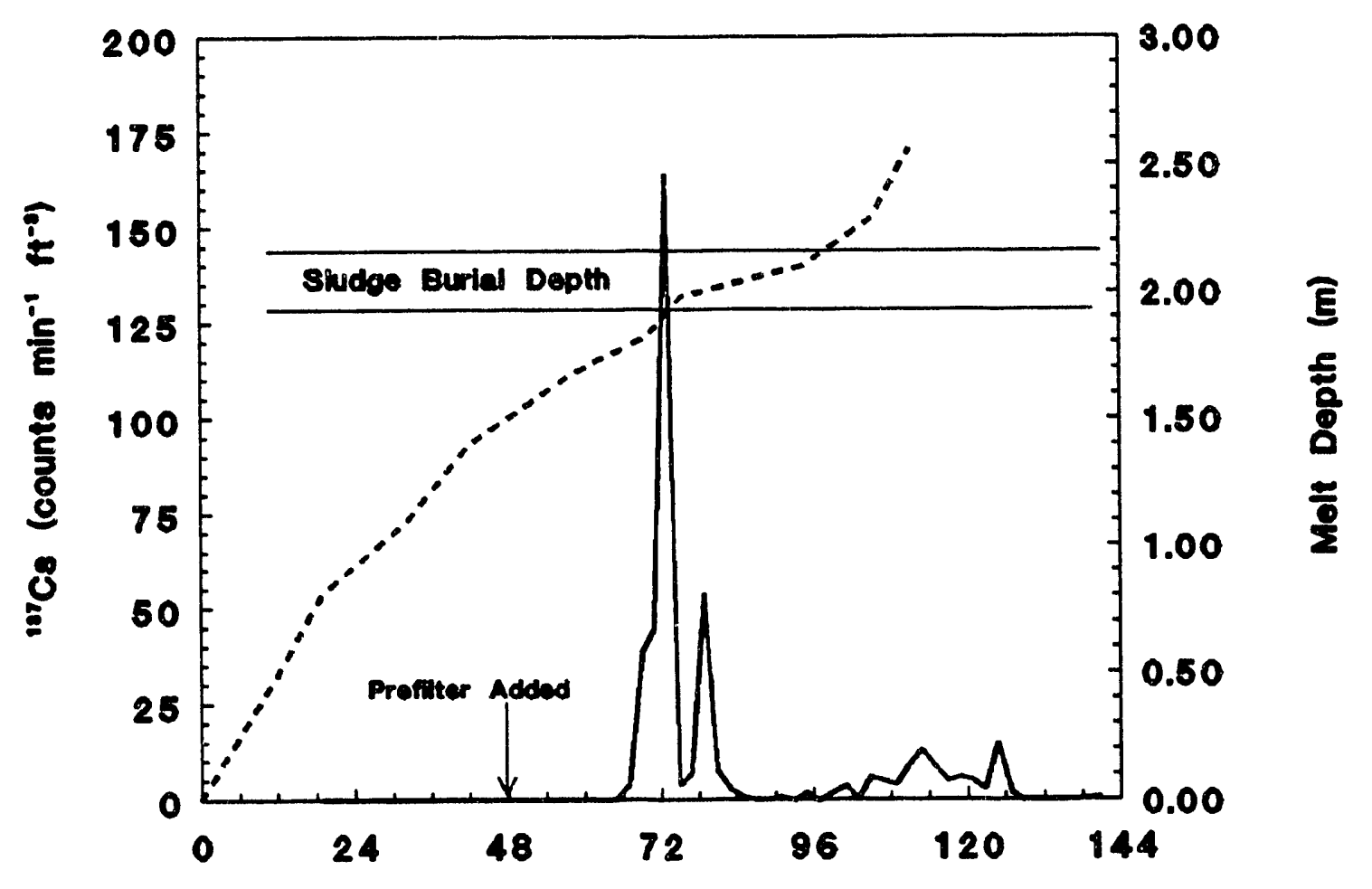

Rin Time (h)

Fig. 67. Volatilization of ${ }^{137} \mathrm{Cs}$ from the 1991 ORNL ISV melt as a function of depth of melting and radioactive sludge burial depth interval.

dehydration of mineral phases. The continuing reduced emissions of ${ }^{137} \mathrm{Cs}$ after $84 \mathrm{~h}$, when full power was restored to the melt (Fig. 67), may be ascribed to continued outgassing as more limestone and soil were incorporated into a well-mixed melt in which the remaining ${ }^{137} \mathrm{Cs}$ was much diluted.

\section{DIFFERENCES IN CESIUM VOLATILITY BETWEEN 1987 AND 1991 ORNL FIELD TESTS}

The differences between the 1987 and 1991 tests, which might have influenced the volatilization of $\mathrm{Cs}$, include many possible factors. The following is a list of differences that may have influenced cesium volatilization. The order presented does not suggest probability of cause.

- The 1987 test used $526 \mathrm{~kg}$ of simulated sludge $\left(18 \% \mathrm{Cs}_{2} \mathrm{CO}_{3}\right.$ and $\left.82 \% \mathrm{SrCO}_{3}\right)$ with chemicals, whereas the 1991 test used $490 \mathrm{~g}$ of sludge with radioisotopes rather than chemicals. The 1991 melting of the sludge would have occurred over a much shorter time interval than the 1987 test because of the thousandfold difference in mass of material.

- The 1987 test used a trench dug into undisturbed soil, whereas the 1991 test was carried out in reconstituted soil. The 1987 test melt might have better contained any volatile ${ }^{137} \mathrm{Cs}$ species because of the higher bulk density (and, thus, lower porosity) of the soil formation surrounding the irelt. The lower bulk density may also have facilitated the movement of water and steam away from and/or through the molten product. Lower bulk density soil 
would certainly increase the water-holding capacity of the soil surrounding the melt and would have provided more water vapor to the melt.

- The 1987 test produced only $0.91 \mathrm{~m}$ of subsidence when forming product from the higher bulk density soil. In the 1991 test, $1.57 \mathrm{~m}$ of subsidence was observed after melting to a comparable total melt depth in a lower bulk density (and higher porosity) soil. The larger subsidence crater in 1991 may have facilitated more volatilization by providing conduits to lower bulk density soil and, hence, more steam to the melt or to the cold caps where a greater fraction of emitted cesium may otherwise have condensed.

- The 1991 test contained the sludge and other tracers in a PVC pipe, whereas the simulated sludge used in the 1987 test was placed without any containers. The PVC pipe or containers provide conduits for off-gas escape of ${ }^{137} \mathrm{Cs}$. Alternately, the PVC material might produce $\mathrm{HCl}$ during its combustion and/or pyrolysis, which might provide a source of halide element to form an ion pair with $\mathrm{Cs}$ and facilitate its volatilization.

- The 1987 test used a true limestone, whereas the 1991 test used a dolomitic limestone or actual dolomite. The difference in the chemical composition of the earthen materials may have affected the degree of ${ }^{137} \mathrm{Cs}$ volatilization.

- The 1991 test used the electrode feed system, which allows electrode movement, whereas the 1987 test used fixed depth electrodes, which were placed in augered holes prior to the run. The effects of the electrode system on cold cap production or collapse may have affected the degree of $\mathrm{Cs}$ volatilization or its interception by cold caps.

- The 1991 test used the larger off-gas containment hood, which may have affected off-gas aerodynamics in some subtle manner, drawing off-gas into the line in a manner different from that of the smaller rectangular hood used in 1987. The degree of air leakage into the two hoods may have been quite different even when maintained at the same vacuum. A tighter hood or better ground seal would facilitate more soil atmosphere withdrawal, which could affect the amount of gas leaving the melt.

\section{CONCEPTUAL MODEL OF SEMIVOLATILE METAL VOLATILIZATION FROM ISV MELTS}

The amount of ${ }^{137} \mathrm{Cs}$ released into the off-gas system and collected by the prefilter was only $-2.4 \%$ of the total inventory present in the test trench. Thus most material remains in the final waste form. However, this small amount is still enough to cause concern when vitrifying an actual trench. Therefore, understanding the mechanisms that result in these small releases is important.

Results from the 1987 and 1991 field tests and laboratory tests were used to develop a conceptual model of semivolatile metal volatilization from ISV melts. Such a model can be used to direct further experimentation and modeling studies to help elucidate the key mechanisms and parameters controlling semivolatile metal releases. To transport semivolatile elements (e.g., ${ }^{137} \mathrm{Cs}$ ) from the melt zone into the off-gas processing system, two requirements must be met. First, the cesium must be speciated in a form that can be transported from the melt-soil region to the off-gas system. Second, a path to the surface must exist. These two constraints will be discussed below.

\section{Physicochemical Forms of Semivolatile Constituents}

A semivolatile element can be transported into the off-gas system only as (1) a vapor of the element or some compound containing the element, (2) an aqueous species in liquid water, (3) a species dissolved in steam, (4) a species dissolved in a supercritical fluid, or (5) a species attached to ash particles released from the surface of the melt. It is unlikely that mechanism (1) is operable in 
an ISV melt-soil system. The trace quantities of Cs compounds and the abundance of fluids suggest that these trace metals would be more likely to be associated with fluids, although additional data need to be collected to confirm this hypothesis. Mechanism (5) can be eliminated as a dominant form because analyses of the particles on the off-gas sampling filters confirm that Cs-halide particies formed during transport within the off-gas system to the filters. Few ash particles were found on any of the filters. The material appears to be predominantly sublimates. Thus some mode of transport related to water is most likely. Mechanism (2) can be dismissed because there is no driving force for liquid water to transport to the surface and any $\mathrm{Cs}$ present in a liquid would be sorbed onto the soil particles and be immobilized. Mechanisms (3) and (4) become those that need to be investigated further. The solubility of saits (e.g., $\mathrm{NaCl}$ ) in water vapor at $>374^{\circ} \mathrm{C}$ is low but finite (Anderko and Pitzer in press). Should the fluid become supercritical, the solubility of the salts will increase. In the multicomponent system present in ISV, it is unknown whether the fluid is in a supercritical phase or in a multiphase mixture (vapor \pm liquid \pm solid). However, the calculated fluid compositions indicate a total concentration of halides higher than concentrations typically found in $\mathrm{H}_{2} \mathrm{O}-\mathrm{NaCl}$ vapor at high temperature and low pressure (Anderko and Pitzer in press). The supercritical fluid may be predominantly water, but there are large quantities of both air and $\mathrm{CO}_{2}$ present in the system that may affect the ability of the fluid to carry semivolatile metals. Pure water drawn toward the melt from the saturated zone formed by the boiling water front (Kuhn 1992, Roberts et al. 1992) will become supercritical at $\mathrm{T}=374^{\circ} \mathrm{C}$. However, the multicomponent nature of the system present in ISV melts makes the prediction of phase and solubility more complicated. Water and $\mathrm{CO}_{2}$ bound within minerals will be released just prior to melting over a temperature range of 400 to $800^{\circ} \mathrm{C}$ and will be released in close proximity to the edge of the melt. This fluid will be able to carry dissolved metals, probably in the form of ion pairs, not free ions.

\section{Regions of Transport}

Assuming that a supercritical fluid or vapor is the carrier of volatilized Cs, paths to the surface should now be considered. There are really only 2 alternatives: through the dry zone and directly through the melt. The release of Cs during the latter part of the ISV test, especially at high power near the end of the test, suggests that Cs is carried to the surface in association with a fluid moving through the melt for at least part of the time. At these late times, the melt would have completely encompassed the zone of the Cs tracer. It is possible that fractionation of Cs from the melt into a fluid could occur along the edge of the melt and then be transported to the surface. The relatively higher release of Cs upon first contact with the melt is more diff-'1t to explain. It is possible that enough Cs was present that, rather than a fractionation process of trace Cs from the melt into a fluid, a process of disassociation or dissolution of solid-phase Cs directly into the fluid phase occurred. It is also possible that this phase could be transported to the hood along the surface of the melt; however, more work is needed to evaluate the importance of this process. This process would result in an initially higher release of Cs. Then, as the Cs was dissolved into the melt and mixed via convection, fractionation from the melt into a fluid phase would become the dominant mechanism and would result in lower emissions.

The presence of the PVC pipe has been identified as possibly contributing to the higher-thanexpected volatilization of Cs for this test. Keppler and Wyllie (1991) show that for some metals (e.g., $\mathrm{Cu}$ ), increasing $\mathrm{Cl}$ in the fluid phase significantly increased the fractionation of the metal from the melt into the fluid. Should a $\mathrm{Cl}$-rich fluid be present, the fractionation factor of $\mathrm{Cs}$ from the melt into the fluid could be increased and result in higher emissions. This mechanism would be especially effective if $\mathrm{Cs}$ concentrations in the melt were elevated during the same time period. It is possible that this process occurred as the PVC pipe degraded to $\mathrm{HCl}$. PVC begins to degrade at $\sim 148^{\circ} \mathrm{C}$; however, the relative amounts of $\mathrm{Cl}$ released during the test are not significantly different except for one sample at $-33 \mathrm{~h}$. Otherwise, the concentration of $\mathrm{Cl}$ in the filter samples is roughly the same and dependent on power levels. Thus, although the PVC pipe could have contributed a significant fraction of the total $\mathrm{Cl}$ released, it is not certain that it contributed to any preferential release of Cs. Even 
at a pressure of 1 bar, there is some solubility of $\mathrm{Cl}$ in the melt, and analyses of the ISV product should be performed to look for a mass balance of halides. Data from crucible tests suggest that events just prior to melting and during early periods of melting yield higher emissions of Cs even without halides present. Thus, although the PVC pipe cannot be ruled out as the source of enhanced volatility, it is unlikely that it was the major contributor to the higher-than-expected releases of Cs.

\section{Elucidation of Mechanisms}

To understand the mechanisms of transport that move Cs from the melt-soil region into the off-gas system, further experiments will be required. These should be a combination of laboratory tests to increase our understanding of the processes. Then, engineering-scale tests should be performed to confirm the hypothesized mechanisms and to evaluate additional methods to reduce the accumulation of Cs above the melt zone. Some computer modeling, carefully constrained by realistic conceptual models, assumptions, data, and initial and boundary conditions, would be beneficial in looking at the behavior of fluids within the melt, out through the boiling zone, and into the ambient unsaturated zone. Key aspects of the behavior of semivolatile metals to be addressed include:

- importance of direct vaporization of Cs compounds prior to melting;

- behavior of vapor, liquid, and supercritical fluids near the melt interface and whether they can penetrate into the melt;

- fractionation factors of Cs from the melt into fluids;

- role of fluids other than water (e.g., air, carbon dioxide, or halides);

- importance of devolatilication reactions on the enhanced release of Cs upon first contact with the melt (extension of current results); and

- the solubility and chemical form of $\mathrm{Cs}$ in vapor or supercritical fluids of $\mathrm{H}_{2} \mathrm{O}+\mathrm{CO}_{2}+$ halides (cations versus ion pairs; affinity for adsorption).

\section{LABORATORY STUDIES OF FACTORS AFFECTING CESIUM VOLATILITY}

Many of the postulated mechanisms ior the volatilization of cesium during vitrification cannot be discerned from any of the field observations. Several of the potential factors that may influence cesium volatility are better addressed under more controlled laboratory conditions. The following investigations address and test many of the possible differences between the 1987 and 1991 field situations.

\section{Volatilization of Radiocesium at Varying Soil-Limestone Ratio}

A variety of tests or analyses may resolve the potential influences of a number of the plausible scenarios listed above. For example, the effects of the different earthen materials on volatilization of Cs were tested in the laboratory using crucible melts similar to those described in Spalding et al. (1989). Samples of the soil and limestone, used in both 1987 and 1991, were melted in alumina crucibles at $1500^{\circ} \mathrm{C}$ for $16 \mathrm{~h}$ following a sintering treatment at $850^{\circ} \mathrm{C}$ for $4 \mathrm{~h}$. Samples were spiked with $0.1 \mu \mathrm{Ci}$ of ${ }^{134} \mathrm{Cs}$ and mixed well before sintering. Assay for ${ }^{134} \mathrm{Cs}$ was performed by gamma spectroscopy as described previously for all samples before sintering, after sintering, and after melting. The activity of each sample was divided by its activity measured after sintering to compute the fractional volatilization of Cs. The results are expressed in Fig. 68. First, it is obvious that increasing fractions of limestone in soil during melting resulted in an increasing percentage of Cs volatilization; 


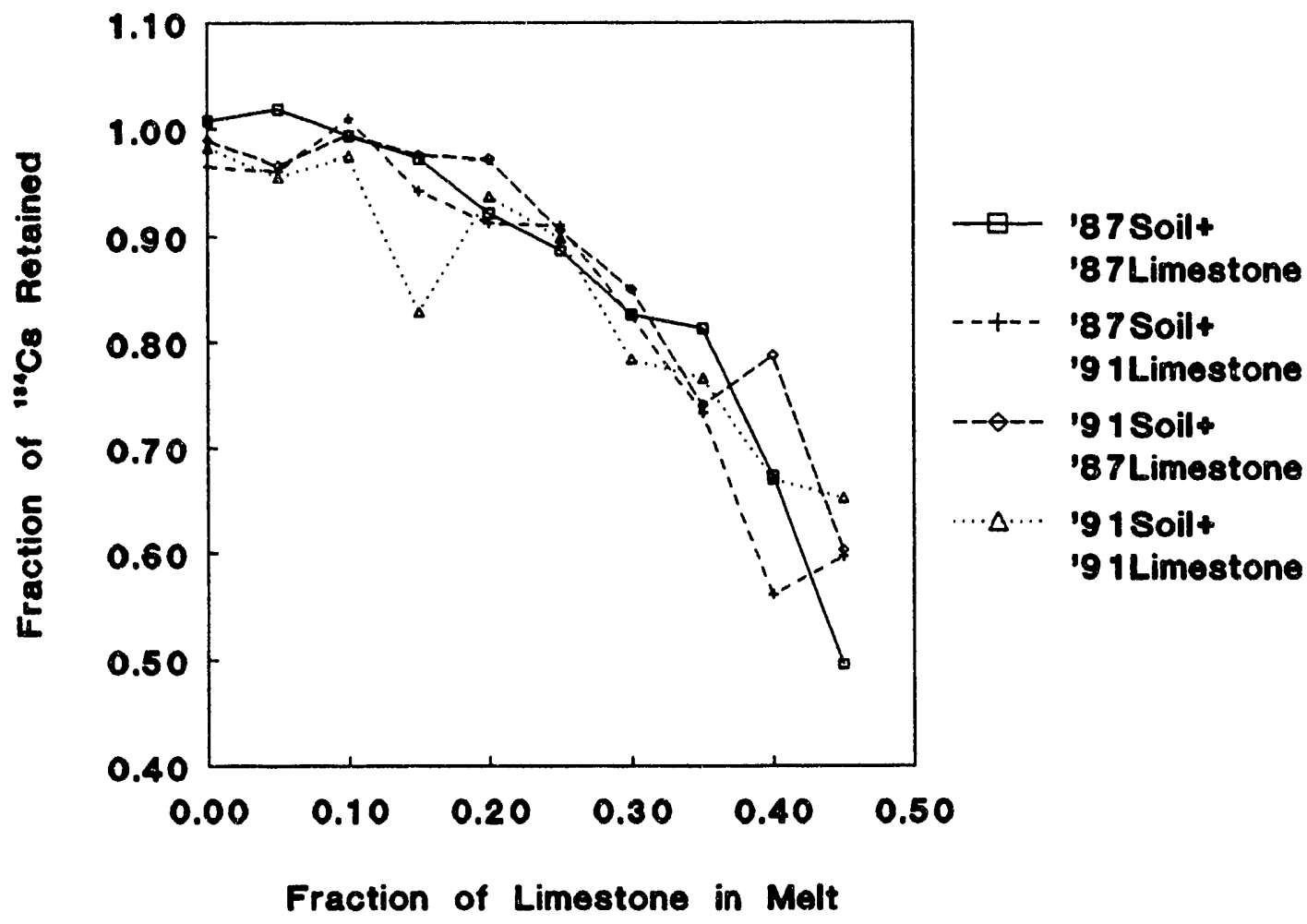

Fig. 68. Volatilization of ${ }^{134} \mathrm{Cs}$ at $1500^{\circ} \mathrm{C}$ from crucibles containing mixtures of soil and limestone materials used in the 1987 and 1991 ORNL ISV field tests.

this finding is identical to the one in the previous study (Spalding et al. 1989); subsequent discussion will address the potential implication of this for the present test. However, the important conclusion to be drawn from this information is that there is no significant difference in the behavior of Cs volatilization with respect to the source of soil or "limestone." Although some variation exists among the observations, the highest addition of 1991 limestone to 1991 soil produced the least Cs volatilization while the 1987 soil plus 1987 limestone treatment produced the most volatilization. Thus, any further search for evidence that differences in Cs volatilization are caused by differences in the chemical composition of earthen material properties would seem futile. It would also seem unlikely that the nature of 1991 sludge would have much effect because there was so little material used $(489 \mathrm{~g}$ ) and that material was largely a carbonate similar to the chemicals used in 1987.

An interesting implication for the present test is the observation that increasing limestone proportions in the melt resulted in increasing Cs volatilization (Fig. 68). Although it might appear that increasing decarbonation with increasing limestone content might affect volatilization, sintering had already reduced the weight of all samples to those expected for complete decarbonation. Thus the samples were completely decarbonated prior to any volatilization of ${ }^{134} \mathrm{Cs}$, which occurred when the samples were melted at $1500^{\circ} \mathrm{C}$. Thus chemical composition rather than out-gassing of $\mathrm{CO}_{2}$ 
appeared to mediate the volatilization of ${ }^{134} \mathrm{Cs}$ in these samples. It would be interesting to know what fraction of the limestone was dissolved in the melt at the time the sludges were incorporated in the 1987 and 1991 field tests. Some indication may be obtained when the elemental analyses of the 1991 product are compared to the 1987 product. Both tests were terminated soon after the melt had progressed through the sludge burial depth. Thus the final composition may provide a good estimate of the melt composition at the time of incorporation of the cesium. The potential for such an effect would be derived from a higher limestone fraction at the time of melting in 1991 vs a lower limestone fraction at the time of melting in 1987. However, the bulk elemental composition of the 1991 product ( $25 \% \mathrm{CaO}$ equivalent) was only slightly greater in $\mathrm{Ca}$ plus $\mathrm{Mg}$ content than the 1987 product (23\% $\mathrm{CaO}$ equivalent) (see ISV product composition section). 'The $\mathrm{CaO}$ equivalent is defined as the sum of alkaline earth element ( $\mathrm{Ca}, \mathrm{Mg}$, and $\mathrm{Sr}$ ) oxides in equivalent $\mathrm{CaO}$ percentages. Actually, the 1991 product, although greater in $\mathrm{CaO}$ equivalent, actually incorporated less "limestone" than the 1987 product (i.e., 20 vs $30 \%$, respectively; see ISV product composition section). This apparent contradiction was caused by the much higher $\mathrm{CaO}$ equivalent content of 1991 soil and the higher clastic content, as evidenced by the $\mathrm{SiO}_{2}$ and $\mathrm{Al}_{2} \mathrm{O}_{3}$ content, of the 1991 "limestone." Because the volatility of cesium in the crucible tests in Fig. 68 depended only on the mixing ratio of soil and limestone and not on the chemical composition of specific soil or limestone, a greater volatility of ${ }^{137} \mathrm{Cs}$ would have been expected in the 1987 test, where the melt contained $30 \%$ limestone, than in the 1991 test, where the melt contained only about $20 \%$ limestone. Thus, alternate explanations for the increased degree of ${ }^{137} \mathrm{Cs}$ volatility, observed in the 1991 test, must be examined.

\section{Influence of Material Bulk Density on ${ }^{137} \mathrm{Cs}$ Volatility}

To determine the possible influence of bulk density of the premelt material on the degree of volatilization of $C s$ during vitrification, another series of laboratory crucible tests were performed. For these crucible studies, a mixture of ${ }^{137} \mathrm{Cs}$-contaminated soil, from the floodplain below ORNL SWSA 4, and crushed limestone used in the 1987 demonstration (descriptions and analyses in Spalding and Jacobs 1989) were used. A bulk quantity of 7:3 soil:limestone, moistened to $10 \%$, was used for these melt tests. The soil contained $16,280 \mathrm{dpm} / \mathrm{g}$ of ${ }^{137} \mathrm{Cs}$. The previously moistened mixture $(1.000 \mathrm{~g})$ was packed into a crucible whose inside diameter, depth, and weight had been individually and previously measured. The soil was compressed using a snugly fitting nylon ramrod to a depth that was calculated to attain the desired bulk density. After assaying each crucible for ${ }^{137} \mathrm{Cs}$ activity by gamma spectroscopy, the samples were oven-dried for $2 \mathrm{~h}$, weighed again, and sintered for $4 \mathrm{~h}$ at $850^{\circ} \mathrm{C}$. After cooling, the crucibles were reweighed, depth to the compacted mixture was redetermined, and the assay for ${ }^{137} \mathrm{Cs}$ was repeated. The samples were then placed in the Lindberg crucible furnace, heated to $1500^{\circ} \mathrm{C}$ and held for $4 \mathrm{~h}$, allowed to cool, reweighed, and reassayed for ${ }^{137} \mathrm{Cs}$. The moistening of the soil-limestone mixture facilitated packing to higher bulk densities, up to $2.3 \mathrm{~g} / \mathrm{cm}^{3}$, and cohesion of the soil after drying. The results of the various premelt bulk densities vs the degree of ${ }^{137} \mathrm{Cs}$ volatilization are presented in Fig. 69 . The scatter of observed degrees of volatilization would indicate that there was no major influence of bulk density on the degree of ${ }^{137} \mathrm{Cs}$ volatilization from such mixtures during their melting. This does not indicate, however, that bulk density does not have an important influence on Cs volatility in the field. Sivil bulk density may influence the movement of off-gas around the melt, particularly in the dehydrated zone immediately preceding the melting front. Additionally, lower bulk density would result in greater subsidence as the melt condenses to its product density of $2.83 \mathrm{~g} / \mathrm{cm}^{3}$; increased subsidence could result in greater volatilization due to enhanced access to the subsurface. Occasionally, several samples yielded ${ }^{134} \mathrm{Cs}$ activities after melting that were apparently greater than those measured before treatment (e.g., Fig. 69 where fraction retained is greater than 1). This apparent increase in activity is ascribed to the calculated ratio of two counting rates, each with a $\pm 2 \sigma$ activity uncertainty of $2.5 \%$. Although the uncertainty of the postmelt counting rate could be lowered by repeated counting for longer periods, the pre-melt counting rate of a particular sample could not be repeated after melting. To overcome this limitation on volatility measurement, treatments can be replicated as performed in the following 


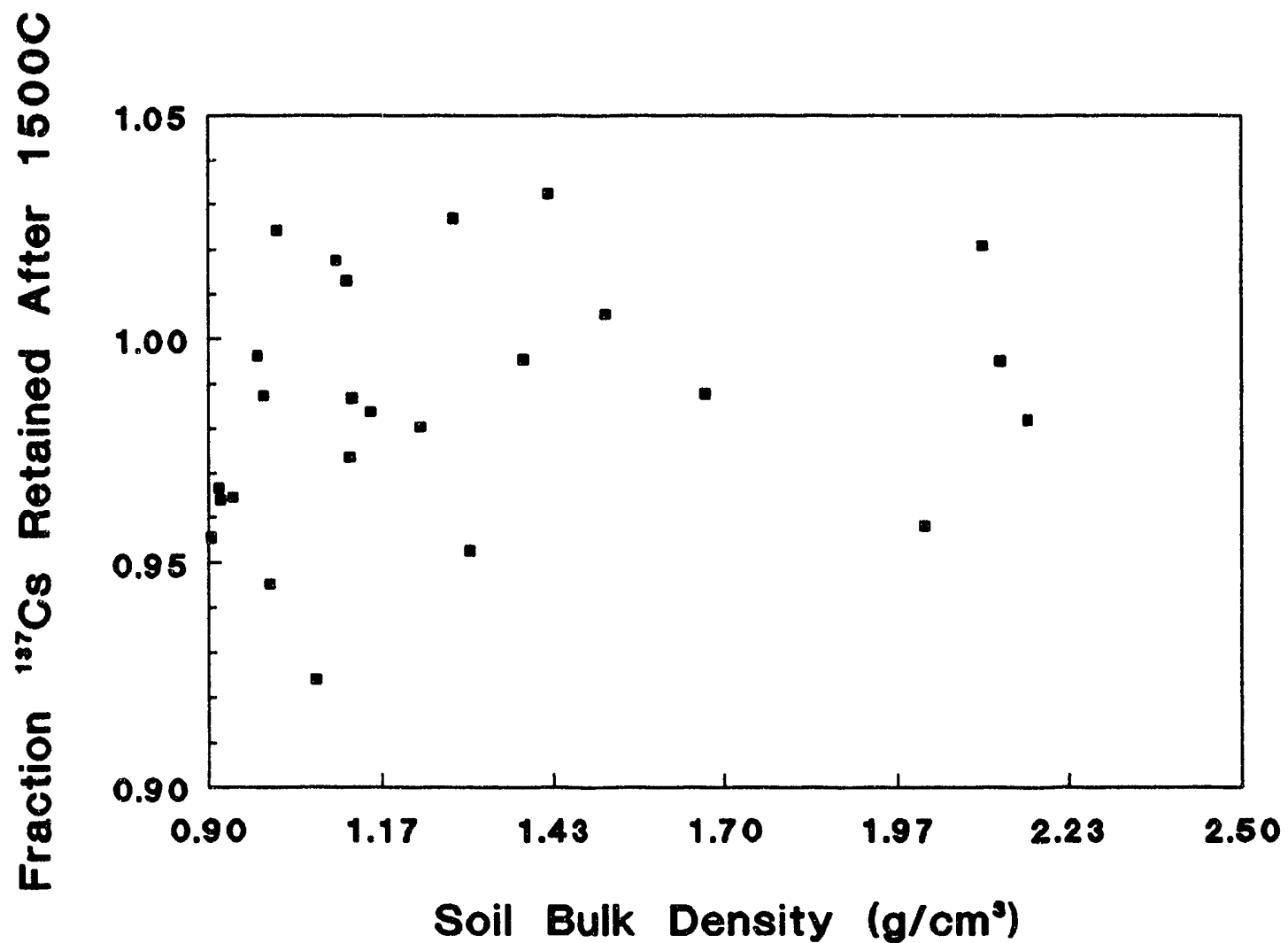

Fig. 69. Volatilization of ${ }^{137} \mathrm{Cs}$ from 7:3 soil:limestone mixtures packed to various premelt bulk densities in laboratory crucible tests.

sections. Thus, counting statistics impose an uncertainty or noise into these results that makes small differences difficult to detect. However, trends, like those in Fig. 68, can readily be discerned.

\section{Influence of Burial Depth on Radiocesium Volatility}

Another factor, related to the degree of subsidence during an ISV melt which may affect the degree of volatilization, would be the presence and amount of uncontaminated melt or mixture above the contaminated depth zone at its time of melting. This has been described as the depth of burial or cold cap thickness effect (Oma et al. 1982), where a variety of volatile and semivolatile contaminants are believed to be better retained by an ISV melt when the overlying material is thicker. To determine if this effect could be reproduced in laboratory crucible melts, two suites of melting tests were performed where ${ }^{134} \mathrm{Cs}$ was placed at different depths in crucibles that were subsequently subjected to melting. In the first suite, a spike of ${ }^{134} \mathrm{Cs}$ (about $10,000 \mathrm{dpm}$ ) was placed on a specific stratum of soil in a crucible that was packed in $0.50 \mathrm{~g}$ increments up to a total of $2.50 \mathrm{~g}$. The soil mixture employed for all these tests consisted of a 7:3 mixture of the <2-mm fraction of the 1987 field test soil and the 1987 field test limestone (Spalding and Jacobs 1989). Thus the ${ }^{134} \mathrm{Cs}$ was placed at 
depths within the crucible from the surface ( 0 relative depth) to the bottom sixth or $0.50 \mathrm{~g}(0.83$ relative depth). After the final addition of uncontaminated mixture, the crucible contents were compressed with the ramrod to bulk densities between 2.05 and $2.26 \mathrm{~g} / \mathrm{cm}^{3}$. The maximum depth of uncontaminated mixture above the level of ${ }^{134} \mathrm{Cs}$ placement was only about $2.0 \mathrm{~cm}$. Thus in actual physical dimensions the "burial" depths were quite small. The results from this suite of crucibles are depicted in Fig. 70.

There was an obvious trend that greater depth of placement resulted in less ${ }^{134} \mathrm{Cs}$

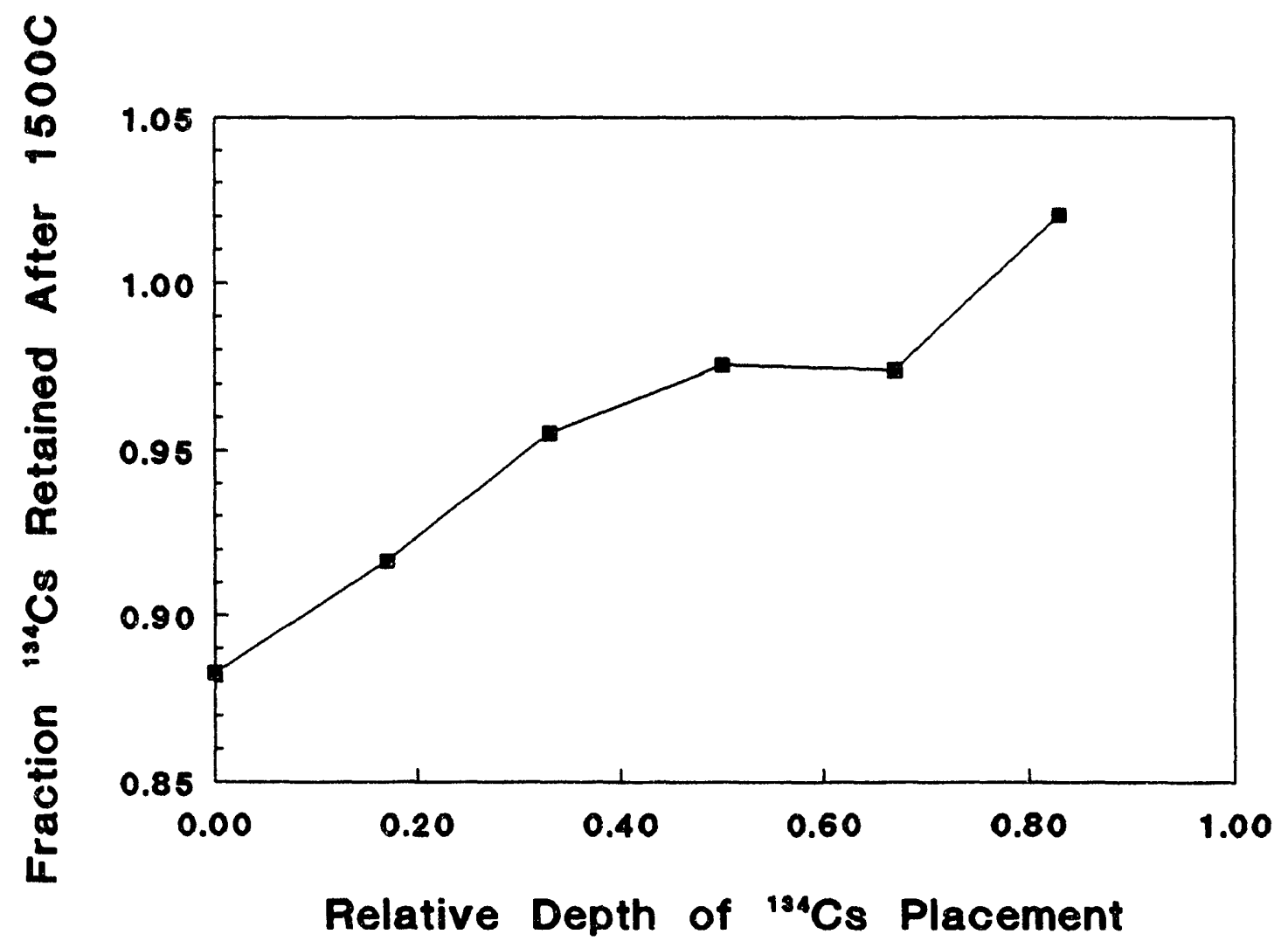

Fig. 70. Average depth of placement of ${ }^{136} \mathrm{Cs}$ activity in laboratory crucibles on its volatilization from a 7:3 soil:limestone mixture during melting.

volatilization. Thus the field effects of increasing cold cap depth appear to be simulated in these laboratory crucibles. However, there is a significant difference between the laboratory crucible melts and field melts. In the field, ISV melts occur from the surface downward. In the laboratory crucibles, downward melting may not be quite so dominant. The crucibles were open from the top, often with secondary containment within another alumina crucible should the melt break through the primary crucible. Heat is applied from both the surface and the sides of the crucible so that the melt may actually occur from several directions, although the open top would facilitate heat transfer from that 
direction. The field melting condition might be more closely approximated by melting contents with crucibles embedded in insulation with only the open top exposed to the furnace heat source. This type of laboratory melting geometry would be a productive approach for future studies of Cs volatilization and off-gas movement simulations.

In the second suite of crucible melts, rather than placing the ${ }^{134} \mathrm{Cs}$ at the desired depth within

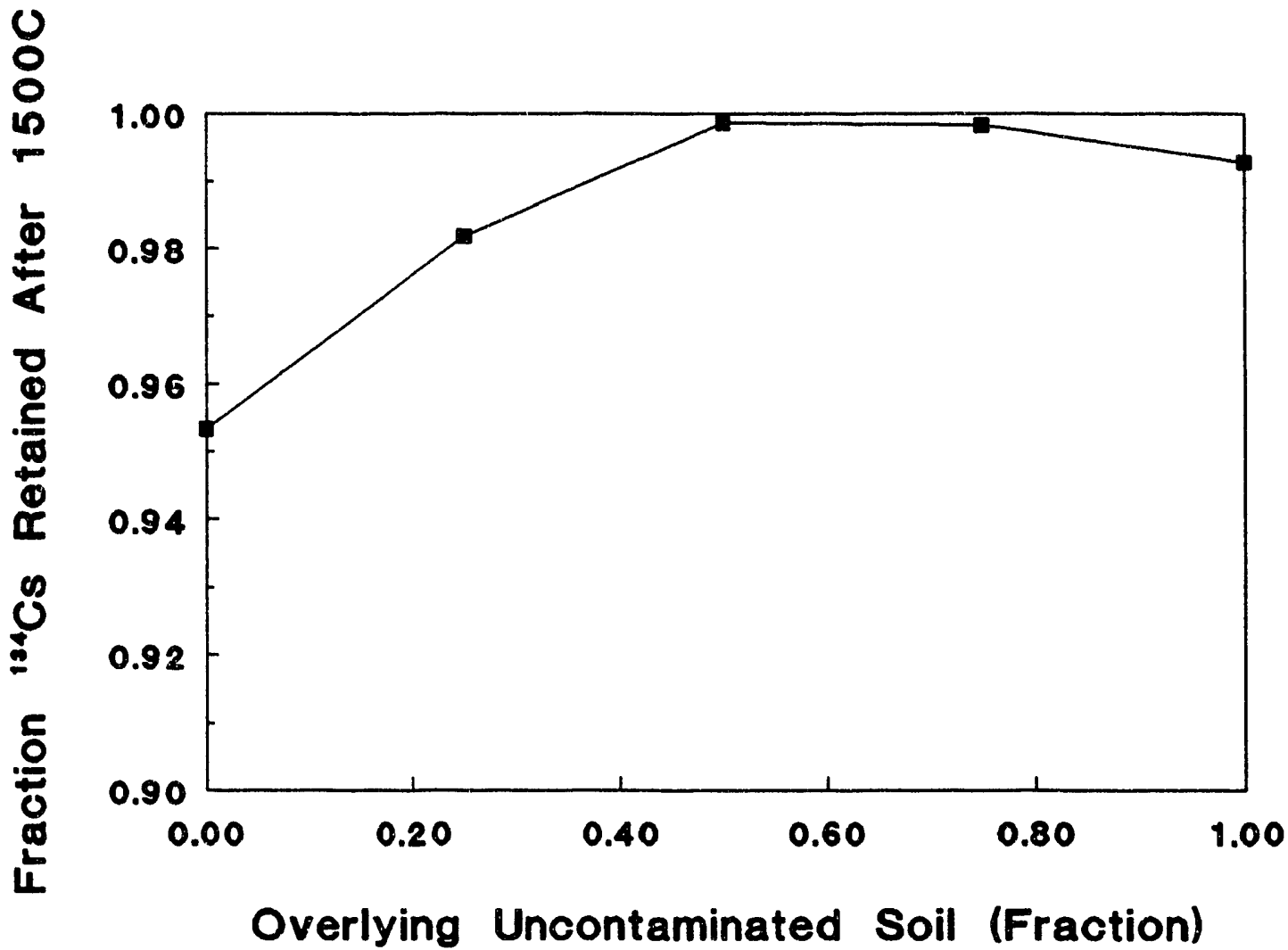

Fig. 71. Effect of depth of overlying uncontaminated soil:limestone mixture on the degree of volatilization of ${ }^{134} \mathrm{Cs}$ from laboratory crucibles during melting.

the crucible mixture, the ${ }^{134} \mathrm{Cs}$ was mixed well within the fraction of the mixture below the depth of placement. In this suite, only $1.00 \mathrm{~g}$ of mixture was used and was placed in increments of $0.25 \mathrm{~g}$. Thus the relative overlying uncontaminated mixture ranged from 0 , where the ${ }^{134} \mathrm{Cs}$ was distributed throughout the entire crucible mixture, to 1.0 , where the ${ }^{134} \mathrm{Cs}$ was placed on the crucible floor with the entire mixture above uncontaminated. These samples were packed to bulk densities between 1.17 and $1.28 \mathrm{~g} / \mathrm{cm}^{3}$. The results are presented in Fig. 71 and are similar to those described above when using a more defined band of placement within the crucibles. Because these mixtures used only a total of $1 \mathrm{~g}$ of soil:limestone, the greater degree of ${ }^{134} \mathrm{Cs}$ retention with the previousiy described $2.5 \mathrm{-g}$ samples does not seem surprising. Crucibles containing ${ }^{134} \mathrm{Cs}$ but no soil mixture exhibited complete 
volatilization of their ${ }^{134} \mathrm{Cs}$ in these tests. Thus the $\mathrm{Cs}$ is inherently volatile at the ISV operating temperatures, but its volatility is controlled by interaction with the earthen mixtures. Regardless, increased depth of placement or thickness of cold cap does seem to result in a decreased degree of Cs volatilization during laboratory melts.

\section{Influence of Melting Rate on Radiocesium Volatility}

The majority of Cs volatilization from the ISV melt probably occurs just before or during the process of melting, although smaller amounts appear to be released continuously. Previous work has identified two lines of evidence that support this conclusion. First, when molten soils in laboratory crucibles were held at $1600^{\circ} \mathrm{C}$ for up to 13 days, only a weak relationship between time and degree of volatilization was observed (Spalding et al. 1989). The linear regression between ${ }^{137} \mathrm{Cs}$ retained in the melt and time was $0.93-0.0036 / \mathrm{d}$ with a correlation coefficient of 0.90 . Thus, although $7 \%$ of the ${ }^{137} \mathrm{Cs}$ volatilized after $4 \mathrm{~h}$, further volatilization of only $0.36 \%$ per day was observed when the molten mixture was held for longer periods. In addition, once a mixture had been melted, cooled, and reassayed for ${ }^{137} \mathrm{Cs}$, repeated melting did not produce any additional volatilization of the ${ }^{137} \mathrm{Cs}$. Once $\mathrm{Cs}$ is incorporated into a vitreous phase, little volatilization occurs. But whether the volatilization of the ${ }^{137} \mathrm{Cs}$ occurred at or below the melting temperature is not presently known. Spalding and Jacobs (1989) did heat ${ }^{137} \mathrm{Cs}$-contaminated soil (without limestone amendment) to various temperatures between 100 and $1700^{\circ} \mathrm{C}$ at increments of $100^{\circ} \mathrm{C}$ for periods of $16 \mathrm{~h}$. Volatility of the ${ }^{137} \mathrm{Cs}$ became detectable at $1400^{\circ} \mathrm{C}$ and above. When these thermally altered products were subjected to leaching with dilute $\mathrm{HCl}$, the extractability of the ${ }^{137} \mathrm{Cs}$ peaked for samples heated between 800 and $900^{\circ} \mathrm{C}$ and reached a minimum at temperatures above $1200^{\circ} \mathrm{C}$. If the latter minimum is ascribed to incorporation of the ${ }^{137} \mathrm{Cs}$ into a vitreous form, then Cs mobility, as inferred from leachability observations, was significantly greater at temperatures a few hundred degrees below vitrification. If gaseous mobility of Cs were also maximal in this temperature range, then this temperature range might be the interval where the volatilization occurs during melting. The actual temperature range might be shifted slightly when mixtures of soil and limestone are examined. However, it would be predicted that, if Cs volatilization occurs by diffusion of a gaseous ion pair during this temperature interval, then the more slowly this interval is negotiated by a melting mixture, the more volatilization of Cs would be expected. In all of the previous laboratory crucible studies, virtually no attention has been focused on the rate of heating and melting of Cs-spiked mixtures. Although the process of sintering mixtures at $850^{\circ}$ for $4 \mathrm{~h}$ prior to actual melting has been routinely employed, its objective was to prevent the splattering of molten contents, presumably caused by decarbonation and dehydration of materials, which was observed when mixtures were heated too fast to allow for gas removal. Weight losses for carbonate minerals have been found to approximate their carbonate content after this routine sintering, although no detectable volatilization of $\mathrm{Cs}$ has been observed.

Further consideration of the possible effects of heating and melting rates on Cs volatilization indicated that the rate of heating performance of the two high-temperature furnaces should be examined. It should be noted that, although the box furnace cannot be programmed to heat at a specified rate, the crucible furnace has this capability. More importantly, however, the default heating rates for each furnace needed to be established for evaluation of heating rate effects on the many previous investigations with laboratory crucibles. To establish these rates both furnaces were set to $1500^{\circ}$, allowed to attain equilibrium with their set points, and allowed to cool (Fig. 72). The box furnace heated much more rapidly than the crucible furnace, with an average, although nonlinear, heating rate of $23^{\circ} / \mathrm{min}$; the default heating rate for the crucible furnace was at its maximum of about $11^{\%} / \mathrm{min}$. Cooling rates for the two furnaces from $1500^{\circ}$ to ambient are quite similar. The crucible furnace has the additional capability to set its heating rate below this maximum and has two programmable set points and dwell times at those temperatures. Thus crucible mixtures can be sintered by programming a 4-h dwell at $850^{\circ}$ prior to heating to $1500^{\circ}$ at any desired rate between 0.1 and $11^{\circ} \mathrm{C} / \mathrm{min}$ and holding that temperature for whatever time is desired. It should be emphasized that these default thermal regimes are for the thermocouple near the top of the heating chamber in 


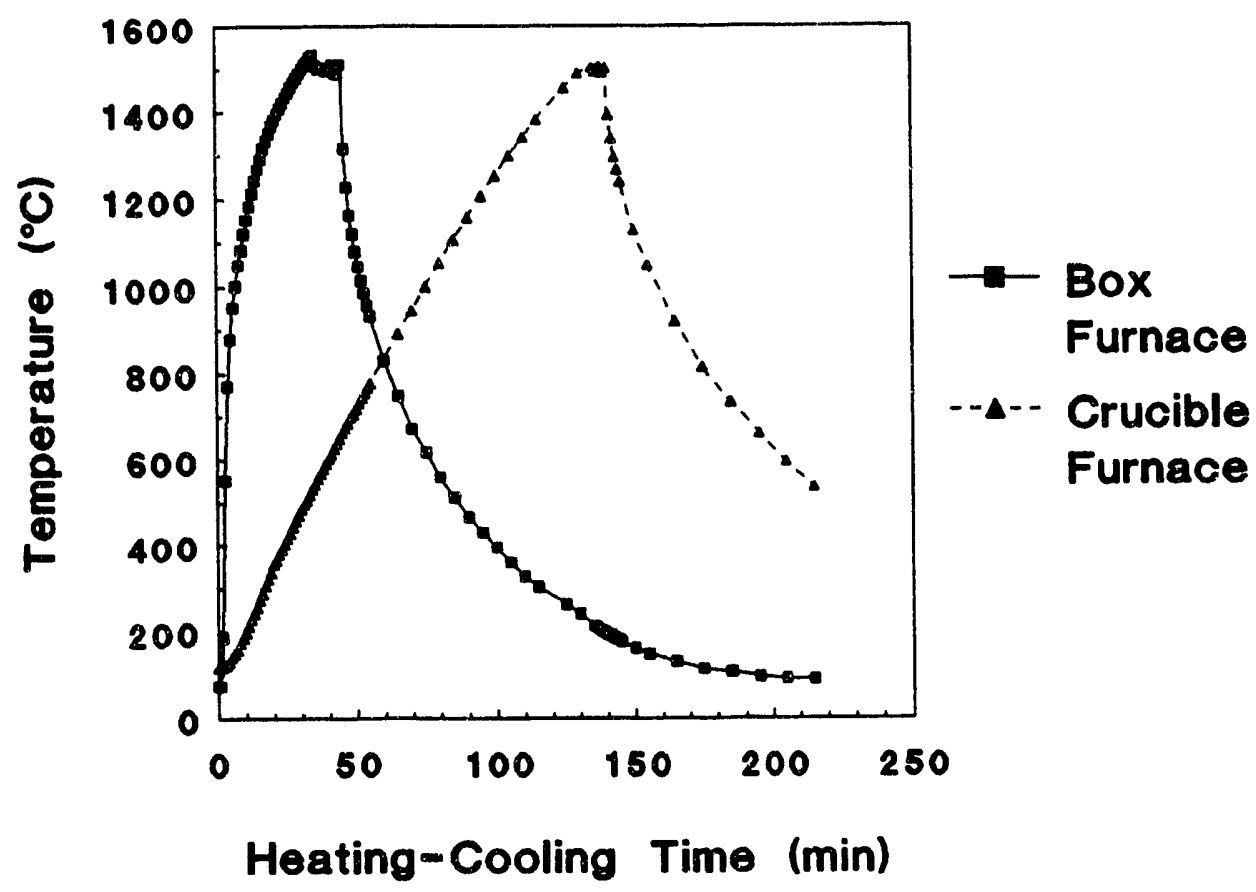

Fig. 72. Heating regimes for two high-temperature furnaces (box and crucible) used for laboratory crucible studies of ${ }^{134} \mathrm{Cs}$ and ${ }^{137} \mathrm{Cs}$ volatilization.

both types. Crucibles and contents will obviously lag this thermal regime somewhat because of their massiveness relative to the furnace atmosphere.

The heating rate of the crucible furnace was employed to determine the effect of the rate of heating on the volatilization of $\mathrm{Cs}$ from mixtures in crucibles. For these studies, the ${ }^{137} \mathrm{Cs}$ contaminated soil described previously and the limestone from the 1987 field test were used in a 7:3 ratio. One-gram samples were used and packed to bulk densities between 1.17 and $1.28 \mathrm{~g} / \mathrm{cm}^{3}$. Assays for Cs activity were performed as described previously. All samples were subjected to the same sintering regime prior to heating at the rates described in Table 30. All treatments were carried out in quadruplicate so that accurate standard deviations within thermal treatments could be calculated.

These preliminary experiments have demonstrated that heating rate is an important factor in determining the degree of $\mathrm{Cs}$ volatilization. The default setting for the box furnace produced the most rapid heating rate $\left(23^{\circ} / \mathrm{min}\right)$ and resulted in the least amount of ${ }^{137} \mathrm{Cs}$ volatilization. When the crucibles were heated at $10 \%$ min, volatilization of $10 \%$ of the ${ }^{137} \mathrm{Cs}$ was observed whether the crucibles were held at $1500^{\circ}$ for 2,7 , or $13 \mathrm{~h}$. Notably, when the crucibles were heated at a rate of $1 \% \mathrm{~min}, 19 \%$ volatilization of ${ }^{137} \mathrm{Cs}$ was observed and was significantly different from all the $10^{\circ} / \mathrm{min}$ treatments. Obviously, such crucible melt experiments need to be expanded to define more precisely the parameters contributing to the volatilization of ${ }^{137} \mathrm{Cs}$. First, slower heating regimes could be tried and greater degrees of volatilization would be expected. Alternately, prolonged thermal treatments to temperatures below $1500^{\circ}$, attained at slow rates of heating, would also be expected to result in enhanced volatilization. 
Table 30. Effects of heating and melting rates on the volatilization of ${ }^{137} \mathrm{Cs}$ from laboratory crucibles of 7:3 soil:limestone.

\begin{tabular}{lll} 
Thermal treatment & \multicolumn{3}{l}{$\frac{137 \mathrm{Cs} \text { Retained }}{(\%)}$} & $1 \mathrm{\sigma}$ \\
\hline $850^{\circ} \mathrm{C}$ for $2 \mathrm{~h}$, then $1500^{\circ} \mathrm{C}$ for $2 \mathrm{hr} @ 23^{\circ} \mathrm{C} / \mathrm{min}$ & 102 & \pm 5 \\
$850^{\circ} \mathrm{C}$ for $2 \mathrm{~h}$, then $1500^{\circ} \mathrm{C}$ for $2 \mathrm{hr} @ 10^{\circ} \mathrm{C} / \mathrm{min}$ & 90 & \pm 5 \\
$850^{\circ} \mathrm{C}$ for $2 \mathrm{~h}$, then $1500^{\circ} \mathrm{C}$ for $2 \mathrm{hr} @ 1^{\circ} \mathrm{C} / \mathrm{min}$ & 81 & \pm 7 \\
$850^{\circ} \mathrm{C}$ for $2 \mathrm{~h}$, then $1500^{\circ} \mathrm{C}$ for $7 \mathrm{hr} @ 10^{\circ} \mathrm{C} / \mathrm{min}$ & 90 & \pm 2 \\
$850^{\circ} \mathrm{C}$ for $2 \mathrm{~h}$, then $1500^{\circ} \mathrm{C}$ for $13 \mathrm{hr} @ 10^{\circ} \mathrm{C} / \mathrm{min}$ & 88 & \pm 2
\end{tabular}

In all of these laboratory crucible melts, diffusion of the Cs from the melting mixture would occur without significant convection of gaseous phase. In the field, gas movement through sintered or melting material may be important in the advection of ${ }^{137} \mathrm{Cs}$ and thus its volatilization from the melt. In these laboratory crucibles, this might be approximated with gas flow delivered into or over the crucibies during their heating. The effect of gas composition on Cs volatility could also be investigated. At present, it appears that minimizing gas generation during ISV melting could result in reduced $C s$ volatilization. Thus, drying out volumes of soil or waste prior to ISV may have a possible benefit to minimize Cs volatilization. Further work needs to be performed to firmly establish such a benefit prior to actual field applications or tests with significant ${ }^{137} \mathrm{Cs}$ inventories.

\section{DESCRIPTION AND ANALYSES OF FIELD ISV PRODUCT}

\section{FIELD DESCRIPTIONS AND SAMPLING METHODS}

When the mass had cooled to near-ambient temperature after about a month and the off-gas containment hood had been removed, the site was surveyed to measure the subsidence that had occurred as a result of the melting (Fig. 73). The hood and electrodes were decontaminated by extensive and exhaustive wiping with moistened cloth towels. This decontamination was required so that loose contamination would not be spread when the hood was lifted and placed on a nearby plastic pad for final decontamination. The electrodes were frozen in the melt and were cut off approximately flush with the ground surface using a hand-operated bow saw; this operation was quite facile, requiring less than 2 min per electrode. The electrodes were then lifted through the hood and placed in plastic sheeting for disposal. The cut electrode tops were completely decontaminated by wiping with damp towels and were disposed as nonradioactive nonhazardous solid waste. The electrode bottoms, remaining in the subsidence pit, had been significantly reduced in diameter near the interface with the melt and could be easily broken off at the melt surface by kicking. They were then removed by hoisting with a crane and were placed in plastic bags for disposal as radioactive solid waste. The "necking down" or consumption of electrodes near the melt surface was a frequent problem; each electrode broke at least once during the test and required the addition of replacement sections. Before the hood was lifted off, the fiberglass cloth, which covered the ground surface inside the hood, was rolled up and placed in plastic bags for disposal as low-level radioactive solid waste. 


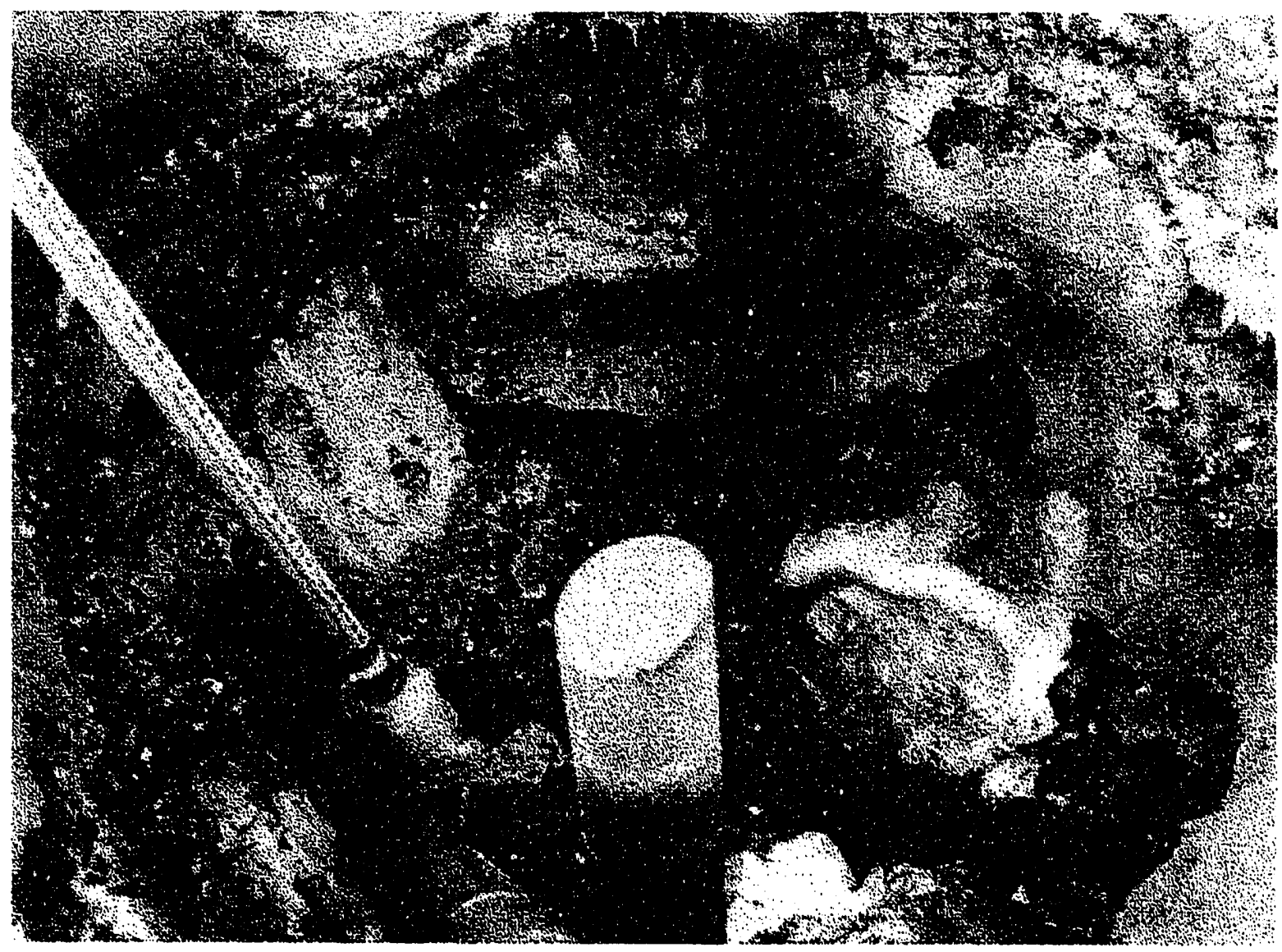

Fig. 73. Subsidence crater after completion of the 1991 ORNL ISV field test showing cut-off electrodes and at least four relict cold cap layers adhering to walls.

\section{Subsidence Crater}

The subsidence crater exhibited an average depth of $1.57 \mathrm{~m} \mathrm{(62} \mathrm{in.)} \mathrm{and} \mathrm{average} \mathrm{diameter} \mathrm{of}$ $1.52 \mathrm{~m}$ (60 in.). The remnants of at least four collapsed cold caps, as well as melt surface as a fifth, were apparent on the walls of the subsidence crater (Figs. 73 and 74). Cold caps form when the surface of the melt cools and solidifies forming a spanning structure over the melt. As the melt continues to subside, cold caps can collapse as obviously happened on four occasions during the present test. The timing of these cold cap collapses may be significant in understanding the volatilization of cesium. The cold cap can be viewed a: an in situ filter, except where penetrated by the electrodes, which may function to remove or trap Cs as it volatilizes from the melt. It may be possible to reconstruct the timing of their formation and collapse by looking at the melt depth vs time relationship (Fig. 21). Collapse has often been accompanied by a rapid rise in hood plenum and offgas temperature as the hood loses the radiant heat shield afforded by the cold cap. Possible effects on Cs emission events will be studied when such reconstructions can be completed. Samples of the various cold cap materials were taken before the subsidence crater was backfilled. A significant amount of dust was deposited over the surface of the subsidence crater. Therefore, these surfaces were wetted before the surface soil was pushed into the crater from around its edge with a front end loader. Additional loads of clean soil were brought to the side of the crater and pushed in with the loader until the crater was filled. No detectable radiation field was present at the soil surface after 


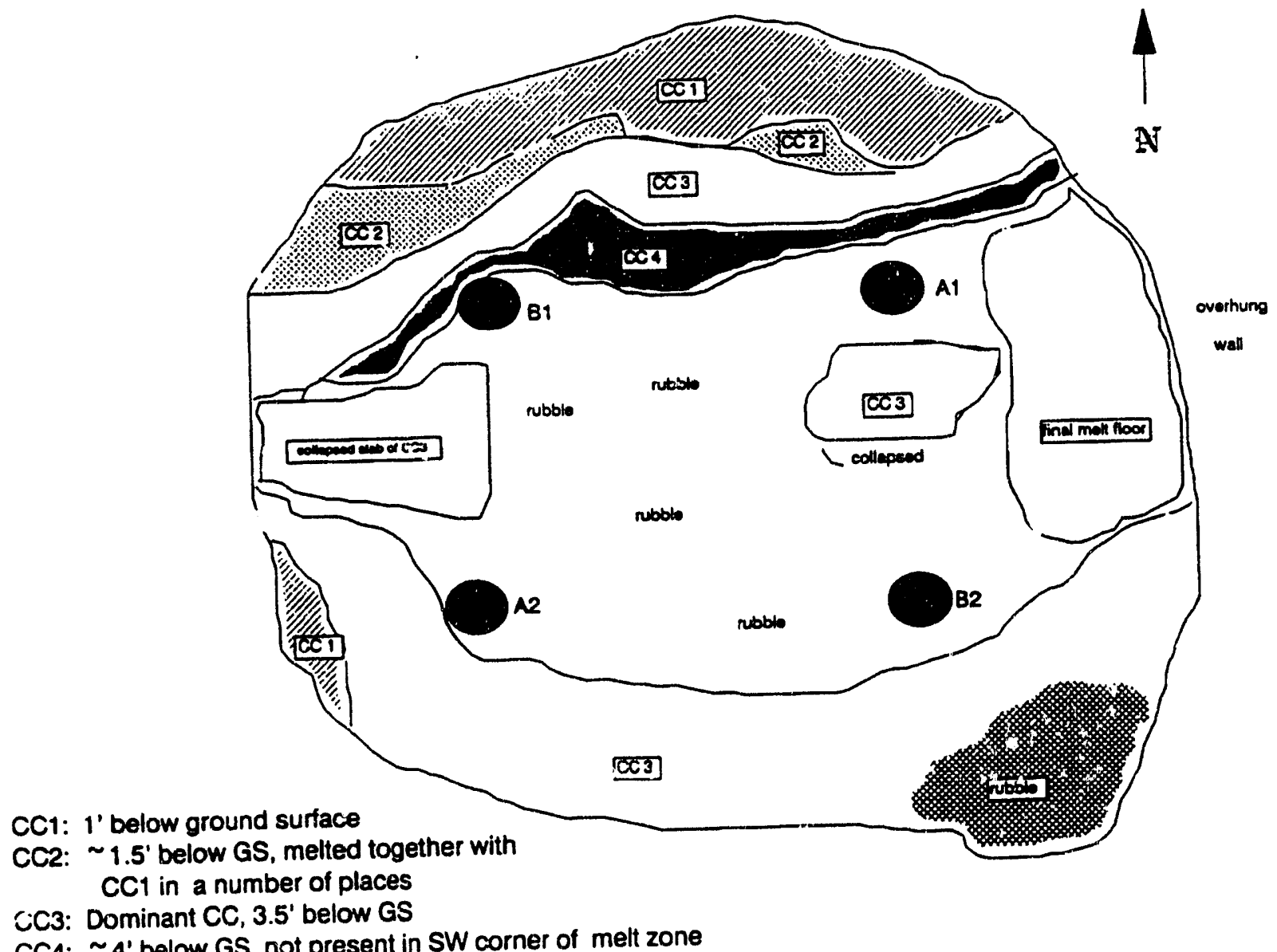

CC4: $\sim 4$ ' below GS, not present in SW corner of melt zone

Final melt surface can be seen 1 ' below $\mathrm{CC} 4$ around the NW electrodic

Fig 74. Orientation and position of cold caps exposed in the subsidence crater after the 1991 ORNL ISV ield tec:

the soil fill had been placed in the subsidence crater.

\section{Field Measurement of Depth to Top of ISV Product}

On August 22, 1991, a survey of the depths and lateral extent of the ISV solidified mass was completed. The soil backfill, used to fill the subsidence crater, and the original soil backfill were of relatively low bulk density so that rather easy penetration would be expected relative to the solidified ISV product. Thus, several 6-ft lengths of 0.5 -in-diam steel reinforcement bar were cut and then hammered into the ground until refusal. Four transects across the ISV melt area were set up at roughly $45^{\circ}$ angles with penetrations attempted about every foot (Fig. 75). By marking the point on each rod at the ground surface, the depth to top of hard object, i.e., ISV product, could be measured after bar withdrawal. Rods were checked for contamination with a beta/gamma survey meter after withdrawal, but none was observed. Rods were relatively easy to pull out by hand because of the low bulk density of the soil. The lateral extent of the melt was also determined at both ends of each transect by those penetrations that extended the full 6-ft depth of the rod. This survey metho/ provided good information from which to select positions for the more labor-intensive core sampling. 


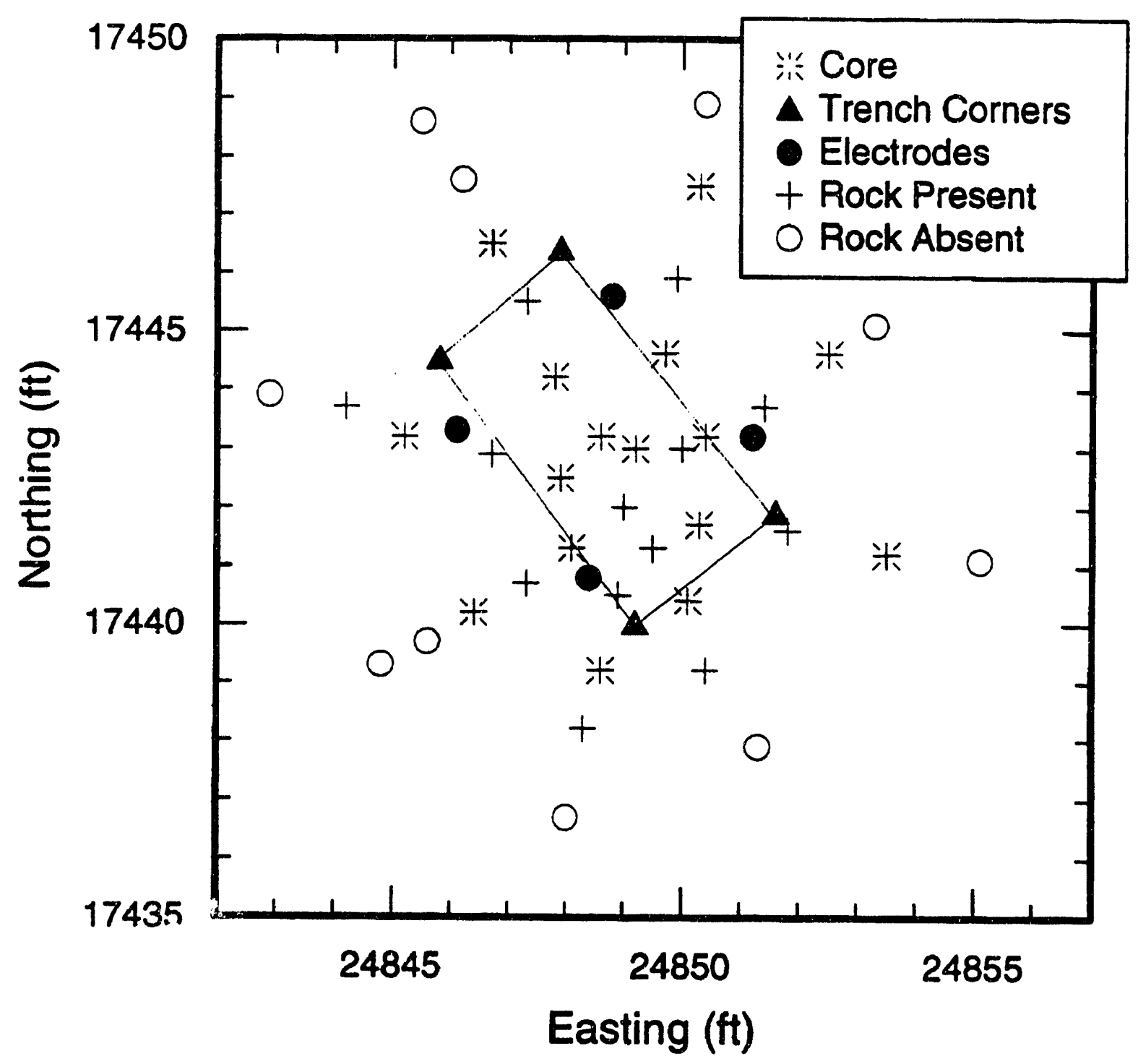

Fig. 75. ORNL grid locations of the upper layer of the limestone-filled trench corners, the electrode placements, the four transects for penetration tests, and core samples.

\section{Core Sampling of ISV Product}

Core sampling was conducted between August 26 and September 6, 1991, using an AWGsized (Diamond Core Drill Manufacturer's Association) rock core drill with diamond-tipped drill bit. The hole for coring was opened through the overlying soil by driving a "boulder-buster" bit (Acker Drill Co.), attached to the AW-sized drill rod to the depth of refusal. When the rod was withdrawn, a borehole resulted to the desired depth and of sufficient stability to allow completion of core drilling. The drilling was accomplished by using a water swivel at the top of the drill stem, which was supplied 
with a portable centrifugal pump and a portable tank to hold water. The flow of water was maintained at a low enough level that no return of fluid was observed at the ground surface. About an hour was usually required to drill through the 3 to $5 \mathrm{ft}$ of solidified product. Breakthrough at the bottom of the ISV product was accompanied by a rapid drop in drill stem pressure and a rapid increase in penetration rate. An attempt was made to quickly shut off the drill and the water supply via a valve on the water swivel so there would be minimum penetration into the underlying soil. Best core recovery and integrity were obtained when using an AWG-sized double-tube core barrel (Acker Drill $C_{0}$.) rather than a single-tube core barrel. Diamond-tipped drill bits were necessary because carbide-tipped drill bits proved to be very slow at penetrating the ISV product although these had worked quite well in coring the 1987 ISV test product. The present product was largely crystalline and apparently much harder than the glass-rich product of the 1987 test. Seventeen locations were selected for core sampling, covering a systematic array of locations relative to the central melt axis and the electrodes. Field measurements of the length of core recovered and measured depths of core hole were recorded. Core recovery (the percentage of the depth penetrated that was recovered as core material) varied from 57 to $91 \%$ with an average of about $74 \%$. Average depth to the top of core was $154 \mathrm{~cm}$, while the average depth to the bottom of the core was $240 \mathrm{~cm}$. Thus the ISV product had an average thickness of $85 \mathrm{~cm}$ with an average core length of $64 \mathrm{~cm}$. Depth to bottom of ISV product was determined by marking the drill stem flush with the ground surface at the point of rapid penetration after the prolonged drilling interval. Core was pushed or slid out of the core barrel onto plastic sheets where it was photographed. Core orientation was marked directly on the material using indelible marker pens. Field descriptions were recorded of the colors and textures of the core material, and all significant core fragments were numbered sequentially from top to bottom. Core sections were wrapped in plastic or, for smaller fragments, placed in seal-lock plastic bags, which were labeled with the core identification information and date. Cores were placed in waxed-cardboard core boxes for storage and transport to the laboratory for analyses and sample preparation.

After removal of the core barrel, the soil beneath the ISV product was sampled with a handcorer by attaching sufficient extension rods to reach the hole bottom. The hand-corer was an 18- $x$ 1.25-in. sampling tube (Clements Associates, Inc.) fitted with acetate sample-holding tubes for the 0.90 -in.-diam soil core. Usually, two sequential cores were collected from each hole by driving the sample tube with a hammer the nominal 18 in. further than the apparent bottom of the core hole. Soil core recovery was highly variable with this procedure. By collecting two soil-depth increments per core hole, potential migration of contamination from the melt might be observed both at the melt boundary and slightly below that boundary. When the sample was removed, the vertical orientation was marked on the clear tube and both ends were sealed with plastic caps. The sample length was recorded in the laboratory and the contents removed and weighed. The soil was then dried for several days at $80^{\circ} \mathrm{C}$ and reweighed. The soil moisture content was determined and the sample bulk density was calculated from the known sample volume and its dry weight. Samples were then sieved to less than $2 \mathrm{~mm}$ and $10.0-\mathrm{g}$ aliquots were weighed into $25-\mathrm{mL}$ plastic scintillation vials. In addition, the $>2$-mm material was also weighed and 10.0 -g aliquots were prepared. Assays for ${ }^{137} \mathrm{Cs},{ }^{60} \mathrm{Co}$, and ${ }^{90} \mathrm{Sr}$ were performed as described previously on both the coarse fragments $(>2 \mathrm{~mm})$ and soil $(<2 \mathrm{~mm})$ fractions.

\section{Posttest Soil Sampling Around ISV Product}

Below each of the cores, samples of soil exhibited much lower but detectable activities of ${ }^{137} \mathrm{Cs}$ (Fig. 76). This sample population exhibited an average ${ }^{137} \mathrm{Cs}$ activity of $74 \pm 100$ (SD) pCi/g. Whether this observed activity represents any actual migration or incomplete incorporation of ${ }^{137} \mathrm{Cs}$ is difficult to determine. Obviously, the core drilling technique presents an excellent opportunity for contamination of soil below the core. The coring operation generated cuttings that were washed from the drill bit by the flow of water maintained during drilling. However, the wash water did not return to the surface; presumably this wash water and cutting residue were being discharged along the voids at the top of the melt. But as the drill stem broke through the bottom of solidified material, wash 


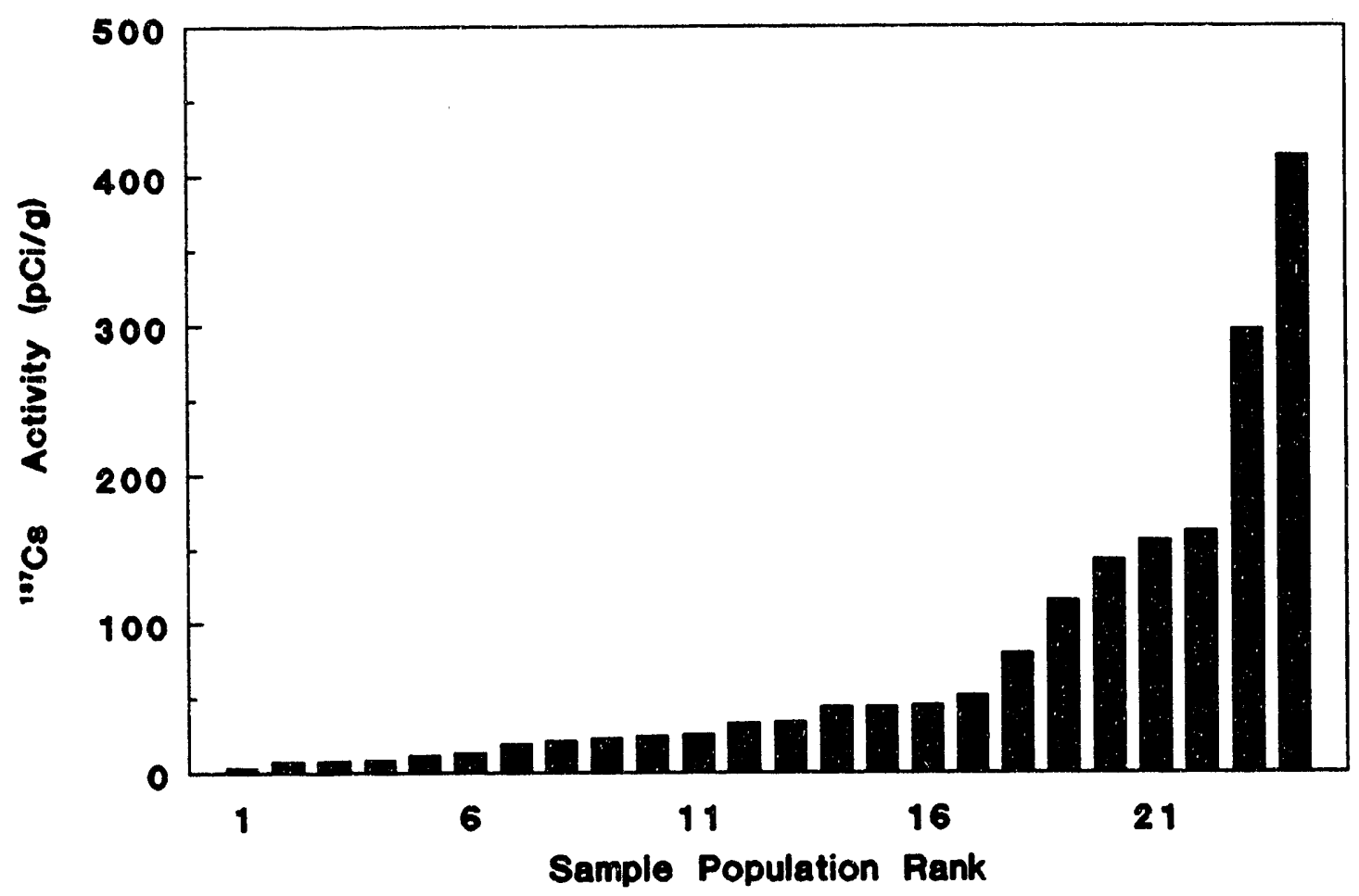

Fig. 76. Activity of ${ }^{137} \mathrm{Cs}$ in the population of all soil samples obtained from beneath core holes into the 1991 ORNL ISV test site.

water and cuttings would be free to drain down into the low bulk density soil beneath the melt because the water feed and drilling operations could not be stopped instantaneously. In addition, contamination could have been driven down during sampling from fallen-in fragments at the bottom of the core hole when the core barrel was withdrawn from the hole. The soil samples from beneath the core holes averaged $22 \%$ moisture, when finally sampled about 3 months after completing the melt, and a bulk density of $1.54 \mathrm{~g} / \mathrm{cm}^{3}$ that would be consistent with some penetration by wash water and cuttings. The average bulk density of soil just outside the circumference of the melt was 1.35 $\mathrm{g} / \mathrm{cm}^{3}$. Thus some soil densification beneath the melt may have occurred due to the weight of molten material during ISV. Although the molten weight would have been less than that of the starting materials, molten material would have no structural strength and thus would exert considerably more static load at its point of contact than the starting materials would. The soil samples collected after cooling on either side of the product and extending to $15 \mathrm{ft}$ deep did not exhibit any ${ }^{137} \mathrm{Cs}$ activity; these samples would be expected to be free from any drilling contamination artifacts but, unfortunately, do not represent soil properties directly beneath the melt. Efforts to resolve this potential artifact of contamination below the melt need to be addressed in future work. For this purpose, several of the core materials from the bottom of the melt could be sampled intensely along 
the melt boundary. If no migration had occurred, then it would be expected that ${ }^{137} \mathrm{Cs}$ activity would fall off rapidly and completely during the transition from melted to fused material. The samples, which contained fused materials discussed above, consisted of mixtures of fragments that contained both partially fused and melted materials; they could not, therefore, be used to resolve such boundary transitions. Future detailed sampling along fusion zone-melt transitions may help resolve this issue of potential migration vs coring artifacts.

\section{COMPOSITION OF ISV PRODUCT BY ANALYSES OF SAMPLE DIGESTS}

The pulverized samples of starting soil (9), dolomite (2), cold caps (5), and assorted ISV products (39) were subjected to $\mathrm{HF} / \mathrm{HNO}_{3}$ digestion as described in the section on prefilter analyses. Sample weights between 0.400 and $0.500 \mathrm{~g}$ were employed, and a final volume of $50 \mathrm{~mL}$ of $6.5 \%$ $\mathrm{HNO}_{3}$ was prepared for each sample. In addition, three samples of the starting Pit 1 sludge were also digested by this procedure, although sample weights of only $0.1383,0.1654$, and $0.1714 \mathrm{~g}$ were used to reduce the levels of radioactivity to within routine laboratory operations guidelines. Further dilutions of $20: 1$ of these digests were made to reduce the activities of ${ }^{137} \mathrm{Cs}$ to near that of the standards used for their assay. Twenty milliliters of each digest was placed into a $25-\mathrm{mL}$ scintillation vial and assayed for ${ }^{137} \mathrm{Cs}$ via gamma-ray spectroscopy using a $\mathrm{NaI}$ detector as described previously. The same scintillation vials were assayed for ${ }^{90} \mathrm{Sr}$ via Cerenkov radiation emission, also as described previously. In addition, $10.00 \mathrm{~g}$ of pulverized samples were counted directly for ${ }^{137} \mathrm{Cs}$ activity using standards prepared in $10 \mathrm{~g}$ of low-background soil. Using a subgroup of 37 samples of ISV product, the direct assay of ${ }^{137} \mathrm{Cs}$ on the pulverized specimens yielded a mean activity of $1845 \mathrm{dpm} / \mathrm{g}$, while assays of the digests yielded a mean activity of $1856 \mathrm{dpm} / \mathrm{g}$. This agreement confirmed that all the ${ }^{137} \mathrm{Cs}$ was recovered during the $\mathrm{HF} / \mathrm{HNO}_{3}$ digestion procedure and built confidence that ${ }^{90} \mathrm{Sr}$ recovery was also quantitative. Direct assays for ${ }^{90} \mathrm{Sr}$ via emission of bremsstralung have high detection limits compared with Cerenkov counting and are subject to considerable background correction caused by the presence of the ${ }^{137} \mathrm{Cs}$. A subgroup of 29 out of the 37 ISV product samples was defined and contained only those samples without fusion zone materials or other anomalous characteristics; this group includes samples ISV-WR-\#'s 2 to $10,12,13,14,16,17,19,20,21,23,24,27$, and 30 to 38 . Ten selected ISV product samples were submitted for routine ICP atomic emission analyses of elements and for $\mathrm{La}, \mathrm{Ce}, \mathrm{Nd}$, and Ir via atomic adsorption; these samples included ISV-WR-\#'s 5, 6, $7,9,10,11,16,22,25$, and 34 ; this selection included every fourth sample from the complete group of $39 \mathrm{ISV}$ product samples when arranged in order of increasing ${ }^{137} \mathrm{Cs}$ activities. In computing average ISV product composition for all these elements, sample ISV-WR-25 was not included because it had been contaminated by one of the grinding mill's agate balls.

Results for the assays of ${ }^{137} \mathrm{Cs}$ and ${ }^{90} \mathrm{Sr}$ in the population of $29 \mathrm{ISV}$ products are presented in Fig. 77. These distributions of measured activities for both radioisotopes exhibited smallpercentage standard deviations of 4.6 and $6.9 \%$, respectively, for ${ }^{137} \mathrm{Cs}$ and ${ }^{90} \mathrm{Sr}$. The average activities of ${ }^{137} \mathrm{Cs}$ and ${ }^{90} \mathrm{Sr}$ were $1900.4 \mathrm{dpm} / \mathrm{g} \pm 87.1 \mathrm{dpm} / \mathrm{g}$ (S.D.) and $519.9 \mathrm{dpm} / \mathrm{g} \pm 36.1$ (S.D.), respectively. Median values of 1915.4 and $514.1 \mathrm{dpm} / \mathrm{g}$, respectively, were used as the best estimate of the activities of these radioisotopes in the ISV product. The average ratio of ${ }^{90} \mathrm{Sr} /{ }^{137} \mathrm{Cs}$ in the ISV product calculates to 0.274 , which is slightly higher than the ratio of 0.217 in the starting sludge sample. This increase in radionuclide ratio probably resulted from the volatile losses of ${ }^{137} \mathrm{Cs}$ to the off-gas system and cold cap materials above the more homogeneous ISV melt product.

The presence of radionuclides and tracer elements in the specimens of the four collapsed cold caps and the final melt surface was particularly illustrative of the volatile nature of both the ${ }^{137} \mathrm{Cs}$ and $\mathrm{Sb}$ during ISV (Table 31). The nonvolatile tracers $\left(\mathrm{Ce}, \mathrm{La}\right.$, and $\mathrm{Nd}$ ) and the nonvolatile ${ }^{90} \mathrm{Sr}$ exhibited very little, if any, above-background presence in the cold caps, whereas both the volatile ${ }^{137} \mathrm{Cs}$ and $\mathrm{Sb}$ exhibit considerable enrichment over either the starting soil or dolomite. In several cold caps, both $\mathrm{Sb}$ and ${ }^{137} \mathrm{Cs}$ were present at levels considerably above the final ISV product composition. However, because this deposition from the melt had not gone beyond the original soil surface, it was not considered volatilized material. 


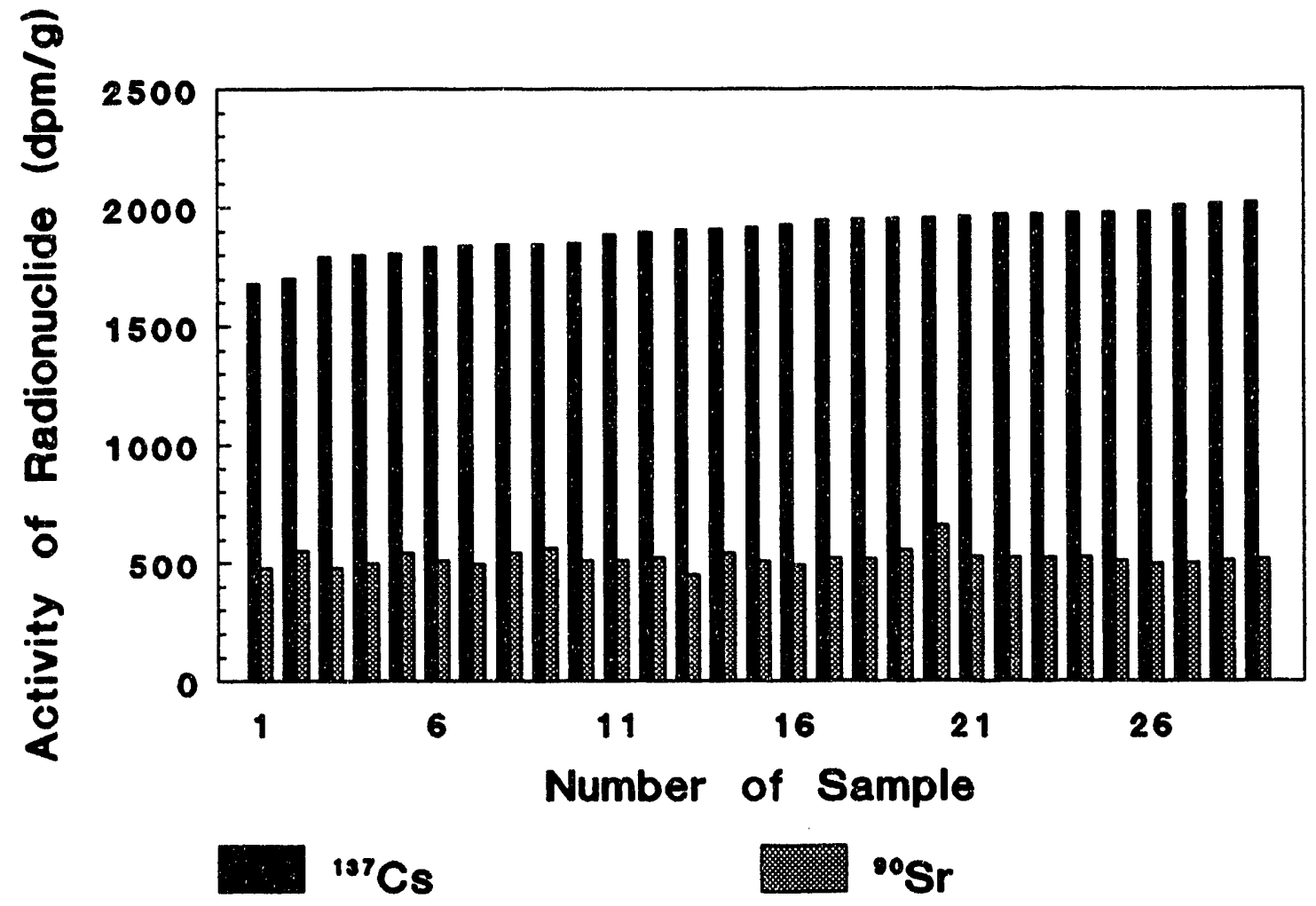

Fig. 77. Activities of ${ }^{137} \mathrm{Cs}$ and ${ }^{90} \mathrm{Sr}$ in the population of samples from the ISV product arranged by increasing ${ }^{137} \mathrm{Cs}$ activity.

The chemical and radionuclide composition of the ISV product and starting materials is presented in Table 32. In general, there was good agreement between the two basic methods of sample analyses: inductively coupled plasma atomic emission (ICPAE) on $\mathrm{HF} / \mathrm{HNO}_{3}$ digests and the $\mathrm{X}$-ray fluorescence and/or neutron activation (XRF/NA). None of the methods could be used for all the desired analyses, so there were a number of elements that were not mutually verified. There were two notable discrepancies between the analytical procedures. First, Si analyses were considerably lower for the ICPAE method; this is a traditional problem due to the volatility of $\mathrm{SiF}_{4}$ during $\mathrm{HF}$ digestions. Thus the XRF/NA analyses were the only meaningful Si analyses. Second, the ICPAE analyses for Sb were unusually high for "uncontaminated" starting soil and limestone; these high concentrations of $\mathrm{Sb}$ in the starting materials must be regarded as suspect because background $\mathrm{Sb}$ concentrations in soil are usually below the ppm level. Thus, the NA method should be considered the best for analyzing this element.

The chemical and radionuclide composition can be used for several calculations of interest to the ISV product. First, from the measured compositions of the ISV product, the starting soil, and the starting limestone, a soil:dolomite melt mixing ratio for the ISV product can be calculated. This was done for all elements (Table 33) by calculating the ratio of soil to dolomite at their ambient 
Table 31. Activities of ${ }^{137} \mathrm{Cs}$ and ${ }^{95}$ and concentrations of tracer elements in the five cold caps of ISV products above the bulk melt zone.

\begin{tabular}{|c|c|c|c|c|c|c|c|}
\hline $\begin{array}{l}\text { Cold Cap } \\
\text { Number }\end{array}$ & $\begin{array}{r}\text { B Below } \\
\text { Surface } \\
(\mathrm{m})\end{array}$ & $\begin{array}{l}{ }^{137} \mathrm{Cs} \\
\text { (--dpm/g }\end{array}$ & $\begin{array}{l}{ }^{90} \mathrm{Sr} \\
\mathrm{g}----)\end{array}$ & $\begin{array}{l}\mathrm{Ce} \\
(---\end{array}$ & $\mathrm{La}$ & $\mathrm{Nd}$ & \begin{tabular}{r}
$\mathrm{Sb}$ \\
\hdashline--$)$
\end{tabular} \\
\hline 1 & 0.30 & 240 & 16 & 95 & 44 & 35 & 5 \\
\hline 2 & 0.46 & 2537 & 22 & 86 & 42 & 37 & 761 \\
\hline 3 & 1.07 & 196 & 18 & 100 & 48 & 39 & 34 \\
\hline 4 & 1.22 & 2270 & 24 & 94 & 46 & 44 & 72 \\
\hline Melt Surface & 1.52 & 2090 & 13 & 88 & 41 & 36 & 42 \\
\hline Average ISV Product & - & 1915 & 514 & 178 & 132 & 99 & 27 \\
\hline Average Soil & - & $<0.2$ & $<0.5$ & 106 & 49 & 48 & 0.13 \\
\hline Average Dolomite & - & $<0.2$ & $<0.5$ & 7.0 & 3.4 & 2 & 0.03 \\
\hline
\end{tabular}

element concentrations, which would yield the composition found after vitrification; obviously, the starting chemical compositions have to be adjusted for their weight loses on ignition (i.e., vitrification), which were determined to be 9.57 and $41.78 \%$ of oven-dried weight for the soil and dolomite, respectively. It is also obvious that the greater the contrast in the starting element concentrations between soil and dolomite, the more accurate the melt mixing estimate will be. In addition, the tracer elements $\mathrm{Ce}, \mathrm{La}, \mathrm{Nd}$, and $\mathrm{Sb}$ cannot be used because of the exogenous additions made. Nor can elements with any appreciable volatility, such as $\mathrm{Pb}, \mathrm{Zn}, \mathrm{Cd}$, or $\mathrm{Hg}$ be used for such calculations because they are not fully conserved within the melt. The best estimates are probably based on the 14 trace elements ( $C s$ through $\mathrm{Yb}$ ) in Table 33 because almost all exhibited at least an order of magnitude difference in composition between the starting soil and dolomite. The average fractional soil inclusion in the melt from these 14 elements was 0.775 . This value is similar to the calculated soil inclusion based on the nonvolatile major elements $\mathrm{Al}$ and $\mathrm{Si}$ (both 0.81 ).

\section{ISV PRODUCT WEIGHT ESTIMATION BY TRACER DILUTION}

Using the known additions to the test melt of ${ }^{90} \mathrm{Sr}$ and ${ }^{137} \mathrm{Cs}$ as well as the known additions of the three rare earth tracers $(\mathrm{Ce}, \mathrm{La}$, and $\mathrm{Nd})$ and the final concentrations and activities in the bulk ISV product, estimates of the weight of ISV product can be calculated. In the case of ${ }^{90} \mathrm{Sr}$ the calculation is straight forward: the sludge contained $189,400 \mathrm{~Bq} / \mathrm{g}$ and $490 \mathrm{~g}$ were added, resulting in an addition of $9.28 \times 10^{7} \mathrm{~Bq}$. The ISV product had a median activity of ${ }^{90} \mathrm{Sr}$ of $8,568 \mathrm{~Bq} / \mathrm{g}$, which, when divided into the starting inventory, yields a product weight of $10.8 \mathrm{Mg}$. Because no volatilization of ${ }^{90} \mathrm{Sr}$ was detected in the off-gas processing scrub solution or in the prefilter, the residual inventory for this calculation did not require adjustment. In the case of ${ }^{137} \mathrm{Cs}$, the activity added $(766,000 \mathrm{~Bq} / \mathrm{g}$ $\times 490 \mathrm{~g}=3.75 \times 10^{8} \mathrm{~Bq}$ ) was corrected for the amount volatilized as measured on the prefilter, MM5 sampler filters, and off-gas hood and ducting $\left(8.81 \times 10^{6} \mathrm{~Bq}\right)$. When the net retained ${ }^{137} \mathrm{Cs}$ activity was divided by the median ${ }^{137} \mathrm{Cs}$ activity in the ISV product $(31.92 \mathrm{~Bq} / \mathrm{g})$, the resulting ISV product weight was $11.5 \mathrm{Mg}$ (Table 34). Similar calculations can be performed for the three rare earth tracers; however, significant corrections for the background concentrations in the starting soil and limestone need to be made (Table 32). The added $\mathrm{Ce}, \mathrm{La}$, and $\mathrm{Nd}$ in the tracers amounted to 124, 282, and $193 \%$, respectively, of the indigenous starting materials' contribution to the final ISV product. Thus, unlike the radioisotopes, the correction for these background concentrations were quite significant. 
Table 32. Chemical and radionuclide composition of ISV product and starting materials.

\begin{tabular}{|c|c|c|c|c|c|c|}
\hline Element & $\begin{array}{r}\text { ISV } \\
\text { Product } \\
\text { (ICPAE) } \\
(\mathrm{mg} / \mathrm{g})\end{array}$ & $\begin{array}{r}\text { ISV } \\
\text { Product } \\
(\mathrm{XRF} / \mathrm{NA}) \\
(\mathrm{mg} / \mathrm{g})\end{array}$ & $\begin{array}{r}\text { Starting } \\
\text { Soil } \\
(\text { ICPAE }) \\
(\mathrm{mg} / \mathrm{g})\end{array}$ & $\begin{array}{r}\text { Starting } \\
\text { Soil } \\
(\mathrm{XRF} / \mathrm{NA}) \\
(\mathrm{mg} / \mathrm{g})\end{array}$ & $\begin{array}{r}\text { Starung } \\
\text { Dolomite } \\
\text { (ICPAE) } \\
(\mathrm{mg} / \mathrm{g})\end{array}$ & $\begin{array}{r}\text { Starting } \\
\text { Dolomite } \\
\text { (XRF/NA) } \\
(\mathrm{mg} / \mathrm{g})\end{array}$ \\
\hline $\mathrm{Ag}$ & $<0.0005$ & NA & $<0.003$ & NA & $<0.003$ & NA \\
\hline Al & 85.85 & 83.10 & 92.40 & 89.55 & 7.141 & 7.56 \\
\hline As & $<0.005$ & 0.0013 & $<0.03$ & 0.00234 & $<0.03$ & 0.00125 \\
\hline B & 50.00 & NA & 4.254 & NA & 8.452 & NA \\
\hline $\mathrm{Ba}$ & 0.35 & 0.425 & 0.436 & 0.411 & 0.0398 & 0.039 \\
\hline $\mathrm{Be}$ & 0.0026 & NA & 0.00359 & NA & 0.000815 & NA \\
\hline $\mathrm{Ca}$ & 117.00 & 121.21 & 30.10 & 26.94 & 218.1 & 191.5 \\
\hline $\mathrm{Cd}$ & $<0.0005$ & NA & 0.00459 & NA & 0.00982 & NA \\
\hline $\mathrm{Ce}$ & 0.204 & 0.182 & NA & 0.106 & NA & 0.00695 \\
\hline Co & 0.0140 & 0.0139 & 0.0238 & 0.0146 & 0.00769 & 0.0212 \\
\hline $\mathrm{Cr}$ & 0.444 & 0.0983 & 0.365 & 0.0819 & 0.884 & 0.00614 \\
\hline $\mathrm{Cu}$ & 0.0260 & NA & 0.0278 & NA & 0.00921 & NA \\
\hline $\mathrm{Fe}$ & 35.75 & 37.69 & 47.26 & 43.91 & 7.88 & 3.88 \\
\hline $\mathrm{Hg}$ & NA & 0.00005 & NA & NA & NA & NA \\
\hline Ir & 0.000108 & NA & NA & NA & NA & NA \\
\hline $\mathbf{K}$ & NA & 27.06 & NA & 29.05 & NA & 6.72 \\
\hline $\mathrm{La}$ & 0.161 & 0.137 & NA & 0.0490 & NA & 0.00346 \\
\hline $\mathrm{Li}$ & $<1.6$ & NA & $<9.4$ & NA & $<9.4$ & NA \\
\hline $\mathrm{Mg}$ & 30.85 & 35.82 & 14.74 & 14.11 & 96.85 & 97.76 \\
\hline $\mathrm{Mn}$ & 0.714 & 0.929 & 1.110 & 1.006 & 0.330 & 0.232 \\
\hline Mo & $<0.004$ & NA & $<0.02$ & NA & $<0.02$ & NA \\
\hline $\mathrm{Na}$ & 7.077 & 1.48 & 6.33 & 1.335 & 7.23 & -0.593 \\
\hline Nd & 0.143 & 0.102 & NA & 0.0482 & NA & 0.002 \\
\hline $\mathrm{Ni}$ & 0.0370 & NA & 0.0587 & NA & 0.0298 & NA \\
\hline$P$ & $<0.034$ & 0.480 & $<0.19$ & 0.523 & $<0.19$ & 0 \\
\hline $\mathrm{Pb}$ & 0.0143 & 0.016 & $<0.03$ & 0.0227 & $<0.03$ & 0.00186 \\
\hline $\mathrm{Sb}$ & 0.0550 & 0.027 & 0.0479 & 0.000132 & 0.0432 & 0.00003 \\
\hline Se & $<0.005$ & NA & 0.0481 & NA & 0.0171 & NA \\
\hline $\mathrm{Si}$ & 67.00 & 243.51 & 40.90 & 259.7 & 87.88 & 35.00 \\
\hline Sn & 0.0224 & NA & 0.0484 & NA & 0.0409 & NA \\
\hline $\mathrm{Sr}$ & 0.141 & 0.153 & 0.0746 & 0.0717 & 0.0956 & 0.0937 \\
\hline $\mathrm{Ti}$ & 4.67 & 4.49 & 4.250 & 4.67 & 0.229 & 0.179 \\
\hline V & 0.079 & NA & 0.0867 & NA & 0.00873 & NA \\
\hline $\mathrm{Zn}$ & 0.169 & 0.172 & 0.112 & 0.0934 & 1.59 & 1.489 \\
\hline $\mathrm{Zr}_{\mathbf{r}}$ & 0.261 & 0.249 & 0.170 & 0.248 & 0.0755 & 0.0178 \\
\hline $\mathrm{Br}$ & NA & 0.001 & NA & 0.00071 & NA & 0.004 \\
\hline Cs & NA & 0.00372 & NA & 0.00414 & NA & 0.00021 \\
\hline Eu & NA & 0.00174 & NA & 0.00221 & NA & 0.0001 \\
\hline Hf & NA & 0.00708 & NA & 0.00741 & NA & 0.00033 \\
\hline Lu & NA & 0.000496 & NA & 0.00059 & NA & 0.00002 \\
\hline $\mathrm{Nb}$ & NA & 0.016 & NA & 0.0153 & NA & 0.00498 \\
\hline $\mathrm{Rb}$ & NA & 0.109 & NA & 0.122 & NA & 0.00796 \\
\hline Sc & NA & 0.0139 & $\mathrm{NA}$ & 0.0147 & NA & 0.0009 \\
\hline Sn & NA & 0.00822 & NA & 0.0104 & NA & 0.00048 \\
\hline $\mathrm{Ta}$ & NA & 0.000782 & NA & 0.000843 & NA & 0.00009 \\
\hline $\mathrm{Tb}$ & NA & 0.001043 & NA & 0.00132 & NA & 0.00007 \\
\hline Th & NA & 0.0101 & NA & 0.0116 & NA & 0.0003 \\
\hline U & NA & 0.0026 & NA & 0.00254 & NA & 0.00085 \\
\hline Y & NA & 0.037 & NA & 0.0482 & NA & 0.00193 \\
\hline $\mathrm{Yb}$ & NA & 0.00333 & NA & 0.00408 & NA & 0.00016 \\
\hline Isotope & $(\mathrm{Bg} / \mathrm{kg})$ & $(\mathrm{Bq} / \mathrm{kg})$ & $(\mathrm{Bq} / \mathrm{kg})$ & $(\mathrm{Bg} / \mathrm{kg})$ & $(\mathrm{Bq} / \mathrm{kg})$ & $(\mathrm{Bg} / \mathrm{kg})$ \\
\hline$\overline{\mathrm{Am}-241}$ & 23.6 & NA & NA & NA & NA & NA \\
\hline Co-60 & 11.9 & NA & $<11$ & NA & $<11$ & NA \\
\hline Cs-137 & 31923 & NA & $<11$ & NA & $<11$ & NA \\
\hline $\mathrm{K}-40$ & 918 & NA & NA & NA & NA & NA \\
\hline Pu-239 & 4.8 & NA & NA & NA & NA & NA \\
\hline $\mathrm{Sr}=90$ & 8568 & NA & $<19$ & NA & $<17$ & NA \\
\hline
\end{tabular}

The amounts added to the test melt were determined from the weight of chemical multiplied by the theoretical percentage of that element in the particular chemical species. For these calculations, the 
Table 33. Elemental and radionuclide retention factors and percent retention in the ISV melt and calculated soil incorporation fraction during the 1991 ORNL ISV pilot-scale test.

\begin{tabular}{|c|c|c|c|}
\hline $\begin{array}{l}\text { ciement/ } \\
\text { isotope }\end{array}$ & $\begin{array}{r}\text { Retention } \\
\text { factor } \\
\text { (retained/ } \\
\text { volatilized }\end{array}$ & $\begin{array}{r}\text { Percent } \\
\text { melt } \\
\text { retention } \\
(\%)\end{array}$ & $\begin{array}{r}\text { Calculated } \\
\text { ISV product } \\
\text { soil inclusion } \\
\text { fraction }\end{array}$ \\
\hline $\mathrm{Ag}$ & $>65.80$ & $>98.50$ & NA \\
\hline $\mathrm{Al}$ & 34200 & 99.9971 & 0.81 \\
\hline As & 6.479 & 86.63 & -1.9 \\
\hline B & 30590 & 99.9967 & NA \\
\hline $\mathrm{Ba}$ & 57620 & 99.9983 & 0.92 \\
\hline $\mathrm{Be}$ & 11470 & 99.9913 & NA \\
\hline $\mathrm{Ca}$ & 20490 & 99.9951 & 0.69 \\
\hline $\mathrm{Cd}$ & $>281$ & $>73.79$ & NA \\
\hline $\mathrm{Ce}$ & 196500 & 99.99949 & 1.62 \\
\hline Co & 423 & 99.764 & 1.10 \\
\hline $\mathrm{Cr}$ & 234 & 99.575 & 1.10 \\
\hline $\mathrm{Cu}$ & 212.5 & 99.532 & NA \\
\hline $\mathrm{Fe}$ & 1083 & 99.908 & 0.74 \\
\hline $\mathrm{Hg}$ & 93.6 & 98.943 & NA \\
\hline Ir & 2821 & 99.965 & NA \\
\hline $\mathrm{K}$ & NA & NA & 0.75 \\
\hline $\mathrm{La}$ & 210600 & 99.99952 & 273 \\
\hline $\mathrm{Li}$ & $>26.2$ & $>96.3204$ & NA \\
\hline $\mathrm{Mg}$ & 11160 & 99.9910 & 0.87 \\
\hline $\mathrm{Mn}$ & 1962 & 99.949 & 0.74 \\
\hline Mo & $>93.18$ & $>98.94$ & NA \\
\hline $\mathrm{Na}$ & $>1684$ & $>99.941$ & 1.00 \\
\hline $\mathrm{Nd}$ & 222300 & 99.99955 & 1.99 \\
\hline $\mathrm{Ni}$ & 33.85 & 97.13 & NA \\
\hline$P$ & 370 & 99.731 & 0.82 \\
\hline $\mathrm{Pb}$ & 5.75 & 85.189 & 0.58 \\
\hline $\mathrm{Sb}$ & 9.23 & 90.23 & 285 \\
\hline $\mathrm{Se}$ & $>69.5$ & $>98.58$ & NA \\
\hline $\mathrm{Si}$ & 5048 & 99.98 & 0.81 \\
\hline Sn & 428 & 99.77 & NA \\
\hline $\mathrm{Sr}$ & 14490 & 99.9931 & 0.10 \\
\hline $\mathrm{Ti}$ & 38650 & 99.9974 & 0.86 \\
\hline $\mathrm{V}$ & 2045 & 99.951 & NA \\
\hline$Z_{n}$ & 9.23 & 90.23 & 0.97 \\
\hline $\mathrm{Zr}$ & 8180 & 99.988 & 0.89 \\
\hline $\mathrm{Br}-$ & NA & NA & 0.96 \\
\hline Cs & NA & NA & 0.79 \\
\hline $\mathrm{Eu}_{u}$ & NA & NA & 0.69 \\
\hline $\mathrm{Hf}$ & NA & $\mathrm{NA}$ & 0.85 \\
\hline Lu & NA & $\mathrm{NA}$ & 0.75 \\
\hline $\mathrm{Nb}$ & NA & NA & 0.88 \\
\hline $\mathbf{R b}$ & NA & NA & 0.78 \\
\hline Sc & NA & NA & 0.84 \\
\hline Sm & NA & $\mathrm{NA}$ & 0.69 \\
\hline $\mathrm{Ta}$ & NA & $\mathrm{NA}$ & 0.81 \\
\hline $\mathrm{Tb}$ & $\mathrm{NA}$ & NA & 0.69 \\
\hline Th & NA & NA & 0.78 \\
\hline $\mathrm{U}$ & NA & NA & 0.85 \\
\hline Y & NA & NA & 0.67 \\
\hline $\mathrm{Yb}$ & NA & NA & 0.72 \\
\hline Am-241 & 15050 & 99.9933 & NA \\
\hline $\mathrm{Co}-60$ & 595 & 99.832 & NA \\
\hline Cs -137 & 4241 & 97.696 & NA \\
\hline $\mathrm{K}-40$ & 5528 & 99.819 & NA \\
\hline $\mathrm{Pu}-239$ & $>15700$ & $>99.994$ & NA \\
\hline $\mathrm{Sr}-90$ & $>1130000$ & $>99.9999$ & NA \\
\hline
\end{tabular}

average concentration in the 29 non-anomalous samples of ISV product were used. These concentrations were reduced by the amounts contributed by the starting soil and limestone: 
Table 34. The estimated weight of ISV product formed during the 1991 ORNL pilot-scale test based on the calculated dilution of radionuclides and rare earth tracers.

\begin{tabular}{rr}
\hline Tracer & $\begin{array}{r}\text { Calculated } \\
\text { ISV Mass } \\
(\mathrm{Mg})\end{array}$ \\
\hline${ }^{137} \mathrm{Cs}$ & 11.5 \\
${ }^{90} \mathrm{Sr}$ & 10.8 \\
$\mathrm{Ce}$ & 11.4 \\
$\mathrm{La}$ & 12.5 \\
$\mathrm{Nd}$ & 12.6
\end{tabular}

net ISV product concentration $=$ mean measured ISV product concentration

$-[($ mean soil concentration $\times$ soil melt fraction $\times$ soil weight retention on ignition $)$

$+($ mean dolomite concentration $\times$ dolomite melt fraction $\times$ dolomite weight retention on ignition)].

The soil melt fraction equals 0.775 and soil weight retention on ignition (vitrification) equals 0.9043 ; the dolomite melt fraction equals 0.225 and dolomite weight retention on ignition equals 0.5822 . The weight retentions on ignition were measured for the various samples, and the melt fractions were computed independently from the trace element ratios as discussed previously. The mean concentrations of elements in the starting soil were based on nine samples, while the dolomite concentrations were based on two samples (Table 32). The estimated weights of ISV product from these rare earth tracers are listed in Table 34. Corrections for volatilization were insignificant and not performed because $99.9995 \%$ of each tracer was retained in the melt (Table 33). Similarly, the actual contributions from the starting dolomite to the final product concentration of these three elements were extremely small because of their low concentrations (Table 32). The mean weight estimate for all five of these tracers was $11.8 \mathrm{Mg} \pm 0.8 \mathrm{Mg}$ (S.D.). The radionuclide weight estimates are probably the more accurate because they required the least correction/calculation and because added sources were actually measured. Underestimation of ISV product weight could be caused by an underestimate of the activity added or by an overestimate of the activity in the ISV product. The activities of both ${ }^{90} \mathrm{Sr}$ and ${ }^{137} \mathrm{Cs}$ in the sludge were found to agree when analyzed by independent analysts. The activities in the ISV product samples were quite uniform (Fig. 77), removing uncertainty in those analyses. Although the activities of all radionuclides were based on reference materials, these materials were the same for all analyses (prefilter, ISV products, and pit sludge). Thus, absolute activities in materials would not be a source of error because all assays were referenced to the same standards. Thus, using only the ${ }^{90} \mathrm{Sr}$ and ${ }^{137} \mathrm{Cs}$, the ISV product weight estimate was $11.2 \mathrm{Mg}$.

Several potential sources of error could contribute to the slightly higher estimate of ISV product weight $(12.2 \mathrm{Mg}$ ) calculated from the concentrations of three rare earth tracers, $\mathrm{Ce}, \mathrm{La}$, and Nd. In addition to the uncertainty in the analyses, the computation of a net concentration, to correct for contributions by the starting soil and dolomite, introduces a compounding effect of additive uncertainties in two separate analyses. In addition, the actual assay of the starting compounds that were placed in the test trench was assumed to be the manufacturer's assay; weights vere also assumed to be oven-dried to the formula weight of the purchased compounds. Thus any overestimate of the actual weight added or chemical assay would lead to an overestimate of product weight. Nonetheless, 
the discrepancies between the radionuclide and tracer-based weights were less than $10 \%$, and it has been assumed that the average of all five tracers would be the most accurate weight, i.e., $11.8 \mathrm{Mg}$.

\section{CRYSTALLIZATION AND COMPOSITIONAL EVOLUTION WITHIN THE ISV MELT}

\section{Melting Process and Convection}

The geometry of the SV rock body was inferred by examining the length of the cores. A three-dimensional image was obtained by contouring data from the 17 cores and the penetration tests to locate the upper surface and lateral extent of the ISV product. Visual inspection of the recovered

\section{Ground Surface}

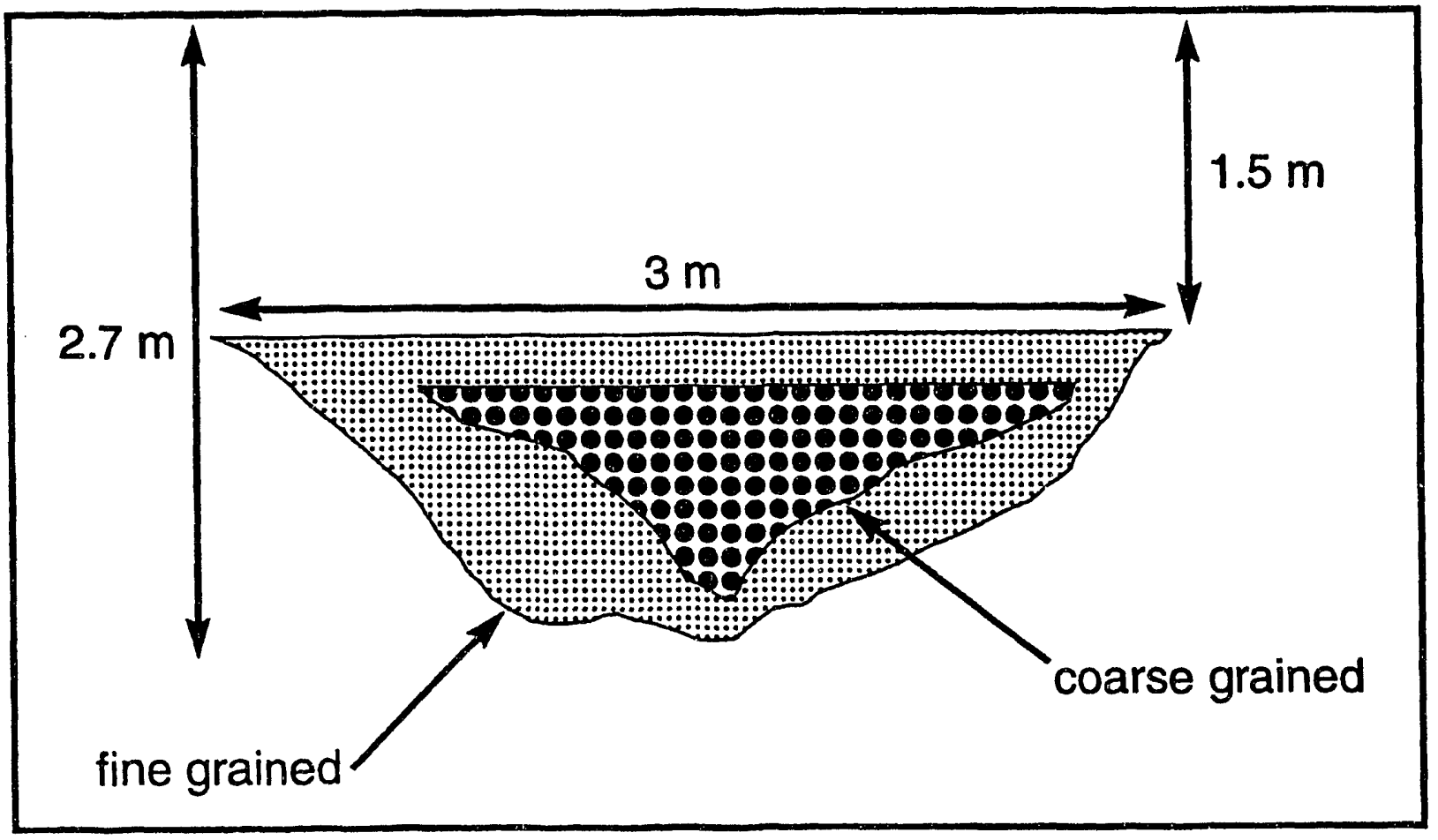

Fig. 78. Shape of ISV melt as determined by cores drilled through the cooled body showing the fine and coarse grained crystallinity.

core material was used to identify the more coarsely crystalline interior portion of the ISV rock body. Figure 78 illustrates a two-dimensional cross section of the melt body based. The shape is roughly hemispheric, but is slightly elongated in one direction, possibly as a result of (1) the shape of the trench $(2 \mathrm{~m}$ long $\times 1 \mathrm{~m}$ wide $\times 2 \mathrm{~m}$ deep) filled with crushed dolomitic limestone, which was within the melt area, or (2) the slight downhill slope of the test site in that direction. The melt elongation appears to have occurred in the same orientation as trench elongation, suggesting that the trench 
influenced melt patterns. The rock body is $\sim 3 \mathrm{~m}$ in diameter, up to $1.5 \mathrm{~m}$ thick, and attained a final depth of $\sim 3 \mathrm{~m}$ below the original ground surface.

Whole-rock major and trace element analyses were made on a number of samples from within the melt body, the rock-soil interface (partial melt zone), and glassy cold caps. Samples for analyses were selected from each core which recovered material from the base to the top of the ISV rock. Samples approximately $3 \mathrm{~cm}$ long were taken from each core at positions near the base, the very top, and at several intervals in the central part of each core. Thus the samples analyzed represent extreme positions in the ISV product and would be capable of detecting any inhomogeneities in chemical composition that may be present within the ISV product. Samples for whole-rock analysis were crushed with a hammer; they were then powdered using a Brinkman grinder with agate grinding vessels. Whole-rock analyses of major and trace elements were made by X-ray fluorescence (XRF) and neutron activation analysis (NAA). XRF determinations of major elements and trace elements $\mathrm{Rb}, \mathrm{Sr}, \mathrm{Y}, \mathrm{Zr}, \mathrm{Nb}$, and $\mathrm{Pb}$ were made with a Rigaku model 3062 spectrometer, following the methods of Bence and Albee (1968) and Norrish and Chappell (1977). Four NIST standard reference materials

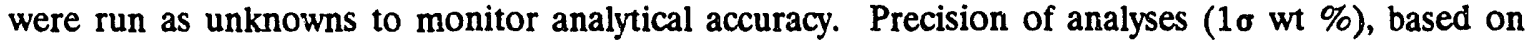
counting statistics for levels analyzed in this study for major elements, is: $\mathrm{SiO}_{2} \pm 0.3 ; \mathrm{TiO}_{2} \pm 0.01$; $\mathrm{Al}_{2} \mathrm{O}_{3} \pm 0.17 ; \mathrm{Fe}_{2} \mathrm{O}_{3} \pm 0.1 ; \mathrm{MnO} \pm 0.01 ; \mathrm{MgO} \pm 0.3 ; \mathrm{CaO} \pm 0.08 ; \mathrm{Na}_{2} \mathrm{O} \pm 0.03 ; \mathrm{K}_{2} \mathrm{O} \pm 0.03$. For trace elements, precision of analysis ( $1 \sigma$ in $\mathrm{ppm}$ ) is: $\mathrm{Nb} \pm 1 ; \mathrm{Th}, \mathrm{Y} \pm 2 ; \mathrm{Sr} \pm 3 ; \mathrm{Rb}, \mathrm{Zr} \pm 4$.

Neutron activation samples were irradiated and counted using high-purity coaxial germanium detectors. SRM 1633-A (NIST) was used as a standard. Sample preparation and data reduction follow Jacobs et al. (1977) and Korotev and Lindstrom (1985). Standard reference materials BCR-1 and G-2 were analyzed to monitor analytical accuracy and procedure. Analytical precision for elements reported in this study, to $1 \sigma$ as determined by counting statistics, is (all in ppm, except where noted otherwise): $\mathrm{Na} \pm 0.02 \mathrm{wt} \% ; \mathrm{Ba} \pm 20 ; \mathrm{La} \pm 1 ; \mathrm{Sm} \pm 0.09 ; \mathrm{Yb} \pm 0.06 ; \mathrm{Lu} \pm 0.01 ; \mathrm{U} \pm 0.02 ; \mathrm{Sc}$ $\pm 0.13 ; \mathrm{Fe} \pm 0.05 ; \mathrm{Co} \pm 0.16 ; \mathrm{Zn} \pm 4 ; \mathrm{Rb} \pm 3 ; \mathrm{Cs} \pm 0.06 ; \mathrm{Nd} \pm 2 ; \mathrm{Eu} \pm 0.02 ; \mathrm{Hf} \pm 0.1 ; \mathrm{Ta} \pm 0.03, \mathrm{Th}$ \pm 0.1 .

Major element composition (Table 35) indicates that the 1991 ORNL melt was relatively low in $\mathrm{SiO}_{2}$ and extremely low in $\mathrm{Na}_{2} \mathrm{O}$, but high in $\mathrm{CaO}, \mathrm{MgO}$, and $\mathrm{FeO}$. This rather low concentration of $\mathrm{Na}_{2} \mathrm{O}$, from the point of view of glass formation, may have contributed to the rather strong crystallizing tendency of this melt composition. In geological terms, the melt approximates a basaltic composition with respect to a number of elements. The unusual parent materi. 'saprolitic soil and dolomitic limestone) and complete, vs fractional, melting precludes the major element composition from exactly matching any typical natural igneous rock composition.

Mixing calculations based on initial dolomitic limestone and soil compositions suggest that melt incorporated approximately $80 \%$ soil and $20 \%$ dolomitic limestone (Table 36 ). The soil melted in the ISV test appears to be somewhat inhomogeneous (Table 35), and choosing an initial soil composition was difficult. However, the composition of a fusion zone sample (see Table 36) appears to yield the most consistent results, so this was used as an initial soil composition for the mixing calculations. The mixing calculations for certain trace elements are problematic and were not included in the mixing average. These include $\mathrm{Sr}$ and $\mathrm{Ba}$, for which the dolomite composition analyzed does not appear to be representative of the true dolomite composition incorporated in the melt. Other elements, such as $\mathrm{Pb}$ and $\mathrm{Zn}$, are volatile and therefore are preferentially lost from the melt.

The melt appears to have been well-mixed and homogeneous, as evidenced by the close chemical similarity of all samples within the rock body (Fig. 79 and see standard deviation of rock samples, Table 35). Further evidence for complete mixing during the melting process is the homogeneous distribution of rare earth element tracers. Known amounts of tracers (Nd, Ce, and La) were present at several depths in the projected melt area (Table 10) and were incorporated into the melt at different times during the melting process. Concentration of these tracers in the melt were also used to calculate final melt mass (Table 37). The homogeneous distribution of the tracers within the entire melt indicates that convection was vigorous throughout the melting process and involved all parts of the melt, including the lateral limbs (Fig. 78) as well as the central area. Vigorous convection was observed on the melt surface throughout active melting. Rock samples from within 
Table 35. Major and trace element analyses from the rock body and from premelt soil and limestone as analyzed by $\mathrm{X}$-ray fluorescence and neutron activation.

\begin{tabular}{|c|c|c|c|c|c|c|}
\hline & \multicolumn{2}{|c|}{ Rock $n^{2}=23$} & \multicolumn{2}{|c|}{ Soil $n=9$} & \multicolumn{2}{|c|}{ Limestone $n=2$} \\
\hline & mean & SD & mean & $\mathrm{SD}$ & mean & $\mathrm{SD}$ \\
\hline \multicolumn{7}{|c|}{$X$-ray fluorescence (all in \%) } \\
\hline $\mathrm{SiO}_{2}$ & 52.10 & 0.17 & 62.44 & 2.12 & 14.02 & 2.15 \\
\hline $\mathrm{TiO}_{2}$ & 0.75 & 0.01 & 0.88 & 0.03 & 0.06 & 0.02 \\
\hline $\mathrm{Al}_{2} \mathrm{O}_{3}$ & 15.70 & 0.16 & 19.02 & 0.82 & 2.70 & 0.24 \\
\hline $\mathrm{FeO}$ & 4.85 & 0.13 & 6.35 & 0.24 & 0.94 & 0.13 \\
\hline $\mathrm{MnO}$ & 0.12 & 0.00 & 0.14 & 0.03 & 0.07 & 0.01 \\
\hline $\mathrm{MgO}$ & 5.94 & 0.24 & 2.63 & 0.30 & 30.40 & 0.16 \\
\hline $\mathrm{CaO}$ & 16.96 & 0.20 & 4.28 & 2.61 & 50.30 & 1.66 \\
\hline $\mathrm{Na}_{2} \mathrm{O}$ & 0.20 & 0.06 & 0.20 & 0.09 & 0.00 & 0.00 \\
\hline $\mathrm{K}_{2} \mathrm{O}$ & 3.26 & 0.05 & 3.93 & 0.16 & 1.51 & 0.03 \\
\hline $\mathrm{P}_{2} \mathrm{O}_{5}$ & 0.11 & 0.01 & 0.13 & 0.01 & 0.01 & 0.00 \\
\hline Loss on & & & & & & \\
\hline ignition & 0.18 & 0.47 & 9.57 & 1.66 & 41.78 & 0.00 \\
\hline Total & 99.22 & 0.86 & 98.53 & 0.48 & 95.01 & 1.99 \\
\hline \multicolumn{7}{|c|}{$X$-ray fluorescence analyses (all in ppm) } \\
\hline Th & 11 & 2 & 12 & 1 & 0 & 0 \\
\hline $\mathrm{Rb}$ & 109 & 2 & 123 & 5 & 8 & 1 \\
\hline $\mathrm{Sr}$ & 153 & 2 & 72 & 16 & 94 & 8 \\
\hline $\mathbf{Y}$ & 37 & 1 & 48 & 16 & 2 & 1 \\
\hline $\mathrm{Zr}$ & 249 & 3 & 249 & 9 & 18 & 0 \\
\hline $\mathrm{Nb}$ & 16 & 0 & 15 & 0 & 5 & 0 \\
\hline \multicolumn{7}{|c|}{ Neutron activation analyses (in ppm unless noted) } \\
\hline $\mathrm{Na}(\mathrm{wt} \%)$ & 0.22 & 0.05 & 0.29 & 0.04 & 0.03 & 0.01 \\
\hline Sc & 13.92 & 0.37 & 14.79 & 0.96 & 0.90 & 0.00 \\
\hline $\mathrm{Fe}$ & 4.75 & 0.04 & 5.55 & 0.32 & 0.45 & 0.02 \\
\hline Co & 13.97 & 0.10 & 21.29 & 3.28 & 3.59 & 2.29 \\
\hline $\mathrm{Zn}$ & 172 & 5 & 93 & 4 & 1490 & 937 \\
\hline $\mathbf{R b}$ & 109 & 3 & 126 & 8 & 9 & 1 \\
\hline Cs & 3.72 & 0.10 & 4.14 & 0.24 & 0.21 & 0.02 \\
\hline $\mathrm{Ba}$ & 425 & 21 & 411 & 19 & 39 & 7 \\
\hline La & 137.8 & 2.0 & 49.1 & 6.0 & 3.5 & 0.0 \\
\hline $\mathrm{Nd}$ & 102.8 & 2.8 & 48.3 & 12.8 & 2.0 & 0.0 \\
\hline $\mathrm{Sm}$ & 8.22 & 0.08 & 10.45 & 3.2 & 0.48 & 0.05 \\
\hline $\mathrm{Eu}$ & 1.74 & 0.02 & 2.22 & 0.7 & 0.10 & 0.07 \\
\hline$Y b$ & 3.33 & 0.10 & 4.08 & 0.98 & 0.16 & 0.02 \\
\hline $\mathrm{Lu}$ & 0.496 & 0.015 & 0.587 & 0.122 & 0.024 & 0.002 \\
\hline $\mathrm{Hf}$ & 7.08 & 0.08 & 7.41 & 0.38 & 0.33 & 0.02 \\
\hline $\mathrm{Ta}$ & 0.782 & 0.020 & 0.844 & 0.061 & 0.086 & 0.025 \\
\hline Th & 10.19 & 0.18 & 10.94 & 0.66 & 0.84 & 0.15 \\
\hline$U$ & 2.6 & 0.2 & 2.5 & 0.2 & 0.850 & 0.071 \\
\hline
\end{tabular}

a few centimeters of the margin of the rock body near the soil interface are compositionally identical 
Table 36. Calculation of soil:limestone mixing ratio in producing the ISV product.

\begin{tabular}{|c|c|c|c|c|}
\hline & Soill $^{\mathrm{a}}$ & Limestone $^{b}$ & Rock & Mixing \\
\hline $\mathrm{SiO}_{2}(\mathrm{wt} \%)$ & 58.9 & 14.05 & 51.65 & 84 \\
\hline $\mathrm{TiO}_{2}$ (wt \%) & 0.84 & 0.06 & 0.74 & 87 \\
\hline $\mathrm{Al}_{2} \mathrm{O}_{3}$ (wt \%) & 18.16 & 2.68 & 15.55 & 83 \\
\hline $\mathrm{FeO}(\mathrm{wt} \%)$ & 6.03 & 0.94 & 4.82 & 76 \\
\hline $\mathrm{MnO}$ (wt \%) & 0.14 & 0.06 & 0.12 & 71 \\
\hline $\mathrm{MgO}$ (wt \%) & 3.99 & 30.4 & 5.95 & 93 \\
\hline $\mathrm{CaO}$ (wt \%) & 5.30 & 50.3 & 16.80 & 74 \\
\hline $\mathrm{K}_{2} \mathrm{O}$ (wt \%) & 3.93 & 1.52 & 3.23 & 71 \\
\hline $\mathrm{P}_{2} \mathrm{O}_{5}(\mathrm{wt} \%)$ & 0.14 & 0.01 & 0.11 & 79 \\
\hline Th (ppm) & 15 & 0 & 11 & 76 \\
\hline $\mathrm{Rb}$ (ppm) & 138 & 8 & 107 & 76 \\
\hline$Y(\mathrm{ppm})$ & 42 & 2 & 37 & 88 \\
\hline $\mathrm{Nb}$ (ppm) & 17 & 5 & 16 & 92 \\
\hline $\mathrm{Na}(\mathrm{wt} \%)$ & 0.28 & 0.03 & 0.22 & 78 \\
\hline Sm (ppm) & 9.32 & 0.48 & 8.22 & 88 \\
\hline $\mathrm{Yb}(\mathrm{ppm})$ & 3.92 & 0.16 & 3.33 & 84 \\
\hline Lu (ppm) & 0.587 & 0.024 & 0.496 & 84 \\
\hline Sc (ppm) & 15.90 & 0.90 & 13.92 & 87 \\
\hline $\mathrm{Fe}(\mathrm{ppm})$ & 6.02 & 0.45 & 4.75 & 77 \\
\hline $\mathrm{Rb}$ (ppm) & 146 & 9 & 109 & 73 \\
\hline Cs (ppm) & 4.61 & 0.21 & 3.72 & 80 \\
\hline $\mathrm{Eu}(\mathrm{ppm})$ & 1.996 & 0.098 & 1.741 & 87 \\
\hline $\mathrm{Tb}(\mathrm{ppm})$ & 1.255 & 0.066 & 1.043 & 82 \\
\hline Hf (ppm) & 7.91 & 0.33 & 7.08 & 89 \\
\hline Ta (ppm) & 0.844 & 0.086 & 0.782 & 92 \\
\hline Th (ppm) & 11.98 & 0.84 & 10.19 & 84 \\
\hline \multicolumn{4}{|c|}{ Average Mixing Ratio $=$} & 82 \\
\hline
\end{tabular}

${ }^{9}$ Fusion zone sample ISV-WR-26.

to the core of the body, suggesting that convection was active throughout the melting process and that a mushy zone, such as might be present in a larger melt (Brandeis and Jaupart 1986), was not present during active melting.

The rapid and complete convective mixing within the small melt body is likely to be a result of relatively low melt viscosity. Temperatures were probably highest near the four electrodes, and the resulting thermal gradients drive convection during the melting process. Viscosity of the melt from 1000 to $1500^{\circ} \mathrm{C}$ was calculated following Shaw (1972). The calculated viscosity at a melt temperature of $1400^{\circ} \mathrm{C}$ is 97 poise, which is low compared with many natural magmas. For comparison, the viscosity of a dry Hawaiian basalt at a temperature of $1200^{\circ} \mathrm{C}$ is $\sim 280$ poise (Ryan and Blevins 1987), and a rhyolite containing $5 \% \mathrm{H}_{2} \mathrm{O}$ at $750^{\circ} \mathrm{C}$ is $-3.2 \times 10^{6}$ poise (Kuentz 1986).

\section{Distribution, Appearance, and Composition of Crystals}

When examined, the ISV rock was found to have crystallized almost to completion during cooling. Polished sections for petrographic observation and microbeam geochemical analysis were made from core samples mounted in epoxy on 1 in.-round glass slides, then ground and polished with 


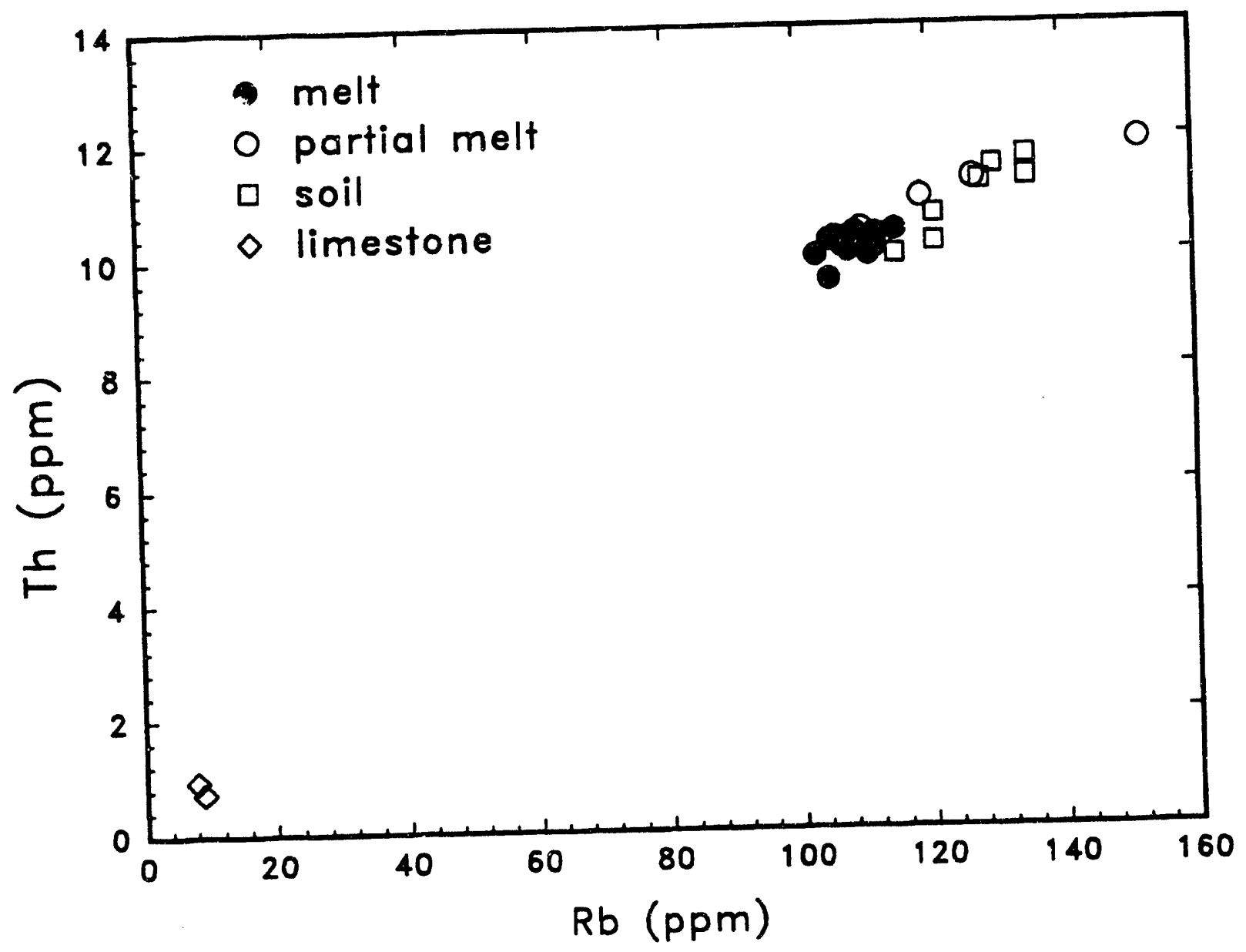

Fig. 79. Rubidium and thorium content of ISV rock, suil and dolomitic limestone as analyzed by $x$-ray fluorescence.

pure diamond grit suspended in distilled water. Electron microprobe analyses of crystals within ISV rock samples were made with a Cameca SX-50 microprobe at The University of Tennessee, using ZAF correction procedures. An excitation potential of $10 \mathrm{kV}$ and a beam current of $20 \mathrm{nA}$ were used with natural and synthetic standards, as well as with the unknowns. The beam size was adjusted to accornmodate the sample type and was generally a $20-\mu \mathrm{m}$-diam beam for glassy areas and a 5- to 10 $\mu \mathrm{m}$ beam for crystals. During calibration, an intermediate $(10 \mu \mathrm{m})$ beam size was used. Reference materials KN-18 and KE-12 were used to monitor analytical accuracy. Precision of analysis, based on counting statistics ( $1 \mathrm{\sigma} \mathrm{wt} \%$ ), at the levels of analysis in this study is: $\mathrm{SiO}_{2} \pm 0.5, \mathrm{TiO}_{2} \pm 0.1 ; \mathrm{Al}_{2} \mathrm{O}_{3}$ $\pm 0.2 ; \mathrm{FeO} \pm 0.3 ; \mathrm{CaO} \pm 0.5 ; \mathrm{MgO} \pm 0.3 ; \mathrm{Na}_{2} \mathrm{O} \pm 0.2 ; \mathrm{K}_{2} \mathrm{O} \pm 0.2 ;$ and $\mathrm{MnO} \pm 0.1$.

The crystalline assemblage is dominated by pyroxene, plagioclase, and potassic feldspar crystals, but contains a small amount of dark green glass in the upper areas of the body. In the interior part of the rock body, acicular crystals up to $9 \mathrm{~mm}$ long and $1 \mathrm{~mm}$ wide are visible in hand sample (see Fig. 88). These crystals are arranged in radiating masses throughout much of the body and are best developed in the central part of the body. Void space is present as interstices between 
Table 37. Calculation of final melt mass based on amounts of added tracers and their ambient concentrations in starting materials.

\begin{tabular}{llcc}
\hline Melt characteristic & Nd & Ce & La \\
\hline Mass added to melt $(\mathrm{g})$ & 864 & 1228 & 1288 \\
$\begin{array}{l}\text { Concentration in product }(\mathrm{ppm}) \\
\begin{array}{l}\text { Melt composition expected } \\
\text { without tracer additions: }\end{array}\end{array}$ & 102.8 & 182.8 & 137.8 \\
$\begin{array}{l}\text { A. from cold cap glass } \\
\text { B. calculated for 80\% soil } \\
\text { plus 20\% limestone }\end{array}$ & 38.2 & & \\
$\begin{array}{l}\text { Calculated mass of melt }\left(\times 10^{6} \mathrm{~g}\right) \\
\quad 13.4\end{array}$ & 92.4 & 44.2 \\
\end{tabular}

masses of crystals, presumably as a result of volume reducticn during crystallization. The amount of pore space is highest in the central part of the body and roughly correlates with the size of crystals and degree of crystallinity. On the basis of this observation, an area of greatest crystallinity and pore space was delineated within the central part of the rock body (Fig. 78). The greatest crystallinity zone is not centrally located, but is slightly offset towards the upper surface of the rock body. A basal zone of lesser crystallinity appears to be uniformly $\sim 50 \mathrm{~cm}$ thick. The uppermost surface of the melt is characterized by small ( $<5 \mathrm{~mm}$ ) spherulitic masses of crystals in a glassy matrix.

Examination of polished sections in reflected light revealed the presence of four identifiable phases: pyroxene, plagioclase, feldspar, and a low reflectivity residual phase that was identified with the electron microprobe as a combination of potassic feldspar and glass. A few small $(\sim 1-\mu \mathrm{m})$, highly reflective blebs, possibly an Fe-Ti oxide, were observed in some parts of the most crystalline samples.

The size, distribution, and abundance of crystals changed systematically with position of the sample within the rock body, but some features were common to all areas (Fig. 80A-C). A bimodal size distribution of crystals was always present; large pyroxene crystals dominate the assemblage, and the interstices between these were filled with a "groundmass" assemblage consisting of plagioclase, pyroxene, and glass \pm potassic feldspar. Potassic feldspar is present only in the most crystalline, central part of the rock body. Large pyroxene crystals in the core of the body are present as large, acicular crystals arranged in radiating masses (Fig. $80 \mathrm{C}$ ). Pyroxene crystals also dominate samples from nearer the edge, but the crystal size is much smaller and crystals are more closely spaced than in the central part of the rock body. The pyroxene crystals in the edge zones still appear to have grown in clusters, but the distinct radiating habit observed in the central zone samples is not present. Samples from intermediate zones contain intermediate-sized and spaced acicular pyroxene crystals, which also occur as discrete radiating clusters. Within the groundmass assemblage, plagioclase appears to dominate over the other phases, particularly in samples obtained from nearer the edge of the body. The size of the groundmass crystals varies with position of the sample within the rock body, with the largest crystals present in the core of the rock body. In some samples from nearest the body's edge, this groundmass assemblage is virtually absent, and the interstices between the large pyroxene crystals contain only glass.

The morphology of crystals also varies systematically as a function of sample location. Within the central part of the body, the large pyroxene crystals are acicular but flat-sided (Fig. 80C). Pyroxene crystals nearer the body's edge are generally smooth-sided, but the last deposited crystal 

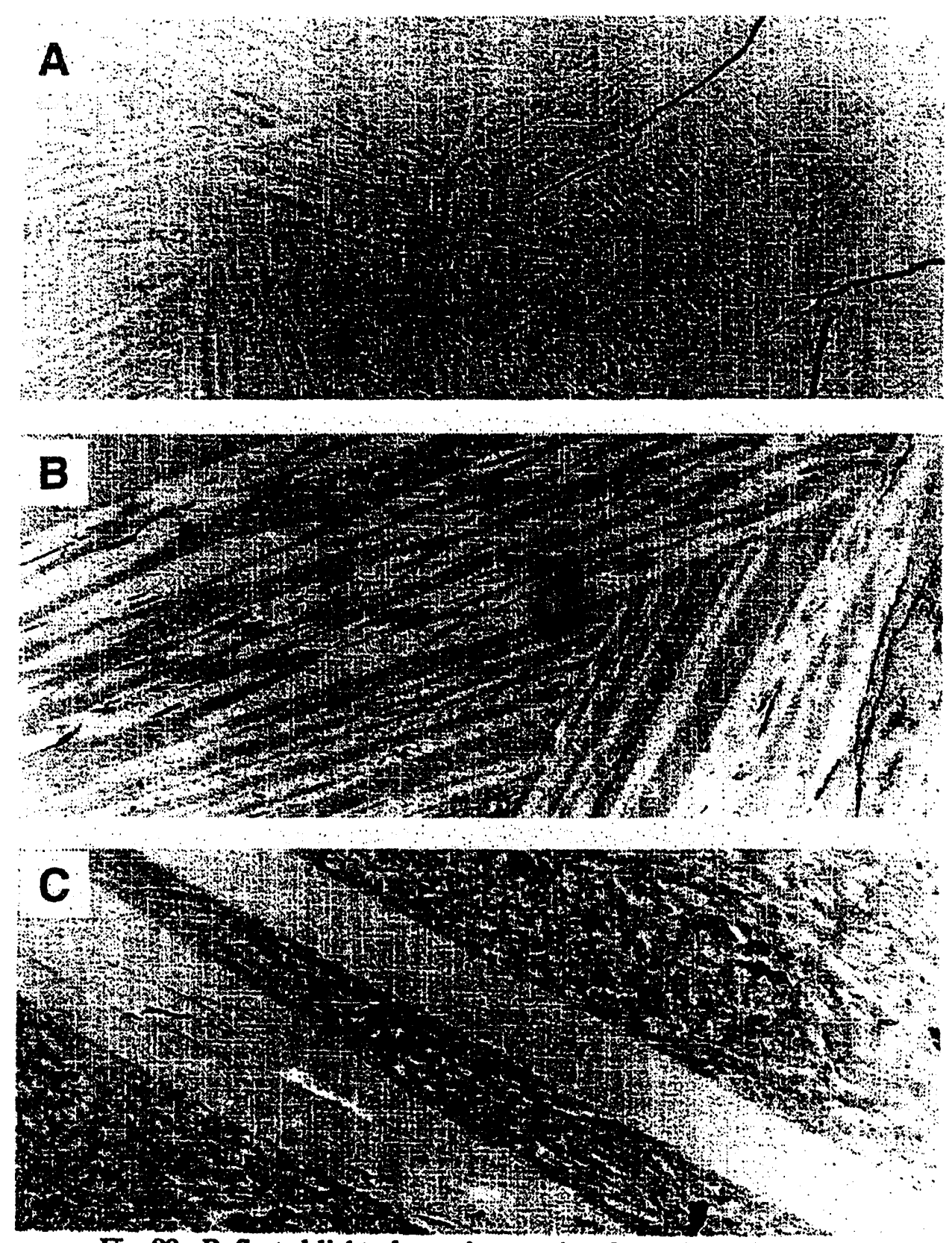

Fig. 80. Reflected-light photomicrographs of samples of ISV rock

taken at various distances from the margin. Field of view of all photos is $1 \mathrm{~mm}$.

margin appears to have grown epitaxially and forms skeletal protrusions off the otherwise flat sides. With increasing proximity to the edge of the melt, pyroxene growth becomes less acicular and more skeletal and dendritic (Fig. 80A and B). Although the grain size of the groundmass crystals decreases with proximity to the edge of the body, their morphology does not appear to change. The variations of crystal morphology are similar to those described by Lofgren (1980), with tabular forms dominant in the central area of the body, changing progressively to skeletal, dendritic and spherulitic forms nearer the edge (Fig. 80a-c). These variations can be attributed either to degree of undercooling at the time that crystallization was initiated or to more rapid cooling rates (Lofgren 1980). Some 
crystals, particularly in areas of the melt midway between the core and the edge, are characterized by initial growth in a faceted habit followed by skeletal growth of the outer part of the crystal. This change may be due to increased undercooling and resultant disequilibrium growth during the late stages of crystallization (Lofgren 1980), which may result from variations in cooling rate through the crystallization interval as a result of the thermal arrest.

The ISV rock body is characterized by a porphyritic texture, similar to that observed in some extrusive volcanic rocks, with a set of large pyroxene crystals and a groundmass of fine-grained pyroxene, plagioclase, orthoclase, and glass. In volcanic rocks this texture is often explained by the presence of preexisting phenocrysts at the time of eruption and subsequent growth of groundmass crystals (Cashman 1992). However, in the case of the ISV melt, no initial population of phenocrysts was present to explain this texture. The larger "first generation" crystals in the ISV rock are all unzoned diopsidic pyroxenes and all have a thin rim of hedenbergitic composition. The smaller groundmass pyroxene crystals have magnesian diopside cores with hedenbergitic rims. The Fe-rich rims on both the large and small pyroxene crystals suggest that, at least in the later stages of growth, the two sets of crystals were growing simultaneously. Although detailed crystal size distribution characteristics of the samples have not been determined by procedures like those of Cashman and Marsh (1988) simple homogeneous nucleation and growth of a single crystal population seem unlikely to explain the observed crystal size characteristics. However, the observed variations may be produced by a scenario such as that described by Lofgren (1980), in which a porphyritic texture can be produced from an initially homogeneous melt. As the melt cools, one phase, in this case diopside, nucleates and begins to grow. As diopside growth continues, the residual melt composition changes and the melt further cools, until a second phase, in this case anorthite, becomes saturated. At this point, large-scale saturation and growth of anorthite would occur, causing another change in the residual melt composition, promoting a second stage of pyroxene nucleation and growth. The final texture would appear similar to that observed in the ISV melt: a dominant first-generation of pyroxene and a groundmass of plagioclase and pyroxene, slightly dominated by plagioclase. The polymodal crystal size populations agree qualitatively with models of Spohn et al. (1988) for crystal growth in a system where the initial undercooling was greater than the undercooling at maximum nucleation rate. As will be discussed later, some crystal growth, particularly of pyroxene, is likely to have taken place after the thermal arrest period.

\section{Chemical Composition of Crystals}

The pyroxene crystals range in composition from diopside $\left(\mathrm{CaMgSi}_{2} \mathrm{O}_{6}\right)$ to hedenbergite $\left(\mathrm{CaFeSi}_{2} \mathrm{O}_{6}\right)$ (Fig. 81, Table 38). The cores of the large pyroxene crystals are composed of homogeneous diopside, but a thin rim of last-grown crystal is Fe-rich hedenbergite (Fig. 82). The transition from the diopsidic core to hedenbergitic rim is sharp, and the thickness of the Fe-rich pyroxene rim appears to be greater in samples nearer the edge of the rock body. The groundmass pyroxene crystals are also composed of diopsidic cores and hedenbergitic rims, but detailed zonation profiles were difficult to determine. Backscatter imaging suggests that the diopside-to-hedenbergite transition is also sharp in the groundmass pyroxene. The composition of the diopsidic pyroxene varies subtly with distance from the center of the rock body (Fig. 83). The cores of pyroxene crystals from the central part of the body are slightly more $\mathrm{Mg}$-rich, but Fe- and $\mathrm{Al}$-poor ("rapid growth" trend on Fig. 83). Ca content is approximately the same in all pyroxene. The other trend apparent on Fig. 83 ("depletion") is the rim depletion of $\mathrm{Mg}$ mentioned earlier.

Groundmass plagioclase is of anorthitic composition and appears to be homogenous throughout (Fig. 84, Table 38). The potassic feldspar, where present, is of orthoclase composition, although the crystalline structure is not known (Fig. 84, Table 38). Several points in Fig. 84 that appear to fall in the two-feldspar field are likely to represent a composite analysis of two adjacent feldspar phases produced by simultaneous beam excitation.

The phenocryst phases in the ISV melt are surprisingly homogeneous, particularly considering the rapid rates of crystallization. Although there are some variations in pyroxene composition, as will 


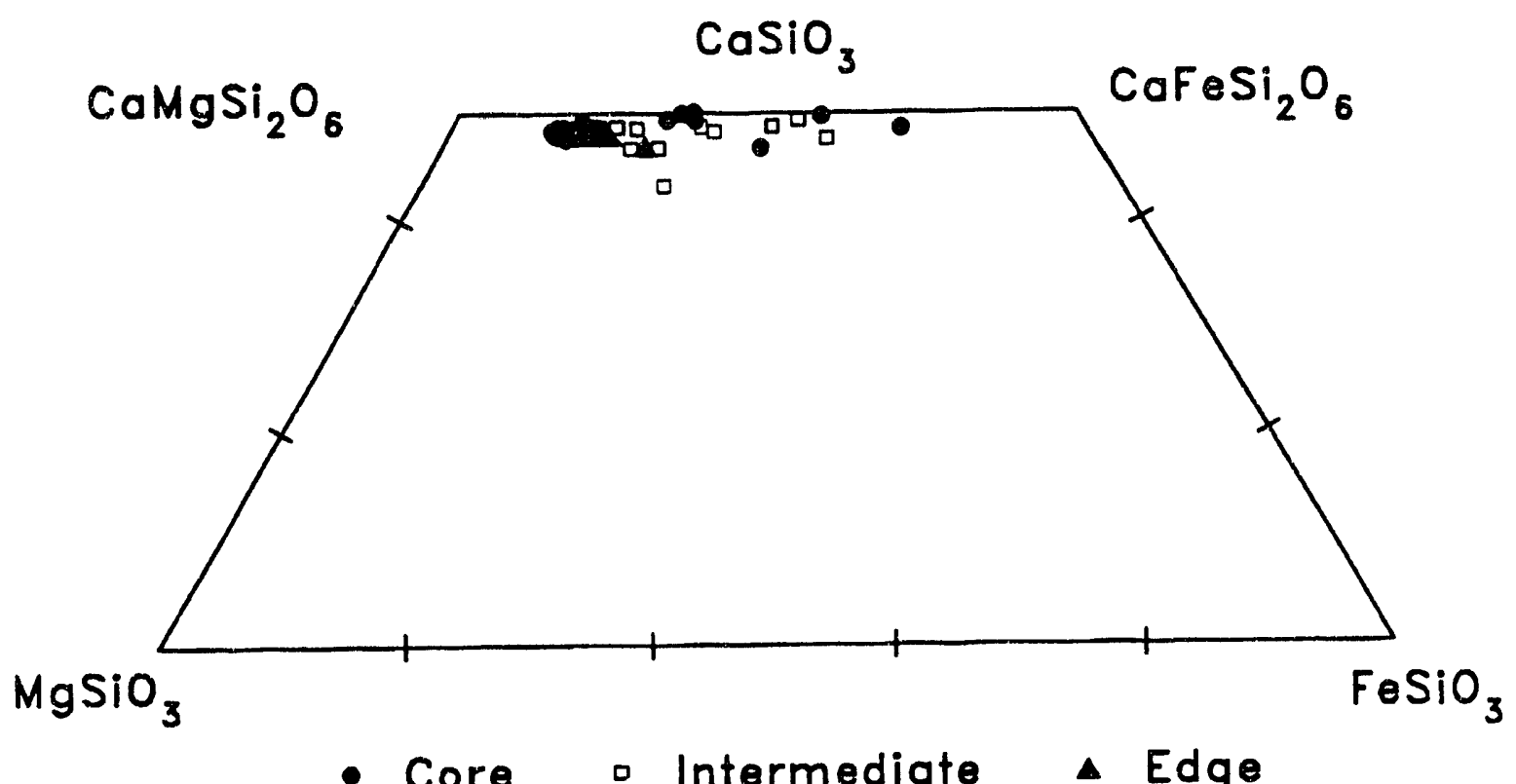

Fig. 81. Pyrozene compositions as analyzed by electron microprobe displayed on a standard pyrozene quadrilateral diagram.

be discussed later, there does not appear to have been any progressive buildup or depletion of compatible or incompatible components at the crystal-melt interface during growth of individual crystals, as has been suggested during rapid crystal growth (Burton et al. 1953, Albarede and Bottinga 1972). In all cases where crystals are large enough to analyze, the compositions of plagioclase and $\mathrm{K}$-feldspar appear to be independent of location within the melt, and therefore of growth rate, although the growth rate is estimated to be near $10^{-6} \mathrm{~cm} / \mathrm{s}$.

Despite the overall homogeneity of crystals, some systematic variations in pyroxene compositions are observed. Some variations are a result of progressive thermal and compositional evolution of the melt, and others are due to cooling history of the melt in which the crystals are found, and therefore presumably due to crystal growth rate. The first type of variation observed is the presence of Fe-rich rims on pyroxenes, mainly from the interior portions of the melt (Fig. 82). These rims, which were present on both first- and second-generation pyroxene, indicate that deposition occurred during latest-stage crystal growth. The Fe-rich rims are also characterized by higher $\mathrm{Ti}$ and slightly lower $\mathrm{Al}$ with respect to $\mathrm{Mg}$-rich compositions. $\mathrm{Ti}$ is incompatible in all crystalline phases; thus it would be expected to be enriched in the evolved melt. The Al composition of the melt remains the same throughout, so the lower Al content is not a result of increasing availability of $\mathrm{Al}$, but rather may be related to charge balance associated with $\mathrm{Ti}$ substitution. Coupled substitution of $\mathrm{Ti}^{\mathrm{V}} 2 \mathrm{Al}^{\mathrm{NV}}$ for $\mathrm{R}^{\mathrm{V}} 2 \mathrm{Si}^{\mathrm{lV}}$ has been noted in other cases, particularly in lunar rocks (Bence et al. 1970). The rims may be caused by $\mathrm{Mg}$ depletion in the melt as a result of large-scale diopside growth. However, the sharp nature of the transition, as opposed to gradual transition to a more hedenbergitic composition, suggests that other factors may be involved in the rapid compositional change. Large-scale crystallization of the homogeneous $\mathrm{Mg}$-rich pyroxene during the pseudocotectic crystallization period could have caused the extreme $\mathrm{Mg}$ depletion, and the thin rims 
Table 38. Representative electron microprobe elemental percentages of phenocryst and glass materials from the 1991 ORNL ISV product.

\begin{tabular}{|c|c|c|c|c|c|c|c|c|c|c|}
\hline Phase & $\mathrm{SiO}_{2}$ & $\mathrm{TiO}_{2}$ & $\mathrm{Al}_{2} \mathrm{O}_{3}$ & $\mathrm{MgO}$ & $\mathrm{CaO}$ & $\mathrm{MnO}$ & $\mathrm{FeO}$ & $\mathrm{Na}_{2} \mathrm{O}$ & $\mathrm{K}_{2} \mathrm{O}$ & Total \\
\hline Glass 1 & 51.5 & 0.7 & 15.6 & 5.6 & 17.1 & 0.2 & 5.2 & 0.2 & 3.4 & 99.5 \\
\hline Glass 2 & 60.8 & 2.4 & 14.7 & 0 & 9.3 & 0.1 & 3.7 & 0.3 & 5.5 & 97.7 \\
\hline Glass 3 & 70.2 & 1.3 & 12.7 & 0 & 3.1 & 0.1 & 1.6 & 0.2 & 7.2 & 96.4 \\
\hline \multicolumn{11}{|l|}{ Pyx 1} \\
\hline core & 48.7 & 0.9 & 6.8 & 14.5 & 24.2 & 0.1 & 3.4 & 0 & 0 & 98.6 \\
\hline rim & 47.0 & 1.9 & 4.4 & 6.9 & 23.2 & 0.3 & 15.5 & 0 & 0 & 99.2 \\
\hline Pyx 2 & 48.4 & 0.8 & 8.2 & 13.7 & 24.6 & 0.1 & 3.4 & 0 & 0 & 99.2 \\
\hline Pyx 3 & 47.2 & 1.1 & 9.9 & 12.6 & 24.3 & 0.1 & 4.3 & 0 & 0 & 99.6 \\
\hline GM Pyx & 48.8 & 1.4 & 4.7 & 11.4 & 24.0 & 0.2 & 8.8 & 0 & 0 & 99.3 \\
\hline GM Plagioclase & 47.3 & 0 & 31.8 & 0.5 & 17.2 & 0 & 0.8 & 0.5 & 1.6 & 99.7 \\
\hline GM Orthoclase & 62.1 & 0.2 & 20.2 & 0 & 2.0 & 0 & 0.3 & 0.3 & 14.7 & 99.8 \\
\hline
\end{tabular}

Glass 1 = glass from margin of rock body

Glass 2 = evolved glass from intermediate part of rock body

Glass 3 = most evolved glass from center of rock body

Pyx $1=$ large pyroxene from rock center

Pyx 2 = large pyroxene from intermediate zone between rock center and edge

Pyx 3 = pyroxene from near rock edge

GM Pyx = groundmass pyroxene

GM Plagioclase $=$ groundmass plagioclase

GM Orthoclase $=$ groundmass orthoclase

of Fe-rich pyroxene may have only crystallized when the temperature fell below the thermal arrest temperature. In a pure diopside-hedenbergite composition system, diopside will crystallize at higher temperature than hedenbergite (Deer et al. 1966). Because the temperature remained constant for a long period of time during the thermal arrest, a single composition of pyroxene would be expected to crystallize as long as the $\mathrm{Mg}$ content of the melt remained relatively constant. Although the pyroxene crystals preferentially incorporate $\mathrm{Mg}$, the $\mathrm{Mg}$ content of the residual melt may have remained relatively constant initially because of plagioclase crystallization. However, when the groundmass pyroxene began to crystallize, $\mathrm{Mg}$ in the melt may have become strongly depleted. As the Mg content of the melt became depleted, bus the temperature of the melt remained constant, pyroxene growth may have slowed or even ceasen. However, without the input of latent heat of crystallization, melt temperature may have dropped, reaching a temperature at which a more Fe-rich pyroxene composition was stable. At this point, the final rim of hedenbergite may have been deposited.

The second type of compositional variation noted in pyroxene is change in Al content as a function of distance of the sin:ple from the edge of the melt, presumably related to crystal growth rate (Fig. 83). The Al content of pyroxene, which grew nearer the edge of the melt, is proporionately 


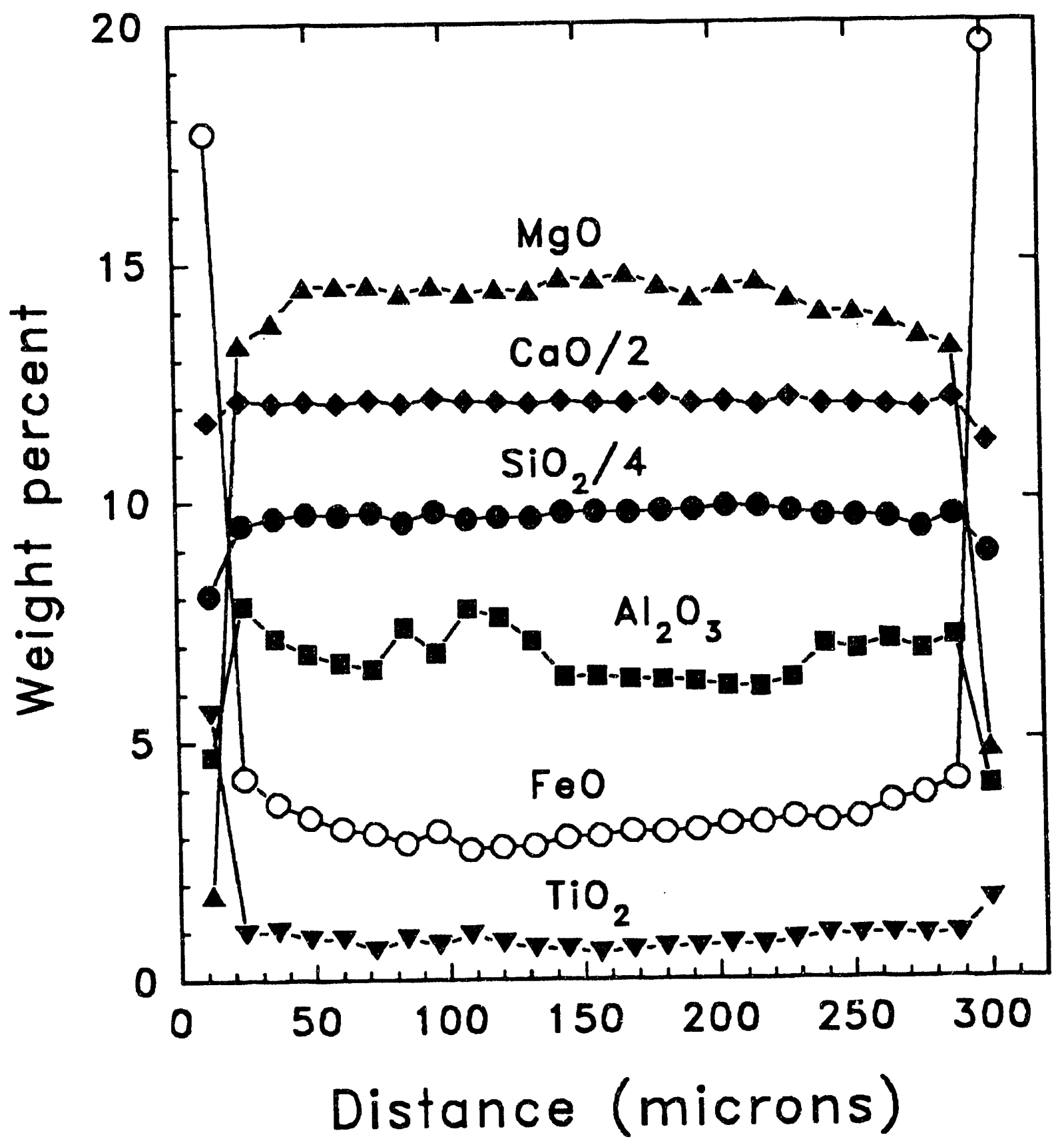

Fig. 82. Electron microprobe step-scan analyses across a single pyroxene lath.

higher than that which grew in the core, although all pyroxenes that grew in a given part of the melt are homogeneous. This type of chemical variation, explained as substitution of $\mathrm{Al}^{\mathrm{V}} \mathrm{Al}^{\mathrm{V}}$ for $\mathrm{Mg}^{\mathrm{V}} \mathrm{Si}^{\mathrm{iv}}$, has been observed in lunar samples (Gamble and Taylor 1980) and has been experimentally shown to be related to crystal growth rate (Grove and Bence 1977). In situations where crystal growth is rapid, slow-diffusing compatible elements, such as $\mathrm{Mg}$, are not able to migrate to the crystal-melt interface fast enough to maintain equilibrium, and relatively incompatible elements, such as $\mathrm{Al}$, 


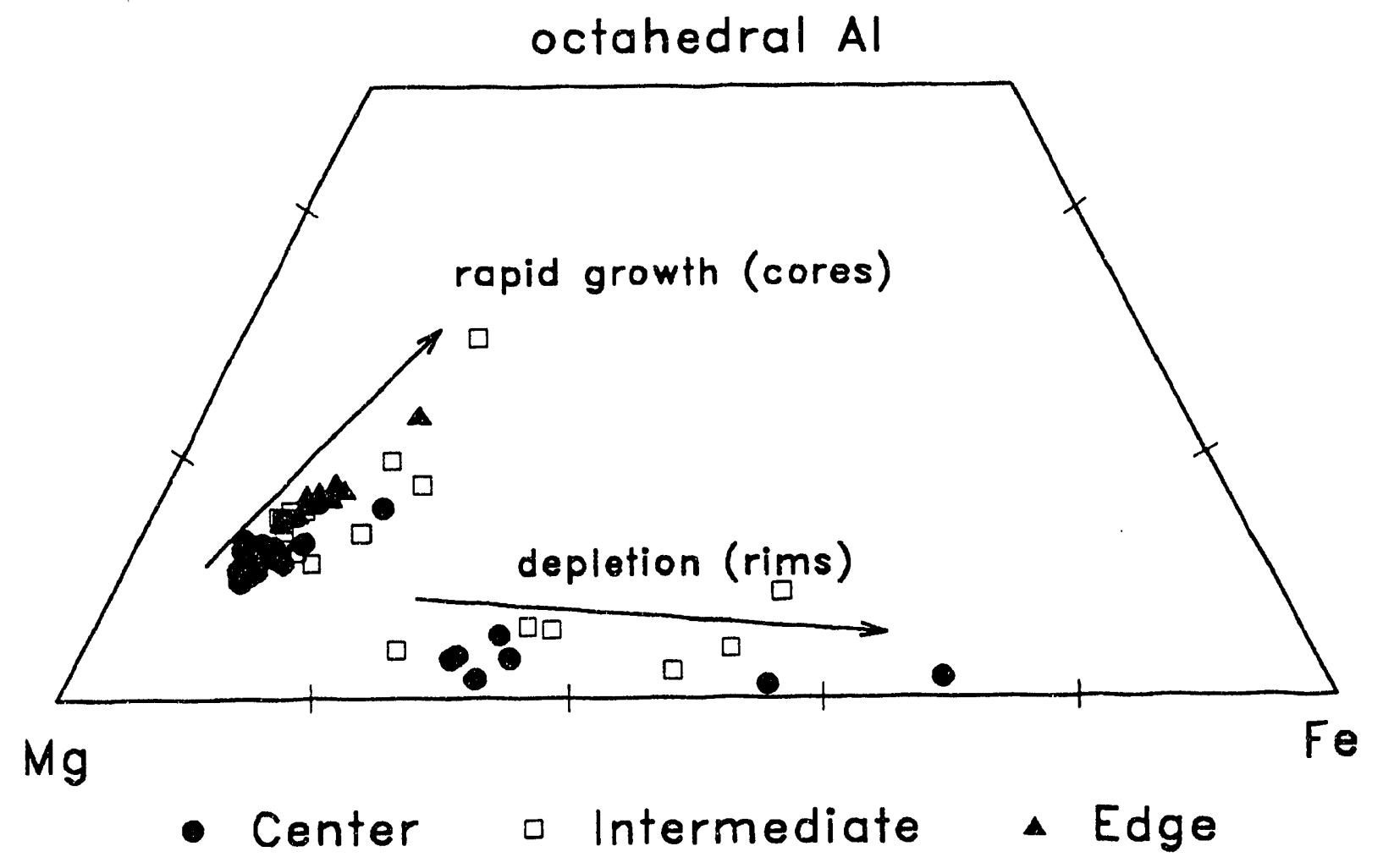

Fig. 83. Pyroxene compositions as analyzed by electron microprobe expressed as a ternary of octahedral $\mathrm{Al}, \mathrm{Fe}$, and $\mathrm{Mg}$.

substitute into the pyroxene structure (Grove and Bence 1977). The observed patterns of systematic pyroxene show compositional variation with distance from the center of the melt, but homogeneity within a given sample suggests that the diffusion profiles of compatible and incompatible elements relative to the crystal-melt interface are established early in the growth of a single crystal and do not change significantly during crystal growth. The observed variations illustrate the wide compositional variations possible in pyroxene crystals grown from a single melt composition as a result of changes in growth rate. These observations also highlight the point that all crystal composition variation in natural systems is not necessarily a result of magmatic compositional variation.

\section{Chemical Composition and Distribution of Residual Glass}

A residual glass phase, consisting of three distinct compositions, was identified in the ISV rock by electron microprobe (Table 38, Fig. 85). The actual location and configuration of glass within the highly crystalline samples could only be determined with secondary ion imaging of incompatible trace elements. A Cameca ims-4f ion microprobe at ORNL was used for qualitative ion imaging to map the relative distribution of elements within the analyzed samples. Analyses were made using a mass-analyzed ${ }^{16} \mathrm{O}$ primary beam accelerated to $12.5 \mathrm{keV}$, detecting positive secondary ion accelerated 


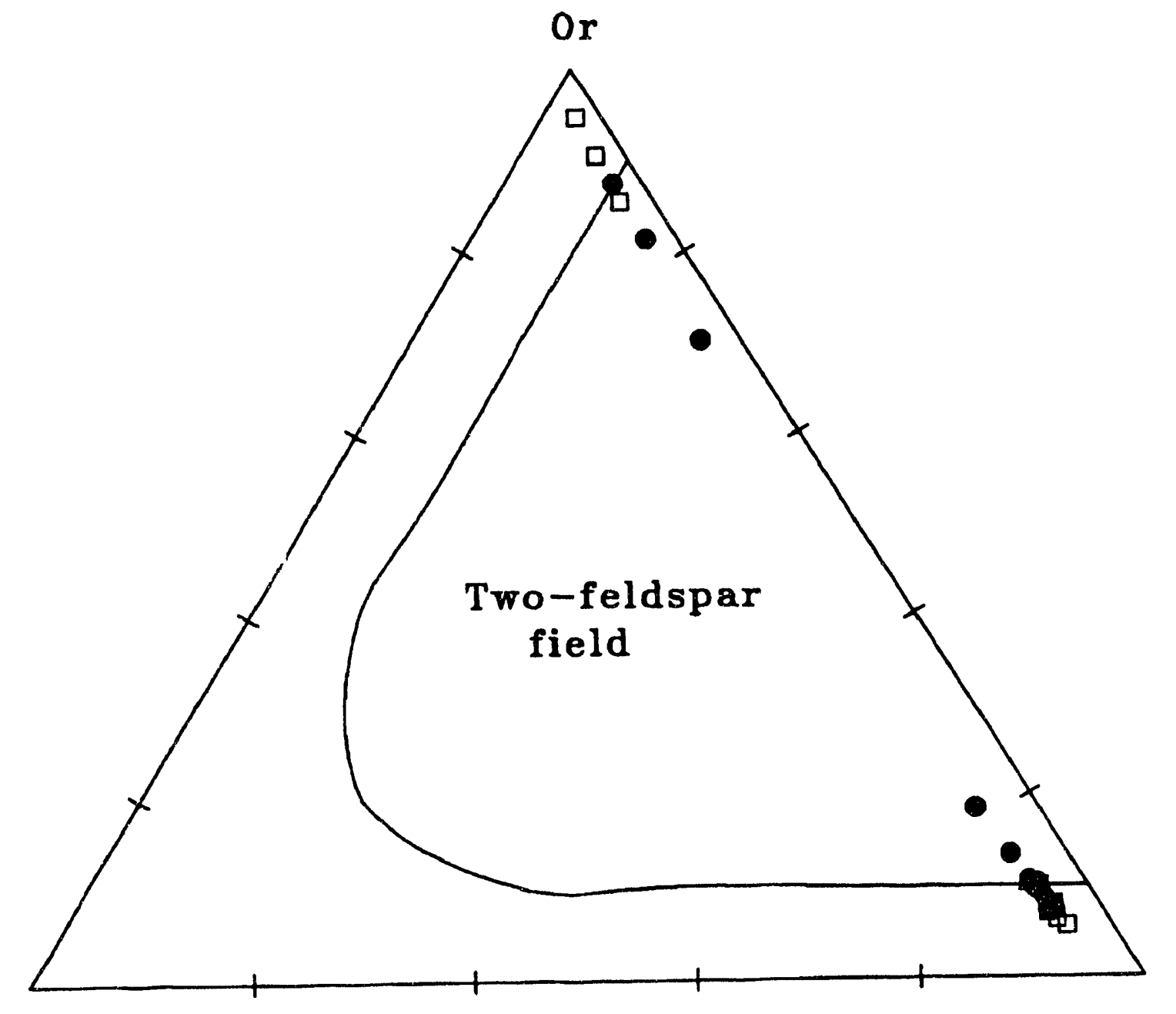

$\mathrm{Ab}$

\section{- Center a Intermediate $\Delta$ Edge}

Fig. 84. Feldspar compositions as analyzed by electron microprobe expressed as orthoclase (Or), albite (Ab), and anorthite (An) end members.

to $4.5 \mathrm{keV}$. Beam currents were 0.1 to $1.0 \mathrm{nA}$, resulting in a beam spot size of $\sim 10 \mu \mathrm{m}$. Images were made by digitally rastering the primary beam over square areas from 100 to $400 \mu \mathrm{m}$ on a side, mapping counts in an electron multiplier. Elemental peaks were checked for interferences from isobaric molecular ions by monitoring isotopic abundances, and offset energies of up to $100 \mathrm{~V}$ were applied to eliminate any interfering species. Images of the distribution of several major and trace elements, including $\mathrm{K}, \mathrm{Rb}, \mathrm{Cs}$, and $\mathrm{Zr}$, on the polished surface of a sample allow distinction to be made between glass and potassic feldspar.

The composition of residual glass (Fig. 85), which is present in all samples, varies systematically with the overall degree of sample crystallinity and spatially within single 1-in.-thin sections. The most evolved glass observed is of rhyolitic composition $\left(\sim 71 \mathrm{wt} \% \mathrm{SiO}_{2}\right)$, but areas of 


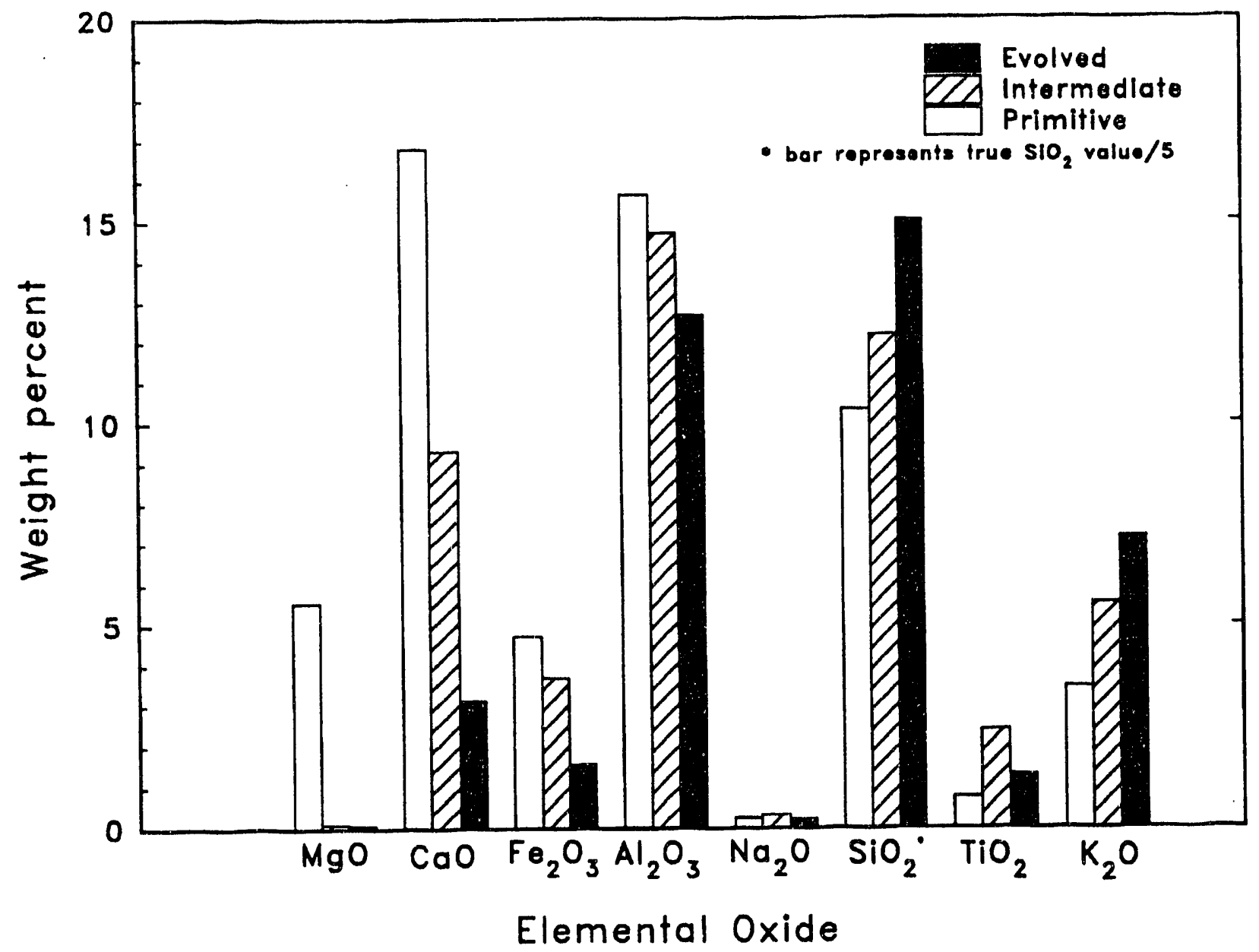

Fig. 85. Histogram of electron microprobe analyses of uncrystallized ISV glass ("primitive"), glass found in partially crystallized area of rock ("intermediate"), and rhyolitic glass from highest crystalline, central area of rock body (evolved).

less evolved glass $\left(\sim 65 \mathrm{wt} \% \mathrm{SiO}_{2}\right)$ are present in different areas of the same 1-in.-diam section. The residual glass is intimately associated with orthoclase feldspar in the most evolved samples, and it is difficult to optically distinguish the two phases. Ion imaging reveals that glass is present in many locations and is generally found in triangular-shaped to slightly elongated interstices between crystalline phases (Fig. 86a). The small glass bodies observed range from $<10 \mu \mathrm{m}$ to approximately $100 \mu \mathrm{m}$ in the longest dimension and appear to be isolated from each other due to the presence of crystalline phases. Once recognized with ion imaging, a distinctive, slightly mottled surface appearance was visible in glass areas when viewed in reflected light (Fig. 86b). The slight mottling results from small reflective blebs in a less reflective matrix and may suggest that some late-stage phase is forming within the glass, possibly a pyroxene. However, the size of these intermixed phases $(<1 \mu \mathrm{m})$ prohibits detailed analysis.

The amount of glass appears to vary with crystallinity of the sample, but is difficult to estimate visually. However, because the composition of the phenocrysts and glass are known, it is 


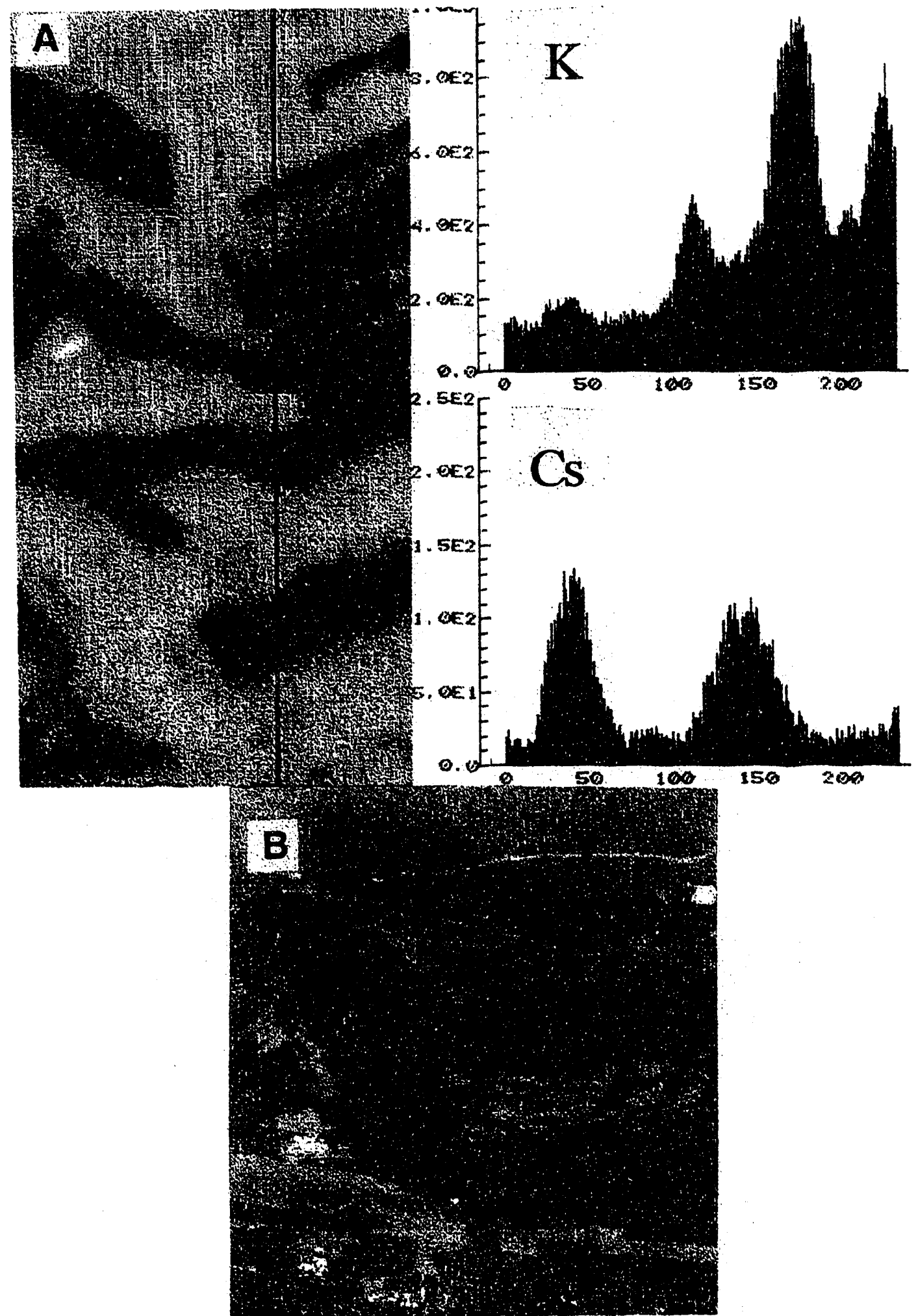

Fig. 86. Ion microprobe image of the distribution of potassium (K) and cesium (Cs) on a $100 \times 100-\mu \mathrm{m}$ area surface (A). Darker color indicates higher concentration of element. Reflected-light photomicrograph of same area $(B)$. 
possible to calculate the amount of phenocrysts and glass present in samples from the interior of the rock body. This type of calculation is not always possible on the basis of the major element composition of a rock's constituent minerals, but the somewhat unusual composition of the phenocrysts present make the calculation relatively straightforward in this case. The diopsidic pyroxene removes all $\mathrm{Mg}$ from the melt, and calculations show that $38 \mathrm{wt} \%$ diopside would contain all $\mathrm{Mg}$ present in the melt. The hedenbergitic pyroxene depletes the melt in $\mathrm{Mn}$ and represents 12 wt $\%$ of the total rock, so all pyroxene together represents $50 \mathrm{wt} \%$ of the rock mass. All residual $\mathrm{Ti}$ is located in the glass phase, and calculations suggest the presence of $12 \mathrm{wt} \%$ glass. The remainder of the material is a mixture of plagioclase and K-feldspar, composed of 31 and $8 \mathrm{wt} \%$, respectively. This calculated estimate agrees with visual observations of phenocryst abundances. These calculations were made for the most evolved glass compositions, and if a less evolved glass composition were chosen, such as is present nearer the edge of the melt, more glass would be calculated to be present in the final assemblage.

Significant trace elements that are incompatible in the crystalline framework will concentrated in the evolved glass phase within the ISV body. For elements of interest in the 1991 ISV melt, Cs, which is incompatible in the crystallized assemblage, will be concentrated in the residual glass, but $\mathrm{Sr}$ will fractionate into plagioclase and, possibly, pyroxene.

However, the distribution of evolved glass within the ISV body suggests that the concentration of Cs may not present a problem in terms of the effectiveness of ISV products as waste forms. The rhyolitic melt occurs in small, triangular-shaped, or slightly elongated interstices between existing crystals (Fig. 86), and as such, shows no evidence of coalescence and migration, which would need to occur in order to generate a rhyolitic magma body. One factor in the observed distribution and lack of migration of the rhyolitic glass may be the geometry of the crystals that grew from the melt, particularly the elongate pyroxene. The presence of these interlocking crystals would effectively cut off any possible glass migration path. Helz (1987) observed limited coalescence of rhyolitic and andesitic glass in the Kilauea Iki lava lake, but the crystals in the Kilauea Iki magmatic system are, on average, nearer to spherical than those observed in the ISV body. The observations of glass distribution in the ISV crystalline body strongly support the arguments made by Marsh et al. (1991) that segregation of rhyolitic melt from a basaltic parent is unlikely to occur without some further perturbation to the system, such as remelting a previously crystallized and fractured igneous rock.

\section{DENSITY OF VITRIFIED PRODUCT}

The fragments of ISV product, which were collected by core sampling of the field product as described elsewhere, provided both a convenient and useful population from which to determine the density of the product formed. Good estimates of product density as well as product performance in the field are required for many models of ISV dynamics. To calculate density, both the weight and volume of a given fragment must be measured. Fragment weight was measured using an analytical balance for a total of 109 fragments ranging between 15 and $635 \mathrm{~g}$. Fragment volume was measured from the increase in weight of a cylinder of distilled water when the fragment was suspended in it by a short length of nylon thread. Because the fluid displaced was water, the buoyant force measured in grams was equivalent to the volume of water displaced (Archimedes $260 \mathrm{BC}$ ) and thus the volume of the fragment in $\mathrm{cm}^{3}$. However, several cautions need to be observed when interpreting the density measurements. The true particle density of the product will be underestimated for those samples that have considerable inaccessible voids within the fragment. The many surface indentations on the core samples (Fig. 88) would be accessible, and many of them probably connect to less visible voids within the core. During submersion of the core in the cylinder of water, trapped air was observed bubbling from many frasments for several minutes. Recording of the displaced weight was delayed until bubbling could no longer be observed. The true product density was probably overestimated for a few samples because of inclusions of dense metallic components. Attached blebs of metal were observed on the edges of several fragments. There was even one fragment of phase-separated metal from the bottom of one of the cores that exhibited a density of $5.01 \mathrm{~g} / \mathrm{cm}^{3}$ but was not included in the 


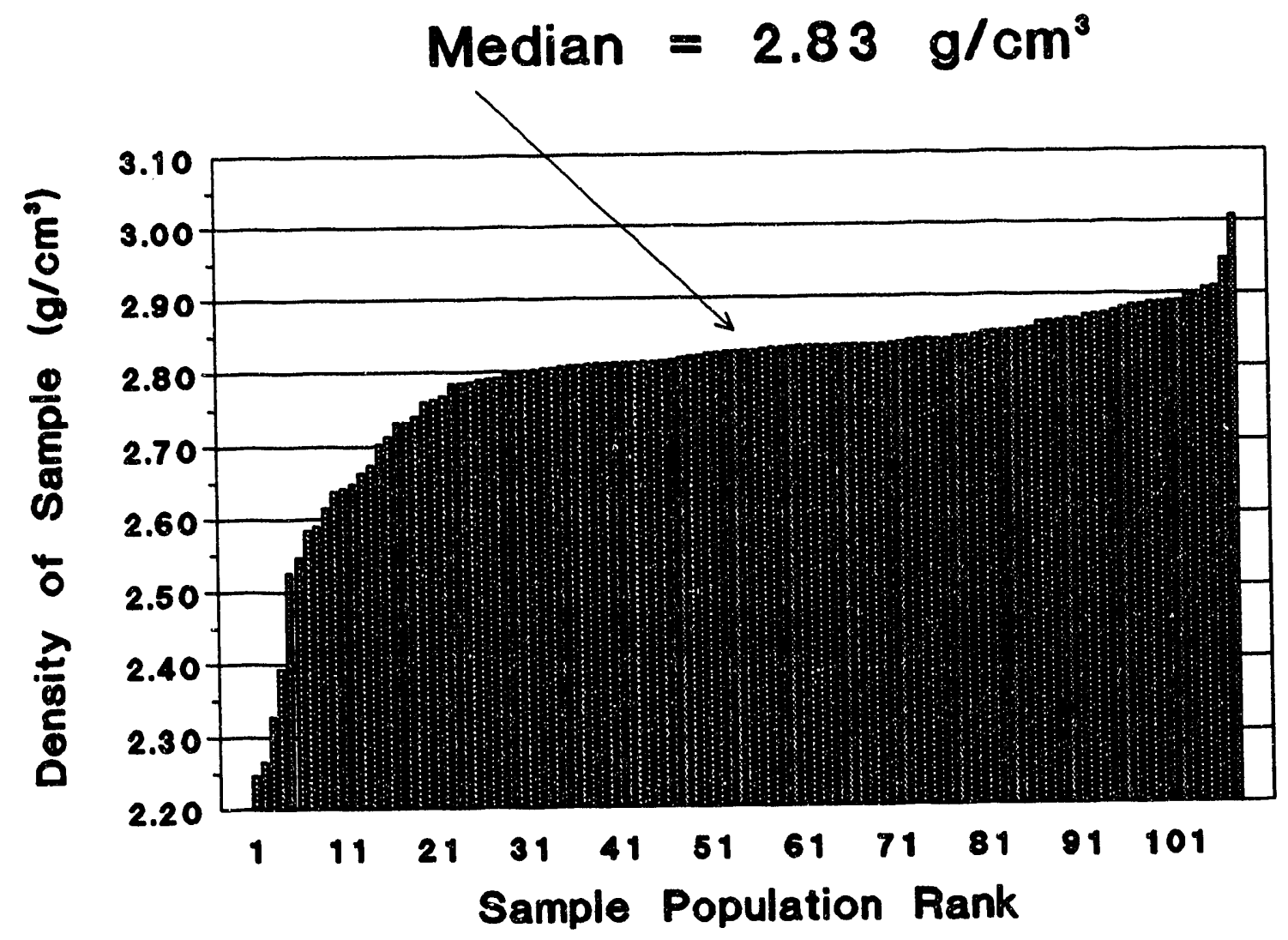

Fig. 87. Density of core fragments from the population of ISV product samples.

population of ISV product densities (Fig. 87). In this population distribution, many of the low density samples include significant sintered attachments that would be similar in density to the bulk density of the soil, i.e. $<1.8 \mathrm{~g} / \mathrm{cm}^{3}$. The average density of the 108 fragments of ISV product was $2.79 \mathrm{~g} / \mathrm{cm}^{3}$, but the best estimate of the true product density is probably that of the population median, $2.83 \mathrm{~g} / \mathrm{cm}^{3}$. The median is not as heavily weighted by the lower density fragments as is the mean of the population. Visual inspection of the population of density measurements shows that the median is located near the middle population plateau. The population also provides a basis for estimating the variance of the density measurement; the standard deviation of the population was $\pm 0.12 \mathrm{~g} / \mathrm{cm}^{3}$. However, this variance is also dominated by the lower density fragments. Evaluation of ISV product density may need to be limited to a more narrowly defined population to provide a better variance estimate.

\section{ISV PRODUCT LEACHING CHARACTERISTICS}

One of the major reasons for considering ISV for the ORNL seepage pits and trenches is the presumed improvement in waste form that will result on vitrification. In previous work, the leachability of ${ }^{90} \mathrm{Sr},{ }^{137} \mathrm{Cs}$, and ${ }^{60} \mathrm{Co}$ was measured for contaminated soils before and after vitrification 

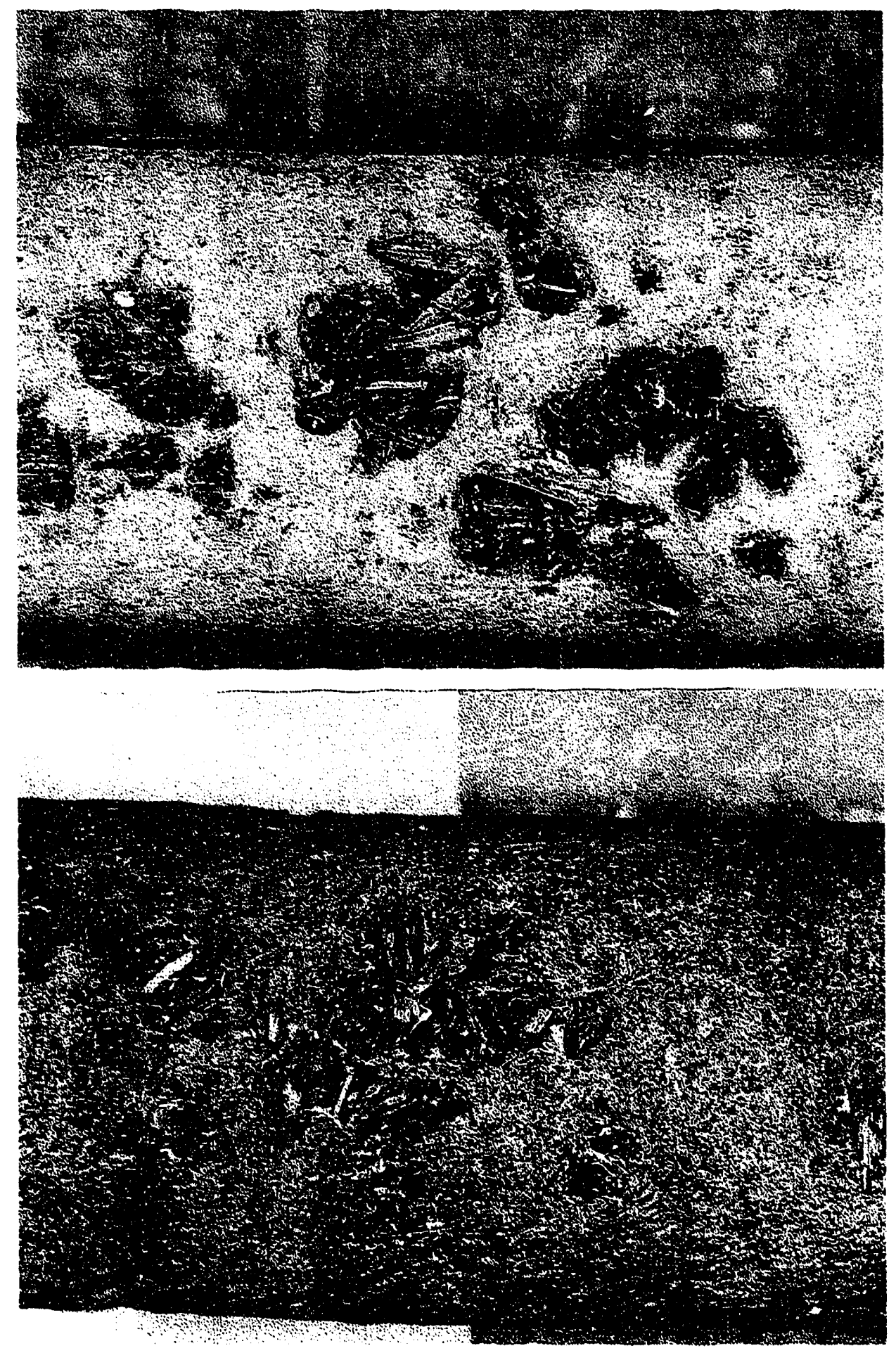

Fig. 88. Sections of 1-in-diam core, recovered from the 1991 ORNL ISV test product, which shows the pore space and acicular crystals frequently found.

in the laboratory (Spalding and Jacobs 1989); vitrification was found to greatly reduce the capacity 
of the soils to leach these radionuclides to solutions of exchangeable cations (using $\mathrm{CaCl}_{2}$ ) or by dissolution from the solids surface (using dilute $\mathrm{HCl}$ ). In addition, the field-produced ISV product from the 1987 demonstration, which was doped with $\mathrm{CS}_{2} \mathrm{CO}_{3}$ and $\mathrm{SrCO}_{3}$ rather than radioisotopes, showed a similar low leachability when subjected to the same sequence of exchangeable cations and dissolving acid (Spalding and Jacobs 1989). However, the present test represented an opportunity to gather leachability characteristics on an "operational type" of ISV product, i.e., one that contains only the radioisotopes from an actual waste sludge from the ORNL pits and trenches along with glassforming materials from the indigenous soil and limestone (or, in this case, dolomite) gravel fill. Thus, no effects from a small but significant compositional change, i.e., the addition of chemical compounds of cesium and strontium, would be expected. In addition, a direct quantitative measure of waste form improvement could be made by performing the same sequence of leaching tests on the starting siudge sample from ORNL, Pit 2. By performing additional tests on sludge and ISV product in both the presence and absence of soil, the influence of surrounding soil on the waste form might be determined. Other tests on ISV product of differing size, e.g., pulvericed us coarsely fragmented ISV product, could be used to simulate the influence of waste form surface area. Thus a significant effort toward such comparative ISV waste form characterization was expended in this project in an effort to produce well-defined and quantitative benefits of the ISV waste form improvement. In particular, the most mobile and hazardous radionuclide in the ORNL pits and trenches, ${ }^{\infty} \mathrm{Sr}$ was selected for special focus.

\section{LEACHING OF ${ }^{\circ}$ SR AND ${ }^{13}$ CS WITH EXCHANGEABLE CATIONS AND DILUTE ACID}

The leaching procedure was similar to that employed previously (Spalding and Jacobs 1989). Five grams of pulverized or fragmented ISV product or soil was placed in a 25-mL capacity "Oak Ridgen polycarbonate centrifuge tube with $20 \mathrm{~mL}$ of $0.1 \mathrm{~N} \mathrm{CaCl}_{2}$. The tubes were shaken lengthw'se at 100 oscillations per min for $16 \mathrm{~h}$ at ambient laboratory temperature. The tubes were then centrifuged at $5000 \mathrm{rpm}$ (3550 relative centrifugal force), and the clear supernatant was filtered through $0.45-\mu \mathrm{m}$ nitrocellulose membranes in disposable filter holder units. The supernatants were decanted into polyethylene scintillation vials with polyethylene-lined caps for storage and radioactivity assays. An additional $20 \mathrm{~mL}$ of $0.1 \mathrm{~N} \mathrm{CaCl}_{2}$ was added to the residual pellet in the tube, and the suspension was shaken as above for $30 \mathrm{~min}$. A second sequential extract was prepared from each sample as above. These sequential extractions were repeated three more times on each sample for a total of five 20-mL extracts from each of four replicate samples. Following completion of the fifth extraction with $\mathrm{CaCl}_{2}$, $20 \mathrm{~mL}$ of $0.1 \mathrm{~N} \mathrm{HCl}$ was added and the resulting suspensions shaken for $16 \mathrm{~h}$. The initial acid extraction was followed by four additional extractions of $30 \mathrm{~min}$ each with additional 20 -mL aliquots of $0.1 \mathrm{~N} \mathrm{HCl}$. All samples were assayed for ${ }^{137} \mathrm{Cs}$ via gamma-ray spectroscopy and for ${ }^{20} \mathrm{Sr}$ via Cerenkov radiation emission as described previously for the characterization of ISV product and prefilter samples. However, duplicate standards for each isotope were prenared in both $0.1 \mathrm{~N} \mathrm{CaCl}_{2}$ and $\mathrm{HCl}$. Assays of these standards for ${ }^{137} \mathrm{Cs}$ via gamma-ray spectroscopy were performed with the same counting efficiency as those of the standards prepared in acid-stabilized distilled water; however, Cerenkov counting efficie ${ }_{\text {scies }}$ for ${ }^{90} \mathrm{Sr}$ averaged $51.9 \%$ compared with $36.7 \%$ for standards in $6.5 \%$ $\mathrm{HNO}_{3}$, used in the filter sample dissolution analyses, or $50.9 \%$ for standards used in acid-stabilized distilled water. These effects of sample solution composition on efficiency of Cerenkov counting have been reported previously (Haberer 1965).

Five different groups, with four replicated samples each, were subjected to the leach test regime. The first group consisted of 5.00-g samples of the pulverized ISV product from a blend of thrse pulverized core samples (samples WR-4, WR-11, and WR-17). An assay of ${ }^{137} \mathrm{Cs}$ activity was performed on each of these blended four replicates prior to initiation of leaching. The second group consisted of $2.50 \mathrm{~g}$ samples of the same blended sample of pulverized ISV product mixed with $2.50-\mathrm{g}$ of pulverized starting soil (sample WR-50); these were also assayed for ${ }^{137} \mathrm{Cs}$ prior to leaching. A third group consisted of samples composed of four fragments of ISV product, retained by a 10 -mesh 
sieve but about $1-\mathrm{cm}$ diam, during the blending of the three pulverized samples. The total weight of the four fragments placed in each tube was between 5.07 and $5.26 \mathrm{~g}$ and was measured for each sample; these were also assayed for ${ }^{137} \mathrm{Cs}$ prior to leaching. A fourth group of samples consisted of $0.100 \mathrm{~g}$ of the blended Pit 2 sludge and $5.00 \mathrm{~g}$ of washed sea sand as an inert filler to aid in concentrating the sludge as a pellet during centrifugation after each sequential leaching; assays of ${ }^{137} \mathrm{Cs}$ were calculated from the measured weights of sludge in each tube and the radiochemical analysis after dissolution of the sludge. The fifth group of samples consisted of $0.100 \mathrm{~g}$ of Pit 2 sludge mixed with $5.00 \mathrm{~g}$ of pulverized starting soil as described above.

From the measured or known starting activities of ${ }^{137} \mathrm{Cs}$ and ${ }^{90} \mathrm{Sr}$ in each sample and the

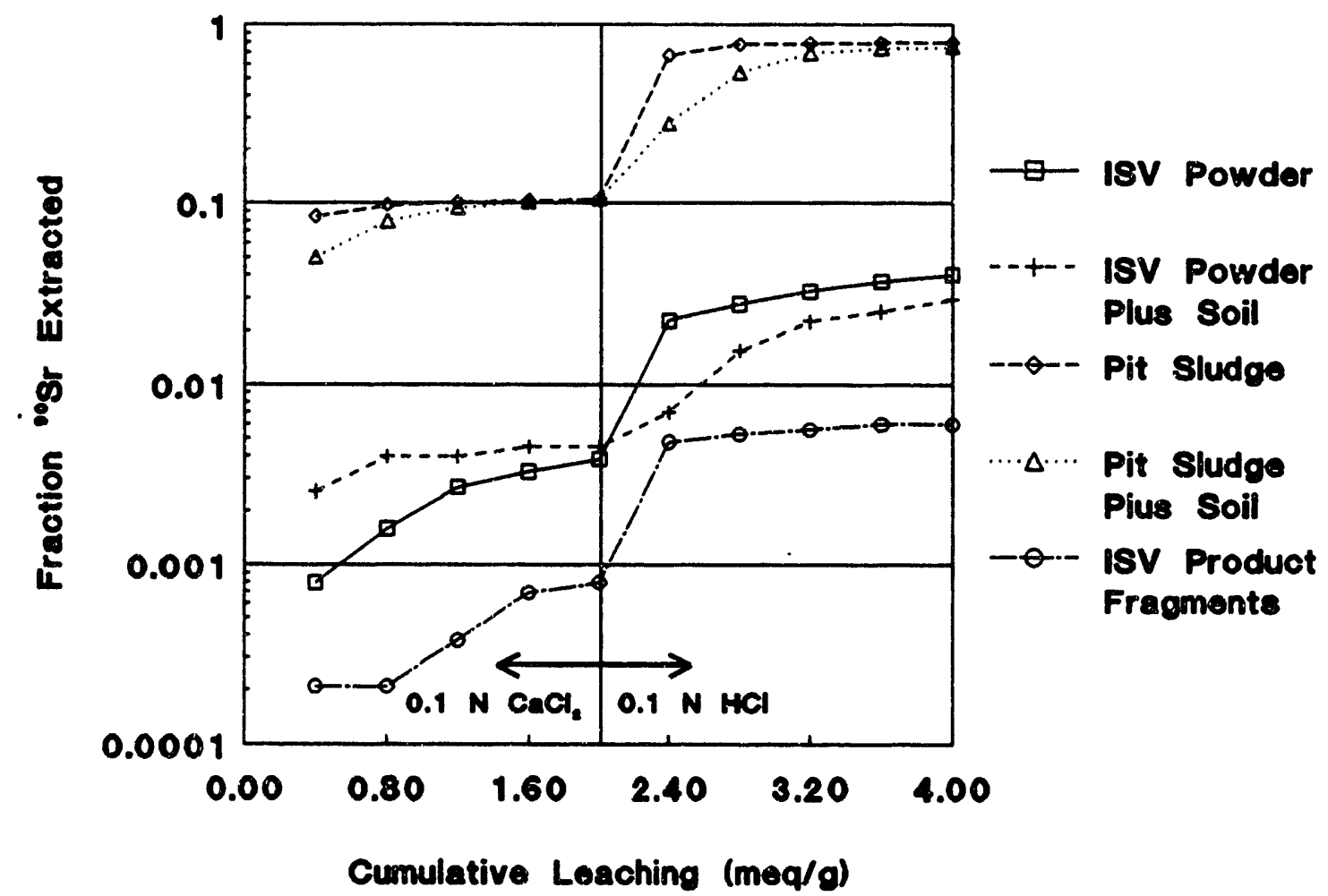

Fig. 89. Sequential leaching of "Sr from whole and pulverized ISV product and from ORNL Seepage Pit 2 sludge.

activities in the various sequential extracts, cumulative fractional release curves were calculated for each isotope (Figs. 89 and 90 ). Considering first the leachability of ${ }^{90} \mathrm{Sr}$ by exchangeable cations, approximately $10 \%$ of the ${ }^{9} \mathrm{Sr}$ was extracted from the Pit 2 sludge whether or not soil was present. This result is not surprising because the soils of SWSA 6, and thus WAG 7 because it resides in the same geologic and geomorphic setting, typically exhibit cation exchange capacities of about $0.21 \mathrm{meg} / \mathrm{g}$ 
(Davis et al. 1984), and these samples were leached with $\mathrm{CaCl}_{2}$ to a total of $2.0 \mathrm{meq} / \mathrm{g}$. Thus any cation exchangeable forms of the radionuclides would be expected to be extracted by this surplus of cations. All of the various ISV products exhibited considerably less removal of the ${ }^{25} \mathrm{Sr}$ with the fragmented samples yielding the least of this isotope. The normalized surface area of these fragments would average about $2.5 \mathrm{~cm}^{2} / \mathrm{g}$, assuming spheres of $1 \mathrm{~cm}$ in diameter. A pulverized spherical ISV product, sieved through 100 mesh, would calculate to a surface area of $>150 \mathrm{~cm}^{2} / \mathrm{g}$ with an assumed particle diameter of $<0.015 \mathrm{~cm}$. Thus the increased leachability of the ${ }^{90} \mathrm{Sr}$ from pulverized ISV product could be ascribed to the two-order-of-magnitude increase in surface area compared with the fragments. The performance of such a waste form in the field, where the equivalent sphere would be approximately $300 \mathrm{~cm}$ in diameter and the calculated surface area about $0.028 \mathrm{~cm}^{2} / \mathrm{g}$, would be expected to be improved roughly another couple of orders of magnitude.

After the extractant was changed to $\mathrm{HCl}$ to initiate dissolution of surface material, almost quantitative dissolution of the ${ }^{9} \mathrm{Sr}$ from the sludge resulted. The carbonate nature of this material, coupled with its high surface area, contributed to its dissolution by dilute acid. This characteristic clearly demonstrates the poor quality of the ambient waste form in the ORNL pits and trenches. Long-term soil weathering, which is basically an acidification process, will result in the dissolution of the pit sludge and thus its enhanced migration from the waste site. The presence of soil, while providing some buffering or delay in the release, did not affect the final fraction of the ${ }^{90} \mathrm{Sr}$ leached. However, considerable improvement was observed in all of the vitrified samples. Notably, in the fragmented samples, less than $1 \%$ of the total ${ }^{90} \mathrm{Sr}$ was ultimately leached. The decrease in surface area in each of these groups of samples is probably the best explanation for these results. Assuming a similar decrease in leachability for a field-size ISV product geometry, a further reduction in leachability by at least two orders of magnitude would be anticipated. Obviously, vitrification results in a greatly reduced surface area for the waste form and, hence, the inaccessibility of the ${ }^{90} \mathrm{Sr}$ to dissolution.

A similar pattern of leachability for ${ }^{137} \mathrm{Cs}$ was observed for the various groups of samples (Fig 90). However, for this radionuclide, the entire suite of cumulative leaching curves was reduced about two orders of magnitude compared to ${ }^{90} \mathrm{Sr}$; the upper limit on ${ }^{137} \mathrm{Cs}$ leachability from the sludge alone was only about $1 \%$. The strong specific adsorption of ${ }^{137} \mathrm{Cs}$ by illitic clay minerals in the soils of SWSA 6 (Davis et al. 1984) makes this radionuclide extremely immobile in the soil environment. The form of the specific adsorption is neither as an exchangeable cation or a carbonate coprecipitate. The sludge itself, in the process of being poured into Pit 2 , probably mixed with a little soil sufficient to specifically adsorb it. It is important to note, however, that even when the illitic minerals are destroyed during vitrification, the ${ }^{137} \mathrm{Cs}$ apparently becomes part of the vitreous solid and thus inaccessible to dissolution by the dilute acid. Actually, the addition of soil to the sludge resulted in the lowest release of any treatment during the sequential leaching procedure. Nonetheless, the quality of the ambient waste form for retaining ${ }^{137} \mathrm{Cs}$ is not deteriorated by vitrification. Notably, it is not the ${ }^{137} \mathrm{Cs}$ but the ${ }^{90} \mathrm{Sr}$ that has generated the need for the waste form improvement in the ORNL seepage pits and trenches.

\section{PRODUCT CONSISTENCY TESTING (PCT)}

Six samples of the ISV material were tested at PNL using the Product Consistency Test (PCT) developed by Westinghouse Savannah River Company (Jantzen and Bibler 1989). The PCT was developed to evaluate the durability of nuclear, hazardous, and mixed-waste vitrified materials. The test uses deionized water to leach crushed samples over a 7-d period.

The samples for testing were chosen to include a variety of textures found within the block. Samples were obtained from $2.5-\mathrm{cm}$-diam cores. The number after the year (91) in the sample identification number indicates which core was used. Samples ISV-91-16-5 and ISV-91-04-7 are from the central, coarsely crystalline portion of the ISV mass with sample ISV-91-16-5 more crystalline than ISV-91-04-7. Samples ISV-91-06-1 and ISV-91-09-7 are from the transition zone that goes from the central densely crystalline zone to the glassy zone at the outer edge of the ISV body. Sample 


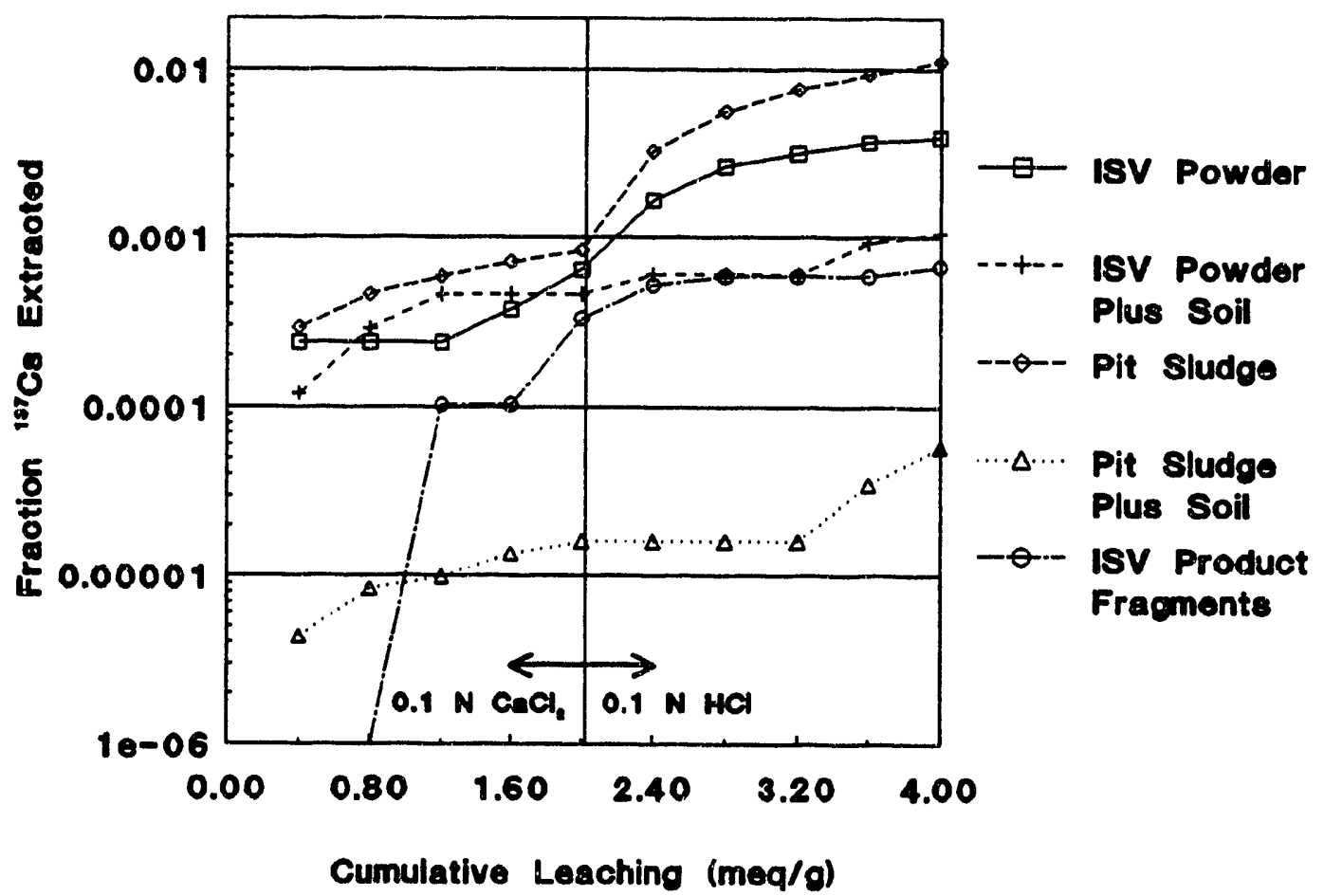

Fig. 90. Sequential leaching of ${ }^{137} \mathrm{C}$ f from whole and pulverized ISV product and from ORNL Seepage Pit 2 sludge.

ISV-91-06-1 is more crystalline than sample ISV-91-09-7. Samples ISV-91-16-2 and ISV-91-09-1 are from the outermost glassy portion of the ISV block. This section, although glassy, is still predominantly crystalline.

The procedure used to evaluate the durability of these rock samples was MCC-TP-19, Rev. 0: Leaching Tests Using the PCT Method. The samples were crushed using a Plattner tool steel crusher. Up to 10 blows of a hammer were required, followed by particle size isolation using 100 -mesh and 200-mesh sieves. Because 3 to $4 \mathrm{~g}$ of sample are required for each test, and triplicate tests were performed for each sample, approximately $30 \mathrm{~g}$ of each of the samples was crushed.

To remove fines and other alien particles, the crushed sample material was washed seven times, four times with pure water and three with ethanol. The material was placed in a $50-\mathrm{mL}$ beaker and agitated by forcibly squirting it with approximately $30 \mathrm{~mL}$ of water. After settling for approximately $15 \mathrm{~s}$, the material separated into solid material and dirty supernate, and the supernate was decanted. This procedure was repeated once. The third and fourth washes were identical to the second except that the beaker containing the test material was placed in an ultrasonic cleaner for 2 min before decanting the supernate. The fifth through seventh cleanings were identical to third and fourth except that ethanol was used. This cleaning procedure varies slightly from that given in MCC-TP-19, Rev. 0. It is, however, the washing procedure described in PCT, Version 3.0. (It should 
be noted that MCC-TP-19 is being revised to conform to the washing procedure of PCT, Version 3.0.)

Three replicate tests were performed on each sample, resulting in 18 tests, and on two blanks. Blanks contain no sample material but are run in an identical manner. The leachant used was deionized water (DIW), defined as water having a minimum electrical resistivity of $16.67 \mathrm{M} \Omega-\mathrm{cm}$ at $23^{\circ} \mathrm{C}$. For each test, approximately $3 \mathrm{~g}$ of $-100-+200$-mesh crushed glass test material were used with approximately $30 \mathrm{~mL}$ of DIW. The crushed glass and leachant were sealed inside a Teflon test vessel and maintained at a temperature of $90^{\circ} \mathrm{C}$.

At the end of the 7-d tests, the Teflon containers were removed from the oven, weighed, and allowed to cool. The Teflon leaching vessels were opened, and approximately $1 \mathrm{~mL}$ of leachate was removed for $\mathrm{pH}$ measurement with a Ross combination electrode. The remaining leachate was filtered using a $0.45-\mu \mathrm{m}$ filter and split into three aliquots. Approximately $10 \mathrm{~mL}$ was acidified to $1 \%$ with Ultrex $\mathrm{HNO}_{3}$ and analyzed by ICP emission spectrometry and atomic absorption for Cs.

Leachate elemental concentration values in $\mathrm{mg} / \mathrm{L}(\mathrm{ppm})$ are generally normalized by composition and surface area so that comparisons between elements can be made. To obtain this value, the product of the blank-corrected concentration of an element found in the leachate and the volume of the leachant is divided by the product of the mass fraction of the element in the sample and the surface area per unit mass of the crushed sample particles used in the test.

The formula for normalizing is

$$
N L_{i}=\frac{\left(C_{i j}-B_{i}\right) \times V_{j}}{f_{i} \times S A_{j} \times m_{j}}=\frac{\left(C_{i j}-B_{j}\right)}{f_{j} \times m_{j} \times\left(S A_{j} / V_{j}\right)}
$$

where:

$N L_{\mathrm{i}} \quad=$ release of element $\mathrm{i}$ from specimen $\mathrm{j}$ in terms of the surface area,

$C_{i j} \quad=$ concentration of element $i$ observed in leachate from specimen $j$,

$B_{\mathrm{i}} \quad=$ concentration of element $\mathrm{i}$ observed in leachate from blank,

$V_{\mathrm{j}} \quad=$ initial volume of leachant in test vessel containing specimen $\mathrm{j}$,

$f_{\mathrm{i}} \quad=$ average mass fraction of element $i$ in the specimen $=$ (mass fraction oxide in material) $\times$ (atomic weight metal in oxide) / (atomic weight of oxide),

$m_{\mathrm{j}} \quad=$ original mass of specimen $\mathrm{j}$,

$S A_{\mathrm{j}} \quad=$ surface area per unit mass of specimen $\mathrm{j}$.

Calculating the surface area per unit mass involves assuming a spherical particle of mean diameter between the sizes of the screen mesh openings. The openings of the sieves were 100 mesh $=0.150$ $\mathrm{mm}$ and 200 mesh $=0.075 \mathrm{~mm}$. Therefore, the mean diameter of particles passing a 100-mesh screen and retained on a 200 -mesh screen is $-0.110 \mathrm{~mm}$. A density of $2.7 \mathrm{~g} / \mathrm{cm}^{3}$ for the ISV material was used in the calculation.

Surface area (sphere) $=4 \pi r^{2}$

Volume (sphere) $=4 / 3\left(\pi r^{3}\right)$

So, 


$$
S A=\frac{4 \pi r^{2}}{4 / 3 \pi r^{3} \times 2.7 \mathrm{~g} / \mathrm{cm}^{3}}=0.02 \mathrm{~m}^{2} / \mathrm{g}
$$

The final normalized elemental release values are given in $\mathrm{g} / \mathrm{m}^{2}$ ( $\mathrm{g}$ of element released per $\mathrm{m}^{2}$ of specimen surface area). Table 39 lists the normalized releases for $\mathrm{Si}, \mathrm{Al}, \mathrm{Ca}, \mathrm{Mg}, \mathrm{K}$, and $\mathrm{Fe}$

Table 39. Normalized leachate elemental values from Product Consistency Tests of 1991 ORNL ISV product $\left(g / \mathrm{m}^{2}\right)$.

\begin{tabular}{lllllll}
\hline & \multicolumn{6}{c}{ Sample Number } \\
\cline { 2 - 7 } Element & $91-16-5$ & $91-04-7$ & $91-06-1$ & $91-09-7$ & $91-16-2$ & $91-09-1$ \\
& & & & & & \\
$\mathrm{Al}$ & 0.0232 & 0.0212 & 0.0275 & 0.0288 & 0.0243 & 0.0199 \\
$\mathrm{Ca}$ & 0.0141 & 0.0145 & 0.0168 & 0.0158 & 0.0202 & 0.0285 \\
$\mathrm{Fe}$ & nd $^{\mathrm{a}}$ & 0.0006 & nd & nd & 0.0010 & 0.0004 \\
$\mathrm{~K}$ & 0.0216 & 0.0154 & 0.0154 & 0.0400 & 0.0585 & 0.0708 \\
$\mathrm{Mg}$ & 0.0074 & 0.0047 & 0.0073 & 0.0072 & 0.0043 & 0.0011 \\
$\mathrm{Si}$ & 0.0283 & 0.0286 & 0.0264 & 0.0275 & 0.0306 & 0.0305 \\
& & & & & & \\
\hline
\end{tabular}

${ }^{2}$ nd $=$ not detected in leachate.

from all of the ISV samples. The leachate samples were counted for 12 to $25 \mathrm{~h}$ each at ORNL to determine the activity of ${ }^{137} \mathrm{Cs}$. The uncertainty in the reported activities average $\pm 25 \%$ because of the small sample size $(5 \mathrm{~mL})$ and low activities $(0.1$ to $0.5 \mathrm{pCi} / \mathrm{mL})$. The activity of ${ }^{90} \mathrm{Sr}$ was determined from Cerenkov radiation emission from the same samples during repeated $30 \mathrm{~min}$ counting intervals using the same assay conditions described in the product analysis section. Uncertainty in the ${ }^{90} \mathrm{Sr}$ activity determination was also estimated at $\pm 25 \%$. No correction for Cerenkov radiation emission by the ${ }^{137} \mathrm{Cs}$ was necessary due to the low activities of this radionuclide in these samples. A normalized release value cannot be calculated for a radioisotope as it can for the major elements. Instead, the percentage of the ${ }^{137} \mathrm{Cs}$ and ${ }^{90} \mathrm{Sr}$ present in the solid material, leached via PCT testing, was calculated from the known mass of sample and leachate and the measured ${ }^{137} \mathrm{Cs}$ and ${ }^{90} \mathrm{Sr}$ activities.

For simulated waste glasses, the elements of interest are $\mathrm{B}, \mathrm{Li}$, and $\mathrm{Na}$. These three elements are released in the highest amounts during glass testing. The elements most often used as an indicator of glass durability are $\mathrm{B}$, and sometimes $\mathrm{Li}$, because they remain soluble even in high concentrations in the leachate. While this is also true for $\mathrm{Na}$, the data are less reliable. However, the ORNL ISV material contains very little $\mathrm{B}, \mathrm{Li}$, or $\mathrm{Na}$. The elements found in the leachates were $\mathrm{Al}, \mathrm{Ca}, \mathrm{K}, \mathrm{Si}$, small amounts of $\mathrm{Mg}$, and sometimes small amounts of $\mathrm{Fe}$. As a general rule, $\mathrm{Al}, \mathrm{Ca}$, and $\mathrm{Si}$ are not used as indicators of durability because the solubility decreases greatly as the elemental level increases in the leachate. In addition, precipitates can be formed in the leachates, although that does not appear to have been the case here. Potassium would normally be a good indicator of glass durability, just as $\mathrm{Li}$ and $\mathrm{Na}$ are good indicators; however, detection limits for $\mathrm{K}$ are high. For example, even in the 


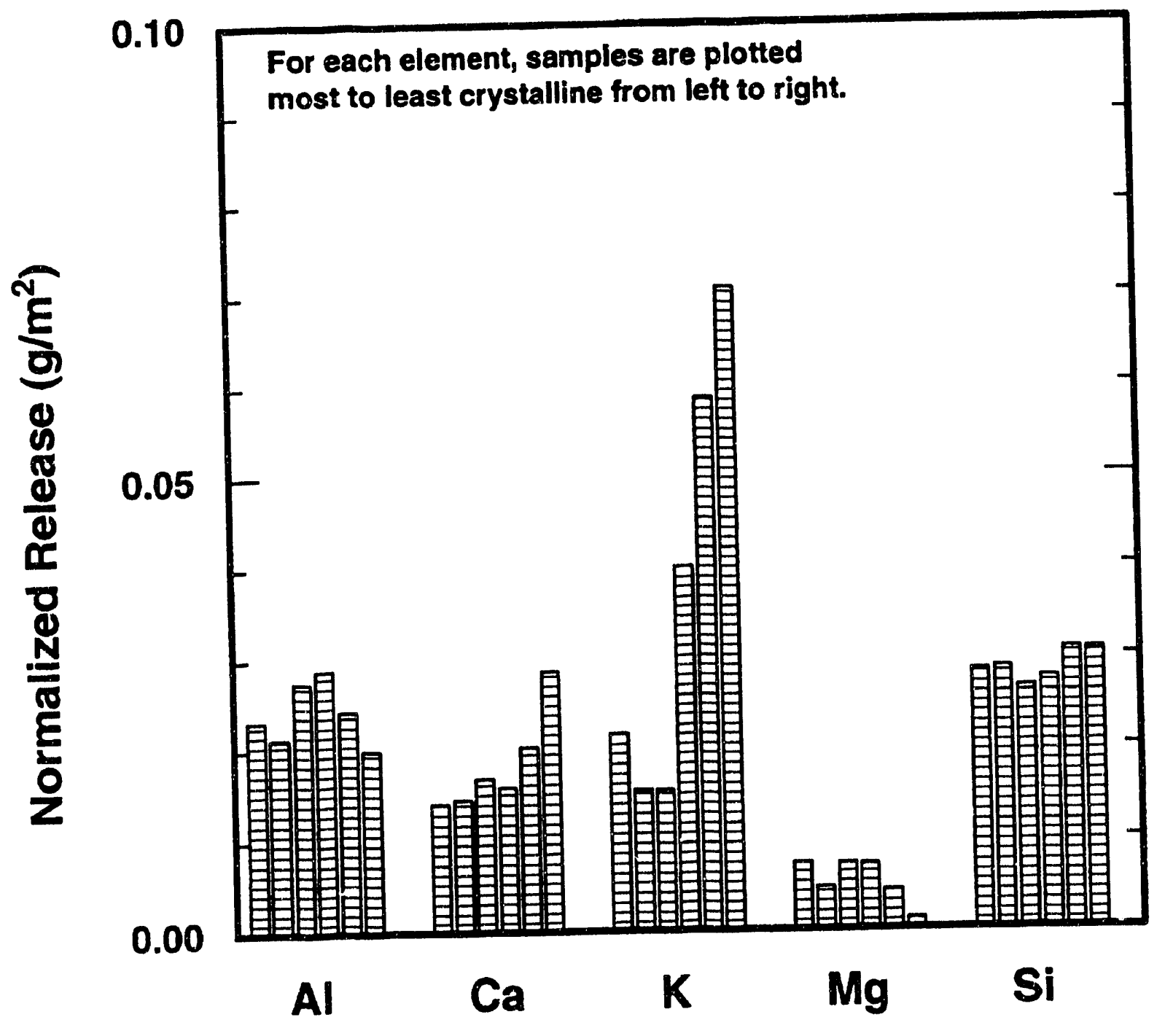

Fig. 91. Normalized release rates $\left(\mathrm{g}^{\mathrm{m}} \mathrm{m}^{2}\right)$ for $\mathrm{Al}, \mathrm{Ca}, \mathrm{K}, \mathrm{Mg}$, and $\mathrm{Si}$ from ORNL ISV samples. For each element, bars represent most crystalline to least crystalline from left to right.

blanks low levels of $\mathrm{K}$ are found.

Figure 91 illustrates the normalized release of $\mathrm{Si}, \mathrm{Al}, \mathrm{Ca}, \mathrm{Mg}$, and $\mathrm{K}$ from the ORNL ISV samples. Figure 92 illustrates the percentage of ${ }^{137} \mathrm{Cs}$ and ${ }^{90} \mathrm{Sr}$ removed during the PCT tests as a function of sample crystallinity. These values are comparable to those of the cumulative leach test (Fig. 90). In both the cumulative leach test and the PCT test (Fig. 92), the percentage of ${ }^{137} \mathrm{Cs}$ or ${ }^{90} \mathrm{Sr}$ mobilized was between 0.1 and $2 \%$. There is no trend apparent due to sample crystallinity. This result confirms that, although the ${ }^{137} \mathrm{Cs}$ is concentrated in the residual glass phase of the ISV product, it is not preferentially released on leaching with either deionized water or dilute cation solutions. No significant trend with increasing glass content exists for the elements $\mathrm{Al}, \mathrm{Mg}$, and $\mathrm{Si}$. However, the samples with greater proportions of glass may have $\mathrm{Ca}$ and $\mathrm{K}$ preferentially leached from them compared with the more coarsely crystalline samples. The overall release rate is, however, very low 


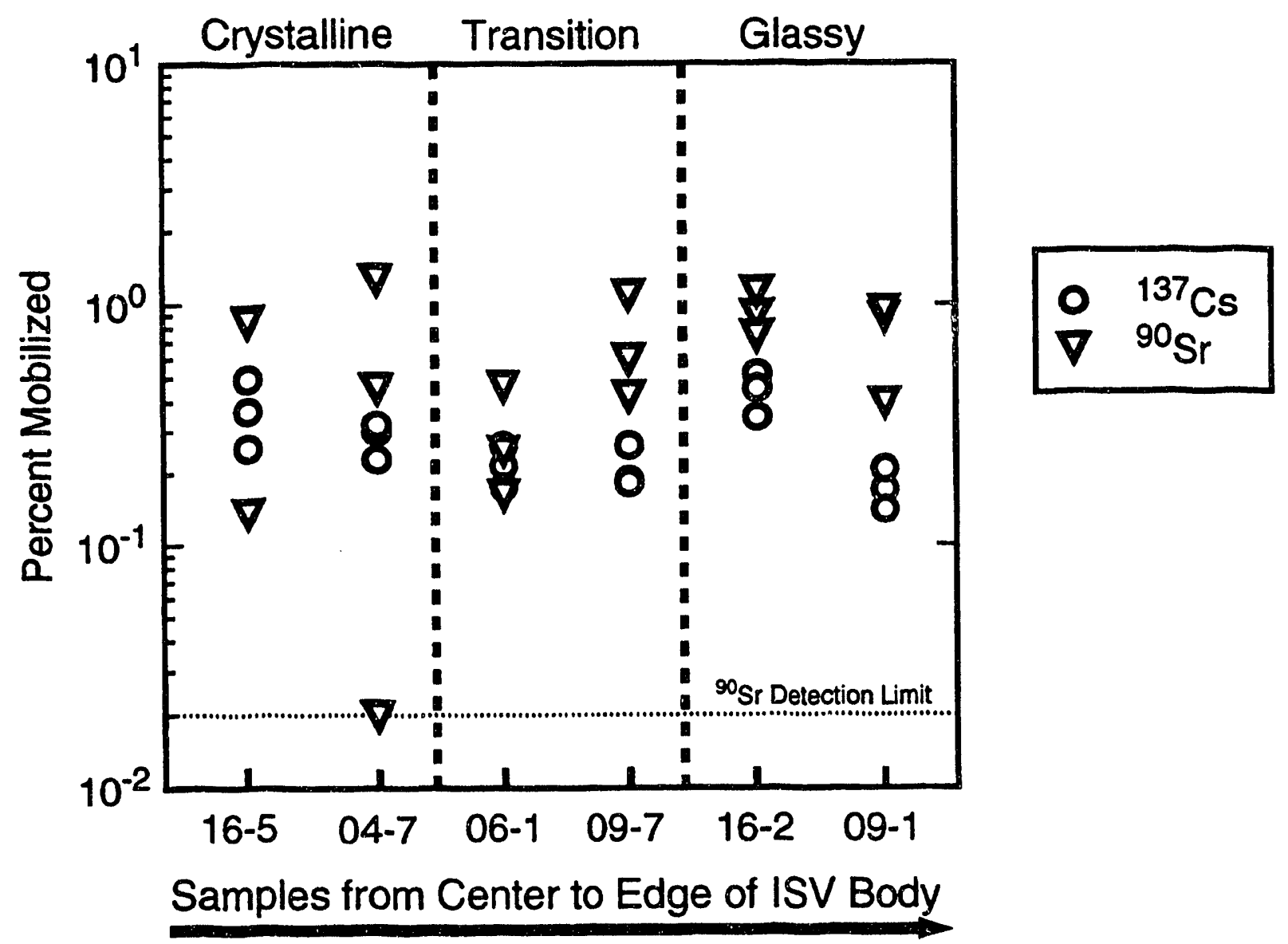

Fig. 92. Percentage of ${ }^{137} \mathrm{Cs}$ and ${ }^{90} \mathrm{Sr}$ removed from ISV products of different crystallinity during Product Consistency Tests.

when compared with other vitreous waste forms (Fig. 93). Figure 93

compares the normalized release values for the ORNL ISV material with samples from the Hanford 116-B-6A Crib ISV melt (Luey et al. 1992) and glasses for high-level radioactive waste (K. A. Olson, unpublished data, 1992). The normalized releases from the ORNL ISV material are typically equal to or less than those from the nuclear waste glasses and the Hanford ISV material. The only way to create high release rates would be to drastically increase the available surface area contacted by infiltrating groundwater. Given the typical strength of ISV material (Buelt et al. 1987), it is unlikely that an ISV mass would fracture into a powdered material in the environment. If the mass remains 


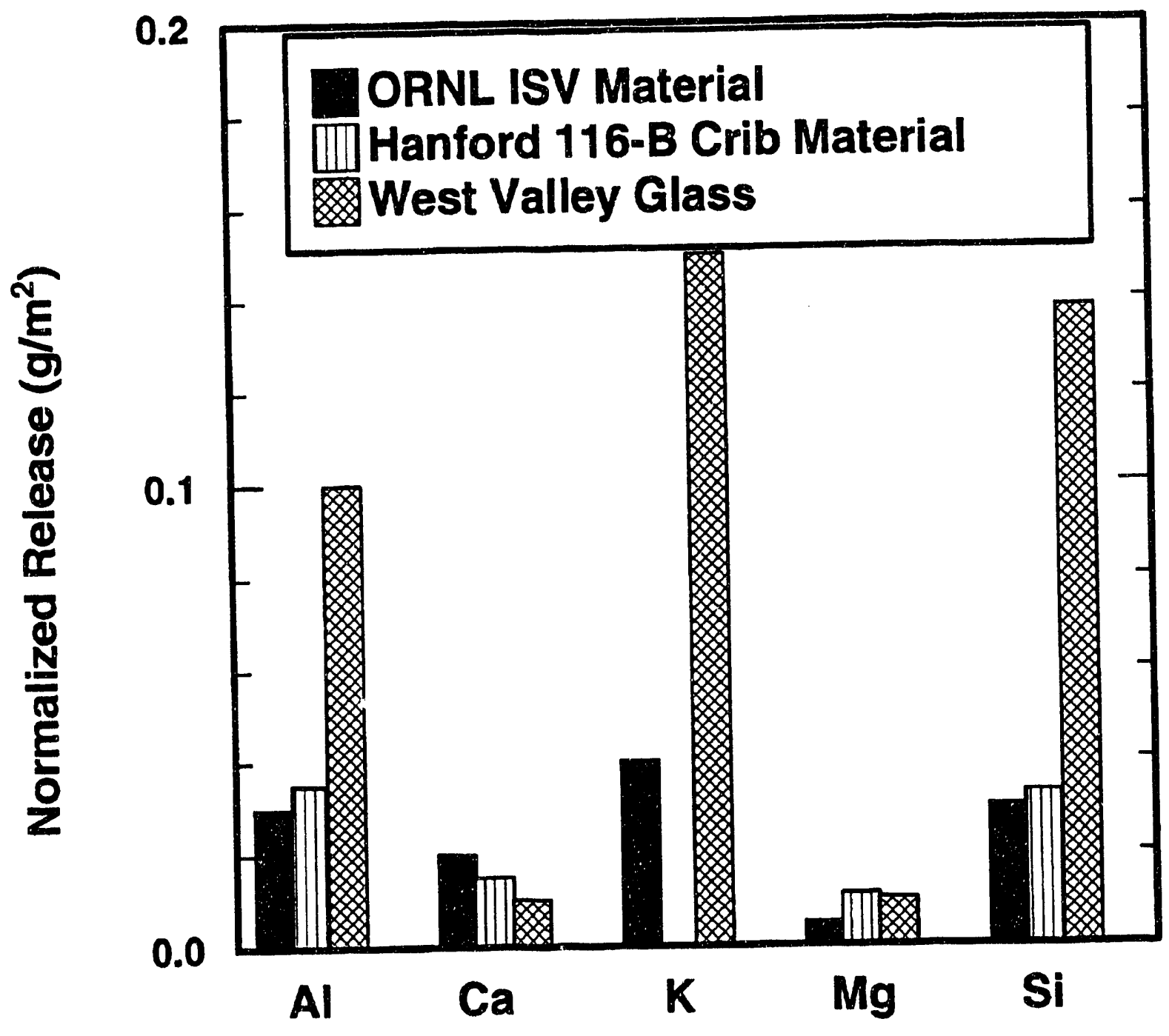

Fig. 93. Comparison of normalized releases $\left(\mathrm{g} / \mathrm{m}^{2}\right)$ for $\mathrm{Al}, \mathrm{Ca}, \mathrm{K}, \mathrm{Mg}$, and $\mathrm{Si}$ from ORNL ISV material, Hanford 116-B Crib ISV material, and West Valley glass.

reasonably intact, the surface area of material contacted by water will remain small because only small amounts of groundwater will be present in fractures, which will have a small reactive surface area.

\section{MODELS FOR DEPTH AND SHAPE OF THE 1991 ORNL ISV PRODUCT}

The depth and shape of the ISV melt was determined by using the thermocouples that were placed into the test volume and by coring the solidified mass. This information could then be used to validate the interpretations of the various geophysical methods employed to image the melt during and after the test. This information also provides data to help understand the processes controlling melt generation during ISV and to evaluate methods to estimate or measure the shape and depth of an ISV melt during processing. Monitoring melt shape and depth during applications is important 
for targeting the areas of contamination and for avoiding areas that should not be melted (e.g., buried utilities or adjacent waste sites).

The depth of melting was determined from the central array of type- $\mathrm{K}$ thermocouples. As each one reached $1100^{\circ} \mathrm{C}$, it was assumed to have been contacted by the melt. Figure 94 illustrates

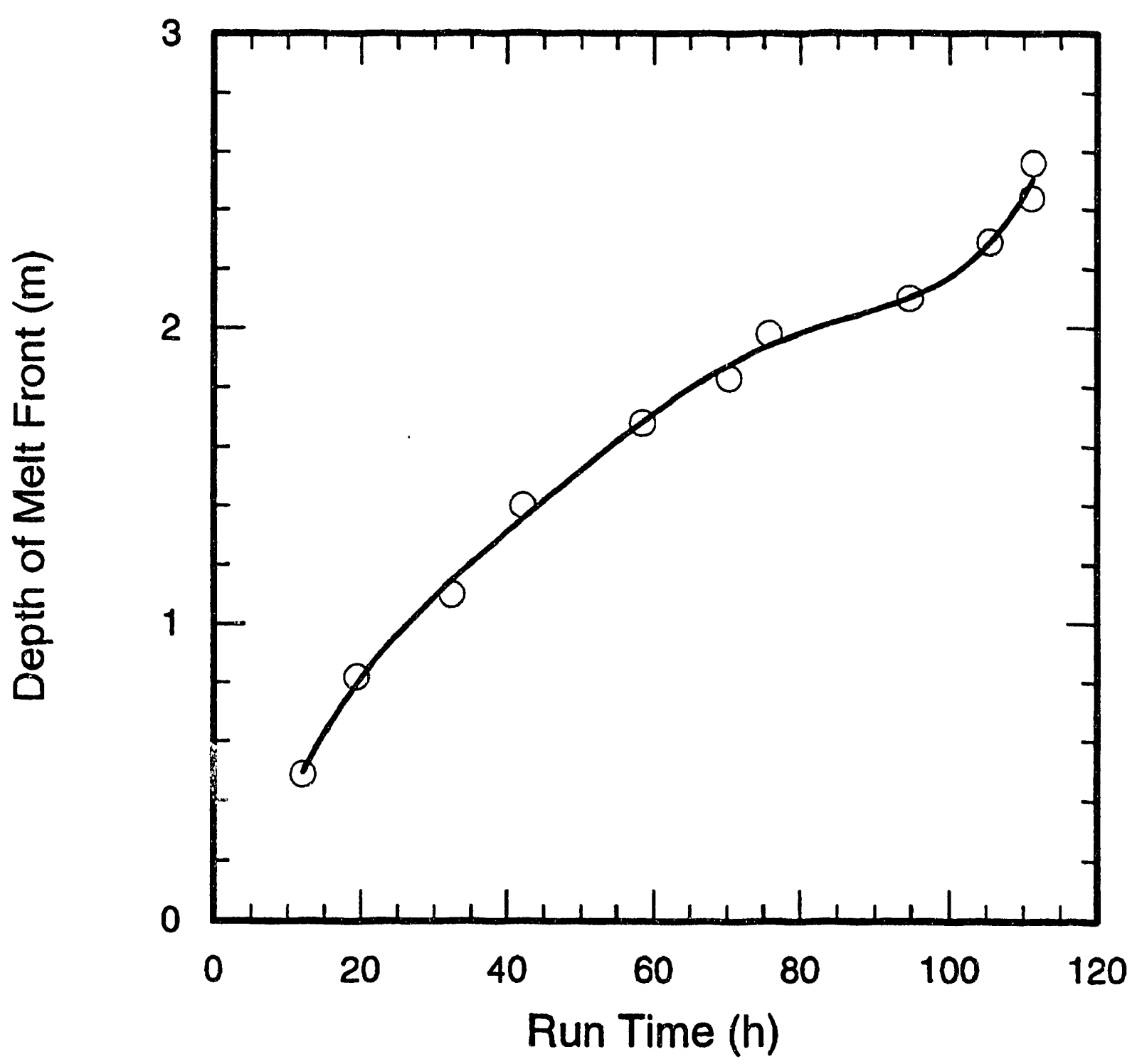

Fig. 94. Depth versus time for the ISV melt front as determined from the central array of type-K thermocouples. A sixth-order polynomial was fit to the data.

the depth of melting as a function of run time. A sixth-order polynomial was fit to the data, with depth in meters and time in hours:

$$
\begin{aligned}
d= & -4.016725 \mathrm{e}-01 \\
& +1.059561 \mathrm{e}-01 \times \mathrm{t} \\
& -3.305609 \mathrm{e}-03 \times \mathrm{t}^{2}
\end{aligned}
$$


$+6.408527 \mathrm{e}-05 \times \mathrm{t}^{3}$

$-6.163466 \mathrm{e}-07 \times \mathrm{t}^{4}$

$+2.406358 \mathrm{e}-09 \times \mathrm{t}^{\mathrm{s}}$

$-1.479599 \mathrm{e}-12 \times \mathrm{t}^{6}$

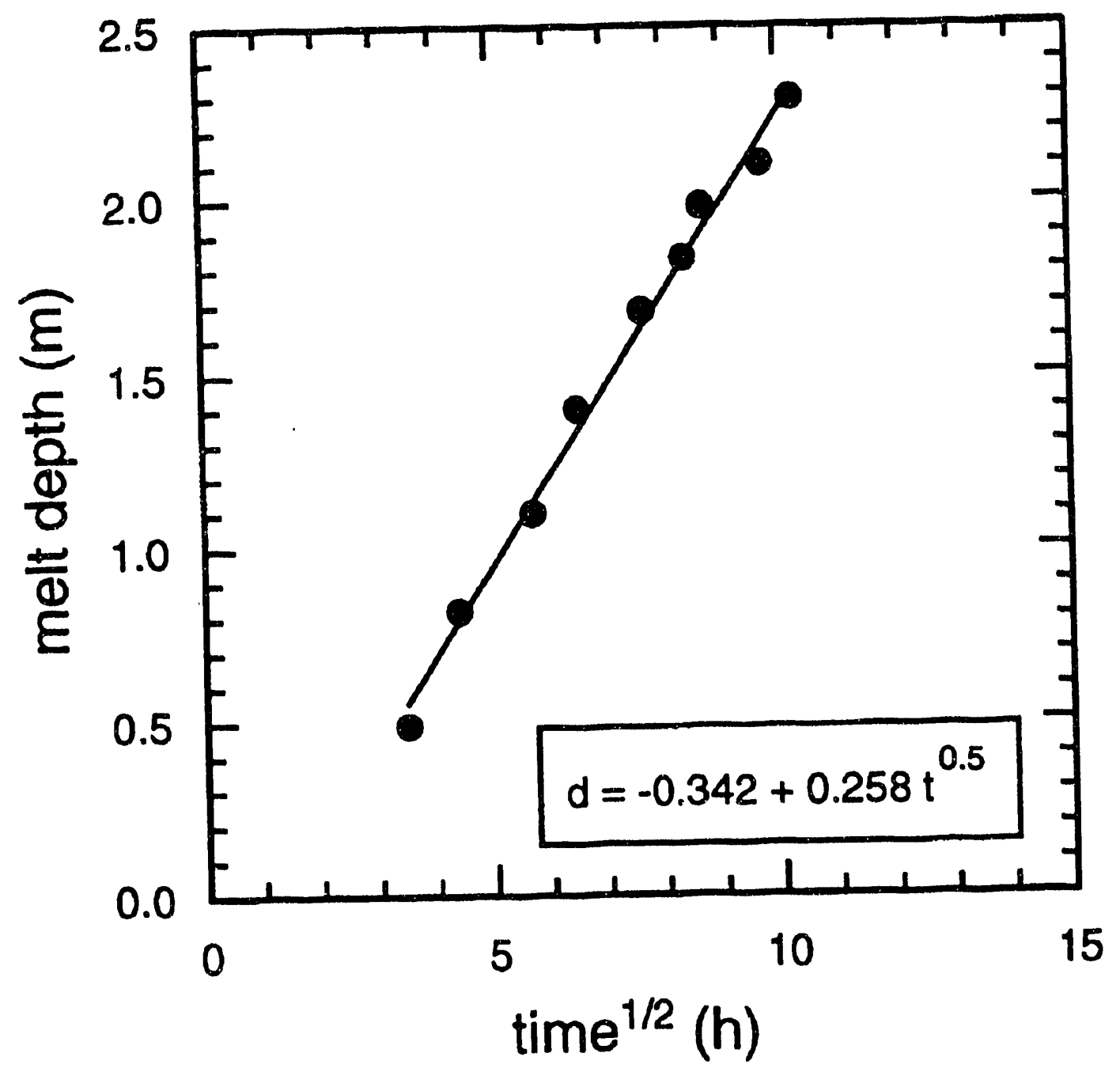

Fig. 95. Depth of the ISV melt front as a function of square root of time.

Figure 95 shows that when melt depth is plotted vs the square root of time, the relationship is linear. This relationship was found to hold for most previous ISV tests at a variety of scales and implies that the growth of the melt front is driven primarily by conduction from a constant-temperature source (Solomon et al. 1991). The derivative (melt rate) of this sixth-order polynomial was used to compare the rate of vertical melting with power input to the melt (Fig. 96). The rate starts out high, but then slows to a value near $0.02 \mathrm{~m} / \mathrm{h}$ as the test proceeds. During the power interruptions around $80 \mathrm{~h}$, the rate of vertical melting slows significantly. As power is restored, the rate again increases to a value of $\sim 0.025 \mathrm{~m} / \mathrm{h}$. The rates at early and late times are probably exaggerated because data was not available to constrain the equation for these times. Thus the rate information is most applicable from 20 to $110 \mathrm{~h}$. 


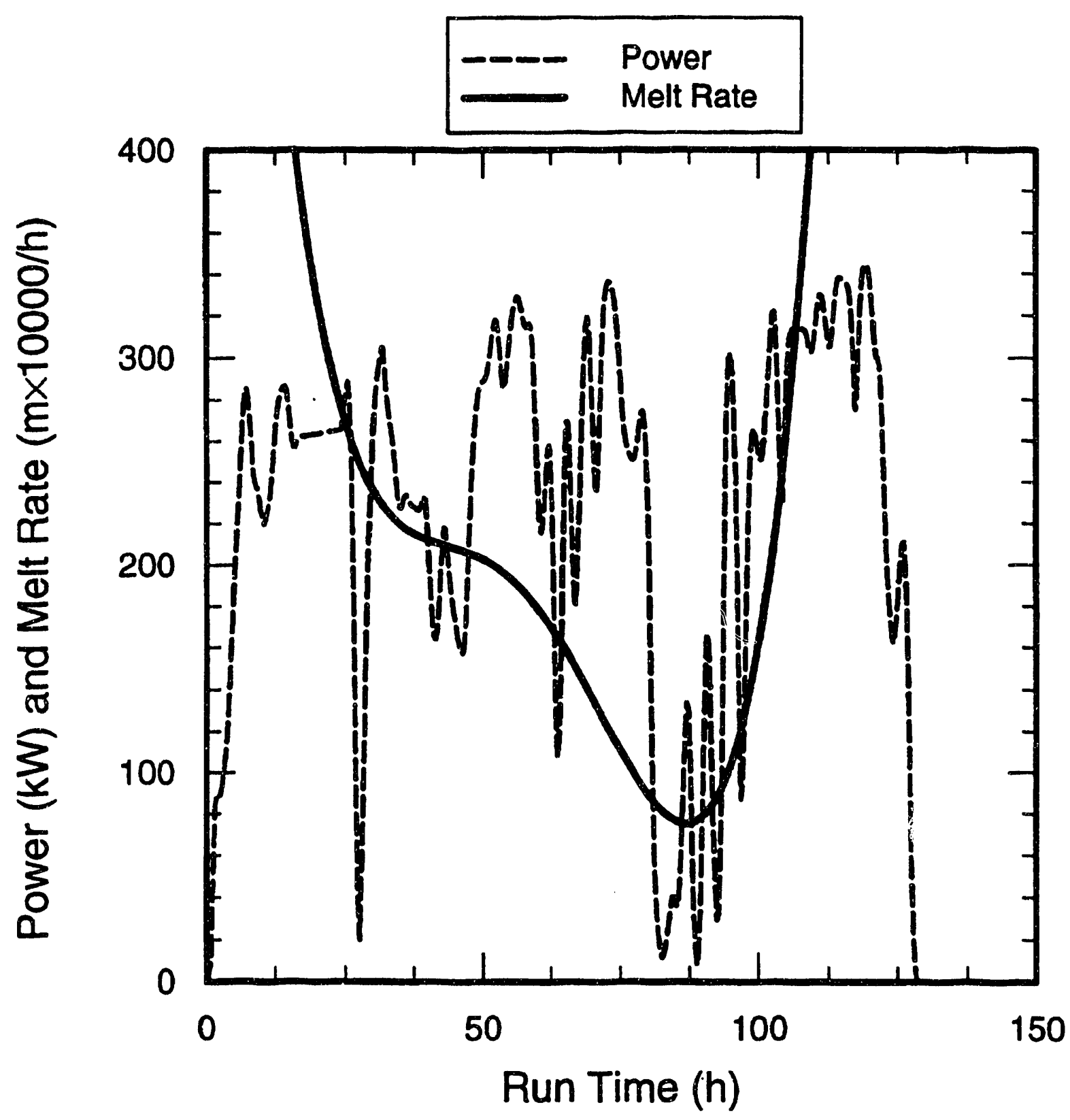

Fig. 96. Melt rate $(\mathrm{m} / \mathrm{h})$ vs run time with power input to the melt superposed.

The melt rate was determined by differentiating the sixth-order polynomial of depth vs time.

The volume of the melt as a function of time was calculated from several observations. The soil had a porosity of $\sim 0.5$. Thus, for each unit volume $\left(\mathrm{m}^{3}\right)$ of soil melted, the melt volume and subsidence volume would be $0.5 \mathrm{~m}^{3}$. The subsidence zone could be divided into two sections (Fig. 97). The first was a cylindrical section $\sim 1.5 \mathrm{~m}$ deep and $1.5 \mathrm{~m}$ in diameter. Knowing depth vs time and the porosity relationship, one can calculate the melt volume during this time from the equation for the 


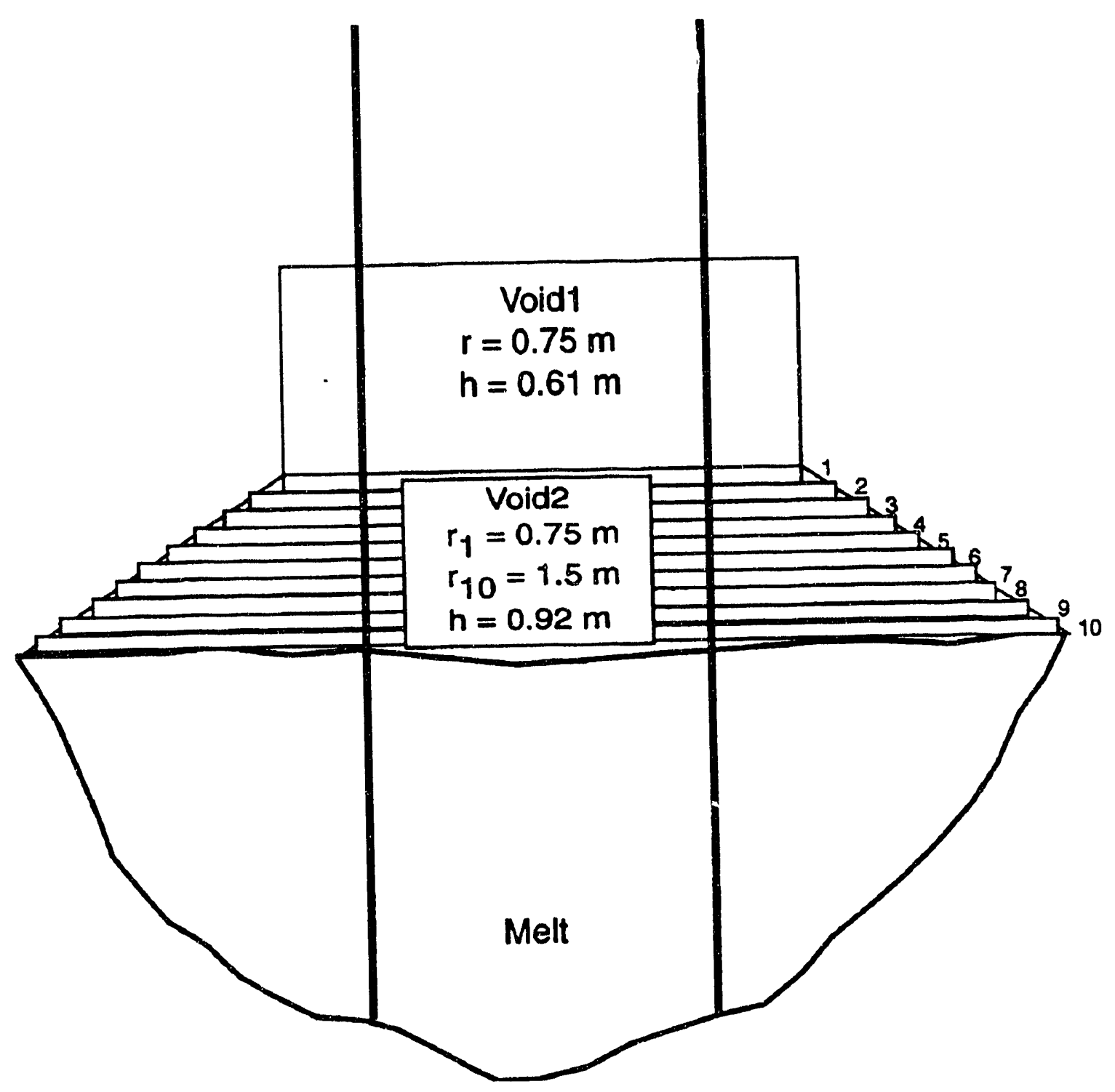

Fig. 97. Schematic diagram of the subsidence zone and melt body.

volume of a cylinder. This relationship holds for the first $\sim 50 \mathrm{~h}$ of melting. The dimensions of the lower subsidence volume (Fig. 97) were estimated from field observations of the subsidence zone Actual measurements of the diameter vs depth could not be made. Thus a straight line was assumed to connect the bottom of the cylindrical zone to the upper edge of the melt, which was determined from coring. Then the volumes of small, incremental slices of the void + melt volume were calculated. Knowing depth as a function of time and that porosity $=0.5$, the melt volume was calculated. The volume is linear with time (Fig. 98), which is also consistent with a conduction-driven melt front (Solomon et al. 1991).

Equations determined for melt shape and depth were:

melt depth (m) vs square root of time (h) 


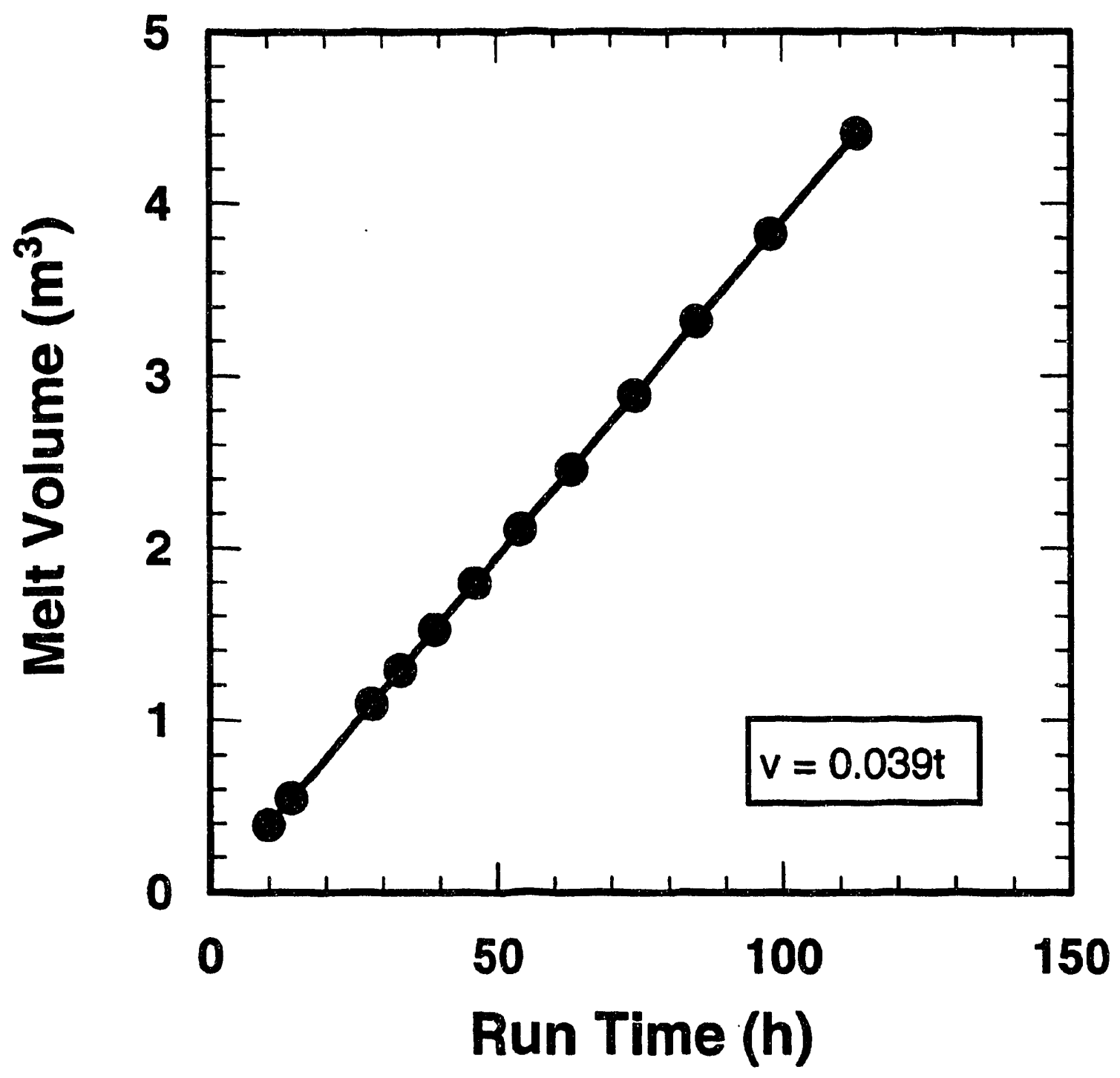

Fig. 98. Volume of ISV melt as a function of time.

$d=-0.342+0.258 \times t^{0.5}$

subsidence depth (m) vs square root of time (h)

$S=-0.247+0.161 \times t^{0 . S}$

diameter of subsidence (m) vs time (h)

$D=1.5 ;$ for $t<28 \mathrm{~h}$

and

$D=0.299+0.242 \times t^{0.5} ;$ for $t>28 h$ 
volume of melt $\left(\mathrm{m}^{3}\right)$ vs time (h)

$$
V=0.039 \times t
$$

From coring the solidified ISV body, a contour map of the bottom of the mass was created. Figure 99a shows the contours of the bottom of the body (the upper surface of the mass is essentially flat and at an elevation of $833 \mathrm{ft}$ ). The ma-r is roughly hemispherical in shape. It did not take on the shape of the trench as much as the melt in 1487 at ORNL. The center of the mass is deeper than the sides. The cross sections (Fig. $99 \mathrm{~b}$ and c) indicate that the central region seemed to grow at a more rapid rate than other areas.

The three-dimensional thermocouple data were interpolated and then placed into a visualization package on a Stardent workstation (Mitchell and Flanery, personal communication). This model allowed viewing of the extent and shape of the melt at any run time. The visualization package could also be set to step through time so as to obtain an animated view of the growth of the melt during time. Figure 100 shows the interpolated thermocouple data at the end of the test with the

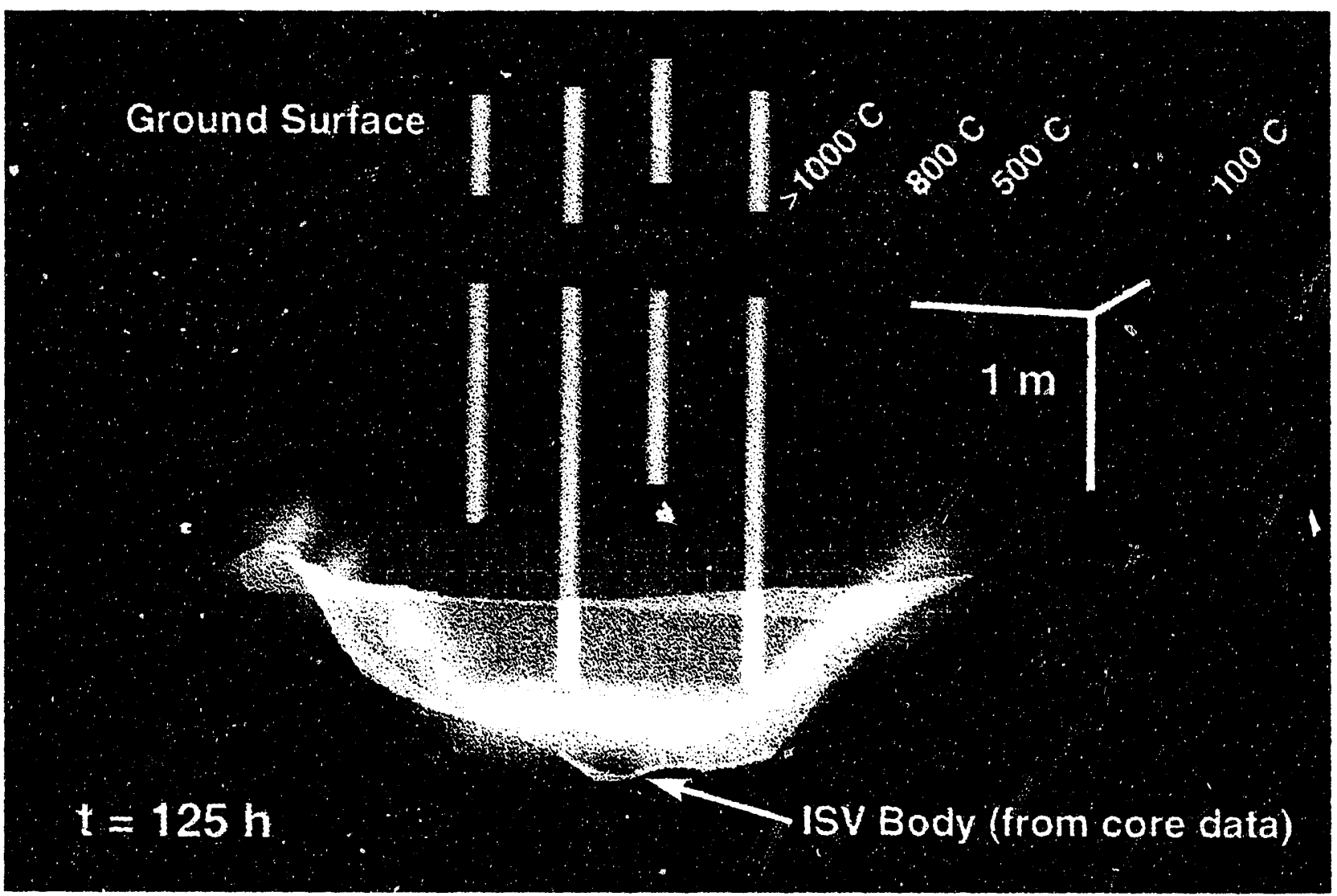

Fig. 100. Three-dimensional interpolation anci visualization of the thermocouple data at $t=125 \mathrm{~h}$. The front half of the image has been removed so that the interior temperatures can be seen. The melt body is shown as the bright white solid.

shape of the mass inferred from coring superposed. 

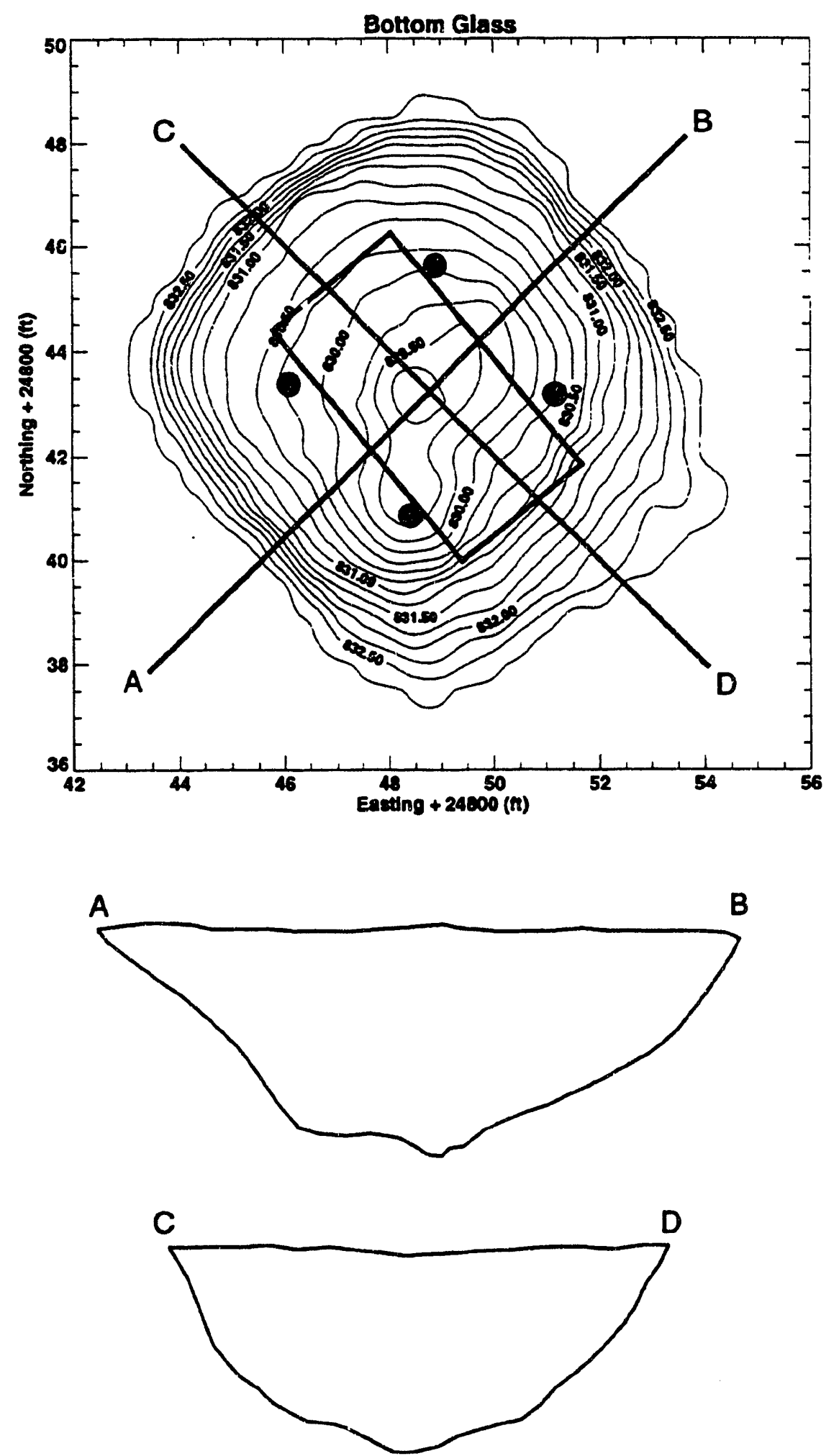

Fig. 99. (a) Elevation contours for the bottom of the ISV body. Northing ( $\mathrm{ft}$ ) and Easting ( $\mathrm{ft}$ ) are in ORNL grid coordinates. (b) Cross section A-B through the ISV body. (c) Cross section C-D through the ISV body. 


\section{GEOPHYSICAL IMAGING OF THE ISV MELT}

Seismic data were recorded at the ISV test site prior to melting, at three times during melting, and at four times during cooling and solidification. The receivers included 3-component $100-\mathrm{Hz}$ geophones located $1 \mathrm{~m}$ apart along two profiles on the surface and at $1-\mathrm{m}$ vertical intervals in two boreholes on opposite sides of the melt. The seismic source was a 21-mm (8-gage) shotgun fired into the ground at intervals of $0.5 \mathrm{~m}$ along each of the two profiles. There was an 8-m-diam area above the melt where it was not possible to locate geophones or shot points because of the off-gas hood. A iypical seismic profile consisted of 45 shots that were recorded by 24 surface geophones and 12 borehole geophones [ $3 \times(24+12)=108$ data traces per shot]. Other geophysical instrumentation included hydrophones in two boreholes along each profile, vertical DC resistivity arrays in six boreholes surrounding the melt, and ground-penetrating radar that was used at the end of the project after all metallic equipment had been removed from the site. Only results from the three-component geophones and resistivity measurements will be summarized. The results from the hydrophone and ground-penetrating radar studies were limited and will be summarized in a separate report.

\section{Pre-Melt Image}

\section{Time \\ $0 \mathrm{~ms}$}

10

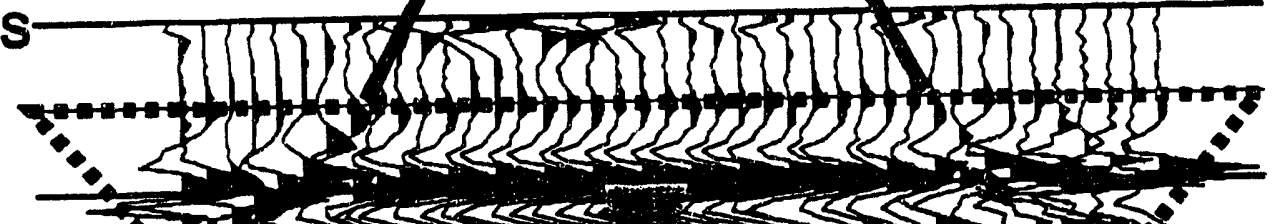
Off-Gas Hood

Depth

20

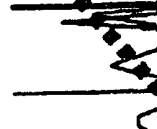
$13<2<3<2$
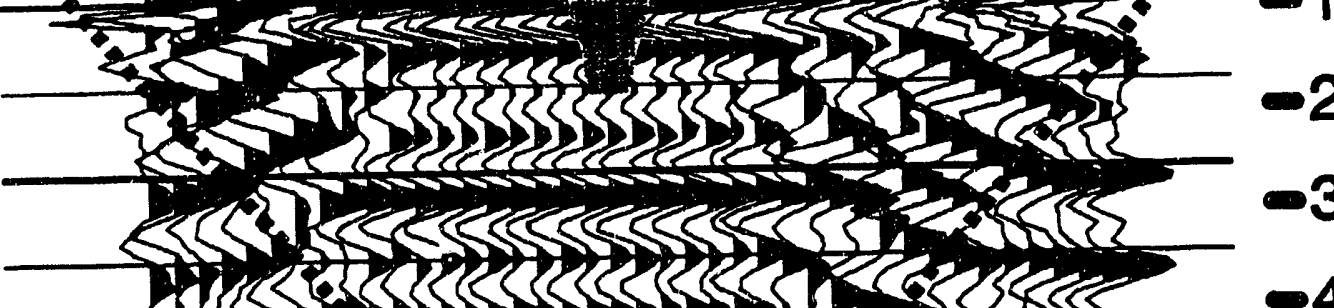

30

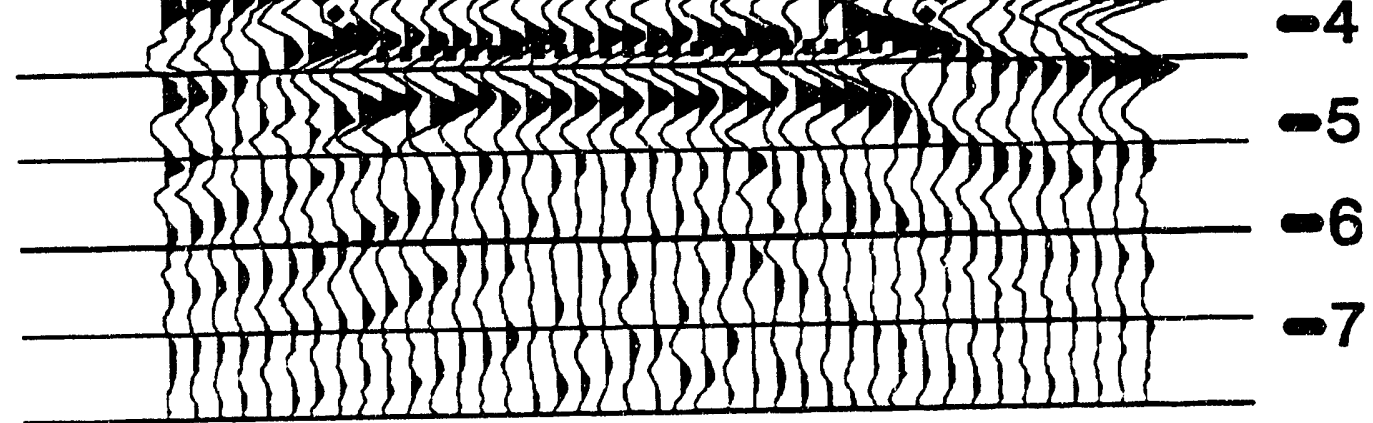

50

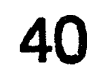

Fig. 101. Seismic section of soil strata following construction of test trench using migrated data from vertical-component, surface geophones. Excavation pit (dashed line), test trench (gray-shaded), and the off-gas hood are superposed on seismic section. 
The seismic data record structures and shapes of pre- and postmelt features. The premelt seismic data (Fig. 101) indicate that the excavated volume around the test trench was stratified following its construction as a resuli of backfilling and compaction. Major differences exist between seismic data recorded at different times during active melting and cooling periods. Data collected before and after the thermal arrest are of particular interest. Two seismic profiles were collected that bracket the period of crystallization, one of the profiles being completed just prior $(t=139 \mathrm{~h})$ to the thermal arrest and another just after $(t=187 \mathrm{~h})$. The boundaries of the melt indicated by the prethermal arrest seismic data (Fig. 102) are consistent with those later determined by coring. The seismic data appear to also detect the altered soil zone around the melt $\left(100-1000^{\circ} \mathrm{C}\right)$. The data aiso indicate the presence of major physical heterogeneities within the melt 12 to $15 \mathrm{~h}$ after termination of power. Cores showed that the entire body was chemically homogeneous, so any interior bourdaries during the early stages of cooling were a result of (1) changes in physical properties, (2) differences in cooling rates and (3) the advance of crystallization fronts. The seismic data are consistent with an early period of crystal growth, prior to the more extensive crystallization that was associated with the thermal arrest. The boundaries of the melt indicated by the postthermal arrest data (Fig. 103) are also consistent with the shape, based on coring, but the seismic character of the interior of the mass is different from the previous data (Fig. 102); the interior boundaries are less prominent. The pre- and postthermal arrest data show that a strong positive (right-going) signal from $2-2.5 \mathrm{~m}$ deep in the prethermal arrest data (Fig. 102) is significantly weaker in the postthermal arrest data (Fig. 103).

There are two possible explanations for this difference: (1) the origin of the signal was a region of relatively high temperature and low crystallinity in the middle of the melt prior to the thermal arrest, which was absent as a strong seismic anomaly after the entire mass had crystallized, and (2) the expected velocities in the body would have been much faster following the thermal arrest than before, so that less seismic energy from shot points outside the body would have penetrated its interior.

\section{COST ANALYSIS OF ISV FOR PITS AND TRENCHES AT ORNL}

The following is a brief description of costs projected for the full-scale remediation of ORNL waste sites using ISV. Where possible, costs have been tailored for application to the pits and trenches at ORNL. It should be noted, however, that there is a difference between costs associated with tests/demonstrations of ISV and with actual treatment operations. The tests and demonstrations are typically more expensive per unit of soil melted than full-scale treatment. This is because some costs associated with demonstrations, such as site preparation, instrumentation, data analysis, and reporting, are not included in actual remediation. Demonstrations are typically one-time operations whereas economies of scale, related to multiple settings and increased operational efficiency, are realized for the latter. The following description is related to the costs associated with actual treatment operations.

Trench dimensions at ORNL are variable. But, for this analysis, a size of $3 \mathrm{~m}$ deep, $1 \mathrm{~m}$ wide at the base, and about $2 \mathrm{~m}$ wide at the top (Fig. 2) was assumed. The ORNL trenches are typically backfilled with limestone and are covered by an additional $2 \mathrm{~m}$ of scil cover. Therefore, the cost analysis is given for an ISV remediation campaign along the length of the trench that is 1 setting wide ( 8 to $10 \mathrm{~m}$ ), $5 \mathrm{~m}$ deep, and $90 \mathrm{~m}$ long. A 90 -m-long campaign would involve about 10 to $12 \mathrm{ISV}$ settings, depending on the amount of overlap required between settings. The analysis is given for a radioactive waste site with 5 to $7 \%$ soil moisture.

The four main cost categories for ISV are site activities, equipment, labor, and consumables. The cost estimates are given in 1991 dollars and reflect only direct costs for performing ISV. No allowance has been made for profit or administrative overhead.

Site activities include transporting equipment to and from the waste site, clearing and grading the area, removing the top layer of uncontaminated scil (overburden), and acquiring and applying backfill material following the treatment. Site characterization costs are not included. These costs will vary enormously depending on the type and extent of contamination and on the site records 


\section{Image Preceding Thermal Arrest}

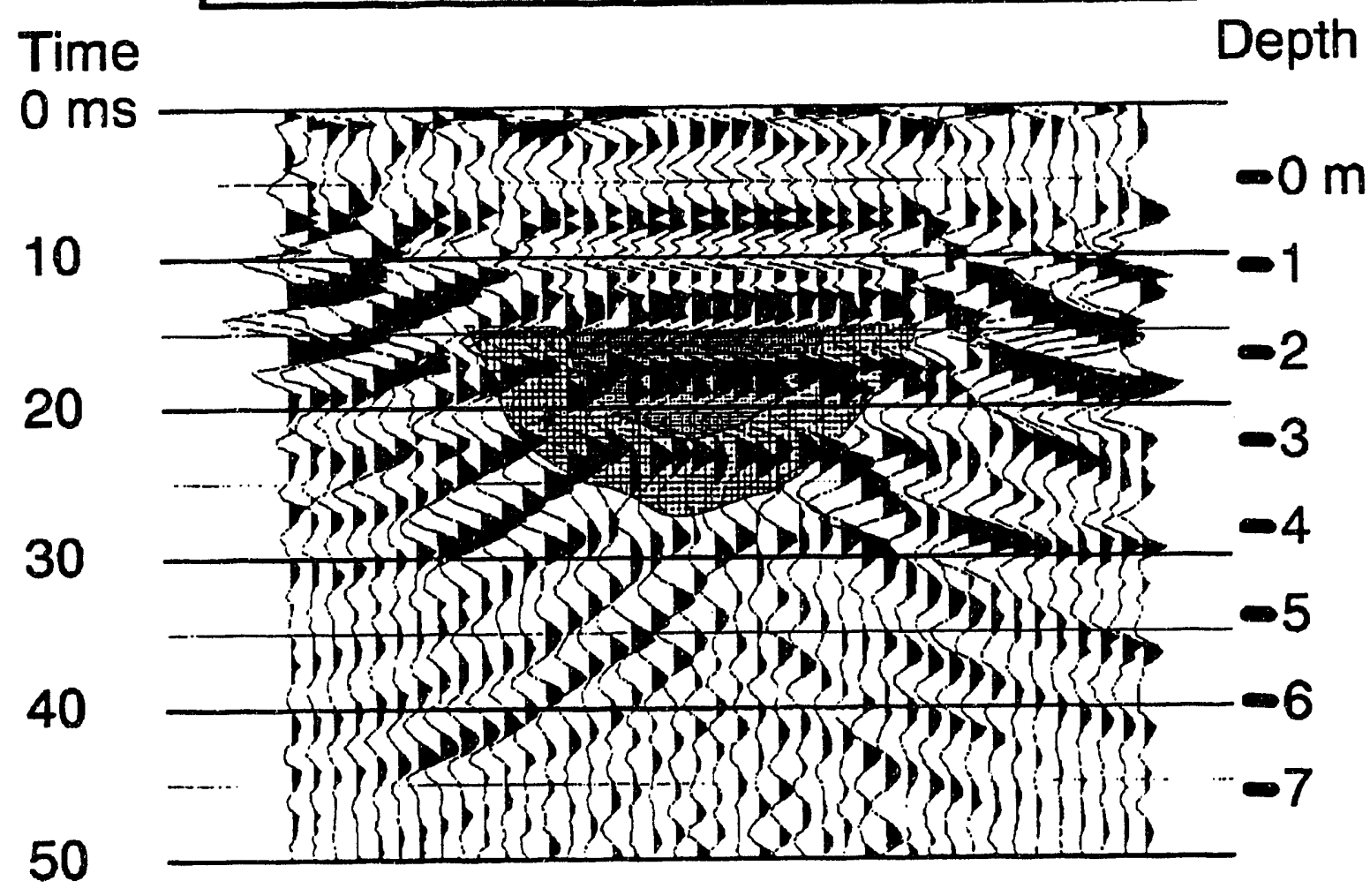

Fig. 102. Seismic section of the partially crystallized melt body before thermal arrest with superimposed cross section of the solidified ISV body (dark pattern) and thermally altered soil (light pattern). Both arrival times and depths are shown.

available. Therefore, these costs would be considered separately when assessing the cost to a particular site. Site activity costs are estimated at $\$ 200,000$ per treatment site.

Equipment costs are estimated on the basis of actual purchased costs of equipment scaled to 1991 dollars. Various equipment changes have occurred in the past few years. An electrode feed system has been implemented, which allows the use of graphite electrodes rather than the combination graphite/ molybdenum electrodes previously used. The pure graphite electrodes do not require predrilling into the ground as did the combination electrodes. This change has resulted in a decrease in site preparation costs because equipment and labor for placing the electrodes into the ground to the desired melt depth is no longer neces":ry.

Another change incorporated into this analysis is that two hoods and related equipment (electrode feed systems, off-gas lines, and blowers) are included rather than one. The use of two hoods enables setup for the next setting during vitrification of the current setting. Though this increases capital costs, the increase in productivity more than compensates for the additional cost. Equipment costs are listed in Table 40.

Personnel costs are based on industry-averaged labor rates. (Site-specific values could be substituted should they differ significantly from the industry average.) The personnel rates used are shown in Table 41. 


\section{Image After Thermal Arrest}

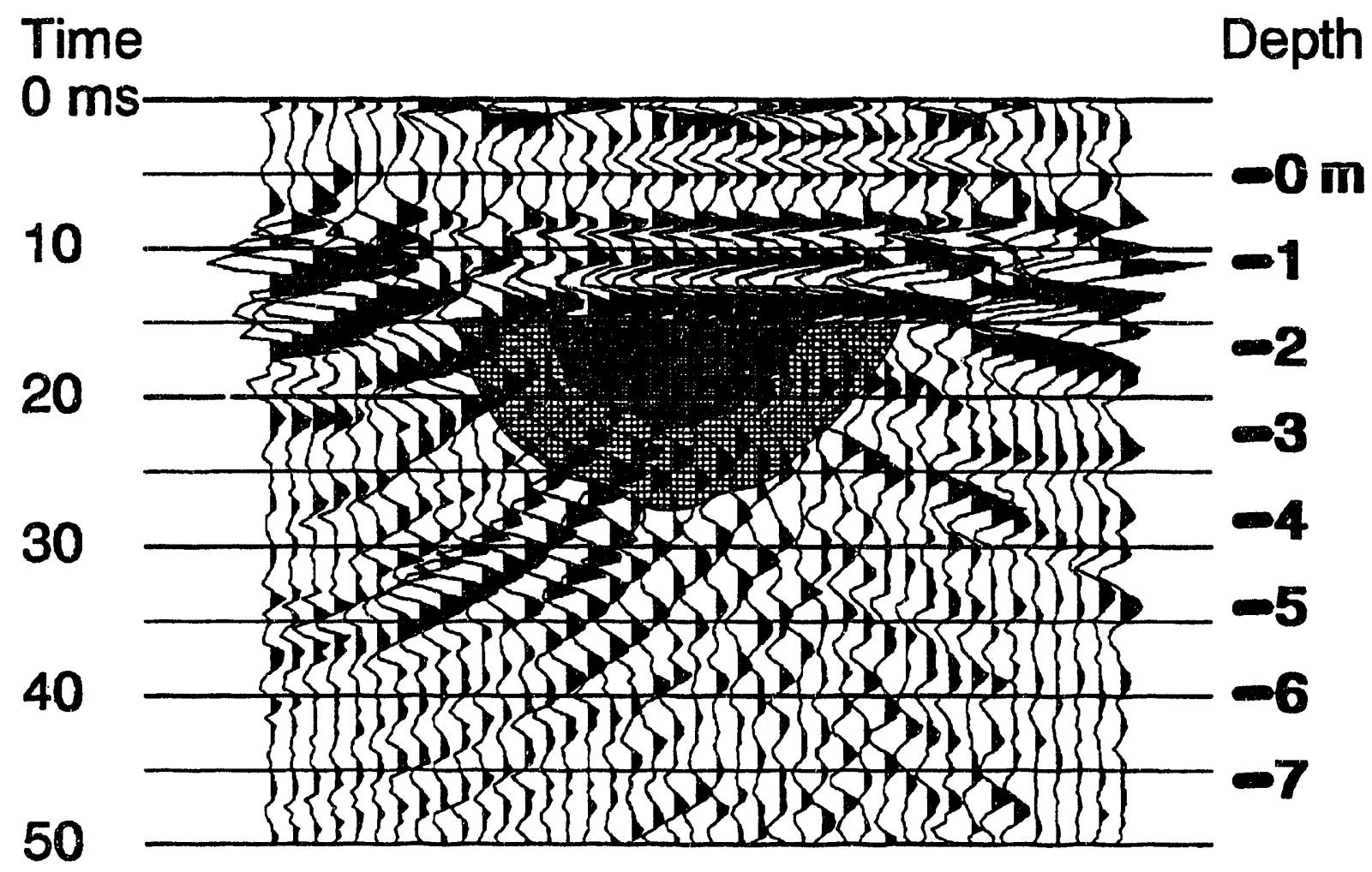

Fig. 103. Seismic section of the fully solidified ISV body after thermal arrest with superimposed cross section of ISV body (dark pattern) and of thermally altered soil (light pattern).

The labor costs will vary based on the vitrification rate. Table 42 gives the estimated vitrification rate based on empirical data and process modeling. The vitrification times are given per setting. There are 12 settings per site for a $90-\mathrm{m}$ long trench, and each setting partially overlaps the previously vitrified setting. In addition to actual vitrification time, times are given for setup between settings. Setup involves moving the hood, preparing the electrodes, and wiring. As explained previously, two hoods will be used to enable the setup of the hood at the next setting while vitrification is taking place concurrently.

The number and type of workers needed per shift for setup and vitrification at a radioactive site are shown in Tables 43 and 44 , respectively. It has been assumed here that all workers will work 8-h shifts. Each ISV operating shift would be staffed with four workers, including a radiation protection technician, as shown in Table 44; additional periodic support would be required by a crane operator and other craftpersons for electrode replenishing and other maintenance activities.

Consumable supplies and costs for the ISV process include electrodes, electrical power, and secondary waste disposal. The electrodes presently used in ISV are assembled from 1.8-m lengths of 30-cm-diam solid graphite rods. There are four electrodes used per setting, and the length of each electrode equals the depth of the melt plus the height from the surface of the soil to the top of the electrode feeder $(-8 \mathrm{~m})$. The section of electrode remaining above the melt will be reused on the next setting. (After the final setting, the contaminated sections of the electrrde above the melt will need 
Table 40. Equipment cost for in situ vitrification of the ORNL seepage pits and trenches.

\begin{tabular}{lc}
\multicolumn{1}{c}{ Item } & Cost (\$K) \\
\hline Backup generator $-0.75 \mathrm{MW}$ & 35 \\
Hood blowers, backup (2) & 80 \\
Transformer & 350 \\
Electrode power cables & 85 \\
Electrode feed systems (2) & 520 \\
Off-gas lines and hoods (2) & 1600 \\
Off-gas treatment system & 1000 \\
Process control system & 250 \\
Crane (25-ton rubber tire) & 200 \\
Glycol cooling system & 45 \\
TOTAL & 4165 \\
\hline Job classification & 25 \\
\hline Table 41. Hourly costs for personnel to be used for in situ vitrification of ORNL seepage pits \\
and trenches. \\
\hline
\end{tabular}

to be decontaminated or disposed.) The cost of the electrodes is $\$ 500 / \mathrm{i}-\mathrm{m}$ secison.

The cost of ISV is highly dependent upon power costs. This and using a power cost of $\$ 83.30 / \mathrm{MWh}$ based on diesel-generator-supplied pewe? $81,0 \mathrm{ng}, 000$ per 30-day rental for a 5-MW generator. Power supplied by a generator was considered tut in is thalysis because line power to the site in currently insufficient for large-scale IS $V$ operations. If line jower to the ISV site were available, power costs for ISV would be negligible. At ORNL, matinum yearly power contracts with the local power generator (Tennessee Valley Authority) have never been attained or even approached; thus, electrical power for ISV would be without any direct project cost. The actual power level required will vary as the melt progresses, but for the purposes of this cost analysis, an average of $3.75 \mathrm{MW}$ is used which allows for $3.0 \mathrm{MW}$ to the melt in addition to the $0.75 \mathrm{MW}$ required 
Table 42. Hourly rates and related parameters for in situ vitrification operations on the ORNL seepage pits and trenches.

Vitrification time/setting (h) $\quad 200$

Setup time/setting (h) 16

Electrode spacing $(\mathrm{m}) \quad 3.5$

Distance between electrodes of adjacent set $(\mathrm{m}) \quad 4.0$

$\begin{array}{ll}\text { Width vitrified per set }(\mathrm{m}) & 10\end{array}$

Area to be vitrified $\left(\mathrm{m}^{2}\right) \quad 900$

Depth of setting $(\mathrm{m}) \quad 5$

Number of settings $\quad 12$

Site volume $\left(\mathrm{m}^{3}\right) \quad 4,500$

Table 43. Personnel requirements for setup of equipment for in situ vitrification of ORNL seepage pits and trenches.

\begin{tabular}{lccc}
\hline & & Workers per shift & \\
Job classification & $\underline{\text { Day }}$ & $\frac{\text { Nvening }}{1}$ & $\frac{\text { Night }}{0}$ \\
Engineer & 1 & 1 & 0 \\
Crane operator & 1 & 1 & 0 \\
Pipefitter & 1 & 2 & 0 \\
Operator/technician & 2 & 1 & 0 \\
Electrician & 1 & 1 & 0 \\
Radiation protection technician & 1 & &
\end{tabular}

by the additional equipment. Obviously, the vitrification time required per setting is the determining factor for energy costs of ISV.

The ISV off-gas system produces two types of secondary wastes. Both liquid scrub solutions and HEPA filters require periodic disposal. Judging from past large-scale operations, approximately $1000 \mathrm{~L} /$ waste setting and 2 HEPA filters/setting will require disposal. However, the waste volume reduction practices implemented during the 1991 pilot-scale test at ORNL (the subject of this report) and during the 1991 large-scale ISV test at Hanford were successful in significantly reducing the volume of secondary wastes compared with past tests. As a result, a conservative estimate of waste generation per setting is $0.5 \mathrm{~m}^{3}$, including both scrub solution effluent and HEPA filters. However, this does not account for waste generated by a special prefiltering technique on the ISV process when applied to the ORNL pits and trenches; it is currently not possible to estimate the amount of waste generated by the prefilter. Due to the concentration of hazardous constituents found naturally in the soil, the waste would likely be designated as radioactive mixed waste and is assumed as such for this estimate. Costs associated with the disposal of secondary wastes are conservatively estimated at $\$ 10,600 / \mathrm{m}^{3}\left(\$ 300 / \mathrm{ft}^{3}\right)$.

The projected costs for vitrifying the described site are given in Table 45. The total cost is estimated to be about $\$ 1.7 \mathrm{M}$ or about $\$ 390 / \mathrm{m}^{3}$. The soil at the site has a density of about $1.6 \mathrm{~g} / \mathrm{cm}^{3}$, 
Table 44. Personnel requirement for in situ vitrification operations at the ORNL seepage pits and trenches.

\begin{tabular}{lccc}
\hline & & Workers per shift & \\
Job classification & $\underline{\text { Day }}$ & $\frac{\text { Evening }}{1}$ & $\frac{\text { Night }}{1}$ \\
Engineer & 1 & 0 & 0 \\
Crane operator & 0.04 & 0 & 0 \\
Pipefitter & 0.04 & 2 & 2 \\
Operator/technician & 2 & 0 & 0 \\
Electrician & 0.08 & 1 & 1 \\
Radiation protection technician & 1 & &
\end{tabular}

Table 45. Cost summary for in situ vitrification of an ORNL seepage trench.

\begin{tabular}{lcc}
\hline & Sk/site & \\
& & \\
& 200 & $\mathrm{~m}^{3}$ \\
\hline Site costs & 131 & 44.44 \\
Labor costs & 288 & 29.21 \\
$\quad$ Site setup & 419 & 64.00 \\
$\quad$ Operations & & 93.21 \\
$\quad$ Total labor costs & 76 & 16.79 \\
Consumable costs & 64 & 14.13 \\
$\quad$ Electrodes & 750 & 166.60 \\
Secondary waste disposal & 890 & 197.52 \\
$\quad$ Electrical power & 228 & 50.67 \\
Total consumables & & \\
Equipment cost & 987 & 219.24 \\
Total cost (without electricity costs) & 1737 & 385.84 \\
Total cost (with electricity costs) & & \\
& & \\
\hline
\end{tabular}

which results in a mass-based cost of about $\$ 617 /$ ton. It should be emphasized again that this projected cost includes only items directly associated with vitrifying the site. It does not include costs associated with technology development, site characterization, regulatory permitting, administration/overhead, or profit.

As shown in Table 45, energy costs are about $40 \%$ of the total, which is higher than average for an ISV operation because of increased power costs associated with generator-supplied power. Ultimately, an analysis of generator-supplied costs to costs for installation and consumption of linesupplied power should be made. However, as discussed earlier, because of the contractual arrangement for power to DOE's Oak Ridge facilities, electrical power at ORNL does not presently have any cost. Equipment costs have been calculated using a 5-year continuous design life and are prorated for the amount of time in use at the site on the basis of the total equipment cost of $\$ 4,165,000$ as listed in Table 40. 


\section{REFERENCES}

Albarede, F., and Y. Bottinga. 1972. Kinetic disequilibrium in trace element partitioning between phenocrysts and host lava. Geochim. Cosmochim. Acta 36:141-56.

Anderko, A., and K. S. Pitzer. 1993. Equation-of-state representation of phase equilibria and volumetric properties of the system $\mathrm{NaCl}-\mathrm{H}_{2} \mathrm{O}$ above $573^{\circ} \mathrm{C}$. Geochim. Cosmochim. Acta (in press).

ASTM (American Society for Testing Materials). 1984. Standard method for penetration test and split-barrel sampling of soils. D1586-84. ASTM, Philadelphia.

Bence, A. E., J. J. Papike, and C. T. Prewitt. 1970. Apollo 12 clinopyroxenes: Chemical trends. Earth Planet. Sci. Lett. 8:393-99.

Bence, A. E., and A. L. Albee. 1968. Empirical correction factors for the electron microanalysis of silicates and oxides. J. Geol. 76:382-403.

Bernard, A., and F. LeGuern. 1986. Condensation of volatile elements in high-temperature gases of Mount St. Helens. J. Volcanol. Geotherm. Res. 28:95-105.

Brandeis, G., and C. Jaupart. 1986. On the interaction between convection and crystallization in cooling magma chambers. Earth Planet. Sci. Lett. 77:345-61.

Brouns, R. A., J. L. Buelt, and W. F. Bonner. 1983. In situ vitrification of soil. U.S. Patent 4,376,598. March 1983.

Buelt, J. L., C. L. Timmerman, K. H. Oma, V. F. Fitzpatrick, and J. G. Carter. 1987. In situ vitrification of transuranic wastes: Systems evaluation and applications assessment. PNL-4800, Supplement 1. Battelle Pacific Northwest Laboratory, Richland, Washington.

Burnham, C. W. 1979. Importance of volatile constituents. pp.. 439-82. In Evolution of Igneous Rocks, Fiftieth Anniversary Perspectives. Princeton University Press, Princeton, N. J.

Burton, J. A., R. C. Prim, and W. P. Slichter. 1953. The distribution of solute in crystals grown from the melt, part 1: Theoretical. J. Chem. Phys. 21:1987-91.

Callow, R. A., L. E. Thompson, J. R. Weidner, C. A. Loehr, B. P. McGrail, and S. O. Bates. 1991. In situ vitrification application to buried waste: final report of intermediate field tests at Idaho National Engineering Laboratory. EGG-WTD-9807. Idaho National Engineering Laboratory, Idaho Falls, Idaho. 
Candela, P. A. and H. D. Holland. 1986. A mass transfer model from copper and molybdenum in magmatic hydrothermal systems: The origin of porphyry-type ore deposits. Econ. Geol. 81:1-19.

Carter, J. G., S. O. Bates, and G. D. Maupin. 1987. In situ vitrification of Oak Ridge National Laboratory soil and limestone. PNL-6174. Battelle Pacific Northwest Laboratory, Richland, Washington.

Carter, J. G., S. S. Koegler, and S. O. Bates. 1988. Process performance of the pilot-scale in situ vitrification of a simulated waste disposal site at the Oak Ridge National Laboratory. PNL-6530. Battelle Pacific Northwest Laboratory, Richland, Washington.

Cashman, K. V. and B. D. Marsh. 1988. Crystal size distributions (CSD) in rocks and the kinetics and dynamics of crystallization II. Makaopuhi lava lake. Contrib. Mineral. Petrol. 99:292-305.

Cashman, K V. 1992. Groundmass crystallization of Mount St. Helens dacite, 1980-1986: A tool for interpreting shallow magmatic processes. Contrib. Mineral. Petrol. 109:431-49.

Cerling, T. E., and B. P. Spalding. 1981. Areal distribution of ${ }^{60} \mathrm{Co},{ }^{137} \mathrm{Cs}$, and ${ }^{90} \mathrm{Sr}$ in streambed gravels of White Oak Creek watershed Oak Ridge, Tennessee. ORNL/TM-7318. Oak Ridge Natiogial Laboratory.

Crowe, B. M., D. L. Finnegan, W. H. Zoller, and W. V. Boynton. 1987. Trace element geochemistry of volcanic gases and particles from 1983-1984 eruptive episodes of Kilauea volcano. J. Geophys. Res. 92:13708-14.

Davis, E. C., W. J. Boegley, E. R. Rothschild, B. P. Spalding, N. D. Vaughan, C. S. Haase, D. D. Huff, S. Y. Lee, E. C. Walls, J. D. Newbold, and E. D. Smith. 1984. Site characterization techniques used at a low-level waste, shallow land burial field demonstration site. ORNL/TM-9146. Oak Ridge National Laboratory.

Deer, W. A., R. A. Howie, and J. Zussman. 1966. An Introduction to the Rock Forming Minerals. Longman Group Limited, London.

Dunbar, N. W. and P. R. Kyle. 1992. Volatile contents of obsidian clasts in tephra from the Taupo Volcanic Zone, New Zealand: Implications to eruptive processes. J. Volcanol. Geotherm. Res. 49:127-45.

Farnsworth, R. K, K. H. Oma, and C. E. Bigelow. 1990. Initial tests on in situ vitrification using electrode feeding techniques. PNL-7355. Pacific Northwest Laboratory, Richland, Washington.

Finnegan, D. L. 1984. The chemistry of trace elements and acidic species in fumarole emissions. Ph. D. Thesis. University of Maryland. College Park, Maryland.

Finnegan, D. L., J. P. Kotra, D. M. Hermann, and W. H. Zoller. 1989. The use of ' LiOH impregnated filters for the collection of acidic gases and analysis by instrumental neutron activation analysis. Bull. Volcanol. 51:83-87.

Gamble, R. P. and L. A. Taylor. 1980. Crystal/liquid partitioning in augite: Effects of cooling rate. Earth Planet. Sci. Lett. 47:21-33. 
Grove, T. L. and A. E. Bence. 1977. Experimental study of pyroxene-liquid interaction in quartz-normative basalt. pp. 1549-79. In, Proceedings of the Eighth Lunar Science Conference. Pergamon Press, Inc. New York.

Haberer, K. 1965. Measurement of beta activities in aqueous samples utilizing Cerenkov radiation. Atomwirtschaft 10:36-43.

Hampton, C. M. and D. K Bailey. 1985. Sublimates obtained during fusion of volcanic glasses. J. Volcanol. Geotherm. Res. 25:145-55.

Helz, R. T. 1987. Differentiation behavior of Kilauea Iki lava lake, Kilauea Volcano, Hawaii: An overview of past and current work. Geochem. Soc. Spec. Publ. 1:241-58.

Jacobs, G. K., B. P. Spalding, J. G. Carter, and S. G. Koegler. 1988. In situ vitrification demonstration for the stabilization of buried wastes at the Oak Ridge National Laboratory. Nuclear Chem. Waste Mgmt. 8:249-59.

Jacobs, J. W., R. L. Korotev, D. P. Blanchard, and L. A. Haskins. 1977. A well-tested procedure for instrumental neutron-activation analysis of silicate rocks and minerals. Geochim. Cosmochim. Acta 40:93-114.

Janzten, C. M., and N. E. Bibler. 1989. Nuclear waste glass product consistency test (PCT) method. Version 3.0. Westinghouse Savannah River Co., Aiken, S. C.

Keppler, H., and P. J. Wyllie. 1990. Role of fluids in transport and fractionation of uranium and thorium in magmatic processes. Nature 348:531-33.

Keppler, H., and P. J. Wyllie. 1991. Partitioning of $\mathrm{Cu}, \mathrm{Sn}, \mathrm{Mo}, \mathrm{W}, \mathrm{U}$, and Th between melt and aqueous fluid in the systems haplogranite- $\mathrm{H}_{2} \mathrm{O}-\mathrm{HCl}$ and haplogranite $-\mathrm{H}_{2}-\mathrm{HF}$. Contrib. Mineral. Petrol. 109:139-50.

Kilinc, I. A, and C. W. Burnham. 1972. Partitioning of chloride between a silicate melt and coexisting aqueous phase from 2 to 8 kilobars. Econ. Geol. 67:231-35.

Korotev, R. L., and D. J. Lindstrom. 1985. Interferences from fission of U-235 in INAA of rocks. Trans. Am. Nucl. Soc. 49:177-78.

Kuentz, D. A 1986. The Otowi member of the Bandelier Tuff: A study of the petrology, petrography, and geochemistry of an explosive silicic eruption, Jemez Mountains, New Mexico. Ph. D. Thesis. Univ. of Texas. Arlington, Texas.

Kuhn, W. L. 1992. Steady-state analysis of the fate of volatile contaminants during in situ vitrification. Informal Report. PNL-8059. Battelle Pacific Northwest Laboratory. Richland, Washington.

Lofgren, G. 1980. Experimental studies on the dynamic crystallization of silicate melts. PP. 487-543. In, Physics of Magmatic Processes. Princeton University Press, Princeton, N.J.

Lomenick, T. F., D. G. Jacobs, and E. G. Struxness .1967. The behavior of strontium-90 and cesium-137 in seepage pits at ORNL. Health Phys. 13:897-905. 
Lowenstern, J. B., P. C. Wallman, and D. D. Pollard. 1991. The west Mageik Lake sill complex as an analogue for magma transport during the 1912 eruption at the Valley of Ten Thousand Smokes, Alaska. Geophys. Res. Lett. 18:1569-72.

Luey, J., T. D. Powell, W. O. Heath, and R. L. Richardson. 1992. Evaluation of new concepts for in situ vitrification: power system, melt insulation, and off-gas containment. PINL-8231. Battelle Pacific Northwest Laboratory. Richland, Washington.

Marsh, B. D., B. Gunnarsson, R. Congdon, and R. Carmody. 1991. Hawaiian basalt and Icelandic rhyolite: indicators of differentiation and partial melting. Geol. Rundsch. 80:481-510.

McTigue, D. F. 1990. Flow to a heated borehole in porous, thermoelastic rock: Analysis. Water Resour. Res. 26:1763-74.

Meeker, K. A. 1988. The emission of gases and aerosols from Mount Erebus volcano, Antarctica. New Mexico Institute of Mining and Technology, Socorro, New Mexico.

Mroz, E. J., and W. H. Zoller. 1975. Composition of atmospheric particulate matter from the eruption of Heimaey, Iceland. Science 190:461-64.

Norrish, K, and B. W. Chappell. 1977. X-ray fluorescence spectrometry. pp. 210-272. In, Physical Methods in Determinative Mineralogy. Academic Press, San Diego, Calif.

Olmez, I., D. L. Finnegan, and W. H. Zoller. 1986. Iridium emissions from Kilauea volcano. J. Volcanol. Geotherm. Res. 35:111-19.

Oma, K. W., R. K. Farnsworth, and J. M. Rusin. 1982. In situ vitrification: Application analysis for stabilization of transuranic waste. PNL-4442. Battelle Pacific Northwest Laboratory, Richland, Washington.

Roberts, J. S., S. L. Woosley, D. L. Lessor, and C. Strachan, 1992. Preliminary investigation of the potential for transient vapor release events during in situ vitrification based on thermal-hydraulic modeling. PNL-8170. Battelle Pacific Northwest Laboratory. Richland, Washington.

Roedder, E. 1984. Fluid Inclusions. Reviews in Mineralogy. Mineralogical Society of America. Washington, D.C.

Ryan, M. P., and J. Y. K. Blevins. 1987. The viscosity of synthetic and natural silicate melts and glasses at high temperatures and 1 bar $\left(10^{5}\right.$ Pascals $)$ pressure and higher pressures. U.S. Geol. Surv. Bull. 1764:1-563.

Shade, J. W., and G. F. Piepel. 1990. Viscosity, electrical conductivity, and cesium volatility of ORNL vitrified soils with limestone and sodium additives. PNL-7331. Pacific Northwest Laboratory. Richland, Washington.

Shaw, H. R. 1972. Viscosity of magmatic silicate liquids: An empirical method of prediction. Am. J. Sci. 272:870-93.

Shevenell, L. 1990. Chemical and isotopic investigation of the new hydrothermal system at Mount St. Helens, Washington. Ph. D. Thesis. University of Nevada. Reno, Nevada. 
Solomon, A. D., J. E. Nyquist, V. Alexiades, G. K. Jacobs, and S. M. Lenhart. 1991. A preliminary study of the controls on melting during in situ vitrification. ORNL/ER-30. Oak Ridge National Laboratory. Oak Ridge.

Spalding, B. P., G. K. Jacobs, and E. C. Davis. 1989. Demonstrations of technology for remediation and closure of Oak Ridge National Laboratory waste disposal sites. ORNL/TM-11286. Oak Ridge National Laboratory, Oak Ridge.

Spalding, B. P., and Jacobs, G. K. 1989. Evaluation of an in situ vitrification field demonstration of a simulated radioactive liquid waste disposal trench. ORNL/TM-10992. Oak Ridge National Laboratory. Oak Ridge, Tenn.

Spalding, B. P. 1987. Environmental data package for the ORNL seepage pits and trenches waste area grouping. ORNL/RAP-10. Oak Ridge National Laboratory. Oak Ridge, Tenn.

Spohn, T., M. Hort, and H. Fischer. 1988. Numerical simulation of the crystallization of multicomponent melts in thin dikes or sills 1 . The liquidus phase. J. Geophys. Res. 93:4880-94.

Symonds, R. B., W. I. Rose, T. M. Gerlach, P. H. Briggs, and R. S. Harmon. 1990. Evaluation of gases, condensates, and SO2 emissions from Augustine volcano, Alaska: The degassing of a $\mathrm{Cl}$-rich volcanic system. Bull. Volcanol. 52:355-74.

Symonds, R. B., M. H. Reed, and W. I. Rose. 1992. Origin, speciation, and fluxes of trace-element gases at Augustine volcano, Alaska: Insights into magma degassing and fumarolic processes. Geochim. Cosmochim. Acta 56:633-57.

Symonds, R. B., W. I. Rose, M. H. Reed, F. E. Lichte, and D. L. Finnegan. 1987. Volatilization, transport and sublimation of metallic and non-metallic elements in high temperature gases at Merapi Volcano, Indonesia. Geochim. Cosmochim. Acta 51:2083-2101.

Toutain, J. P., P. Aloupogiannis, H. Delorme, A. Person, P. Blanc, and G. Robaye. 1990. Vapor deposition of trace elements from degassed basaltic laga, Piton de la Fournaise volcano, Reunion Island. J. Volcanol. Geotherm. Res. 40:257-68.

U.S. EPA (United States Environmental Protection Agency). 1992. Handbook vitrification technologies for treatment of hazardous and radioactive waste. EPA/625/R-92/002. EPA, Office of Research and Development, Washington, D.C.

U. S. EPA (United States Environmental Protection Agency). 1991. Determination of particulate emissions from stationary sources. 40 CFR Pt. 60, Appl. A, Method 5, pp. 742-766. Office of the Federal Register, U.S. Government Printing Office, Washington, D.C.

Webster, J. D. 1990. Partitioning of $\mathrm{F}$ between $\mathrm{H}_{2} \mathrm{O}$ and $\mathrm{CO}_{2}$ fluids and topaz rhyolite melt. Contrib. Mineral. Petrol. 104:424-38.

Webster, J. D. 1992. Water solubility and chlorine partitioning in Cl-rich granitic systems: Effects of melt composition at $2 \mathrm{kbar}$ and $800^{\circ} \mathrm{C}$. Geochim. Cosmochim. Acta 56:679-87.

Williams, R. J., and O. Mullins. 1981. JSC systems using solid ceramic oxygen electrolyte cells to measure oxygen fugacities in gas-mixing systems. NASA Technical Memorandum 58234. NASA, Lyndon B. Johnson Space Center. Houston, Texas. 


\section{INTERNAL DISTRIBUTION}

1. H. L.. Adair

2. V. Alexiades

3. F. P. Baxter

4. H. L. Boston

5. A. G. Croff

6. N. H. Cutshall

7. M.F.P. DeLozier

8. C. Devaney

9. G. L. Dippo

10. W. E. Doll

11. C. W. Francis

12. D. D. Gates

13. L. J. Gray

14. P. J. Halsey

15. S. G. Hildebrand

16. G. K. Jacobs

17. B. L. Kimmel

18. A. J. Kuhaida

19. S. M. Lenhart

20. A. P. Malinauskas
21. M. T. Naney

22. C. E. Nix

23. M. Olszewski

24. P. T. Owen

25. J. G. Pruett

26. R. Selfridge

27. J. T. Shor

28. R. L. Siegrist

29. D. K. Solomon

30. B. P. Spalding

31. S. H. Stow

32. J. R. Trabalka

33. O. M. West

34. R. K. White

35. Central Research Library

36. ER Document Management Center

37-51. ESD Library

52-53. Laboratory Records Department

54. ORNL Patent Section

55. ORNL Y-12 Technical Library

\section{JEXTERNAL DISTRIBUTION}

56. W. C. Alaconis, L4-92, IVestinghouse Hanford Company, P. O. Box 1970, Richland, WA 99352

57. T. D. Anderson, EM-551, DOE/Office of Technology Development, Trevion II Building, 12800 Middlebrook Road, Germantown, MD 20874

58. T. J. Atterbury, Battelle Columbus, 505 King Avenue, Columbus, $\mathrm{OH}$ 43201-2693

59. H. Babad, R2-08, Westinghouse Hanford Company, P. O. Box 1970, Richland, WA 99352

60. E. G. Baker, P8-38, Pacific Northwest Laboratory, Battelle Blvd., P. O. Box 999, Richland, WA 99352

61. D. H. Bandy, U. S. Department of Energy, P. O. Box 5400, Albuquerque, NM 87115

62. Battelle Columbus, Technical Library, 505 King Avenue, Columbus, OH 43201-2693

63. J. E. Baublitz, EM-40, DOE/Office of Environmental Restoration, Trevion II Building, 12800 Middlebrook Road, Germantown, MD 20874

64. J. D. Berger, L0-18, Westinghouse Hanford Company, P. O. Box 1970, Richland, WA 99352

65. D. Berry, Sandia National Laboratory, Technical Library, Department 6620, Albuquerque, NM 87185-5800

66. T. D. Biancosino, EM-551, DOE/Office of Technology Development, Trevion II Building, 12800 Middlebrook Road, Germantown, MD 20874 
67. W. Bixby, EM-60, DOE/Office of Restoration \& Waste Management, Forrestal Building, U. S. Department of Energy, 1000 Independence Ave., SW, Washington, DC 20585

68. E. A. Bracken, A6-95, DOE Richland Operations Office, P. O. Box 550, Richland, WA 99352

69. J. L. Buelt, P7-41, Pacific Northwest Laboratory, Battelle Blvd., P. O. Box 999, Richland, WA 99352

70. H. C. Burkholder, P7-41, Pacific Northwest Laboratory, Battelle Blvd., P. O. Box 999, Richland, WA 99352

71. J. W. Cammann, H4-14, Westinghouse Hanford Company, P. O. Box 1970, Richland, WA 99352

72. B. E. Campbell, Geosafe Corporation, 2950 George Washington Way \#A, Richland, WA $99352-1615$

73. C. C. Chapman, P7-41, Pacific Northwest Laboratory, Battelle Blvd., P. O. Box 999, Richland, WA 99352

74. Peter Colombo, Brookhaven National Lab, Building 703-50 Rutherford, Upton, NY 11973

75. J. Corones, AMES Laboratory, 329 Wilhelm Hall, Iowa State University, Ames, IA 50011

76. S. P. Cowan, EM-30, DOE/Office of Waste Management, Trevion II Building, $\mathbf{1 2 8 0 0}$ Middlebrook Road, Germantown, MD 20874

77. B. Crary, HAZWRAP, P. O. Box 2003, MS-7606, Oak Ridge, TN 37831-7606

78. Dr. Colin Donaldson, Department of Geography \& Geology, Purdie Bldg., The University of St. Andrews, Fife, Scotland, United Kingdom, KY169ST

79. N. W. Dunbar, New Mexico Institute of Mining and Technology, Socorro, NM 07102

80. J. Eckwert, Sandia National Laboratories, P. O. Box 5800, Division 6621, Albuquerque, NM 87185-5800

81. P. H. Edmonds, Radian Corporation, 120 S. Jefferson Circle, Oak Ridge, TN 37830

82. R. E. Einziger, P7-14, Pacific Northwest Laboratory, Battelle Blvd., P. O. Box 999, Richland, WA 99352

83. A. H. Eraslan, P. O. Box 1854, Tullahoma, TN 37388

84. K. R. Fecht, H4-56, Westinghouse Hanford Company, P. O. Box 1970, Richland, WA 99352

85. J. J. Fiore, EM-42, DOE/Office of Environmental Restoration, Trevion II Building, 12800 Middlebrook Road, Germantown, MD 20874

86. W. Fitch, U. S. Department of Energy, Idaho Field Office, 785 DOE Place, Idaho Falls, ID 83402

87. C. W. Frank, EM-50, DOE/Office of Technology Division, Forrestal Building, U. S. Department of Energy, 1000 Independence Ave., SW, Washington, DC 20585

88. J. F. Franklin, Bloeciel Professor of Ecosystem Analysis, College of Forest Resources, University of Washington, Anderson Hall (AR-10), Seattle, WA 98195

89. R. L. Gilchrist, L5-63, Westinghouse Hanford Company, P. O. Box 1970, Richland, WA 99352

90. K. E. Hain, EM-55, DOE/Office of Technology Development, Trevion II Building, 12800 Middlebrook Road, Germantown, MD 20874

91. J. E. Hanson, Geosafe Corporation, 2950 George Washington Way \#A, Richland, WA $99352-1615$ 
92. R. C. Harriss, Institute for the Study of Earth, Oceans, and Space, Science and Engineering Research Building, University of New Hampshire, Durham, NH 03824

93. J. C. Haugen, U. S. Department of Energy, Chicago Field Office, 9800 South Class Avenue, Argonne, IL 60439-4837

94. M. D. Herd, EG\&G Idaho, P. O. Box 1625, Idaho Falls, ID 83415

95. G. H. Hewig, Battelle Europe, Am Romerhof 35, D 6000 Frankfurt/Main 90

96. A. C. Heywood, P. O. Box 808, 7000 East Avenue, MS L-207, Livermore, CA 94550

97. W. J. Hinze, Department of Earth \& Atmospheric Sciences, 1397 CIVL Building, Purdue Univeristy, West Lafayette, Indiana 47907

98. W. Holman, U. S. Department of Energy, San Francisco Field Office, 1333 Broadway, Oakland, CA 94612

99. C. M. Jantzen, Westinghouse Savannah River Company, P. O. Box 616, Aiken, SC 29801

100. George Y. Jordy, Director, Office of Program Analysis, Office of Energy Research, ER-30, G-226, U.S. Department of Energy, Washington, DC 20545

101. J. R. Kannard, Program Manager, Bechtel National, Inc., P.O. Box 350, Oak Ridge Corporate Center, 151 Lafayette Drive, Oak Ridge, TN 37830

102. C. H. Kindle, H4-55, Westinghouse Hanford Company, P. O. Box 1970, Richland, WA 99352

103. R. Knowlton, Sandia National Laboratory, Technical Library, Department 6620, Albuquerque, NM 87185-5800

104. D. W. Koppenaal, P7-07, Pacific Northwest Laboratory, Battelle Blvd., P. O. Box 999, Richland, WA 99352

105. W. L. Kuhn, P8-38, Pacific Northwest Laboratory, Battelle Blvd., P. O. Box 999, Richland, WA 99352

106. J. C. Lehr, EM-44, DOE/Office of Environmental Restoration, Trevion II Building, 12800 Middlebrook Road, Germantown, MD 20874

107. R. E. Lerch, B2-35, Westinghouse Hanford Company, P. O. Box 1970, Richland, WA 99352

108. S. T. Lien, EM-54, DOE/Office of Technology Development, Trevion II Building, 12800 Middlebrook Road, Germantown, MD 20874

109. N. J. Lombardo, K7-02, Pacific Northwest Laboratory, Battelle Blvd., P. O. Box 999, Richland, WA 99352

110. P. S. Lowery, K7-15, Pacific Northwest Laboratory, Battelle Blvd., P. O. Box 999, Richland, WA 99352

111. J. Luey, P7-34, Pacific Northwest Laboratory, Battelle Blvd., P. O. Box 999, Richland, WA 99352

112. J. E. Lytle, EM-30, DOE/Office of Wastc Operations, Forrestal Building, U. S. Department of Energy, 1000 Independence Ave., SW. Washington, DC 20585

113. P. E. MacDonald, EG\&G Idaho, P. O. Box 1625, Idaho Falls, ID 83415

114. W. J. Madia, Battelle Columbus, 505 King Avenue, Columbus, $\mathrm{OH}$ 43201-2693

115. B. G. Maiden, Battelle Columbus, 505 King Avenue, Columbus, $\mathrm{OH}$ 43201-2693

116. H. Maier, Battelle Europe, Am Romerhof 35, D 6000 Frankfurt/Main 90

117-122. R. K. Major, Nuclear Regulatory Commission, Advisory Committee on Nuclear Waste, MS P-315, Washington, DC 20555

123. S. A. Mann, EM-44, DOE/Office of Environmental Restoration, Trevion II Building, 12800 Middlebrook Road, Germantown, MD 20874 
124. R. M. Marusich, H5-32, Westinghouse Hanford Company, P. O. Box 1970, Richland, WA 99352

125. J. L. McElroy, P7-46, Pacific Northwest Laboratory, Battelle Blvd., P. O. Box 999, Richland, WA 99352

126. H. E. McGuire, B3-63, Westinghouse Hanford Company, P. O. Box 1970, Richland, WA 99352

127. Dr. D. Brooks McKinney, Department of Geology, Hobart and William Smith Colleges, Geneva, NY 14456

128. S. K. Merrill, EG\&G Idaho, P. O. Box 1625, Idaho Falls, ID 83415

129. J. Moore, U. S. Department of Energy, Oak Ridge Field Office, P. O. Box E, Oak Ridge, TN 37831

130. H. D. Murphy, Los Alamos National Laboratory, P. O. Box 1663, Los Alamos, NM 87545

131. R. L. Nace, U.S. Department of Energy, Office of Environmental Restoration, Office of Eastern Area Programs, Oak Ridge Program Division, Washington, DC 20585-0002

132. D. F. Nickelson, EG\&G Idaho, P. O. Box 1625, Idaho Falls, ID 83415

133. R. L. Norlund, EG\&G Idaho, P. O. Box 1625, Idaho Falls, ID 8341.5

134. K. Nuhfer, Environmental Management, Westinghouse Materials Co. of Ohio, P. O. Box 398704, Cincinnati, OH 45239-8704

135. M. G. O'Rear, U. S. Department of Energy, Savannah River Field Office, RFD \#1, Bldg. 703A, Rm E208 North, P. O. Box A, Aiken, SC 29802

136. R. H. Olsen, Vice President for Research, University of Michigan Medical Science Building II, \#5605, 1301 East Catherine Street, Ann Arbor, MI 48109-0620

137. Pacific Northwest Laboratory, Publishing Coordination, Battelle Blvd., P. O. Box 999, Richland, WA 99352

138. Pacific Northwest Laboratory, Technical Library, Battelle Blvd., P. O. Box 999, Richland, WA 99352

139-143. Pacific Northwest Laboratory, Technical Report Files, Battelle Blvd., P. O. Box 999, Richland, WA 99352

144. A. Patrinos, Director, Environmental Sciences Division, Office of Health and Environmental Research, ER-74, U.S. Department of Energy, Washington, DC 20585

145. J. L. Peterson, EG\&G Rocky Flats, Inc., P. O. Box 464, Golden, CO 80402-0464

146. M. E. Peterson, P7-41, Pacific Northwest Laboratory, Battelle Blvd., P. O. Box 999, Richland, WA 99352

147. J. Phelan, Sandia National Laboratory, Technical Library, Department 6620, Albuquerque, NM 87185-5800

148. J. M. Pope, West Valley Nuclear Services Company, P. O. Box 191, West Valley, NY 14171

149. T. D. Powell, P7-46, Pacific Northwest Laboratory, Battelle Blvd., P. O. Box 999, Richland, WA 99352

150. S. M. Prestwich, EM-52, DOE/Office of Technology Development, Trevion II Building, 12800 Middlebrook Road, Germantown, MD 20874

151. M. A. H. Reimus, Los Alamos National Laboratory, P. O. Box 1663, Los Alamos, NM 87545

152. L. Rogers, EG\&G Energy Measurements, Inc., P. O. Box 1912, MS RSL-11, Las Vegas, NV 89125

153. Sandia National Laboratory, Technical Library, Department 6620, Albuquerque, NM $87185-5800$ 
154. P. A. Saxman, U. S. Department of Energy, Albuquerque Field Office, P. O. Box 5400, Albuquerque, NM 87115

155. J. W. Shade, R4-03, Westinghouse Hanford Company, P. O. Box 1970, Richland, WA 99352

156. M. W. Shupe, EM-541, DOE/Office of Technology Development, Trevion II Building, 12800 Middlebrook Road, Germantown, MD 20874

157. R. L. Skaggs, K6-77, Pacific Northwest Laboratory, Battelle Blvd., P. O. Box 999, Richland, WA 99352

158. S. C. Slate, K1-19, Pacific Northwest Laboratory, Battelle Blvd., P. O. Box 999, Richland, WA 99352

159. R. C. Sleeman, U.S. Department of Energy Oak Ridge Field Office, P.O. Box 2001, Oak Ridge, TN 37831-8541

160. R. F. Smiecinski, U. S. Department of Energy, Nevada Field Office, P. O. Box 98518, Las Vegas, NV 89109

161. J. L. Steele, Savannah River Site, SRL, 773A, room A208, Aiken, SC 29802

162. S. L. Stein, BSRC, Pacific Northwest Laboratory, Battelle Blvd., P. O. Box 999, Richland, WA 99352

163. R. R. Stiger, EG\&G Idaho, P. O. Box 1625, Idaho Falls, ID 83415

164. R. B. Stults, K2-20, Pacific Northwest Laboratory, Battelle Blvd., P. O. Box 999, Richland, WA 99352

165. J. T. Sweeney, U.S. Department of Energy Oak Ridge Field Office, P.O. Box 2001, Oak Ridge, TN 37831-8541

166. L. H. Taylor, EM-43, DOE/Office of Environmental Restoration, Trevion II Building, 12800 Middlebrook Road, Germantown, MD 20874

167-168. L. E. Thompson, P7-34, Pacific Northwest Laboratory, Battelle Blvd., P. O. Box 999, Richland, WA 99352

169. C. L. Timmerman, Geosafe Corporation, 2950 George Washington Way \#A, Richland, WA 99352-1615

170-177. J. S. Tixier, P7-34, Pacific Northwest Laboratory, Battelle Blvd., P. O. Box 999, Richland, WA 99352

178. D. E. Trader, A5-90, DOE Richland Operations Office, P. O. Box 550, Richland, WA 99352

179. L. Tyler, Sandia National Laboratory, Technical Library, Department 6620, Albuquerque, NM 87185-5800

180. R. Tyler, U. S. Department of Energy, Rocky Flats Field Office, DOE Building 1166, Golden, CO 80402-0464

181. G. E. Voelker, EM-50, DOE/Office of Technology Development, Trevion II Building, 12800 Middlebrook Road, Germantown, MD 20874

182. R. P. Whitfield, EM-40, DOE/Office of Environmental Restoration, Forrestal Building, U. S. Department of Energy, 1000 Independence Ave., SW, Washington, DC 20585

183. C. L. Widrig, K1-21, Pacific Northwest Laboratory, Battelle Blvd., P. O. Box 999, Richland, WA 99352

184. Frank J. Wobber, Environmental Sciences Division, Office of Health and Environmental Research, ER-74, U.S. Department of Energy, Washington, DC 20545

185. D. D. Wodrich, L6-27, Westinghouse Hanford Company, P. O. Box 1970, Richland, WA 99352 
186. R. D. Wojtasek, L4-92, Westinghouse Hanford Company, P. O. Box 1970, Richland, WA 99352

187. B. A. Wolfe, G6-02, Westinghouse Hanford Company, P. O. Box 1970, Richland, WA 99352

188. J. G. Woolard, H4-55, Westinghouse Hanford Company, P. O. Box 1970, Richland, WA 99352

189. S. L. Woosley, P7-34, Pacíic Northwest Laboratory, Battelle Blvd., P. O. Box 999, Richland, WA 99352

190. J. L. Yow, Jr., Lawrence Livermore National Laboratory, 7000 East Avenue, Livermore, CA 94550

191. Office of Assistant Manager for Energy Research and Development, U.S. Department of Energy Oak Ridge Field Office, P.O. Box 2001, U.S. Department of Energy, Oak Ridge, TN 37831-8600

192-201. Office of Scientific and Technical Information, P.O. Box 62, Oak Ridge, TN 37831 

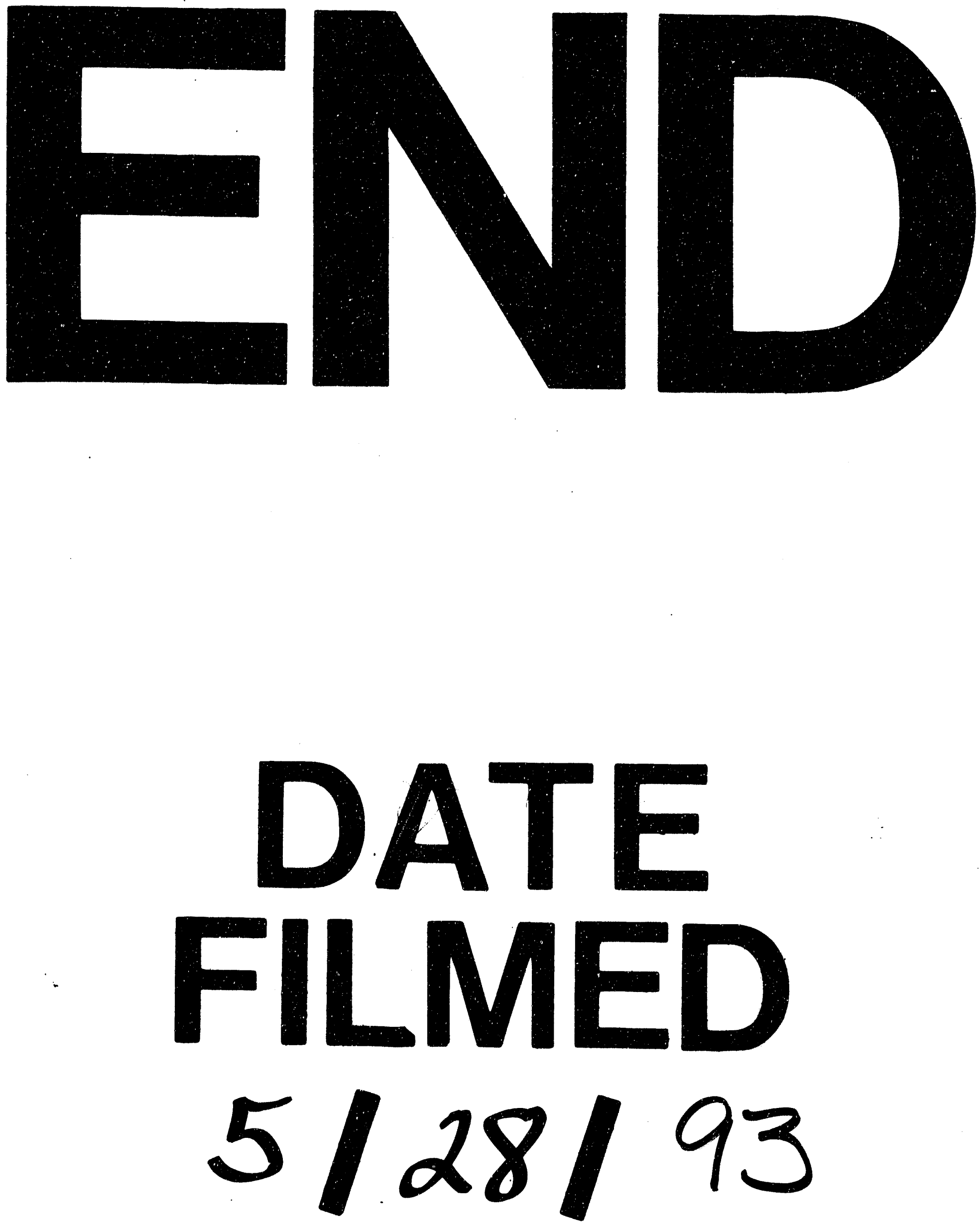
